\title{
Control Technology for
} Radioactive Emissions to the Atmosphere at U.S. Department of Energy Facilities

E. B. Moore, Project Manager

October 1984

Prepared for

the Eastern Environmental Radiation Facility U.S. Environmental Protection Agency Montgomery, Alabama

Pacific Northwest Laboratory Operated for the U.S. Départment of Energy by Battelle Memorial Institute 


\title{
DISCLAIMER
}

This report was prepared as an account of work sponsored by an agency of the United States Government. Neither the United States Government nor any agency thereof, nor any of their employees, makes any warranty, express or implied, or assumes any legal liability or responsibility for the accuracy, completeness, or usefulness of any information, apparatus, product, or process disclosed, or represents that its use would not infringe privately owned rights. Reference herein to any specific commercial product, process, or service by trade name, trademark, manufacturer, or otherwise, does not necessarily constitute or imply its endorsement, recommendation, or favoring by the United States Government or any agency thereof. The views and opinions of authors expressed herein do not necessarily state or reflect those of the United States Government or any agency thereof.

\author{
PACIFIC NORTHWEST LABORATORY \\ operated by \\ BATTELLE \\ for the \\ UNITED STATES DEPARTMENT OF ENERGY \\ under Contract DE-AC06-76RLO 1830
}

Printed in the United States of America
Available from
National Technical Information Service
United States Department of Commerce
5285 Port Royal Road
Springfield, Virginia 22161
NTIS Price Codes
MicroficheA01
Printed Copy
Pages
$\begin{gathered}001-025 \\ 026-050\end{gathered}$
$051-075$
$076-100$


CONTROL TECHNOLOGY FOR RADIOACTIVE EMISSIONS TO THE ATMOSPHERE AT U.S. DEPARTMENT OF ENERGY FACILITIES

E. B. Moore, Project Manager

October 1984

Prepared for the Eastern Environmental Radiation Facility U.S. Environmental Protection Agency Montgomery, Al abama

Under a Related Services Agreement Contract DE-AC06-76RLO 1830

Pacific Northwest Laboratory

Richland, Washington 99352 

The purpose of this report is to provide information to the U.S. Environmental Protection Agency (EPA) on existing technology for the control of radionuclide emissions into the air from U.S. Department of Energy (DOE) facilities, and to provide EPA with information on possible additional control technologies that could be used to further reduce these emissions.

Included in this report are generic discussions of emission control technologies for particulates, iodine, rare gases, and tritium. Also included are specific discussions of existing emission control technologies at 25 DOE facilities. Potential additional emission control technologies are discussed for 14 of these facilities. The facilities discussed were selected by EPA on the basis of preliminary radiation pathway analyses.

A draft report (PNL-4621 Draft) was published in March 1983. This final report differs from the draft report as follows:

1. Addition of Section 7.0, Feed Materials Production Center, and deletion of Section 21.3, Feed Materials Production Center;

2. Addition of Section 15.3, Oak Ridge Y-12 Plant, as an addendum to Section 15.0, Oak Ridge;

3. Appropriate changes in the Summary and Section 1.0, Introduction, and

4. Editorial additions to the table of contents and list of study participants.

Input to the draft and final reports, and comments on the draft and final reports, were sought from appropriate DOE operations offices. 



\title{
PROJECT PARTICIPANTS
}

The project participants listed here are staff members of the Pacific Northwest Laboratory, which is operated by the Battelle Memorial Institute for the U.S. Department of Energy. The list is repeated in Appendix B, along with U.S. Department of Energy operations office resource persons and the sections to which each contributed.

\author{
Emmett Moore, Project Manager \\ Rosanne Aaberg \\ Garry H. Bryan \\ Lee L. Burger \\ Cary A. Counts \\ David A. Dingee \\ Harold T. Fullam \\ Cal M. Heeb \\ J. Donald Ludwick \\ Edward D. MCClanahan \\ Jofu Mishima \\ Larry G. Morgan \\ Alice M. Schreiber \\ Richard I. Smith
}



SECTIONS

1.0 INTRODUCTION

2.0 PARTICULATE CONTROL TECHNOLOGY

3.0 IODINE CONTROL TECHNOLOGY

4.0 RARE GAS CONTROL TECHNOLOGY

5.0 TRITIUM CONTROL TECHNOLOGY

6.0 NOT USED

7.0 FEED MATERIALS PRODUCTION CENTER

8.0 ARGONNE NATIONAL LABORATORY

9.0 BROOKHAVEN NATIONAL LABORATORY

10.0 FERMI NATIONAL ACCELERATOR LABORATORY

11.0 HANFORD

12.0 IDAHO NATIONAL ENGINEERING LABORATORY

13.0 LAWRENCE LIVERMORE NATIONAL LABORATORY/SANDIA NATIONAL LABORATORY - LIVERMORE

14.0 LOS ALAMOS NATIONAL LABORATORY

15.0 OAK RIDGE

16.0 PADUCAH GASEOUS DIFFUSION PLANT

17.0 PORTSMOUTH GASEOUS DIFFUSION PLANT

18.0 ROCKY FLATS PLANT

19.0 SAVANNAH RIVER PLANT

20.0 STANFORD LINEAR ACCELERATOR

21.0 OTHER SITES

\section{APPENDICES}
A U.S. DEPARTMENT OF ENERGY EFFLUENT INFORMATION SYSTEM, EPA RELEASE POINT ANALYSIS REPORT FOR CALENDAR YEAR 1981
$B$ STUDY PARTICIPANTS 



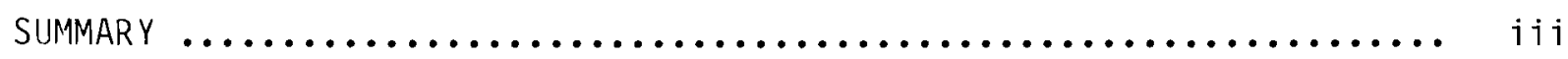

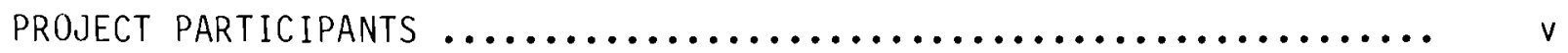

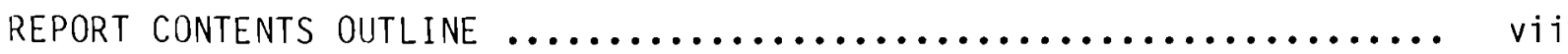

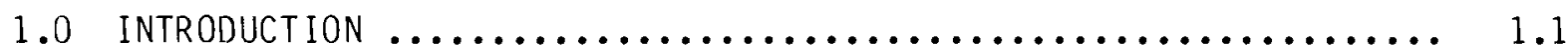

1.1 PROJECT DESCRIPTION $\ldots \ldots \ldots \ldots \ldots \ldots \ldots \ldots \ldots \ldots \ldots \ldots \ldots \ldots \ldots \ldots \ldots \ldots \ldots \ldots$

1.2 EMISSIONS DATA $\ldots \ldots \ldots \ldots \ldots \ldots \ldots \ldots \ldots \ldots \ldots \ldots \ldots \ldots, 1.2$

1.3 SITE SELECTION $\ldots \ldots \ldots \ldots \ldots \ldots \ldots \ldots \ldots \ldots \ldots \ldots \ldots \ldots, 1.2$

1.4 STACK SELECTION, EXISTING AND POTENTIAL CONTROL

TECHNOLOGY, AND COST ESTIMATION $\ldots \ldots \ldots \ldots \ldots \ldots \ldots \ldots \ldots . . .1 .3$

1.5 HISTORY OF DOE PROGRAMS TO REDUCE AIRBORNE

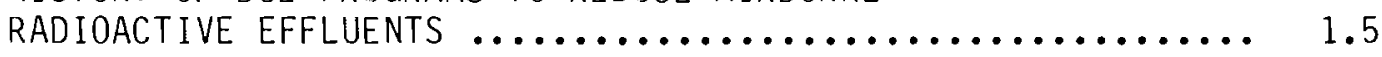

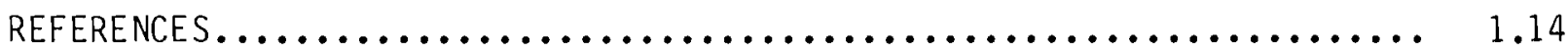

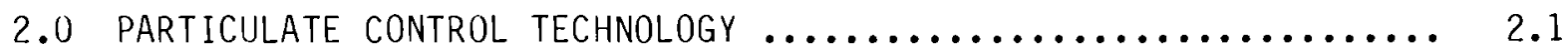

2.1 TECHNIQUES IN USE AT DOE SITES FOR EMISSION

CONTROL OF AIRBORNE PARTICULATE MATERIALS $\ldots \ldots \ldots \ldots \ldots \ldots .2 .1$

2.1.1 High Efficiency Particulate Air Filters ........... 2.1

2.1.2 Deep Bed Sand Filters ...................... 2.7

2.1.3 Deep-Bed Glass Fiber Filters ............... 2.9

2.2 OTHER CONVENTIONAL EMISSION CONTROL TECHNOLOGIES $\ldots \ldots \ldots \ldots .2 .10$

2.2.1 Electrostatic Precipitators $\ldots \ldots \ldots \ldots \ldots \ldots \ldots \ldots . \quad 2.10$

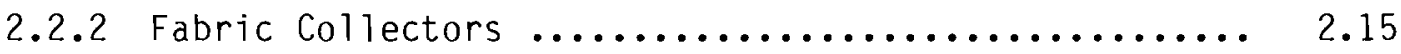

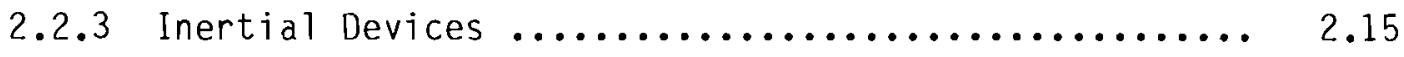

2.2.4 Wet Collectors $\ldots \ldots \ldots \ldots \ldots \ldots \ldots \ldots \ldots \ldots \ldots \ldots, 2.18$

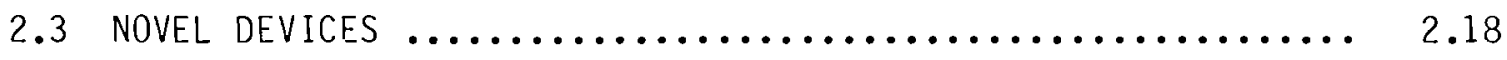

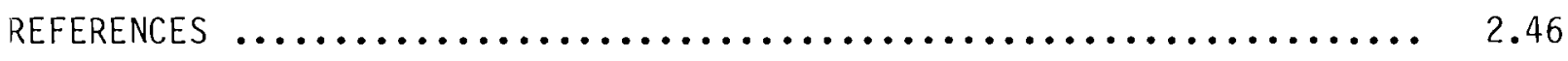




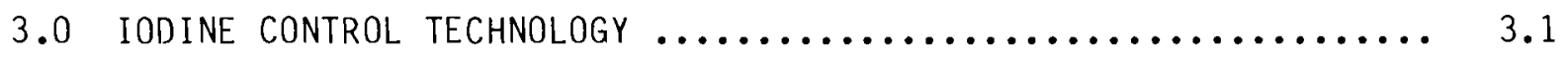

3.1 IODINE CHARACTERISTICS $\ldots \ldots \ldots \ldots \ldots \ldots \ldots \ldots \ldots \ldots \ldots \ldots \ldots \ldots \ldots \ldots . \ldots .1$

3.1 .1 Isotopes of I $\ldots \ldots \ldots \ldots \ldots \ldots \ldots \ldots \ldots \ldots \ldots, 3.1$

3.1.2 Chemical and Physical Forms $\ldots \ldots \ldots \ldots \ldots \ldots \ldots . . . . . .1$

3.1 .3 Sources of Iodine $\ldots \ldots \ldots \ldots \ldots \ldots \ldots \ldots \ldots \ldots, 3.2$

3.1.4 Distribution of Iodine in the Environment ......... 3.3

3.1.5 Radiochemical and Radiological Properties ......... 3.4

3.2 EXISTING CONTROL TECHNOLOGIES $\ldots \ldots \ldots \ldots \ldots \ldots \ldots \ldots \ldots . . .5$

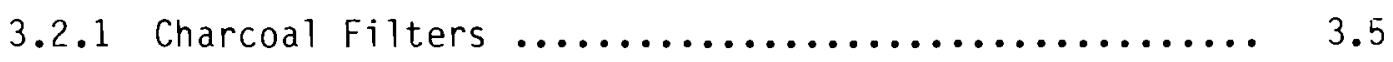

3.2.2 Silver-Containing Solid Sorbents .............. 3.7

3.2 .3 Caustic Scrubbing $. \ldots \ldots \ldots \ldots \ldots \ldots \ldots \ldots \ldots . . \ldots \ldots$

3.2.4 Silver Nitrate Scrubbing $\ldots \ldots \ldots \ldots \ldots \ldots \ldots \ldots \ldots . \quad 3.10$

3.3 POTENTIAL CONTROL TECHNOLOGIES $\ldots \ldots \ldots \ldots \ldots \ldots \ldots \ldots \ldots \ldots . \ldots \ldots . . \ldots \ldots$

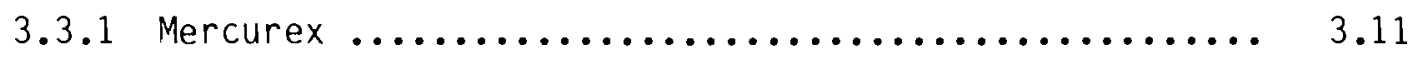

3.3 .2 Iodox $\ldots \ldots \ldots \ldots \ldots \ldots \ldots \ldots \ldots \ldots \ldots \ldots \ldots \ldots \ldots \ldots \ldots \ldots \ldots, 3.12$

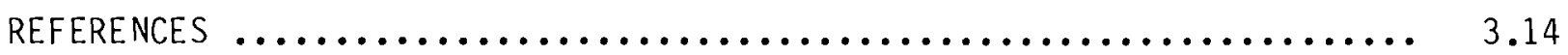

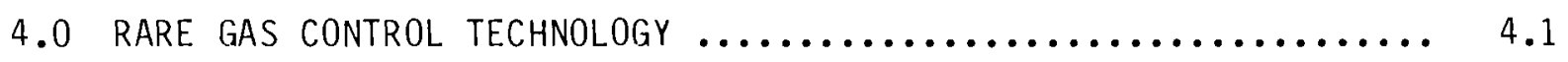

4.1 RARE GAS CHARACTERISTICS $\ldots \ldots \ldots \ldots \ldots \ldots \ldots \ldots \ldots \ldots \ldots \ldots \ldots \ldots \ldots \ldots \ldots \ldots \ldots \ldots$

4.1.1 Physical and Chemical properties .............. 4.1

4.1 .2 Nuclear Properties $. \ldots \ldots \ldots \ldots \ldots \ldots \ldots \ldots \ldots \ldots . .6 .2$

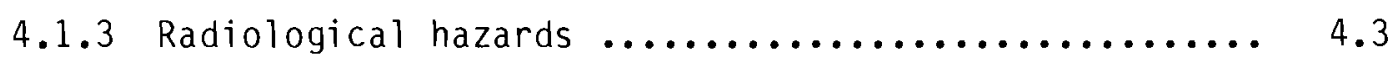

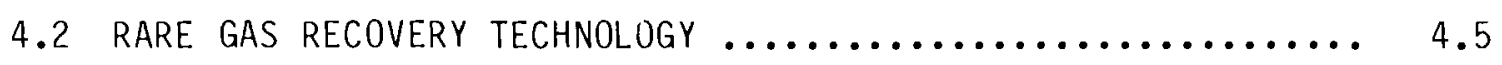

4.2 .1 Cryogenic Distillation $\ldots \ldots \ldots \ldots \ldots \ldots \ldots \ldots \ldots . .6 .6$

4.2.2 Fluorocarbon Absorption $\ldots \ldots \ldots \ldots \ldots \ldots \ldots \ldots \ldots, 4.8$

4.2 .3 Solid Adsorption $. . \ldots \ldots \ldots \ldots \ldots \ldots \ldots \ldots \ldots, 4.12$ 
4.2.4 Economic Comparison ....................... 4.15

4.3 KRYPTON IMMMOBILIZATION TECHNOLOGY $\ldots \ldots \ldots \ldots \ldots \ldots \ldots \ldots, 4.18$

4.3.1 Pressurized Cylinder Technology ................ 4.20

4.3.2 Ion Implantation/Sputtering $\ldots \ldots \ldots \ldots \ldots \ldots \ldots \ldots .4 .21$

4.3.3 Zeolite Encapsulation ....................... 4.23

4.3.4 Economic Comparison ........................ 4.26

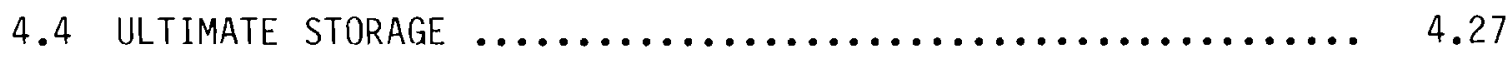

4.4.1 Storage in a Building ....................... 4.29

4.4.2 Storage in a Drywe $11 \ldots \ldots \ldots \ldots \ldots \ldots \ldots \ldots \ldots . .4 .30$

4.4.3 Storage in a Deep Geologic Medium .............. 4.31

4.4.4 Economic Comparison ....................... 4.34

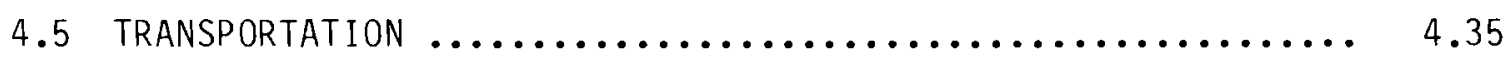

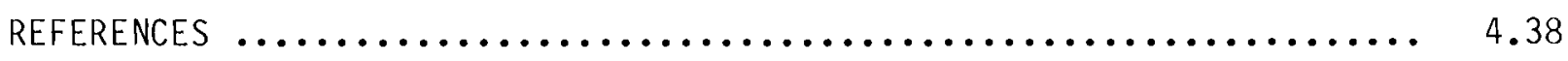

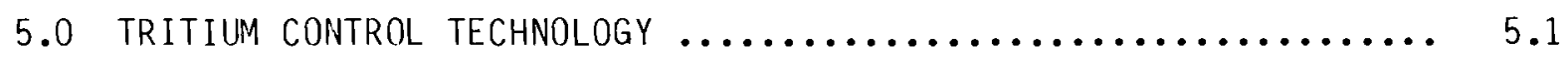

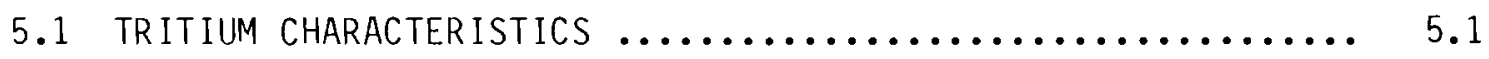

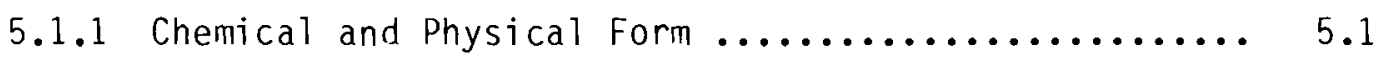

5.1 .2 Sources of Tritium $\ldots \ldots \ldots \ldots \ldots \ldots \ldots \ldots \ldots \ldots . \ldots .1$

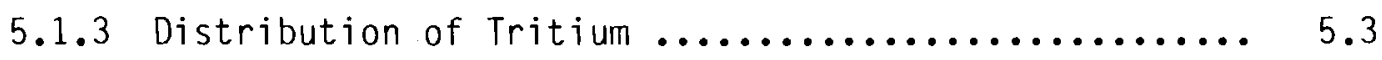

5.1.4 Radiochemical and Radiological Properties ......... 5.3

5.2 EXISTING CONTROL TECHNOLOGIES $\ldots \ldots \ldots \ldots \ldots \ldots \ldots \ldots \ldots \ldots \ldots \ldots \ldots \ldots \ldots \ldots$

5.2.1 0xidation Followed by Water Sorption $\ldots . . \ldots \ldots \ldots . .5 .5$

5.2.2 Other Technologies ......................... 5.7

5.3 POTENTIAL CONTROL TECHNOLOGIES $\ldots \ldots \ldots \ldots \ldots \ldots \ldots \ldots \ldots . . \ldots .7$

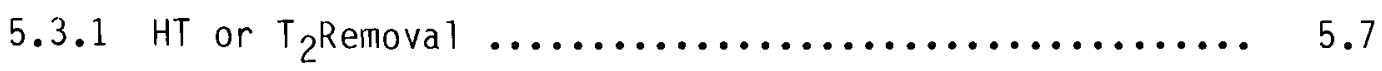

5.3.2 Conversion of HTO to HT Followed by Release ....... 5.7 
5.3.3 Tritium Control in Nuclear Fuel Reprocessing ...... 5.7

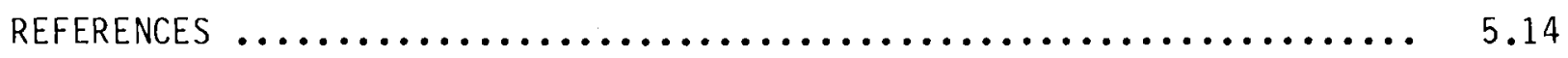

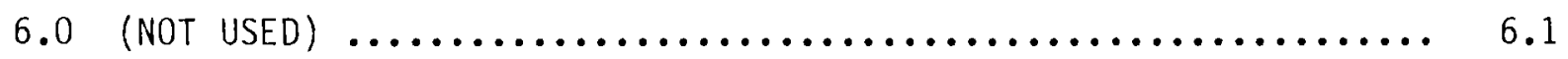

7.0 FEED MATERIALS PRODUCTION CENTER $\ldots \ldots \ldots \ldots \ldots \ldots \ldots \ldots \ldots \ldots \ldots \ldots \ldots$

7.1 SITE AND MAJOR SOURCE DESCRIPTION ................ 7.1

7.1.1 Location of Site and Description of Facilities ..... 7.1

7.1.2 Identification and Location of

Specific Sources ........................ 7.5

7.1 .3 Nonspecific and Minor Sources $\ldots \ldots \ldots \ldots \ldots \ldots . . \ldots .7$

7.2 EMISSION CONTROL TECHNOLOGY AT THE

FEED MATERIALS PRODUCTION CENTER $\ldots \ldots \ldots \ldots \ldots \ldots \ldots \ldots \ldots \ldots . \ldots \ldots$

7.2 .1 Specific Sources $\ldots \ldots \ldots \ldots \ldots \ldots \ldots \ldots \ldots \ldots \ldots \ldots \ldots$

7.3 STRATEGIES TO REDUCE DOSE RATE BY

50 PERCENT AND 75 PERCENT $\ldots \ldots \ldots \ldots \ldots \ldots \ldots \ldots \ldots \ldots \ldots \ldots . \ldots \ldots$

7.4 COST ESTIMATES FOR ADDITIONAL EMISSION CONTROL $\ldots \ldots \ldots \ldots \ldots .7 .17$

7.4.1 Proposed Emission Control Equipment ............ 7.17

7.4.2 Existing and Proposed Stack Monitoring Systems ..... 7.38

7.4.3 Estimated Cost of Proposed Equipment ........... 7.39

7.4.4 Effect of Proposed Equipment ............... 7.40

7.5 OPERATION AND MAINTENANCE COSTS $\ldots \ldots \ldots \ldots \ldots \ldots \ldots \ldots \ldots \ldots$

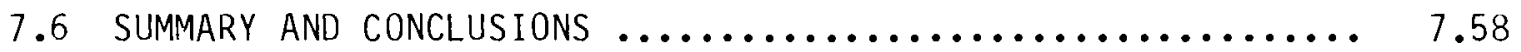

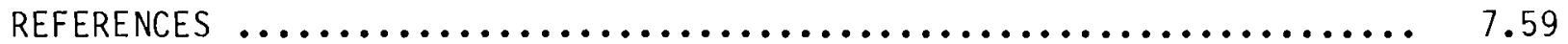

8.0 ARGONNE NATIONAL LABORATORY $\ldots \ldots \ldots \ldots \ldots \ldots \ldots \ldots \ldots \ldots \ldots \ldots \ldots \ldots \ldots \ldots$

8.1 SITE AND MAJOR SOURCE DESCRIPTIONS $\ldots \ldots \ldots \ldots \ldots \ldots \ldots \ldots \ldots . . .1$

8.1.1 Location of Site and Description of Facilities ..... 8.1

8.1.2 Identification and Location of Major Sources ...... 8.3

8.1.3 Nonspecific and Minor Sources $\ldots \ldots \ldots \ldots \ldots . \ldots . . . . . .6$ 
8.2 EMISSION CONTROL TECHNOLOGY AT ARGONNE

NATIONAL LABORATORY ........................ 8.5

8.2.1 Specific Source 1: Hot Cells ................. 8.6

8.2.2 Specific Source 2: The Janus Reactor ............ 8.8

9.0 BROOKHAVEN NATIONAL LABORATORY $\ldots \ldots \ldots \ldots \ldots \ldots \ldots \ldots \ldots \ldots \ldots \ldots . . . . \ldots$

9.1 SITE AND MAJOR SOURCE DESCRIP.TIONS $\ldots \ldots \ldots \ldots \ldots \ldots \ldots \ldots \ldots . . \ldots . \ldots$

9.1.1 Location of Site and Description of Facilities ..... 9.1

9.1.2 Identification and Location of Specific Sources .... 9.4

9.2 EMISSION CONTROL TECHNOLOGY AT BROOKHAVEN

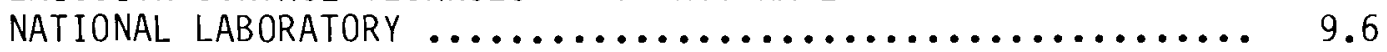

9.2.1 Specific Source 1: HFBR Stack $\ldots \ldots \ldots \ldots \ldots \ldots \ldots \ldots . . . . . . .6$

9.2.2 Specific Source 2: Brookhaven LINAC Isotope

9.2.3 Specific Source 3: Brookhaven Medical

Research Reactor ........................... 9.9

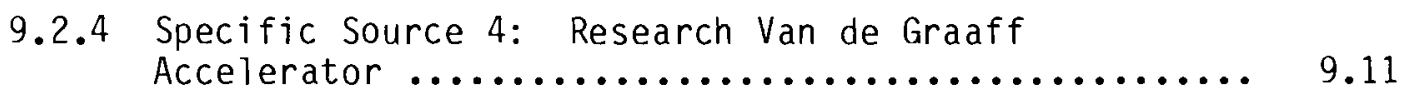

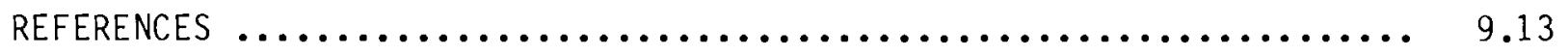

10.0 FERMI NATIONAL ACCELERATOR LABORATORY $\ldots \ldots \ldots \ldots \ldots \ldots \ldots \ldots \ldots$

10.1 SITE AND MAJOR SOURCE DESCRIPTIONS $\ldots \ldots \ldots \ldots \ldots \ldots \ldots \ldots \ldots 10.1$

10.1.1 Location of Site and Description of Facilities .... 10.1

10.1.2 Identification and Location of Specific Sources .... 10.5

10.1.3 Nonspecific and Minor Sources .............. 10.7

10.2 EMISSION CONTROL TECHNOLOGY AT FERMI NATIONAL
ACCELERATOR LABORATORY $\ldots \ldots \ldots \ldots \ldots \ldots \ldots \ldots \ldots \ldots \ldots \ldots \ldots \ldots \ldots$
$10.6 \ldots \ldots \ldots$

10.2.1 Specific Source 1: Labyrinth Stack ............ 10.6

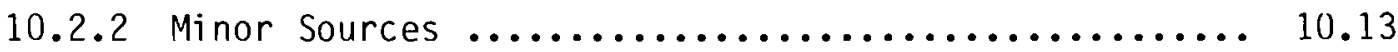

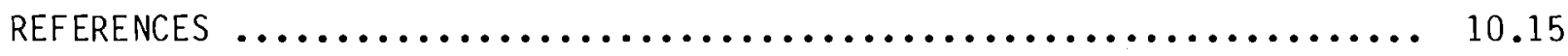


11.0 HANFORD SITE

11.1

11.1 SITE AND MAJOR SOURCE DESCRIPTIONS $\ldots \ldots \ldots \ldots \ldots \ldots \ldots \ldots, 11.1$

11.1.1 Location of Site and Description of Facilities ..... 11.1

11.1.2 Identification and Location of Specific Sources .... 11.4

11.1.3 Nonspecific and Minor Sources $\ldots \ldots \ldots \ldots \ldots \ldots \ldots . . \ldots \ldots$

11.2 EMISSION CONTROL TECHNOLOGY AT HANFORD $\ldots \ldots \ldots \ldots \ldots \ldots, 11.5$

11.2.1 Specific Source 1: Stack 116-N Serving the

$105-N$ Reactor Building ........................ 11.5

11.2.2 Specific Source 2: PUREX

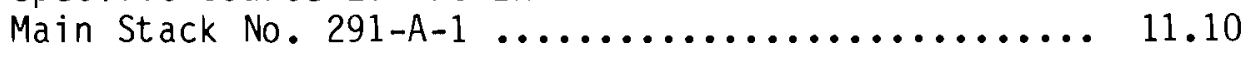

11.2.3 Specific Source 3: Combined Exhaust from

Buildings 405, 4621E, 4717; Building 491-S

Heating and Ventilating Discharge; and

Building 4717 Lower Area Heating and

Ventilating Exhaust, Serving the FFTF ........... 11.21

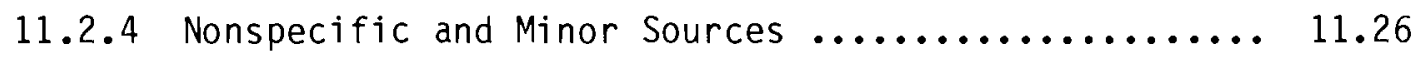

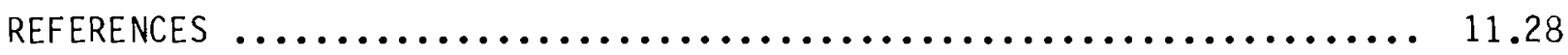

12.0 IDAHO NATIONAL ENGINEER ING LABORATORY $\ldots \ldots \ldots \ldots \ldots \ldots \ldots \ldots \ldots \ldots \ldots$

12.1 SITE AND MAJOR SOIJRCE DESCRIPTIONS $\ldots \ldots \ldots \ldots \ldots \ldots \ldots \ldots \ldots \ldots \ldots \ldots \ldots$

12.1.1 Location of Site and Description of Facilities ..... 12.1

12.1.2 Identification and Location of Specific Sources .... 12.5

12.1.3 Nonspecific and Minor Sources ................ 12.5

12.2 EMISSION CONTROL TECHNOLOGY AT THE IDAHO

NATIONAL ENGINEER ING LABORATORY $\ldots \ldots \ldots \ldots \ldots \ldots \ldots \ldots \ldots . \ldots \ldots$

12.2.1 Specific Source 1: Advanced Test Reactor ........ 12.5

12.2.2 Specific Source 2: Idaho

Chemical Processing Plant .................. 12.9

12.2.3 Nonspecific and Minor Sources $\ldots \ldots \ldots \ldots \ldots \ldots \ldots .12 .18$

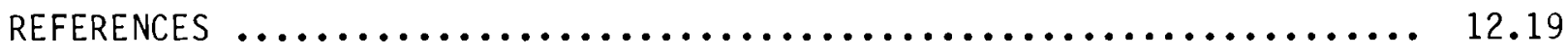


13.0 LAWRENCE LIVERMORE NATIONAL LABORATORY/SANDIA NATIONAL

LABORATORY - LIVERMORE

13.1 SITE AND MAJOR SOURCE DESCRIPTIONS $\ldots \ldots \ldots \ldots \ldots \ldots \ldots \ldots \ldots . . \ldots$

13.1.1 Location of Sites and Description of Facilities .... 13.1

13.1.2 Identification and Location of Specific Sources .... 13.2

13.2 EMISSION CONTROL TECHNOLOGY AT LAWRENCE

LIVERMORE NATIONAL LABORATORY AND SANDIA

NATIONAL LABORATORY - LIVERMORE ................. 13.7

13.2.1 Specific Source 1: Tritium

Research Facility - LLNL ................... 13.7

13.2.2 Specific Source 2: Rotating

Target Neutron Source - LLNL ............... 13.9

13.2.3 Specific Source 3: 100-MeV Linear

Accelerator Facility - LLNL ................... 13.10

13.2.4 Specific Source 4: Tritium

Research Laboratory - SNLL ................ 13.12

13.2.5 Specific Source 5: Metallurgy

Laboratory - SNLL ....................... 13.14

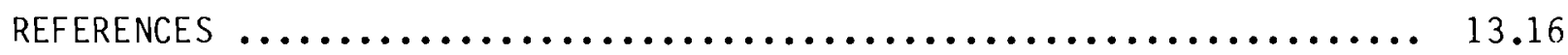

14.0 LOS ALAMOS NATIONAL LABORATORY $\ldots \ldots \ldots \ldots \ldots \ldots \ldots \ldots \ldots \ldots \ldots \ldots$

14.1 SITE AND MAJOR SOURCE DESCRIPTIONS $\ldots \ldots \ldots \ldots \ldots \ldots \ldots \ldots \ldots 14.1$

14.1.1 Location of Site and Description of Facilities ..... 14.2

14.1.2 Radionuclides Routinely Released to the

Atmosphere at the Los Alamos National

Laboratory in $1981 \ldots \ldots \ldots \ldots \ldots \ldots \ldots \ldots \ldots \ldots \ldots . \ldots \ldots$

14.1.3 Nonspecific and Minor Sources .............. 14.9

14.2 EMISSION CONTROL TECHNOLOGY AT LOS ALAMOS

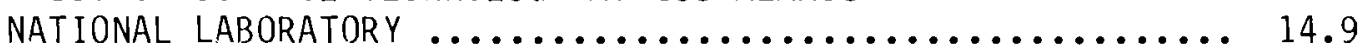

14.2.1 Specific Source 1: Omega West Reactor Stack ...... 14.10

14.2.2 Specific Source 2: LAMPF Main Stack ............ 14.14

14.2.3 Specific Source 3: Stack FE-6-HP Site ........... 14.19 
14.2.4 Specific Source 4: South Stack-Wing 3 - CMR ...... 14.25

14.2.5 Specific Source 5: main Stack - Building

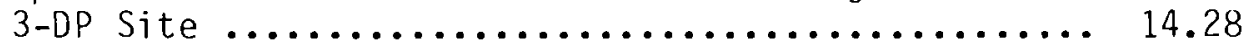

14.2.6 Specific Source 6: Core Wing Stack-Building RC-1-Radiochemistry Site .................. 14.30

14.2.7 Nonspecific or Minor Sources ............... 14.34

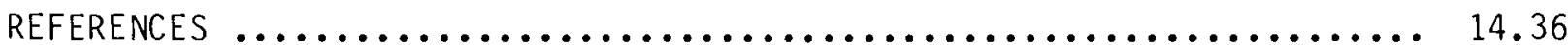

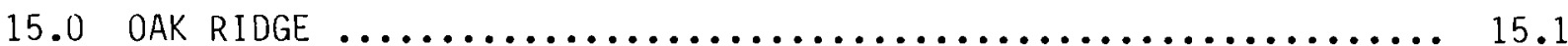

15.1 SITE AND MAJOR SOURCE DESCRIPTIONS $\ldots \ldots \ldots \ldots \ldots \ldots \ldots \ldots \ldots . . \ldots$

15.1.1 Location of Site and Major Areas .............. 15.1

15.1.2 Identification and Location of Specific Sources .... 15.2

15.1.3 Nonspecific and Minor Sources $\ldots \ldots \ldots \ldots \ldots \ldots \ldots . . . .15$

15.2 EMISSION CONTROL TECHNOLOGY AT OAK RINGE $\ldots \ldots \ldots \ldots \ldots \ldots \ldots$

15.2.1 ORNL, Specific Source 1: Central Radioactive Gas Disposal Facility ...................... 15.8

15.2.2 ORNL Specific Source 2: High Flux Isotope Reactor and TRU Processing Plant .............. 15.11

15.2.3 ORNL, Specific Source 3: Tritium Target Fabrication Building ................. 15.13

15.2.4 Y-12 Plant: Specific Source 4: Uranium Product Recovery ........................ 15.14

15.2.5 Y-12 Plant: Specific Source 5: Uranium Product Preparation ........................ 15.16

15.2.6 Y-12 Plant: Specific Source 6: Uranium Fuel Element Fabrication .................... 15.17

15.2.7 Oak Ridge Gaseous Diffusion Plant:

Specific Source 7: Purge Cascade ............. 15.19

15.2.8 Minor Sources at Oak Ridge ................ 15.22

15.2.9 Current Discharge Rate ................... 15.30

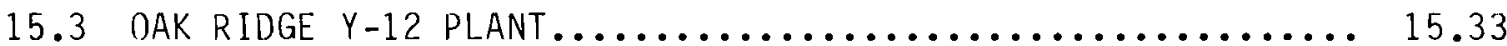


15.3.1 Strategies to Reduce Dose Rate by at Least $50 \%$

15.3.2 Cost Estimates for Additional

Emission Control Technology ..........................

15.3.3 Operation and Maintenance Costs ............... 15.45

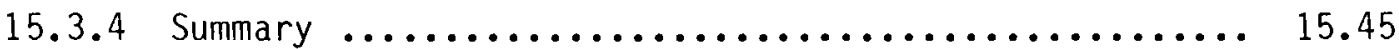

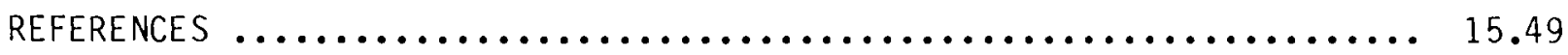

16.0 PADUCAH GASEOUS DIFFUSION PLANT $\ldots \ldots \ldots \ldots \ldots \ldots \ldots \ldots \ldots \ldots \ldots \ldots$

16.1 SITE AND MAJOR SOURCE DESCRIPTIONS $\ldots \ldots \ldots \ldots \ldots \ldots \ldots \ldots \ldots . .1$

16.1.1 Location of Site and Description of Facilities ..... 16.1

16.1.2 Identification and Location of Specific Sources .... 16.4

16.1.2 Nonspecific and Minor Sources .............. 16.4

16.2 EMISSION CONTROL TECHNOLOGY AT THE PADUCAH
GASEOUS DIFFUSION PLANT $\ldots \ldots \ldots \ldots \ldots \ldots \ldots \ldots \ldots \ldots \ldots \ldots \ldots \ldots . \ldots \ldots$

16.2.1 Specific Source 1: C-400 PuTverizer Vent ....... 16.5

16.2.2 Specific Source 2: C-310 Purge Vent .......... 16.8

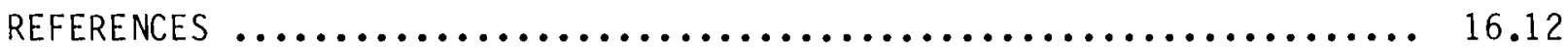

17.0 PORTSMOUTH GASEOUS DIFFUSION PLANT $\ldots \ldots \ldots \ldots \ldots \ldots \ldots \ldots \ldots \ldots \ldots$

17.1 SITE AND MAJOR SOURCE DESCRIPTIONS $\ldots \ldots \ldots \ldots \ldots \ldots \ldots \ldots \ldots . \ldots \ldots$

17.1.1 Location of Site and Description of Facilities ..... 17.1

17.1.2 Identification and Location of Specific Sources .... 17.5

17.1.3 Nonspecific and Minor Sources $\ldots \ldots \ldots \ldots \ldots \ldots \ldots \ldots$

17.2 EMISSION CONTROL TECHNOLOGY AT THE PORTSMOUTH

GASEOUS DIFFUSION PLANT $\ldots \ldots \ldots \ldots \ldots \ldots \ldots \ldots \ldots \ldots \ldots \ldots \ldots \ldots \ldots \ldots \ldots \ldots$

17.2.1 Specific Source $1: \quad x-326$ Top and
Side Purge Vent $\ldots \ldots \ldots \ldots \ldots \ldots \ldots \ldots \ldots \ldots \ldots \ldots \ldots$

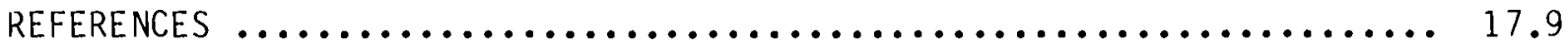

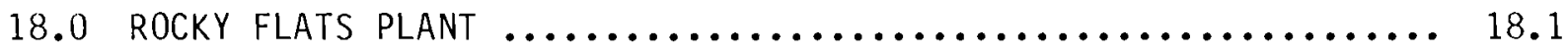


18.1 SITE AND MAJOR SOURCE DESCRIPTIONS $\ldots \ldots \ldots \ldots \ldots \ldots \ldots \ldots \ldots \ldots$

18.1.1 Location of Site and Description of Facilities ..... 18.1

18.1.2 Identification and Location of Specific Sources .... 18.1

18.2 EMISSION CONTROL TECHNOLOGY AT THE

ROCKY FLATS PLANT .......................... 18.4

18.2.1 Specific Source 1: Building 771 Main Plenum ...... 18.7

18.2.2 Specific Source 2: Building 881 -

Ducts $1,2,3$ and $4 \ldots \ldots \ldots \ldots \ldots \ldots \ldots \ldots \ldots \ldots \ldots \ldots \ldots \ldots \ldots \ldots$

18.2.3 Specific Source 3: Plutonium Analytical

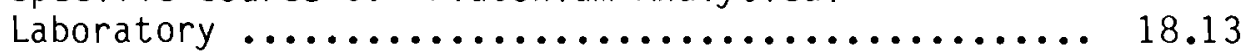

18.2.4 Nonspecific and Minor Sources ................ 18.18

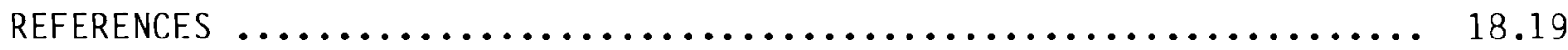

19.0 SAVANNAH RIVER PLANT $\ldots \ldots \ldots \ldots \ldots \ldots \ldots \ldots \ldots \ldots \ldots \ldots \ldots \ldots \ldots \ldots \ldots \ldots \ldots \ldots \ldots \ldots \ldots$

19.1 SITE AND MAJOR SOURCE DESCRIPTIONS $\ldots \ldots \ldots \ldots \ldots \ldots \ldots \ldots \ldots \ldots$

19.1.1 Location of Site and Description of Facilities ..... 19.1

19.1.2 Identification and Location of Major Sources ...... 19.4

19.2 EMISSION CONTROL TECHNOLOGY AT

SAVANNAH RIVER PLANT ........................... 19.4

19.2.1 Specific Source 1: 200-H Area Tritium

Facility Stacks ........................ 19.7

19.2.2 Specific Source 2: Production Reactor

Area Stacks ........................... 19.11

19.2.3 Specific Source 3: $200-F$ and 200-H Area

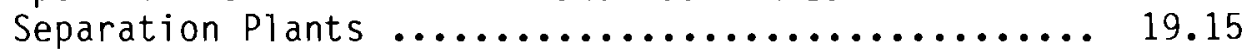

REFERENCES

19.20

20.0 STANFORD LINEAR ACCELERATOR CENTER $\ldots \ldots \ldots \ldots \ldots \ldots \ldots \ldots \ldots \ldots$

20.1 SITE AND MAJOR SOURCE DESCRIPTIONS $\ldots \ldots \ldots \ldots \ldots \ldots \ldots \ldots \ldots . \ldots \ldots$

20.1.1 Location of Site and Description of Facilities .... 20.1

20.1.2 Identification and Location of Specific Sources .... 20.1 
20.2 EMISSION CONTROL TECHNOLOGY AT STANFORD

LINEAR ACCELERATOR CENTER $\ldots \ldots \ldots \ldots \ldots \ldots \ldots \ldots \ldots \ldots \ldots . \ldots \ldots \ldots$

20.2.1 Specific Source 1: 8-Target Room Exhaust Fan ..... 20.6

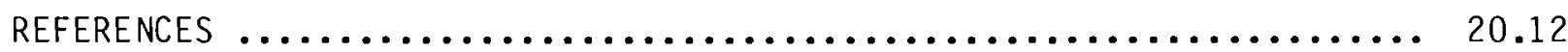

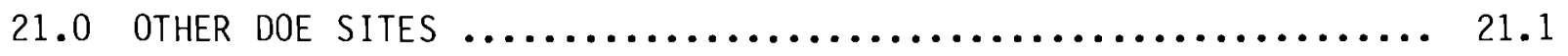

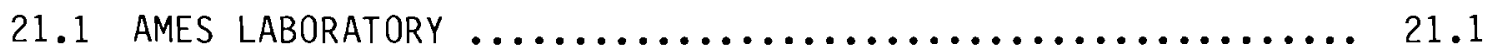

21.1.1 Specific Sources of Emissions $\ldots \ldots \ldots \ldots \ldots \ldots \ldots .21 .1$

21.1.2 Emission Control Technology .................. 21.1

21.1.3 Current Discharge Rate $\ldots \ldots \ldots \ldots \ldots \ldots \ldots \ldots \ldots . . .21 .2$

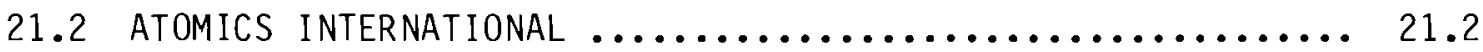

21.2.1 Specific Sources of Emissions $\ldots \ldots \ldots \ldots \ldots \ldots \ldots \ldots, 21.3$

21.2.2 Emission Control Technology $\ldots \ldots \ldots \ldots \ldots \ldots \ldots \ldots .21 .3$

21.2.3 Current Discharge Rate $\ldots \ldots \ldots \ldots \ldots \ldots \ldots \ldots \ldots .21 .3$

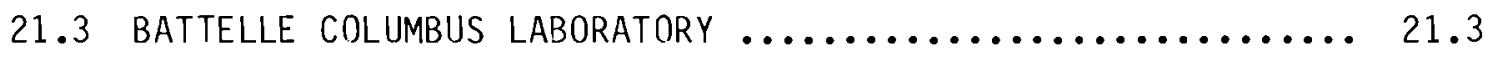

21.3.1 Specific Sources of Emission $\ldots \ldots \ldots \ldots \ldots \ldots \ldots . . \ldots .621 .5$

21.3.2 Emission Control Technology ................. 21.5

21.3.3 Current Discharge Rate $\ldots \ldots \ldots \ldots \ldots \ldots \ldots \ldots \ldots .21 .5$

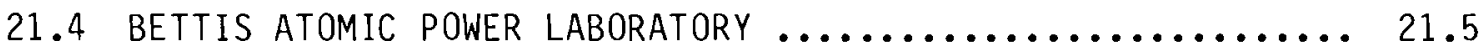

21.4.1 Specific Sources of Emissions $\ldots \ldots \ldots \ldots \ldots \ldots \ldots .21 .6$

21.4.2 Emission Control Technology $\ldots \ldots \ldots \ldots \ldots \ldots \ldots \ldots .21 .6$

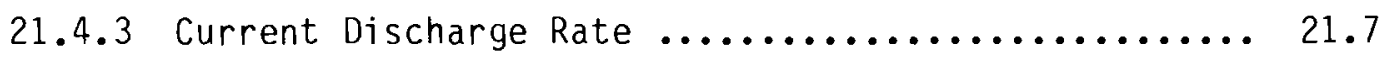

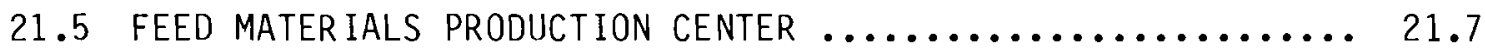

21.6 KNOLLS ATOMIC POWER LABORATORY $\ldots \ldots \ldots \ldots \ldots \ldots \ldots \ldots \ldots . \ldots \ldots . . \ldots$

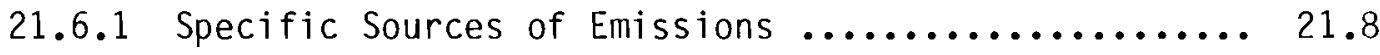

21.6.2 Emission Control Technology $\ldots \ldots \ldots \ldots \ldots \ldots \ldots \ldots . . . \ldots$

21.6 .3 Current Discharge Rate $\ldots \ldots \ldots \ldots \ldots \ldots \ldots \ldots \ldots .21 .9$ 
21.7 LAWRENCE BERKELEY LABORATORY $\ldots \ldots \ldots \ldots \ldots \ldots \ldots \ldots \ldots \ldots \ldots \ldots \ldots \ldots \ldots$

21.7.1 Specific Sources of Emissions $\ldots \ldots \ldots \ldots \ldots \ldots \ldots .21 .10$

21.7.2 Emission Control Technology .................. 21.10

21.7.3 Current Discharge Rate .................... 21.11

21.8 MOUND FACILITY $\ldots \ldots \ldots \ldots \ldots \ldots \ldots \ldots \ldots \ldots \ldots \ldots \ldots \ldots \ldots \ldots \ldots \ldots \ldots, 21.11$

21.8.1 specific Sources of Emissions $\ldots \ldots \ldots \ldots \ldots \ldots \ldots .21 .12$

21.8.2 Emission Control Technology $\ldots \ldots \ldots \ldots \ldots \ldots \ldots \ldots .21 .12$

21.8.3 Current Discharge Rate ...................... 21.14

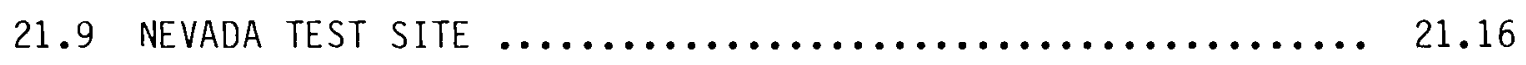

21.9.1 Specific Sources of Emissions ................ 21.14

21.9.2 Emission Control Technology ................. 21.15

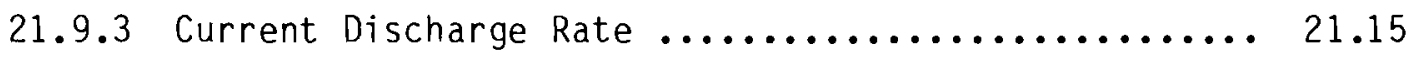

21.10 PANTEX PLANT $\ldots \ldots \ldots \ldots \ldots \ldots \ldots \ldots \ldots \ldots \ldots \ldots \ldots \ldots \ldots \ldots \ldots \ldots \ldots \ldots, 21.16$

21.10.1 Specific Sources of Emission ................ 21.16

21.10.2 Emission Control Technology ................ 21.16

21.10.3 Current Discharge Rate .................. 21.16

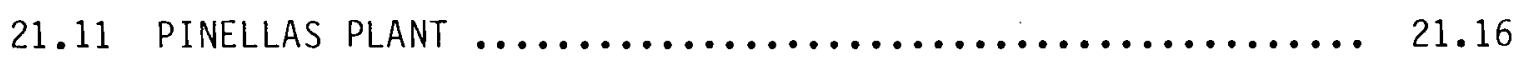

21.11.1 Specific Sources of Emission ................ 21.17

21.11.2 Emission Control Technology ................ 21.17

21.11 .3 Current Discharge Rate $\ldots \ldots \ldots \ldots \ldots \ldots \ldots \ldots \ldots .21 .18$

21.12 SANdia laboratories, Albuquerque Site $\ldots \ldots \ldots \ldots \ldots \ldots \ldots . . \ldots \ldots$

21.12.1 Specific Sources of Emissions ................ 21.19

21.12.2 Emission Control Technology ................. 21.19

21.12.3 Current Discharge Rate $\ldots \ldots \ldots \ldots \ldots \ldots \ldots \ldots \ldots .21 .19$

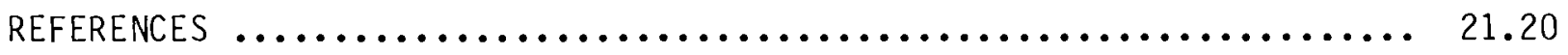


$\begin{aligned} \text { APPENDIX A }- & \text { U.S. DEPARTMENT OF ENERGY EFFLUENT INFORMATION } \\ & \text { SYSTEM, EPA RELEASE POINT ANALYSIS REPORT } \\ & \text { FOR CALENDAR YEAR } 1981 \ldots \ldots \ldots \ldots \ldots \ldots \ldots \ldots \ldots \ldots \ldots \ldots \ldots \ldots \ldots \ldots \ldots \ldots \ldots \ldots \ldots \ldots \ldots \ldots \ldots \ldots \ldots \ldots \ldots \ldots \ldots \ldots \ldots \ldots \ldots \ldots \ldots \ldots \\ \text { APPENDIX B }- & \text { STUDY PARTICIPANTS } \ldots \ldots \ldots \ldots \ldots \ldots \ldots \ldots \ldots \ldots \ldots\end{aligned}$ 



\section{FIGURES}

1.1 Total Radioactivity Released from DOE Facilities .......... 1.7

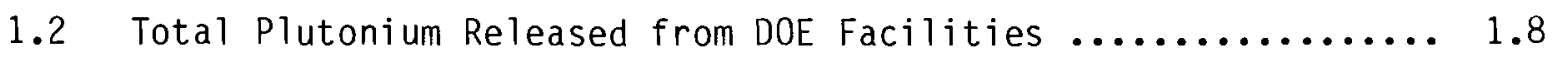

1.3 Total Argon-41 Released from DOE Facilities ............. 1.10

1.4 Total Krypton-85 Released from DOE Facilities ............ 1.11

1.5 Total Tritium Released from DOE Facilities ............... 1.12

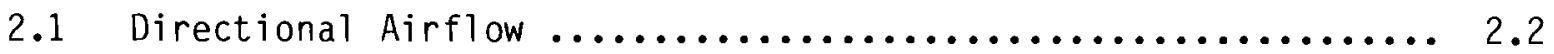

2.2 Construction of Open-Face HEPA Filter Units $\ldots \ldots \ldots \ldots \ldots \ldots \ldots .4$

2.3 HEPA Filter Penetration for DEHP Particles $\ldots \ldots \ldots \ldots \ldots \ldots \ldots \ldots$

2.4 HEPA Filter Efficiency Versus Flow Rate $\ldots \ldots \ldots \ldots \ldots \ldots \ldots \ldots \ldots$

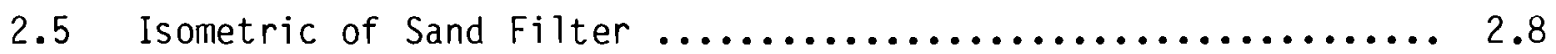

2.6 Sand Filter Efficiency Versus Velocity ................ 2.9

2.7 Pressure Versus Pounds of Carbon Black ................ 2.11

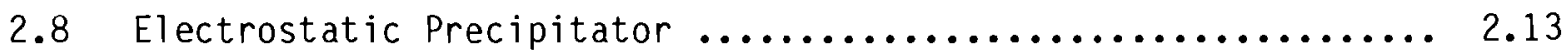

2.9 Typical Fractional Efficiencies for Existing Collectors ...... 2.14

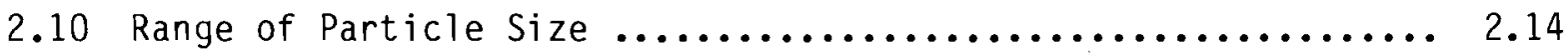

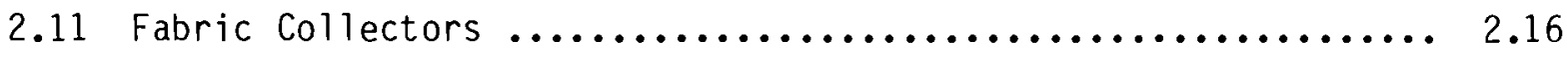

2.12 Dry-Type Centrifugal Collectors .................... 2.17

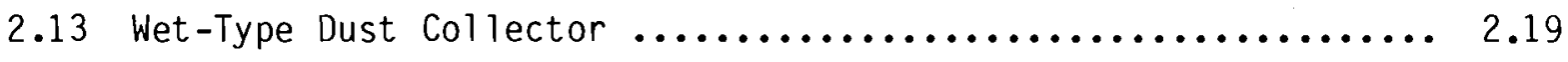

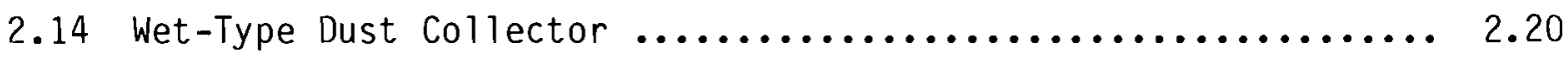

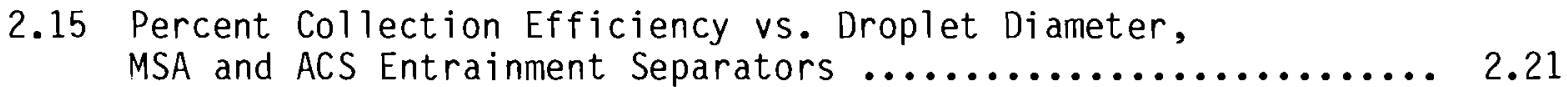

Predicted Iodine Path in Typical Reprocessing Plant,
Values in Percent $\ldots \ldots \ldots \ldots \ldots \ldots \ldots \ldots \ldots \ldots \ldots \ldots \ldots \ldots \ldots \ldots \ldots \ldots$

3.2 Distribution of Natural Iodine $\ldots \ldots \ldots \ldots \ldots \ldots \ldots \ldots \ldots \ldots \ldots . . \ldots$

3.3 Iodox Process Flowsheet for Iodine Removal ..................... 3. 


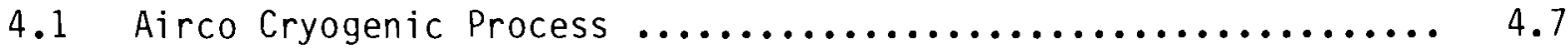

4.2 Block Diagram of Basic Fluorocarbon Process $\ldots . \ldots . \ldots . \ldots . . .4 .9$

4.3 Schematic of the Simplified Selective

Absorption Process ................................... 4.10

4.4 Principal Components of a BWR Off-Gas System $\ldots \ldots \ldots \ldots \ldots \ldots . . . . .13$

4.5 Schematic of Product Purification System ................. 4.16

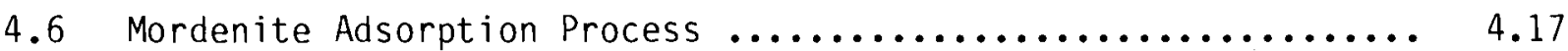

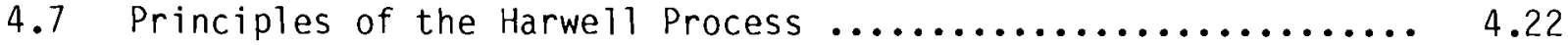

4.8 Sputtering/Ion Impiantation $\ldots \ldots \ldots \ldots \ldots \ldots \ldots \ldots \ldots \ldots \ldots \ldots, 4.24$

4.9 Krypton-85 Immobilization by High Temperature/

4.10 Krypton Storage Facility Plot Plan ..................... 4.30

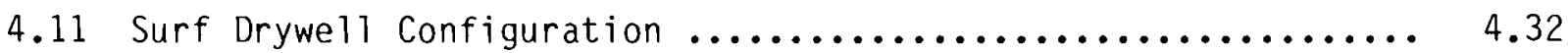

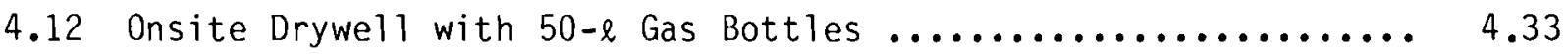

4.13 Conceptual Design of Shipping Cask for Cylinders
of Compressed Krypton-85 ................................... 47

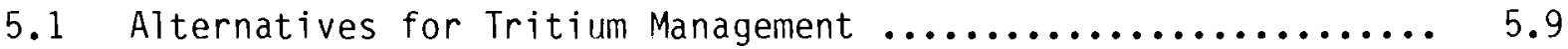

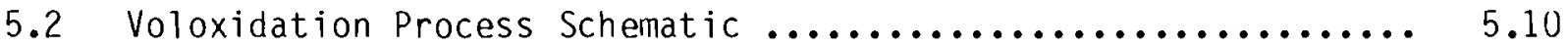

5.3 Thermal Outgassing Schematic $\ldots \ldots \ldots \ldots \ldots \ldots \ldots \ldots \ldots \ldots \ldots \ldots . . .11$

7.1 Location of Feed Materials Production Plant $\ldots \ldots \ldots \ldots \ldots \ldots . . .2$

7.2 Plant Locations at the Feed Materials Production Center ...... 7.3

7.3 Conceptual Design, FMPC, Plant 4, G4-2 ................. 7.22

7.4 Conceptual Design, FMPC, Plant 4, G4-5 ................. 7.23

7.5 Conceptual Design, FMPC, Plant 4, G4-7 ................. 7.24

7.6 Conceptual Design, FMPC, Plant 4, G4-14 ................. 7.25

7.7 Conceptual Design, FMPC, PIant 5, G5-249 ............... 7.26

7.8 Conceptual Design, FMPC, Plant 5, G5-254 ............... 7.27 
7.9 Conceptual Design, FMPC, Plant 5, G5-256 ............... 7.28

7.10 Conceptual Design, FMPC, Plant 5, G5-260 ................ 7.29

7.11 Conceptual Design, FMPC, P1 ant 5, G4-261 .............. 7.30

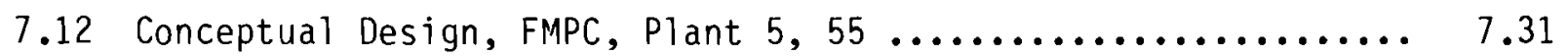

7.13 Conceptual Design, FMPC, Plant 8, G43-27 ............... 7.32

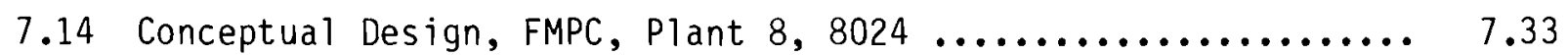

7.15 Conceptual Design, FMPC, Plant 8, Rotary Kiln(s) ............ 7.34

7.16 Conceptual Design, FMPC, Plant 8, Oxidation No. 1(s) ........ 7.35

8.1 Location of Argonne National Laboratory $\ldots \ldots \ldots \ldots \ldots \ldots \ldots . .2$

8.2 Locations of Atmospheric Release Points at
Argonne National Laboratory $\ldots \ldots \ldots \ldots \ldots \ldots \ldots \ldots \ldots \ldots . \ldots .4 . \ldots \ldots$

8.3 Hot Cell Emission Control System ..................... 8.7

8.4 Building 202 Ventilation System $\ldots \ldots \ldots \ldots \ldots \ldots \ldots \ldots \ldots \ldots . .6 .9$

9.1 Regional Map Showing Location of BNL $\ldots . \ldots \ldots \ldots \ldots . . . . . .9 .2$

9.2 BNL Site Map ...................................... 9.3

9.3 Block Diagram of Emission Control Technology
in Use at the HFBR and the Hot Laboratory $\ldots \ldots \ldots \ldots \ldots \ldots \ldots . . . . .$.

9.4 Block Diagram of Emission Control Technology at BLIP ........ 9.9

9.5 Block Diagram of Emission Control Technology at BMRR ........ 9.10

9.6 Block Diagram of Emission Control Technology at

10.1 Location of the Fermi National Accelerator Laboratory and Population Concentrations Within $80 \mathrm{~km}$................ 10.2

10.2 Map of the Fermi National Accelerator Laboratory Site ....... 10.3

10.3 Map of the Target Experimental Areas at the FNAL $\ldots \ldots \ldots \ldots . . .10 .4$

10.4 Air Storage System for Reducing Carbon-11 Emissions ......... 10.11

11.1 Hanford Site $\ldots \ldots \ldots \ldots \ldots \ldots \ldots \ldots \ldots \ldots \ldots \ldots \ldots \ldots \ldots, 11.2$ 
11.2 117-N Filter and Diversion Facility $\ldots \ldots \ldots \ldots \ldots \ldots \ldots \ldots . . .611 .8$

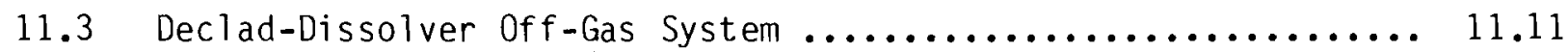

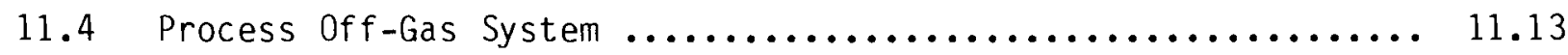

11.5 Plutonium 0xide Conversion Facility Off-Gas System ......... 11.15

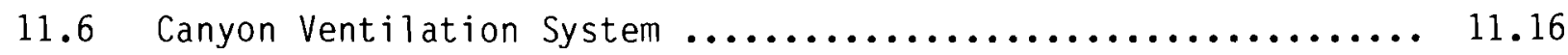

11.7 Pretreatment Sequence for Removing Contaminants

from the Dissolver Off-Gas Prior to Krypton-Xenon

Recovery ........................................ 11.19

11.8 Diagram of the RAPS System $\ldots \ldots \ldots \ldots \ldots \ldots \ldots \ldots \ldots \ldots \ldots \ldots \ldots \ldots \ldots \ldots, 11.23$

11.9 Diagram of the CAPS System $\ldots \ldots \ldots \ldots \ldots \ldots \ldots \ldots \ldots \ldots \ldots \ldots \ldots \ldots \ldots \ldots \ldots \ldots, 24$

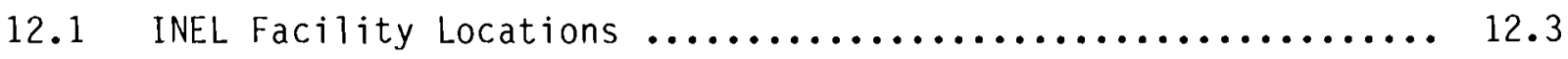

12.2 Gaseous Waste Systems Exhausting to the Main Stack .......... 12.10

12.3 Simplified Flow Diagram for Recovering Krypton and

Xenon from the Purified Dissolver Off-Gas Using

Cryogenic Distillation .............................. 12.16

13.1 Regional Map Showing Location of LLNL and SNLL $\ldots \ldots \ldots \ldots \ldots 13.3$

13.2 Site Map of LLNL $\ldots \ldots \ldots \ldots \ldots \ldots \ldots \ldots \ldots \ldots \ldots \ldots \ldots \ldots \ldots \ldots . \ldots \ldots, 13.4$

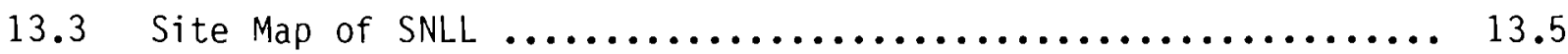

13.4 Block Diagram of the ECT in Use at the Tritium Research

Facility $\ldots \ldots \ldots \ldots \ldots \ldots \ldots \ldots \ldots \ldots \ldots \ldots \ldots \ldots \ldots \ldots \ldots \ldots \ldots, 13.8$

13.5 Block Diagram of the ECT in Use at the Rotating

Target Neutron Source ................................... 13.10

13.6 Block Diagram of the ECT in Use at the $100-\mathrm{MeV}$

Linear Accelerator Facility ............................ 13.11

13.7 Block Diagram of the Gas Purification System at the
Tritium Research Laboratory $\ldots \ldots \ldots \ldots \ldots \ldots \ldots \ldots \ldots \ldots \ldots \ldots \ldots \ldots \ldots \ldots \ldots$

13.8 Block Diagram of the Vacuum Effluent Recovery System
at the Tritium Research Facility $\ldots \ldots \ldots \ldots \ldots \ldots \ldots \ldots \ldots \ldots \ldots \ldots \ldots \ldots \ldots \ldots$

Block Diagram of the ECT in Use at the
Metallurgy Laboratory $\ldots \ldots \ldots \ldots \ldots \ldots \ldots \ldots \ldots \ldots \ldots \ldots \ldots \ldots \ldots \ldots \ldots \ldots \ldots \ldots$
13.14 
14.1 Location of the Los Alamos National Laboratory $\ldots \ldots \ldots \ldots \ldots . . . .14 .3$

14.2 Los Alamos National Laboratory's Technical Areas and Adjacent Communities ................................. 14.4

14.3 Block Diagram of Existing Emission Control Technology

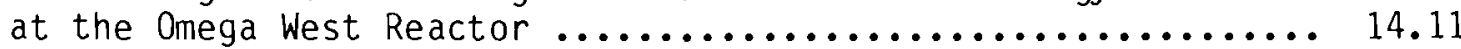

14.4 Block Diagram of an Atmospheric Pressure Air Storage System to Reduce Argon-41 Emissions from the Omega West Reactor Stack

14.5 Block Diagram of the LAMPF Ventilation System $\ldots \ldots \ldots \ldots \ldots \ldots . .14 .15$

14.6 Block Diagram of an Air Storage System for the Air Flowing to the LAMPF Ma in Stack $. . . \ldots \ldots \ldots \ldots \ldots \ldots . . . .14 .18$

14.7 Block Diagram of Existing Emission Control Technology ........ 14.19

14.8 Block Diagram for a Tritium Recovery System for Air Flowing to Stack FE-6 at the Tritium Handling Facility ........ 14.22

14.9 Block Diagram of the Filtration System for the South Stack Serving Wing 3 of the Chemistry Metallurgy Research Building ................................... 14.26

14.10 Block Diagram of a HEPA Filter System to Process the Air Flowing to the South Stack of Wing 3 of the Chemistry Metallurgy Research Laboratory

14.11 Block Diagram of a HEPA Filter System to Treat Air Flowing to the Main Stack of Building 3 at the DP Site ....... 14.30

14.12 Block Diagram of Existing Emission Control Technology for the Core Wing Stack at the Radiochemistry Site .......... 14.32

14.13 Block Diagram of a HEPA Filter System to Remove Plutonium from the Air Flowing to the Core Wing Stack

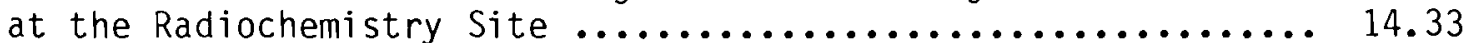

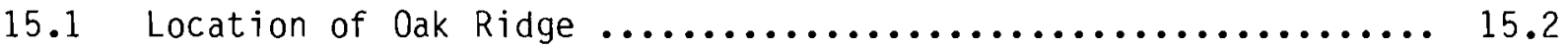

15.2 Location of Facilities at Oak Ridge National Laboratory, with Major Sources Highlighted ................ 15.4

15.3 Location of Facilities at Oak Ridge Gaseous Diffusion Plant ..................................... 15.5

15.4 Location of Facilities at the Y-12 Plant, with Major Sources Highlighted 
15.5 Flow Diagram of the ORGDP Purge Cascade $\ldots \ldots \ldots \ldots \ldots \ldots \ldots \ldots . \ldots \ldots$

15.6 Proposed Emission Control at West Head House $\ldots . . . \ldots \ldots \ldots . . .15 .38$

15.7 Proposed Emission Control at $\mathrm{C}-1$ Wing $\ldots \ldots \ldots \ldots \ldots \ldots \ldots \ldots . \ldots \ldots 2$

15.8 Air Emission Pathway During $1981 \ldots \ldots \ldots \ldots \ldots \ldots \ldots \ldots \ldots \ldots \ldots \ldots$

15.9 Emission Pathways Planned by March $1985 \ldots \ldots \ldots \ldots \ldots \ldots \ldots \ldots$

15.10 Proposed Emission Control of E-Wing Laboratories .......... 15.46

16.1 Paducah Gaseous Diffusion Plant ..................... 16.2

16.2 Paducah Gaseous Diffusion Plant Site Plan ................ 16.3

16.3 C-310 B1dg. Top Purge Effluent Treatment System .......... 16.9

17.1 Map of the Portsmouth Gaseous Diffusion Plant Area ........ 17.2

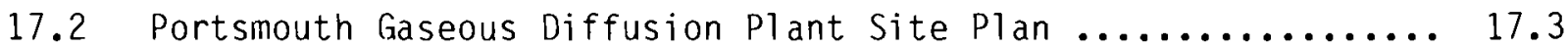

$17.3 \quad \mathrm{X}-326 \mathrm{Bldg}$. Top Purge Effluent Treatment System .......... 17.7

18.1 General Location of the Rocky Flats Plant Within
a $50-M i l$ Radius $\ldots \ldots \ldots \ldots \ldots \ldots \ldots \ldots \ldots \ldots \ldots \ldots \ldots \ldots \ldots \ldots \ldots . \ldots \ldots$

18.2 Typical Building Dry Air Ventilation System $\ldots \ldots \ldots \ldots \ldots \ldots \ldots$.......

18.3 Typical Glove Box Dry Air Ventilation System ............ 18.6

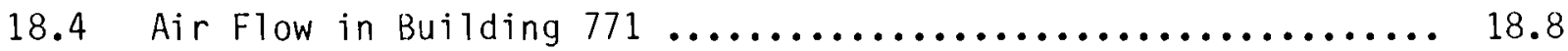

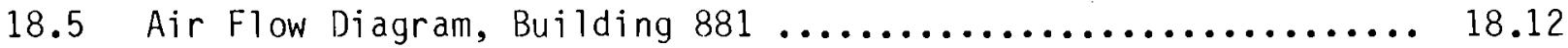

18.6 Air Flow Diagram, Buildings 559 and $561 \ldots \ldots \ldots \ldots \ldots \ldots \ldots \ldots$

18.7 General Exhaust Air Flow ........................ 18.15

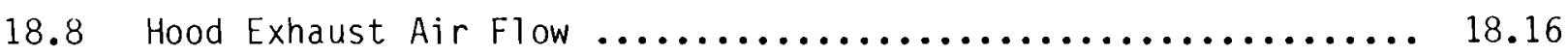

18.9 Glove Box Exhaust Air Flow ............................. 18.17

19.1 Location of Savannah River Plant $\ldots \ldots \ldots \ldots \ldots \ldots \ldots \ldots \ldots \ldots \ldots \ldots \ldots$

19.2 Savannah River Plant Site $\ldots \ldots \ldots \ldots \ldots \ldots \ldots \ldots \ldots \ldots \ldots \ldots \ldots . \ldots \ldots$

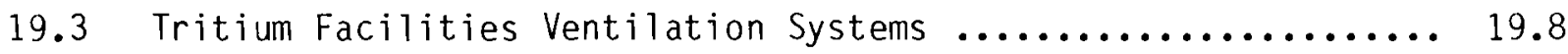


19.4 Hopcalite Stripper and Zeolite Bed System, with

"Serpentine" Holdup Line ............................ 19.9

19.5 Holdup Tank System, with Hopcalite ${ }^{\circledR}$ Stripper and Zeolite Bed

19.6 105-P, K, and C Reactor Airborne Effluents Emission

Controls and Measurements

19.7 F-Area Airborne Effluents Emission Controls and

Measurements

19.8 H-Area Separations Plant Ventilation System and Associated H-Area Ventilation Systems

20.1 SLAC Site Location Relative to Stanford University and Surrounding Communities ....................... 20.2

20.2 Air View of the SLAC Site Showing the Accelerator and Research Facility

20.3 SLAC Research Area and Surrounding Community ............ 20.5

21.1 Flow Diagram of Effluent Removal System at Mound Facility ................................... 21.13

21.2 Schematic of Tritium Recovery System, Pinellas Plant ....... 21.18 



\section{TABLES}

1.1 EPA-Calculated Annual Weighted Sum Radiation Dose

Equivalents to the Maximum-Exposed Individual at the

Site Boundary from Radionuclide Emissions to the

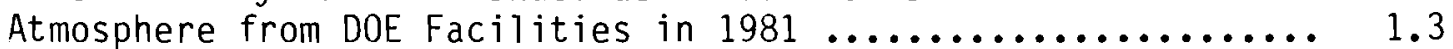

2.1 Particle Collection Efficiencies for DBGF Filters,

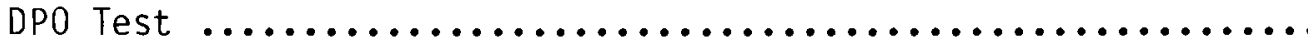

2.2 Comparison of Some Important Dust

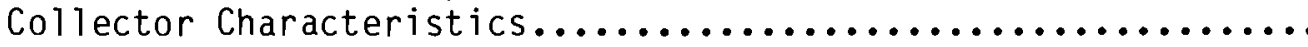

3.1 Identified or Postulated Gaseous Iodine Forms $\ldots \ldots \ldots \ldots \ldots \ldots . . .2$

4.1 Properties of the Rare Gases $\ldots \ldots \ldots \ldots \ldots \ldots \ldots \ldots \ldots \ldots \ldots \ldots . \ldots . \ldots . \ldots$

4.2 Half-Lives of the Noble Gas Nuclides .................... 4..3

4.3 Collective Dose Commitment $\ldots \ldots \ldots \ldots \ldots \ldots \ldots \ldots \ldots \ldots \ldots \ldots \ldots . \ldots . \ldots . \ldots$

4.4 Capital Cost Comparison for Krypton Removal .............. 4.19

4.5 Overall Differential Cost Comparison ................... 4.19

4.6 Properties of 50-Liter Cylinders Containing Krypton-85 ...... 4.20

4.7 Capital Cost Comparison for Krypton Immobilization ......... 4.28

4.8 Annual Storage Costs for $169 \mathrm{~m}^{3}$ of Radiokrypton

in a Reference Krypton Storage Facility ................. 4.35

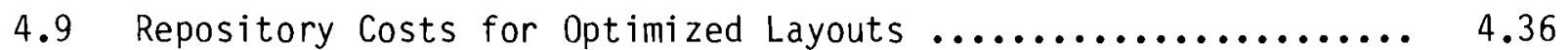

4.10 Nonradiological Transportation Hazards During 30 Years with Cylinders of Pressurized Gas in a

Geologic Facility .............................. 4.37

5.1 Tritium-Producing Reactions $\ldots \ldots \ldots \ldots \ldots \ldots \ldots \ldots \ldots \ldots \ldots \ldots \ldots \ldots \ldots \ldots \ldots$

5.2 Tritium Production Rates $\ldots \ldots \ldots \ldots \ldots \ldots \ldots \ldots \ldots \ldots \ldots \ldots \ldots \ldots$

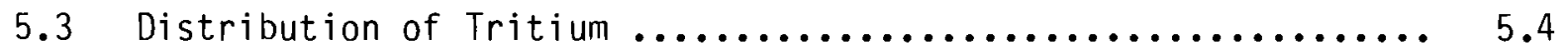

7.1 Atmospheric Emissions of Radionuclides, Feed
Materials Production Center, CY 1981 and CY $1982 \ldots \ldots \ldots \ldots \ldots$

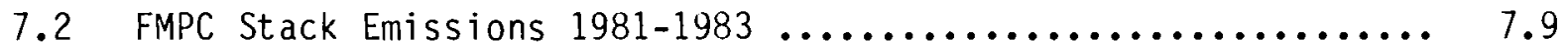


7.3 FMPC Stacks Not Operated in 1981 or $1982 \ldots \ldots \ldots \ldots \ldots \ldots \ldots \ldots$

7.4 FMPC Operating Stacks with No Emissions

Recorded in 1981 or 1982 ............................ 7.11

7.5 Dust Collector Characteristics $\ldots \ldots \ldots \ldots \ldots \ldots \ldots \ldots \ldots \ldots \ldots \ldots . \ldots \ldots$

7.6 Correlation of Mass to Curie Value for Natural Uranium

Emissions at the FMPC ............................ 7.14

7.7 FMPC Stack Emissions Recorded in $1981 \ldots \ldots \ldots \ldots \ldots \ldots \ldots \ldots \ldots$

7.8 Major 1981 Emission Sources at the FMPC .............. 7.16

7.9 Efficiency of Emission Control Technology Needed to

7.10 Emission from the Primary Particulate

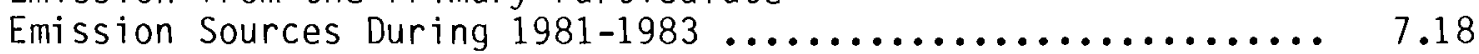

7.11 Dust Collectors and Scrubbers with Annual Emissions

$\geqslant 5 \mathrm{~kg} \mathrm{U}$ During the Period 1981-1983 ..................... 7.19

7.12 Stack Information 0btained from Blueprints $\ldots \ldots \ldots \ldots \ldots \ldots \ldots . . \ldots 7 . \ldots$

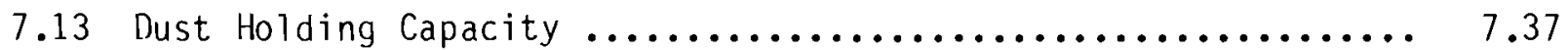

7.14 Conceptual Design Cost Estimate - Plant 4, G4-2 .......... 7.41

7.15 Conceptual Design Cost Estimate - Plant 4, G4-5 .......... 7.42

7.16 Conceptual Design Cost Estimate - Plant 4, G4-7 .......... 7.43

7.17 Conceptual Design Cost Estimate - Plant 4, G4-14 ........... 7.44

7.18 Conceptual Design Cost Estimate - P1ant 5, G5-249 ........ 7.45

7.19 Conceptual Design Cost Estimate - Plant 5, G5-254 ......... 7.46

7.20 Conceptual Design Cost Estimate - Plant 5, G5-256 ......... 7.47

7.21 Conceptual Design Cost Estimate - Plant 5, G5-260 ......... 7.48

7.22 Conceptual Design Cost Estimate - Plant 5, G5-261 ......... 7.49

7.23 Conceptual Design Cost Estimate - Plant $5,55 \ldots \ldots \ldots \ldots \ldots \ldots . . . . .50$

7.24 Conceptual Design Cost Estimate - Plant 8, G43-27 ......... 7.51

7.25 Conceptual Design Cost Estimate - Plant 8, $8024 \ldots \ldots \ldots \ldots \ldots .7 .52$ 
7.26 Conceptual Design Cost Estimate - Plant 8, Rotary Kiln(s) .... 7.53

7.27 Conceptual Design Cost Estimate - Plant 8, 0xidation \#1(s).... 7.54

7.28 Cost Estimates for Acquisition and Installation of HEPA Filter Systems on Stacks Having Emissions $\geqslant 5 \mathrm{~kg}$

Uranium During 1981-1983; in 1984 Dollars

7.29 Summary of Estimated Cost of and Expected Pulmonary Dose

Resulting from Installation of Proposed Emission Control

Technology at the FMPC

10.1 Reduction in Carbon-11 Emissions as a Function of

Air Storage Volume

10.2 Capital Cost Estimate for an Air Storage Tank System to Provide a Carbon-11 Decontamination Factor of 100

10.3 Operating Cost Estimate for an Air Storage System to

Provide a Carbon-11 Decontamination Factor of 100

10.4 Estimated Capital Costs for Air Storage Systems as a Function of the Carbon-11 Decontamination Factor Required - in 1982 Dollars

11.1 Estimated Annual Airborne Radionuclide Releases

from PUREX

11.2 Major Release Points at Hanford $\ldots \ldots \ldots \ldots \ldots \ldots \ldots \ldots \ldots \ldots$

11.3 Airborne Releases in 1981 from the $N$-Reactor

105-N Ventilation Stack

11.41981 Emissions from the Fast Flux Test Facility ........... 11.26

12.1 INEL Major Contractors and Facility Responsibility ........ 12.2

12.2 INEL Airborne Radioactive Releases for $1981 \ldots \ldots \ldots \ldots \ldots \ldots \ldots$

12.3 ATR Waste Gas Stack Airborne Activity ................. 12.7

12.4 Typical ATR Gaseous Effluent Composition $\ldots \ldots \ldots \ldots \ldots \ldots \ldots \ldots$

12.5 ICPP Waste Gas Stack Airborne Activity ................ 12.15

14.1 Descriptions of the Active Technical Areas at the Los Alamos National Laboratory and Their Associated Programs 
14.2 Radionuclides Routinely Released to the Atmosphere at the Los Alamos National Laboratory in $1981 \ldots \ldots \ldots \ldots \ldots \ldots . . . .14$

14.3 The Major Atmospheric Discharge Points at LANL to be Evaluated in Detail Based on 1981 Release Data ........... 14.8

14.4 The Estimated Reductions in the Argon-41 Released from the Omega West Reactor Stack as a Function of the Air Storage Volume Provided ............................ 14.12

14.5 Capital Cost Estimate for An Atmospheric Pressure Air Storage Tank System to Provide an Argon-41 Decontamination Factor of Eight for Air Flowing to the Omega West Reactor Stack

14.6 Operating Cost Estimate for an Atmospheric Pressure Air Storage System Providing an Argon-41 Decontamination Factor of Eight

14.7 Estimated Capital Cost for Air Storage Systems as a Function of the Argon-41 Decontamination Factor Required

14.8 Atmospheric Emissions from the LAMPF Main Stack in CY 1981

14.9 Estimated Capital Cost for a Tritium Removal System, Including Waste Handling

14.10 Estimated Operating Cost for a Tritium Removal System, Including Waste Disposal

14.11 Capital Cost Estimate for HEPA Filter System for the Air Flowing to South Stack of Wing 3 of the Chemistry Metallurgy Research Building

15.1 Anticipated New Discharge Rates for Radioactivity at CRGDF

15.2 Lesser Sources of Airborne Radioactive Emissions at Oak Ridge

15.3 Pulmonary Dose to the Maximum Exposed Individual from Identified Sources at the Oak Ridge Y-12 Plant

15.4 Efficiency of Emission Control Technology Needed to Reduce Oak Ridge Pulmonary Dose by $50 \%$ 
15.6 Comparison of Particulate Emissions from Important Sources

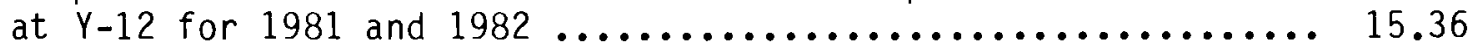

15.7 Estimated Cost for Emission Control at West Head House $\ldots \ldots \ldots$ 15. 39

15.8 Estimated Cost for Emission Control on $C-1$ Wing ........... 15.43

15.9 Estimated Cost for Emission Control at E-Wing ........... 15.47

15.10 Annual Operating Costs for ECT Proposed at $Y-12 \ldots \ldots \ldots \ldots . \ldots 15.47$

5.11 Summary of Estimated Cost of and Expected Pulmonary Dose

Resulting from Installation of Proposed Emission Control

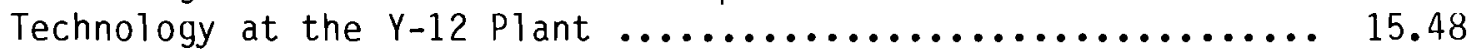

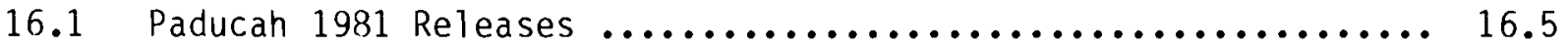

16.2 Principal Past Release Points at Paducah $\ldots \ldots \ldots \ldots \ldots \ldots \ldots \ldots$..........

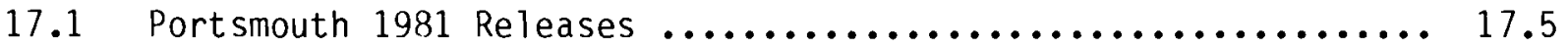

18.1 RFP Airborne Radioactive Releases for $1981 \ldots \ldots \ldots \ldots \ldots \ldots \ldots$...... 18.3

18.2 Estimated Capital Costs of Providing a Third Stage

of HEPA Filters on the 771 Building Main Plenum ............ 18.10

19.1 Atmospheric Releases and Calculated Dose

Commitments -1981 ................................. 19.5

19.2 1981 Dose to Population, by Radionuclide and Source ........ 19.6

19.3 Radioactivity Releases from Reactor Areas - 1981 .......... 19.13

19.4 Radioactivity Releases from Separations Areas - 1981 ....... 19.19

20.1 Airborne Radioisotopes Produced by Operation of the

Linear Accelerator at SLAC ......................... 20.4

20.2 Reduction in Argon-41 Emissions Obtainable as a

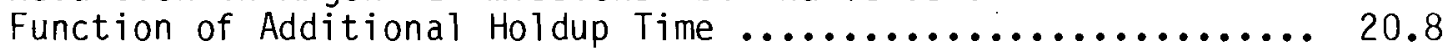

20.3 Estimated Capital Cost for an Atmospheric Pressure

Air Storage Tank for Air Vented Through the B-Target

Room Exhaust Fan ................................. 20.10

21.1 Atmospheric Emissions of Radionuclides from Ames

Laboratory Research Reactor Containment Stack

for CY 1981 
21.2 Atmospheric Emissions from DOE Facilities at SSFL

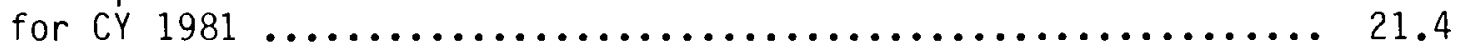

21.3 Atmospheric Emissions of Radionuclides from BCL

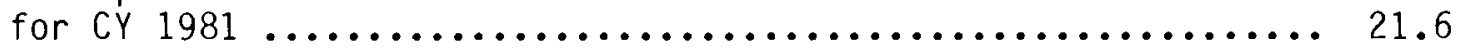

21.4 Atmospheric Emissions of Radionuclides from BAPL

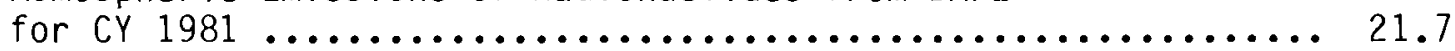

21.5 Atmospheric Emissions of Radionuclides, Feed Materials

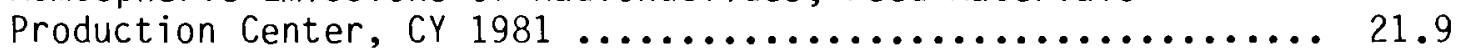

21.6 Major Airborne Radionuclide Emissions from KAPL

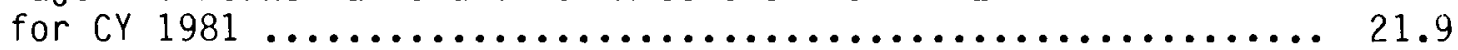

21.7 Airborne Radionuclide Emissions from LBL for CY $1981 \ldots \ldots \ldots \ldots$ 21.11

21.8 Sources of Major Tritium Releases from Mound Facility,

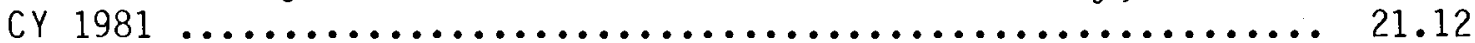

21.9 Airborne Radioactive Effluents from Operations at Nevada Test Site ................................ 21.15

21.10 Airborne Radionuclide Releases from Pinellas Plant

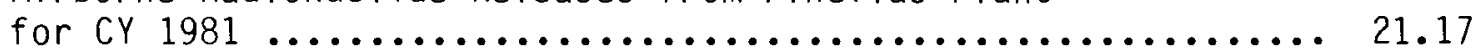

21.11 Airborne Radionuclide Emissions from Sandia Facilities for CY 1981 


\subsection{INTRODUCTION}

The U.S. Environmental Protection Agency (EPA) has authority, under the Clean Air Act as amended, to set standards for the emission of hazardous pollutants into the atmosphere. (1) The Act specifically includes emissions from facilities owned by the federal government and specifically provides for a review of radioactive pollutants. In 1979, the EPA Administrator declared radionuclides to be hazardous air pollutants, (2) and in 1983 the Administrator published proposed standards. (2a) At the same time the Pacific Northwest Laboratory (PNL) prepared the draft of this document (PNL-4621 Draft), (2b) and EPA published a draft background information document. (2C) No specific comments on PNL-4621 Draft were entered into the EPA docket. (2a) Thus the final document contains no responses to comments.

The PNL draft document contains information on existing control technology for emission of radionuclides into the atmosphere from U.S. Department of Energy (DOE) facilities and on potential new technology that could be used to further reduce these emissions. The EPA draft document contains dose rate calculations for DOE facilities based on 1981 radionuclide emissions as reported by DOE.

Particulate uranium emissions to the atmosphere from the Oak Ridge $Y-12$ Plant and the Feed Materials Production Center (FMPC) prompted EPA to ask PNL to look again at control technology at these two facilities. In March 1984, a team from PNL and Kaiser Engineers Hanford (KEH) visited the Oak Ridge $\mathrm{Y}-12$ Plant and the FMPC as guests of the DOE Oak Ridge Operations Office. From information obtained during these visits and later from the 0ak Ridge Operations Office, PNL prepared Section 7.0, Feed Materials Production Center, and Section 15.3, 0ak Ridge $Y-12$ Plant, of this final document. PNL wishes to thank B. J. Mavis and G. J. Marciante of DOE's Oak Ridge Operations Office, for their assistance.

\subsection{PROJECT DESCRIPTION}

The purpose of this project is to provide information to the EPA on existing technology for the control of emission of radionuclides into the air from 
DOE facilities, and to provide EPA with information on possible additional control technologies that could be used to further reduce these emissions. This final report differs from the draft in the Summary and in Sections 1.0 , 7.0 and 15.3 .

This report includes discussions of emission control technologies for particulates, iodine, rare gases, and tritium; and includes specific discussions of existing emission control technologies at 25 DOE facilities. Potential additional emission control technologies are discussed for 14 of these facilities. The facilities discussed were selected by EPA on the basis of preliminary radiation pathway analyses.

\subsection{EMISSIONS DATA}

Emissions data used in this project were supplied by DOE for each of its sites. Calendar year 1981 data are reproduced in Appendix A. (3) Emissions data for 1979 were used by EPA to select the DOE sites included here, and 1981 emissions data were used by Pacific Northwest Laboratory (PNL) to select the individual stacks on each site for further study (i.e., stacks considered in the draft document).

As required by DOE policy, DOE prepares an environmental monitoring report annually for each of its sites. These reports include a summary of radioactive and nonradioactive emissions (both airborne and liquid) at the site, as well as the results of DOE's onsite and offsite monitoring activities. Emissions are sufficiently low that offsite dose rates generally cannot be measured and must be calculated. The site reports are summarized in an annual report for a 11 DOE sites. (4)

\subsection{SITE SELECTION}

DOE sites were selected by EPA for inclusion in this study on the basis of preliminary pathway analyses carried out at EPA's Eastern Environmental Radiation Facility (EERF), based on 1979 data. Those sites yielding the largest individual (organ or whole-body) or collective calculated dose rates were 
selected for detailed study, and those yielding lesser dose rates were selected for a more cursory study. Calculated dose rates based on 1981 emission data are discussed in Reference $2 c$.

\subsection{STACK SELECTION, EXISTING AND POTENTIAL CONTROL TECHNOLOGY, AND COST ESTIMATION}

Only the stacks at each site contributing the most to the dose rate at the site boundary were selected for study. An attempt was made to include those stacks whose combined contribution was at least $90 \%$ of the dose.

Because dose calculations had not yet been completed by EPA for individual stacks (now available in Reference $2 c$ ), a procedure for stack selection was developed by PNL that involved use of the concentration limits specified in Table II of Appendix B of Title 10 Part 20 of the Code of Federal Regulations (10 CFR 20, Appendix B). Column 1 of Table II lists maximum permissible concentrations of radionuclides in air as specified by the U.S. Nuclear Regulatory Commission (NRC) for unrestricted areas. Because each of these concentrations should be based on the same unit dose or risk, each can be used as a factor to determine the approximate relative risk from annual releases at a given stack: (annual release by isotope from a given stack) $\div$ (allowed concentration by isotope/unit risk) $=$ (risk from a given isotope at a given stack). Comparison and summation of the risks by isotope and by stack gives both a relative risk from each stack and a relative risk from each isotope. Simple inspection then leads to selection of appropriate stacks for study. This stack selection method ignores local geography and meteorology, and does not properly include pathway analyses; it does, however, permit stack selection on the basis of a simple conversion of curie releases to approximate potential risks. In order not to confuse EPA's dose calculations with PNL's stack selection process, the term "hypothetical" dose or risk is used when referring to PNL's stack selection process in Sections 7 through 21 .

A table virtually identical to Table II in Appendix B of 10 CFR 20 appears in Chapter XI of DOE Order 5480.1A. The entries in the NRC table (10 CFR 20) are sometimes referred to as maximum permissible concentrations (MPC), while 
the entries in the DOE table are sometimes referred to as concentration guides (CG). These two terms are used synonymously in this report.

In some instances, a stack is monitored to ensure that the concentration of radionuclides in the stack never exceeds MPC or CG for unrestricted areas. If this is known to be the case, potential additional technology is not described unless there is some unique reason to do so.

Following site and stack selection, PNL contacted appropriate DOE operations offices (see Appendix B) for information on each site. Existing and potential control technologies, and costs of potential control technologies, as furnished by the DOE operations offices, were used in this report wherever possible. Other information was taken from the cited references. DOE operations offices were also invited to review and comment on the working draft document.

PNL does not endorse the need or lack of need for additional control technology. Rather, PNL presents in this document control technology that is presently installed at DOE sites, and other technology already in existence that could be applied.

Information on the cost of potential control technology was prepared by DOE site representatives, by PNL, and/or by Kaiser Engineers Hanford (KEH). The reader is advised not to rely too heavily on the cost information presented here, because the specifications from which the costs were estimated were often incomplete and not in sufficient engineering detail to permit accurate costs to be estimated. PNL initially did not make site visits, and in most cases assumed that a retrofit could be made without extensive structural modifications or additions and without extensive upgrading of air handling equipment. This assumption is not appropriate in all cases. However, neither the time, the information, nor the resources were available to permit PNL to prepare a complete conceptual design and cost estimate on each stack in the study (over 40 stacks). The cost estimates do not, in general, include the cost of radioactive waste disposal. Costs of additional radiation monitoring equipment are also not included.

Following publication of EPA's proposed regulations and background information document, EPA asked PNL to reexamine the FMPC and Oak Ridge Y-12 Plant 
(as stated in Section 1.0). PNL and KEH staff members visited these two plants, received further information from DOE and contractor representatives, and prepared Sections 7.0 and 15.3 .

1.5 HISTORY OF DOE PROGRAMS TO REDUCE AIRBORNE RADIOACTIVE EFFLUENTS

Historically, the Department of Energy and its predecessor agencies(a) have followed the recommendations of the International Commission on Radiological Protection (ICRP), the National Council on Radiation Protection and Measurements (NCRP), and the Federal Radiation Council (FRC) in controlling airborne radioactive effluents. This includes the principle of maintaining radioactive effluents at levels As Low As Reasonably Achievable (ALARA) below the recommended radiological standards. In 1960, the Department (Atomic Energy Commission at that time) adopted the FRC radiation protection guides as its standards for protecting members of the public in the vicinity of DOE facilities. The FRC guide for maximum exposure to individual members of the public is 500 millirem per year, a continuation of the ICRP and NCRP recommended limit. The Department's ALARA program objective has been used to limit public exposure to less than a few percent of the FRC guide.

In 1970, the Department (then the AEC) initiated a comprehensive effluent reduction program, in addition to its routine ALARA program, in an effort to assure the public that exposures would be held to the lowest levels feasible. In November of 1970, the AEC's general manager instructed all operations office managers to initiate effluent reduction activities in two phases. The first phase began in FY 1971 using available funds. The second phase began in FY 1972 using funds specifically earmarked for controls. The Effluent Reduction Program involved between $\$ 12$ and $\$ 25$ million per year in funds to upgrade radioactive emission controls at AEC facilities, for an estimated total of over $\$ 500$ million in the decade 1970-1980.(5)

The focus of the Effluent Reduction Program was to reduce quantities (rather than concentrations) of radioactivity released to the environment.

(a) The U.S. Department of Energy was created from the Energy Research and Development Administration (ERDA) in 1977, which was created from the Atomic Energy Commission (AEC) in 1974. 
Emphasis was first placed on those radionuclides in emissions having the greatest potential for exposing individual members of the public and population groups. Radionuclides that received the greatest attention were argon-41, krypton-85, tritium, and transuranic elements, which are alpha emitters.

As part of the Effluent Reduction Program, a uniform system of reporting effluent data and information was developed ${ }^{(6)}$ to facilitate overall management of effluent control, surveillance and reduction programs, including a computerbased system for handling effluent monitoring data. Prior to establishment of the Effluent Information System, such data were collected manually on a nonuniform basis.

Effluent monitoring is required to verify that each DOE facility is functioning as designed and that the effluent control systems are performing as planned and expected. Effluent data are acquired by each site, usually on a daily or weekly frequency, and evaluated for irregularities or trends. On an annual basis, effluents that have a potential to go offsite are required to be monitored and reported to central computer-based information systems. These are the Effluent Information System (EIS) and the Onsite Discharge Information System (ODIS), developed in 1971. Through these systems DOE can identify and observe effluent control problems on a year-to-year basis. The EIS has become a useful DOE management tool in monitoring and reducing effluent releases from its facilities.

Some measure of the effectiveness of the DOE Effluent Reduction Program can be seen in the series of bargraphs following this discussion. Figure 1.1 shows the total offsite radioactivity released to the air (and water) from 1971 through 1980. The general reduction noted is not adjusted for variations in operational activities. The largest increases in effluents in the years 1977 and 1978 consisted of increased releases at the Hanford site and the release of short-lived radionuclides produced in the then just-operational Los Alamos Meson Physics Facility. Reductions at the Savannah River Plant occurred over the same years.

In the early 1970s, plutonium particulate effluent filtration systems were extensively upgraded at all major DOE plutonium installations resulting in the substantial reductions in plutonium discharges evident in Figure 1.2 . 


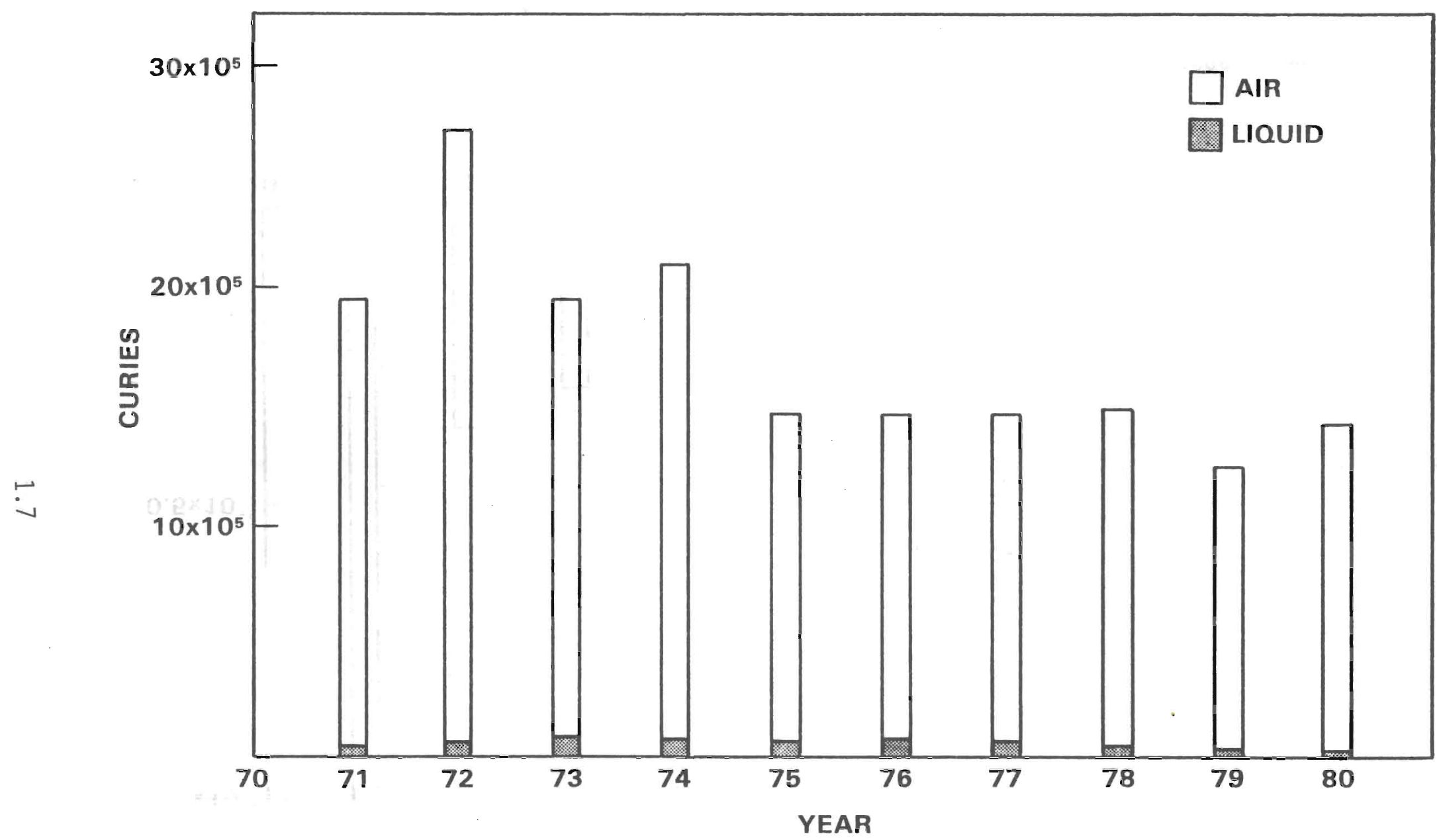

FIGURE 1.1. Total Radioactivity Released from DOE Facilities 


$$
\text { Illysument }
$$


Likewise, Figures 1.3, 1.4, and 1.5 provide an indication of the generally downward trend achieved at DOE facilities in ${ }^{4} 1_{\mathrm{Ar}},{ }^{85} \mathrm{Kr}$ and ${ }^{3} \mathrm{H}$ emissions. These isotopes comprise over $95 \%$ of the effluent from DOE facilities.

Environmental monitoring serves as a backup to the effluent monitoring system and is the most reliable indicator of environmental impact. Environmental radiological monitoring, including preoperational monitoring as appropriate, with emphasis on pathways of human exposure, is conducted by all DOE sites pursuant to DOE Order 5484.1. Since 1960, sites have been required to publish routine environmental monitoring reports evaluating environmental radioactivity concentrations and potential exposure. In 1977, DOE issued a comprehensive environmental monitoring guide( ${ }^{(7)}$ to assist the sites in performing the required environmental monitoring. Starting with CY 1977, a single annual executive summary of all of the site environmental monitoring reports has been published. In 1982, DOE developed a draft guide on effluent monitoring practices. This guide will be published for use in 1983.

Also beginning in 1971, DOE installations have been required, pursuant to DOE Order 5484.1, to assess annually the impact of radiation exposure to offsite populations. Assessments include estimation of site boundary exposure rate, exposure to the maximum potentially exposed individual, and the man-rem population dose within a radius of $80 \mathrm{~km}$. All significant exposure pathways are considered. In those instances in which pathway data are not available, dose calculations are based on diffusion/dispersion and uptake modeling using effluent source terms. Results of the public exposure assessments are required to be included in the annual environmental monitoring reports.

DOE also provides an overview and confirmation process to assure that its requirements are implemented. Overview is accomplished by: 1) routine contacts, 2) environmental information reporting systems, and 3) environmental protection program appraisals and audits. The appraisal program is set forth in DOE Order 5482.1A, "Environmental, Safety, and Health Appraisal Program." The program consists of internal audits by the operating level, confirmatory 


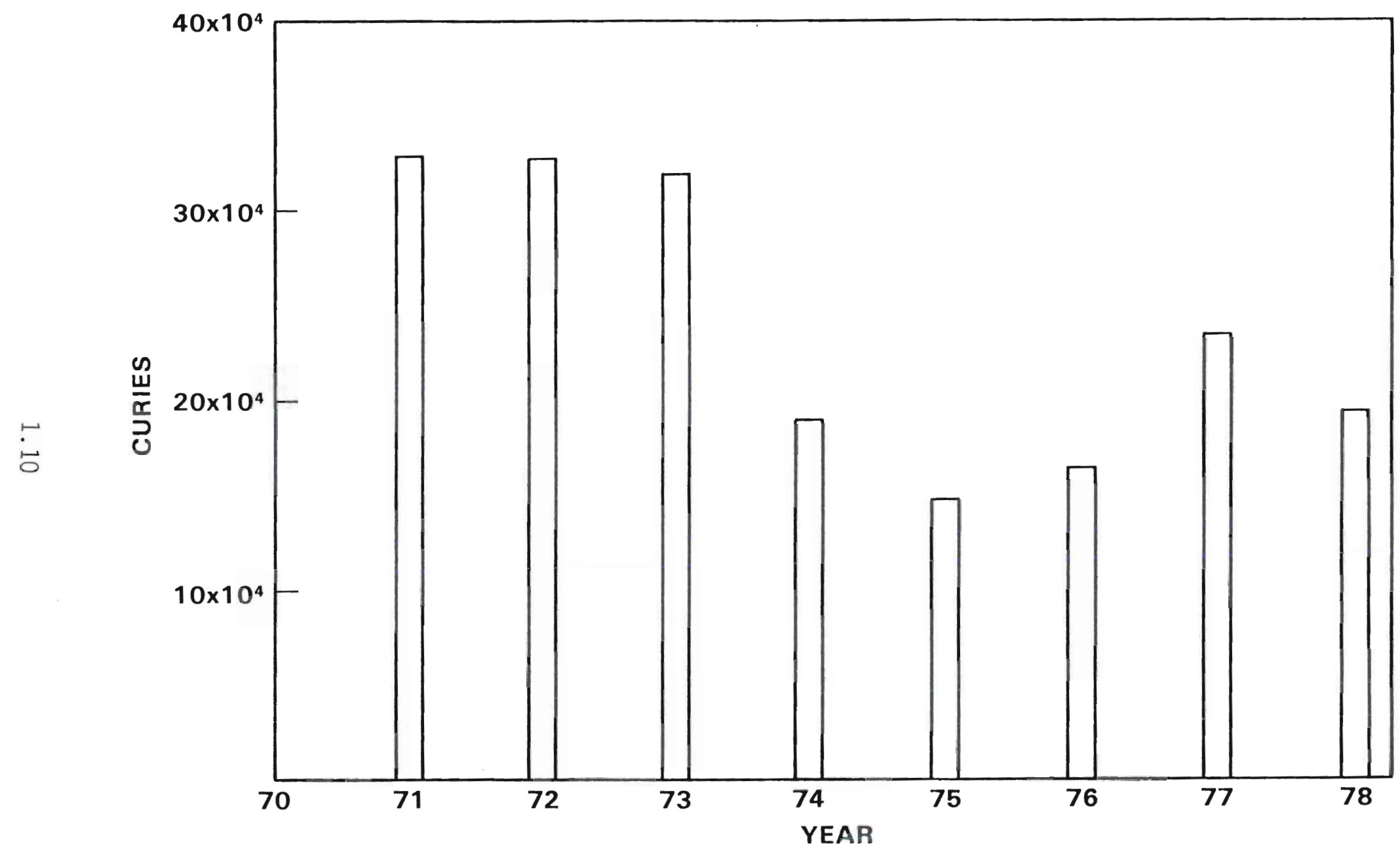

FIGURE 1.3. Total Argon-41 Released from DOE Facilities - Airborne Streams 


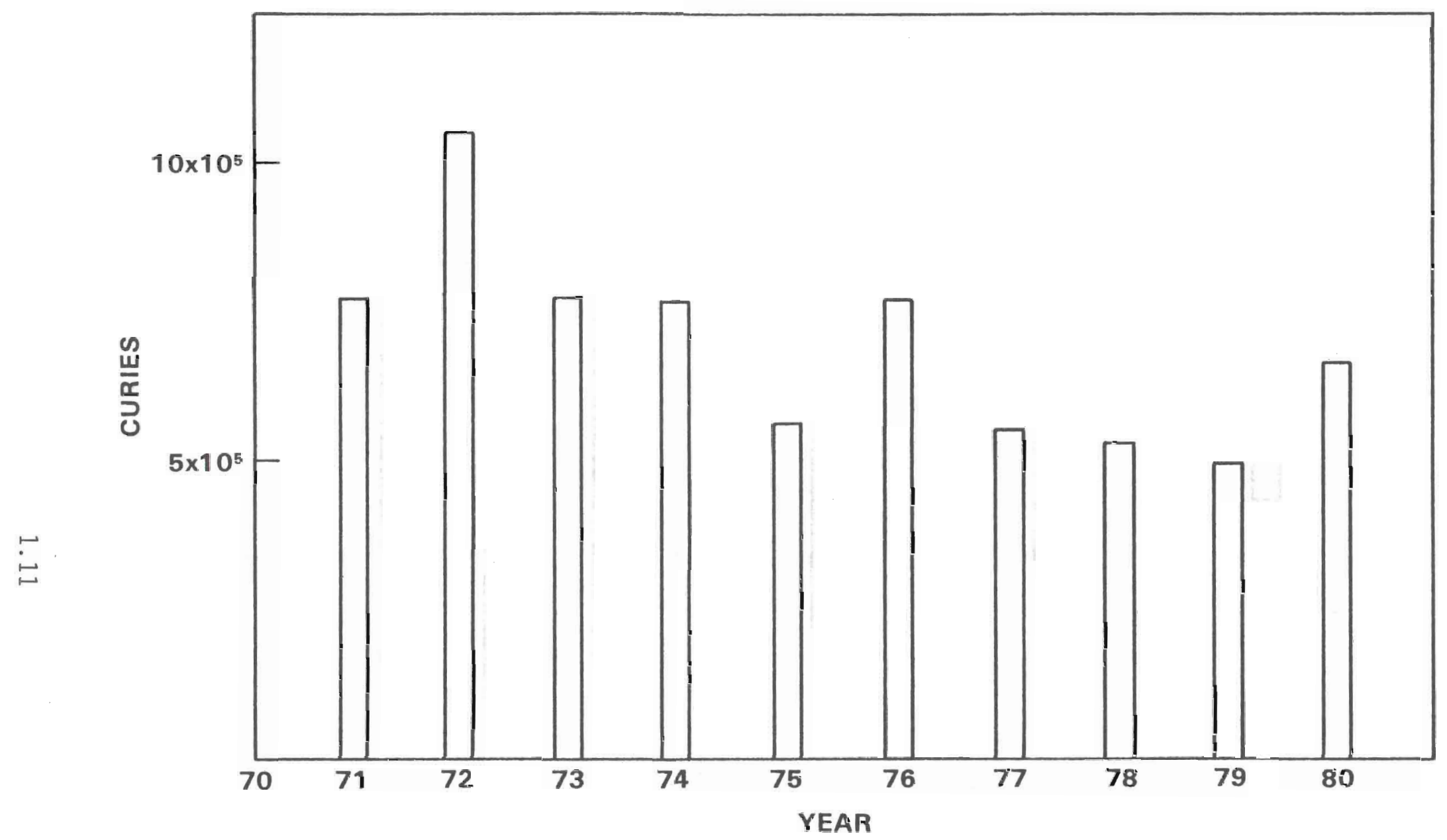

FIGURE 1.4. Total Krypton-85 Released from DOE Facilities - Airborne Streams 


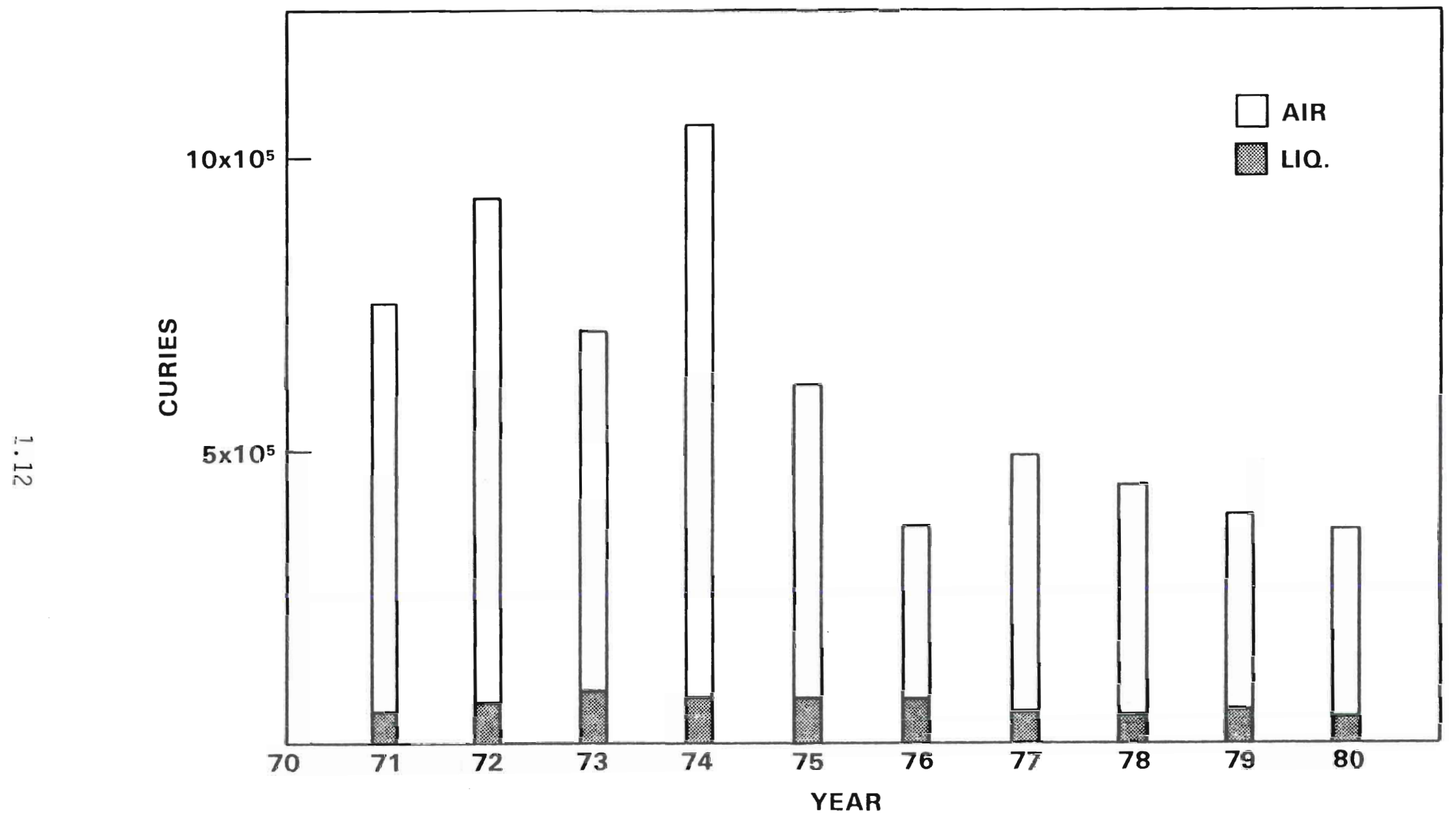

FIGURE 1.5. Total Tritium Released from DOE Facilities 
functional and management appraisals by a second-line organizational level, and functional and management appraisals by an independent office of DOE.

In summary, DOE efforts were intensified in FY 1970 to improve the management and control of radioactive releases from DOE facilities. The result has been a general downward trend in overall radioactive releases since that time in spite of an increase in operations at some installations. 


\section{REFERENCES}

1. 72 United States Code 7401 et seq.

2. Federal Register, December 27, 1979 (44 FR 76738).

3. U.S. Department of Energy Effluent Information System, EPA Release Point Analysis Report for Calendar Year 1981.

4. Summary of Annual Environmental Reports for CY 1980, Department of Energy Nuclear Sites. U.S. DOE, DOE/EP-0038, August 1982.

5. C. G. Welty, et a1., "The DOE Program for Control of Radioactive Releases to the Environment," In Proceedings of the Second U.S. DOE Environmental Control Symposium. CONF 800334, Vol. 2, p. 477ff, June 1980.

6. "Effluent and Environmental Monitoring and Reporting," U.S. Atomic Energy Commission Manual, Chapter 0513, 1973.

7. A Guide for Environmental Radiological Surveillance at ERDA Installations, ERDA 77-24, Energy Research and Development Administration, March 1977; revised as A Guide for Radiological Surveillance of U.S. Department of Energy Installations, D0E/EP-0023, JuTy 1981. 


\subsection{PARTICULATE CONTROL TECHNOLOGY}

In this section technologies available to control the emission of particulate matter into the atmosphere are discussed, including those technologies currently in use at DOE facilities and those that could be used. Also discussed are some novel particulate control technologies that are undergoing research and development.

\subsection{TECHNIQUES IN USE AT DOE SITES FOR EMISSION CONTROL} OF AIRBORNE PARTICULATE MATERIALS

The basic philosophy for controlling the emission of airborne particulate material in DOE facilities where significant quantities of radionuclides are handled is directional airflow coupled with a control technology (predominantly filtration). Figure 2.1 is a schematic diagram of the basic elements of the directional airflow philosophy. Airflow is directed from areas of less potential contamination to areas of greater potential contamination by the maintenance of a pressure differential between the areas. The lowest pressures are maintained at the locations of the greatest potential contamination. Air is exhausted from the facility at these locations through control devices such as filters. Other control devices may also be used on various pieces of equipment or for various areas which possess known potential for the generation of airborne particulate material. Control devices used for these purposes are selected for the local conditions and span the range of conventional and nonconventional devices. The exhaust from these devices is combined with the general facility exhaust and passed through the facility airborne particulate control technology. In all cases addressed here, the control technology used is a form of filtration. The three types of filters used and addressed here are: 1) high-efficiency particulate air (HEPA); 2) deep bed sand; and 3) deep bed glass fiber.

\subsubsection{High-Efficiency Particulate Air (HEPA) Filters}

By definition, a HEPA filter is a throwaway, extended medium, dry-type filter having: 1) a minimum particle removal efficiency of greater than 


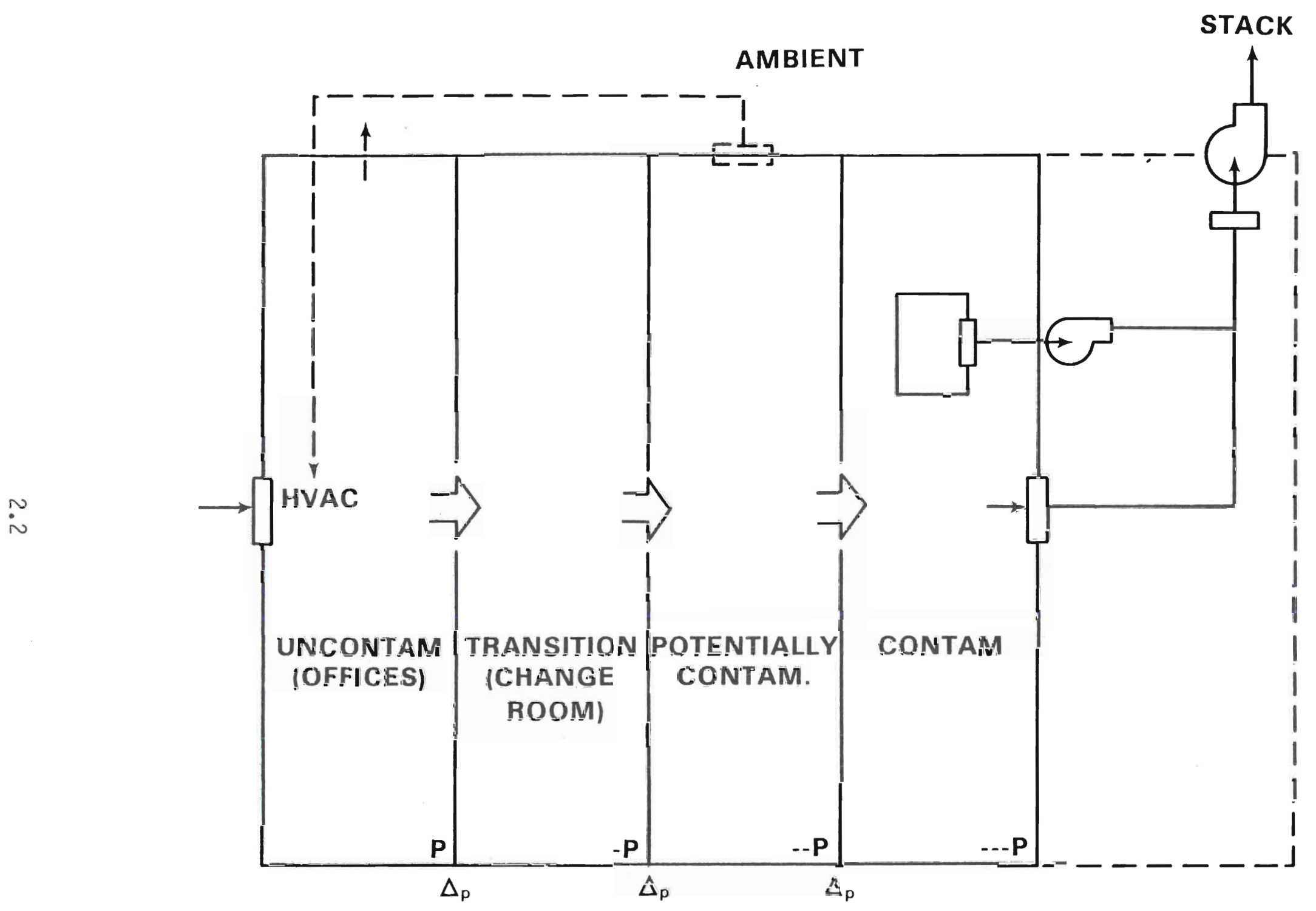

FIGURE 2.1. Directional Airflow 
99.97\% for $0.3 \mu \mathrm{m}$ particles, 2) a maximum resistance, when clean, of $250 \mathrm{~Pa}$ ( 1 inch $\mathrm{H}_{2} \mathrm{O}$ ) when operated at rated airflow capacity, and 3) a rigid casing extending the full depth of the medium (see Figure 2.2)(1).

Collection efficiency (the reciprocal of penetration) can be a function of particle size and nominal air velocity (see Figures 2.3 and 2.4). The Burchsted, Fuller, and Kahn(1) report is an excellent compendium of the essential information on the construction and testing of nuclear air cleaning systems (including those using HEPA, deep bed sand, and deep bed glass fiber). Readers desiring more specific and detailed information are referred to it.

Control of airborne particulate emission has been the theme of a biennial meeting of the nuclear industry in which filtration has been one of the major topics for over three decades.(2-9) In the 16 th of these conferences, first and Gilbert(10) reviewed some of the significant developments in highefficiency filtration for nuclear application and some of their observations are applicable here:

- The handbook by Burchsted, Fuller, and Kahn(1) is an excellent compendium on essential information for the construction and testing of high-efficiency air cleaning systems.

- Although intended as standards for the construction and testing of engineered safety systems for U.S. licensed nuclear power stations, ANSI N 509-1980, "Nuclear Power Plant Air Cleaning Units and Components", (12) and N 510-1980, "Testing of Nuclear Air Cleaning Systems, (13) can be and usually are applied to air cleaning systems in a wide range of nuclear facilities.

- Gains in understanding basic filtration mechanisms have been modest; with improvements achieved primarily from experimentation. Much remains to be done in this area. The 1974 paper by Anderson, Magee, and Jonas (14) "confirmed that 1) the inertial parameters make an insignificant contribution to the filtration of particles of this size $(0.26-0.32 \mu \mathrm{m})$ at the filtration velocities utilized, 2) the 


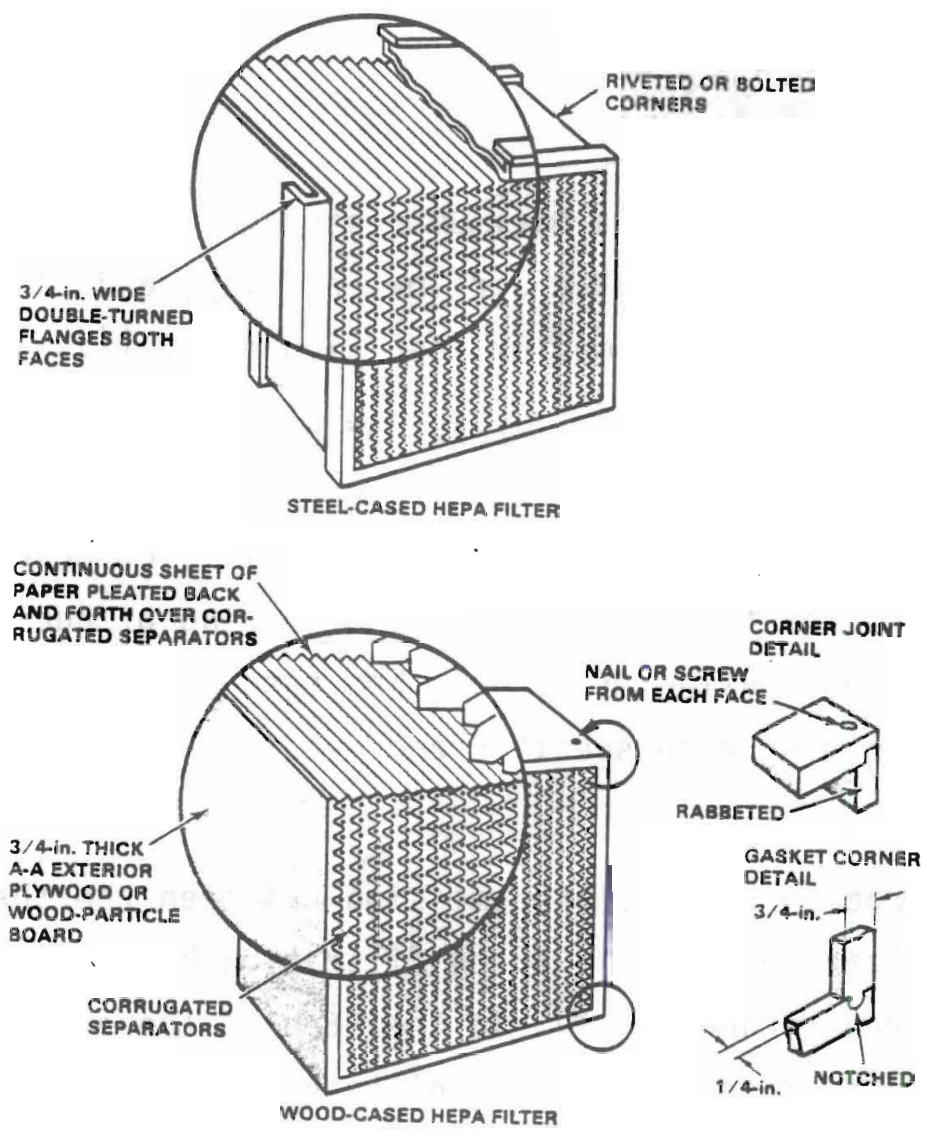

FIGURE 2.2. Construction of Open-Face HEPA Filter Units(1)

interception parameter is independent of particle size, and

3) diffusion parameter is the most important for HEPA filtration and shows 'a non-monotonic dependence on aerosol size'."

- Research continues in many areas--testing methods, reliability under severe stresses, construction techniques to improve filter performance, etc.

- Filter manufacturers have improved construction that has resulted in filters exceeding the required particle retention efficiency of $99.97 \%$ by an order of magnitude while improving resistance to chemicals, flames, elevated temperature, and radiation. HEPA filter rejection rates at DOE Quality Assurance Filter Test Stations have decreased from 49\% for filters manufactured prior to 1960 (the year when the stations were established) to $5 \%$ over the next 8 years. The rejection rate had decreased to such a level by 1978 that the 


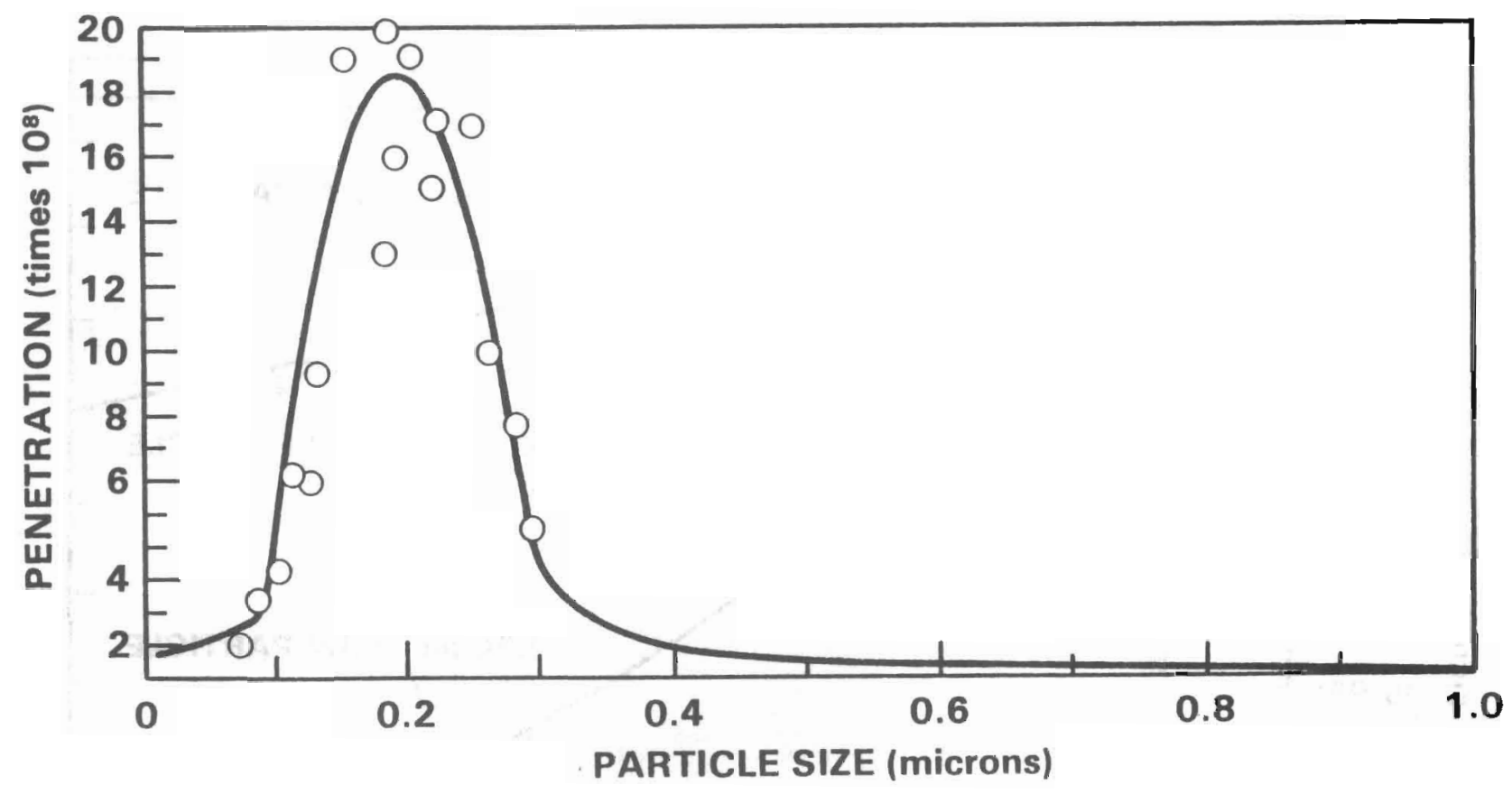

FIGURE 2.3. HEPA Filter Penetration for DEHP Particles(11)

U.S. Nuclear Regulatory Commission was willing to forego QA Filter Test Station inspection requirements. Indeed, the record of HEPA filters has been so good that some consideration has been given to basing acceptance of filtration systems upon testing and certification of the filter media and an in-place testing for defects.

It is apparent from the preceding that HEPA filters are a well-studied, highly efficient, and under ambient air atmospheres, very reliable device for the control of airborne particulate materials. Only one reference was found on the cost of this filtration system and it estimated original costs at $\$ 150 /$ filter and total costs (buy, insta11, test, remove, decontaminate, etc.) at 3 to 10 initial costs $(15)$.

Due to their size and cost, HEPA filters have the flexibility to fit into many arrangements. Small increases in the volume of exhaust processed can often be handled by simply increasing the number of filters and size of fans. If increased particle removal capability is required, exhausts can be passed sequentially through HEPA filters. Opinions were and still are divided 


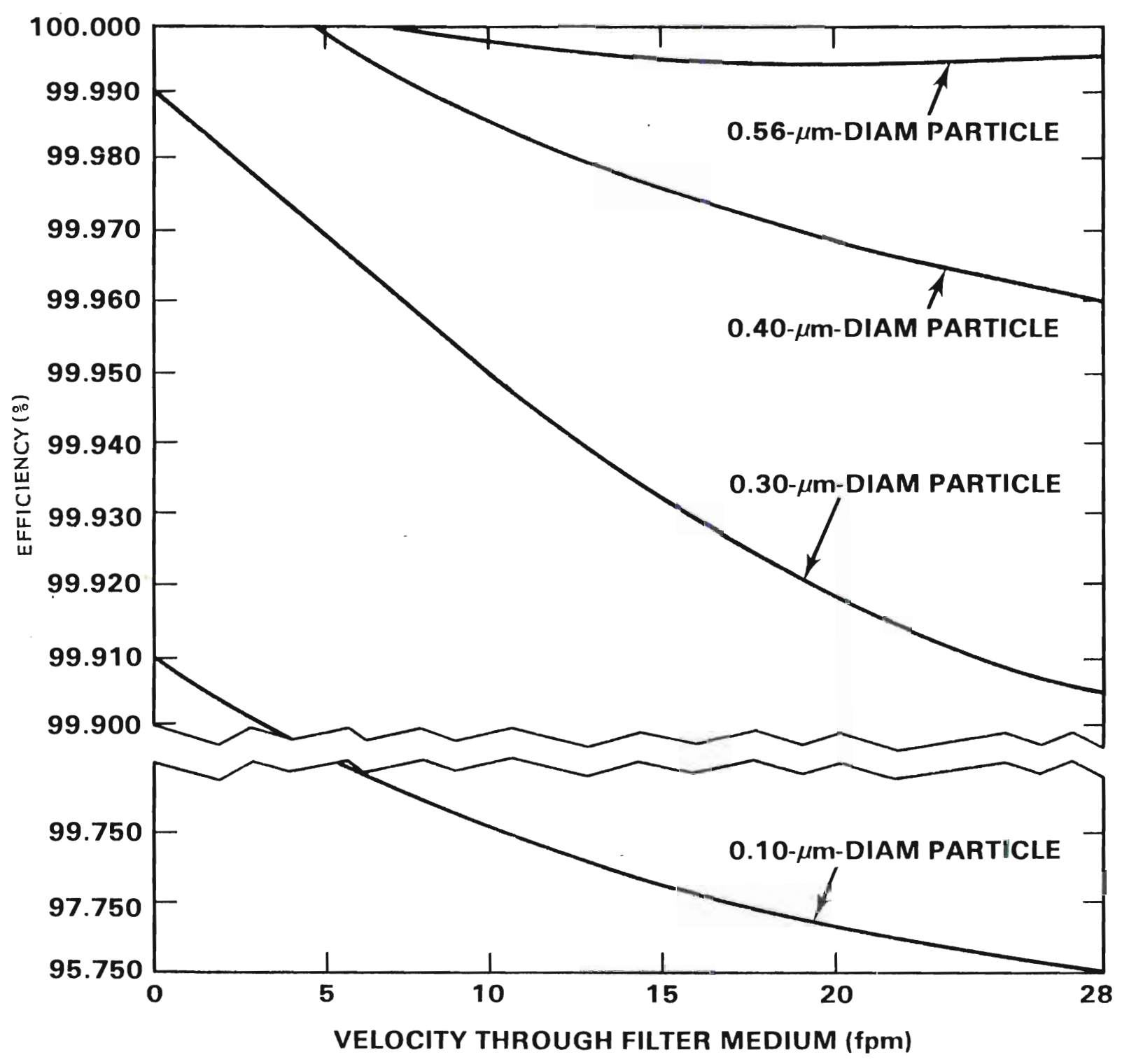

FIGURE 2.4. HEPA Filter Efficiency Versus Flow Rate(1)

as to whether each successive filter has the same efficiency (>99.97\%) as the first or whether efficiency decreases due to the extraction of the morereadily collected particles by the initial filter. Generating the quantity of particles and having measurement techniques to test more than a single stage of HEPA filters is not a trivial matter. Such tes ts were first performed by Gonzales, Elder, and Ettinger ${ }^{(16)}$ using plutonium with an activity median 
aerodynamic diameter of 0.22 to $1.6 \mu \mathrm{m}$ and three HEPA filters in series. Their findings indicated that the overall efficiency and efficiency as a function of size for successive filters exceeded $99.98 \%$, although the data from the third filter was of limited value due to the low level of activity. Thus, it appears that addition of successive stages of HEPA filters is a costeffective and viable means of reducing airborne particulate materials in exhausts.

It is primarily a concern for the reliability of filter devices under conditions other than ambient air atmosphere that prompted development of other high-efficiency filtration systems.

\subsubsection{Deep Bed Sand Filters}

Deep-bed sand filters have been used as air cleaning devices on DOE facilities for over 30 years. (1) Major advantages of such filters include: large capacity, low maintenance requirements, high heat capacity, fire resistance, and the ability to withstand shock loadings and large changes in airstream pressure without becoming inoperative. Major disadvantages include: high capital cost; large area; high-pressure drop and power cost; uncertainty in selection, availability, and grading of suitable sand; and disposal of spent units. No standards exist and sand filters are characteristically one of a kind. The approximate capital cost is estimated at $\$ 35$ per cfm in 1976 dollars. Again, Burchsted, Fuller, and Kahn(1) contains a compendium of useful information.

Figure 2.5 is an example of a deep bed sand filter. The area is $31 \mathrm{~m}$ (103 ft) by $43 \mathrm{~m}$ (140 ft) and consists of layers of rock, gravel, and sand to a depth of $2.3 \mathrm{~m}(7.5 \mathrm{ft})$. Composition and depth of each layer is shown in the figure. Design flow is $35 \mathrm{~m}^{3}$ per sec $(74,000 \mathrm{cfm}) .(17)$ Collection efficiency for particulate (Figure 2.6) exceeds the nominal installed efficiency of a single-staged HEPA filtration--99.97->99.98\%.(17-21) Passing the exhaust from a sand filter through a HEPA filter provides an additional $99 \%$ removal of activity. (19) 


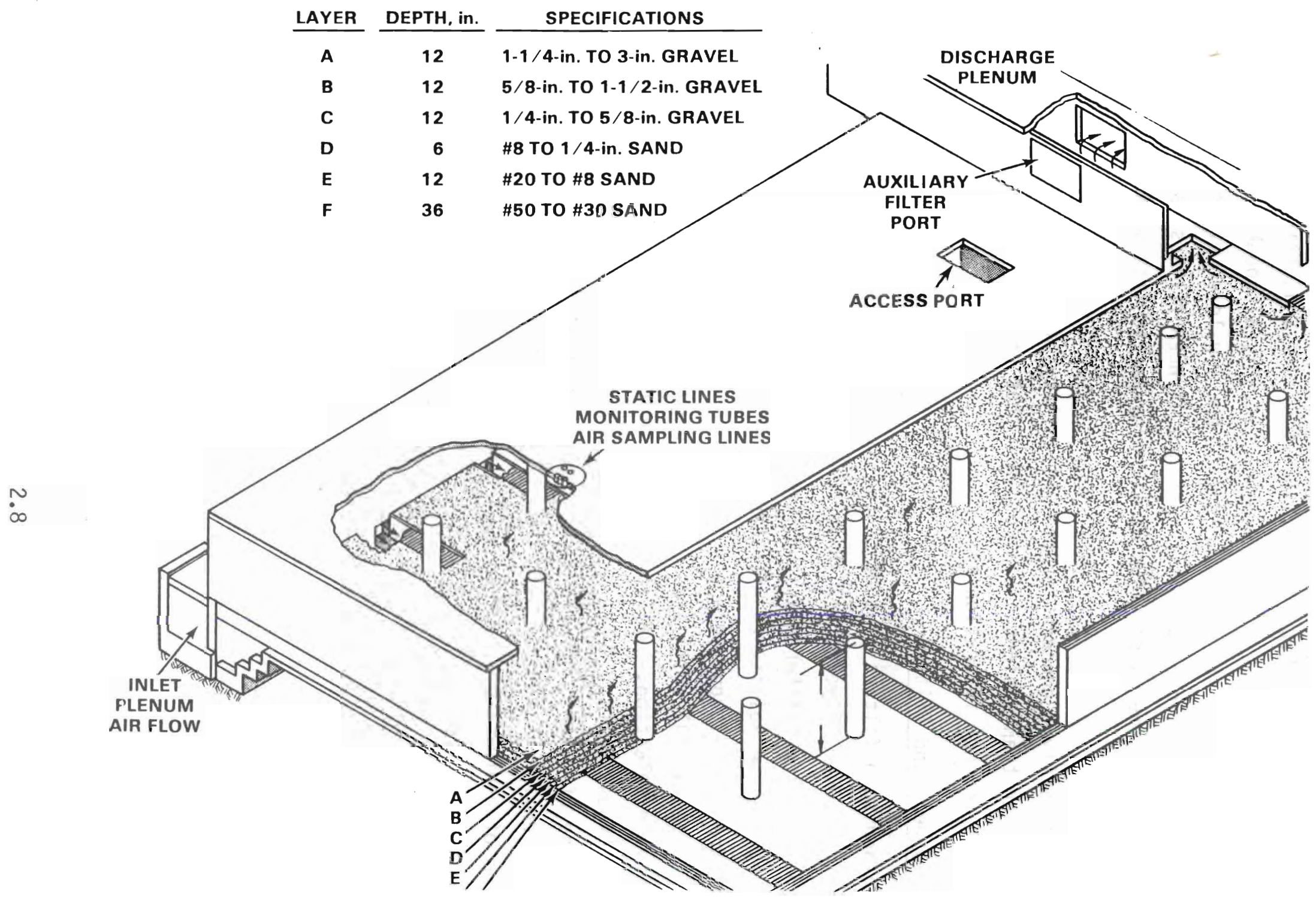

FIGURE 2.5. Isometric of Sand Filter(17) 


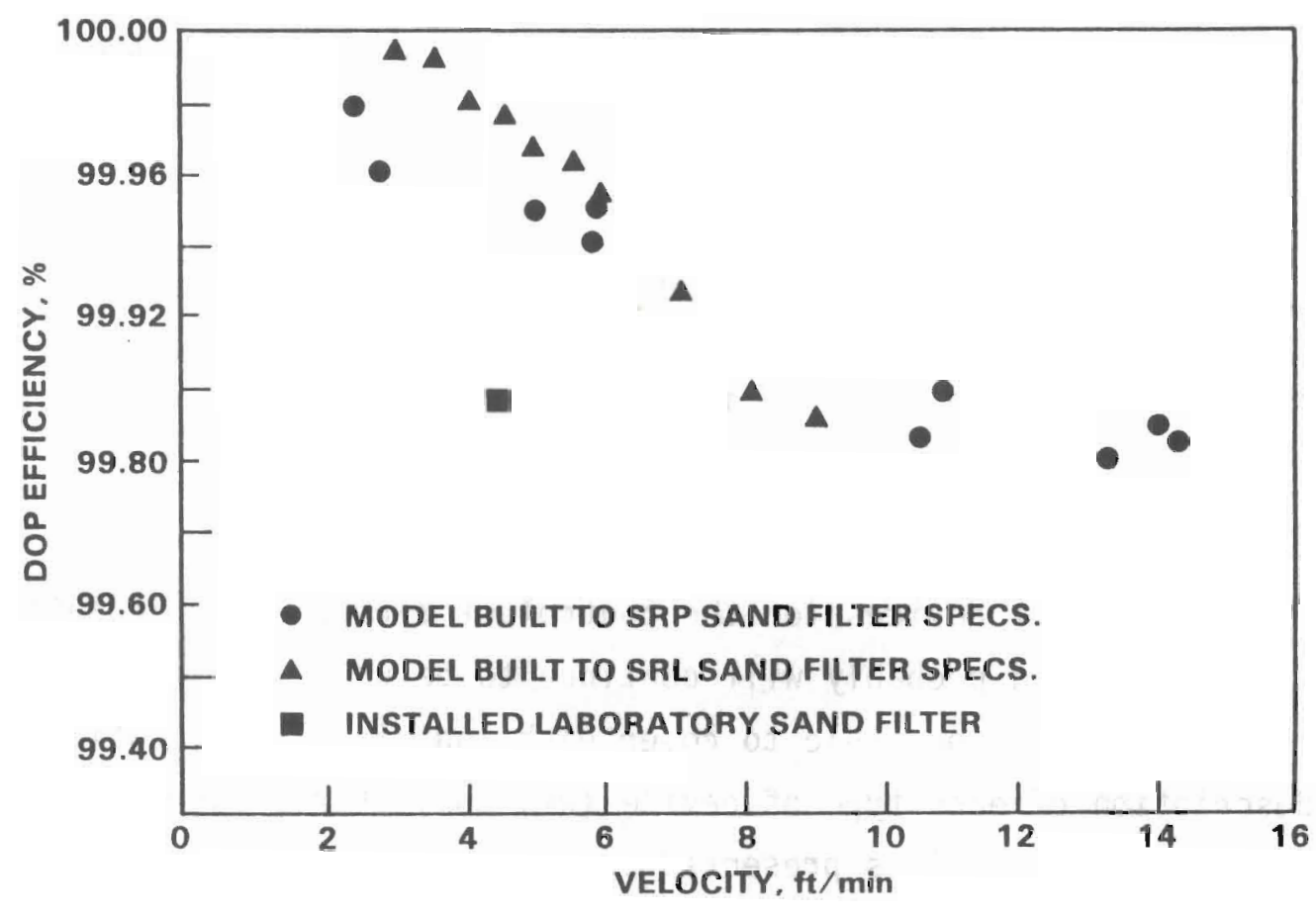

FIGURE 2.6. Sand Filter Efficiency Versus Velocity(17)

\subsubsection{Deep-Bed Glass Fiber Filters}

Another technology for the control of airborne particulate materials of long standing on DOE facilities is deep-bed glass fiber (DBGF) filters. Again, Burchsted, Fuller, and Kahn(1) provide a good collection of essential basic information. As an alternative for deep-bed sand filters, DBGF filters have the following advantages: more predictable physical characteristics, larger airflow per unit volume at lower pressure drop, lower operating costs, and potentially lower spent unit disposal costs. Their disadvantages compared to sand are: lower particle collection efficiency, less resistance to corrosion and fire, lack of heat capacity and self-healing characteristics, and lack of resistance to shock and high-pressure transient. Only one fiber (with a permanent curl that resists matting) was found to be satisfactory.

Schurr, Zippler, and Guyton(18) conducted a direct comparison of models of deep-bed sand and glass fiber filters. Table 2.1 gives the calculated particle removal efficiencies for DBGF filters. Figure 2.7 shows the pressure drop across the model for various loadings of a smoke simulant. 
TABLE 2.1. Particle (1ollection Efficiencies for DBGF Filters,
DPO Test (18)

\begin{tabular}{|c|c|c|}
\hline $\begin{array}{c}\text { Flow } \\
(\mathrm{m} / \mathrm{min})\end{array}$ & $\begin{array}{c}\text { Total } \\
\triangle \mathrm{P}(\mathrm{Pa})\end{array}$ & $\begin{array}{l}\text { Efficiency } \\
\% \text { Total }\end{array}$ \\
\hline 0.76 & 340 & 99.95 \\
\hline 1.42 & 750 & 99.94 \\
\hline 3.68 & 1250 & 99.92 \\
\hline
\end{tabular}

\subsection{OTHER CONVENTIONAL EMISSION CONTROL TECHNOLOGIES}

Other conventional devices for the control of airborne particulate material have been used and probably will continue to be used for specific applications. It is not possible to cover each individual application. A general description of each type of device (wet collectors, baghouse, and electrostatic precipitator) is presented in the following subsections, with references to more-detailed information. Table 2.2 shows a comparison of some characteristics of these control devices.

\subsubsection{Electrostatic Precipitators}

The high-voltage electrostatic precipitator (ESP) is the predominant industrial, high-efficiency, high-cost device for airborne particulate material control.(22) Figure 2.8 is a schematic diagram of or ESP. "The principal of collection relies on the ability to impart a negative charge to particles in the gas stream causing them to move and adhere to the grounded or positively charged collector plates. Most precipitators are made for horizontal air flows with velocities of 100 to $600 \mathrm{fpm}$. ... Voittage difference between electrode and plate is 60,000 to 75,000 volts. ... Removal of the collected material is obtained by rapping or vibrating the element continuously or at predetermined intervals..."(22) Some advantages of $\operatorname{ESP}(23)$ are: high removal efficiencies (in excess of $99 \%$ ) can be attained, efficiency is a function of particle size and type of ESP (see Figures 2.9 and 2.10); there is no theoretical lower limit for a size of particle that can be collected; pressure and temperature drops through ESPs are small (Ap seldom exceeds $125 \mathrm{~Pa}$ ); has few moving parts, can operate continuously with little maintenance; can handle large exhaust flows; and power requirements can 


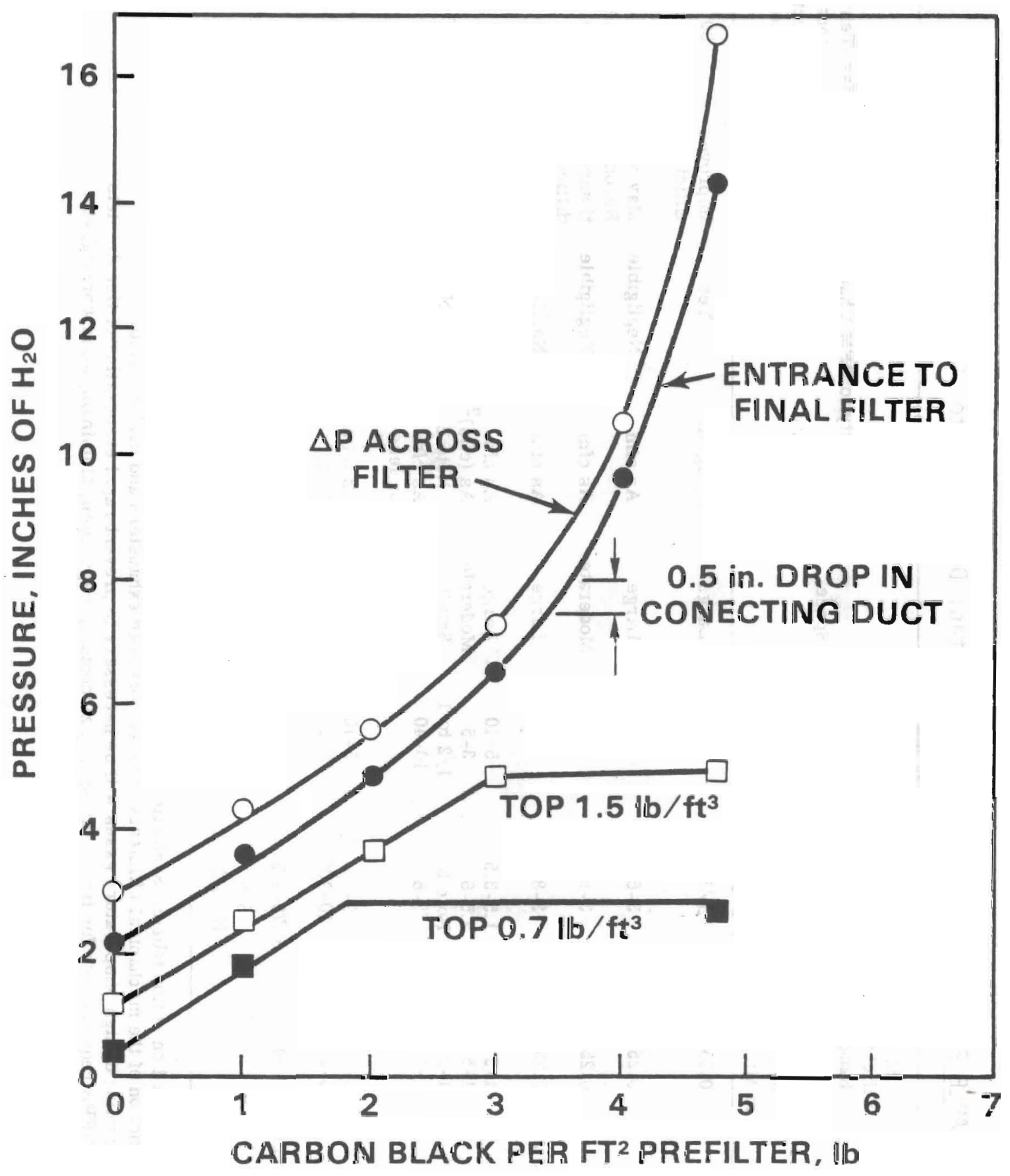
FIGURE 2.7. Pressure Versus Pounds of Carhon Black ("Fiberglas" filter
smoke simulation) 
TABLE 2.2. Comparison of Some Important Dust Collector Characteristics (22)

\begin{tabular}{|c|c|c|c|c|c|c|c|c|}
\hline Type & $\begin{array}{l}\text { Higher } \\
\text { Efficiency } \\
\text { Range on } \\
\text { Particles } \\
\text { Greater than } \\
\text { Mean size } \\
\text { in Microns }\end{array}$ & $\begin{array}{l}\text { Pressure } \\
\text { Loss } \\
\text { Inches }\end{array}$ & $\begin{array}{l}\mathrm{H}_{2} \mathrm{O} \mathrm{Gal} \\
\operatorname{per} 1,000 \\
\text { CFM }\end{array}$ & Space & $\begin{array}{l}\text { Sensitivity t } \\
\text { Pressure }\end{array}$ & $\begin{array}{l}\text { FM Change } \\
\text { Efficiency }\end{array}$ & $\begin{array}{l}\text { Humid Air } \\
\text { Influence }\end{array}$ & $\begin{array}{c}\text { Max. Temp., F. } \\
\text { Standard } \\
\text { Construction } \\
\text { Note } 4\end{array}$ \\
\hline Electrostatic & 0.25 & $1 / 2$ & - & Large & Negligible & Yes & $\begin{array}{l}\text { Improves } \\
\text { Efficiency }\end{array}$ & 500 \\
\hline \multicolumn{9}{|l|}{ Fabric: } \\
\hline Conventional & 0.25 & $3-6$ & - & Large & As cim & Negligible & \multirow{3}{*}{$\begin{array}{l}\text { May Make } \\
\text { Recondi- } \\
\text { tioning } \\
\text { difficult }\end{array}$} & $\begin{array}{l}180 \\
\text { Note } 1\end{array}$ \\
\hline Reverse Jet & 0.25 & $3-8$ & - & Moderate & As cfm & Negligible & & 180 \\
\hline $\begin{array}{l}\text { Glass, Reverse flow } \\
\text { Wet: }\end{array}$ & 0.25 & $3-8$ & - & Large & As $\mathrm{cfm}$ & Negligible & & 550 \\
\hline Packed Tower & $1-5$ & $1.5-3.5$ & $5-10$ & Large & As cfm & Yes & \multirow{4}{*}{ None } & \multirow{4}{*}{ Unlimited } \\
\hline Wet Centrifugal & $1-5$ & $2.5-6$ & $3-5$ & Moderate & As $(\mathrm{cfm})^{2}$ & Yes & & \\
\hline Wet Dynamic & $1-2$ & Note 2 & $1 / 2$ to 1 & Small & Note 2 & No & & \\
\hline Orifice Types & $1-5$ & $21 / 2-6$ & $10-40$ & Small & $\begin{array}{l}\text { As cfm } \\
\text { or less }\end{array}$ & $\begin{array}{c}\text { Varies with } \\
\text { design }\end{array}$ & & \\
\hline \multicolumn{9}{|l|}{ Higher Efficiency: } \\
\hline Fog Tower & $0.5-5$ & $2-4$ & $5-10$ & Moderate & As $(\mathrm{cfm})^{2}$ & Slightly & \multirow[t]{2}{*}{ None } & Note 3 \\
\hline Venturi & $0.5-2$ & $10-100$ & $5-15$ & Moderate & As $(\mathrm{cfm})^{2}$ & Yes & & Unlimited \\
\hline \multicolumn{9}{|c|}{ Dry Centrifugal: } \\
\hline Low Pressure Cyclone & $20-40$ & $0.75-1.5$ & - & Large & As $(\mathrm{cfm})^{2}$ & Yes & \multirow{3}{*}{$\begin{array}{l}\text { May cause } \\
\text { condensation } \\
\text { and plugging }\end{array}$} & 750 \\
\hline High Eff. Centrifugal & $10-30$ & $3-6$ & - & Moderate & As $(\mathrm{cfm})^{2}$ & Yes & & 750 \\
\hline Dry Dynamic & $10-20$ & Note 2 & - & Small & Note 2 & No & & 750 \\
\hline
\end{tabular}

Note 1: $180 \mathrm{~F}$ based on cotton fabric. Synthetic fabrics may be used to $275 \mathrm{~F}$.

Note 2: A function of the mechanical efficiency of these combined exhausters and dust collectors.

Note 3: Precooling of high temperature gases will be necessary to prevent rapid evaporation of fine droplets.

Note 4: See NFPA requirements for fire hazards; i.e., zirconium, magnesium, aluminum, wood working, etc. 
HIGH-TENSION SUPPORT FRAME
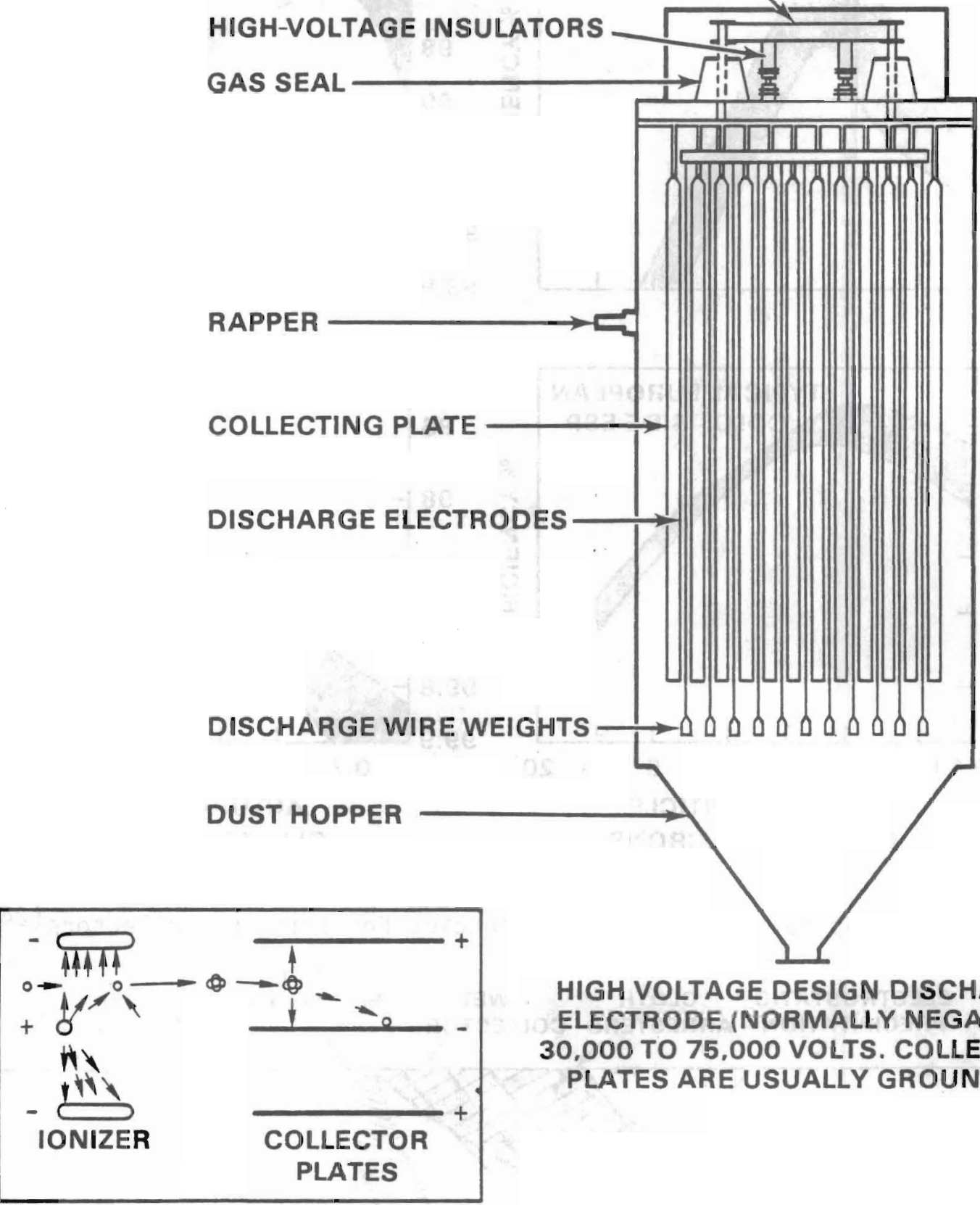

HIGH VOLTAGE DESIGN DISCHARGE ELECTRODE (NORMALLY NEGATIVE) 30,000 TO 75,000 VOLTS. COLLECTING PLATES ARE USUALLY GROUNDED

LOW VOLTAGE DESIGN

12,000 TO 13,000 VOLTS ON IONIZER 6,000 TO 7,000 VOLTS ON COLLECTOR PLATES

FIGURE 2.8. Electrostatic Precipitator(22) 

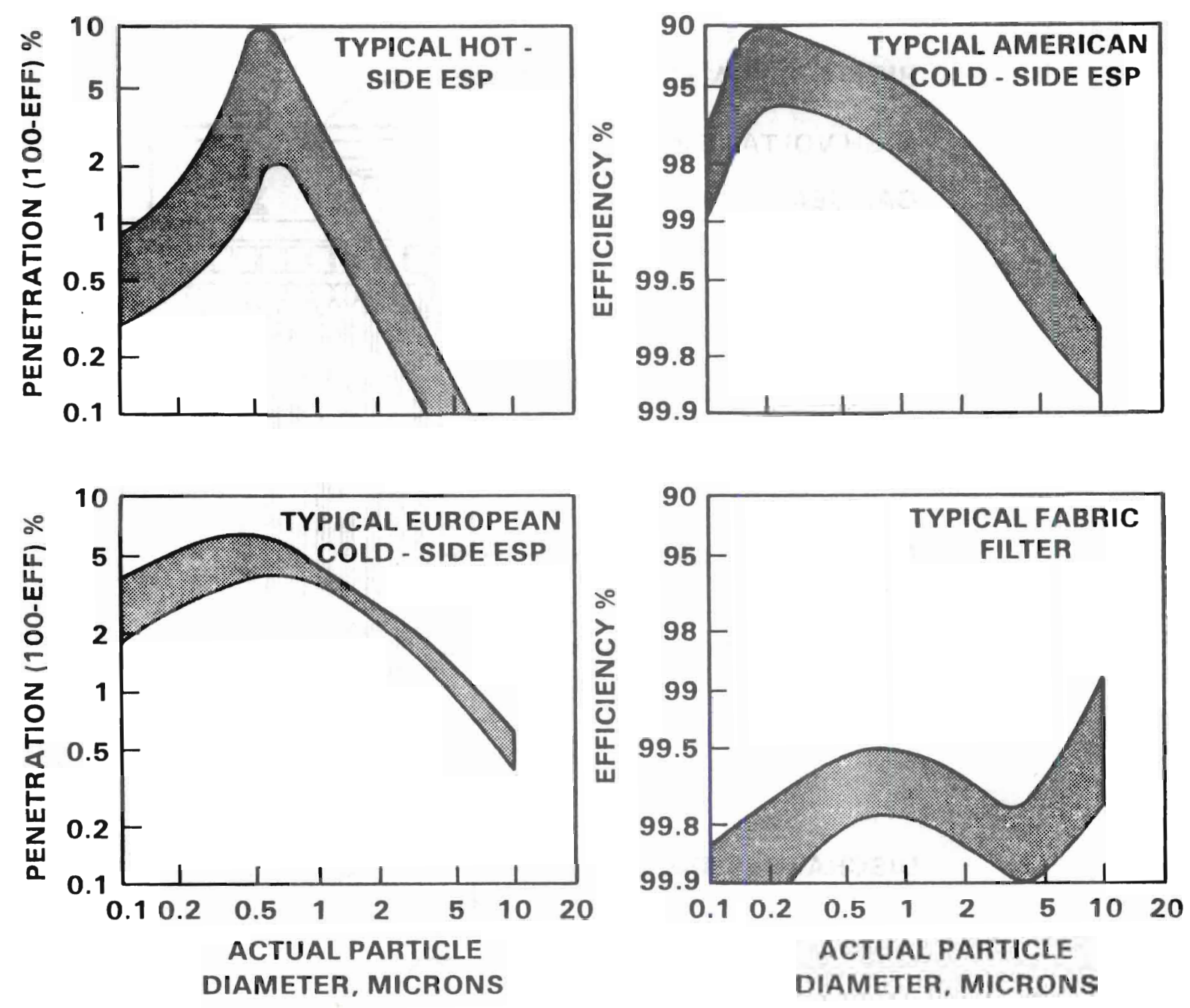

FIGURE 2.9. Typical Fractional Efficiencies For Existing Collectors(24)

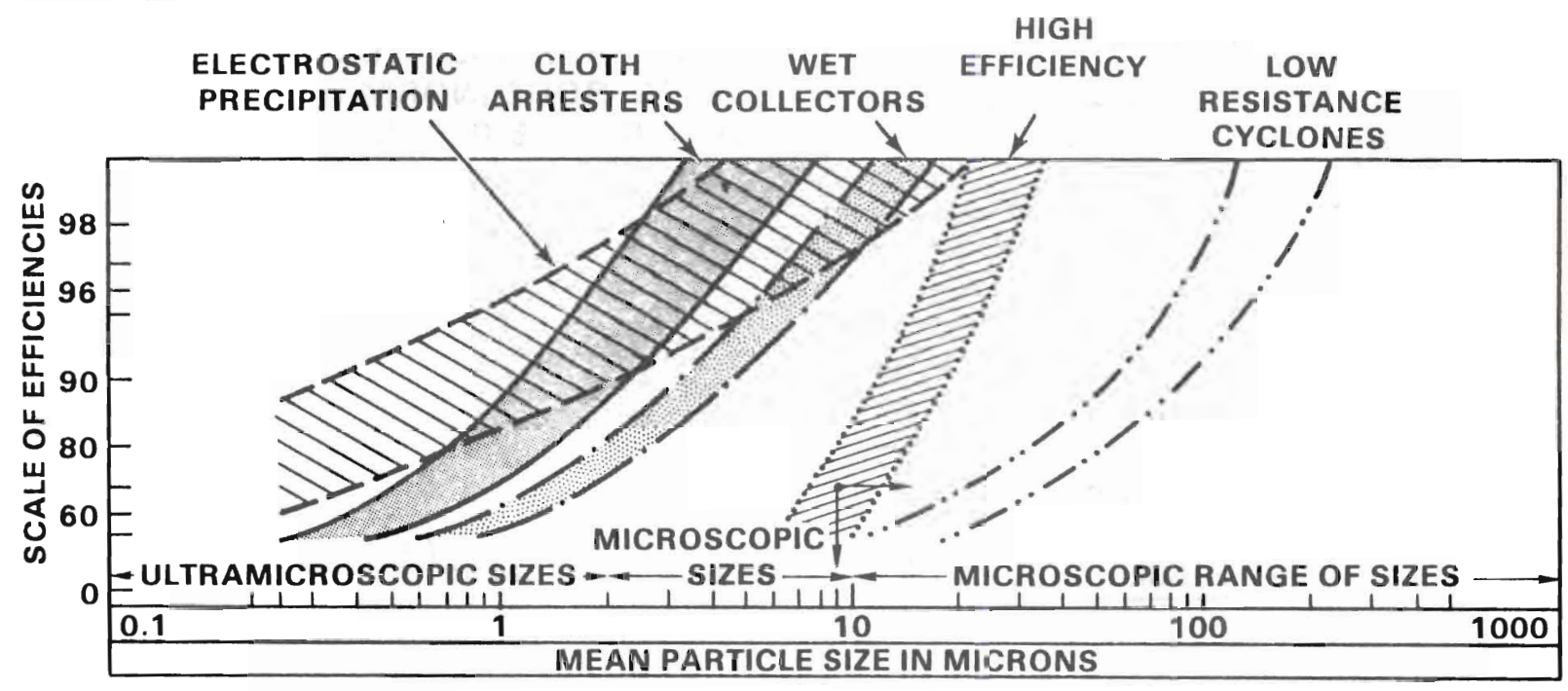

FIGURE 2.10. Range of Particle Size ${ }^{(22)}$ 
be low. Some of the drawbacks of ESPS (23) are: initial costs are high (see References 22 and 24 for further discussion of costs); they cannot be used for all airborne particles (extremely high or low resistivity or other causes make them difficult to collect); space requirements can be high; and special precautions are required to safeguard personnel from the high voltage.

\subsubsection{Fabric Collectors (Baghouses)}

Fabric arresters are high-efficiency (see Figures 2.9 and 2.10), mediumcost collectors. (22) The fabric is arranged in envelope or tubular (stocking) shapes and the entire arrangement is called a baghouse. Several such arrangements are shown in Figure 2.11. The filtering process, especially for submicron particles, is obviously not simple sieving but is obtained by the buildup of a mat of material on the dirty side of the fabric initially by interception, impingment, diffusion and electrostatic attraction.(22,23) As dust is collected on the fabric, resistance to flow increases and the fabric must periodically be reconditioned by shaking, vibrating, reverse-jet or reverse-flow collapse. Reconditioning techniques form subclassification groups in fabric collectors. Woven cotton or wool is frequently used, a)though a wide range of materials (including fine metallic mesh) are ${ }^{e}$ is possible. Readers are referred to Reference 22 for an overview of the topic, to Reference 23 for a thorough engineering treatment and to References 25 and 26 for more recent developments.

\subsubsection{Inertial Devices (Cyclones)}

The use of centrifugal force to throw a dust particle to the periphery of an airstream has been used in cyclone and other types of inertial collectors for many years. (22) These types of devices are most suitable for medium to coarse particles (see Table 2.2 and Figure 2.10). Inertial collectors can be classified in two groups based upon their particle removal efficiency, especially for particles $10 \mu \mathrm{m}$ and less. Figure 2.12 is a schematic diagram of various representative inertial devices. The low-pressure cycione often acts as a pre-cleaner for high-efficiency devices. Higher. efficiencies are obtained by increasing peripheral velocities or angular acceleration. Highefficiency centrifugals use several techniques to achieve these ends, while 

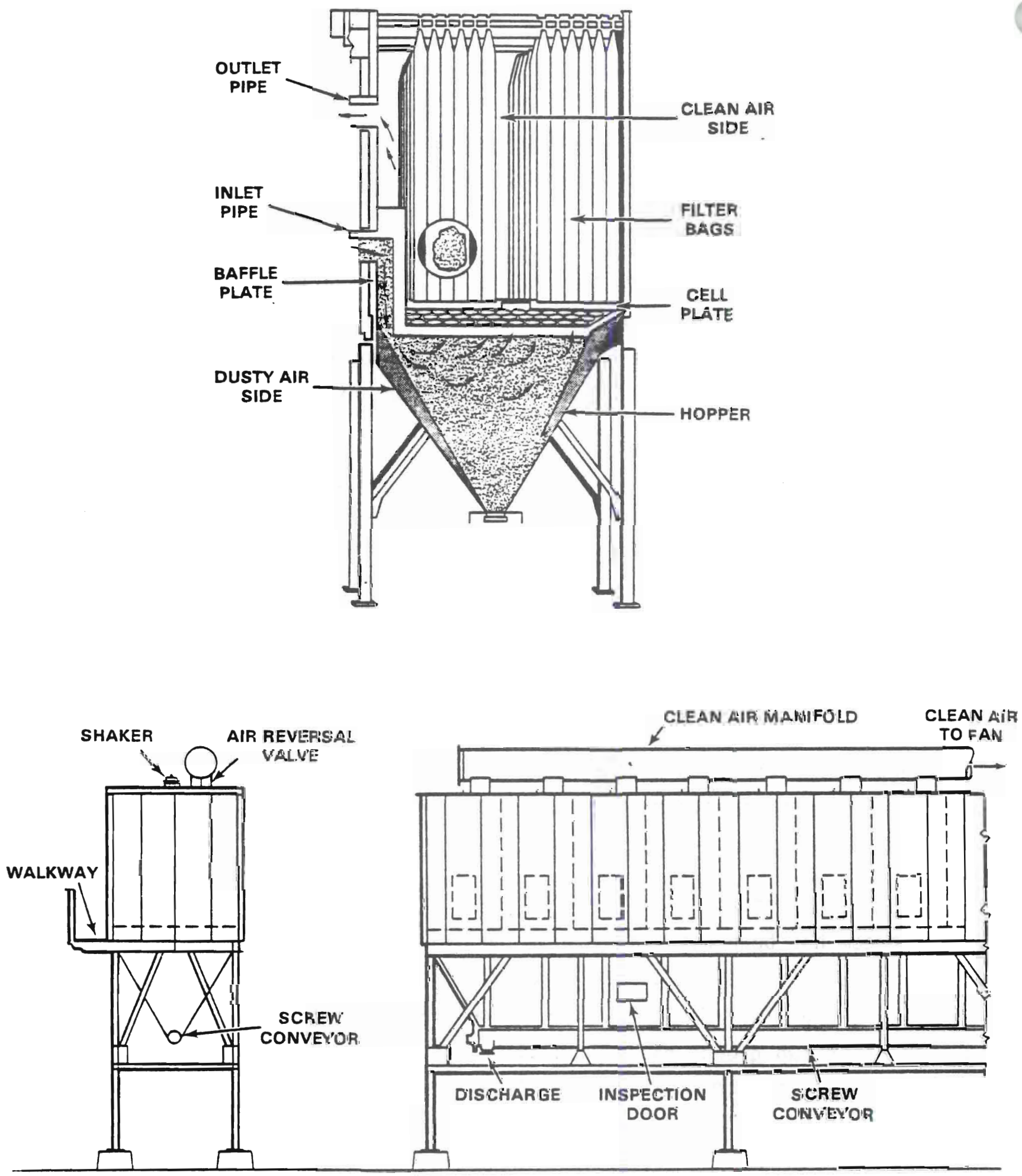

FIGURE 2.11. Fabric Collectors(23) 

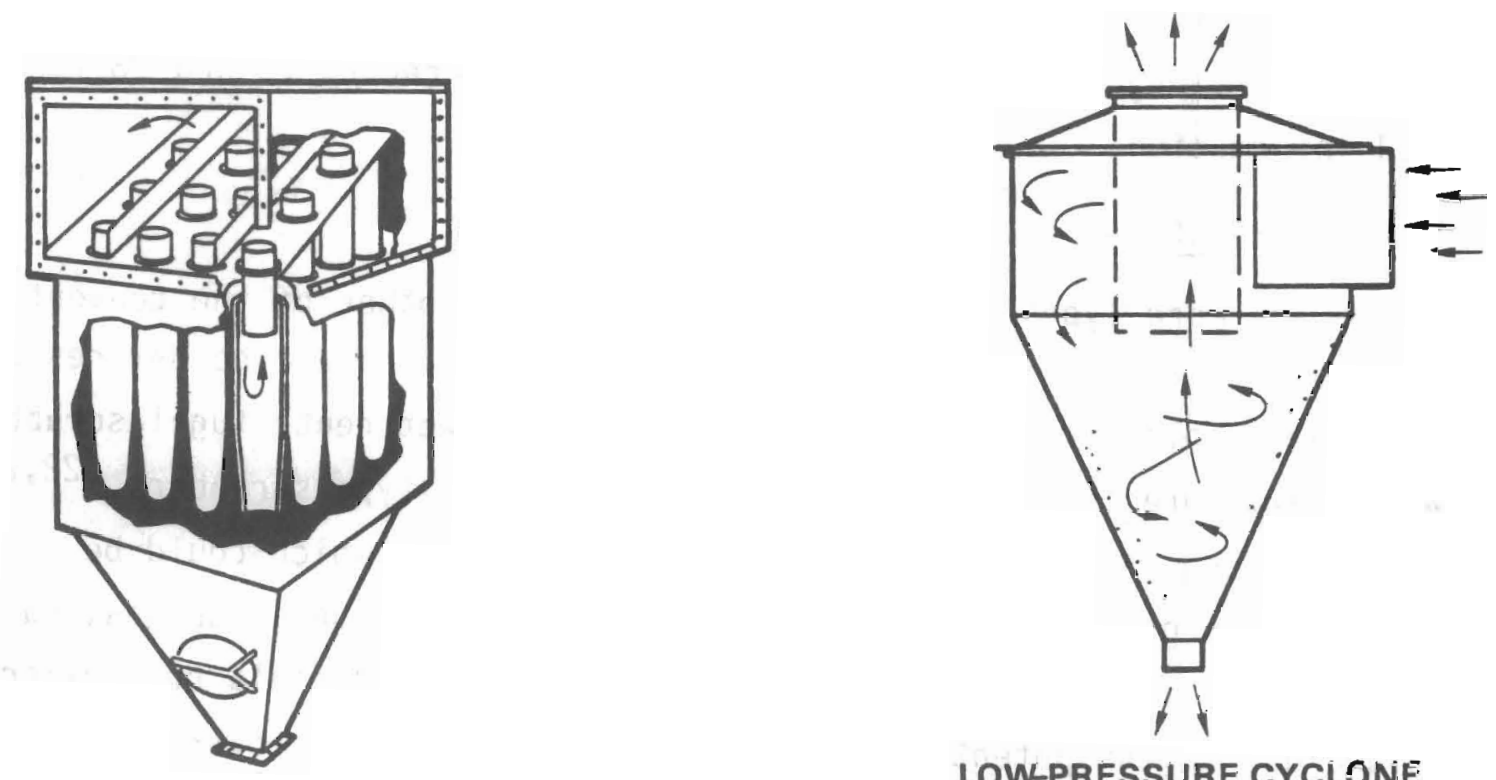

LOW-PRESSURE CYCLONE
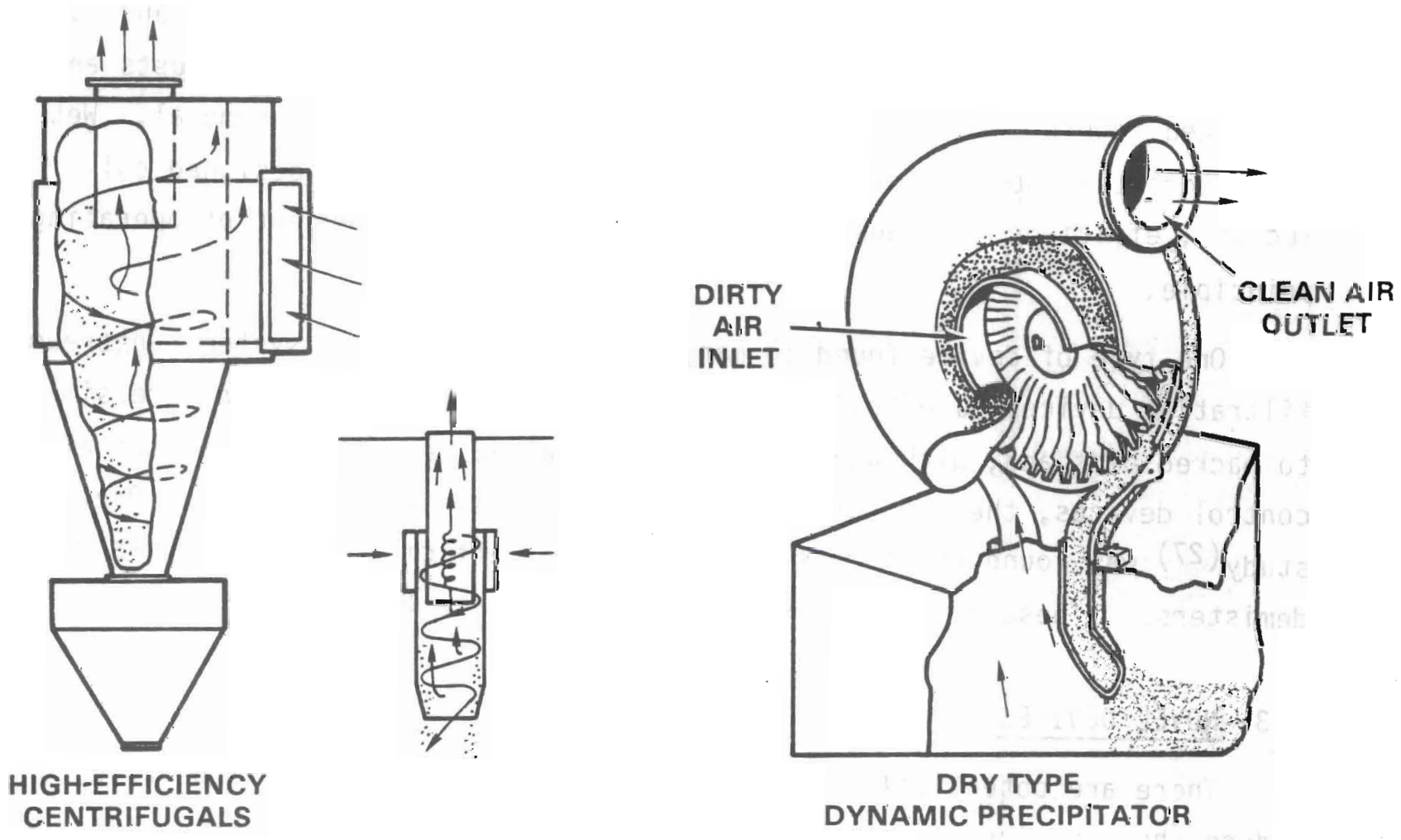

FIGURE 2.12. Dry-Type Centrifugal Collectors(22) 
the dry-type dynamic precipitator uses specially shaped blades on the exhauster wheel. Again, readers are directed to References 22 and 23 for more detailed information.

\subsubsection{Wet Collectors}

There are more types of wet collectors than any other of the conventional airborne particulate material control devices covered here. The devices span a range from simple scrubbers (i.e., spray towers), wet centrifugal scrubbers, and wet dynamic precipitators, to orifice and venturi-type scrubbers. $(22,23)$ Packed towers are another type of wet collection device which could be included in this group; but are more suitable as contact beds for gas, vapor or mist removal. Such devices do collect particulate materials but collection is avoided due to the potential for plugging. Thus, packed towers are not included among the airborne particulate material control devices. Examples of the wet collection devices are shown schematically in Figures 2.13 and 2.14. Wet collectors can handle high temperature and moisture-laden exhausts and, as in packed towers, can offer some level of gas, vapor or mist removal. Wet collectors can show a wide range of performance. For well-designed collectors, efficiency depends on energy input and is independent of operating principle.

One type of device found in many nuclear air-cleaning systems upstream of filtration devices is entrainment separators, or demisters. Many are similar to packed beds and, although not considered airborne particulate material control devices, their function is to remove particulate material. One

study (27) was found which measured the removal efficiency of two types of demisters. These efficiencies are shown in Figure 2.15.

\subsection{NOVEL DEVICES}

There are potentially a large number of devices that could be used to reduce the quantity of particulate materials suspended in exhaust gases from DOE facilities. Currently, there are efforts to increase the volume of 


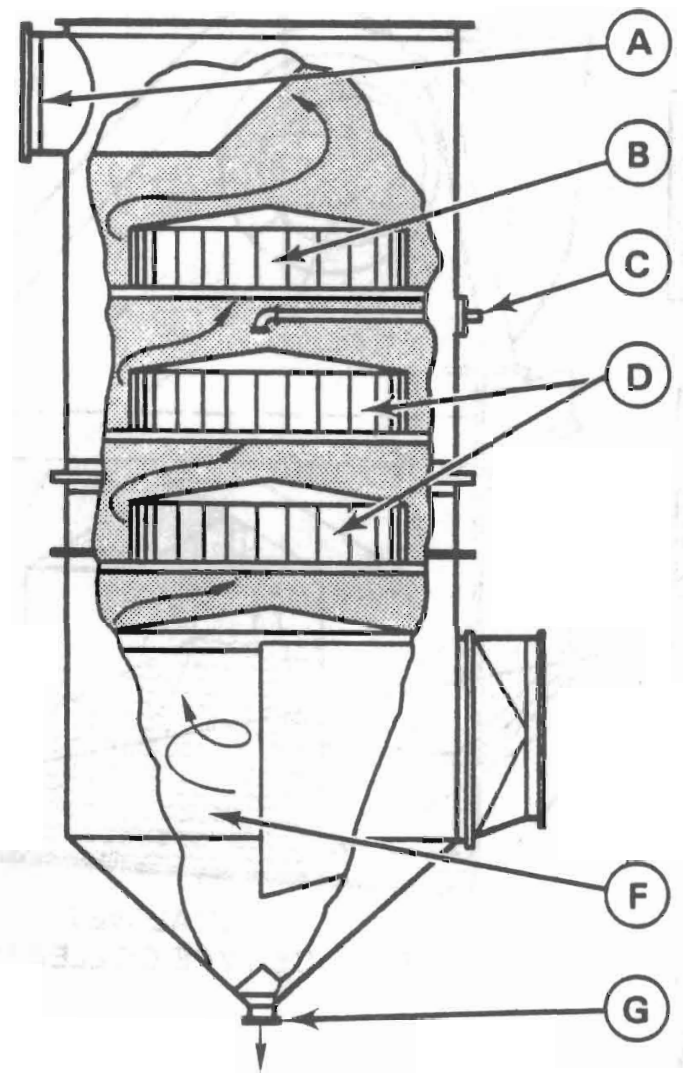

\begin{tabular}{|c|l|}
\hline SYMBOLS & \multicolumn{1}{|c|}{ PARTS } \\
\hline A & CLEAN AIR OUTLET \\
B & ENTRAINIMENT SEPARATOR \\
C & WATER INLET \\
D & IMPINGEMENT PLATES \\
E & DIRTY AIR INLET \\
F & WET CYCLONE FOR COLLECTING \\
& HEAVY MATERIAL \\
G & WATER AND SLUDGE DRAIN \\
\hline
\end{tabular}

WET CENTRIFUGAL

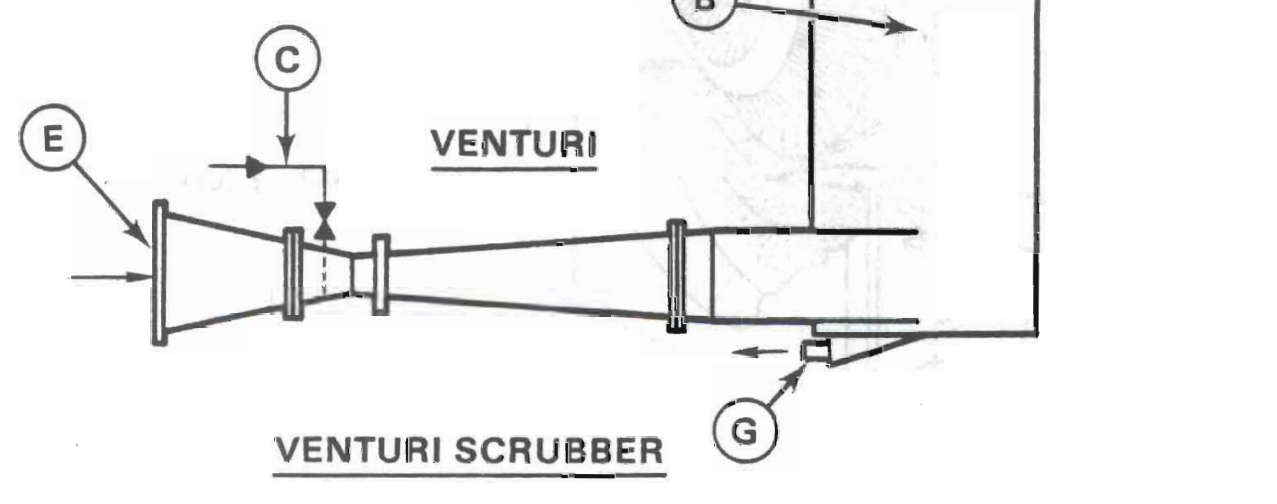

FIGURE 2.13. Wet-Type Dust Collector(22) 

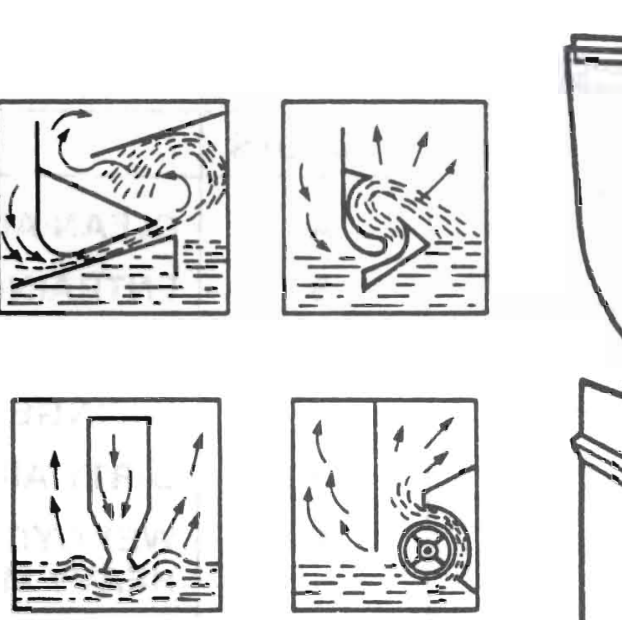
COLLECTING ELEMENTS
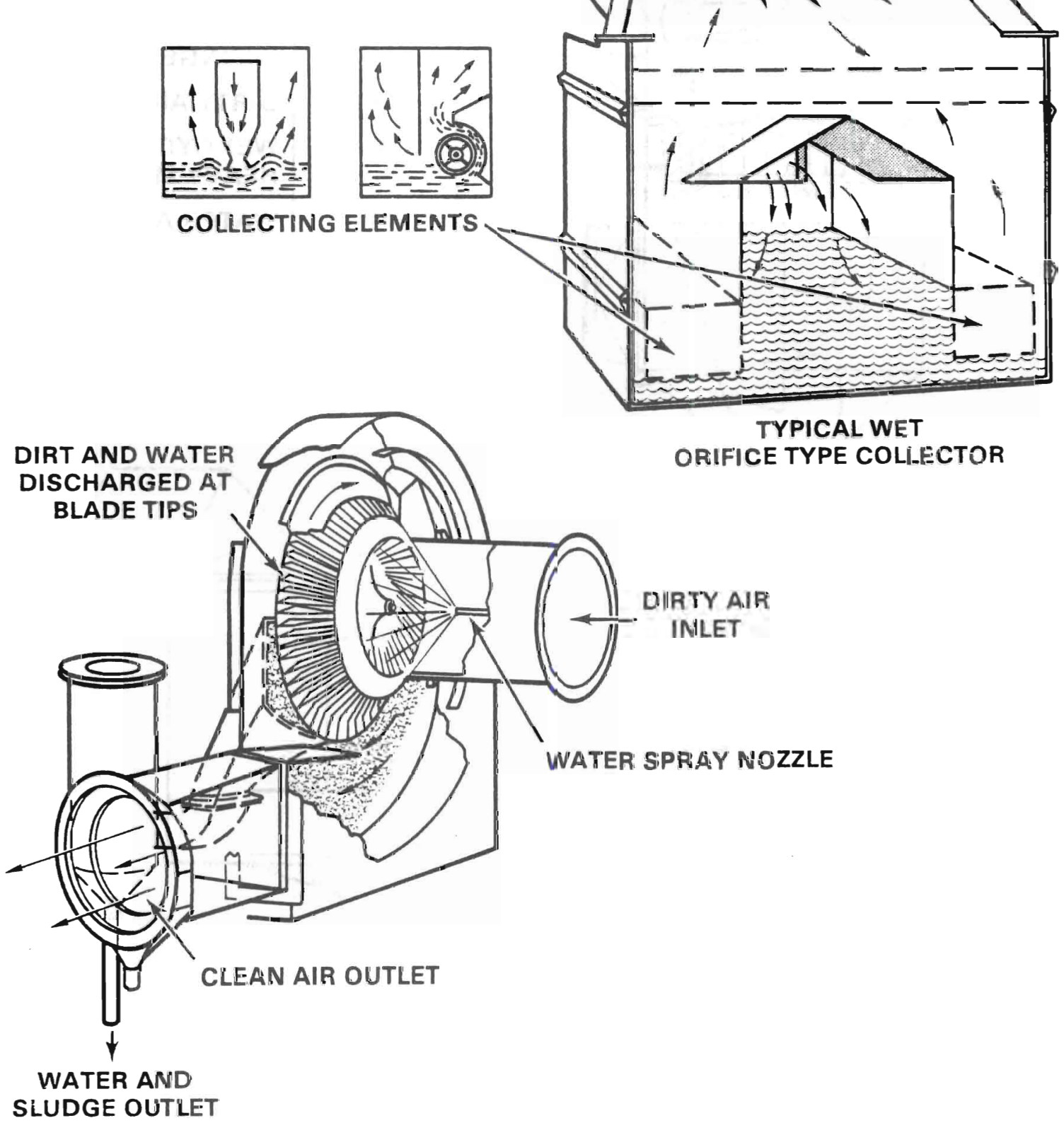

FIGURE 2.14. Wet-Type Dust Collector(22) 


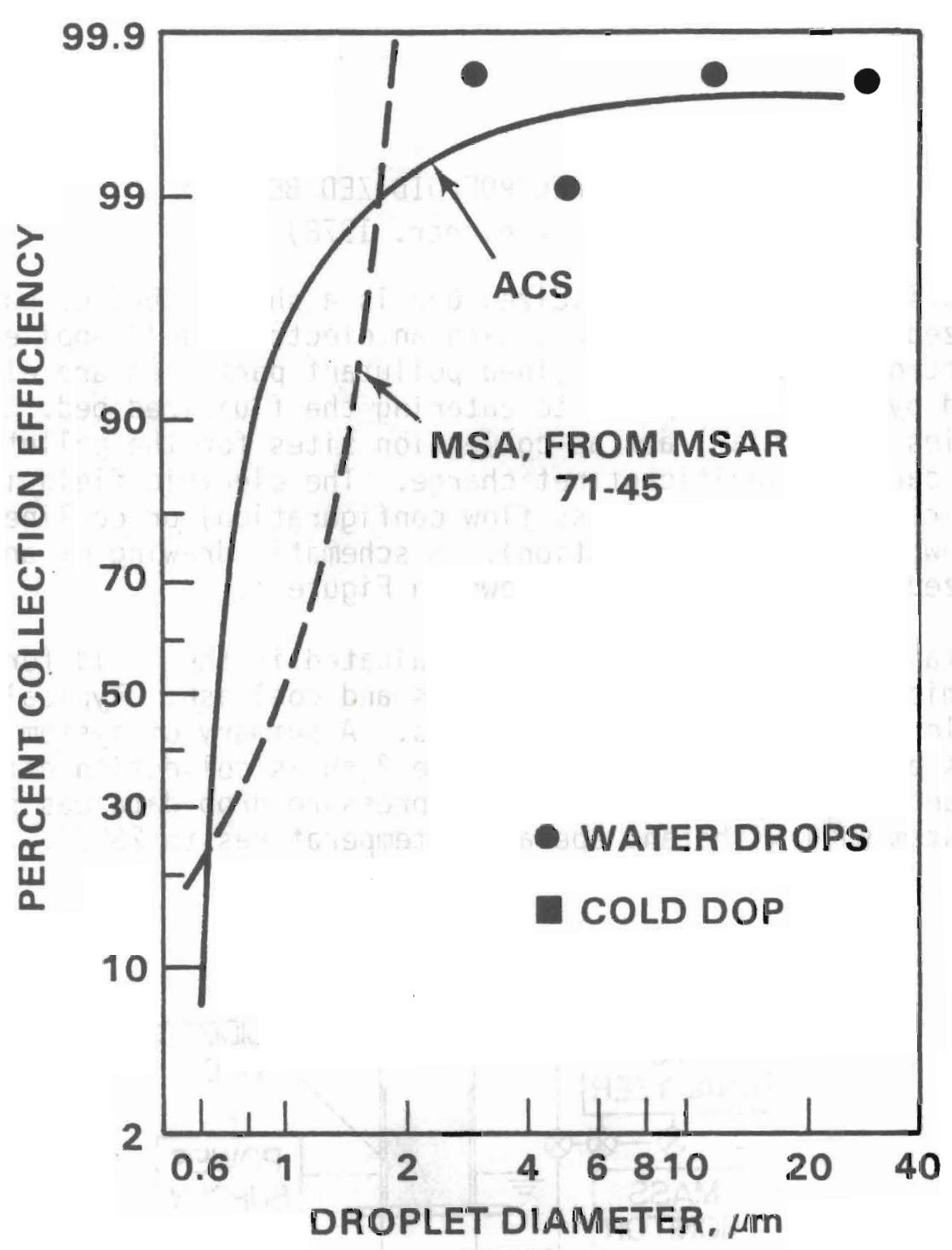

FIGURE 2.15. Percent Collection Efficiency vs. Droplet Diameter,
MSA and ACS Entrainment Separators

exhausts that can be treated per filter, $(10,28)$ but such developments do not alter the particle removal efficiency of the filters and are not covered in this discussion.

The mode of presentation for the devices covered in the following discussion is a review of the most recent or most informative article on a particle. The reference is included in the presentation and those desiring additional information can use these references as points of departure. 


\section{ELECTROFLUIDIZED BED(29) \\ (Melcher, 1978)}

Description: An electrofluidized bed is a shallow bed of particles, fluidized by the polluted gas, with an electric field applied by means of electrodes. The gas-entrained pollutant particles are electrically charged by ion impact prior to entering the fluidized bed. The bed particles ( $2 \mathrm{~mm}$ diam) act as collection sites for the pollutant and do not carry a significant net charge. The electric field is either transverse to the flow (cross flow configuration) or co-linear with the flow (co-flow configuration). A schematic drawing of an electrofluidized bed test system is shown in Figure 1 .

Performance: The system has been evaluated in the field for collection of submicron oil ash, asphaltic fumes and coal ash. Typical fluidized bed particles are 1 to $2 \mathrm{~mm}$ sand or glass. A summary of system performance is presented in Table 1. Figure 2 shows collection efficiency as a function of particle size. No pressure drop data was presented. The system will withstand operating temperatures to $260^{\circ} \mathrm{C}$.

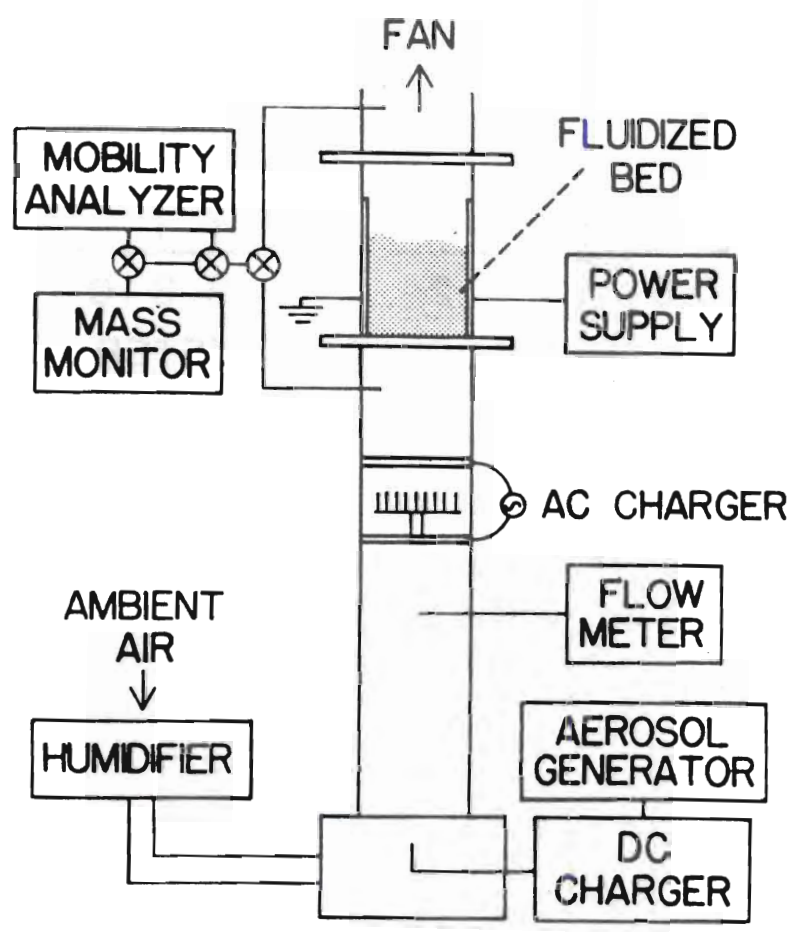

Fig 1 Electrofluidized Bed 


\section{TABLE 1. Electrofluidized Bed Performance}

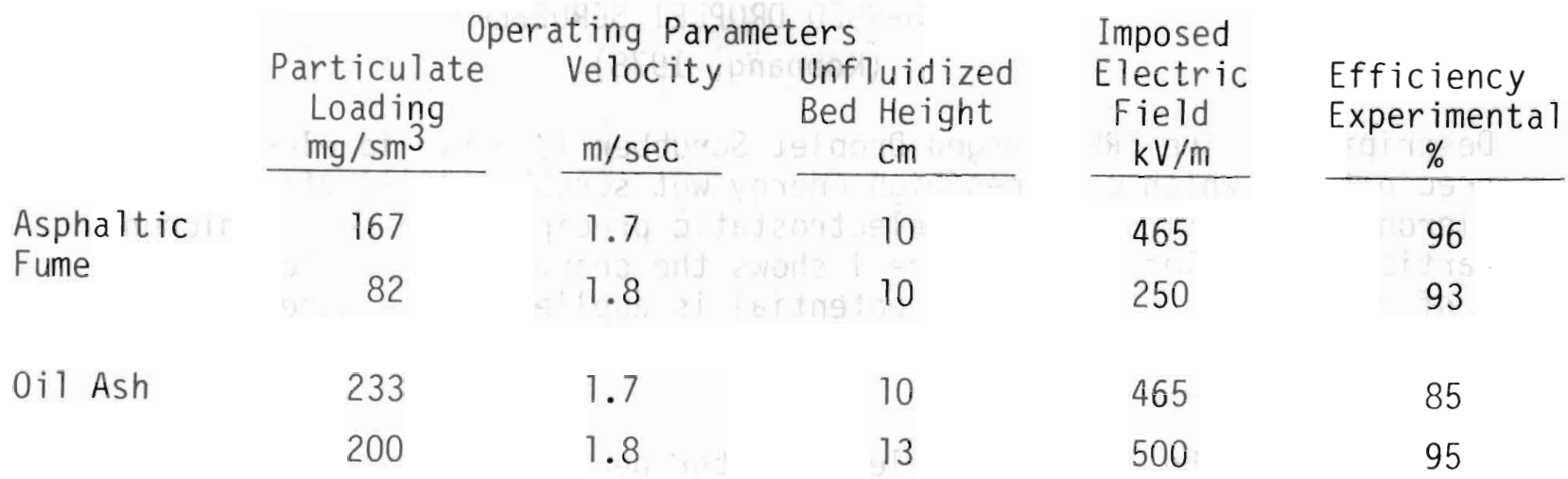

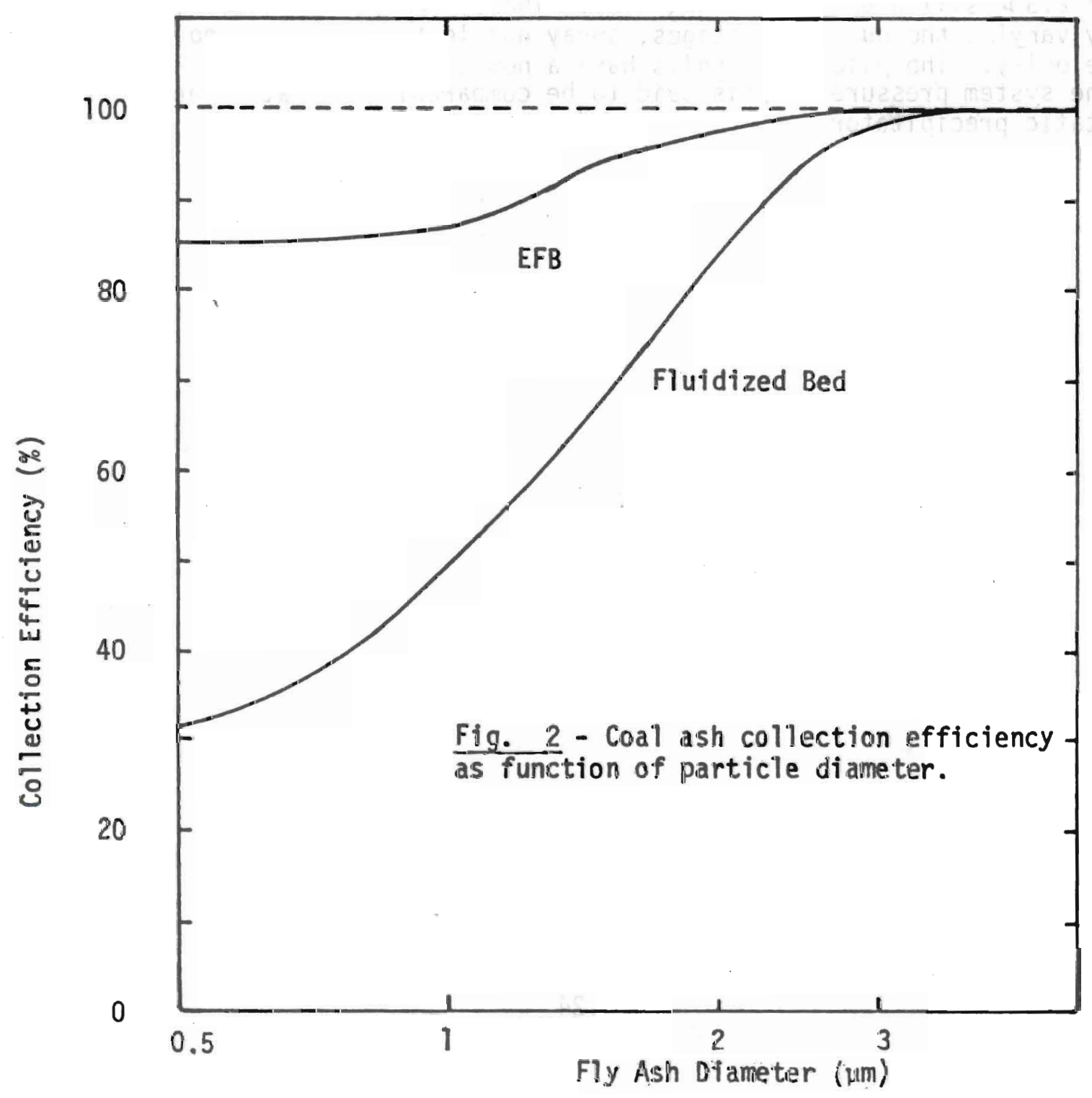


TRW CHARGED DRUPLET SCRUBBER (30)

(Koppang, 1978)

Description: The TRW Charged Droplet Scrubber is a hybrid electrostatic precipitator which combines high energy wet scrubbing collection for micron size particulate with electrostatic precipitation for submicron particulate collection. Figure 1 shows the charged droplet scrubber configuration. An electrical potential is applied to the water spray system. The charged spray captures particulates as it migrates to the collector plates.

Performance: The charged droplet scrubber performance has been evaluated during pilot scale tests at a urea prilling tower and at a commercial scale flue gas site. Figure 2 details the system performance for collection of 0.7 to $1.2 \mu$ urea particles. Figure 3 shows system collection of $2.3 \mu$ silica and $0.46 \mu \mathrm{SO}_{3}$ mist. The system performance is optimized by varying the number of stages, spray nozzle to plate spacing, and gas velocity. The pilot size units have a nominal rating of $0.5 \mathrm{~m}^{3}$ per sec. The system pressure drop is said to be comparable to that of an electrostatic precipitator. 

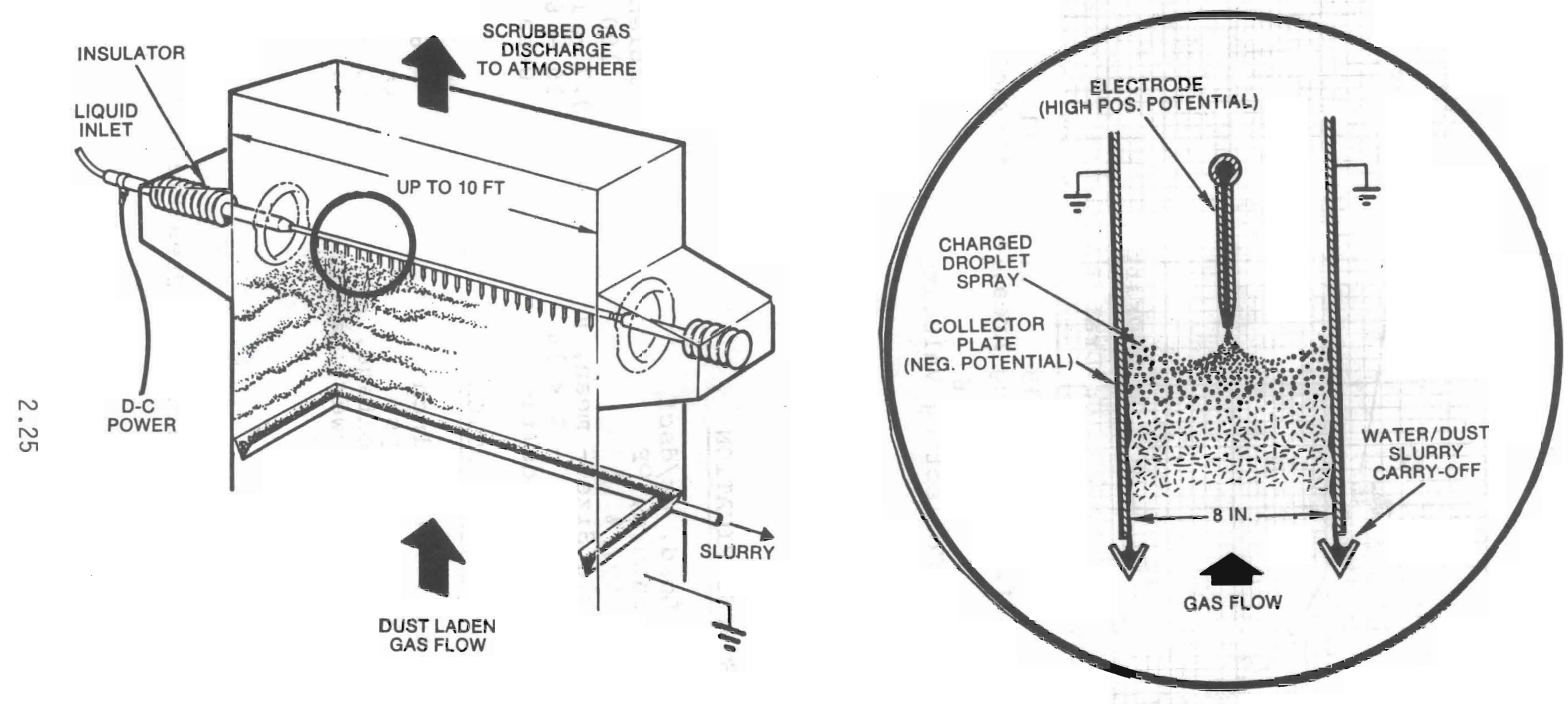

Figure 1 Charged Droplet Scrubber Operating Principle and General Component Arrangement for a Single Electrostatic Spraying Stage 


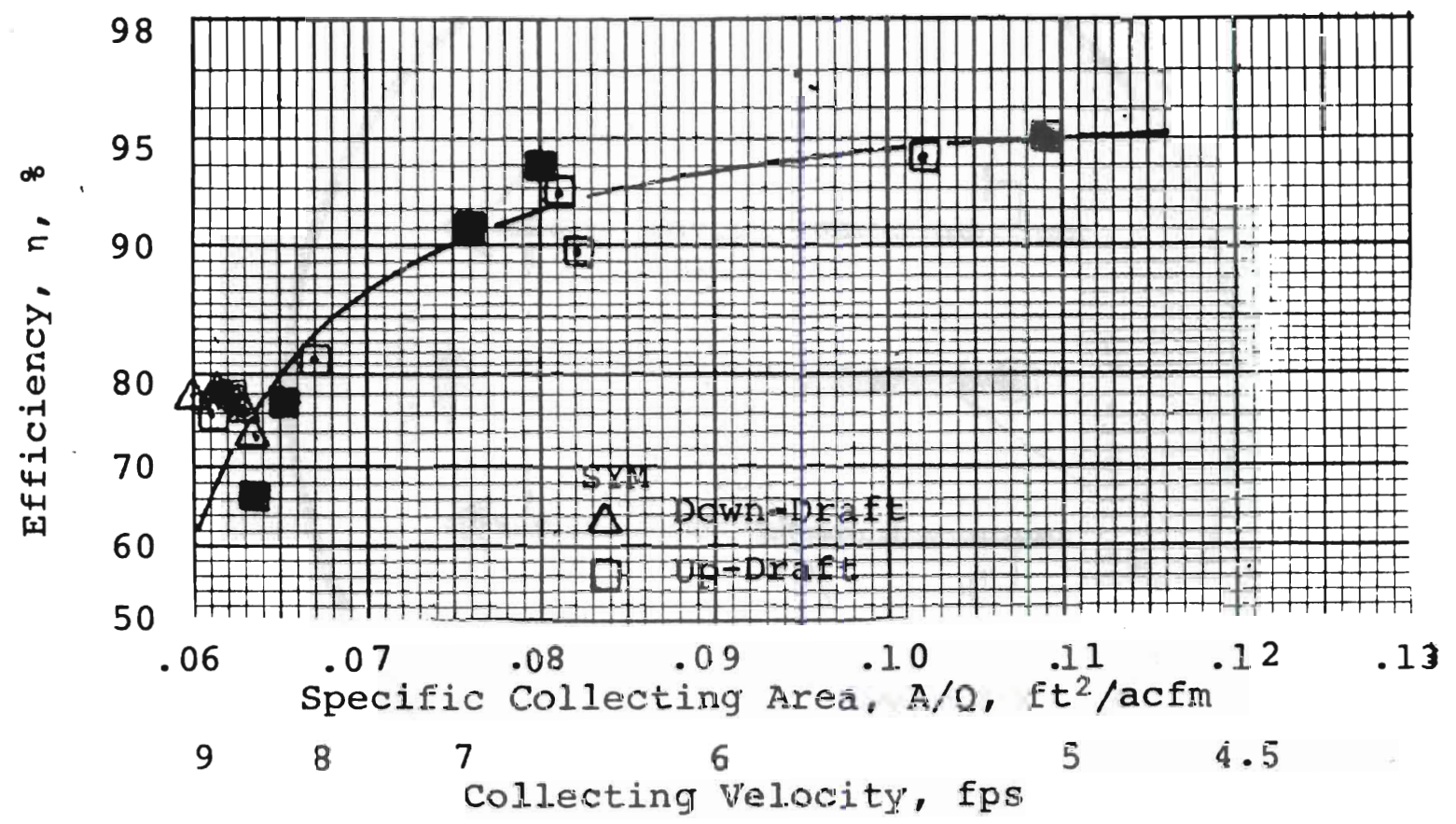

PROCESS SPECIFICATION

Dust Load, gr/dscf

Temperature, $\mathrm{OF}_{\mathrm{F}}$

Humidity, \&

Particle Size - mean, $\mu$

$-\frac{o}{\partial}<1 \mu$

Particle Composition

$$
\begin{aligned}
& 90-30 \mathrm{mg} / \mathrm{m}^{3} \\
& \text { Ambient } \\
& 100 \\
& 0.7-1.2 \\
& 30-60 \\
& \text { Urea }
\end{aligned}
$$

CDS DESIGN AND OPERATION

$\begin{array}{lc}\text { Plate Spacing, inch } & 6 \\ \text { Gas Velocity, fps } & 4 \frac{1}{2}-9 \\ \text { Transformer - Voltage, KV } & 50-55 \\ \text { - Power, va/cfm } & 0.4-0.8 \\ \text { Number of Stages } & 4\end{array}$

Figure 2 CDS Pilot Performance Urea Prilling Tower 


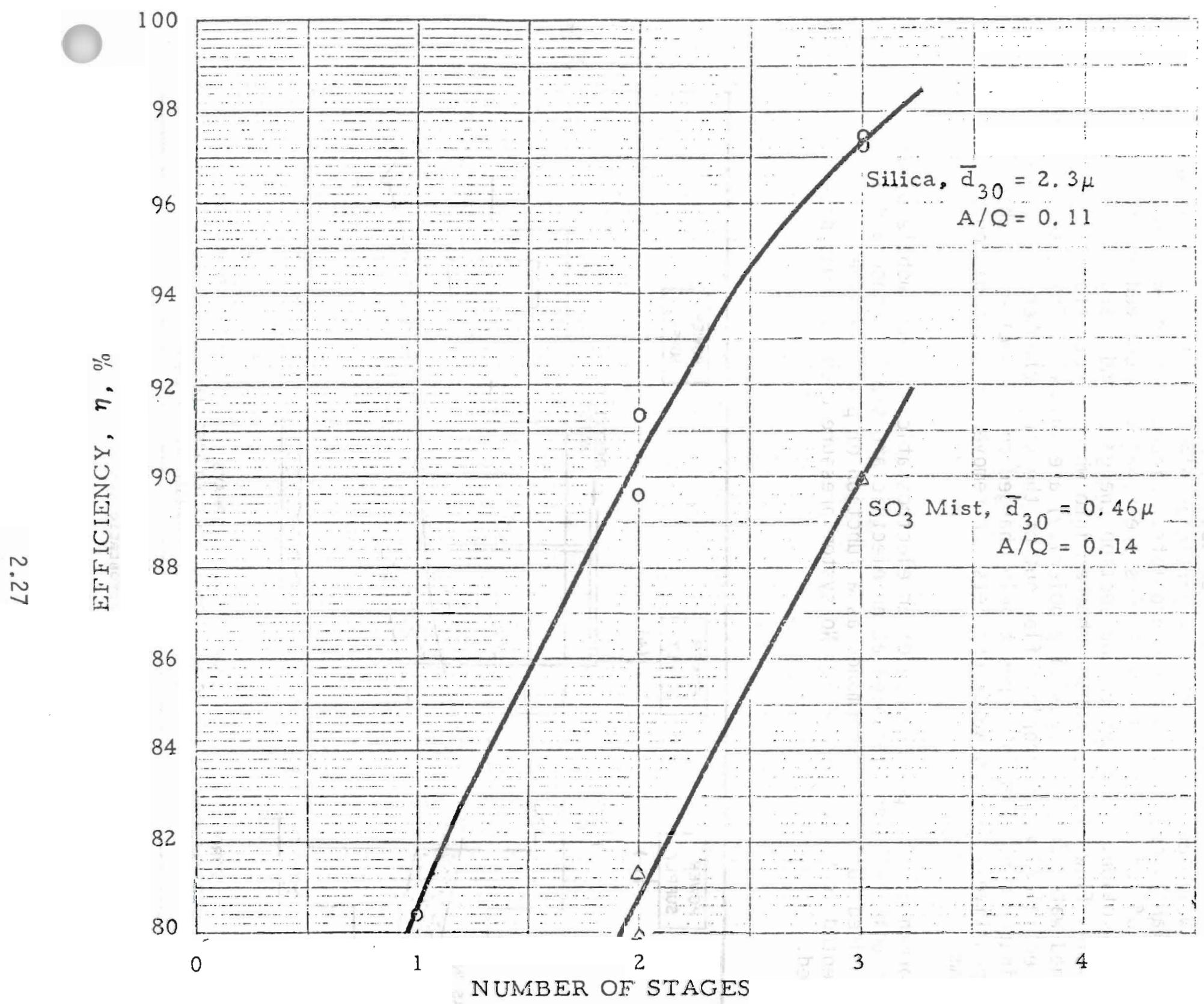

Figure 3 Effect of Series Electrostatic Spraying Stages on Overall Collecting Efficiencies 


\section{UNIVERSITY OF WASHINGTON ELECTROSTATIC SCRUBBER (31) \\ (Pilat, 1978)}

Description: The UW Electrostatic Scrubber uses electrostatically charged water droplets to collect particles electrostatically charged to a pclarity opposite from the droplets. Figure 1 shows an illustration of the system. The particles are negatively charged in the corona section. From the corona section the gases and charged particles flow into a scrubber chamber into which electrostatically charged water droplets (positive polarity) are sprayed. The gases and some entrained water droplets flow out of the spray chamber into a mist eliminator consisting of a positively charged corona section in which the positively charged water droplets are removed from the gaseous stream.

Performance: The performance of an electrostatic scrubber mobile pilot plant unit has been evaluated at an electric arc steel furnace and a coal fired boiler. Performance as a function of particle size is presented in Figures 2 and 3 . No system pressure drop data was presented.

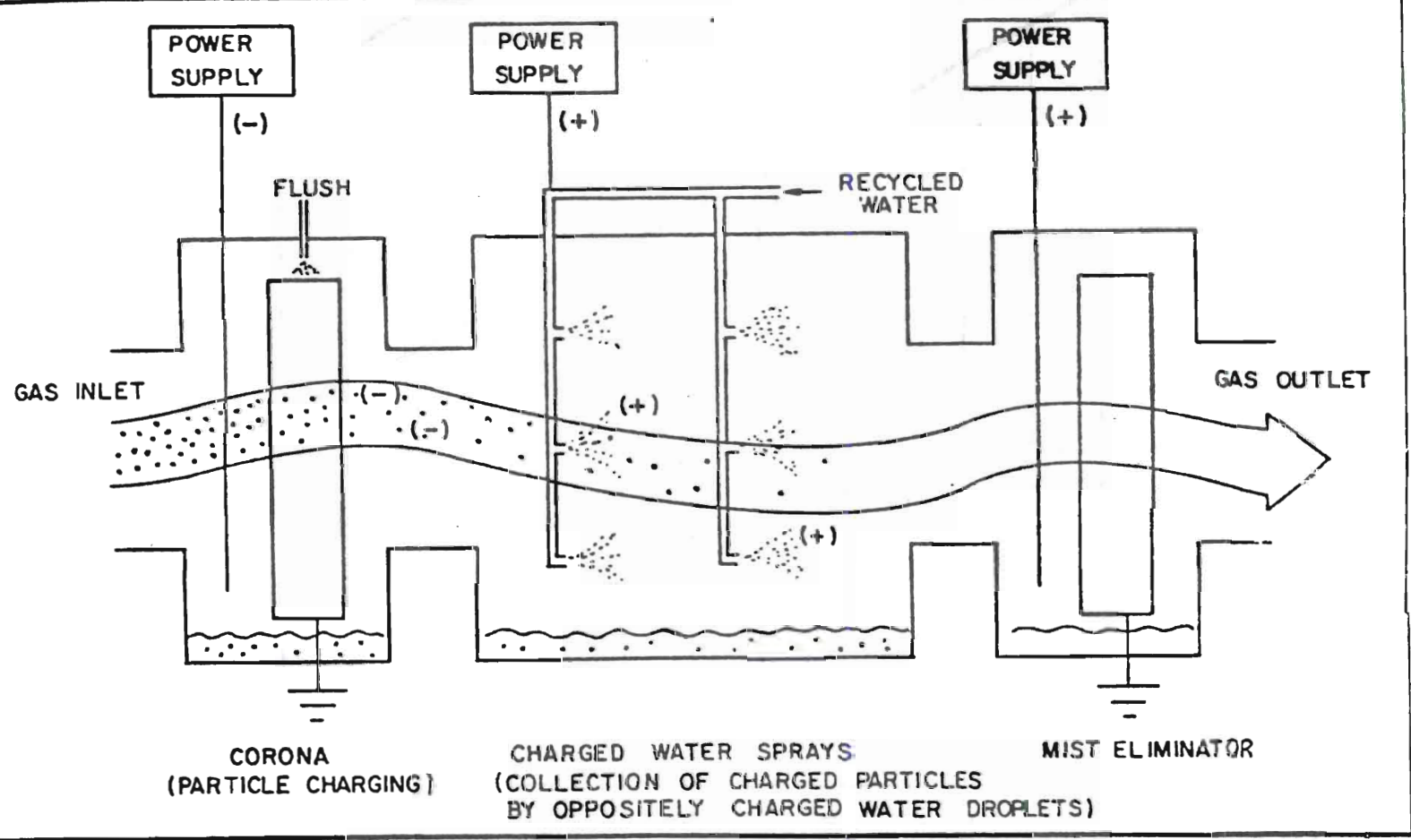

Fig. 1 UW Electrostatic Scrubber 


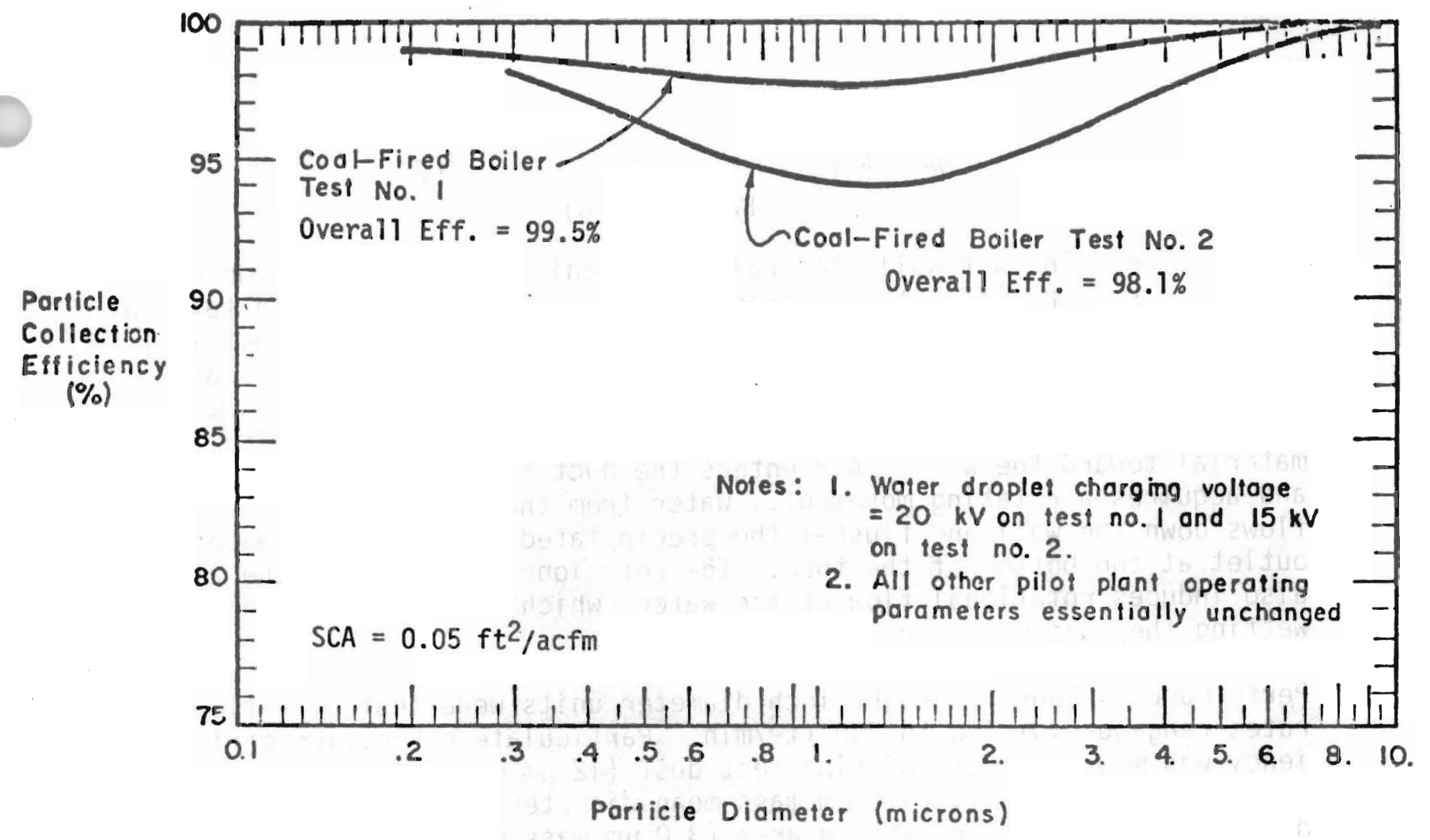

Particle Collection Efficiency

(\%)
Fig. 2 Influence of Water Droplet Charging Voltage on Particle Collection
Efficiency

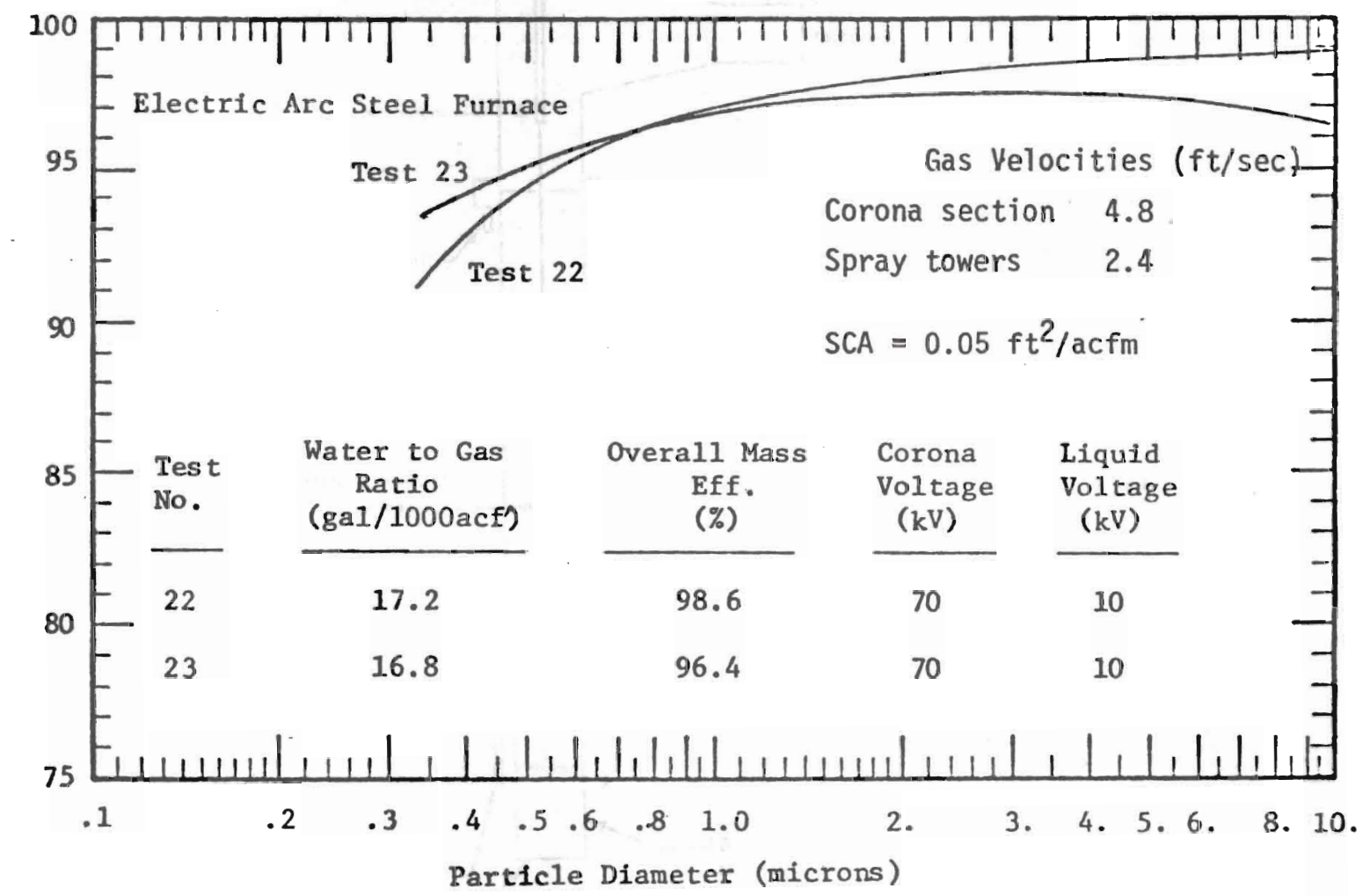

Fig. 3 Collection Efficiencies With Similar Operating Conditions At Electric Arc Steel Furnace 


\section{WET WALL ELECTROINERTIAL UNIT AIR CLEANER(32)}

$$
\text { (Bari1, 1978) }
$$

Description: The Wet Wall Electroinertial Unit air cleaner was developed to remove respirable dust less than $15 \mu \mathrm{m}$ from the air in cotton textile mills and related operations. Figure 1 shows a diagram of the wet wall electroinertial unit. An electrostatic precipitation system was combined with a wet wall to flush away the precipitated material and minimize maintenance. Inertial effects were added to assist in moving material toward the wall. Air enters the duct tangentially at the top and acquires a rotating movement. Water from the upper water inlet flows down the wall and flushes the precipitated dust into the water outlet at the bottom of the tube. The rotational movement of the air also induces rotational flow of the water, which assists in uniformly wetting the surface of the tube.

Performance: Four and eight inch diameter units were tested at flow rates ranging from 100 to $800 \mathrm{ft}^{3} / \mathrm{min}$. Particulate collection efficiency was measured with $A C$ fine test dust (12 um mass mean diameter), artificial cotton dust ( $4.0 \mu \mathrm{m}$ mass mean diameter) and cotton dust drawn from the card processing area (3.0 $\mu \mathrm{m}$ mass mean diameter). Performance data for the $4 \mathrm{in}$. and $8 \mathrm{in}$. diameter units are presented in Tables 1 and 2. Pressure drop through the 4 in. unit ranged from 1.25 to $3.75 \mathrm{in}$. $\mathrm{H}_{2} \mathrm{O}$. No performance data was presented for submicron particulate collection.

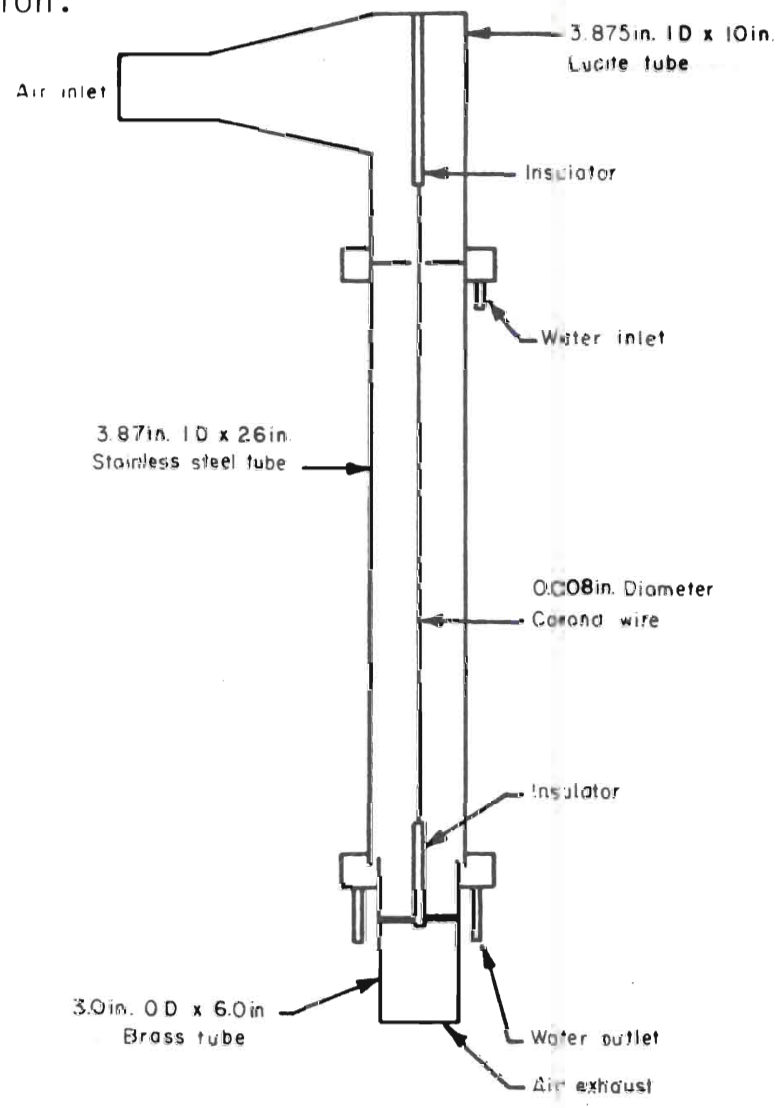

F1g. 1. Wet Wall Electrolnertial Unit 
TOTAL MASS EFFICIENCY OF THE 4 IN. WET WALL ELECTROINERTIAL UNITa/b-

\begin{tabular}{lcccccc} 
& & \multicolumn{4}{c}{ Dust } & Pres- \\
Test & Circulation & Poten- & Cur- Feed & sure \\
Dust & Rate & tial & rent & Rate & Drop & Efficiency \\
\hline & $\mathrm{k} / \mathrm{sec}$ & $\mathrm{kV}$ & $\mathrm{mA}$ & $\mathrm{g} / \mathrm{min}$ & $\mathrm{kPa}$ & $\mathrm{m}$
\end{tabular}

$\begin{array}{lrrrrrr}\text { AC fine } & 47.2 & 0 & 0 & 1.0 & .31 & 81.2 \\ \text { AC fine } & 94.4 & 0 & 0 & 2.0 & .93 & 87.6 \\ \text { AC fine } & 47.2 & -30 & 2.4 & 0.2 & .31 & 99.0 \\ \text { AC fine } & 94.4 & -30 & 2.4 & 0.2 & .31 & 99.0 \\ \text { AC fine } & 47.2 & +33 & -- & 1.0 & .37 & 98.5 \\ \text { Cotton dust } & 47.2 & -30 & 2.2 & 0.83 & .31 & 98.1 \\ \text { Card trash } & 94.4 & -30 & 2.2 & 0.67 & .93 & 99.7 \\ \text { Cotton dust } & 94.4 & -30 & 2.1 & 0.62 & .93 & 96.1\end{array}$

a/ Length of WWEU was $2 \mathrm{ft}$.

b/ Water flow was $0.25 \mathrm{gal} / \mathrm{min}$.

TABLE 2

TOTAL MASS EFFICIENCY OF 8 IN. WET

WALL ELECTROINERTIAL UNITa-/

\begin{tabular}{cccccc} 
Poten- & Cur- Water & Alr & \\
Test Dust & tial & rent & Flow & Flow & Efflciency \\
\hline $\mathrm{KV}$ & $\mathrm{ma}$ & $\mathrm{m} / \mathrm{min}$ & $\mathrm{m}^{3} / \mathrm{sec}$ &
\end{tabular}

$\begin{array}{lrrrrr}\text { AC fine dust } & -60 & -- & 3.5 & .38 & 97.6 \\ \text { Card trash } & -60 & -7 & 3.5 & .38 & 98.4 \\ \text { Card trash } & 0 & 0 & 3.5 & .38 & 99.8 \\ \text { Art1f1c1al } & & & & & \\ \quad \text { cotton dust } & -60 & -7 & 3.5 & .38 & 99.4 \\ \text { Artificial } & & & & & 80.2 \\ \text { cotton dust } & 0 & 0 & 3.5 & .38 & 30.3 \\ \text { Card outputb/, } & 0 & 0 & 2.4 & .38 & 99.9 \\ \text { Card outputb/, } & -58 & -6 & 2.5 & .38 & 96.9 \\ \text { Card outputb/ } & +60 & +5.8 & 2.5 & .38 & \end{array}$

a/ Length of WWEU was 66 in.

b/ Tested at SRRC on output of V-cell filter. 
FLUID ELECTRODE PRECIPITATOR (32)

(Bari1, 1978)

Description: A fluid electrode precipitator uses flowing columns of grounded water for particulate collection instead of rigid grounded plates used in a conventional electrostatic precipitator. A diagram of the system is shown in Figure 1. The falling columns of grounded water act as cylinders in cross flow and create vortices which enhance particulate collection. Auxiliary electrodes and discharge electrodes are positioned in arrays to direct the charged dust into the grounded fluid. Intermediate flow tubes at $1 \mathrm{ft}$. interval of vertical fall catch the fluid, decelerate and return it to laminar conditions.

Performance: The performance of a small scale unit $0.2 \mathrm{~m} \times 0.2 \mathrm{~m} \times 2.7 \mathrm{~m}$ was evaluated in a cotton dust test facility. Two types of dust, model card dust with a mass mean diameter of $3.6 \mu$ and cotton dust with a mass mean diameter of 4.5 to $6.7 \mu$ were evaluated. Concentrations ranged from 0.5 to $1.5 \mathrm{mg} / \mathrm{m}^{3}$. A summary of the collection efficiency is presented in Table 1. No pressure drop information was presented.

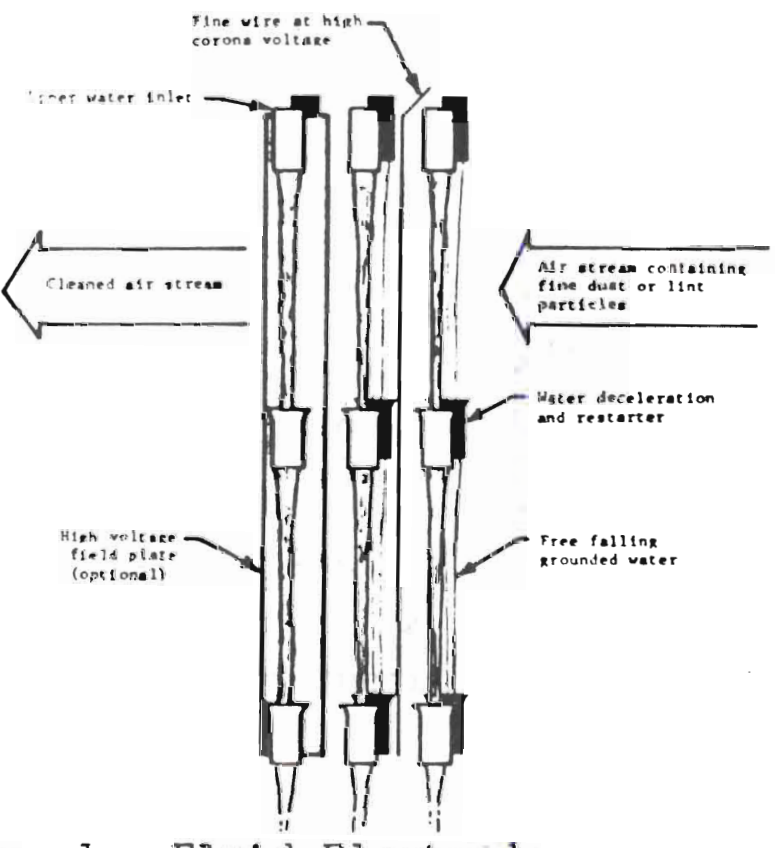

Fig. 1. Fluid Electrode

Precipitator 


\section{TABLE 1}

EFFICIENCY OF TYPICAL FLUID ELECTRODE

PRECIPITATOR CONFIGURATION

\begin{tabular}{ccccc} 
Velocity & $\begin{array}{c}\text { Field } \\
\text { Strength }\end{array}$ & $\begin{array}{c}\text { Dust Supply } \\
\text { Concentration }\end{array}$ & $\begin{array}{c}\text { Count } \\
\text { Efficiency } \\
1.54-10 u\end{array}$ & $\begin{array}{c}\text { Mass } \\
\text { Efficiency }\end{array}$ \\
\hline $\mathrm{m} / \mathrm{sec}$ & $\mathrm{kV} / \mathrm{cm}$ & $\mathrm{mg} / \mathrm{m}^{3}$ & $\%$ & $\%$ \\
1.3 & 6.2 & 0.8 & 75 & 86 \\
1.8 & 5.9 & 0.5 & 81 & 93 \\
2.5 & 4.9 & 0.8 & 60 & 78
\end{tabular}




\section{ELECTROSTATIC FIBER BED FILTER (33) \\ (Bamberger, 1981, 1982 and Reid, 1976)}

Description: The Electrostatic Fiber Bed Filter is a highly efficient system for removing electrically resistive submicron and larger particles from gas strearis. Basic components of the system shown in Figure 1 include a corona chamber where the particles are negatively charged followed by a highly porous bed of dielectric fibers which occupy 5 to $8 \%$ of the bed volume. An electric field develops in the fiber bed due to the deposition of negatively charged particles. This electric field is significantly larger near a fiber than local coulomb repulsion and dramatically increases the particle capture cross section. The system can be cleaned using air jets or water sprays.

Performance: The Electrostatic Fiber Bed Filter performance has been evaluated for fly ash collection at several coal fired power plants using a $1.9 \mathrm{~m}^{3} / \mathrm{sec}$ pilot plant unit installed at the electrostatic precipitator outlet. Commercial units are available for collection of welding fumes and other building air cleaning applications.

Table 1 lists system performance for collection of fly ash, submicron welding fume and ammonium chloride.

The fiber bed filter system pressure drop is less than $0.25 \mathrm{kPa}$.

\section{FIGURE 1. SCHEMETIC DRAWING OF EFBE EXPERIMENTAL APPARATUS}

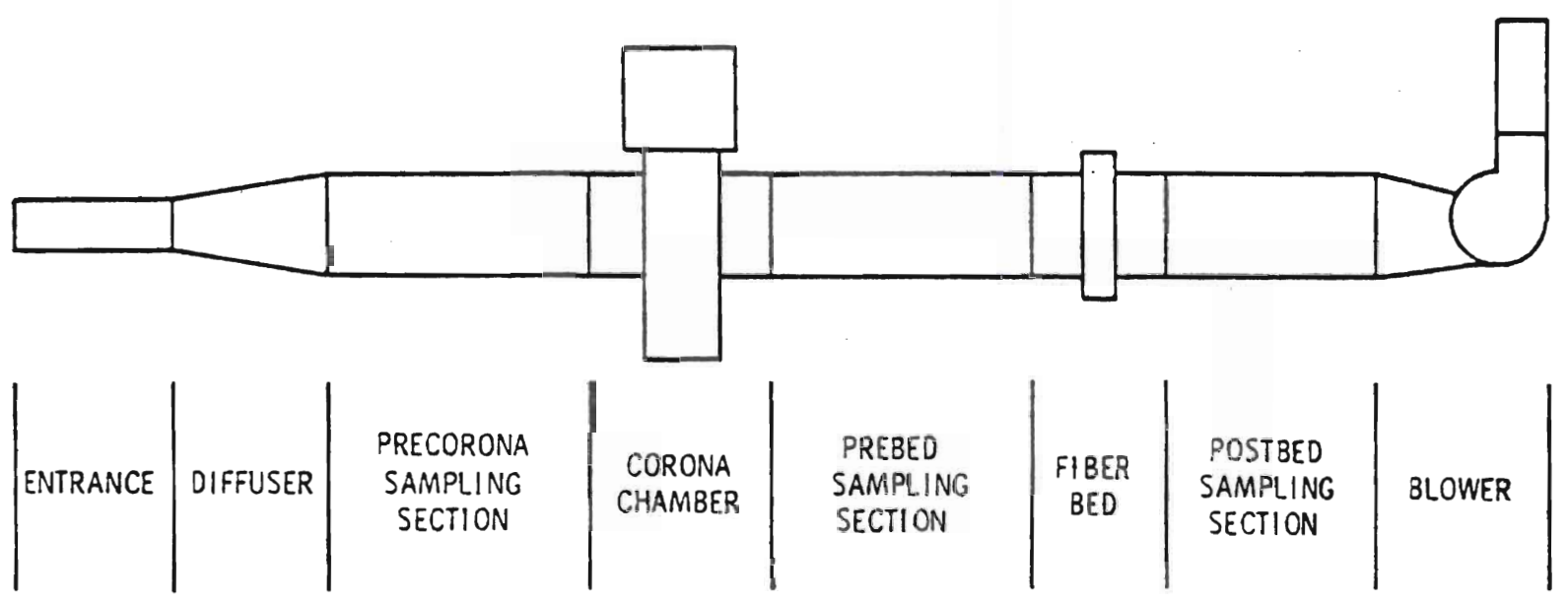


TABLE 1. Electrostatic Fiber Bed Performance

\begin{tabular}{|c|c|c|c|c|c|c|}
\hline Particulate & $\begin{array}{c}\text { Operating } \\
\text { Particulate } \\
\text { Loading } \\
\mathrm{mg} / \mathrm{m}^{3}\end{array}$ & $\begin{array}{l}\text { AMD } \\
\mu \mathrm{m}\end{array}$ & $\begin{array}{l}\text { Velocity } \\
\mathrm{ft} / \mathrm{min}\end{array}$ & $\begin{array}{l}\text { Fiber Bed } \\
\text { Void Fractior: }\end{array}$ & $\begin{array}{l}\text { Temperature } \\
\text { OF }\end{array}$ & $\begin{array}{c}\text { Efficiency } \\
\text { Average } \\
\%\end{array}$ \\
\hline \multirow[t]{2}{*}{ Fly Ash } & $100-150$ & $2-3$ & 300 & 0.93 & 70 & 99.9 \\
\hline & $100-150$ & $2-3$ & 300 & 0.93 & 280 & 92.5 \\
\hline $\begin{array}{l}\text { We ld ing } \\
\text { Fume }\end{array}$ & $1-35$ & $<1$ & $200-400$ & 0.93 & 70 & $92-99.9$ \\
\hline $\mathrm{NH}_{4} \mathrm{Cl}$ & $10-250$ & 0.25 & 200 & 0.96 & 70 & $80-99$ \\
\hline
\end{tabular}




\section{DIELECTROPHORETIC AIR FILTRATION (34) \\ (Thompson, 1978)}

Description: Dielectrophoresis is defined as the accelerated separation (filtration) of solid or liquid particles from air in nonuniform electric fields. Dielectrophoresis is the movement of a particle in a nonuniform electric field, the direction of movement usually being toward the most intense part of the field. Applied to air filtration, air flow is through a thin layer of air filter material which is sandwiched between metal screen electrodes. The air moves through the sandwich perpendicular to its plane; since every fiber or element in the mat locally distorts the applied electric field the mat contains an enormous number of field inhomogeneities. If the material dielectric constant is greater than that of air, the field is more intense close to a fiber than remote from it. Therefore, airborne particles within the filter medium experience a dielectrophoretic force. This force is approximately described by

$$
F=2 r^{3} k_{1}\left(\frac{k_{2}-K_{1}}{K_{2}+2 K_{1}}\right) E^{2}
$$

The dielectric force $F$ is proportional to the square of the applied field $E$ and to the cube of the particle radius $r$; the dielectric constants of the medium, $K_{1}$, and of the particles, $K_{2}$, are also involved.

Performance: This collection mechanism was evaluated using a $0.64 \mathrm{~cm}$ thick flat glass fiber mat separating two steel wire screen electrodes. The performance was measured using the Dielectrophoretic Augmentation Factor (DAF), the ratio of the aerosol percent penetration (100\% minus percent aerosol retention) at zero voltage to the percent penetration at the voltage of interest. Tables 1 and 2 present data for one filter medium. The penetration at zero voltage was not listed. The filter was rated at $20 \mathrm{~cm} / \mathrm{sec}(40 \mathrm{fpm})$ velocity and $99 \mathrm{~Pa}\left(0.40 \mathrm{in}\right.$. $\left.\mathrm{H}_{2} \mathrm{O}\right)$ pressure drop. 
TABLE 1

DAF VS AIR SPEED AND VOLTAGE FOR HP-100 FILTER MEDIUM; AEROSOL 0.3 MICROMETER DOP

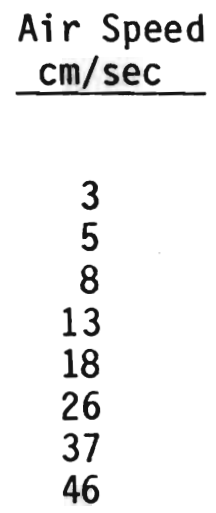

TABLE 2

DAF VS AIR SPEED AND VOLTAGE FOR HP-100 FILTER MEDIUM; AEROSOL 0.8 MICROMETER DOP

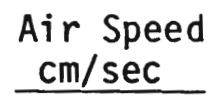

3
5
8
13
18
26
37
46

\begin{tabular}{l}
2 \\
\hline \\
8 \\
3 \\
3 \\
2 \\
2 \\
2 \\
2 \\
1
\end{tabular}

19

13

11

6

4

3

\begin{tabular}{r}
7 \\
\hline \\
330 \\
120 \\
100 \\
42 \\
27 \\
14 \\
9 \\
6
\end{tabular}

7

1100

360

170

50

35

18

11 


\section{SINTERED METAL FILTERS $(35,36)$ \\ (Bjorkland, 1976, and Kirstein, 1982)}

Description: Sintered metal filters are constructed by fusing a mass of metal particles by application of pressure and temperature below the metal melting point. The filter porosity is about 0.5 absolute. The filters can be cleaned by pulsing or reversing the air flow.

Performance: Sintered metal filters were evaluated by Idaho National Engineering Laboratory for use in their Transuranic Waste Treatment Facility downstream from a high temperature slagging pyrolysis incinerator. Figure 1 shows a schematic of the pilot plant used to conduct the tests. Fly ash with 50 wt \% less than $10 \mu \mathrm{m}$ and concentration of $3 \mathrm{~g} / \mathrm{Nm}^{3}$ was used for the test aerosol. Six sintered metal cylindrical filters $0.91 \mathrm{~m}$ long by $6.8 \mathrm{~cm} O D$ and $0.15 \mathrm{~cm}$ wall thickness were tested. The flow velocity ranged from 1.2 to $2.1 \mathrm{~m} / \mathrm{min}$. The filters were cleaned by pulsed blow back. The cleaning cycle was initiated at a pressure of $6.25 \mathrm{kPa}$; the recovery pressure drop stabilized between 3.75 to $4.25 \mathrm{kPa}$. The filters were operated for 4900 hours and 5100 blow backs without any observed plugging. The filter efficiencies were measured to be between $99.999 \%$ and $99.99999 \%$ on a mass basis. No measurable weight gain was observed on any of the downstream filters.

Battelle Northwest evaluated the use of sintered metal filters to remove particulate entrained in the off-gas from a spray calciner and a fluidized bed calciner. Decontamination factors of $10^{3}$ to $10^{5}$ (efficiencies of $99.9 \%$ to $99.999 \%$ ) were reported for the fluidized bed calciner. The test conditions are presented in Table 1.

TABLE 1. Fluidized Bed Calciner Off-Gas Sampling (a)

$\frac{\text { Wt\% Lost }}{0.008-0.024} \frac{\mathrm{DF}}{10^{3}-10^{5}} \frac{\begin{array}{c}\text { Mass } \\ \text { Concentration, } \\ \mathrm{mg} / \mathrm{m}^{3} \text { (b) }\end{array}}{0.14-12.3} \frac{\begin{array}{c}\text { Aerodynamic } \\ \text { Microns }\end{array}}{2.5-3.8}$

a. Average Conditions

$\begin{array}{lccc}\text { Pressure Drop, in. } \mathrm{H}_{2} \mathrm{O} & 20 & - & 40 \\ \text { Total acfm } & 80 & - & 90 \\ \text { Temperature, }{ }^{\circ} \mathrm{C} & 300 & - & 400 \\ \text { Face velocity, ft/min } & 3.97 & \pm & 0.66 \\ \text { Permeability, ft/min--in. } \mathrm{H}_{2} \mathrm{O} & 0.14 & \pm & 0.03 \\ \text { Pressure, in. } \mathrm{H}_{2} \mathrm{O} & -2 & \text { to } & -10\end{array}$

b. Noncondensable off-gas. 


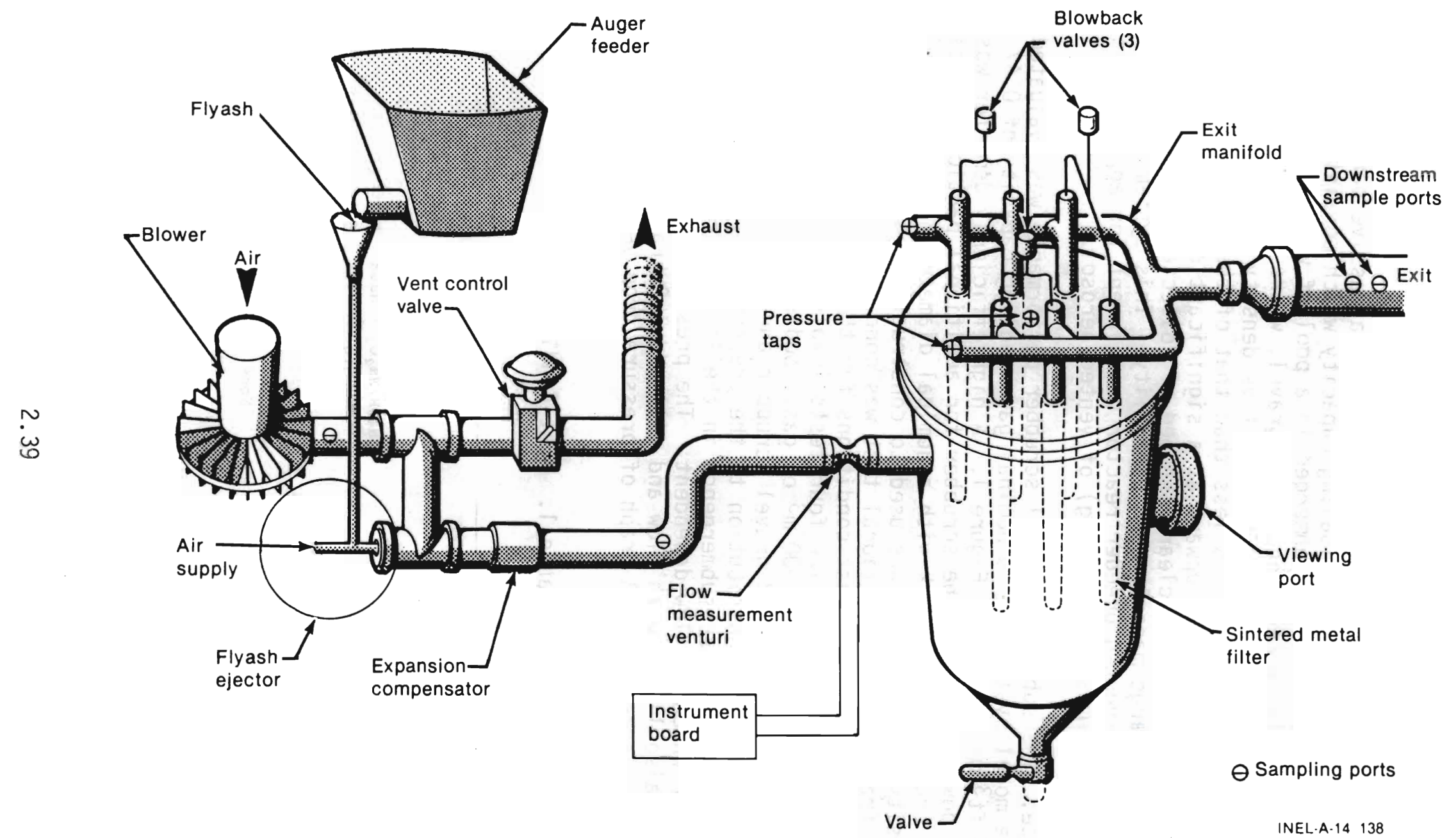

Figure 1. General Schematic of Pilot-plant apparatus for testing sintered metal filters. 


\section{SLIBMERGED GRAVEL SCRUBBER(37) \\ (McCormack, 1982)}

Description: The submerged gravel scrubber is a passive particulate collection system with a high loading capacity which consists of a bed of gravel (or other packing) submerged in a pool of water. Gas, laden with aerosol is discharged beneath the gravel, where it subsequently flows upward through the bed. The effective density of the two-phase mixture in the gravel region is less than that of the pool outside the gravel bed and liquid flows upward at a significant rate. This inherent liquid pumping action clears the bed of collected aerosol and provides a very large mass loading capability. This system was developed for use in a vented breeder reactor containment for applications involving a large mass $(100,000 \mathrm{~kg})$ of vented aerosol.

Performance: The submerged gravel scrubber performance was evaluated in a scale model system with a nominal gas handling capacity of 0.47 $\mathrm{m}^{3 / \mathrm{s}}\left(1000 \mathrm{ft}^{3} / \mathrm{min}\right)$ shown in Figure $]$. A high efficiency demister was installed downstream from the scrubber for additional particulate collection. Crushed basalt rock with a nominal diameter of $3 / 8$ to $1 / 2$ in. and a density of $2.84 \mathrm{~g} / \mathrm{cm}^{3}$ was used to construct a bed with a $0.46 \pm$ 0.02 void fraction. An additional test was conducted with a bed of ceramic spheres. Typical test conditions for the sodium aerosol tests are presented in Table 1. The four tests involved collection of 2000 $\mathrm{kg}$ of aerosol mass from $100,000 \mathrm{~m}^{3}$ of gas. Sodium aerosol removal efficiency for the submerged gravel scrubber and demister are presented in Table 2. The main contribution to the pressure drop through the scrubber is the downcomer submergence in the liquid pool plus a small pressure drop which is flow dependent. The pressure drop through the demister is also linear with flow and will add $1.2 \mathrm{kPa}$ at $0.47 \mathrm{~m} / \mathrm{s}$ to the system pressure drop. A graph of pressure drop versus flow rate is shown in Figure 2 .

Table 1. Test Conditions

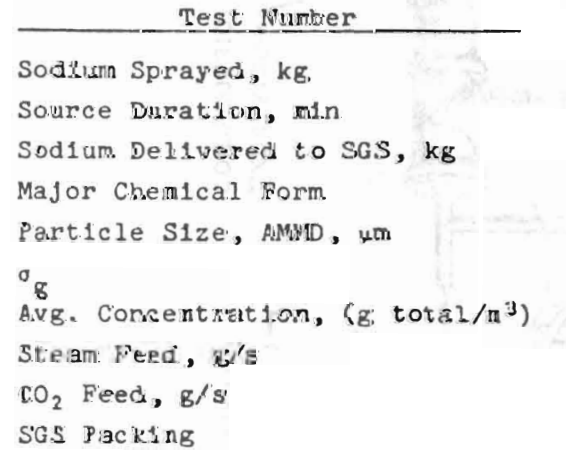

- Pool Fire Continued to $780 \mathrm{~min}$

\begin{tabular}{|c|c|c|c|}
\hline $\mathrm{AC} 7$ & $\underline{A C 8}$ & AC9 & AC10 \\
\hline 1210 & 1239 & 887 & 1198 \\
\hline 1930 & 1890 & $490 *$ & 1520 \\
\hline 245 & 255 & 81 & 253 \\
\hline $\mathrm{NaOH} / \mathrm{Na}_{2} \mathrm{O}_{2}$ & $\mathrm{NaOH}$ & $\mathrm{Na}_{2} \mathrm{CO}_{3}$ & $\mathrm{NaOH}$ \\
\hline 5.0 & 4.6 & 5.2 & 6.2 \\
\hline 3.0 & 3.4 & 3.4 & 2.4 \\
\hline 13.3 & 18.1 & 13.4 & 18.5 \\
\hline None & 6 & 6.4 & 7.0 \\
\hline None & None & 1.6 & None \\
\hline Gravel & $9-13$ & $\mathrm{~min}$ & $\begin{array}{l}\text { Ceramic } \\
\text { Spheres, } \\
9.5 \mathrm{mal}\end{array}$ \\
\hline
\end{tabular}




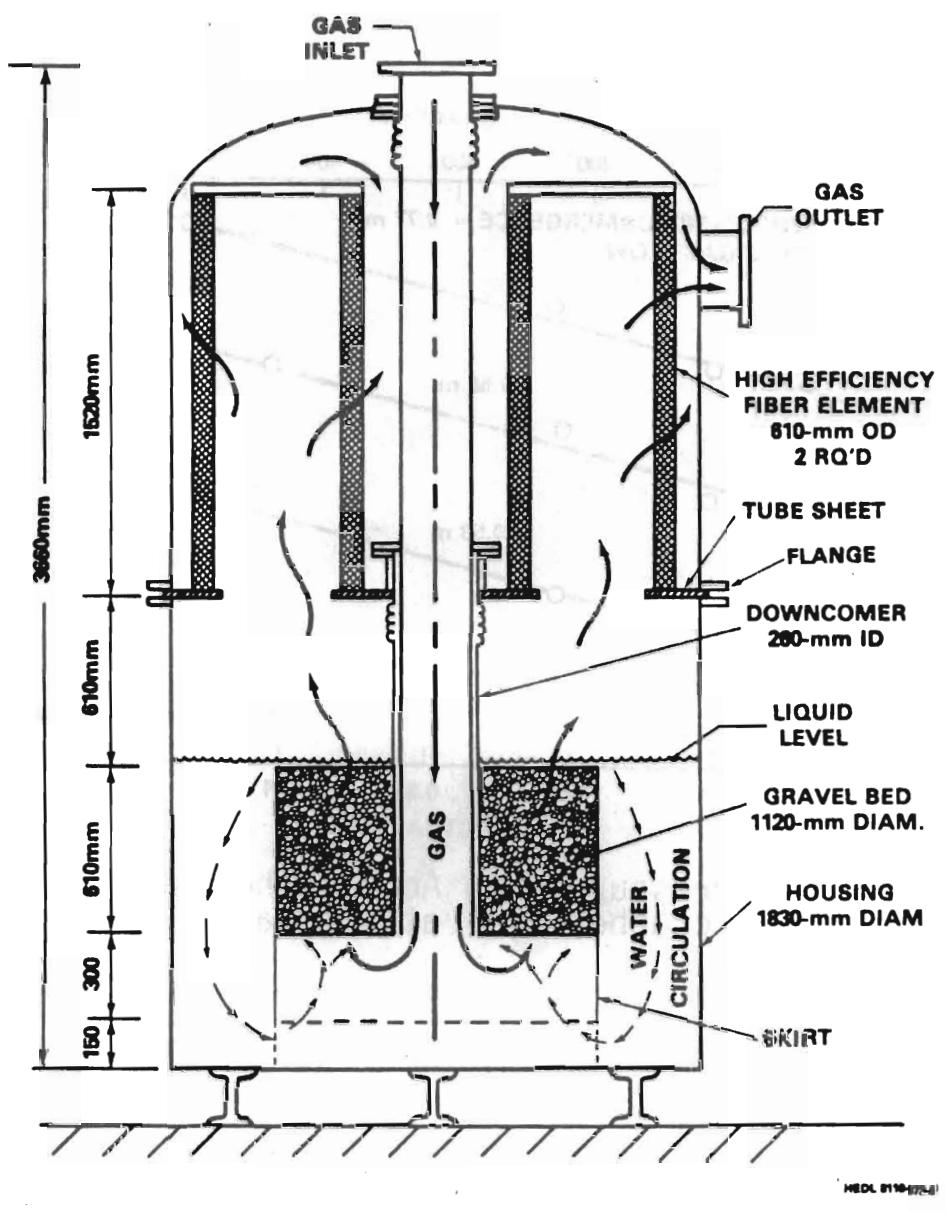

Figure 1. Schematic Diagram of the Submerged Grave1 Scrubber/Demister Test System

Table 2. Sodium Aerosol Removal Efficiency

SGS

Demister

SGS + Demister

\begin{tabular}{|c|c|c|c|c|}
\hline $\begin{array}{r}\text { Test } \\
\text { AC7 } \\
\end{array}$ & $\begin{array}{r}\text { Test } \\
\text { AC8 } \\
\end{array}$ & $\begin{array}{l}\text { Test } \\
\text { AC9 } \\
\end{array}$ & $\begin{array}{l}\text { Test } \\
\text { AC } 10 \\
\end{array}$ & Average \\
\hline 99.5 & 99.1 & 99.1 & 99.3 & 99.2 \\
\hline 97.1 & 97.7 & 99.6 & 98.4 & 98.2 \\
\hline 99.98 & 99.98 & 99.99 & 99.99 & 99.99 \\
\hline
\end{tabular}




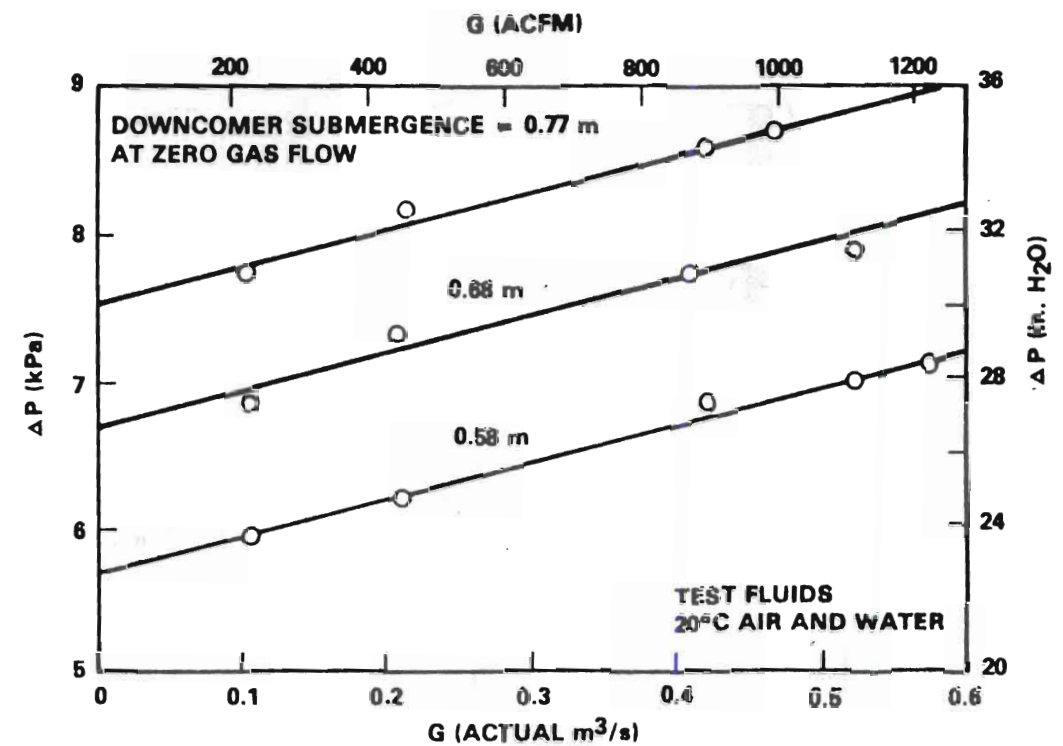

Figure 2. Pressure Drop Across the Submerged Gravel Scrubber Pool at Several Liquid Levels 


\title{
HIGH TEMPERATURE AEROSOL FILTRATION WITH DEEP BED FILTERS(38)
}

\author{
(Dillmann, 1982)
}

Description: Several types of high temperature stainless steel and ceramic fiber filters have been evaluated for use in vented containment designs to control containment pressures after light water reactor core meltdown accidents. Stainless steel filters which are temperature resistant up to $550^{\circ} \mathrm{C}$ are available with $22,12,8,4$ and $2 \mu \mathrm{m} f$ iber diameters. Ceramic fiber filters (fiber diameter $8 \mu \mathrm{m}$ ) can be used in the temperature range from $1000^{\circ} \mathrm{C}$ to $1600^{\circ} \mathrm{C}$.

Performance: The performance of stainless steel and ceramic fiber filters were evaluated in the test apparatus shown in Figure 1. Uranine particles (sodium fluorescein) with an aerodynamic mean diameter of about $0.17 \mu \mathrm{m}$ were used as the test aerosol. Figures 2 and 3 present decontamination factors (1-EFFICIENCY)-1 for stainless steel and ceramic fiber filters. Pressure drop data for a typical stainless steel filter is presented in Figure 4. All the tests were conducted at room temperature.

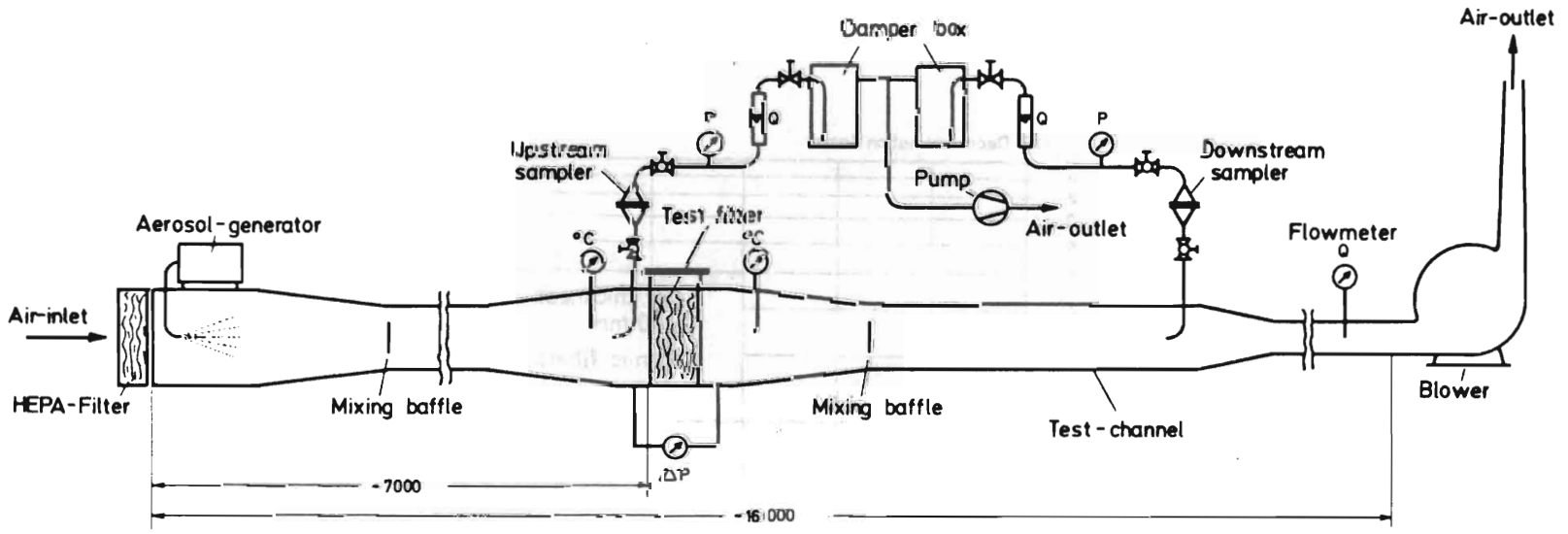

Figure 1. Test-rig for Particle Filters Under Ambient Conditions 


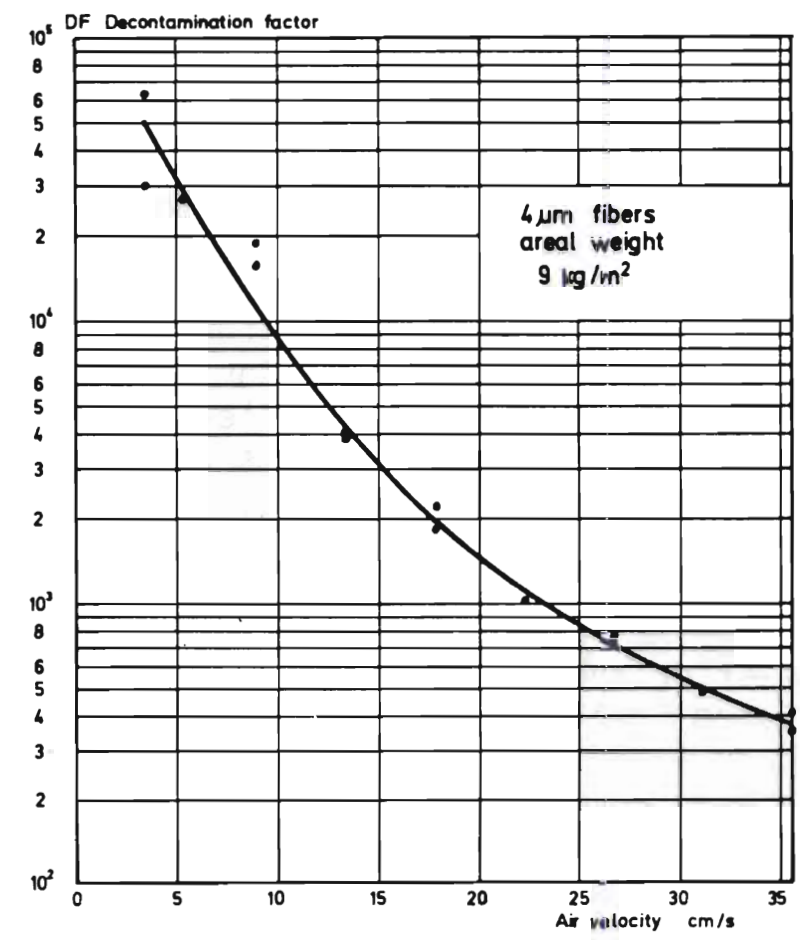

Figure 2. Decontamination Factor of a Stainless Steel Fiber Particulate Air Filter

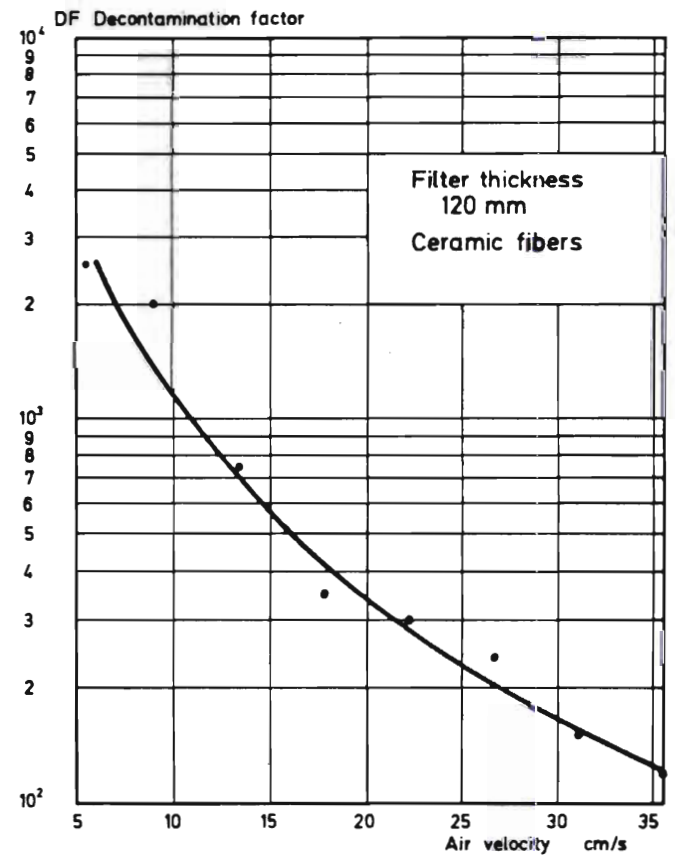

Figure 3. Decontamination Factor of Ceramic Fibers 


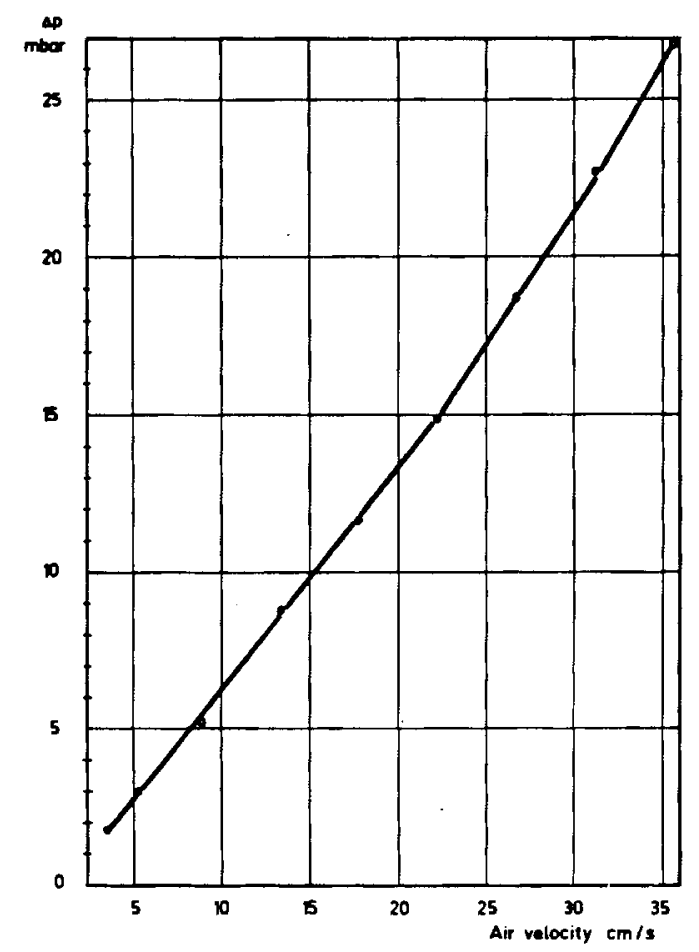

Figure 4. Pressure Drop of a Stainless Steel Fiber Filter, $4 \mu \mathrm{m}$ Fibers, $9 \mathrm{~kg} / \mathrm{m}^{2}$ Areal Weight 


\section{REFERENCES}

1. C. A. Burchsted, A. B. Fuller and J. E. Kahn, Nuclear Air Cleaning Handbook, ERDA 76-21, NTIS Springfield, Virginia, 1976.

2. M. W. First, ed., Proceedings of the $10^{\text {th }}$ AEC Nuclear Air Cleaning Conference (New York, New York), CONF-680821, USAEC/The Harvard Air Cleaning Laboratory, Boston, Massachusetts, 1968.

3. M. W. First, ed., Proceedings of the $11^{\text {th }}$ AEC Nuclear Air Cleaning Conference (Richland, Washington), CONF-700816, USAEC/The Harvard Air Cleaning Laboratory, Boston, Massachusetts, 1970.

4. M. W. First, ed., Proceedings of the $12^{\text {th }}$ AEC Nuclear Air Cleaning Conference (Oak Ridge, Tennessee), CONF-720823, USAEC/The Harvard Air Cleaning Laboratory, Boston, Massachusetts, 1972.

5. M. W. First, ed., Proceedings of the $13^{\text {th }}$ AEC Nuclear Air Cleaning Conference (San Francisco, CaTifornia), CONF-740807, USAEC/The Harvard Air Cleaning Laboratory, Boston, Massachusetts, 1974.

6. M. W. First, ed., Proceedings of the 14th ERDA Nuclear Air Cleaning Conference (Sun ValTey, Idaho), CONF-760822, USERDA/The Harvard Air Cleaning Laboratory, Boston, Massachusetts, 1976.

7. M. W. First, ed., Proceedings of the $15^{\text {th }}$ DOE Nuclear Air Cleaning Conference (Boston, Massachusetts), CONF-780819, USD0E/The Harvard Air Cleaning Laboratory, Boston, Massachusetts, 1978.

8. M. W. First, ed., Proceedings of the $16^{\text {th }}$ DOE Nuclear Air Cleaning Conference (San Diego, California), CONF-801038, USDOE/The Harvard Air Cleaning Laboratory, Boston, Massachusetts, 1980.

9. M. W. First, ed., Proceedings of the $17^{\text {th }}$ DOE Nuclear Air Cleaning Conference (in preparation), (Denver, Colorado), USDOE/The Harvard Air Cleaning Laboratory, Boston, Massachusetts, 1980.

10. M.W. First and H. Gilbert, "Aerosol Filtration, In Proceeding of the $16^{\text {th }}$ DOE Nuclear Air Cleaning Conference (M.W. First, ed.), CONF-801038, USDOE/The Harvard Air Cleaning Laboratory, Boston, Massachusetts, 1980.

11. M. I. Tillery, G. C. Salzman and H. J. Ettinger, "The Effect of Particle Size Variation on Filtration Efficiency Measured by the HEPA Filter Quality Assurance Test," in Proceedings of the $17^{\text {th }}$ DOE Nuclear Air Cleaning Conference (M.W. First ed.), USDOE/The Harvard Air Cleaning Laboratory, Boston, Massachusetts, 1982. 
12. Nuclear Power Plant Air Cleaning Units and Components, ANSI/ASME N5001980, Am. Soc. Mech. Eng., New York, New York, 1980.

13. Testing of Nuclear Air Cleaning Systems, ANSI/ASME N510-1980, Am. Soc. Mech. Eng., New York, New York, 1980.

14. W. L. Anderson, W. S. Magee and L. A. Jones, "Aerospl Filtration by Fibrous Filter Mats: Part III," In Proceedings 13 th AEC Nuclear Air Cleaning Conference (M.W. First ed.), CONF-740807, USAEC/The Harvard Air Cleaning Laboratory, Boston, Massachusetts, p. 445, 1974.

15. G. 0. Nelson, et al., "Filtration Enhancement Using Electronic Techniques," In Proceedings of the 14th ERDA Nuclear Air Cleaning Conference (M.W. First ed.), CONF-760822, USERDA/The Harvard Air Cleaning Laboratory, Boston, Massachusetts, p. 602, 1976.

16. M. Gonzales, J. Elder and H. Ettinger, "Performance of Multiple HEPA Filters Aqainst Plutonium"Aerosols," In Proceedings of the $13^{\text {th }}$ AEC Nuclear Air Cleaning Conference (M.W. First ed.), CONF-740807, USAEC/The Harvard Air Cleaning Laboratory, Boston, Massachusetts, p. 501, 1974.

17. R. A. Moyer, J. H. Crawford and R. E. Tatum, "Deep Bed Sand Filter at Savannah River Laboratory," In Proceedings of the $13^{\text {th }}$ AEAC Nuclear Air Cleaning Conference (M.W. First ed.), CONF-740807, USAEC/The Harvard Air Cleaning Laboratory, Boston, Massachusetts, p. 632, 1974.

18. G. A. Schurr, D. B. Zippler and D. C. Guyton, "Deep Bed Filter Performance Tests," In Proceedings of the $12^{\text {th }}$ AEC Nuclear Air Cleaning Conference (M.W. First ed.), CONF-720823, USEAEC/The Harvard Air Cleaning Laboratory, Boston, Massachusetts, p. 596, 1972.

19. D. B. Zippler, "Evaluation of Multistage Filtration to Reduce Sand Filter Exhaust Activity," In Proceedings of the 13th AEC Nuclear Air Cleaning Conference (M.W. First ed.), CONF-740807, USAEC/The Harvard Air Cleaning Laboratory, Boston, Massachusetts, p. 609, 1974.

20. D. A. Orth, G. H. Sykes and G. A. Schurr, "The SRP Sand Filter: More than a Pile of Sand, " in Proceedings of the 14th ERDA Nuclear Air Cleaning Conference (M.W. First ed.), CONF-760822, USERDA/The Harvard Air Cleaning Laboratory, Boston, Massachusetts, p. 542, 1976.

21. D. A. Orth, G. H. Sykes and J. M. Mckibben, "Performance of Sand Filters for the Separations Areas at the Savannah River Plant," In Proceedings of the $16^{\text {th }}$ DOE Nuclear Air Cleaning Conference (M.W. First ed.), CONF801038, USED0E/The Harvard Air Cleaning Laboratory, Boston, Massachusetts, p. 745, 1980. 
22. Industrial Ventilation, A Manual of Recommended Practices, $15^{\text {th }}$ Edition, American Conference of Governmental Industrial Hygienists, Committee on Industrial Ventilation, Lansing, Michigan, 1978.

23. H. Dey, J. Maloney, et al., "Air Pollution Control Equipment for Particulate Matter," Chapter 4 in Air Pollution Engineering Manual (J. A. Danielson ed.), National Center for Air Pollution Control, Cincinnati, Ohio, 1967.

24. L. R. Skoski, et al., Airborne Radioactive Emission Control Technology, Volume I, II, and III, Dames and Moore, White Plains, New York.

25. K. M. Cushing and W. B. Smith, Procedures Manual for Fabric Filter Evaluation, EPA-600/7-78-113, Southern Research Institute, Burmingham, Alabama, 1978.

26. The User and Fabric Filtration Equipment III, Air Pollution Control Association, 1978.

27. M. W. First and D. Leith, "Entrainment Separator Performance," In Proceedings of the $14^{\text {th }}$ ERDA Nuclear Air Cleaning Conference (M.W. First ed.), CONF-760822, USERDA/The Harvard Air Cleaning Laboratory, Boston, Massachusetts, p. 694, 1976.

28. C. A. Gunn and D. M. Eaton, "HEPA Filter Performance Comparative Study," In Proceedings of the $14^{\text {th }}$ ERDA Nuclear Air Cleaning Conference (M.W. First ed.), CONF-760822, USERDA/The Harvard Air Cleaning Laboratory, Boston, Massachusetts, p 630, 1976.

29. J. R. Melcher, "Electrofluidized Beds for Industrial Scale Air Pollution Control," In Proceedings: Symposium on New Concepts for Fine Particle Control, EPA-60077-78-170, p. 237-254, 1978 .

30. R. P. Koppang, "Fine Particulate and Gaseous Emissions Control Experience with the TRW Charged Droplet Scrubber," In Proceedings: Symposium on New Concepts for Fine Particle Control, EPA-600/7-78-170, p. 320-338, 1978.

31. M. J. Pilat, "Written Discussion," In Proceedings: Symposium on New Concepts for Fine Particle Control, EPA-600/7-78-170, p. 338-343, 1978.

32. A. Baril, Jr., et al., "Research on New Equipment for Dust Collection," In Proceedings: Symposium on New Concepts for Fine Particle Control, EPA-600/7-78, P. 344-356, 1978. 
33. D. L. Reig and L. M. Browne, Electrostatic Capture of Fine Particles in Fiber Beds, EPA-600/Z-76-13, 1976.

34. J. K. Thompson, R. C. Clark, and G. H. Fielding, "Dielectrophoretic Air Filtration: Progress and Problems," In Proceedings: Symposium on New Concepts for Fine Particle Control, EPA-600/7-78-170, 1978.

35. B. E. Kirstein, W. J. Paplawsky and D. T. Pence, "High Efficiency Particulate Removal with Sintered Metal Filters," In Proceedings of Third Symposium on the Transfer and Utilization of Particle Control Technology, Vo1. 3. EPA-600/9-82-005C, P. 3/3-381, 1982.

36. W. J. Bjorkland, Development and Use of Scintered Metal Filters with Fluidized Bed and Spray Calcination of Simulated High-Level Waste, BNWL-2074, Pacific Northwest Laboratory, Richland, Washington, 1976.

37. J. D. McCormack, R. K. Hilliard and A. K. Postma, "Testing of A Passive Submerged Gravel Scrubber for Containment Venting Applications," Paper presented at the $17^{\text {th }}$ DOE Nuclear Air Cleaning Conference, August 2-5, 1982, Denver, Colorado, 1982.

38. H. G. Dillmann and H. Pasler, "Experimental Investigations of Aerosol Filtration with Deep Bed Fiber Filters," Paper presented at the $17^{\text {th }}$ DOE Nuclear Air Cleaning Conference, August 2-5, 1982, Denver, Colorado, 1982. 



\subsection{IODINE CONTROL TECHNOLOGY}

This section briefly summarizes the control technology of iodine. Iodine control technology has been reviewed in many comprehensive reports. (1-9) There are hundreds of other papers and reports on selected areas such as iodine chemistry, capture, fixation forms, and environmental aspects. In addition, there have been several symposia dealing solely with radioactive iodine. The most recent of these was the Commission of the European Community meeting held in Mol, Belgium, in 1981.(10)

\subsection{IODINE CHARACTERISTICS}

Information on the physical, chemical, and radiological properties of iodine is presented below.

\section{1 .1 Isotopes of I}

Iodine is a major nuclear fission product and isotopes of masses 115-142 exist. The significant ones with respect to half-life are those from 125135. Of these 127, 129, and 131 are important in terms of fission yield and half-life. ${ }^{127}$ I is stable. ${ }^{129}$ I has a half-life of $1.6 \times 10^{7}$ years and ${ }^{131_{I}}$ has a half-life of 8.05 days. Isotopes of masses 132-135 have very short half-lives and exist in significant concentration only in the reactor core. From the standpoint of long-term management, only ${ }^{129}$ I is significant.

\subsubsection{Chemical and Physical Forms}

Besides elemental iodine, iodine exists in $-1,+1,+3,+5$, and +7 valence states, and forms innumerable compounds. Of these, -1 iodides, +1 hypoiodates, and +5 iodates are the only significant ones with regard to the present discussion. The volatile species are constrained to valences of -1 and 0 and possibly +1 as Table 3.1 shows. 


\section{TABLE 3.1. Identified or Postulated}

Gaseous Iodine Forms

$\begin{array}{ll}\mathrm{I}_{2} \text { and I } & \mathrm{HOI} \\ \mathrm{HI} & \mathrm{C}_{2} \mathrm{H}_{5} \mathrm{I} \text { and higher alkyl iodides } \\ \mathrm{ICN} & \text { Aromatic iodides } \\ \mathrm{CH}_{3} \mathrm{I} & \end{array}$

Iodine is also found in fine particulates, presumably largely as iodides and iodates. These, although airborne, will not be included here. The form $\mathrm{I}_{2}$ is normally the major component in gas streams. Methyl iodide may comprise up to several percent of the total iodine and may be an even larger fraction of the amount actually released to the atmosphere. Other compounds are present in much smaller amounts.

\subsubsection{Sources of Iodine}

The fission yields for ${ }^{127}$ I range from about 0.12 to $0.5 \%$ and for ${ }^{129} \mathrm{I}$ from about 0.7 to $1.5 \%$ depending upon the reactor fuel, $i . \epsilon$. , upon the $U$ or Pu isotopes present. This amounts to about $1.5 \mathrm{~kg} 127 \mathrm{I}$ and $6.0 \mathrm{~kg} 129 \mathrm{I}$ per GWe $\mathrm{yr}$. The latter value corresponds to about $1 \mathrm{Ci}$, or $0.037 \mathrm{Ci} / \mathrm{t}$ of uranium fuel reprocessed. The short-lived isotopes, of which $131_{I}$ is the most important, are largely decayed by the time the fuel is to be reprocessed. After 180 days out of the reactor, the $131 \mathrm{I}$ level is about $0.25 \mathrm{ci} / \mathrm{t}$, having decayed by a factor of about $5 \times 10^{6}$. The small amount of the short-lived isotopes that is released from fuel to the gaseous effluent stream at the reactor is largely removed by particulate filters and by the activated carbon noble gas retention filters. Large banks of activated charcoal filters are also installed to control any accident-caused releases. The technology in use at the reactor is described in the Dames and Moore report. (3)

The ${ }^{129} \mathrm{I}$ and remaining $131_{\mathrm{I}}$, along with the stable ${ }^{127} \mathrm{I}$, are released at the reprocessing plant largely in the dissolving operation. Figure 3.1 shows a typical iodine path in a reprocessing operation. Actually the dissolver may be operated to either release $>98 \%$ of the iodine or retain it in the liquid. 


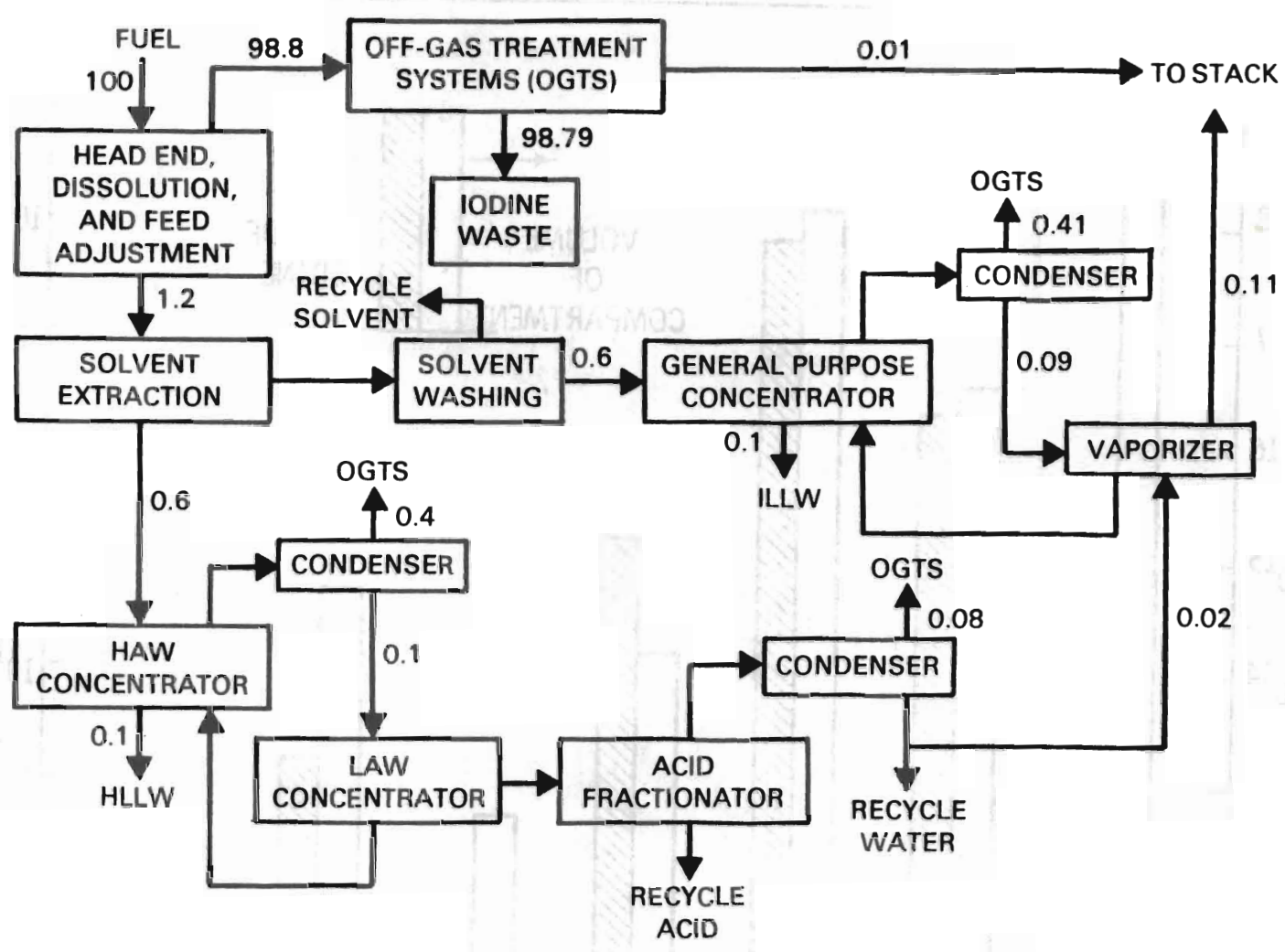

FIGURE 3.1. Predicted Iodine Path in Typical Reprocessing Plant, Values in Percent

In the latter case, it is volatilized in subsequent steps. An alternative is to precede the process shown with a head-end step to volatilize a major portion of the iodine prior to dissolution. Two head-end processes that have been examined are 1) voloxidation, studied at the Oak Ridge National Laboratory, which oxidizes the fuel to $\mathrm{U}_{3} \mathrm{O}_{8}$, and 2) thermal outgassing, studied at the Pacific Northwest Laboratory, which uses a reducing or inert sweep gas at a high temperature. In the voloxidation process, a large portion of the iodine is retained in the fuel. Iodine behavior for either process has not been fully demonstrated.

\subsubsection{Distribution of Iodine in the Environment}

The total amount of iodine (neglecting that in the earth's subsurface, i.e., below about $2 \mathrm{~m}$ ) is about $10^{17} \mathrm{~g}$. The distribution is shown in Figure 3.2. The natural inventory of $129 \mathrm{I}$ is about $2 \times 10^{5} \mathrm{~g}$ or $40 \mathrm{Ci},(11)$ 


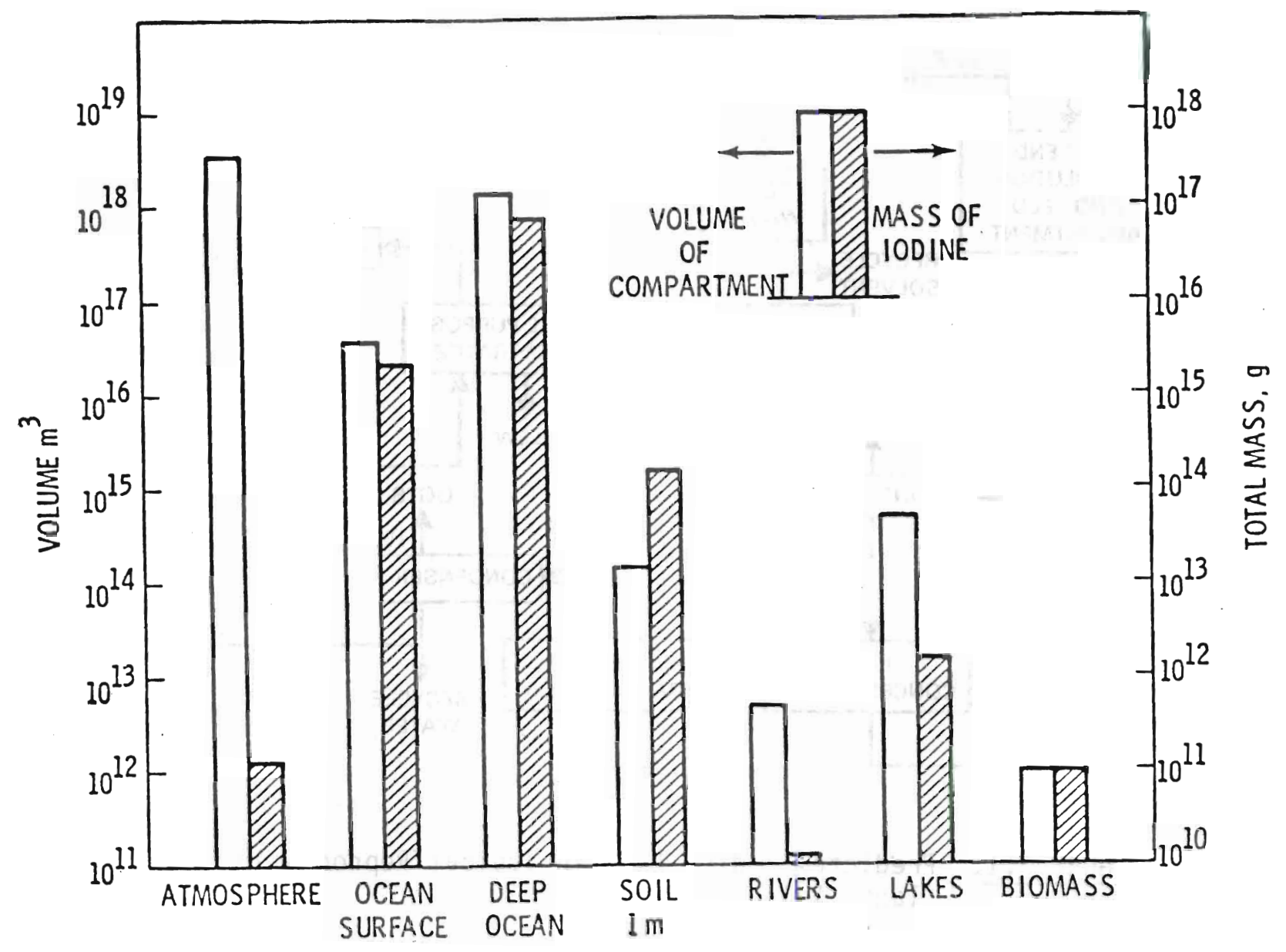

FIGURE 3.2. Distribution of Natural Iodine

while the actual total inventory, mostly in unprocessed irradiated fuel, is of the order of 300-1000 Ci. The present $129 \mathrm{I} / 127$ I ratio may be about 10-11. However, most of the 129 I that has been released is still localized and ratios from about $10^{-7}$ to $10^{-10}$ are observed. Most of the world's available iodine is in the ocean. The ${ }^{129} \mathrm{I}$ content of the deep ocean has not been reported.

\subsubsection{Radiochemical and Radiological Properties}

Iodine-129 decays to stable xenon with a decay constant of $1.38 \times 10^{-15}$ $\mathrm{sec}^{-1}$ and an average beta energy of $60 \mathrm{keV}$. Photon emission is small, about $7.5 \%$ of the xenon isomeric transitions are by $40 \mathrm{keV}$ gammas, the remainder 
yielding low energy $x$-rays. The latter also are produced by $131_{\text {I decay. }}$ However, for $131_{I}$, the major radiations are the $0.606 \mathrm{MeV} B$ and the associated high energy $0.36 \mathrm{MeV} \gamma$.

The biological significance of radioactive iodine results from the thyroid specificity; the thyroid contains about $90 \%$ of the $13 \mathrm{mg}$ of iodine in the adult human body. The effective biological half-life of this iodine is 120 days. It is estimated that the ${ }^{129} \mathrm{I} /{ }^{127} \mathrm{I}$ ratio should be below about $10^{-3}$ in the thyroid to keep the individual dose rate below $75 \mathrm{mrem} /$ year. This can be compared to the ratios $10^{-7}$ to $10^{-10}$ found in areas where ${ }^{129}$ I has been previously deposited and 10-11 to $10^{-12}$ elsewhere. Pre-1946 values are estimated at $10^{-12}$ to $10^{-15}$.

\subsection{EXISTING CONTROL TECHNOLOGIES}

The two iodine isotopes of concern in radioactivity control are ${ }^{131_{I}}$ and ${ }^{129} \mathrm{I}$. The former is of major importance in reactor effluents and when irradiated nuclear fuel is processed soon after leaving the reactor. After a year, only the ${ }^{129} \mathrm{I}$ is significant. Because of its low specific activity, it is a hazard only when not adequately dispersed. Processing operations on power reactor fuel release ${ }^{129}$ I in sufficient concentrations that control measures have been deemed advisable. When processing operations on any shortcooled reactor fuel are undertaken, the control of $131_{I}$ is vital. The control can take two forms: 1) hold-up for decay to inactive xenon, or 2) removal and fixation. Both have been practiced. When only small amounts are involved, as from reactor effluents, the hold-up method may be adequate. In reprocessing plants, both hold-up and disposal have been used, with more recent effort concentrating on the trapping and disposal concept.

\subsubsection{Charcoal Filters}

Activated charcoal is made from coconut, nut shells, wood, coal or petroleum. It is activated by heating in steam, which expands it and drives off volatile materials. It is then used as is or impregnated with materials 
such as $\mathrm{KI}, \mathrm{KI}-\mathrm{I}_{2}, \mathrm{KOH}-\mathrm{I}_{2}$, or organic amines. Of the latter, triethylene diamine (TEDA) is most commonly used.

Charcoal filters have been used worldwide to trap radioactive iodine in effluents from both normal and accident situations. $I_{2}$ is trapped primarily by physical adsorption on pure charcoal. When additives are used and for other iodine species, the chemistry gets quite complex. When one adds the complications resulting from aging of the charcoal, addition of impurities, etc., it appears that the use of charcoal is to a degree an art rather than a science. However, years of experience have provided effective modes of use in spite of the uncertain chemistry.

\subsubsection{Description of Process}

The charcoal is often employed as a 2-5 cm bed supported by fine-mesh stainless-steel screens. Thicker beds may sometimes be used. Filter units, housing, and specifications are discussed by Burchsted.(12) The filters are used under ambient conditions and are moderately effective over a wide range of humidities, air flow rates, iodine concentrations, and moderate temperatures (up to about $150^{\circ} \mathrm{C}$ ). Higher temperatures, $>\sim 200^{\circ} \mathrm{C}$, are to be avoided because of the possibility of ignition.

\subsubsection{Specifications}

- Efficiency

The efficiency is highly variable depending on the particular charcoal sample, the age and weathering, iodine concentration, flow rate, humidity, temperature, and impregnants used. A retention factor (RF) or decontamination factor (DF) of greater than $10^{3}$ is possible, although the above factors may reduce the DF to 100 or even 10 under some conditions. Wilhelm, (13) Holladay, (14) and Jubin(15) reviewed the use of charcoal filters, their applications, and limitations.(a) Impregnation of the charcoal with TEDA

(a) The reports of Holladay and of Jubin also survey the general capture technology of iodine. 
and similar compounds is necessary for obtaining high RF's for organic iodides. Monitoring is essential as the efficiency decreases with age.

- Reliability

Charcoal filters are efficient for removal of all volatile iodine species. They are inexpensive and adaptable to high gas flow rates. Disadvantages are: 1) iodine is desorbed as the temperature is raised, and 2) they have a low ignition temperature; with impregnants this may be as low as $180^{\circ} \mathrm{C} .(12)$ In the presence of $\mathrm{NO}-\mathrm{NO}_{2}$, the charcoal may spontaneously ignite. Because of this factor, it is no longer considered for use in reprocessing plants.

\subsubsection{Wastes}

The waste product is the carbon filter itself. Normal practice is to encapsulate the filter and bury it.

\subsubsection{Silver-Containing Solid Sorbents}

There is some question as to whether these materials can be considered as existing technology. The effectiveness of two of them, silver-nitrateimpregnated silica and silver-exchanged mordenite (a high-silica zeolite), has been demonstrated on a moderate scale, and the conditions for effective use are known. AC-6120 is a German-developed material containing silver nitrate in amorphous silica. AgZ is the designation given silver-exchanged mordenite, although AgM would be more in line with literature convention. Silverexchanged type $X$ zeolites are also effective and have higher iodine capacity, but suffer from instability in the acid environment characteristic of reprocessing plants.

\subsubsection{Description of Process}

These materials are used in granular or pellet form in beds of $5-20 \mathrm{~cm}$ thickness. Although they will absorb some $I_{2}$ at ambient conditions, the temperature must be above about $110^{\circ} \mathrm{C}$ to avoid interference from water absorption. Common $1 \mathrm{y} 150^{\circ} \mathrm{C}$ is used, although there is some evidence that $200^{\circ} \mathrm{C}$ gives 
better results. Under these conditions, high humidities and low concentrations of $\mathrm{NO}-\mathrm{NO}_{2}$ are not detrimental.

Consideration has been given to reuse of silver mordenite by iodine removal with hydrogen. Although the regenerated material is usable, the removal step itself does not appear to be a viable process. $(16,17)$

The recommended application is to employ two beds in series and to remove the first from service at the designed "breakthrough" concentration.

\subsubsection{Specifications}

- Efficiency

The RF achieved depends on flow rate, particle size, gas composition, iodine loading, and temperature. RF values of $10^{3}$ are found at moderate loadings of iodine. RF values as high as $10^{4}$ have been reported for $\mathrm{AC}$ 6120. Organic iodides are efficiently removed at temperatures of $150^{\circ} \mathrm{C}$ or above.

- Reliability and Limitations

These materials are very stable chemically and thermally, and are especially attractive for use with either low flow gas streams in fuel processing operations or for cleanup of trace iodine following other sorption processes.

The chemistry involved in the sorption process on silver zeolites is not completely understood. For example, only a portion, perhaps 30-40\%, of the iodine trapped on $\mathrm{AgZ}$ at the theoretical limit $(\mathrm{I} / \mathrm{Ag}=1.0)$ is held as $\mathrm{AgI}$ or $\mathrm{AgIO}_{3}$. The remainder may be a less stable molecular complex and can be volatilized upon heating to $300-500^{\circ} \mathrm{C}$. There is also some uncertainty regarding decrease in efficiency of these solid sorbents from poisoning by organic vapors. Other halogens and sulfur compounds react with the silver and destroy the capacity for iodine sorption.

Advantages of these materials include the excellent chemical and physical stability and the ease of use. 


\subsubsection{Wastes}

The process is simple and the only wastes are the trapping material itself. It has been proposed to place the zeolite in drums with multiple barriers. It is probably desirable to first encapsulate the zeolite in cement. Because of the very long half-life, 16 million years, there is no way to guarantee either the waste form or the container. Disposal to a location where the natural iodine will dilute the ${ }^{129}$ I to an innocuous level is a possible solution. A moderately stable waste form placed in the deep ocean appears to meet any reasonable criteria. $(11,16)$

\subsubsection{Caustic Scrubbing}

Caustic scrubbing is probably the earliest iodine removal method tried. Although it has a limited trapping efficiency, it is suitable as a primary trap preceding silver sorbents.

\subsubsection{Description of Process}

Caustic scrubbing employs a $\mathrm{NaOH}$ or $\mathrm{KOH}$ solution in a packed column or bubble plate column. Dilute solutions, $5 \%$ (1.2M) have been commonly used, although much higher concentrations, up to $10 \underline{M}$ have also been tried. Gas flow rates have likewise been reported as covering a large range, with some as high as $100 \mathrm{~m} / \mathrm{min}$ face velocity.

\subsubsection{Specifications}

\section{- Efficiency}

Retention factors of 100 or greater have been achieved. While $I_{2}$ is effectively trapped, organic species are not, and thus, depending upon the species in the gas stream, RF's may be as high as $10^{3}$ or as low as 10 .

- Reliability and Limitations

Consideration must be given to the iodine species and to the purity of the caustic solution since there is some indication that organic impurities may actually produce volatile iodine compounds. Also, if the gas stream contains large amounts of acidic species, e.g., $\mathrm{NO}_{2}, \mathrm{CO}_{2}$, then large quantities of caustic will be consumed. In addition, large amounts of $\mathrm{CO}_{2}$ may 
cause precipitation of sodium carbonate which interferes with scrubber operation. Although for many applications, the RF achieved with caustic alone ( 50 to 100 is a reasonable guess) may not be adequate, the process could be a good first step, to be followed, for example, by silver mordenite beds.

\subsubsection{Wastes}

Caustic waste will contain both iodide and iodate. This can be combined with other alkaline waste streams for subsequent solidification. Information on iodine releases from the solidification step is not available. Alternatively, the iodine could all be oxidized to iodate and precipitated as insoluble iodates. These may be mixed with cement and concrete monoliths formed. Another method would be to reduce all the iodine to insoluble iodides. These may be mixed with cement or bitumen.

\subsubsection{Silver Nitrate Scrubbing}

This process has been employed at the Purex plants at Hanford and at Savannah River, and is usually described as the "silver reactor."

\subsubsection{Description of Process}

The process employs ceramic solids such as Berl saddles which have been coated with a concentrated silver nitrate solution. The heated gas is passed over the dried saddles, and iodine is trapped as $\mathrm{AgI}$ and $\mathrm{AgIO}_{3}$. Temperature control has typically not been very precise, but an attempt is usually made to keep the temperature in the vicinity of $190^{\circ} \mathrm{C}$. The silver reactor is regenerated by flushing with a concentrated silver nitrate solution.

\subsubsection{Specifications}

- Efficiency and Reliability

The silver reactor is probably capable of a DF of 100 or greater; however, in general, it is operated well below that level. Its real purpose has been to hold up most of the ${ }^{131_{I}}$ until it decayed. The amount of ${ }^{129}$ I released from the fuels processed at the two plants was small relative to LWR or LMFBR fuel. Good control over the temperature is necessary as is frequent regeneration. Other halogens destroy the capacity to remove iodine. 


\subsubsection{Wastes}

No specific treatment has been reported for wastes from the silver reactor. It has not been used in a commercial facility. Silver nitrate regeneration wastes could be sent to general alkaline waste storage tanks. However, the practice has been to remove the reactor and bury it rather than attempt to wash off the silver-iodine.

\subsection{POTENTIAL CONTROL TECHNOLOGIES}

Many iodine control schemes have been proposed and studied. These include trapping in mercuric nitrate-nitric acid solution (Mercurex), oxidative trapping with $22 \mathrm{M} \mathrm{HNO}_{3}$ (Iodox), sorption in fluorocarbons, liquid $\mathrm{CO}_{2}$ or tributyl phosphate, sorption on organic solids, on other silvercontaining solids, and on other metal zeolites. Some, like the use of fluorocarbons, appear attractive when considered as part of an integrated system to remove several or all volatile fission products. Indeed, iodine removal is best considered in context with control of other airborne wastes.

Two of these methods, Mercurex and Iodox, have received considerable study and, except for lack of large-scale demonstration including iodine product waste handling, could be considered available technology. These processes are described below.

\subsubsection{Mercurex}

The Mercurex process utilizes the ability of the mercuric ion to form strong polyanionic complexes with the iodide ion. A mercuric nitrate nitric acid scrub solution contacts the gas stream, normally in a packed or bubblecap column.

\subsubsection{Description of Process}

As originally tested, the scheme utilized a dilute mercury solution: $\sim 0.4$ $\underline{\mathrm{Mg}}\left(\mathrm{NO}_{3}\right)_{2}$ in dilute nitric acid $\sim 4-5 \mathrm{M}$. Later work showed improved organic iodide removal if concentrated acid, $>\sim 10 \mathrm{M}$ was used. The reaction with $\mathrm{I}_{2}$ produces $\mathrm{HgI}_{x}(2-\mathrm{x})$ complexes and $\mathrm{Hg}\left(\mathrm{IO}_{3}\right)_{2}$ by disproportionation. The presence 
of $\mathrm{NO}_{2}$ in gas will prevent iodate formation. Typically, the iodine content is allowed to build up to an $\mathrm{I} / \mathrm{Hg}$ ratio of $1: 4$.

\subsubsection{Specifications}

- Efficiency and Reliability

An RF of as high as 500 has been claimed; however, 100 is more likely. The RF has been reported to decrease with time. Disadvantages include: toxicity and cost of mercury, a low average RF, and lack of demonstrated conversion technology for treatment of the Mercurex solution.

\subsubsection{Wastes}

Methods of treating the resulting solution to produce an iodine waste (disposal or storage) form have included oxidation of $\mathrm{Hg}\left(\mathrm{IO}_{3}\right)_{2}$ by boiling (the $\mathrm{Hg}\left(\mathrm{IO}_{3}\right)_{2}$ precipitates and is filtered), metathesis with sodium hydroxide to precipitate the mercury for reuse, electrolytic oxidation to $\mathrm{Hg}\left(\mathrm{IO}_{3}\right)_{2}$ or electrolytic reduction to produce $\mathrm{Hg}$ metal and $\mathrm{I}^{-}$which is precipitated as CuI. All are in the developmental stage. The solid precipitates would be placed in cement or bitumen (for CuI) and packaged in drums.

\section{3 .2 Iodox}

The Iodox process treats the gas stream with concentrated nitric acid to produce iodic acid.

\subsubsection{Description of Process}

The process requires hyperazeotropic acid, up to $22 \underline{M}$ as the scrubbing medium in a bubble-cap or packed column, usually at elevated temperature 60$80^{\circ} \mathrm{C}$. All iodine species are converted to $\mathrm{I}^{+5}$. The acid is then concentrated in an evaporator, and a stream bled off to further evaporate and precipitate iodic acid, $\mathrm{HI}_{3} \mathrm{O}_{8}$ (or iodine pentoxide, $\mathrm{I}_{2} \mathrm{O}_{5}$ ). The condensed nitric acid is either used in other parts of the plant or distilled with $\mathrm{Mg}\left(\mathrm{NO}_{3}\right)_{2}$ to reform the hyperazeotropic acid. One conceptual scheme is shown in Figure 3.3. 


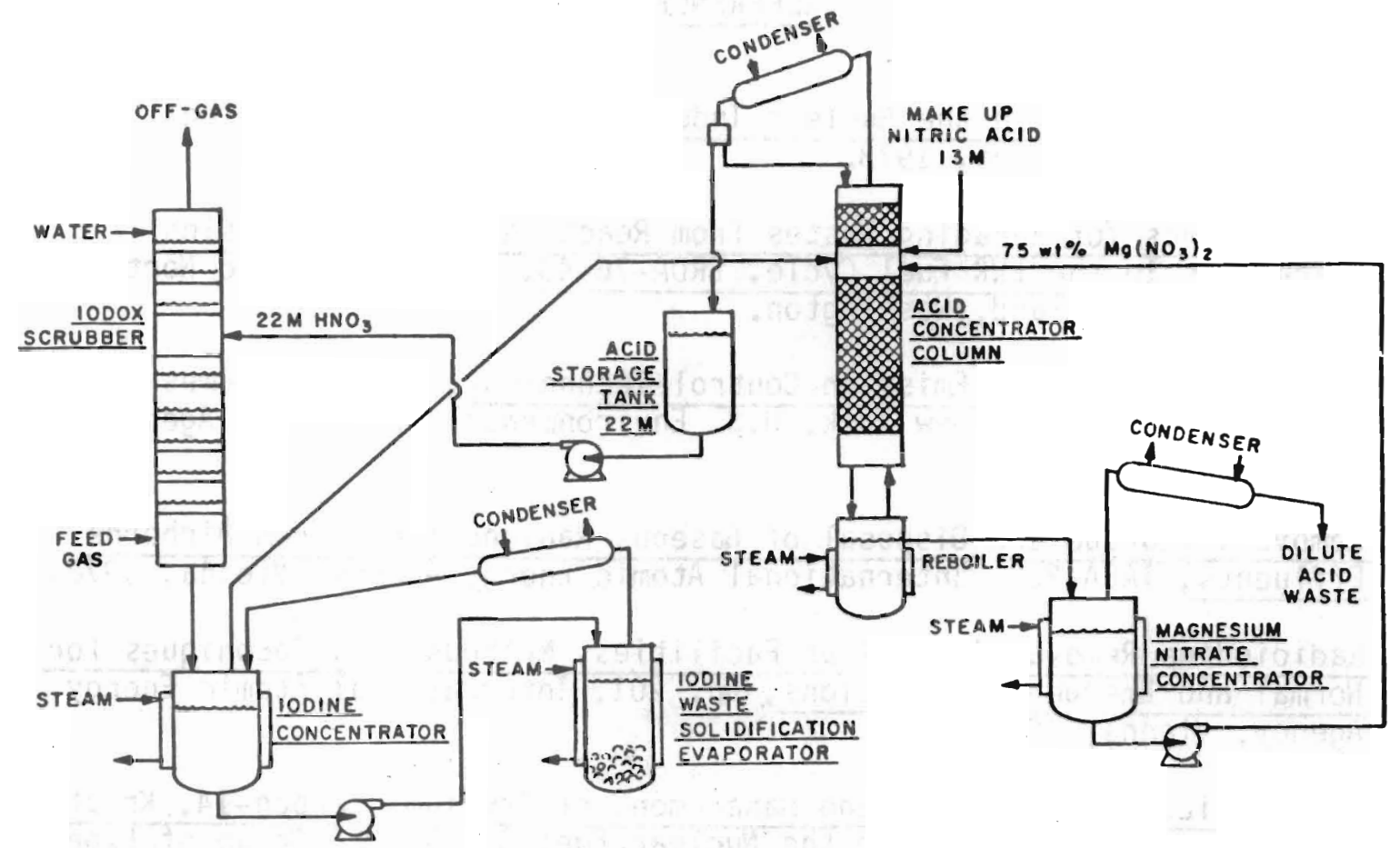

FIGURE 3.3. Iodox Process Flowsheet for Iodine Removal

\subsubsection{Specifications}

- Efficiency and Reliability

The inherent efficiency is very high, and RF values of greater than $10^{4}$ have been reported. Organic iodides are readily oxidized. The product is a stable solid which can be temporarily stored or readily converted to an insoluble metal iodate such as $\mathrm{Ba}\left(\mathrm{IO}_{3}\right)_{2}, \mathrm{Sr}\left(\mathrm{IO}_{3}\right)_{2}$, or $\mathrm{Ca}\left(\mathrm{IO}_{3}\right)_{2}$. Another attractive feature is that it does not introduce any new chemicals to the reprocessing plant. Disadvantages include corrosion problems and the requirement for special materials of construction.

\subsubsection{Wastes}

An advantage of the Iodox process is the potential simple waste treatment. Barium, strontium, or even calcium iodates are good fixation forms and are easily produced by direct reaction with the iodic acid. However, the integrated steps from $129 \mathrm{I}$ capture to an insoluble iodate in cement or other matrix have not been demonstrated. 


\section{REFERENCES}

1. Control of Iodine in the Nuclear Industry, No. 148, International Atomic Energy Agency, Vienna, 1973.

2. Alternatives for Managing Wastes from Reactions and Post Fission Operations in the LWR Fuel Cycle, ERDA-76-43, Vol. 2, Pacific Northwest Laboratory, Richland, Washington.

3. Airborne Radioactive Emission Control Technology, Vol. II, Dames and Moore, White PTains, New York, U.S. Environmental Protection Agency, Washington, D.C.

4. Removal, Storage and Disposal of Gaseous Radionuclides from Airborne Effiuents, IAEA-209, International Atomic Energy Agency, Vienna, 1978.

5. Radioiodine Removal in Nuclear Facilities, Methods, and Techniques for Normal and Emergency Situations, No. 201, International Atomic Energy Agency, Vienna, 1980.

6. Radiological Significance and Management of Tritium, Carbon-14, Krypton85, Iodine-129 Arising from the Nuclear Fuel Cycle, NEA Group of Experts, Nuclear Energy Authority of the Organization for Economic Cooperation and Development, Paris, 1980.

7. H.A.C. McKay ed., Management Modes for Iodine-129, Commission of the European Communities, Brussels (to be published in 1982-1983).

8. Draft Program Strategy Reference Document for the Management of Radioactive Airborne Wastes, Exxon Nuclear Idaho Co., Inc., Idaho Falls, Idaho, 1982.

9. L. Trevorrow et al., Airborne Waste Disposal: Compatability of Proposed Systerns with Regulations - Part I. Initial Information Base, Argonne National Laboratory (Draft), September, 1982.

10. Seminar on Iodine Removal from Gaseous Effluents in the Nuclear Industry, Commission of the European Communities, Mol, Belgium, September 29-24, 1982.

11. L.L. Burger, Determining Criteria for the Disposal of Iodine-129, PNL3496, Pacific Northwest Laboratory, Richland, Washington, 1979.

12. C. A. Burchsted, A. B. Fuller, and J. E. Kahn, Nuclear Air Cleaning Handbook, ERDA-76-21, Oak Ridge National Laboratory, Oak Ridge, Tennessee, 1976. 
13. J. G. Wilhelm, "Inorganic Absorber Materials for Trapping Fission Product Iodine," Control of Iodine in the Nuclear Industry, Technical Reports Series No. 148, International Atomic Energy Agency, Vienna, 1973.

14. D. W. Holladay, A Literature Survey: Methods for the Removal of Iodine Species from off-Gases and Liquid Waste Streams of Nuclear Power and Nuclear Fuel Reprocessing Plants with Emphasis on Solid Sorbents, ORNL/TM-6350, Oak Ridge National Laboratory, Oak Ridge, Tennessee, 1979.

15. R. T. Jubin, A Literature Survey of Methods to Remove Iodine from Off-Gas Streams Using Solid Sorbents, ORNL7TM-6607, Oak Ridge National Laboratory, Oak Ridge, Tennessee, 1979.

16. R. D. Scheele, L. L. Burger, and K.D. Wiemers, Selection of a Form for Fixation of Iodine-129, PNL-4045, Pacific Northwest Laboratory, RichTand, Washington, 1981 .

17. L. L. Burger, and R. D. Scheele, Recycle of Iodine-Loaded Silver Mordenite by Hydrogen Reduction, PNL-4490, Pacific Northwest Laboratory, Richland, Washington, 1982. 



\subsection{RARE GAS CONTROL TECHNOLOGY}

Only argon, krypton, and xenon are of importance for airborne waste management. Argon-41 is produced from naturally occurring argon-40 in reactors or accelerators by neutron or deuteron capture. Isotopes of krypton and xenon are produced as fission products in reactor fuels. The artificially produced rare gas isotopes fall into three categories: stable, short-lived, and long-lived. Krypton-85 is the only isotope with a half-life long enough to require a recovery process. The short-lived isotopes can be controlled by interim storage prior to fuel reprocessing or by holding up the release of the gas to the atmosphere by an absorption technique. The discussion of rare gas control technology falls naturally into four tasks: recovery or separation, isolation or immobilization, ultimate storage, and transportation. If ultimate storage is conducted at the reprocessing site, the last task may be incidental.

\subsection{RARE GAS CHARACTERISTICS}

The rare or noble gases have the unique chemical property that they form no chemical compounds, but exist only in the free state. A description of the physical and chemical properties of the rare gases that are relevant to the control technology is presented in this section, together with the nuclear properties of the important isotopes and background information concerning their radiological hazards. The naturally occurring atmospheric concentrations for the noble gases are: $0.93 \% \mathrm{Ar}, 1 \mathrm{ppm} \mathrm{Kr}$ and $0.08 \mathrm{ppm} \mathrm{Xe}$ on a volume basis.

\subsubsection{Physical and Chemical Properties}

Argon, krypton, and xenon are monatomic gases belonging to group 0 in the periodic table. The outer shells of the atoms contain eight electrons, an extraordinarily stable configuration, which implies chemical inactivity. There are no known compounds of the rare gases that could be considered stable enough to immobilize these isotopes safely. There are, however, cage-like 
molecules such as the zeolites and sodalites that can retain large rare gas atoms. Their value for immobilizing krypton is discussed in later sections. At room temperature, quinol, an organic compound, can retain krypton in its cage-like molecule, called a clathrate, but begins to release it above $70^{\circ} \mathrm{C}$. oxygen, moisture and rubidium (the decay product of $85 \mathrm{Kr}$ ) adversely effect the stability of the clathrate. Table 4.1 shows the properties of the rare gases.

TABLE 4.1. Properties of the Rare Gases

Chemical Symbol

Atomic Number

Atomic Weight

Melting Point, $(1 \mathrm{~atm})^{\circ} \mathrm{C}$

Boiling Point, (Sat $1 \mathrm{~atm})^{\circ} \mathrm{C}$

Density of Liquid,

(at atm bp) $\mathrm{kg} / \mathrm{m}^{3}$

Specific Heat, cal/g ${ }^{\circ} \mathrm{C}$

Thermal Conductivity, $\mathrm{w} / \mathrm{m}{ }^{\circ} \mathrm{C}$

Critical Temperature, ${ }^{\circ} \mathrm{C}$

Critical Pressure, atm

Atomic Radius, $\AA$

\begin{tabular}{|c|c|c|}
\hline Argon & Krypton & Xenon \\
\hline Ar & $\mathrm{Kr}$ & $\mathrm{xe}$ \\
\hline 18 & 36 & 54 \\
\hline 39.948 & 83.80 & 131.30 \\
\hline-189.2 & -169 & -140 \\
\hline-186 & -153 & -108 \\
\hline 1400 & 2413 & 3060 \\
\hline
\end{tabular}

0.125

0.059

0.038

0.172

0.0093

0.0052

$-122$

48

1.5
$-63.8$

54.3

1.7
16.1

58

1.9

\subsubsection{Nuclear Properties}

The thermal neutron capture cross-sections for naturally occurring argon, krypton, and xenon are $0.65,31$, and 35 barns, respectively. The thermal neutron cross-section for the reaction $40 \mathrm{Ar}+n+41_{A r}+\gamma$ is 0.66 barns. Nuclear fission is the main source for the production of radioactive $\mathrm{Kr}$ and Xe. Examination of the half lives given in Table 4.2 for the radioactive noble gas isotopes shows that ${ }^{85} \mathrm{Kr}$ is the only isotope for which long-term storage need be considered. As mentioned earlier, the remainder of the noble gas isotopes are either stable or short-lived. The longest-lived Xe isotope, 
TABLE 4.2. Half-Lives of the Noble Gas Nuclides

$\begin{array}{lllllll}\text { Isotope: } & { }^{41} \mathrm{Ar} & 83 \mathrm{~m}_{\mathrm{Kr}} & 85 \mathrm{~m}_{\mathrm{Kr}} & 85_{\mathrm{Kr}} & 87 \mathrm{Kr} & { }^{88} \mathrm{Kr} \\ \text { Half-Life } & 110 \mathrm{~min} & 114 \mathrm{~min} & 4.48 \mathrm{hrs} & 10.72 \mathrm{yrs} & 76 \mathrm{~min} & 2.84 \mathrm{hrs} \\ \text { Isotope: } & 131 \mathrm{~m}_{\mathrm{Xe}} & 133 \mathrm{~m}_{\mathrm{Xe}} & 133 \mathrm{Xe} & 135 \mathrm{~m} \mathrm{Xe} & 135 \mathrm{Xe} & 138 \mathrm{Xe} \\ \text { Half-Life } & 11.92 \mathrm{~d} & 2.19 \mathrm{~d} & 5.25 \mathrm{~d} & 15.3 \mathrm{~min} & 9.09 \mathrm{hrs} & 14.2 \mathrm{~min}\end{array}$

$131 \mathrm{Xe}$, has a half-life of 12 days and the second longest $\mathrm{Kr}$ isotope, $85 \mathrm{~m}_{\mathrm{Kr}}$, has a half-life of 4.5 days. Argon-41 and $85 \mathrm{Kr}$ have half-lives of 1.83 hours and 10.72 years and decay according to the following patterns:

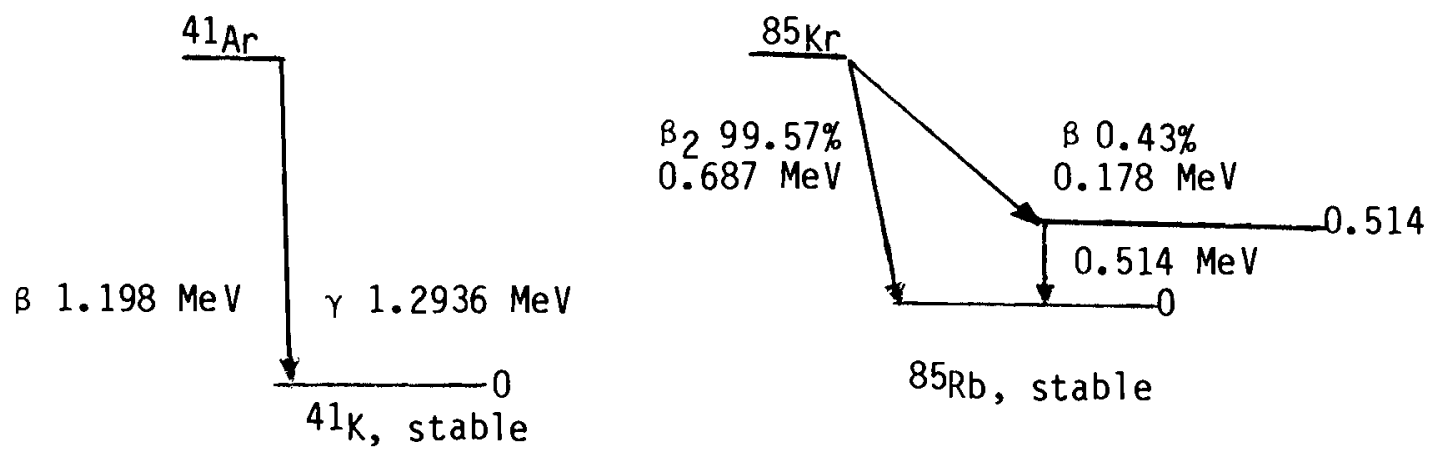

The fission product yield for $85 \mathrm{Kr}$ is $\sim 0.3 \%$. The heat produced by $85 \mathrm{Kr}$ decay is 0.623 watts per gram. The specific activity is $392 \mathrm{Ci} / \mathrm{g}$.

\subsubsection{Radiological Hazards}

The skin is the critical organ for an individual exposed to radioactive noble gases as they are all beta emitters with the one exception of radon-222, which is an alpha emitter(1) The noble gases are soluble in body fluids and tissues, especially in lipids; however, Cohn, Ellis and Susskind estimate the whole-body dose only increases about $1 \%$ when the inhalation dose is added to the irradiation received from external exposure of $85 \mathrm{Kr}$. (2)

Krypton-85, because of its long half-life, is the only noble gas radionuclide whose inventory can build up in the atmosphere. Krypton-85 discharged from a tall stack will become uniformly distributed throughout the global atmosphere in about 2 years. In spite of the high solubility of krypton in 
both salt and fresh water, it is estimated by NCRP that only $3 \%$ of atmospheric krypton exists in the world's oceans. (3)

The collective dose to the population from atmospheric krypton-85, integrated over the entire period concerned, amounts to:

$$
D_{\text {Collective }}=\frac{\text { Ao } P \text { Df }}{\gamma_{1}}
$$

where:

Ao $=$ specific initial activity $\left(\mathrm{Ci} / \mathrm{m}^{3}\right)$

$P \quad=$ population

$r_{1}=\frac{.693}{10.7}=.0648 \mathrm{yr}^{-1}$

Df $\quad=$ dose factor $\left(\mathrm{rem} \mathrm{m}^{3} / \mathrm{Ci} \mathrm{yr}\right)$

This simple formula ignores nonuniform concentration of krypton- 85 during the first few trips about the earth.

If we take the volume of the earth's atmosphere to be $3.96 \times 10^{18} \mathrm{~m}^{3}$, a world population of $6.4 \times 10^{9}$ (reached around 1995), and the dose factors from Reference 4 , we can calculate specific total collective doses (man-rem/Ci) as given in Table 4.3. Krypton-85 is primarily a beta emitter; therefore, a weighting factor of 0.001 is applied to the skin dose, since only $10 \%$ reaches the skin through clothing.

TABLE 4.3. Collective Dose Commitment

\begin{tabular}{|c|c|c|}
\hline & $\begin{array}{l}\text { Dose Façtor } \\
\frac{r e m \mathrm{~m}^{3}}{\mathrm{Ci} \mathrm{yr}} \\
\end{array}$ & $\begin{array}{c}{ }^{\mathrm{D}} \mathrm{Col} 1 \\
(\operatorname{man}-\mathrm{rem} / \mathrm{Ci})\end{array}$ \\
\hline Gonads & $16.9 \times 10^{3}$ & $4.2 \times 10^{-4}$ \\
\hline Red Bone Marrow & $18.5 \times 10^{3}$ & $4.6 \times 10^{-4}$ \\
\hline Skin & $1530 \times 10^{3}$ & $382 \times 10^{-4}$ \\
\hline Whole-Body, Effective & $16.5 \times 10^{3}$ & $4.1 \times 10^{-4}$ \\
\hline
\end{tabular}




\subsection{RARE GAS RECOVERY TECHNOLOGY}

Noble gas radionuclide management technology utilized by existing DOE facilities is based on dilution and dispersion from tall stacks. This is the case for reactors, accelerators and fuel reprocessing plants, with the exception of the Idaho Chemical Processing Plant (ICPP) which processes Navy and research reactor fuels. ICPP recovers $60-65 \%$ of the ${ }^{85} \mathrm{Kr}$ for resource value by cryogenic distillation in the Rare Gas Plant when aluminum-clad fuels are dissolved. Hydrogen from zircaloy-clad fuel dissolution interferes with cyrogenic distillation and $85 \mathrm{Kr}$ is not recovered. The short-lived noble gas nuclides are contained in the fuel elements and are not processed until most of the rare gas activity has decayed (with the exception of $85_{K r}$ ). In the case of leaking fuel elements, DOE reactors are shut down and the defective element removed. The maximum unplanned emission is thus limited to that which escapes from the leaking capsule. By contrast, commercial power reactors do not shut down for ruptured fuel elements, thus allowing the buildup of rare gas nuclides in the primary coolant.

The largest noble gas releases from DOE facilities occur at the Savannah River Plant (SRP) and the Idaho Chemical Processing Plant (ICPP) where spent nuclear fuel is reprocessed. The rare gas is evolved during fuel dissolution and contains $4.7 \mathrm{~kg}$ Xe and $.325 \mathrm{~kg} \mathrm{Kr}$ per metric ton of heavy metal. $85_{\mathrm{Kr}}$ comprises about $6 \%$ of the $\mathrm{Kr}$ content. Cryogenic distillation and fluorocarbon absorption or a combination of the latter with an absorption process using solid adsorbents are considered to be the most promising alternatives for krypton recovery. Cryogenic distillation was chosen as the reference process to isolate $\mathrm{kr}$ from dissolver off-gas (DOG) streams because it was considered to be currently available technology. A fluorocarbon-based selective absorption system for removal of ${ }^{85} \mathrm{Kr}$ and ${ }^{14} \mathrm{CO}_{2}$ from DOG streams developed by the Oak Ridge Gaseous Diffusion Plant in conjunction with Oak Ridge National Laboratory has been demonstrated as an alternative recovery process. A 
description of the two processes is presented in the following section. In addition, the absorption of noble gases on solids is briefly discussed and cost estimates are included.

\subsubsection{Cryogenic Distillation}

The cryogenic separation process has been used by industry to separate rare gases on a commercial scale much larger than that required for removing radioactive noble gases from various effluent streams. A cryogenic process has been operated to recover $85 \mathrm{Kr}$ from DOG streams at the $\mathrm{ICPP}(5)$ on an intermittent basis since 1958. At KFK in Germany extensive cold testing of cryogenic distillation on an engineering scale is in progress, (6) and in also France $(7)$ and Belgium. (8) In Japan the Tokai Fuel Reprocessing Plant operation has recently completed a cryogenic separation facility for removing ${ }^{85} \mathrm{Kr}$ from a combined fuel chop and DOG stream. The 0.7 MTHM per day plant was expected to complete "cold" testing January 1, 1983. Full scale ${ }^{85} \mathrm{Kr}$ recovery is to begin in 1984. The product will be stored in pressurized, double-walled cylinders for a period of 5 years. A brief description of the Airco cryogenic distillation process, designed for both fuel reprocessing and power generation plants, where the off-gas stream contains nitrogen to serve as the carrier gas and process medium, is given in the next section. Specifications are included.

The Airco system described here is optimized to remove ${ }^{85} \mathrm{Kr}$ from two different off-gas streams:

Fuel Reprocessing off-Gas

High Uncombined $\mathrm{O}_{2}$ Content

$X e$ not Radioactive

No $13 \mathrm{~N}$

$\mathrm{Kr}$ Xe Concentration 100-500 ppm Considerable $\mathrm{NO}_{x} \& \mathrm{I}_{2}$ Present Stream Predominantly $\mathrm{N}_{2} \& \mathrm{O}_{2}$
BWR Off-Gas

Radiolytic $\mathrm{H}_{2}$ Present

Xe Radioactive

$13 \mathrm{~N}$ Present

$\mathrm{Kr}$ Xe Concentration <1 ppm Insignificant $\mathrm{NO}_{x} \& \mathrm{I}_{2}$ Present

Stream Predominantly $\mathrm{H}_{2} \mathrm{OG}$ 
After various pretreatment steps to remove potentially hazardous or troublesome components, such as $\mathrm{CO}_{2}$, nitrogen oxides and $\mathrm{O}_{2}$, the gas is cooled and then enters the recovery column. Krypton and xenon are stripped from the gas stream by a counter current flow of liquid $\mathrm{N}_{2}$. The concentrated $\mathrm{Kr}$ and $\mathrm{Xe}$ are fed to the separation column, which operates in two stages. Krypton and xenon are collected continuously in the first stage while light gases, mainly $\mathrm{N}_{2}$ and $\mathrm{Ar}$, are recycled in the holding tank. The second stage is operated periodically by shunting the feed stream to the separation column, and by fractioning the contents to yield krypton at the top and xenon at the bottom.

A simplified description of the process components is given in Figure 4.1. For more complete information the reader is referred to the facility description by Brown et al. (9)

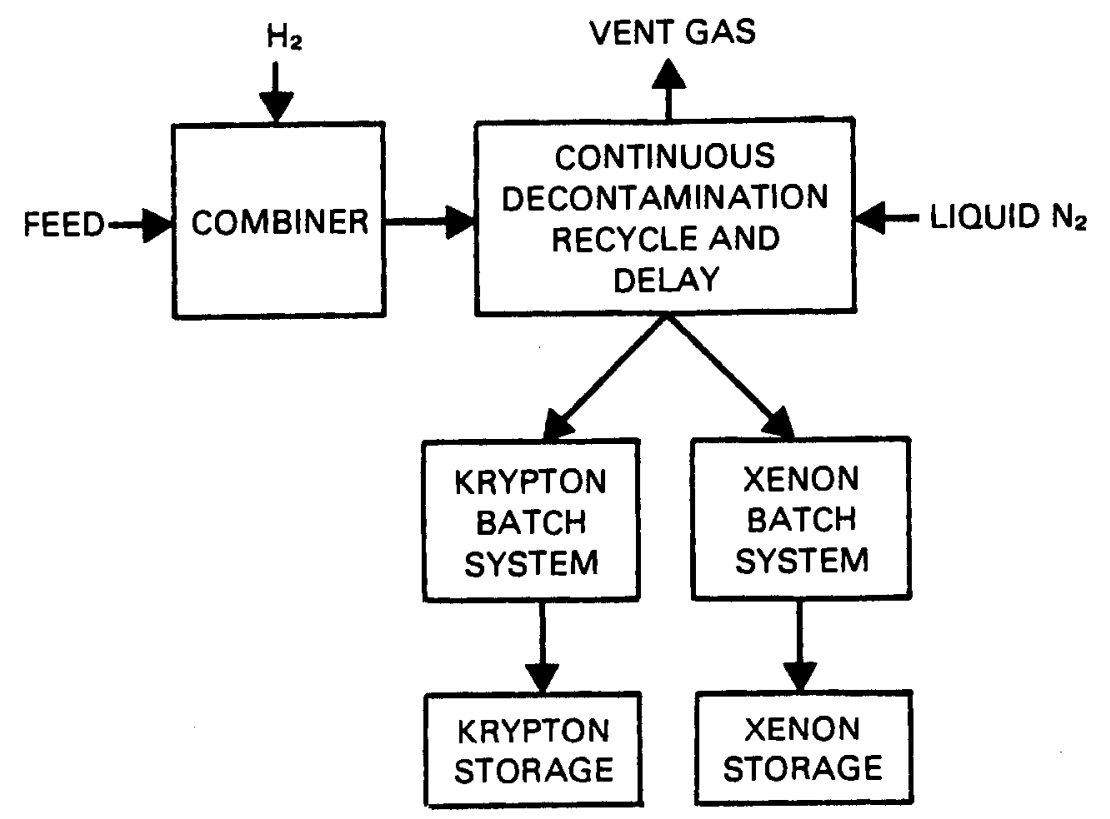

FIGURE 4.1. Airco Cryogenic Process

The nitrogen oxides must be removed to prevent plugging by freezing of these gases. 0xygen must be eliminated to minimize radiolytic ozone formation in the cryogenic distillation columns (an explosion hazard). 0xygen is removed from the process stream by adding $\mathrm{H}_{2}$ and passing the mixture over a palladium-platinum catalyst at $\sim 550^{\circ} \mathrm{C}$. 


\subsubsection{Fluorocarbon Absorption}

The fluorocarbon selective absorption process has been developed at the Oak Ridge Gaseous Diffusion Plant (ORGDP), in conjunction with the Oak Ridge National Laboratory and at Kernforschungszentrum Karlsruhe (KFK) in the Federal Republic of Germany. Fluorocarbon absorption is one of the more versatile processing schemes proposed for the decontamination of gaseous effluent streams from nuclear facilities. The control technology has been taken to pilot plant scale at the ORGDP and at KFK. Plans are being made to demonstrate the recovery of $85 \mathrm{Kr}$ from the DOG stream in the Breeder Reprocessing Experimental Test (BRET).

The selective absorption process is based on the solubility differences which exist among the various gas components and the solvent chosen for the process. The solvent dichorodifluoromethane, $\mathrm{CC}_{2} \mathrm{~F}_{2}$, commonly referred to as refrigerant-12 or simply R-12, was chosen based on its good noble gas separation factors and relatively good thermal and radiation stability, as well as overall process safety and economic considerations.

\subsubsection{Description}

The fluorocarbon absorption process has been developed to remove gaseous radioactive isotopes from nuclear facility off-gas streams and concentrate the contaminants for an encapsulation or immobilization process prior to final storage. A typical flow sheet includes of $f$-gas purification, rare gas absorption and separation, rare gas concentration and purification, solvent purification, and rare gas product removal. Pilot plant-scale fluorocarbon processes have been in developmental stages at the ORGDP since 1968. A block diagram of one version of the basic process is given in Figure 4.2. The following description has been taken from the work of $D$. K. Little et al. (10) The main separation of radioactive components from the bulk gas is effected in the absorber section. The intermediate or fractional stripper section serves first to remove the coabsorbed carrier gas from the solvent, thereby enriching the remaining dissolved gas in the more soluble components. Secondly, the intermediate stripper collects the product gases prior 


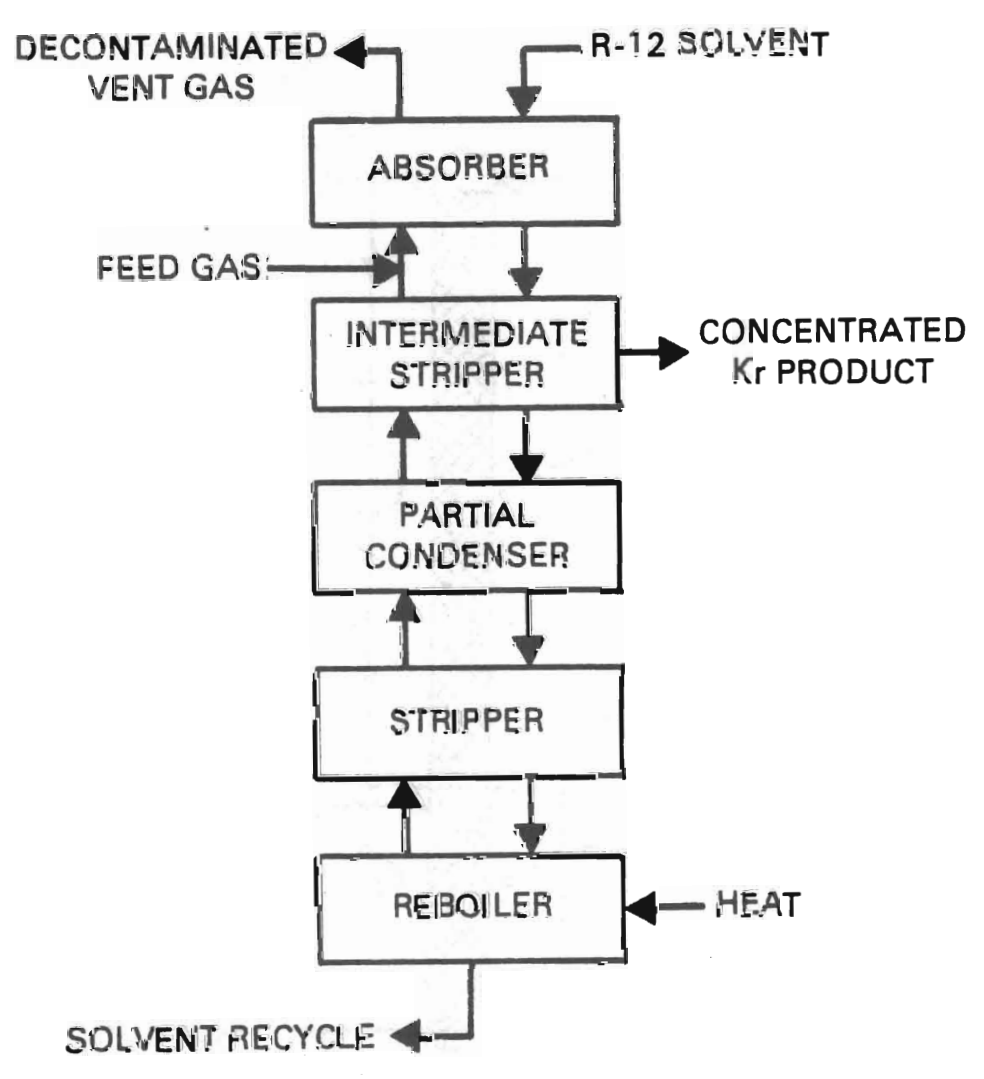

FIGURE 4.2. Block Diagram of Basic Fluorocarbon Process

to removal from the column. The final stripper removes remaining dissolved gases from the process solvent, thus regenerating the solvent for recycle to the absorber. As shown in Figure 4.3, it is now preferred to perform all process operations in a single combination column. The original process utilized a conventional arrangement of three separate columns. (11) Each column section is filled with a high-efficiency wire mesh packing for intimate gas-liquid contacting. Decontaminated off-gas flows from the top of the combination column and regenerated solvent from the bottom, while the fission product gases are collected as a side stream. Support equipment items for the basic process include a reboiler to provide necessary stripping vapor upflow, a solvent condenser, a process gas compressor, a feed gas heat exchanger, a solvent pump, a solvent cooler, storage tanks, and several refrigeration compressors. 


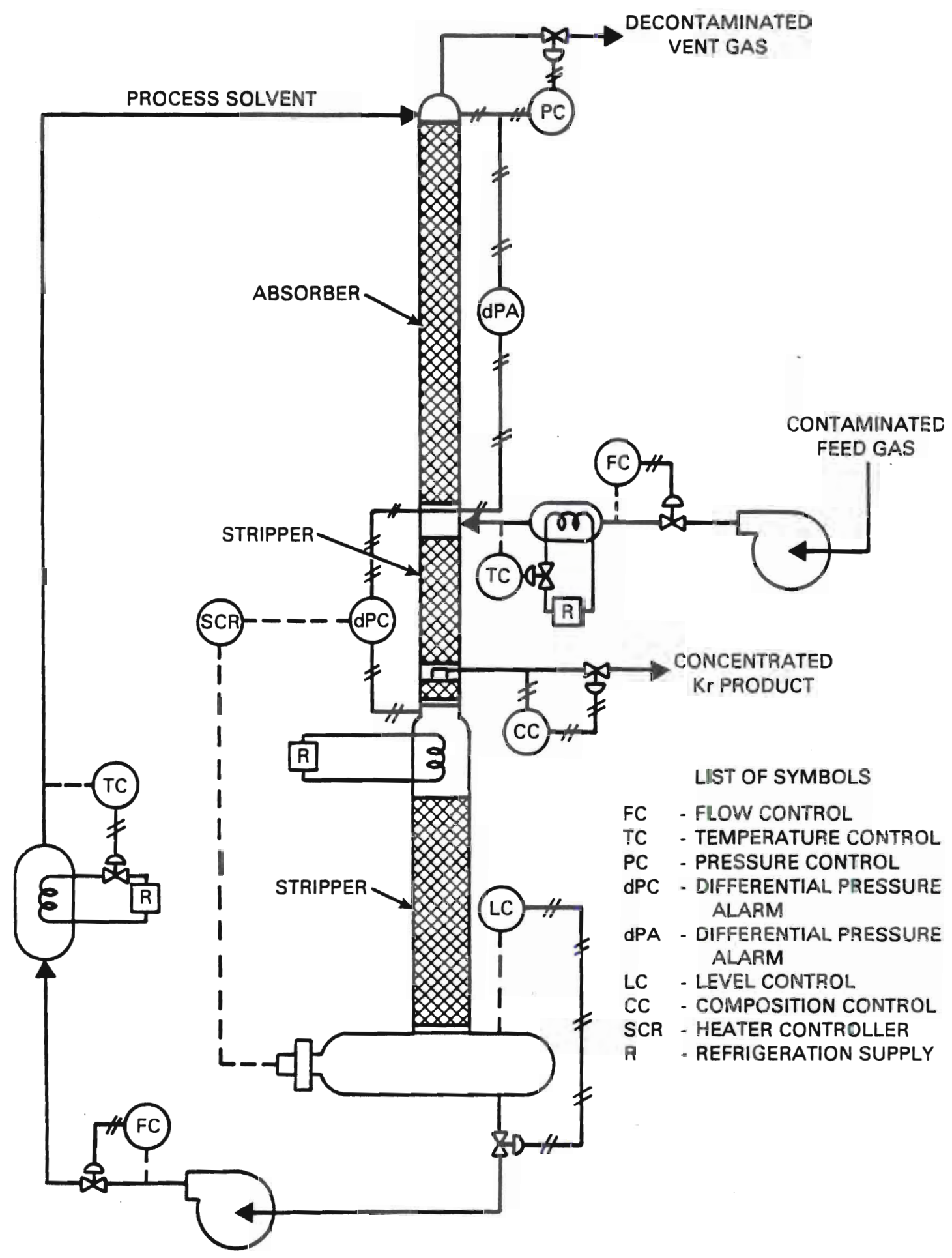

FIGURE 4.3. Schematic of the Simplified Selective Absorption Process 
The combination column employs an internal condensation zone and soluble gas concentration peak in the intermediate section of the column. The concentration peak is a result of the gross internal condensation of the upflowing stripping vapor from the reboiler as it meets the cold downflowing liquid from the absorbent section. Technical details of the combination column and design models have been described elsewhere. $(12,13)$

The combination column requires substantially less equipment and control instrumentation than the previous more conventional system utilizing three separate columns. Moreover, because of its greater simplicity, a single column offers numerous operational and economic advantages. The obvious primary advantages include simplified construction, increased reliability, easier operation, lower $\mathrm{Kr}$ inventory, lower costs, less hot cell space requirements, and a better demonstrated combined performance of process decontamination factor (DF) and concentration factor (CF). The less significant drawbacks include less freedom in design, which requires all column operations to take place at the same pressures; thus, the solvent reboiler temperature is fixed and greater stripper vapor upflow is required. The column is approximately $7.3 \mathrm{~m}$ tall and has a nominal flow capacity of 25 $\mathrm{m}^{3} / \mathrm{hr}$ at STP. The absorber section is $7.6 \mathrm{~cm}$ in diameter, while the intermediate stripper is $10.1 \mathrm{~cm}$, and the final stripper is $15.2 \mathrm{~cm}$.

The liquid absorption process is a very well known technology and one of its principal advantages is that it is a continuous process. The tolerance to feed-gas impurities such as water, carbon dioxide, nitrogen oxides, and iodine is much higher for a fluorocarbon absorption system than for a cryogenic distillation system. Furthermore, the fluorocarbon system appears to be less susceptible to fire and explosion. The long-term reliability of the fluorocarbon process needs to be established to insure that corrosion problems resulting from radiation damage to the solvent are manageable and that unwanted impurities do not build-up in the solvent. Presently, the product stream contains both $\mathrm{Xe}$ and $\mathrm{Kr}$ and may require further purification and separation to reduce volume and storage costs. 


\subsubsection{Solid Adsorption}

Adsorption processes are used commercially to purify rare gases from mixtures of gases. Helium is successfully enriched from dilute ( 0.1 to $0.3 \%$ ) He - natural gas mixtures. Historically, activated charcoal is probably the most widely used adsorbent for producing research grade purity $\mathrm{Kr}$. Charcoal has two disadvantages when considered for use as a solid adsorbent for removing rare gases from nuclear plant process streams. First, it is combustible; hence the removal of oxygen, $\mathrm{NO}_{\mathrm{x}}$ or other oxidizing gases from the feed stream must be accomplished. And second, a wide variation in reported adsorption coefficients for activated charcoal for $\mathrm{Kr}$ and $\mathrm{Xe}$ necessitates using the most conservative values.

During the past 30 years synthetic zeolites (molecular sieves) have offered many new possibilities in the technology of separating and purifying gases. A big advantage for synthetic zeolites is they are noncombustible. They are more expensive but there is less variability in the product. By changing their structure and composition the molecular sieves may be made more selective for particular gases. Both molecular sieves and activated charcoal adsorption coefficients are affected adversely by the presence of water. The removal of water and the pickup of fines must be considered when using these materials. V. G. Fastovskii, et al., have compiled adsorption data for inert gases on synthetic zeolites. (14) An experimental program at the ORGDP tested the use of a silver-exchanged synthetic mordenite zeolite (AgZ) recommended by Pence and Kirstein for the removal of Xe from streams containing $\mathrm{kr} .(15,16)$

The major existing solid adsorbent rare gas waste control technology is used to limit the radiation exposure of the public from volatile fission products in off-gas streams of nuclear power plants. The cryogenic charcoal adsorption method has been used by the Isotope Sales Department at ORNL for over 20 years to purify $\mathrm{kr}$.

Basically the solid adsorbent process concentrates the preferentially adsorbed species (the adsorbate) from a dilute process stream on a bed of the adsorption column. The adsorbate is then desorbed in a more concentrated 
stream in a second step by passing a heated carrier gas through the column. Parallel adsorption beds are required if continuous operation is desired. Also, series adsorption beds may be required if several different gases need to be separated or if a high degree of purification cannot be obtained in single-stage operation. Solid adsorbent separation may be used to better advantage when installed in series with other separation processes (e.g., cryogenic distillation or a selective liquid adsorption process). The adsorption is more effective when treating concentrated streams.

Emissions from short-lived isotopes in reactor off-gas streams may be reduced by delaying the release, by storing the gases in pressure vessels or by adsorbing the isotopes on activated charcoal beds. The charcoal adsorption system may be designed with the option to separate the ${ }^{85} \mathrm{Kr}$ for long-term storage or for release to the environment. A schematic of the principal components of a BWR off-gas system is shown in Figure 4.4.

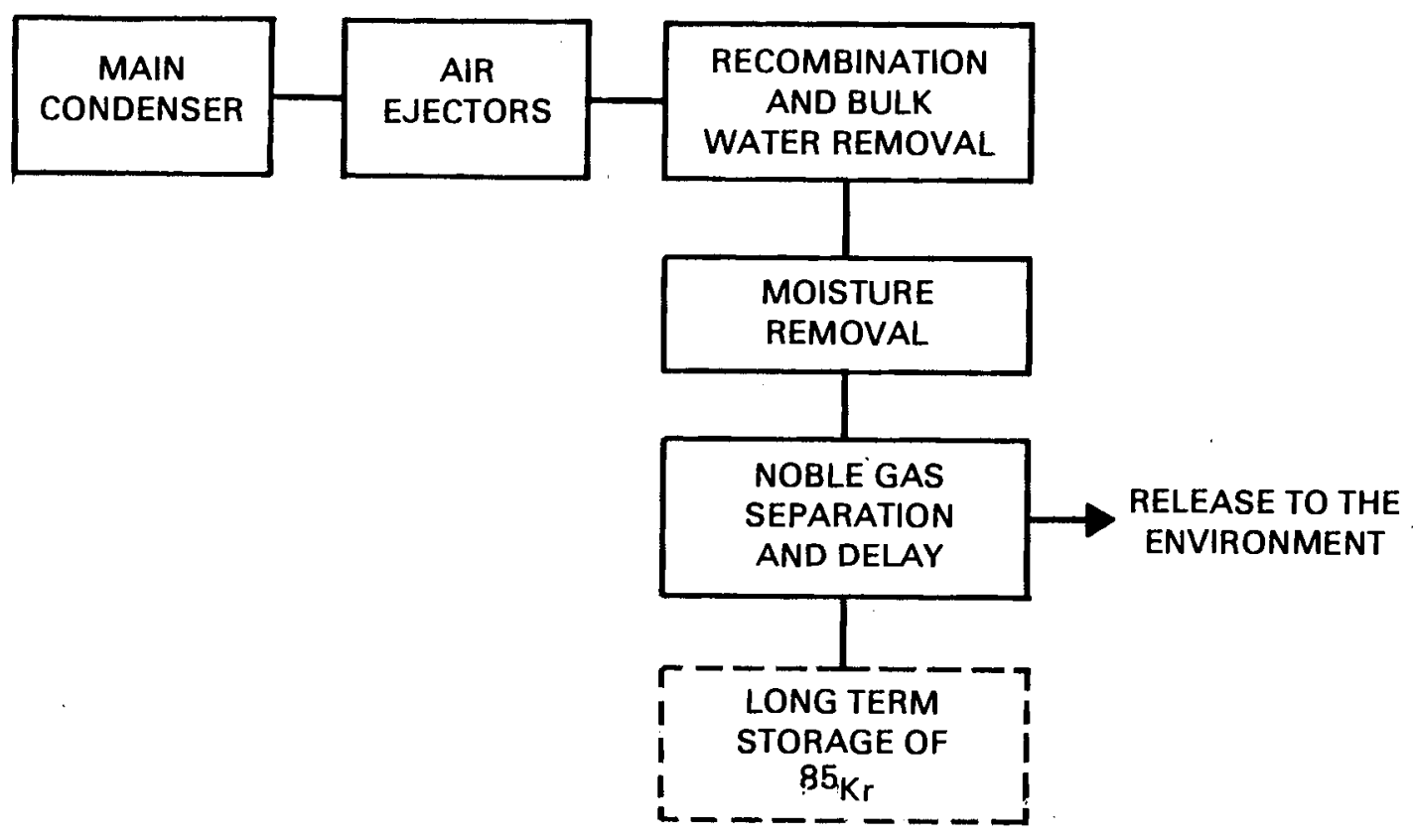

FIGURE 4.4. Principal Components of a BWR Off-Gas System 
The delay time for such a system is given by the equation:

$$
T=\left(2.4 \times 10^{-5}\right) \frac{\mathrm{MK}}{\mathrm{F}}
$$

where

$T=$ holdup time (days),

$K=$ dynamic adsorption coefficient $\left(\mathrm{cm}^{3} / \mathrm{g}\right)$,

$M=$ mass of charcoal $(\mathrm{kg})$, and

$F=$ flowrate through system $(\mathrm{cfm})$.

The following are recommended dynamic adsorption coefficients:

\begin{tabular}{|c|c|c|c|}
\hline \multirow{2}{*}{$\begin{array}{l}\text { Operating } \\
\text { Temperature, } \\
{ }^{\circ} \mathrm{C} \\
\end{array}$} & \multirow{2}{*}{$\begin{array}{l}\text { Dew } \\
\text { Point, } \\
{ }^{\circ} \mathrm{C} \\
\end{array}$} & \multicolumn{2}{|c|}{$\begin{array}{l}\text { Dynamic Adsorption } \\
\text { Coefficient }\left(\mathrm{cm}^{3} / \mathrm{g}\right)\end{array}$} \\
\hline & & $\mathrm{Kr}$ & $\mathrm{Xe}$ \\
\hline-18 & -29 & 105 & 2410 \\
\hline 25 & -18 & 25 & 440 \\
\hline 25 & 7 & 18.5 & 330 \\
\hline
\end{tabular}

In BWR of $f$-gas streams the radiolytic $\mathrm{H}_{2}$ and $\mathrm{O}_{2}$ must be diluted with steam so that the $\mathrm{H}_{2}$ concentration is below 4 volume percent. After catalytic recombination of the hydrogen and oxygen and water removai, the gas is passed through a charcoal bed. In PWR off-gas streams $\mathrm{N}_{2}$ is used to strip the fission product gases from the primary coolant and enough is added to reduce the hydrogen concentration below the explosive limit. A typical system with a noncondensable gas flow rate if $30 \mathrm{scfm}\left(0.15 \mathrm{~m}^{3} / \mathrm{s}\right)$ and a 21 metric ton charcoal bed held at a temperature of $-18^{\circ} \mathrm{C}$ could hold up xenon for 42 days and krypton for 1.8 days. Fortunately, except for the $85 \mathrm{kr}$, the krypton isotopes have shorter half-lives than xenon isotopes. The charcoal delay system which provides a satisfactory xenon dose reduction will also achieve a similar dose reduction for krypton. Charcoal bed volumes may be reduced considerably by lowering the temperature, since the dynamic adsorption 
coefficient increases exponentially with the reciprocal of the absolute temperature. The cost savings to be realized from smaller charcoal volumes must be balanced against the added cost of refrigeration equipment and insulation for the sorption unit.

Selective adsorption of noble gases on synthetic zeolites and mordenites is quite similar to the activated charcoal process. A schematic diagram is shown in Figure 4.5 of how adsorption on molecular sieves can be used as a product purification system in combination with the fluorocarbon selective absorption process. This process requires three pretreatment steps to remove the fluorocarbon solvent, R-12, carbon dioxide, and xenon. Ultimate krypton removal is carried out in a simple cold trap. Verification tests at ORGDP using molecular sieve sorbents $13 x, 5 A$ and silver zeolite for removing $R-12$, $\mathrm{CO}_{2}$ and $\mathrm{Xe}$, respectively, showed impurity removals from the krypton product were greater than 90\%. (16) Waggoner at the SRL has made a technical and economic evaluation of the mordenite (silver zeolite) process for a pilot plant proposed by $D$. T. Pence of Scientific Applications, Inc. (15) but resized for a $100-\mathrm{scfm}\left(0.5 \mathrm{~m}^{3} / \mathrm{s}\right)$ off-gas stream. A schematic of the mordenite process is shown in Figure 4.6. Xenon is adsorbed preferentially to krypton. The off-gas stream must pass through an adsorber to remove the xenon. Krypton and air pass to the second adsorber fixing the krypton. The krypton fixed on the second adsorber is desorbed in a concentrated stream and is adsorbed on the third mordenite column. A stream of approximately $30 \%$ krypton in nitrogen is then desorbed and the krypton is separated from the nitrogen in the cold trap.

\subsubsection{Economic Comparison}

The economic evaluation was taken from the work of Waggoner at the SRL. (17) In this evaluation he compared four potential separation processes for removing $85_{\mathrm{Kr}}$ from the off-gas from a typical reprocessing plant. The engineering basis for this study was chosen to be a $100 \mathrm{scfm}\left(0.5 \mathrm{~m}^{3} / \mathrm{s}\right)$ off gas stream expected from a 1500 MTHM/year power fuel reprocessing plant. 
宁
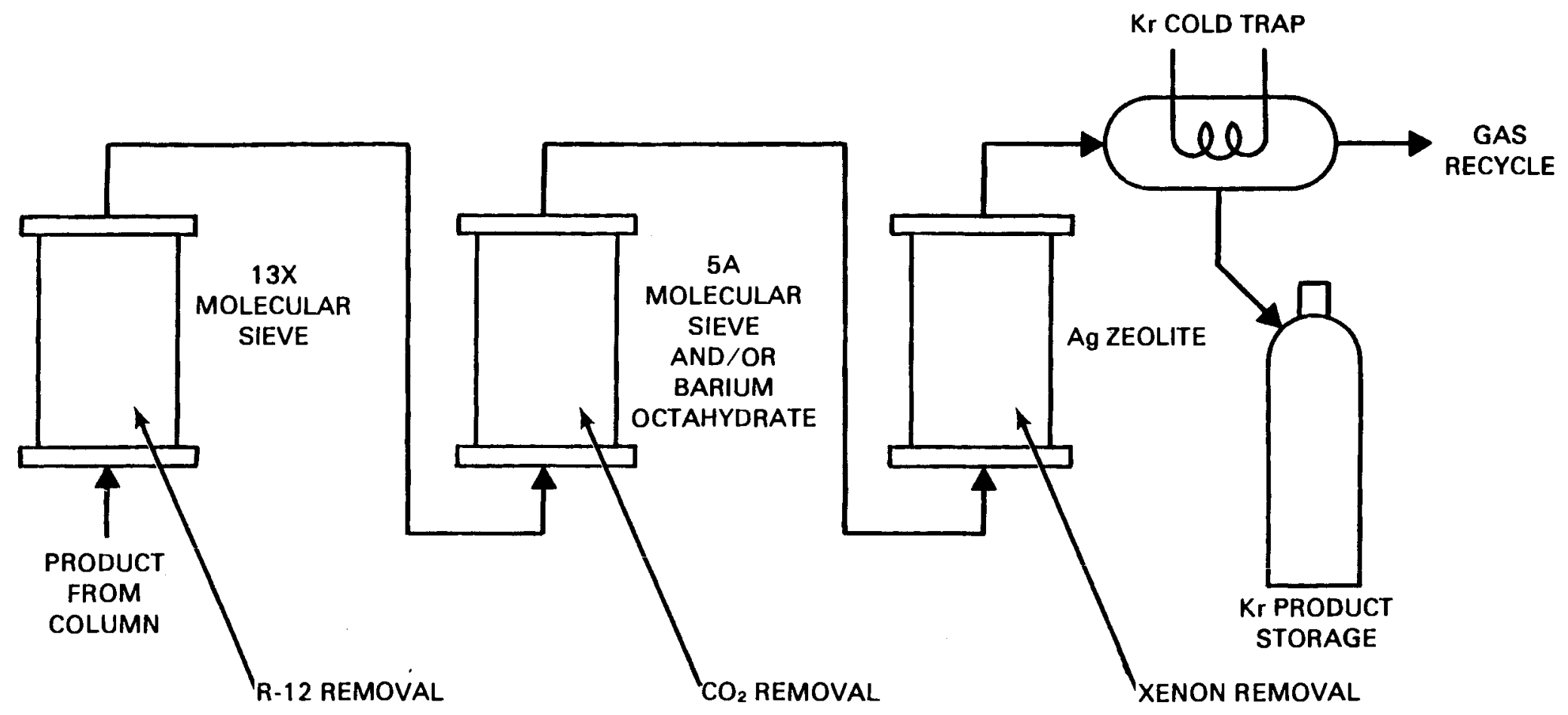

FIGURE 4.5. Schematic of Product Purification System 


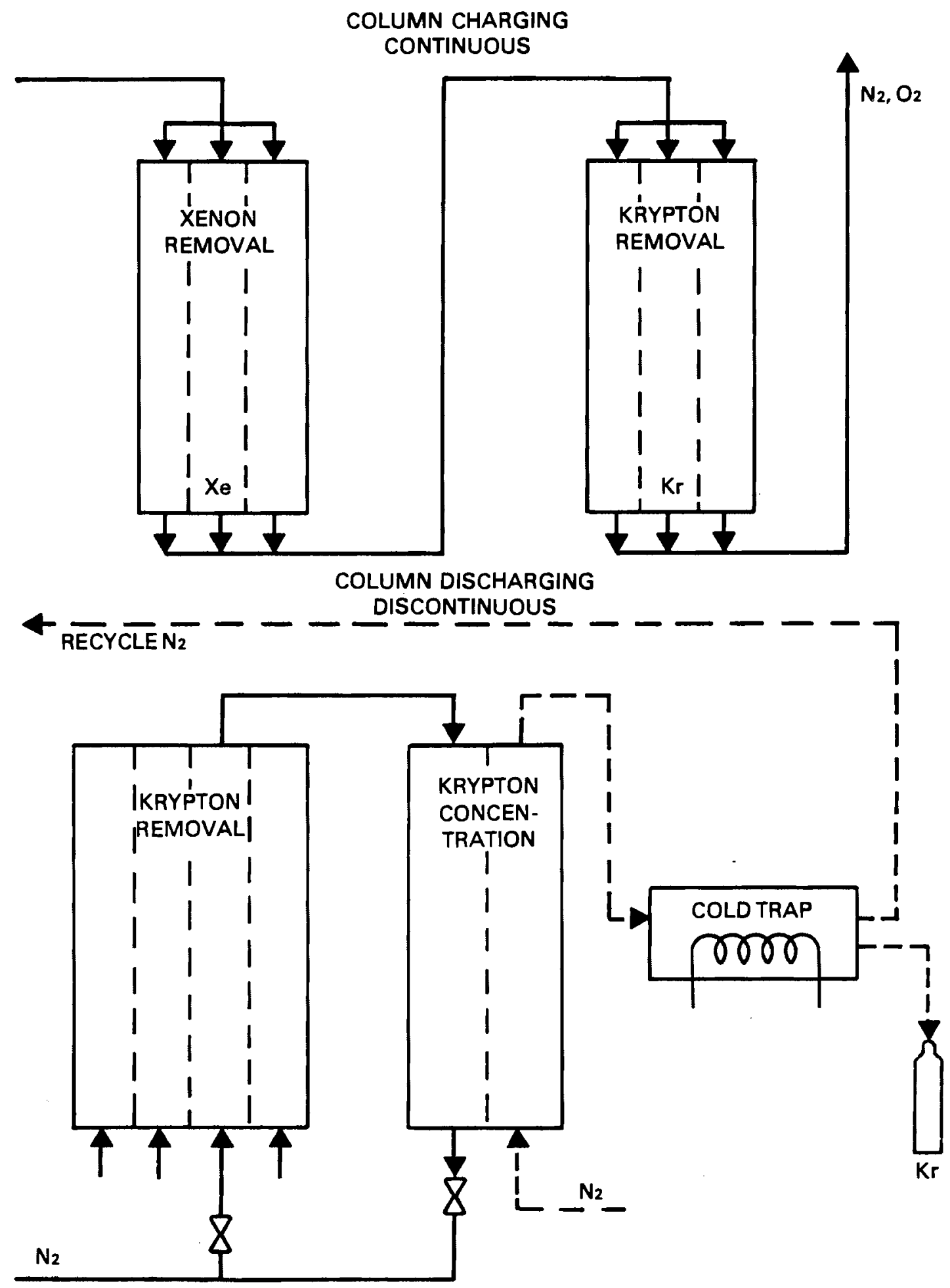

FIGURE 4.6. Mordenite Adsorption Process 
Removal processes were defined to remove krypton from the off-gas stream and purify the krypton making it suitable for immobilization or fixation for long-term storage. Upstream treatment included the removal of all off-gas components except nitrogen, oxygen, argon, krypton and xenon. Since the pretreatment costs were common to all processes, they were not included in the comparison. Nor were the fixation costs since they too were common to all processes. The four processes evaluated in this study were cryogenic distillation, fluorocarbon adsorption, mordenite adsorption, and selective permeation. The last method using silicone rubber membranes was found not to be cost-effective and was not included in the economic comparison. Table 4.4 gives the detailed results of the cost comparison for the three processes. The overall differential cost comparison is given in Table 4.5 .

\subsection{KRYPTON IMMOBILIZATION TECHNOLOGY}

$85_{\mathrm{Kr}}$ is the only rare gas with a half-life long enough to require longterm storage. The immobilization or fixation of ${ }^{85} \mathrm{Kr}$ poses particular problems since it is an inert gas and does not form stable monolithic solid compounds which are the preferred forms for storage or disposal. At present, the only existing technology for containment of radioactive noble gases is storage in pressurized gas cylinders. $(18,19)$ Pressurized cylinder storage was chosen as the reference containment technique for the draft environmental impact statement on waste management $(20,21)$ for a program to build and operate an Integrated Hot Off-Gas Facility at the Savannah River Plant. (9)

Alternative immobilization techniques include ion implantation in growing sputter-deposited metallic films (22-24) and encapsulation in zeolites.(25-27) Thamer, Mihlfeith, and Macbeth(28) have conducted an extensive survey of methods of immobilizing krypton-85. In addition to the above, their review considers disposal in porous underground media, hydrofracture, extra terrestrial, disposal in the ocean, low-pressure storage in caverns, transmutation and others. (29) 
TABLE 4.4. Capital Cost Comparison for Krypton Removal

Process Equipment

Thousands of 1981 Dollars

Installation

\begin{tabular}{|c|c|c|}
\hline $\begin{array}{l}\text { FTuorocarbon } \\
\text { Adsorption }\end{array}$ & $\begin{array}{l}\text { Mordenite } \\
\text { Adsorption }\end{array}$ & $\begin{array}{c}\text { Cryogenic } \\
\text { Distillation }\end{array}$ \\
\hline 768 & 1350 & 700 \\
\hline 125 & 158 & 331 \\
\hline
\end{tabular}

Engineering, Design, etc.

$0.75 \times$ Installed Equipment cost

Total Direct Process Costs

$\frac{670}{1563} \quad \frac{1072}{2580} \quad \frac{773}{1804}$

Structural Costs

Building W/HVAC

Cold Box Barriers, etc.

Total Direct Costs

760

760

760

Indirect Costs

$0.5 \times$ Di rect Costs

$\frac{1162}{3485}$

1670

1389

Total Cost

$\frac{--}{2323} \quad \frac{--}{3340} \quad \frac{214}{2778}$

Contingencies

Factor

Factored Total Costs

Adsorbents, Catalysts, etc.

Grand Total
0.30

1045

4530
0.45

0.10

2204

417

320

900

5483

TABLE 4.5. Overall Differential Cost Comparison

\begin{tabular}{|c|c|c|c|}
\hline \multirow[b]{2}{*}{ Process } & \multicolumn{3}{|c|}{ Thousands of 1981 Dollars } \\
\hline & $\begin{array}{l}\text { Facility } \\
\text { Cost } \\
\end{array}$ & $\begin{array}{l}\text { Power (d) } \\
\text { Cost }\end{array}$ & $\begin{array}{c}\text { Cost } \\
\text { Differential }\end{array}$ \\
\hline Fluorocarbon Absorption & 4530 & 461 & 0 \\
\hline Mordenite Adsorption & 7434 & 719 & 3222 \\
\hline Cryogenic Distillation(b) & 5483 & 948 & 1500 \\
\hline
\end{tabular}

(a) Differences among processes were not significant for other operating costs.

(b) Reference process. 


\subsubsection{Pressurized Cylinder Technology}

The technology for storing and handling a wide variety of inert, toxic or corrosive industrial gases in pressurized metal cylinders is well estab1ished. Krypton- 85 recovered at ICPP is stored on an interim basis and then shipped to ORNL in cylinders. Double-walled cylinders filled with charcoal to reduce the total pressure have been constructed for a Japanese facility.

A nominal $90 \%$ xenon-10\% krypton-85 gas mixture is routinely shipped to ORNL for ICPP. The 50-liter bottle is filled to a maximum pressure of 500 psi. The bottle is a modified standard compressed-gas cylinder DOT Specification 3A-2015. For safety considerations the valve seat is made of monel and the valve stem of Type 303 stainless steel. The cylinder is pressure tested at least every 5 years and is certified for a pressure of 2015 psig (see Table 4.6).

TABLE 4.6. Properties of 50-Liter Cylinders Containing Krypton-85

\begin{tabular}{|c|c|c|c|c|}
\hline \multicolumn{2}{|c|}{ Pressure } & ${ }^{85} \mathrm{Kr}$ Content, & $\begin{array}{c}\text { Heat } \\
\text { Generation, } \\
\text { W }\end{array}$ & $\begin{array}{c}\text { Wall } \\
\text { Temperature, (a) } \\
{ }^{\circ} \mathrm{C}\end{array}$ \\
\hline 500 & 3.4 & 128,000 & 187 & 64 \\
\hline 1250 & 8.6 & 297,000 & 434 & 98 \\
\hline 2000 & 13.8 & 443,000 & 647 & 125 \\
\hline
\end{tabular}

(a) Assuming natural convection cooling of vertical cylinder in air at $27^{\circ} \mathrm{C}$.

For shipment of hazardous gases, regulations have required that: 1) the cylinder be shielded against radiation exposure, 2) the cylinder be of the nonventing type, and 3) the cylinder pressure not exceed 600-1200 psi. For a reference Krypton Storage Facility, a cylinder pressure of 500 psi (3.4 MPa) has been established. (20) Higher pressures could probably be considered if the cylinders were stored at the reprocessing site.

Potential cylinder corrosion problems arise as a result of the ${ }^{85} \mathrm{Kr}$ decay product, rubidium. Preliminary results of a corrosion test program at the 
INEL show that type 316 stainless steel, A-286 and Nitronic 500 exhibit low corrosion and embrittlement rates with rubidium and rubidium hydroxide. (30) A demonstration to establish the long-term effects of the decay product on the integrity of the storage cylinders is advisable. Corrosion tests are in progress at Karlsruhe, Germany.

Processing cost for filling cylinders is nil if the cost for the bottle is included in the final storage costs. This will be covered in a later section. Facility costs will be negligibly small and it could be considered a part of the separation facility. If a large interim storage area is required this assumption would be false.

\subsubsection{Ion Implantation/Sputtering}

The incorporation of gases in sputter-deposited films is a well recognized phenomenon and serves as the basis for the design of commercial vacuum pumps; however, ion pumps, as they are called, are better suited for pumping chemically active gases. Pumps marketed at the present time lack the necessary noble gas pumping speed and capacity for handling fuel reprocessing plant waste streams. Investigators at AERE Harwell and the Pacific Northwest Laboratory (PNL) have developed ion implantation/sputter deposition pumping units that show the process to be both technically and economically feasible. At PNL the development of a full-scale pilot plant is in progress. At Harwell a pilot-scale plant is being developed.

The implantation/sputtering process has the distinct advantage that the process is carried out in a low-pressure $(\sim 1 \mathrm{~Pa})$ environment at room temperature.

The principles of the process developed at Harwell are shown in Figure 4.7.(22) A glow discharge is established between the two cylindrical electrodes by applying a negative potential of 3 to $5 \mathrm{kV}$ to each of the electrodes in sequence in the presence of krypton gas to a pressure of about $10 \mathrm{~Pa}$. The glow discharge is used as a source of ions, which bombard the negative electrode and cause both implantation and sputtering of the electrode material. Gas is implanted into the outer electrode by applying the negative 


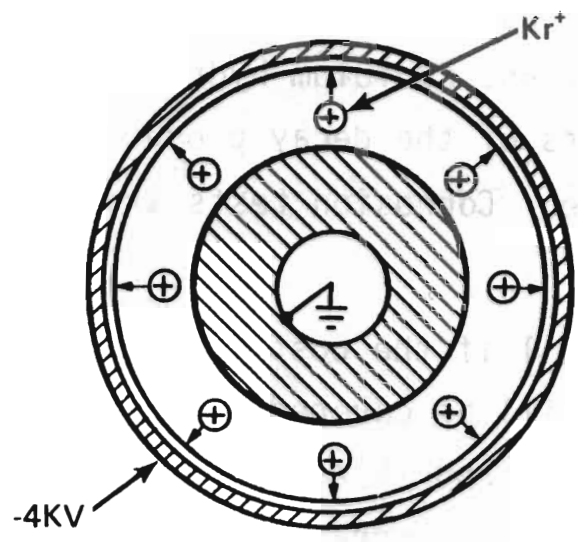

I IMPLANT

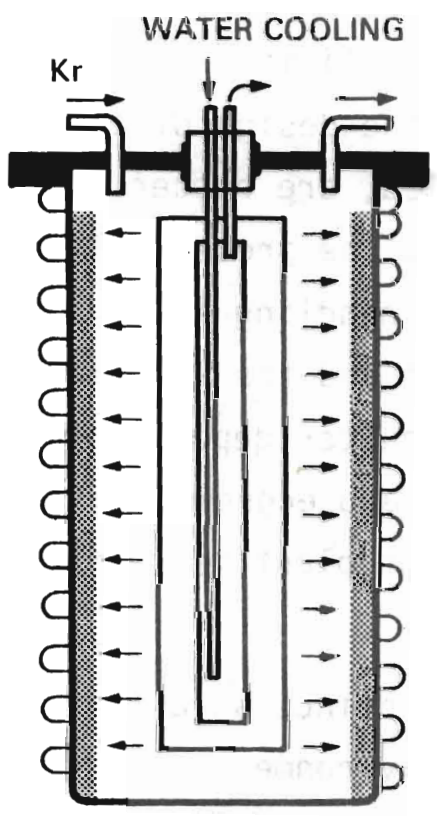

DURING OPERATION

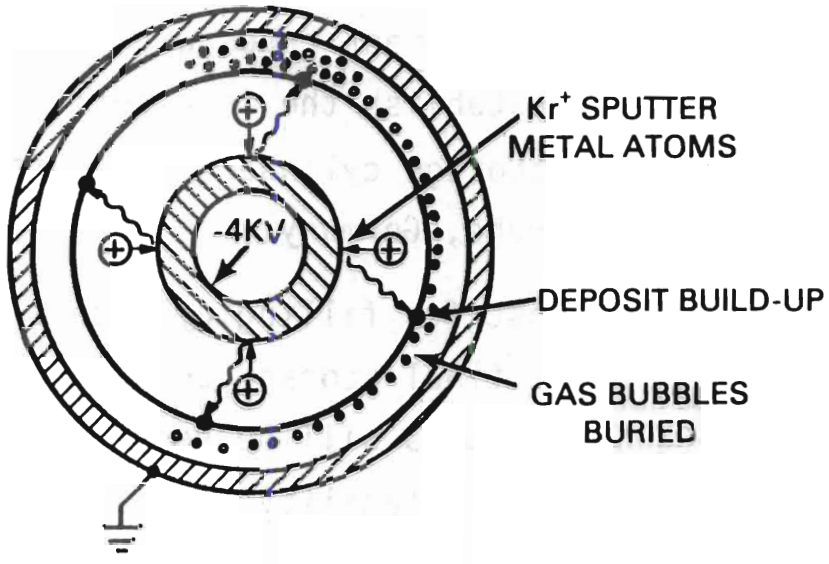

II COAT

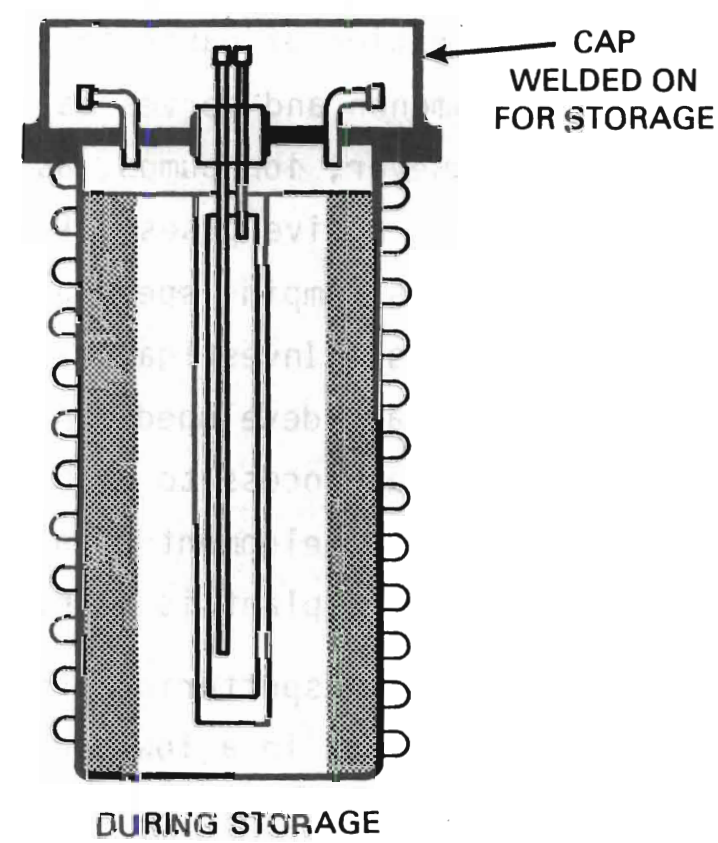

SCHEMATIC REPRESENTATION OF PLANT

FIGURE 4.7. Principles of the Harwell Process 
voltage to this electrode. The implanted gas layer is then coated with a layer of metal sputtered from the central electrode by switching the voltage to the center electrode. By repeating the process (typicaliy, several times per second), a thick deposit is accumulated. The process is controlled by adjusting the voltage and the relative electrical charges used for each cycle. Such a device will be designed so that it can be removed for disposal without contaminating the ancillary equipment. The process can be operated remotely. A similar process under development at PNL is shown schematically in planar geometry in Figure 4.8 but in practice is carried out using coaxial cylindrical electrodes. (23) A thermionically supported discharge operating at lower pressure, typically only $0.5 \mathrm{~Pa}$, is maintained in the annulus between the inner and outer cylindrical target and substrate electrodes. This discharge is established by accelerating electrons emitted from the heated tungsten filament to an auxiliary anode. A thick metallic layer containing 5 to 12 atomic percent krypton can be built up on the outer substrate electrode by adjusting the ratio of the target to the substrate voltage. For crystalline deposits, it is necessary to use a pulsed voltage equal in magnitude to the central target electrode. With certain transition-metal rare-earth alloys, such as $\mathrm{Fe}_{0.9 \mathrm{Y}_{0.1}}$ or $\mathrm{Ni}_{0.9 \mathrm{La}} \mathrm{L}_{.1}$, the ion-sticking coefficient is high enough at low voltages so that the voltage on the outer electrode need be only a tenth that of the voltage applied to the target electrode. The high current density achieved in the supported discharge apparatus and the use of the rare-earth transition metal alloy combine to give a higher pumping capacity and electrical efficiency. The improved efficiency is gained at the expense of a more complicated apparatus and a more costly target material.

\subsubsection{Zeolite Encapsulation}

Zeolite minerals have been known for 200 years, but only for the last 20 years have engineers taken advantage of their adsorptive properties. The zeolite family of minerals is crystalline alumino silicates with regular cagelike structures of varying complexity. The size of the holes or channels in the mineral is controlled by the size of the hydrated cation about which the 


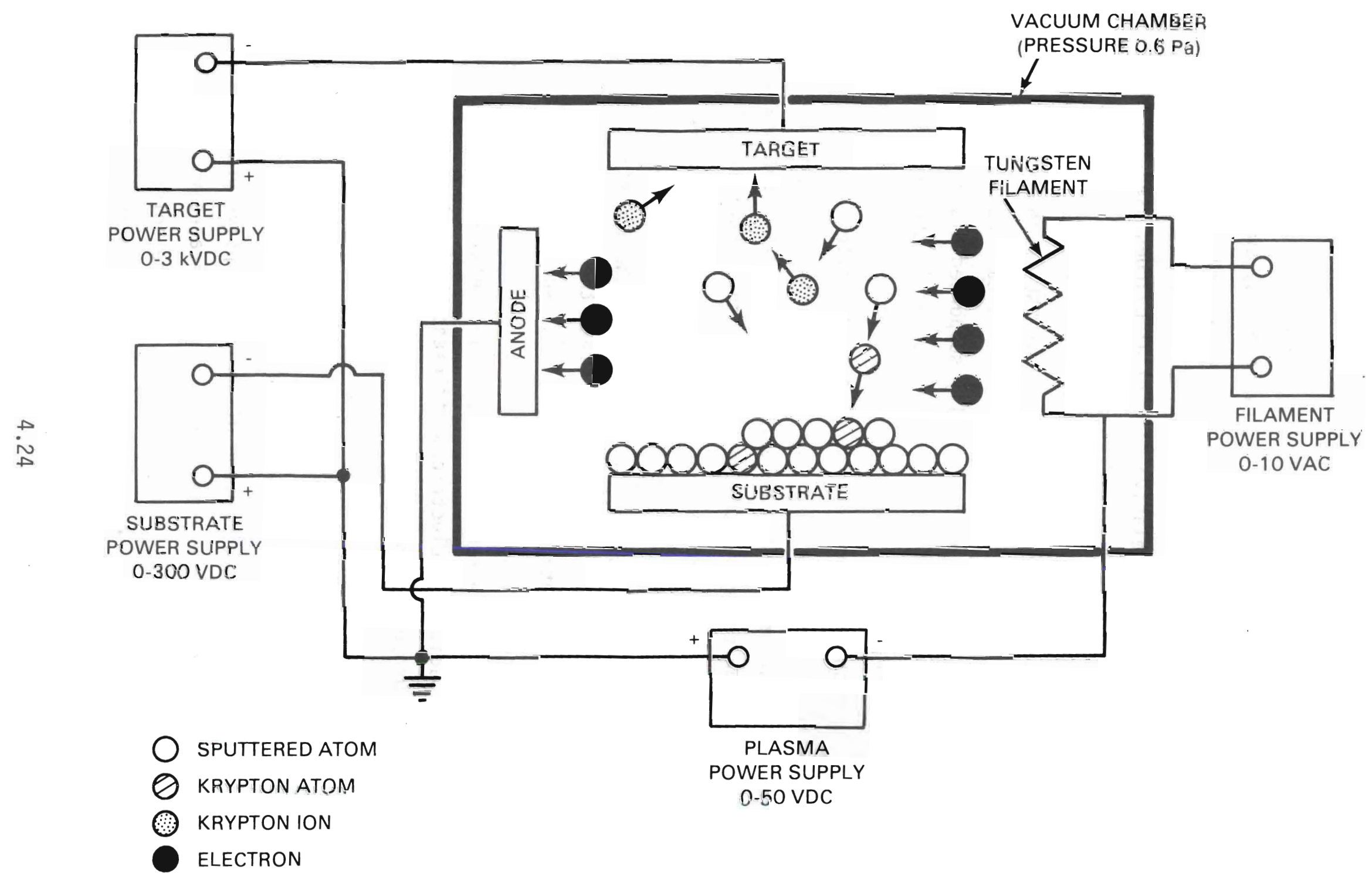

FIGURE 4.8. Sputtering/Ion Implantation 
alumina and silica anions collect. Gas atoms can diffuse in the cages at high temperatures $\left(500^{\circ} \mathrm{C}\right)$ and pressures $(\sim 200 \mathrm{MPa})(2000 \mathrm{~atm}$.$) . At low$ temperatures $\left(<150^{\circ} \mathrm{C}\right)$ the trapped gas is very slow to diffuse out of the holes.

Benedict, et al. showed that sodalite loaded with krypton was stable enough to be considered as a potential long-term waste form for krypton85. (31) Work at Karlsruhe selected zeolite $5 \mathrm{~A}$ over 30 different natural and synthetic zeolites as the preferred absorbent based on loading and stability tests with both argon and krypton. (27) Zeolite $5 \mathrm{~A}$ was also evaluated at INEL but thermal stability measurements showed the product to be inferior to sodalite. Later it was discovered that the better performance for the zeolite $5 \mathrm{~A}$ at Karlsruhe was due to a combination of the vacuum furnace pretreatment of the adsorbent and a higher temperature during encapsulation that changed the crystalline nature of the zeolite to a higher-density glass-like material. This product was somewhat similar to a waste form identified earlier by Tingey at PNL. $(25,32)$ Tingey showed that krypton trapped in porus silica at elevated temperatures and pressures $\left(900^{\circ} \mathrm{C}\right.$ and $\sim 34 \mathrm{MPa}, 340 \mathrm{~atm}$.) for long enough periods to effect sintering was extremely slow to diffuse out of the matrix.

\subsubsection{Description}

The encapsulation process is illustrated schematically in Figure 4.9. The pressure vessel with a working volume of 8 liters is loaded with $\sim 7.7$ liters of pelletized zeolite $5 \mathrm{~A}$. The zeolite has been previously activated by heating for 24 hours at $450^{\circ} \mathrm{C}$ to lower the water content to 0.8 to $1.0 \%$. The vessel is hot isostatically pressed for 2 hours at $700^{\circ} \mathrm{C}$ and $1000 \mathrm{~atm}$. $(\sim 100$ $\mathrm{MPa}$ ) and allowed to cool under pressure. The entire cycle is estimated to take 10 hours including loading, pressurization, heating, processing, cooling, depressurization, purging, and unloading. Six hundred batches per year are required to encapsulate 232,500 liters of gas at STP. A more complete description of this process can be found in a preconceptual design report prepared for the DOE. (33) 


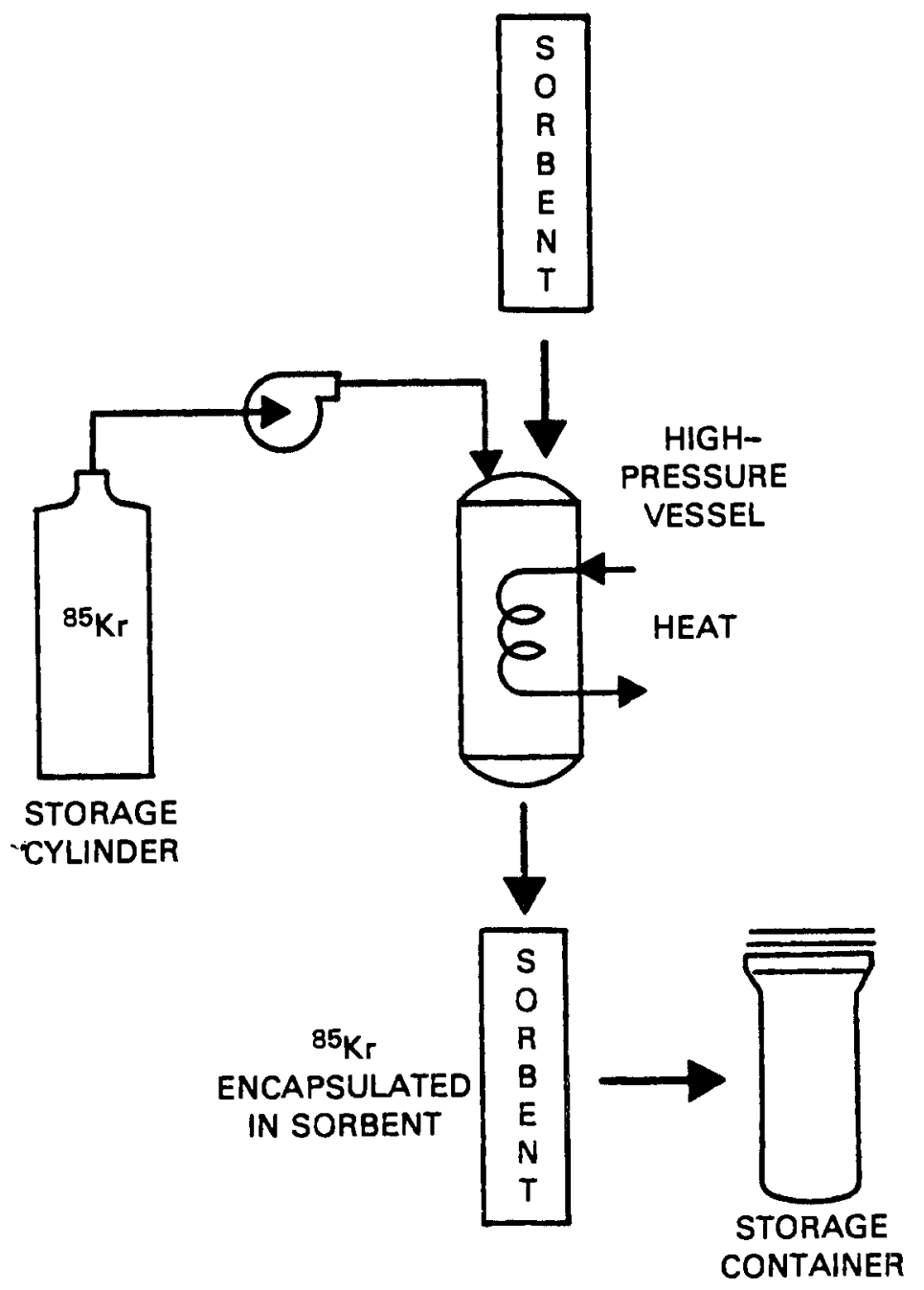

FIGURE 4.9. Krypton-85 Immobilization by High Temperature/Pressure Sorption

\subsubsection{Economic Comparison}

Thirty-year life cycle costs were developed during a preconceptual design study for the Zeolite Encapsulation Facility and the Ion Implantation/ Sputtering Facility performed by the Ralph M. Parsons Co. under contract to the DOE, with technical direction provided by Exxon Nuclear Idaho Company, Inc., by Idaho National Engineering Laboratory, and by Pacific Northwest Laboratory. (33) on a thirty-year basis, the total life cycle costs for 
the Zeolite Encapsulation Facility was $\$ 4.5$ million less than for the Ion Implantation/Sputtering Facility, or a total savings of 16.5\%. A summary of the cost comparisons for zeolite encapsulation and ion implantation/sputtering is given in Table 4.7 .

The costs for immobilizing krypton-85 by placing it in bottles was not included in this section because the cost for the facility would be a small part of either the separation facility or the krypton bottle storage facility and therefore could be neglected. The filling costs could also be considered as negligible. The cylinder and bottling costs are considered as part of the ultimate storage costs and are included in Section 4.4 .

\subsection{ULTIMATE STORAGE}

The short-lived noble gas isotopes can be stored in tanks with or without the use of solid adsorbents (to reduce the total volume). After an appropriate hold-up time the tanks can be vented and flushed. Krypton-85, due to its 10.7-year half-life, requires long-term storage. There are four principal techniques available for the ultimate storage of krypton previously immobilized in a solid or compressed in a steel cylinder, namely storage in a building, a drywell, a geological repository or in the ocean. Thamer et al. evaluated these alternatives in terms of achievability, radiological and nonradiological hazards and comparative costs. (29) Storage of krypton-85 in gas cylinders onsite in an engineered above-ground facility was chosen as the

reference facility for a commercial nuclear fuel reprocessing plant. (22) More recently Klett made a concept evaluation for the $\mathrm{Kr}$ program similar to the Spent Unreprocessed Fuel (SURF) program. Five above-ground and two nearsurface geologic concepts were evaluated. (34) Included in the evaluation were above-ground concrete silos for single and multiple canisters with and without internal air-cooled passages; an actively cooled water basin; a forced convection air-cooled vault; and a single canister drywell with supplemental cooling. 
TABLE 4.7. Capital Cost Comparison for Krypton Immobilization(a)

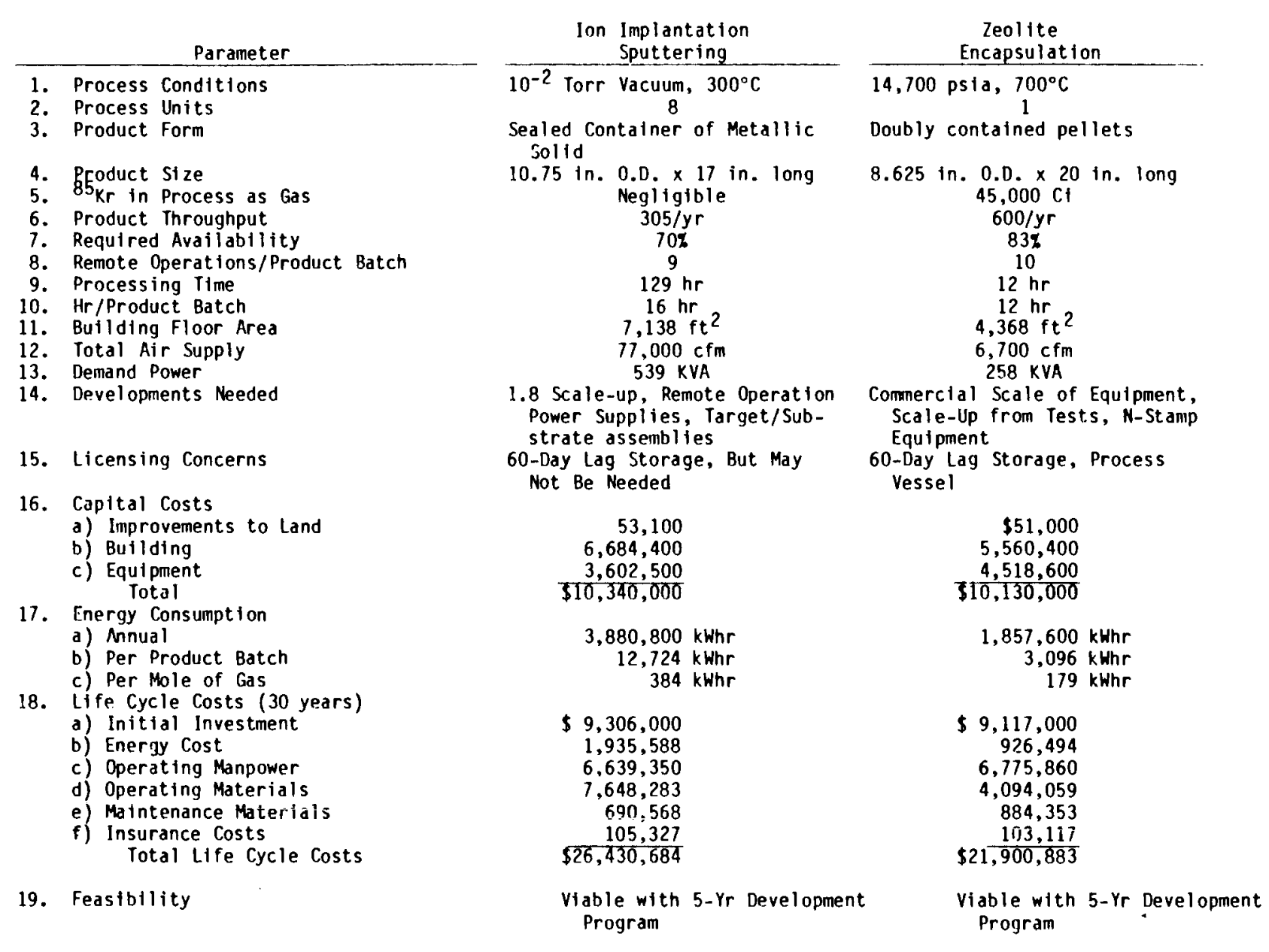

(a) Estimated cost for filling pressurized cylinders is considered negligible to lon Implantation/Sputtering and Zeolite Encapsulation. The cost for the cylinders is included in the uitimate storage costs (see Section 4.4). 


\subsubsection{Storage in a Building}

Steel cylinders containing krypton-85 can be stored in a properly designed engineered storage facility. This technique has the advantage of ready surveillance, retrievability for isotope utilization and maintenance on the primary containment vesse1. Furthermore, such a facility utilizes existing technology. The major disadvantage of storage of krypton in an engineered facility is its high capital and operating costs.

\subsubsection{Description}

The reference krypton storage facility (KSF) was designed to hold krypton-filled cylinders for 50 years before venting the gas to the facility stack. This facility was intended to handle the output of the reference 2000 MTHM fuel reprocessing plant (FRP) and use the same support facilities and services. The reference FRP produces $\sim 145-42.5$ \& cylinders per year of krypton at a pressure of $34 \mathrm{~atm} .(3.4 \mathrm{MPa})$. The storage facility, shown in Figure 4.10, provides 14 storage cells that hold 104 cylinders each. The storage area increases in 10-year increments to a total of 42 cells holding a total of 4368 cylinders. The building is divided into two main parts: the operating area and the storage area. Cylinders are received from a shielded cask and transferred to the hot cell also used for examining gas-filled cylinders. From the hot cell the cylinders move down a central corridor to the storage cells through a gas-tight partition with an airlock.

Operating Area. The operating area consists of the receiving and unloading area, the hot cell, the hot cell operating area, the entrance to the storage room airlock, restrooms, and an equipment service and maintenance area.

Storage Area. Each storage area is a long narrow building, designed as a secondary containment to the cylinder storage cells. The storage cells are stainless-steel-lined, reinforced concrete, Category I structures. The cylinders are supported in a horizontal position on parallel bars. Access to each storage position is through a 25-cm-diameter carbon steel ball valve. Each storage cell is provided with self-contained air circulation and a heat 


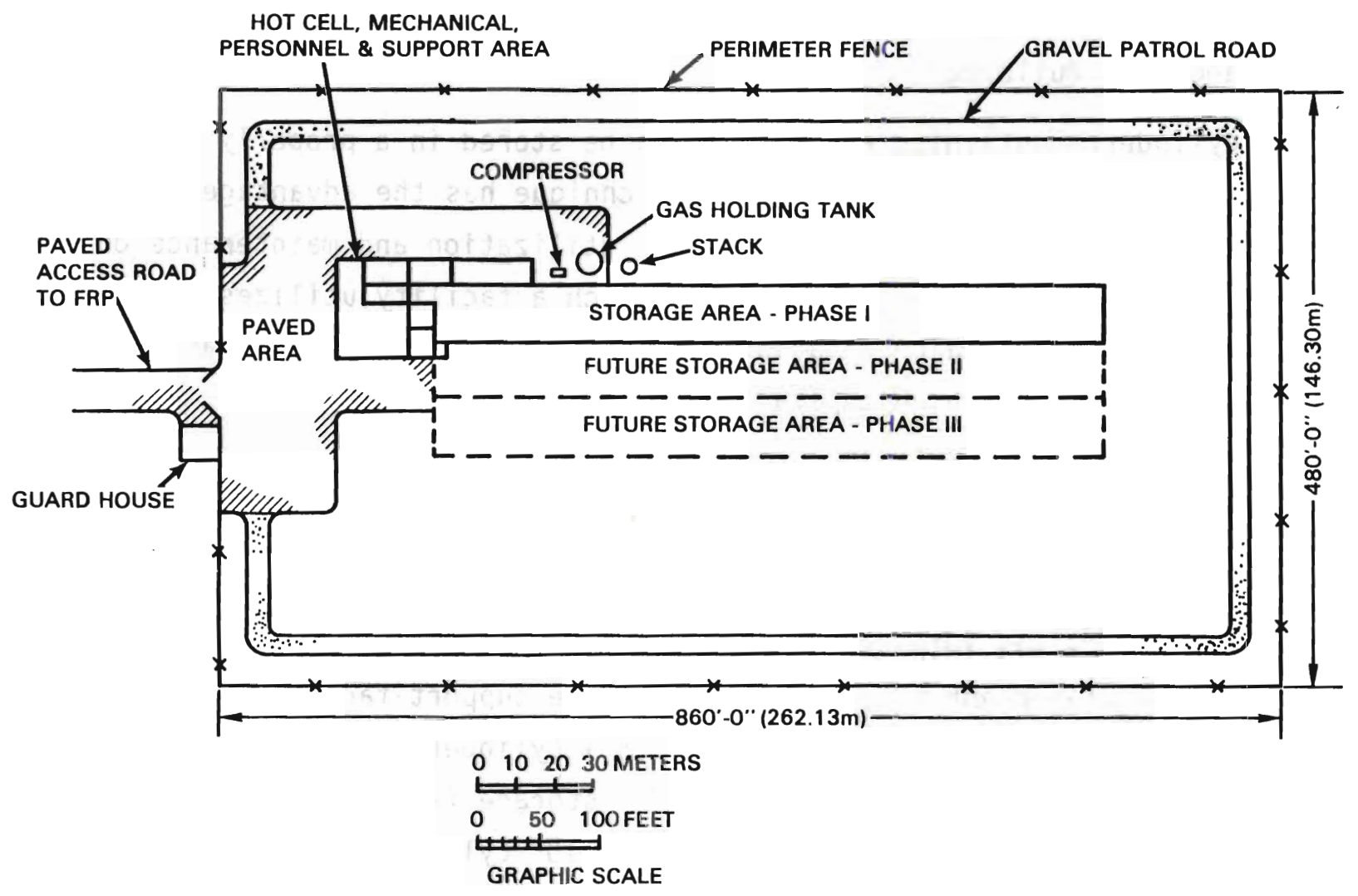

FIGURE 4.10. Krypton Storage Facility Plot Plan

exchanger. Other important features of the operation are the transfer casks, transfer carriages, overhead cranes, and ventilation system and radiation monitoring equipment. For a more complete description of the design and operation of this system the reader is referred to volume three of "Technology for Commercial Radioactive Waste Management."(21)

\subsubsection{Storage in a Drywell}

As a result of a study carried out at Sandia National Laboratories there are two options for the drywell storage concept: 1) a central repository using the SURF, drywell and facilities, and 2) a reprocessing plant (onsite) repository with drywells that would hold multiple 50-l canisters. (34) The drywells and canister-handling equipment can interchangeably accommodate krypton stored in compressed gas cylinders, krypton implanted in sputtered metals, or krypton entrapped in zeolites. 
Conceptual designs were completed for the two repositories. Sensitivity and optimization computer codes were developed to define the most costeffective drywell geometry, canister loading and solid waste form characteristics. In addition, a preliminary cost analysis was made on the immobilization/disposal system.

\subsubsection{Description of Central Repository}

The SURF drywell and canister modified for krypton-85 storage is shown in Figure 4.11. The well liner is a 45.7-cm-diameter standard pipe $5 \mathrm{~m}$ long. The liner is grouted in place in a 63.5-cm-diameter hole. A special gas bottle designated $310-L$ is designed for use in the SURF drywell. The cylindrical portion is made of $30-\mathrm{cm}$ std. wt. 316 stainless steel pipe. The elliptical end cap wall thickness is $1.27 \mathrm{~cm}$. The drywells are arranged in a square array on 3-m centers and are located at a spent fuel or high-level waste facility. The canister is attached to the shield plug at the hot cell, and the assembly is delivered to the drywell and inserted by a shielded transporter. In 1979, the spent fuel drywell and canister designs were modified to facilitate safe handling of the canister. $(35,36)$

\subsubsection{Description of Onsite Repository}

The design of the onsite repository is similar to that of the central repository, with major differences found in the drywell spacing, the number of canisters per well and the depth of burial. In addition, it was possible to optimize the insertion method for the particular ${ }^{85} \mathrm{Kr}$ waste form. The well liners are $25-\mathrm{cm}$ schedule 201030 carbon steel pipes. A 4-m spacing was found to be optimum for a multi-use repository. Figure 4.12 is a conceptual drawing of the onsite repository. With four canisters per well, the depth is $7.91 \mathrm{~m}$. A standard 316 stainless steel $42-\ell$ gas bottle rated at $16.5 \mathrm{MPa}$ (2400 psig) at room temperature was selected for disposal of ${ }^{85} \mathrm{Kr}$ or ${ }^{85} \mathrm{Kr} / \mathrm{Xe}$ mixture.

\subsubsection{Storage in a Deep Geologic Medium}

An alternative to storage of compressed gas cylinders in a building would be to use an abandoned mine shaft tunnel to replace the concrete outer 


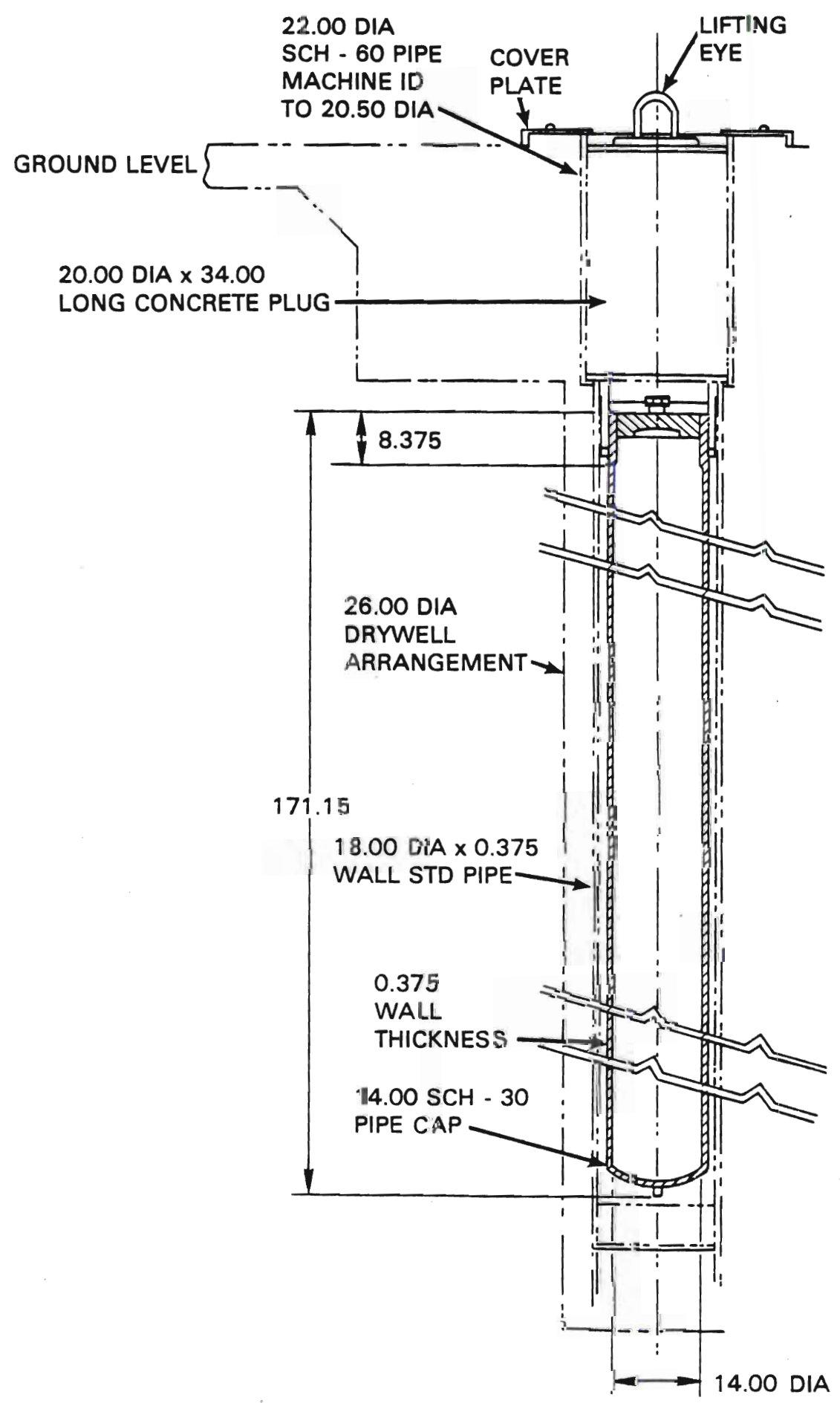

FIGURE 4.11. Surf Drywell Configuration (dimensions in inches) 


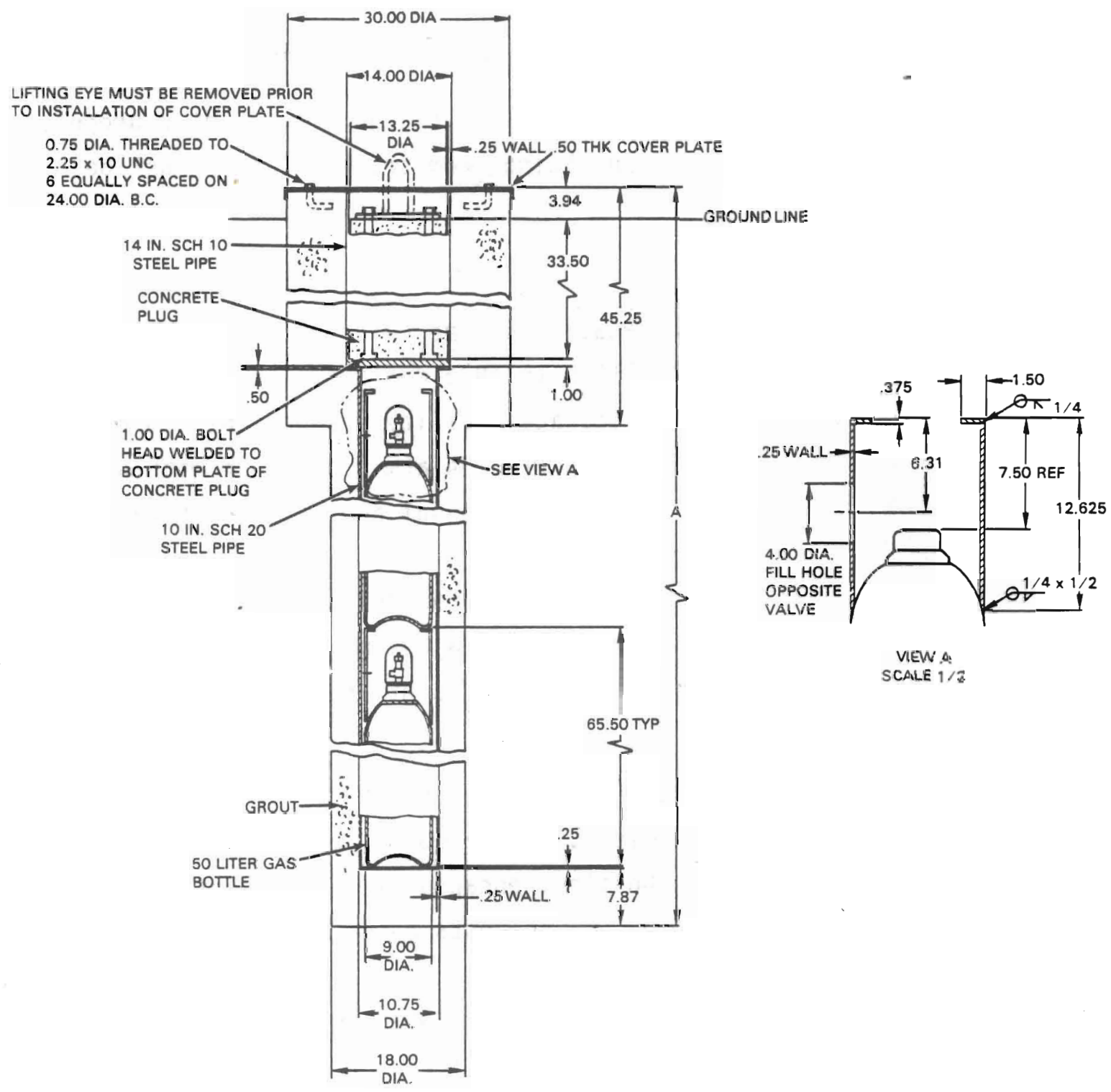

FIGURE 4.12. Onsite Drywell with 50- $\ell$ Gas Bottles (dimensions in inches) 
structure. This would still require the inner concrete cells and heat removal

equipment. A floor area of approximately 2 acres would be required. $(20,21)$

Since any geological site would be removed some distance from the reprocessing plant. the added costs and hazards resulting from transportation must be considered.

\subsubsection{Economic Comparison}

The capital cost estimate for Phase 1 of the Reference Krypton Storage Facility was estimated to be $\$ 75$ million in 1976 dollars. Phases 2 and 3 were estimated at $\$ 44$ million each. The storage facility was designed to receive one hundred four $42.5-\ell$ cylinders at $3.4 \mathrm{MPa}$ (34 atm.) per year with a total capacity of 5200 cylinders in 50 cells. The annual operating cost was estimated at $\$ 900,000 .(21)$ Thamer took these figures, corrected them to 1979 dollars and added the cost of a bottling room, the cylinder costs, and a $30 \%$ contingency to bring the total annual cost for a nominal year's loading of radioactive krypton to $\$ 7.1$ million. The details of Thamer's calculation are shown in Table 4.8.

The repository costs (in 1979 dollars) for optimized layouts of krypton stored in drywells are given in Table 4.9. The costs per cubic meter of krypton are listed for krypton in bottles, encapsulated in zeolites, and implanted in sputter-deposited alloys. The costs range from $\$ 100$ to $\$ 500$ per cubic meter except for the case where the Xe has not been separated, which raises the cost to $\$ 2000$ per cubic meter. The higher repository cost for the $\mathrm{Xe}-\mathrm{Kr}$ mixture could be more than offset by the lower separation cost. (34)

Bloemeke and Perona estimated the annual costs for noble gas bottling and storage in a salt mine for a 2500-ton/year reprocessing plant(37) to be $\$ 200,000$ in 1969 dollars. Thamer re-estimated the cost for an abandoned mine and for a horizontal tunnel, with the addition of a $30 \%$ contingency fee. The total annual cost was $\$ 7.7$ million (1979 dollars). 
TABLE 4.8. Annual Storage Costs for $169 \mathrm{~m}^{3}$ (STP) of Radiokrypton in a Reference Krypton Storage Facility

\begin{tabular}{|c|c|}
\hline & $\begin{array}{l}\text { Annual cost } \\
\text { (\$ thousands) }\end{array}$ \\
\hline Contribution of Capital Cost $=(1 / 30)(73,000)$ & 2,433 \\
\hline KSF Operating Expenses: During Loading & 1,100 \\
\hline During Subsequent Periods $=(50 / 30)(1,100)$ & $\underline{1,850}$ \\
\hline $\begin{array}{l}\text { Total for KSF Exclusive of Cylinders and } \\
\text { Bottling Room }\end{array}$ & 5,383 \\
\hline 145 Cylinders at $0.5 \$ \mathrm{~K}$ each $=145 \times 0.5$ & 73 \\
\hline \multicolumn{2}{|l|}{ Bottling Room: } \\
\hline \multicolumn{2}{|l|}{ Capital Costs: } \\
\hline $\begin{array}{l}\text { Room of } 1-1 / 2 \mathrm{ft} \text { Concrete }+3 \text { in. } \mathrm{Pb} \\
=(1 / 30)(250)\end{array}$ & 8 \\
\hline Compressor of $10-y r$ Life $=(/ 10)(30)$ & 3 \\
\hline Installation Costs $(100 \%)=8+3$ & 11 \\
\hline $\begin{array}{l}\text { Personnel Costs: One Operator Half-Time } \\
\quad=(1 / 2)(40)\end{array}$ & 20 \\
\hline Maintenance & 5 \\
\hline Total for KSF, Cylinders and Bottling Room & 5,503 \\
\hline Contingency $(30 \%)$ & 1,651 \\
\hline Total & 7,154 \\
\hline
\end{tabular}

\subsection{TRANSPORTATION}

Geologic disposal of krypton-85 would require shipment of the final waste form from the separation facility to the storage site. Bloemeke and Perona (37) proposed a water-filled, air-cooled shipping cask (see Figure 4.13) that would hold three $3.44 \mathrm{MPa}$ (500 psi) cylinders. A rail car would hold six casks each. Thamer, Macbeth and Rick(29) summarized the nonradiological hazards during 30 years of shipping cylinders to a geological disposal site. The results of this summary are found in Table 4.10. They considered the maximum credible radiological accident to be the release of $0.31 \mathrm{mCi}$ from three cylinders, and estimated a person remaining in the vicinity of the release for 10 seconds would receive a whole-body dose of 0.09 rem and a skin dose of 20 rem. 
TABLE 4.9. Repository Costs for Optimized Layouts

\begin{tabular}{|c|c|c|c|}
\hline Onsite Granitic Soil & $\$ / \mathrm{m}^{3} \mathrm{Kr}$ STP & Spacing $(m)(a)$ & Canisters/Well $(a)$ \\
\hline $\mathrm{Kr}$ Gas & 361 & $2-10$ & $1-8$ \\
\hline $\mathrm{Xe} / \mathrm{Kr}$ Gas & 1866 & $2-8$ & $3-8$ \\
\hline Sodalite & 373 & $1-2$ & $6-8$ \\
\hline 5A Zeolite & 193 & $1-2$ & $6-8$ \\
\hline Ni-La Sputtered Metal & 125 & $2-10$ & $1-8$ \\
\hline Fe-Y Sputtered Metal & 119 & $2-10$ & $1-8$ \\
\hline \multicolumn{4}{|l|}{ Onsite Hanford Soil } \\
\hline $\mathrm{Kr}$ Gas & 424 & $4-10$ & $1-8$ \\
\hline $\mathrm{Xe} / \mathrm{Kr}$ Gas & 2012 & $4-8$ & $3-8$ \\
\hline Sodalite & 394 & $2-4$ & $6-8$ \\
\hline 5A Zeolite & 207 & $2-4$ & $4-8$ \\
\hline $\mathrm{Ni}$-La Sputtered Metal & 160 & $2-10$ & $2-8$ \\
\hline Fe-Y Sputtered Metal & 151 & $4-10$ & $2-8$ \\
\hline Central Hanford Soil & & (fixed) & (fixed) \\
\hline $\mathrm{Kr}$ Gas & 383 & 5.18 & 1 \\
\hline $\mathrm{Xe} / \mathrm{Kr}$ Gas & 1868 & 5.18 & 1 \\
\hline Sodalite & 494 & 5.18 & 1 \\
\hline 5A Zeolite & 248 & 5.18 & 1 \\
\hline Ni-La Sputtered Metal & 195 & 5.18 & 1 \\
\hline Fe-Y Sputtered Metal & 182 & 5.18 & 1 \\
\hline
\end{tabular}

(a) Within $5 \%$ of minimum cost. 


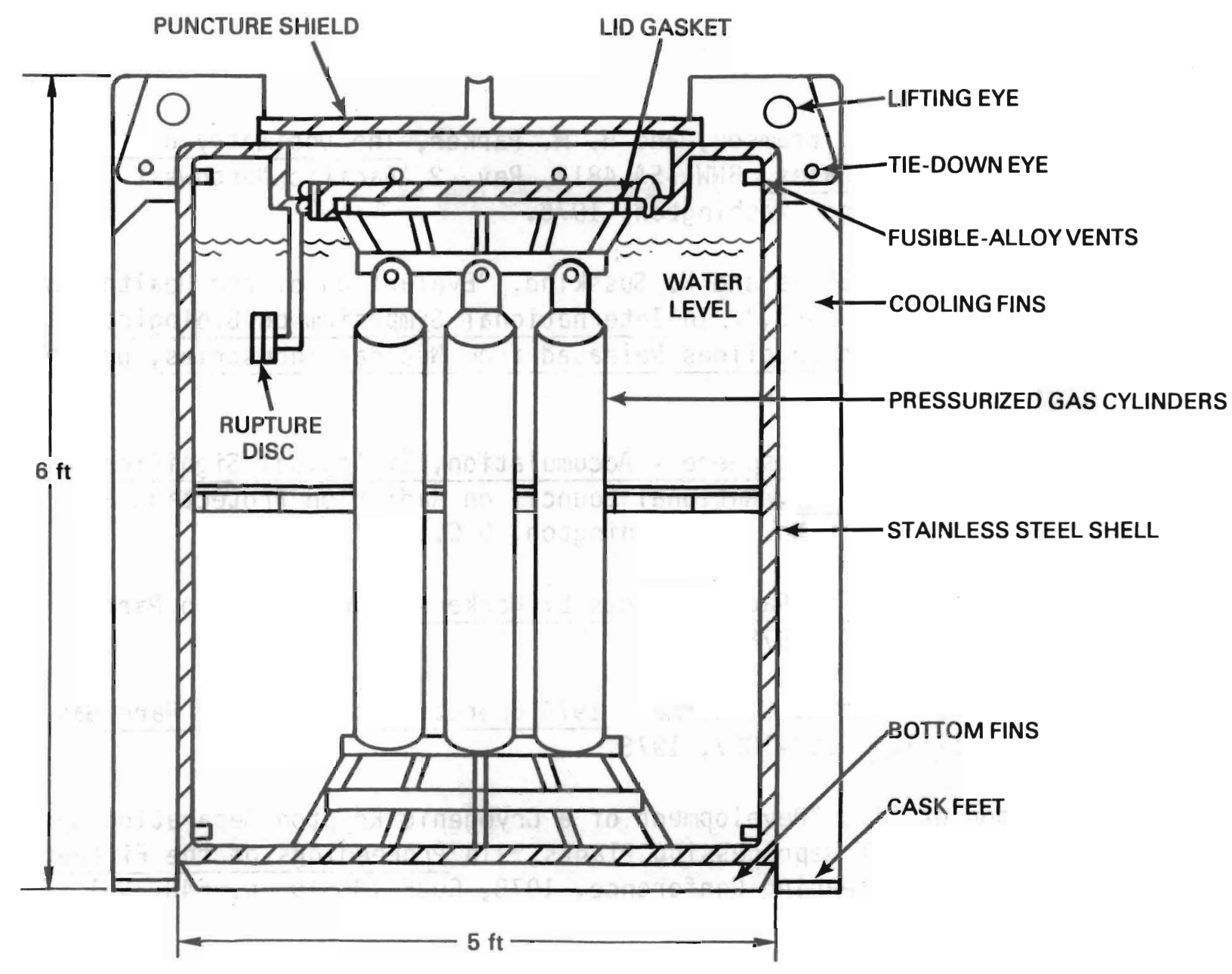

FIGURE 4.13. Conceptual Design of Shipping Cask for Cylinders of Compressed Krypton-85

TÁBLE 4.10. Nonradiological Transportation Hazards During 30 Years, with
Cylinders of Pressurized Gas in a Geologic Facility 38,39$)$

$\begin{array}{lcc} & \text { Eastern Site } & \text { Western Site } \\ \begin{array}{c}\text { Average Transit Distance } \\ \text { (mi) to Disposal Site }\end{array} & 1,000 & 2,000 \\ \text { Total Train Car Distance (mi) } & 230,000 & 460,000 \\ \text { Total Projected Accidents } & 0.03 & 0.07 \\ \text { Total Projected Injuries } & 0.09 & 0.2 \\ \text { Total Projected Fatalities } & 0.02 & 0.03\end{array}$




\section{REFERENCES}

1. J. K. Soldat, P. E. Bramson, and H. M. Parker, The Dosimetry of the Radioactive Noble Gases, BNWL-SA-4813, Rev. 2, Pacific Northwest Laboratory, Richland, Washington, 1976.

2. S. H. Cohn, K. J. Ellis and H. Susskind, "Evaluation of the Health Hazard from Inhaled Krypton-85," In International Symposium on Biological Implications of Radionuclides Released from Nuclear Industries, pp. 2630, Vienna, 1979.

3. Krypton-85 in the Atmosphere - Accumulation, Biological Significance, and Control Technology, National Council on Radiation Protection and Measurements, Report No. 44, Washington, D.C., 1975.

4. Limits for Intakes of Radionuclides by Workers, Supplement to Part 1, ICRP Publication 30, 1978.

5. C. L. Bendixsen and F. 0. German, 1974 Operation of the ICPP Rare Gas Recovery Facility, ICP-1057, 1975.

6. R. V. Ammon et al., "Development of a Cryogenic Krypton Separation System for the Off-Gas of Reprocessing Plants," In Proceedings of the Fifteenth DOE Nuclear Air Cleaning Conference, 1978, CONF-780819, p. 640, Vol. II, 1979.

7. A. Chesne et a1., "Progress Report on French Research and Development in the Treatment of Off-Gases from Reprocessing Plants," In Proceedings of the International Symposium on Management of Gaseous Wastes from Nuclear Facilities, Vienna, February 1980, IAEA-SM-245/49.

8. G. E. R. Collard, "Occupational Experience with a $25 \mathrm{~m}^{3} / \mathrm{h}$ Simulated Dissolver Off-Gas Purification Loop," In Proceedings of the International Symposium on Management of Gaseous Wastes from Nuclear Facilities, Vienna, February 1980, IAEA-SM-245/49.

9. R. A. Brown et al., "Reference Facility Description for the Recovery of Iodine, Carbon, and Krypton from Gaseous Wastes," Report ICP-1126, National Technical Information Service, U.S. Dept. of Commerce, Springfield, Virginia, 1978.

10. D. K. Little et al., "Noble Gas Removal and Concentration by Combining Fluorocarbon Absorption and Adsorption Technologies," In Proceedings of the Seventeenth DOE Nuclear Air Cleaning Conference, 1982, CONF-820851 (In Press). 
11. M. J. Stephenson, and R. S. Eby, Development of the Faster Process for Removing Krypton-85, Carbon-14, and Other Contaminants from the Off-Gas Fuel Reprocessing Plants, U.S. DOE, Rep. k/GD-1398, 1976.

12. E. Henrich, Selective Absorption of FB Noble Gases from the DOG in Liquid R-112 at Atmospheric Pressure, Institute $f$ ü $r$ Heibe Chemil, Kernforschungszentrum, Karlsruhe, Federal Republic of Germany, 1982.

13. R. S. Eby, "The Desublimation of Krypton from a Noncondensible Carrier Gas," M. S. Thesis, The University of Tennessee, Knoxville, Tennessee, 1978.

14. V. G. Fastouskii et al., Inert Gases, Report AEC-tr-6725, U.S. Atomic Energy Commission, (Transiation), 1967.

15. D. T. Pence, and B. E. Kirstein, A Design and Cost Estimate for the SRL Integrated Hot Off-Gas Facility Using Selective Absorption, Science Application, Inc., San Diego, California, 1981.

16. R. S. Eby et al., "Single Column Based Absorption Process for Treating Dissolver Off-Gas," Presented at the Workshop on Integrated Dissolver Off-Gas Treatment Technology, Karlsruhe, Federal Republic of Germany, 1982.

17. R. C. Waggoner, Technical and Economic Evaluation of Processes for Krypton-85 Recovery from Power Fuel Reprocessing Plant Off-Gas, DP-1637, 1982.

18. U.S. Energy Research and Development Administration, Alternatives for Managing Wastes from Reactors and Post-Fission Operations in the LWR Fuel Cycle, ERDA-76-43, pp. 14.1-14.7, 1976.

19. C. L. Bendixsen and D. A. Knecht, "Separation and Storage of Krypton," In Proceedings of the International Symposium on the Management of Wastes from the LWR Fuel Cycle, CONF-760701, p. 343, 1976.

20. U.S. Department of Energy, Draft Environmental Impact Statement: Management of Commercially Generated Radioactive Waste, DOE/EIS-0046-D, Washington, D.C., 1979.

21. U.S. Department of Energy, Technology for Commercial Radioactive Waste Management, D0E/ET-0028, Washington, D.C., 1979.

22. D. W. Whitmell, "Immobilization of Krypton in a Metallic Matrix," Nucl. Energy, 21(3):181-187, June 1982 . 
23. G. L. Tingey et al., Krypton-85 Storage In Sputter-Deposited Amorphous Metals, PNL-SA-10536, Pacific Northwest Laboratory, Richland, Washington.

24. G. L. Tingey et al., "Solid State Containment of Noble Gases in SputterDeposited Metals and Low Density Glasses," In Proceedings of the International Symposium on the Management of Gaseous Wastes from Nuclear Facilities, Vienna, February 1980, IAEA-SM-245/31.

25. R. A. Brow et al., "85 Kr Storage by Zeolite Encapsulation," In Proceedings of the Fourteenth ERDA Air Cleaning Conference, 1976, CONF-76 0822, Vol. 1, pp. 118-131, NTIS, Springfield, Virginia, 1977.

26. R. W. Benedict et al., Technical and Economic Feasibillity of Zeolite Encapsulation for Krypton-85 Storage, ENIC0-1071, 1979.

27. R. D. Penzhorn et al., "Fixation of Krypton-85 in Zeolites," In Proceedings of the International Symposium on Management of Gaseous Wastes from Nuclear Facilities, Vienna, February 1980, IAEA-SM-245/10.

28. B. J. Thamer, C. M. Mihlfeith and P. J. Macbeth, The Evaluation of Alternatives for the Ul timate Disposal of Krypton-856: Task 1-A Compilation of Alternatives, UC-261-01, Ford, Bacon and Davis Inc., Salt Lake City, Utah, 1979.

29. B. J. Thamber, P. J. Macbeth and D. C. Rich, The Evaluation of Alternatives for the Ultimate Disposal of Krypton-85: Tasks 2 and 3 the Evaluation of Storage Techniques and Ultimate Disposal, UC-261-03, Ford, Bacon and Davis, Inc., Salt Lake City, Utah, 1979.

30. T. R. Pinchback, Materials Screening Tests for the Krypton-85 Storage Development Program, TREE-1291, 1979.

31. R. W. Benedict et al., Technical and Economic Feasibility of Zeolite Encapsulation for Krypton-85 Storage, ENICO-1011, 1979.

32. G. L. Tingey et al., "Solid State Storage of Radioactive Krypton in a Silica Matrix," American Ceramic Society, 65(1):5-9, 1982.

R. A. Brown, M. Hoza and D. A. Knecht, $" 85_{\mathrm{Kr}}$ Storage by Zeolite Encapsulation," In Proceedings of the Fourteenth ERDA Air Cleaning Conference, 1976, CONF-760822, Vol. 1, pp. 118-131, NTIS, Springfield, Virginia.

33. Design Documentation - Krypton Encapsulation Preconceptual Design Phase: Final Report, No. 6154-3-1, The Ralph M. Parsons Co., Pasadena, California, 1981. 
34. R. D. Klett, Krypton-85 Disposal Program - Conceptual Design Phase: Final Report, SAND 81-1957, Sandia National Laboratories, Albuquerque, New Mexico, 1981.

35. M. S. Bensky et al., Spent Fuel Storage and Isolation, RH0-SA-102, Rockwell Hanford Operations, Richland, Washington, 1979.

36. Drywell Storage Facility Conceptual Design Study, Rockwell Hanford Operations and Kaiser Engineers, No. 79-8-R, 1979.

37. J. 0. Bloemeke and J. J. Perona, Management of Noble-Gas Fission-Product Wastes from Reprocessing Spent Fuels, ORNL-TM-2677, Oak Ridge National Laboratory, Oak Ridge, Tennessee, 1969.

38. Environmental Survey of Transportation of Radioactive Materials to and from Nuclear Power Plants, WASH-1238, 1972.

39. "Accident Facts - 1977 Edition," National Safety Council, Illinois, 1977. 



\subsection{TRITIUM CONTROL TECHNOLOGY}

Many comprehensive reviews have been written on tritium, its sources, behavior, methods of control, and disposal. The technical papers that have been prepared on the subject number well into the thousands. The purpose of this section is to give an overview of the state-of-the-art of tritium control. References are presented to provide additional information.

\subsection{TRITIUM CHARACTERISTICS}

This section presents information on the physical, chemical and radiological properties of tritium.

\subsubsection{Chemical and Physical Form}

Tritium, the mass 3 isotope of hydrogen, is the only radioactive one. Its natural production is largely by cosmic rays. The principal end product is tritiated water, HTO, most of which finds its way to the ocean. Aside from HTO, the most abundant tritium species is the gas, HT. All isotopic combinations of both water and gas exist and may occur in appreciable amounts in different situations. Although the detailed chemistry and physical properties of these forms such as HT, DT, HTO, $\mathrm{T}_{2} \mathrm{O}$, and DTO are sufficiently different that isotopic separation can easily be achieved, for purposes of control or disposal, the differences are negligible. Thus, the chemistry of tritium is that of hydrogen and of water. A third chemical form of considerable significance is tritiated methane, $\mathrm{CH}_{3} \mathrm{~T}$. Other tritiated molecules exist and indeed the presence of tritium gas together with organic materials of any form will ensure the production of tritiated organic molecules. However, insofar as releases of radionuclides are concerned, the important species are tritiated hydrogen, water, and methane.

\subsubsection{Sources of Tritium}

Table 5.1 lists common source reactions for tritium. The first four are involved in cosmic ray production of tritium. These and reactions 5, 6, and 12 are of interest in high-energy physics studies. The remaining reactions 
TABLE 5.1. Tritium-Producing Reactions

$$
\begin{aligned}
& \text { 1. } 14_{N}+n+3_{H}+12_{C} \\
& \text { 2. } 16_{0}+n+3_{H}+14_{N} \\
& \text { 3. } 14_{N}+p+3_{H}+12_{N} \\
& \text { 4. } 160+p+3_{H}+14_{0} \\
& \text { 5. } 9 \mathrm{Be}+d+3_{H}+8_{B e} \\
& \text { 6. } 2 \mathrm{H}+d+3_{H}+p \\
& \text { 7. } 6 \mathrm{Li}+n+3_{H}+4_{H e} \\
& \text { 8. } 10_{\mathrm{B}}+n+3_{\mathrm{H}}+8_{\mathrm{Be}} \\
& \text { 9. } 11_{\mathrm{B}}+n+3_{\mathrm{H}}+9_{\mathrm{Be}} \\
& \text { 10. } 2 \mathrm{H}+n+3_{\mathrm{H}} \\
& \text { 11. U, Pu, Th, fission } \\
& \text { 12. Photonuclear (r, } \left.3_{\mathrm{H}}\right)
\end{aligned}
$$

represent major contributions of tritium from the nuclear industry. Reactions 7,8 , and 9 are used for reactor control; reaction 10 is responsible for tritium production in heavy water moderated reactors; and reaction 11 is the primary source of tritium in the nuclear fuel cycle. Reaction 7 is utilized for production of large quantities of tritium.

The fission yield of tritium varies from about 0.9 atoms per $10^{4}$ fissions for thermal fission of $235 \mathrm{U}$ to about 2.2 for fast fission of $239 \mathrm{Pu}$. (1) This translates to about $1.5-2 \times 10^{4} \mathrm{Ci} / \mathrm{GWe}-\mathrm{yr}$.

Table 5.2 lists typical tritium production and release data for different reactor types. (2) There is considerable variation in the yields from neutron activation. Production and release data are discussed in more detail by Trevorrow(3) and Bonka.(4) Tritium distribution by source is reviewed by Brown et al.(5) Most is produced in water form. Bonka (4) estimates that 5$20 \%$ of reactor emissions are to the atmosphere.

Most of the tritium is retained in the fuel until it is reprocessed. The exception is the stainless clad fuels for which the tritium largely diffuses into the coolant. No head-end facilities that could remove and isolate 
TABLE 5.2. Tritium Production Rates(a)

\begin{tabular}{|c|c|c|c|}
\hline \multirow[b]{2}{*}{ Reactor Type } & \multicolumn{2}{|c|}{$\begin{array}{l}3 \mathrm{H} \text { Production, } \\
\mathrm{Ci}(\text { GWe }-y r)^{-1} \\
\end{array}$} & \multirow{2}{*}{$\begin{array}{l}3_{\mathrm{H}} \text { Release to Air } \\
\frac{\mathrm{Ci}(\text { GWe-yr) }}{}{ }^{-1} \\
\text { From Reactor }\end{array}$} \\
\hline & Fission & $\mathrm{n}$ Activation & \\
\hline PWR & $2 \mathrm{E} 04$ & $1 \mathrm{E} 03$ & $1 \mathrm{E} 02$ \\
\hline BWR & $2 \mathrm{E} 04$ & 0 & $6 \mathrm{E} 01$ \\
\hline HWR & $2 \mathrm{E} 04$ & 2.4E06 & $1.6 \mathrm{E} 04$ \\
\hline AGR & 2E04 & 2.4E06 & $1.6 \mathrm{E} 04$ \\
\hline HTGR & $2 \mathrm{E} 04$ & $\sim 3 E 03$ & -- \\
\hline FBR & 3E04 & $<2 E 03$ & \\
\hline
\end{tabular}

(a) Table 1, Reference 2 .

tritium are in place at fuel reprocessing plants (FRP). Thus, the bulk of the fission tritium (estimated at $40-80 \%$ for LWRs) is released when the fuel is dissolved, and is normally released to the atmosphere as water vapor. The remainder of the tritium is retained in the cladding hulls. If the cladding is melted, as for consolidation of hulls, the tritium is then released as $T_{2}$ and HT.

\subsubsection{Distribution of Tritium}

The present distribution of tritium is given in Table 5.3.(6) The present tritium level in the world is an order of magnitude higher than the natural steady state due to bomb testing two decades ago. Most of the world's tritium is in the ocean as HTO. However, it is interesting that the portion in the troposphere may contain more HT than HTO, and that the portion as methane is significant. Oxidation of $H T$ and $\mathrm{CH}_{3} \mathrm{~T}$ to HTO is slow. Both photochemical and biological reactions remove them from the troposphere. The residence time is estimated to be $4-10$ years. (6)

\subsubsection{Radiochemical and Radiological Properties}

Tritium decays to ${ }^{3} \mathrm{He}$ with a $0.018 \mathrm{MeV} \beta$. The mean $\beta$ energy is 0.0057 $\mathrm{MeV}$, and no $\gamma$-rays are emitted. The half-life is 12.3 years. The external radiation hazard is trivial. Waterforms, HTO, DTO, and $\mathrm{D}_{2} \mathrm{O}$, present

\section{3}


TABLE 5.3. Distribution of Tritium

Mixed ocean layer top

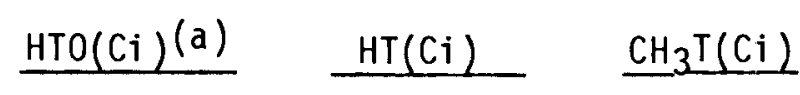

$100 \mathrm{~m} 3.6 \mathrm{E} 19 \mathrm{~kg} \mathrm{H}_{2} \mathrm{O}$

9E08

(1-10)E03

Troposphere

$3.8 \mathrm{E} 18 \mathrm{~kg}$ air

(2-8)E06

(8-18)E06

(2-6)E05

Stratosphere

$1.3 \mathrm{E} 18 \mathrm{~kg}$ air

$(0.6-5) E 08$

$(1-4)$ E06

$<1 \mathrm{E} 05$

(a) $1 \mathrm{Ci}=3.7 \mathrm{E} 10 \mathrm{~Bq}$.

inhalation and ingestion hazards as the tritium is easily assimilated by biological materials. Fortunately, the biological half-life is short, on the order of 8-10 days.

Because of the low solubility of hydrogen gas, and its low reaction rates, the biological effectiveness of elemental tritium forms is lower by a factor of $10^{3}-10^{4}$ than for HTO. Thus, exposure calculations emphasize tritiated water. Evans(7) calculates that chronic exposure of a $70 \mathrm{~kg}$ man to a concentration of $1 \mu \mathrm{Ci} / \ell$ in the body water $(60 \mu \mathrm{Ci}$ total) would result in an annual dose of $97 \mathrm{mrem}(0.97 \mathrm{mSv})$. From the data of Table 5.3, it is seen that the concentration of HTO in tropospheric air is $1-3 \times 10^{-15} \mathrm{Ci} / \mathrm{l}$ in air or about $2-6 \times 10^{-10} \mathrm{Ci} / \ell$ of water in the air $\left(5^{\circ} \mathrm{C}\right.$ dewpoint in the air). So the annual dose from HTO is about $2 \times 10^{-2}$ mrem. Evans assumes a quality factor of 1.0 for tritium $\beta$. There is some evidence that it may be slightly higher than unity.

\subsection{EXISTING CONTROL TECHNOLOGIES}

Because of the greatly different biological effectiveness of elemental tritium (e.g., HT) compared to water forms (e.g., HTO), the control philosophy for each may be quite different. At concentration levels of maximum permissible concentration (MPC) magnitude, it is the water form that is of primary concern. Because of the rapid dispersion of hydrogen and its slow conversion to water, small concentrations of HT are innocuous and may be 
released. It is almost ironic that $\mathrm{HT}$ or $\mathrm{T}_{2}$ at low concentrations must be converted to water form in order to be effectively trapped. Following the oxidation, the crucial step then becomes water removal.

In fusion and other research employing large amounts of tritium and in industrial use, the elemental form is predominant. In nuclear fuel reprocessing, on the other hand, unless a reductive head-end step is employed, virtually all the tritium is released from the fuel as HTO. An exception may occur where metallic fuels are processed. In this case, considerable HT and $\mathrm{NH}_{2} \mathrm{~T}$ have been reported. There is no existing technology for controlling tritium from reprocessing plants, but potential ones exist.

\subsubsection{Oxidation Followed by Water Sorption}

In this process, gaseous tritium is oxidized to tritiated water, which is then absorbed in an appropriate water absorber. Potential processes are described below.

\subsubsection{Description of Process}

Catalytic. Palladium or platinum on a high surface area material such as a molecular sieve or ceramic is an excellent catalyst for conversion of hydrogen forms to water in air or oxygen. In practice, hydrogen is often added as an isotopic diluent before the oxidation step. Water may be added before the drying step. The Los Alamos Tritium Systems Test Assembly (TSTA) illustrates the state-of-the-art.(8) The emergency system handles $0.5 \mathrm{~m}^{3}$ air/s at $3.5 \mathrm{~atm}$. Operating temperature is $450^{\circ} \mathrm{K}$. The catalyst bed consists of $0.225 \mathrm{~m}^{3}$ of $3-\mathrm{mm}$ by $3-\mathrm{mm}$ pellets containing noble metals. The vessel is $0.91 \mathrm{~m}$ diameter by $1.82 \mathrm{~m} \mathrm{tall}$, and is constructed of 316 stainless steel.

To maintain high conversion efficiency, hydrogen is added to the airstream to maintain a concentration of $1000 \mathrm{vppm}$ hydrogen. The oxidizer reduces the level to $1 \mathrm{vppb}$.

The air passes through a cooler, reducing the temperature to $294^{\circ} \mathrm{K}$, then to a condenser to remove as much water as possible before the air reaches the molecular sieve dryers. The dryer system has two stages, with provision for 
adding $\mathrm{H}_{2} \mathrm{O}$ between stages. The dryers have a $1.4-\mathrm{m}$-deep bed of molecular sieve material in a 1.06-m-diameter vessel. The sieve material is type $4 \mathrm{~A}$ (Linde) in $1.5-\mathrm{mm}$ beads. The beds may be regenerated by passing heated air through them and condensing the water. The TSTA design calls for a flow of $0.4 \mathrm{~m} / \mathrm{s}$ at $3.5 \mathrm{~atm}$ at a nominal bed temperature of $478^{\circ} \mathrm{K}$. Other sites may use different molecular sieves (e.g., type 13X).

When tritiated hydrocarbons are present, a higher catalytic temperature must be employed. The TSTA waste treatment process operates on a batch mode from a holding tank, and the catalyst may operate at about $475^{\circ} \mathrm{K}$ (normal) or about $755^{\circ} \mathrm{K}$ (for hydrocarbon combustion). Other workers have used even higher temperatures, e.g., $873^{\circ} \mathrm{K}$ at the Mound Facility. (9)

Tritiated water recovered from the treatment is stored in double-walled stainless steel vessels.

Metal 0xides. In gaseous streams containing no air or oxygen, sufficient $\mathrm{O}_{2}$ can be added, carefully monitored to stay below the explosive limit. Alternatively, an oxide converter can be used to oxidize the tritium to the water form. The standard material for the latter process is a modified copper oxide such as DOW Q-1 ${ }^{\circledR}$ or Hopcalite. ${ }^{\circledR}$ The normal working temperature for a Hopcalite ${ }^{\circledR}$ bed is 773 to $973^{\circ} \mathrm{K}$, the latter temperature being preferred if hydrocarbons are present. The bed may be regenerated at $573-773^{\circ} \mathrm{K}$ with air. (9) Water produced in the oxidation is trapped with molecular sieve as described above.

\subsubsection{Waste Forms and Disposal}

Burial practices for these materials have employed shallow-land burial. Where large quantities of tritium are involved (e.g., 10-30 Ci in vials used for signs), it is first encased in concrete. Sites working with larger amounts have developed multiple wall drums containing both impermeable shields and water sorbents. At Los Alamos National Laboratory, the matrix material containing the tritiated water, e.g., zeolite, is first encapsulated in bitumen (asphalt) before being deposited in deep shafts. 


\subsubsection{Specifications}

The removal efficiencies and retention factors (RFS) depend both on the construction of the units (bed depth, particle size) and operating parameters ( $f$ low rate, temperature, addition of $\mathrm{H}_{2}$, addition of $\mathrm{H}_{2} \mathrm{O}$ before water absorbers, etc.). Thus, no specific RF or residual concentration can be given. However, an RF of $>10^{6}$ is attainable for most systems, and tritium levels can be reduced to below the normal detection level of an ionization counter, $\sim 0.1-1 \mu \mathrm{Ci} / \mathrm{m}^{3}$.

\subsubsection{Other Technologies}

None.

\subsection{POTENTIAL CONTROL TECHNOLOGIES}

This section describes technologies that could potentially be employed to control tritium emissions.

\subsubsection{HT or T 2 Removal}

No alternatives have been developed. Large quantities at high concentrations are normally sequestered by forming a metal tritide such as with $U, \mathrm{Zr}$, or $\mathrm{Tl}$. This technique is applicable to storage and purification. Catalyzed addition to unsaturated organic compounds has been examined on a laboratory scale.

\subsubsection{Conversion of HTO to HT Followed by Release}

Small quantities of HTO could be electrolyzed to HT and $\mathrm{O}_{2}$ or converted with metals to HT and the metal oxide, and the resulting HT could be released to the atmosphere. Because of the greatly reduced biological hazard of the hydrogen form and the rapid dispersion, this is a perfectly feasible approach; however, it has not been practiced.

\subsubsection{Tritium Control in Nuclear Fuel Reprocessing}

At the present time, the tritium produced in nuclear fuels is released at the reprocessing plant, normally as water vapor. Although it is not likely 
that control measures will be used in the near future, considerable study has been directed to the containment of tritium in processing of LWR and LMFBR fuels. Although much development work has been done, no process has been demonstrated in an actual fuel processing operation.

The amount of tritium delivered to the reprocessing plant varies from about 500-700 Ci/ton for LWR fuel to about $85 \mathrm{Ci} /$ ton for LMFBR fuel. These numbers will vary considerably depending on reactor conditions and fuel purity, e.g., lithium content.

\subsubsection{Methods of Control}

The alternatives for tritium control in reprocessing have been discussed by Burger and Scheele(10), by McKay, (1) and more recently by Grimes et al. (11) Figure 5.1 shows the options. They can be described by: nonaqueous processing, aqueous with head-end treatment, aqueous with water recycle, and isotopic separation, or various combinations. Nonaqueous methods for reprocessing--pyrochemical or fluorination--have received considerable attention but are not under study at the present time and will not be considered here.

Head-End Processes. The goal of these processes is to remove tritium before the fuel is converted to the solvent extraction feed solution, keeping it separated from the large aqueous volume of the separations plant. Two processes have been studied, voloxidation and thermal outgasing. The former uses oxidation to convert the $\mathrm{UO}_{2}$ to $\mathrm{U}_{3} \mathrm{O}_{8}$ at $723-773^{\circ} \mathrm{K}$ and releases the tritium as HTO. The latter process employs a higher temperature and an inert sweep gas with or without a small amount of hydrogen present. Voloxidation has been extensively investigated at Oak Ridge National Laboratory. The system is illustrated in Figure 5.2.(11) Engineering and operational problems have prevented its wide acceptance. Thermal outgasing has been studied at the Pacific Northwest Laboratory. (12) It has been shown to remove virtually all the tritium, but as HT instead of HTO. The principal disadvantage is the high temperature employed in the fuel treatment, up to $1500^{\circ} \mathrm{C}$. A suggested flowsheet is shown in Figure 5.3. (12) 


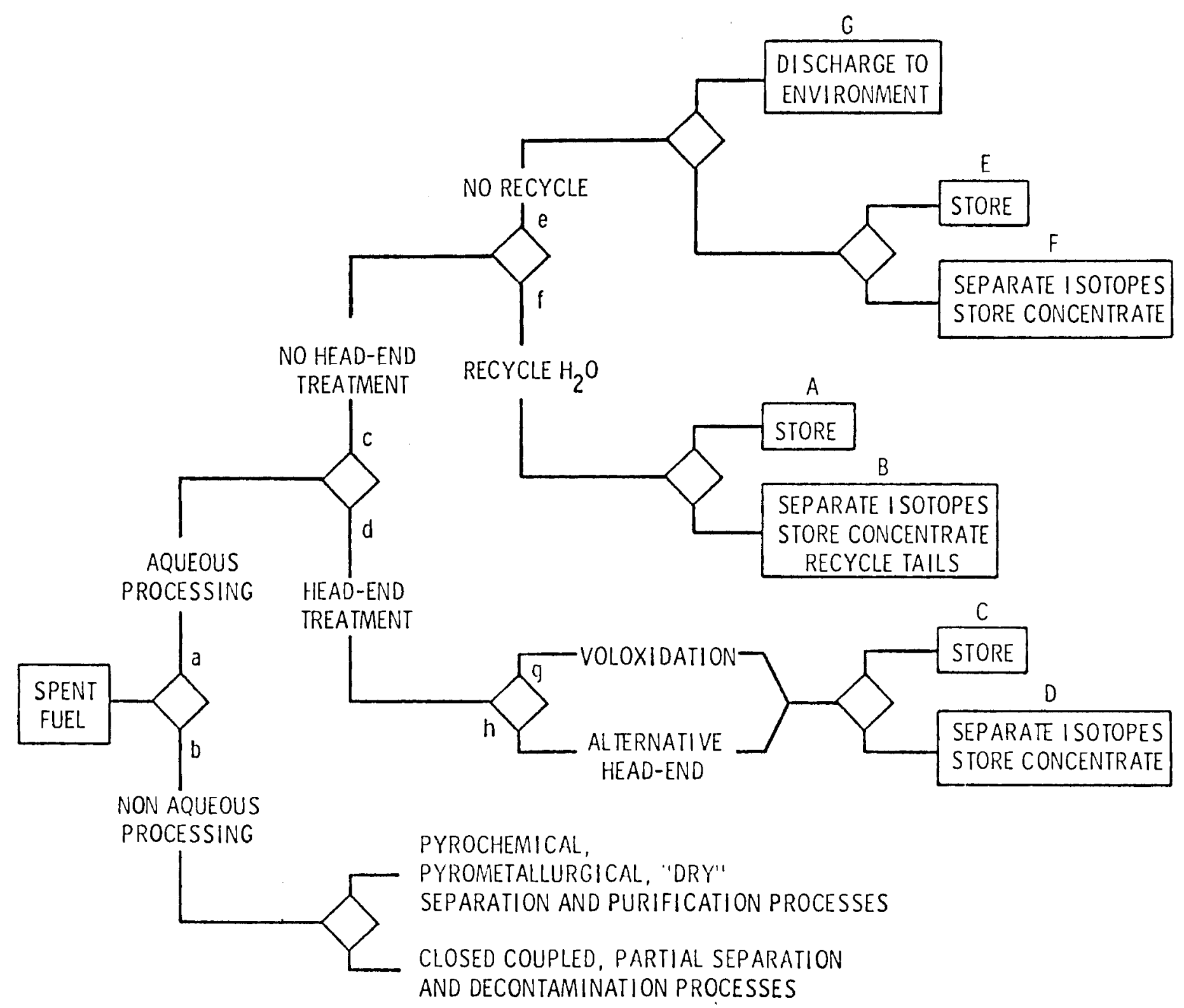

FIGURE 5.1. Alternatives for Tritium Management 


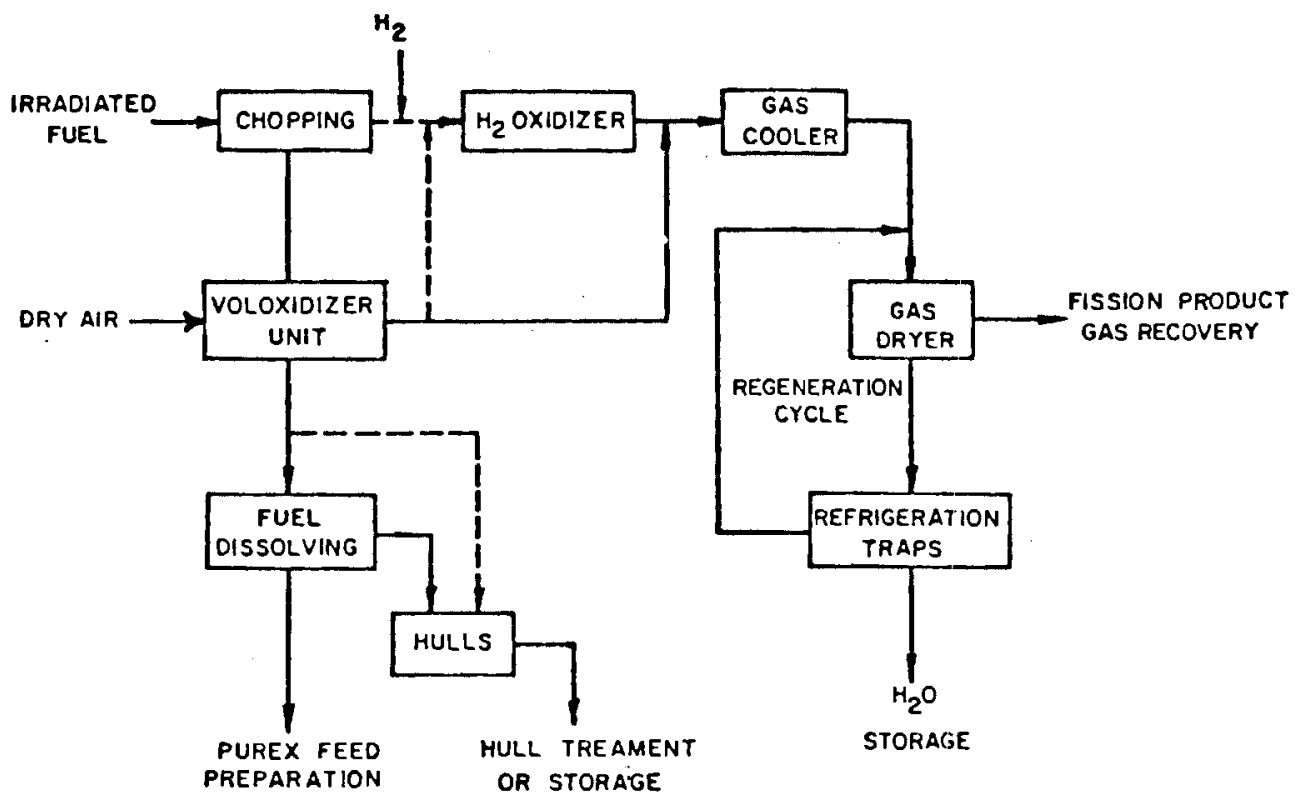

FIGURE 5.2. Voloxidation Process Schematic

- Water Recycle. A separation plant operating on a nominal 1500 ton/yr basis may use $20-100 \mathrm{~m}^{3} \mathrm{H}_{2} \mathrm{O}$ per day. With no head-end tritium removal, the $500-700 \mathrm{Ci} /$ ton of tritium in the fuel is rapidly distributed throughout the reprocessing plant. It is unrealistic to attempt to remove tritium at the resulting level, $<0.1 \mathrm{Ci} / \ell$, from a water stream of this size. If the bulk of the water is recycled, the concentration may be permitted to build up and a portion bled off for storage or treatment. The recycle concept becomes much more attractive if the tritium is confined to the first solvent extraction cycle, thus greatly reducing the volume of water to be processed. The method has intrigued many workers. $(10,13-16)$

- Isotope Separation. The alternative to concentrating the tritium in the water by recycle in the reprocessing plant is to use isotope separation to remove most of the tritium before discharge of the 


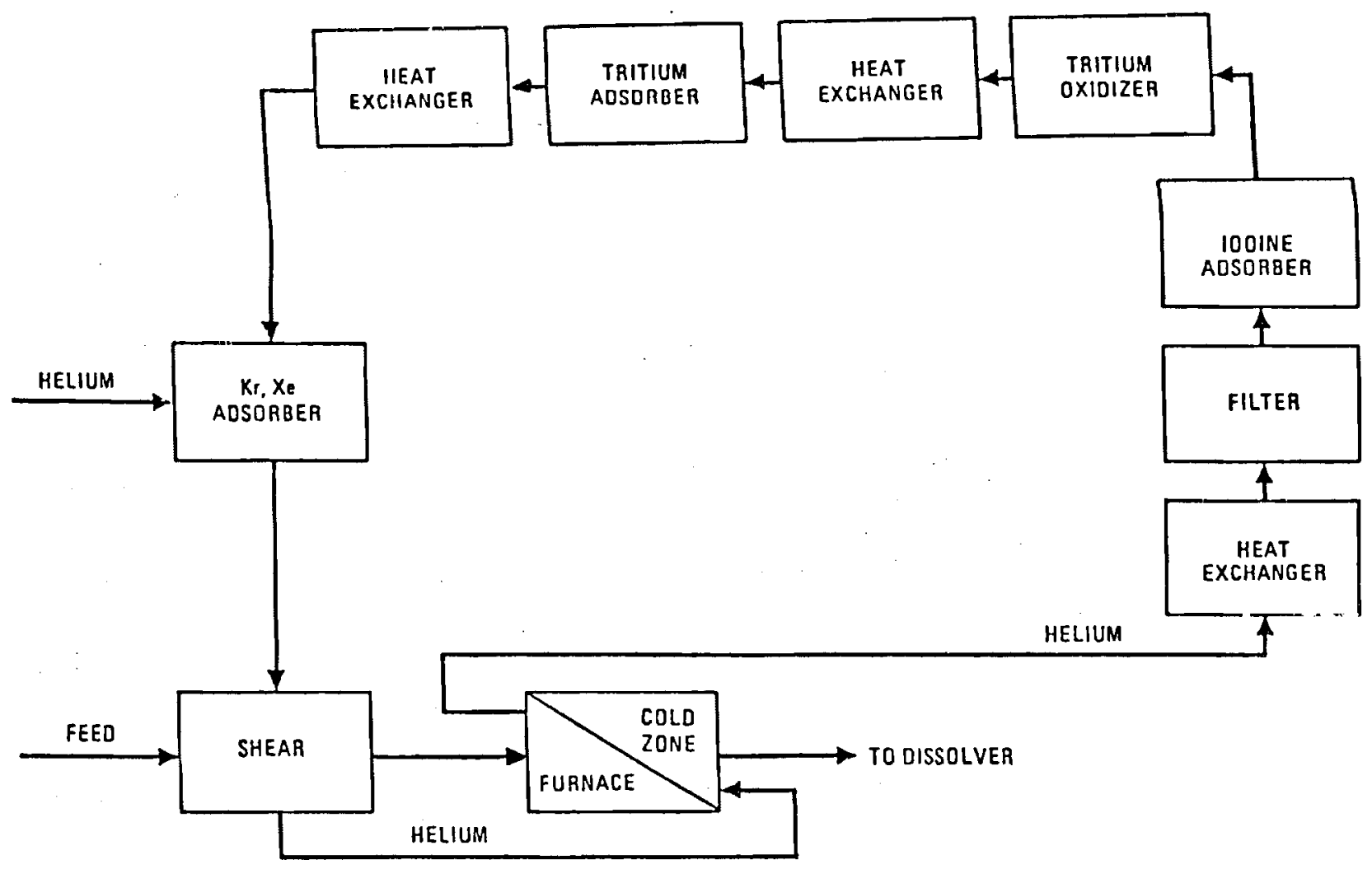

FIGURE 5.3. Thermal Outgasing Schematic

water. Several isotopic separations methods have been demonstrated for T-D-H separations in water. These include: 1) dual temperature $\mathrm{H}_{2} \mathrm{O}-\mathrm{H}_{2} \mathrm{~S}$ exchange, 2) $\mathrm{H}_{2}-\mathrm{H}_{2} \mathrm{O}$ catalyzed exchange, 3) fractional water distillation, 4) electrolysis, and 5) combined electrolysis catalytic exchange. Potential methods that have not been adequately demonstrated include bipolar electrolysis and selective (laser) molecular excitation. (Very good separations methods for elemental species, $\mathrm{H}_{2}-\mathrm{HT}$, etc., [such as cryogenic distillation] are known, but are not applicable here.) At the present time, methods 3 and 5 seem to be preferred for the reprocessing water streams.

Isotope separation does not appear attractive when the HTO is diluted with water to the extent found in normal Purex plant operation. However, with concentration of water by recycle, as described above, the process becomes reasonable. Isotope separation processes were recently reviewed by McKay (1) 
and by Grimes et al.(11) A combination of isotope separation and water recycle may turn out to be the most attractive tritium management scheme. Several possibilities have been presented.(10-11)

\subsubsection{Wastes}

Immobilization and disposal of tritium require the use of certain materials to bind the tritium:(1)

1. inorganic hydrates and desiccants

2. cement

3. metal hydrides

4. organic compounds

For item 3 elemental tritium is required, as it is for certain polymers of item 4. Otherwise, the water form is the feed. Mckay's review(1) is the most recent survey of tritium fixation. References to the original work are given.

Inorganic hydrates, desiccants, and clay materials lose water too readily to be considered good agents for disposal. They are good, however, for immobilization where elevated temperatures or water contact are not expected. Of these, zeolites are perhaps the best. Cement has the same problems: limited temperature stability and tritium loss on contact with water. Because cement is inexpensive and easy to use, methods have been investigated for sealing the cement surface. These have included dipping, painting, and polymer impregnation. The latter treatment, examined at Brookhaven National Laboratory, cut the leach rate from several percent per day to about $0.01 \%$ or less, borderline for protection for the customarily required 10 half-lives. For ocean disposal, this release could be tolerated.

Hydrides of $\mathrm{Zr}, \mathrm{Ti}, \mathrm{Y}$, and $\mathrm{Hf}$ have been considered as fixation and storage forms. Studies to date indicate adequate temperature stability and leach resistance. A disadvantage is the requirement for the tritium to be in rather pure elemental form, $i . e .$, the absence of other reactive gases such as $\mathrm{O}_{2}$ and $\mathrm{N}_{2}$.

About a dozen organic polymers in which tritium has been incorporated as part of the molecule have been studied. Two difficulties have been pointed 
out: 1) the preparation is seldom "clean," i.e. the reactions are not complete and/or byproducts are formed necessitating recycle, and 2) organic compounds are generally subject to oxidation and other destructive reactions. An advantage is the extremely low water leach rate of the product.

The present disposal practice employs a multiple-barrier concept. One such procedure for disposal of tritiated water on zeolite uses a 30-gallon drum for the primary container. This is bolted shut and sealed with plastic cement. The drum is then inserted into a 55-gallon drum with the space filled with vermiculite. This is, in turn, capped with asphalt for a final seal.

The extreme is perhaps the Mound Package. This is made up of three drums. A 27-gallon polyethylene drum is placed inside a 30-gallon steel drum, asphalt coated and in turn placed inside a 55-gallon steel drum. The storage form is a 1:3 cement-plaster mix, and the void spaces are filled with vermiculite. The estimated release rate is $0.002 \%$ in 87 years. 


\section{REFERENCES}

1. H. A. C. McKay ed., "Tritium Immobilization," European Appl. Res. Rept., Nucl. Sci. Technol. 1:597-711, 1979.

2. Radiological Significance and Management of Tritium, Carbon-14, Krypton85, lodine-129, Arising from the Nuclear Fuel Cycle, NEA Group of Experts, Nuctear Energy Authority of the Organization for Economic Cooperation and Development, Paris, 1980.

3. L. E. Trevorrow, et al., Tritium and Noble Gas Fission Products in the Nuclear Fuel Cycle: I. Reactors, ANL-8102, Argonne National Laboratory, 1974.

4. H. Bonka, "Production and Emission of Tritium from Nuclear Facilities and the Resulting Problems," in Behavior of Tritium in the Environment, International Atomic Energy Agency/Nuclear Energy Agency Symp., San Francisco, CA (1978); IAEA, Vienna, 1979.

5. Brown et al., Draft Program Strategy Reference Document for the Management of Radioactive Airborne Wastes, Exxon Nuclear Idaho Company, Idaho Falls, Idaho, 1982.

6. L. L. Burger, "Distribution and Reactions of Tritiated Hydrogen and Methane," in Behavior of Tritium in the Environment. International Atomic Energy Agency/Nuclear Energy Agency Symp., San Francisco, CA 1978; IAEA, Vienna, 1979.

7. A. G. Evans, Report of the Task Group on Reference Man, ICRP Publication 23, Pergamon Press, Oxford, 1975.

8. Preliminary Safety Analysis Report for the Tritium Systems Test Assembly, Los Alamos Scientific Laboratory, Los Alamos, New Mexico, January 1979.

9. T. B. Rhinehammer and P. H. Lamberger, Tritium Control Technology, WASH1269, Monsanto Mound Laboratory, Miamisburg, Ohio, 1973.

10. L. L. Burger and R. D. Scheele, Tritium Removal Alternatives for the Purex Process, PNL-2080-14, Pacific Northwest Laboratory, Richland, Washington, 1978.

11. W. R. Grimes et al., An Evaluation of Retention and Disposal Options for Tritium in Fuel Reprocessing, ORNL-TM-8261, Oak Ridge National Laboratory, Oak Ridge, Tennessee, 1982. 
12. L. A. Bray, et al., Thermal Release of Volatile Fission Products from Irradiated Nuclear Fuel, PNL-4488, Pacific Northwest Laboratory, Richland, Washington, 1983.

13. B. C. Musgrave, Tritium Distribution in the Nuclear Industry, The Requirements for Control Strategies, ICP-1041, AlTied Chemic. Corp., Idaho Falls, Idaho, 1974.

14. H. Schnez, M. Laser and E. Merz, Tritium Reprocessing Plants, A Study of the Inventory, Behavior, and Possibilities of Separation of Tritium Isotopes, GEHTR-19, Kernforschungstage, Julich, Germany, 1974.

15. Savannah River Laboratory Quarterly Report, Light Water Reactor Fuel Cycle, DPST-LWR-76-1-2, p. 12, Savannah River Laboratory, Aiken, South Carotina, 1976.

16. G. P. Miller and L. R. Michels, Water Recycle and Isotopic Dilution for Control of Tritium in a Nuclear Fuel Reprocessing PIant, NEDC-21674, General Electric, Fuel Recovery Operation, San Jose, Cal ifornia, 1977. 

6.0 (NOT USED)

6.1 



\subsection{FEED MATERIALS PRODUCTION CENTER}

The Feed Materials Production Center (FMPC) was completed by the federal government in 1954 and is now operated for the U. S. Department of Energy (DOE) by NLO, Inc. Its primary purpose is to produce purified uranium metal and uranium compounds for use at other DOE sites.

\subsection{SITE AND MAJOR SOURCE DESCRIPTIONS}

The FMPC has the capability to convert a variety of feeds into pure uranium metal and uranium compounds. The feed materials include uranium ore concentrates, recycled uranium from spent reactor fuel, and various uranium compounds. The uranium may be depleted, normal, or slightly enriched. Periodically, thorium has also been processed at the FMPC.

The FMPC consists of eight separate plants and associated facilities. The major sources of airborne radioactive emissions in 1981, 1982, and 1983 are identified and briefly described below.

\subsubsection{Location of Site and Description of Facilities}

The FMPC is located in a rural area in southwestern Ohio near Fernald, about $32 \mathrm{~km}$ from downtown Cincinnati (Figure 7.1). The facility occupies about 55 ha on a 425-ha site. The area east of the site is in the Miami River flood plain. The immediate area is rural and sparsely populated; but the total population within $80 \mathrm{~km}$ of the site is approximately $2.5 \mathrm{million}$, because of the large population of Cincinnati.

Operations at the FMPC are conducted on an integrated basis in eight separate plants (plus associated facilities) where various physical, chemical, and metallurgical processes are carried out. These plants are shown in Figure 7.2 and are described briefly below.

\section{Plant 1, Sampling Plant}

Weighing and sampling of incoming feed materials are carried out in the Sampling Plant to establish the nuclear materials accountability base. Opening of fuel rods, reclamation of uranium from cleaning solvents, and storage of nuclear materials also take place in the Sampling Plant. 


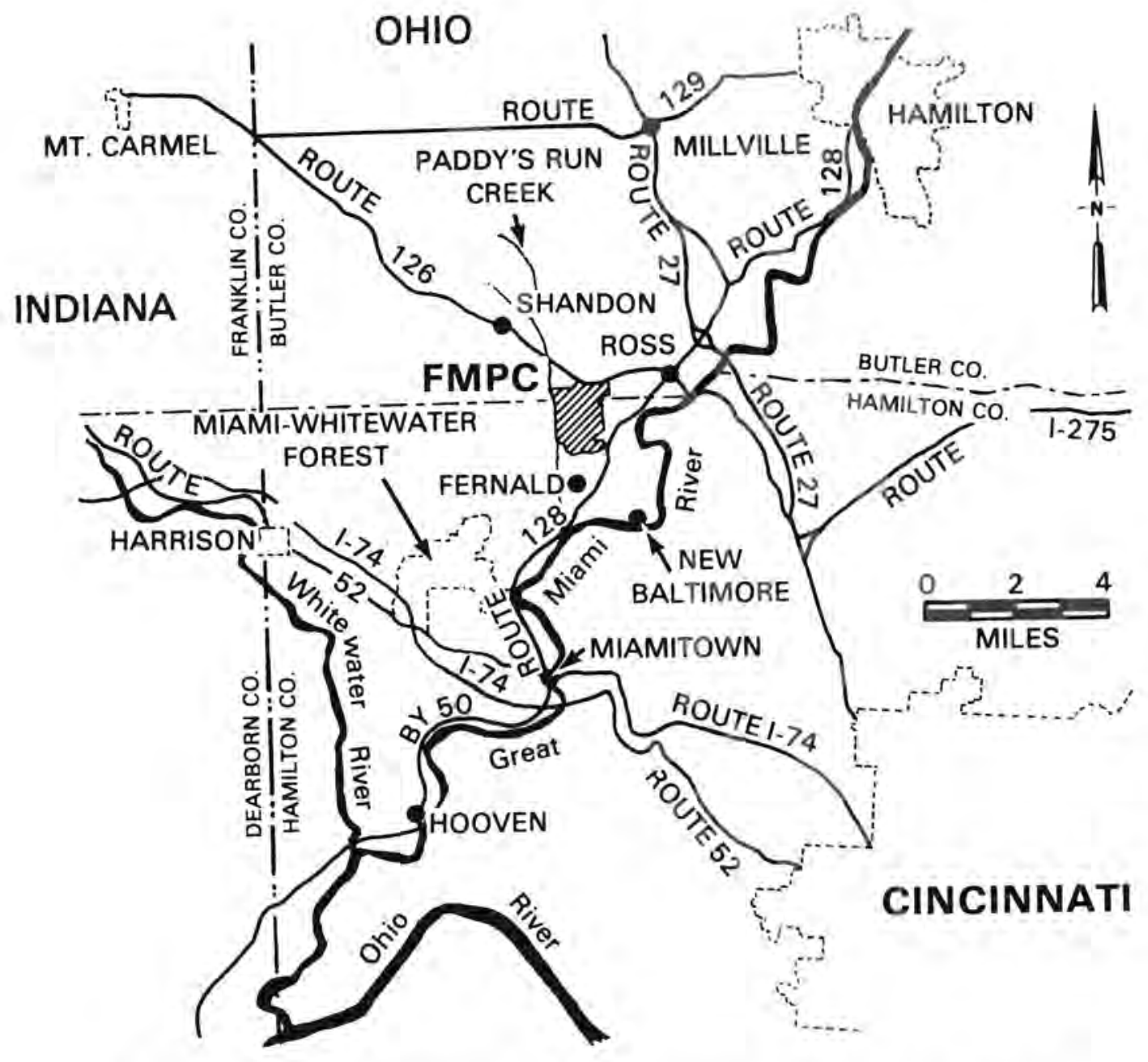

FIGURE 7.1. Location of Feed Materials Production Plant

Plant 2/3, Refinery

Uranium trioxide (orange oxide) is produced in the Refinery in three steps: digestion, extraction, and denitration. Feed materials are digested in nitric acid in tanks. The resulting slurry of uranyl nitrate, nitric acid, and insoluble matter is pumped to the extraction system, where an organic solvent mixture of tributyl phosphate and kerosene extracts the uranyl nitrate, leaving nitric acid and impurities behind. The uranyl nitrate is recovered from the organic solvent stream by a second extraction with deionized water in stripping columns. In the denitration process, aqueous uranyl nitrate is concentrated by evaporation, and then calcined in denitration pots to yield uranium trioxide. 


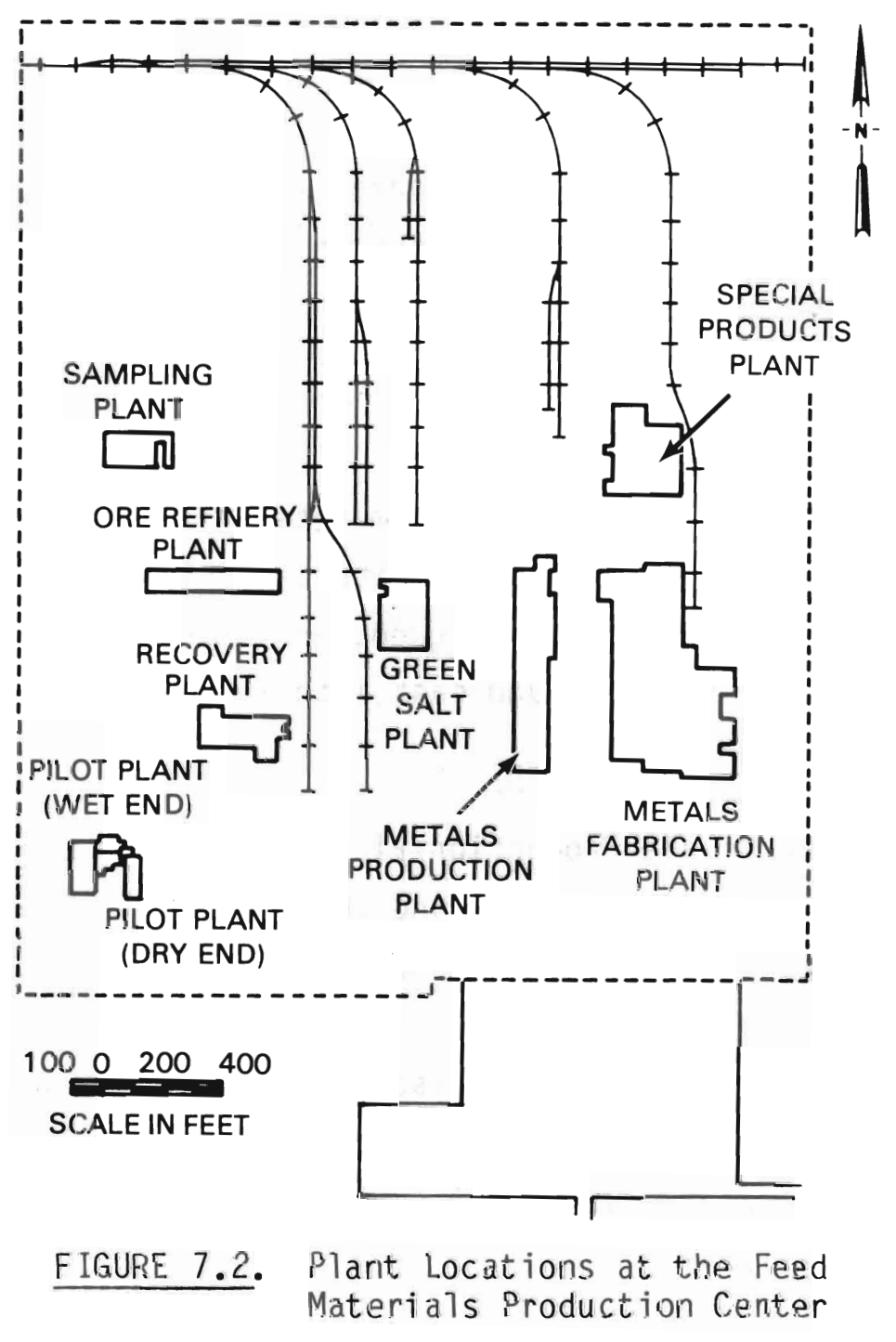

The uranium trioxide is then packaged for further processing at FMPC or for shipment to other DOE sites. A nitric acid recovery plant operates in conjunction with the Refinery to recover nitric acid from off-gases generated in the refinery process.

\section{Incinerator}

The solid waste incinerator is a facility associated with Plant $2 / 3$ and is used for the destruction of combustible trash, paper, and wood. It is equipped with one gas-fired afterburner for the purpose of minimizing particulate emissions. 


\section{Plant 4, Green Salt Plant}

In the Green Salt Plant, uranium trioxide is converted to uranium dioxide by reduction with hydrogen, followed by conversion to uranium tetrafluoride, or green salt, by reaction with anhydrous hydrogen fluoride. The uranium tetrafluoride product is packaged in 38-L cans. Dissociated ammonia is the source of hydrogen used to reduce uranium trioxide.

Plant 5, Metals Production Plant

In the Metals Production Plant, uranium metal is produced from uranium tetrafluoride by a thermite-type reaction with magnesium metal. The resulting uranium metal is cooled, cleaned and weighed, and transferred to the casting area where the uranium is remelted and cast into ingots weighing up to $653 \mathrm{~kg}$.

Plant 6, Metals Fabrication Plant

Ingots made in the Metals Production Plant for later extrusion are heattreated in the Metals Fabrication Plant and then shipped offsite for extrusion. The extruded uranium is then returned to the Metals Fabrication Plant where it is cut, heat-treated, machined, cleaned, and packaged for shipment to another DOE plant. Uranium ingots may also be converted to solid fuel elements in the Metals Fabrication Plant. These ingots are heat-treated, rolled into rods of the desired diameter, cut, machined, and otherwise processed and packaged for offsite shipment.

Plant 8, Scrap Recovery Plant

In the Scrap Recovery Plant, uranium recycle materials are sorted, calcined, and prepared for storage and later recycle at the FMPC and elsewhere.

Plant 9, Special Products Plant

In the Special Products Plant, oversized uranium ingots up to $900 \mathrm{~kg}$ are processed. Reject fuel elements from cladding operations at reactor sites are declad by hydrofluoric acid in the Special Products Plant. The uranium cores are recovered for reuse.

Pilot Plant

The Pilot Plant is used principally for chemical and metallurgical processing of enriched uranium feed materials containing up to $10 \%$ uranium- 235 . 
Critically safe extraction columns are used for uranium purification. The Pilot Plant is also used for the infrequent processing of thorium. The plant can produce purified thorium nitrate, thorium oxalate, thorium metal, and hydrated thorium oxide. Decladding of rejected aluminum-clad fuel cores is done chemically using a sodium hydroxide-sodium nitrate solution. A variety of other processes, including reducing UF 6 to $U_{4}$ and making single uranium melts as large as 3 tons, is possible in the Pilot-Plant facility.

\subsubsection{Identification and Location of Specific Sources}

Emissions to air from five plants at the FMPC were identified in the EPA Release Point Analys is Report for 1981. (7) The U. S. DOE Effluent Information System Nuclide Database Master List for $1982^{(8)}$ reports emissions in 1982 from eight plants at the FMPC. These emissions are listed in Table 7.1. The emissions are identified as natural uranium in the form of particulates. Although Plant 4 emissions decreased in 1982, emissions from Plant 8 (Scrap Recovery Plant) increased. The Green Salt Plant and the Metals Production Plant (Plants 4 and 5 , respectively) contributed $95 \%$ of the uranium emissions in calendar year 1981. Plants 4, 5, and 8 contributed $98 \%$ of the uranium emissions in calendar year 1982 .

Each plant at the FMPC has several stacks. The 1981 emissions by stack are listed in Tables 7.2 and 7.7. Some stacks were not operated in 1981 or 1982, some were operated and showed detectable emissions, while still others were operated and showed no detectable emissions. No component FMPC plant operated at greater than $35 \%$ of capacity in FY 1981, nor greater than $56 \%$ of capacity in FY 1982. Plant emissions, stack usage, and percentage of plant operating capacities utilized in 1983 are not available.

Average uranium concentrations at the boundary sampling stations ranged from $1.3 \times 10^{-15} \mu \mathrm{Ci} / \mathrm{mL}$ to $5.3 \times 10^{-15} \mu \mathrm{Ci} / \mathrm{mL}$ in $1981(1)$ and from $2.1 \times 10^{-15} \mu \mathrm{Ci} / \mathrm{mL}$ to $7.7 \times 10^{-15} \mu \mathrm{Ci} / \mathrm{mL}$ in 1982 . (2) These values were approximately $0.1 \%$ to $0.3 \%$ of the existing DOE standard. (3)

DOE forecasts indicate increased use of the FMPC in support of increased work at other DOE sites. (4) The actual magnitude of this increased FMPC production is dependent upon the needs of other DOE sites, but could reasonably 

TABLE 7.1. Atmospheric Emissions of Radionuclides, Feed Materials Production Center,
CY $1981(a)$ and CY $1982(b)$

\begin{tabular}{|c|c|c|c|c|c|}
\hline \multirow[b]{2}{*}{ Facility } & \multirow[b]{2}{*}{ Process or Operation } & \multicolumn{2}{|l|}{ CY 1981} & \multicolumn{2}{|l|}{ CY 1982} \\
\hline & & $\begin{array}{l}\text { Emissions } \\
\text { Natural } U, C_{i}(c)\end{array}$ & Percent & $\begin{array}{l}\text { Emissions } \\
\text { Natural } \mathrm{U}, \mathrm{Ci}(\mathrm{c})\end{array}$ & Percent \\
\hline Plant 1 & Material Sampling and Grinding & $3.33 E-04$ & 0.3 & -- & -- \\
\hline Plant $2 / 3$ & $\begin{array}{l}\text { Dumping Dry Feeds and Feeding } \\
\text { Digest Tanks }\end{array}$ & -- & -- & -- & -- \\
\hline Incinerator & r Burning & $4.15 E-04$ & 0.4 & $6.044 E-04$ & 0.5 \\
\hline Plant 4 & UF $_{4}$ Production and Repackaging & $6.26 E-02$ & 55.2 & $1.132 \mathrm{E}-02$ & 9.6 \\
\hline Plant 5 & Metal Production and Slag Milling & $4.46 E-02$ & 39.4 & $6.394 E-02$ & 54.1 \\
\hline Pad 74 & Graphite Burner & -- & -- & $1.000 \mathrm{E}-06$ & -- \\
\hline Plant 6 & Machining of Uranium Metal & -- & -- & $3.33 E-04$ & 0.3 \\
\hline Plant 8 & Calcining, Furnacing & $5.32 \mathrm{E}-03$ & 4.7 & $4.029 E-02$ & 34.1 \\
\hline Plant 9 & $\begin{array}{l}\text { Processing of Uranium Metal, } \\
\text { Remelting and Machining }\end{array}$ & -- & -- & $1.665 \mathrm{E}-03$ & 1.4 \\
\hline Pilot Plant & Production of Thorium and Uranium & -- & -- & -- & -- \\
\hline Total & & $1.13 \mathrm{E}-01$ & 100.0 & $1.18 \mathrm{E}-01$ & 100.0 \\
\hline
\end{tabular}

(a) Source: DOE Effluent Information System EPA Release Point Analysis Report for CY 1981. (7)

(b) Source: DOE Effluent Information System Nuclide Database Masłer List for CY 1982. (8)

(c) DOE defines a curie of natural uranium as the sum of $3.7 \times 10^{10}$ disintegrations per second from U-238 plus $3.7 \times 10^{10} \mathrm{dis} / \mathrm{sec}$ from U-234 plus $1.7 \times 10^{9} \mathrm{dis} / \mathrm{sec}$ from $\mathrm{U}-235$. DOE also defines the specific activity of natural uranium to be $3.33 \times 10^{-7} \mathrm{Ci} / \mathrm{g}$ (DOE Order 5480.1 Chg. 2, Attachment XI-1, p. 12, 29 April 81). DOE's definition is the value of the specific activity if only U-238 is considered. 
be expected to double the 1981 production. A corresponding increase in total uranium emissions would therefore be expected using the present emission control technology.

\subsubsection{Nonspecific and Minor Sources}

Neither the 1981 EPA Release Point Analysis Report nor the 1982 DOE Nuclide Database Master List reports thorium or radon emissions. Thorium emissions result from the infrequent processing of thorium in the Pilot Plant. Average thorium concentrations at the boundary sampling stations were measured in 1981 to be no greater than $0.07 \%$ of the DOE standard for offsite areas. (1) Concentrations of Th-228 and Th-232 at the boundary sampling stations in 1982 ranged from $1.9 \pm 0.2 \times 10^{-17} \mu \mathrm{Ci} / \mathrm{mL}$ to $7.9 \pm 0.2 \times 10^{-17} \mu \mathrm{Ci} / \mathrm{mL}$ and from $1.2 \pm$ $0.2 \times 10^{-17} \mu \mathrm{Ci} / \mathrm{mL}$ to $4.8 \pm 0.2 \times 10^{-17} \mu \mathrm{Ci} / \mathrm{mL}$, respectively. (2) These values represent a composite of 52 weekly samples and do not exceed $0.04 \%$ of the applicable DOE standard for offsite areas ${ }^{(3)}$ per individual isotope.

Radon emissions originate primarily from two waste storage tanks used for the storage of Refinery residues that resulted from processing pitchblend ores prior to 1959. (4) The tanks are cylindrical, with approximate dimensions of $24.4 \mathrm{~m}$ diameter, $8 \mathrm{~m} \mathrm{high}$, and walls $20 \mathrm{~cm}$ thick. The capacity of each tank is $3,540 \mathrm{~m}^{3}$. All tank opening have been sealed with gaskets, and the tanks are enclosed by an earth embankment. Average radon concentrations at the boundary stations ranged from $0.28 \mathrm{pCi} / \mathrm{L}$ to $0.70 \mathrm{pCi} / \mathrm{L}$ in $1981(1)$; and from $0.66 \mathrm{pCi} / \mathrm{L}$ to $1.07 \mathrm{pCi} / \mathrm{L}$ in 1982. (2) The applicable DOE standard is $3 \mathrm{pCi} / \mathrm{L} .{ }^{(3)}$ Radon concentrations were measured in $1981^{(1)}$ at sites located five and eight miles $(\sim 8 \mathrm{~km}$ and $13 \mathrm{~km}$, respectively) from the FMPC boundary as $0.36 \mathrm{pCi} / \mathrm{L}$ and $0.67 \mathrm{pCi} / \mathrm{L}$, respectively, and $0.66 \mathrm{pCi} / \mathrm{L}$ and $0.56 \mathrm{pCi} / \mathrm{L}$, respectively, in 1982. (2)

\subsection{EMISSION CONTROL TECHNOLOGY AT THE FEED MATERIALS PRODUCTION CENTER}

Emission control technology at the FMPC differs from that of other sites in two major aspects: 1) emissions are essentially all particulates, with natural uranium being the predominate radionuclide; and 2) each plant at the FMPC has multiple stacks, each with its own emission control device and each providing ventilation to a specific area or specific equipment within a given 
plant. Much of the information in this section was provided by the Oak Ridge Operations Office of the Department of Energy. (a)

\subsubsection{Specific Sources}

The emissions, by stack, for 1981-1983 are shown in Table 7.2. Emissions in Table 7.2 are given in mass units to minimize confusion regarding the specific activity of the uranium emitted to the atmosphere. In 1981, Plants 4 and 5 contributed $95 \%$ of the uranium emissions into the atmosphere at the FMPC. Plants 4,5 , and 8 contributed $98 \%$ of the atmospheric uranium emissions in 1982, and $96 \%$ in 1983. In other years, other plants may contribute a fraction greater than $5 \%$ of the total.

Table 7.3 shows FMPC stacks not operated in 1981 or 1982 , and Table 7.4 shows stacks that were operated and monitored in 1981 and 1982 but showed no radioactive emissions. Similar information for 1983 was not available, but no significant change in the operational status is expected.

\subsubsection{Description of Existing Emission Control Technology}

Chemical and radioactive emissions at the FMPC are controlled by wet scrubbers, bag-type dust collectors, and electrostatic precipitators. The radioactive emissions from the various plants are essentially all particulate emissions, as shown in Tables 7.2 and 7.4; emissions from Plants 4, 5, and 8 are controlled by the bag-type dust collectors or wet scrubbers. Section 2 of this document describes in greater detail the operation of these particulate control technologies. The efficiency of the bag-type dust collectors exceeds $99 \%$. Most of the material losses occur because of cloth bag ruptures or other malfunctions that allow the dust to bypass the filter.

Information on bag-type dust collectors for selected stacks of Plant 5 is given in Table 7.5; these are representative of those installed on other stacks. The dust collectors for these particular stacks have been shown to have total system efficiencies of $\$ 99.9 \%$ over a 2 -year period.

(a) G. J. Marciante, Weapons Division, U. S. Department of Energy, Oak Ridge Operations Office, P. 0. Box E, Oak Ridge, TN 37830. 
TABLE 7.2. FMPC Stack Emissions 1981-1983

\begin{tabular}{|c|c|c|c|c|c|c|}
\hline Plant & $\begin{array}{c}\text { Collector } \\
\text { I.D. }\end{array}$ & \multicolumn{3}{|c|}{ Emission U $(\mathrm{kg})^{(a)}$} & $\begin{array}{l}\text { Compound } \\
\text { Emitted }\end{array}$ & Enrichment ${ }^{(d)}$ \\
\hline 1 & $\begin{array}{l}\text { G2-64 } \\
\text { G2-76 } \\
\text { G2-172 } \\
\text { Sly } \\
\text { Total }\end{array}$ & $\begin{array}{c}--(b) \\
1.3 \\
-- \\
-- \\
1.3\end{array}$ & $\begin{array}{c}1.2 \\
0.9 \\
-- \\
-- \\
2.1\end{array}$ & $\begin{array}{l}1.9 \\
2.0 \\
0.7 \\
1.8 \\
6.4\end{array}$ & $\begin{array}{l}\mathrm{U}_{3} \mathrm{O}_{8} \\
\mathrm{U}_{3} \mathrm{O}_{\mathrm{\beta}} \\
\text { varlous } \\
\text { Various } \\
\text { Various }\end{array}$ & $\begin{array}{l}\text { Enr. } \\
\text { Enr. } \\
\text { Enr. } \\
\text { Enr. } \\
\text { Enr. }\end{array}$ \\
\hline $2 / 3$ & G1-856 & -- & 2.3 & -- & Various & Enr. \\
\hline 4 & $\begin{array}{l}\text { G4-1 } \\
\text { G4-2 } \\
\text { G4-5 } \\
\text { G4-7 } \\
\text { G4-12 } \\
\text { G4-13 } \\
\text { G4-14 } \\
\text { Total }\end{array}$ & $\begin{array}{r}1.8 \\
--(c) \\
11.5 \\
6.0 \\
4.0 \\
-- \\
170.8 \\
194.1\end{array}$ & $\begin{array}{r}0.2 \\
3.2 \\
1.5 \\
5.6 \\
1.3 \\
-- \\
7.3 \\
19.1\end{array}$ & $\begin{array}{r}-\overline{18.5} \\
20.9 \\
2.5 \\
0.9 \\
0.1 \\
-- \\
42.9\end{array}$ & $\begin{array}{l}\mathrm{UO}_{3} \\
\mathrm{UF}^{4} \\
\mathrm{UF}_{4}^{4} \\
\mathrm{Var}_{\mathrm{r}} \text { ious } \\
\mathrm{UF}_{4}^{4} \\
\mathrm{UF}_{4}^{4} \\
\mathrm{UF}_{4}^{4}\end{array}$ & $\begin{array}{l}\text { Enr. } \\
\text { Enr. } \\
\text { Enr. } \\
\text { Enr. } \\
\text { Enr. } \\
\text { Enr. } \\
\text { Depl. }\end{array}$ \\
\hline 5 & $\begin{array}{l}\text { GS-247 } \\
\text { GS-248 } \\
\text { GS-249 } \\
\text { GS-253 } \\
\text { GS-254 } \\
\text { G2-67 } \\
\text { GS-256 } \\
\text { GS-259 } \\
\text { GS-260 } \\
\text { GS-261 } \\
\text { P1t. S5 } \\
\text { GSA-100 } \\
\text { GSA-101 } \\
\text { Total }\end{array}$ & $\begin{array}{r}0.8 \\
4.1 \\
25.8 \\
-\overline{5.1} \\
-\overline{3.8} \\
-\overline{27.9} \\
63.5 \\
0.9 \\
2.7 \\
1.0 \\
135.6\end{array}$ & $\begin{array}{r}0.8 \\
1.6 \\
-- \\
1.3 \\
6.9 \\
0.7 \\
2.0 \\
3.1 \\
105.6 \\
52.8 \\
14.4 \\
-\overline{1.1} \\
190.3\end{array}$ & $\begin{array}{r}0.3 \\
-- \\
0.9 \\
0.8 \\
2.6 \\
2.4 \\
5.3 \\
-- \\
4.4 \\
16.1 \\
5.7 \\
-- \\
2.9 \\
41.4\end{array}$ & $\begin{array}{l}U_{3} 0_{8}^{8} \\
U_{3}^{8} 0_{8} \\
U_{F}^{4} \\
U_{3}^{6} f_{8}^{8} \\
U_{3}^{3} 0_{8}^{8} \\
U_{3}^{3} 0_{8}^{8} \\
U_{3}^{3} 0_{8}^{8} \\
U_{3}^{3} 0_{8}^{8} \\
U_{3}^{3} 0_{8}^{8} \\
U_{3}^{3} 0_{8}^{8}\end{array}$ & $\begin{array}{l}\text { Enr. } \\
\text { Depl. } \\
\text { Depl. } \\
\text { Depl. } \\
\text { Enr. } \\
\text { Enr. } \\
\text { Depl. } \\
\text { Enr. } \\
\text { Depl. } \\
\text { Depl. } \\
\text { Depl. } \\
\text { Depl. } \\
\text { Depl. }\end{array}$ \\
\hline 6 & S Esp & - & 0.5 & -- & $U_{3} 0_{8}$ & Depl. \\
\hline \multirow[t]{2}{*}{8} & $\begin{array}{l}\text { G43-27 } \\
\text { G43-29 } \\
8035 \\
8024 \\
\text { Subt otal }\end{array}$ & $\begin{array}{l}-- \\
-- \\
-- \\
-\overline{0}\end{array}$ & $\begin{array}{r}80.1 \\
0.7 \\
0.4 \\
-\overline{81 .}\end{array}$ & $\begin{array}{l}10.3 \\
-- \\
-- \\
14.4 \\
24.7\end{array}$ & $\begin{array}{l}\text { Various } \\
U_{3} 0_{8} \\
U_{3}^{3} 0_{8}^{8}\end{array}$ & $\begin{array}{l}\text { Enr. } \\
\text { Enr. } \\
\text { Enr. } \\
\text { Enr. }\end{array}$ \\
\hline & $\begin{array}{l}\text { Scrubbers } \\
\text { Total }\end{array}$ & $\begin{array}{l}16 \\
16\end{array}$ & $\begin{array}{r}39.7 \\
120.9\end{array}$ & $\begin{array}{l}48.7 \\
73.4\end{array}$ & Various & Enr. \\
\hline \multirow[t]{3}{*}{9} & G9N1-1039 & -- & 5.1 & -- & $\mathrm{U}_{3} \mathrm{O}_{8}$ & Depl. \\
\hline & & 1981 & 1982 & 1983 & & \\
\hline & Site Totals & 347 & 340.3 & 164.1 & & \\
\hline \multicolumn{7}{|c|}{$\begin{array}{l}\text { (a) Source: Information provided by the FMPC. } \\
\text { (b) Dash indicates no measurable U emissions. } \\
\text { (c) No emission was reported on the Accounting Division records since no } \\
\text { information was available to substantiate a loss of } 238 \mathrm{~kg} U \text { originally } \\
\text { recorded during September, } 1981 \text {. } \\
\text { (d) Enr: slightly enriched in U-235. }\end{array}$} \\
\hline
\end{tabular}


TABLE 7.3. FMPC Stacks not Operated in 1981 or $1982^{(a)}$

\begin{tabular}{cl} 
Plant & \multicolumn{1}{c}{$\begin{array}{c}\text { Stack } \\
\text { Collector }\end{array}$} \\
\cline { 2 - 2 } & G2-63 \\
G2-174 \\
6 & Penthouse \\
8 & G43-44C \\
& G8-1 \\
& G8-2 \\
& G8-3 \\
& G8-4 \\
& G8N1-1000 \\
& 6018 \\
& 8002 \\
& 8024 (b) \\
& G42A-100 \\
9 & G9E2-615 \\
& Oxidation Furnace \\
Pilot & 108843 \\
&
\end{tabular}

(a) These stacks ventilate equipment which was not operated in 1981 or 1982. Use of these collectors and equipment is not currently expected and would require repair or refurbishing.

(b) Collector 8024 was operational in 1983.

Stack emissions are constantly sampled using a permanently installed instack sampling system. These systems require the collection of about $1 \mathrm{gram}$ of material before the collection filters are removed for analysis. A continuous stack monitoring device that will be used in addition to the existing stack samplers has been installed on selected stacks. The results to date indicate the new stack monitoring device is very sensitive to small quantities of material loss; it has detected minor leaks in dust collection bags that, prior to its installation, had gone undetected until a buildup of material on the stack sampler was found. 
TABLE 7.4. FMPC Operating Stacks with No Emissions Recorded in 1981 or $1982^{(a)}$

\begin{tabular}{|c|c|c|}
\hline Plant & $\begin{array}{c}\text { Stack } \\
\text { Collector } \\
\end{array}$ & $\begin{array}{l}\text { Chemical } \\
\text { Form }\end{array}$ \\
\hline \multirow[t]{6}{*}{1} & G2-68 & $\mathrm{U}_{3} \mathrm{O}_{8}$ \\
\hline & G2-77 & Various \\
\hline & G2-171 & Various \\
\hline & G2-172 & Various \\
\hline & G2-235 & Various \\
\hline & Sly & Various \\
\hline \multirow[t]{4}{*}{2} & G1-94 & $\mathrm{UO}_{3}$ \\
\hline & G1-252 & $\mathrm{UO}_{3}$ \\
\hline & Plant 3 North & $\mathrm{UO}_{3}$ \\
\hline & Plant 3 South & $\mathrm{UO}_{3}^{3}$ \\
\hline \multirow[t]{4}{*}{4} & G4-3 & $\mathrm{UF}_{4}$ \\
\hline & G4-4 & $\mathrm{UF}_{4}^{4}$ \\
\hline & G4-8 & $\mathrm{UF}_{4}^{4}$ \\
\hline & G4-13 & $\mathrm{UO}_{3}^{4}$ \\
\hline \multirow[t]{4}{*}{5} & $G 5-250$ & $\mathrm{UF}_{4}$ \\
\hline & G5 -251 & $\mathrm{UF}_{4}^{4}$ \\
\hline & $G 5-252$ & $\mathrm{UF}_{4}^{4}$ \\
\hline & G5 -258 & $\mathrm{U}_{3} \mathrm{O}_{8}$ \\
\hline \multirow[t]{2}{*}{6} & G6-6057 & $\mathrm{U}_{3} \mathrm{O}_{8}$ \\
\hline & Middle ESP & $\mathrm{U}_{3} \mathrm{O}_{8}^{\circ}$ \\
\hline \multirow[t]{2}{*}{8} & 8021 & Various \\
\hline & 8057 & Various \\
\hline 9 & G42-400 & $\mathrm{U}_{3} \mathrm{O}_{8}$ \\
\hline \multirow[t]{3}{*}{ Pilot } & $735-13-7041$ & Various \\
\hline & $735-13-7050$ & Various \\
\hline & $66-93 A$ & Various \\
\hline
\end{tabular}

(a) Emissions from these stacks were monitored. Emissions were less than detect able amounts. Detectable amounts vary depending on the $\% \mathrm{U}$ in the material and the stack dimensions, but generally range from 0.1 to $1.0 \mathrm{~kg} \mathrm{U}$. 
TABLE 7.5. Dust Collector Characteristics

Dust Collectors

G5-258 \& G5-260

Design Capacity

Discharge Velocity

Final Duct Size

No. of Filter Bags

Type of Bags

Bag Size

Total Filter Area $800 \mathrm{ft}^{2}\left(\sim 74 \mathrm{~m}^{2}\right)$

Bag Cleaning Method Reverse air jet
Dust Collectors

G5-259 \& G5-261

$15,000 \mathrm{ft}^{3} / \min \left(-425 \mathrm{~m}^{3} / \mathrm{min}\right)$

$3300 \mathrm{ft} / \mathrm{min}(\sim 1006 \mathrm{~m} / \mathrm{min}$

$30 \mathrm{in} .(0.76 \mathrm{~m})$

32

Virgin Wool

18" dia., 10'10" long

(0.46m dia., 3.30m long)

$1600 \mathrm{ft}^{2}\left(\sim 149 \mathrm{~m}^{2}\right)$

Reverse air jet

\subsubsection{Current Discharge Rate}

The 1981 and 1982 radionuclide discharges for individual plants at the FMPC are presented in Table 7.1; individual stack emissions for 1981-1983 are given in Tables 7.2 and 7.7. The mass of material lost per stack is based on chemical analyses of the uranium collected on the in-stack filter paper sample collectors. The curie value of the emissions is then determined using DOE's definition of the specific activity of the material emitted.

The specific activity of the materials emitted will vary with the isotopic composition of the materials being processed at the FMPC. All uranium emissions in 1981 and 1982 were reported to be natural uranium; no information was available on the nuclide content of 1983 emissions. DOE's definition of the specific activity of natural uranium $\left(3.33 \times 10^{-7} \mathrm{Ci} / \mathrm{g}\right)^{(3)}$ is the specific activity if it is assumed only $U-238$ is present, thereby neglecting the activity resulting from the presence of $U-234$ and $U-235$. For comparison, the Nuclear Regulatory Commission defines the specific activity of natural uranium as $6.77 \times 10^{-7} \mathrm{Ci} / \mathrm{g} .(\mathrm{a})$

The correlation between mass of uranium emitted and the curie value also reported is not very satisfactory. The correlation of mass to curie value for

(a) Source: 10 CFR, Part 20, Appendix B. 
each plant at the FMPC during 1981 and 1982 is shown in Table 7.6. The origin of the discrepancies (varying values) in the calculated specific activities shown in Table 7.6 is not known. Consistent correlation of mass to curie value $\left(3.33 \times 10^{-7} \mathrm{Ci} / \mathrm{g}\right)$ is obtained, however, for the 1981 individual stack emissions reported in Table 7.7 and the mass values given in Table 7.2.

\subsection{STRATEGIES TO REDUCE DOSE RATE BY 50 PERCENT AND 75 PERCENT}

Calculations by EPA $(5)$ based on the emissions reported by DOE $(7)$ in Table 7.1 ( $0.113 \mathrm{Ci}$ of natural uranium) result in a dose equivalent rate of 88 $\mathrm{mrem} / \mathrm{yr}$ to the lung at the FMPC site boundary. With the assumption that the dose rate from each source is proportional to its source emissions, the dose rates from the largest sources can be calculated as shown in Table 7.8 .

The following rationale were used to make these estimates:

- The total pulmonary dose rate at the FMPC was obtained from data supplied by the EPA.

- The pulmonary dose rate resulting from FMPC operations is caused entirely by particulate emissions.

- The EPA dose equivalent rate calculations for the FMPC were based on 1981 emissions of $0.113 \mathrm{Ci}$.

- Individual stack emissions (curie values) for 1981 are given in Table 7.7. The sum of individual stack emissions reported for FMPC operations in 1981 is $0.116 \mathrm{Ci}$. Individual stack emissions were used in these calculations with the assumption that dose equivalent rate values are in direct proportion to the curie level of the emissions.

- The EPA dose equivalent rate calculations were based on the release of equal quantities ( $\mathrm{C} / \mathrm{yr}$ ) of $\mathrm{U}-234$ and $\mathrm{U}-238$ in equilibrium with its daughters Th-234 and Pa-234m(5). The EPA calculations omit any contribution from $\mathrm{U}-235$.

The data in Table 7.8 can then be used to calculate percentage reductions in emissions from combination of sources that would reduce the total pulmonary dose from the FMPC by, say, $50 \%$ or $75 \%$ (Table 7.9). It can immediately be seen 
TABLE 7.6. Correlation of Mass to Curie Value for Natural Uranium Emissions at the FMPC

\begin{tabular}{|c|c|c|c|c|c|c|}
\hline \multirow[b]{2}{*}{ Facility } & \multicolumn{3}{|c|}{ CY 1981} & \multicolumn{3}{|c|}{ CY 1982} \\
\hline & $\begin{array}{l}\text { Emissions (a) } \\
\text { Natural U, kg }\end{array}$ & $\begin{array}{l}\text { Emissions } \\
\text { Natural U, Ci } \\
\end{array}$ & $\begin{array}{l}\text { Calc. Specific } \\
\text { Activity (Ci/g) } \\
\end{array}$ & $\begin{array}{l}\text { Emissions } \\
\text { Natural } \mathrm{U}, \mathrm{kg} \\
\end{array}$ & $\begin{array}{l}\text { Emissions } \\
\text { Natural } U, C i \\
\end{array}$ & $\begin{array}{l}\text { Calc. Specific } \\
\text { Activity (Ci/g) }\end{array}$ \\
\hline Plant 1 & 1.3 & $3.33 E-04$ & 2. $56 \mathrm{E}-07$ & 2.1 & -- & Undef ined \\
\hline $\begin{array}{l}\text { Plant } 2 / 3 \\
\text { (including }\end{array}$ & (ncinerator) & $4.15 E-04$ & Undefined & 2.3 & 6.044 E-04 & $2.63 E-07$ \\
\hline Plant 4 & 194.1 & $6.26 E-02$ & $3.23 \mathrm{E}-07$ & 19.1 & 1. $132 \mathrm{E}-02$ & $5.93 E-07$ \\
\hline Plant 5 & 135.6 & $4.46 \quad E-02$ & $3.29 \mathrm{E}-07$ & 190.3 & $6.394 E-02$ & $3.36 \mathrm{E}-07$ \\
\hline Plant 6 & -- & - & -- & 0.5 & $3.33 E-04$ & $6.66 \mathrm{E}-07$ \\
\hline Plant 8 & -- & $5.32 E-03$ & Undef ined & 120.9 & $4.029 \quad E-02$ & $3.33 E-07$ \\
\hline Plant 9 & -- & -- & -- & 5.1 & $1.665 E-03$ & $3.26 \mathrm{E}-07$ \\
\hline Pilot Plant & -- & -- & -- & -- & -- & -- \\
\hline
\end{tabular}

(a) Source: Material provided by the FMPC; data reported in Table 7.2.

(b) Source: DOE Effluent Information System EPA Release Point Analysis Report for CY 1981. (7)

(c) Source: DOE Effluent Information System Nuclide Database Master List for CY 1982. (8) 
TABLE 7.7. FMPC Stack Emissions Recorded in $1981^{(a)}$

\begin{tabular}{|c|c|c|c|}
\hline Plant & $\begin{array}{c}\text { Stack } \\
\text { Collector } \\
\end{array}$ & $\begin{array}{l}1981 \text { Emissions } \\
\text { Natural U, Ci }\end{array}$ & $\begin{array}{c}\text { Chemical } \\
\text { Form } \\
\end{array}$ \\
\hline 1 & G2-76 & $3.33 \mathrm{E}-04$ & $\mathrm{U}_{3} \mathrm{O}_{8}$ \\
\hline \multirow[t]{5}{*}{4} & G4-1 & $5.99 \mathrm{E}-04$ & $\mathrm{UO}_{3}$ \\
\hline & G4-5 & $3.83 E-03$ & $\mathrm{UF}_{4}$ \\
\hline & G4-7 & $2.0 \quad E-03$ & $\mathrm{UF}_{4} \& \mathrm{U}_{3} \mathrm{O}_{8}$ \\
\hline & G4-12 & $1.33 \mathrm{E}-03$ & $\mathrm{UF}_{4}$ \\
\hline & G4 -14 & $5.69 \mathrm{E}-02$ & $\mathrm{UF}_{4}$ \\
\hline \multirow[t]{10}{*}{5} & G5-247 & $2.66 E-04$ & $\mathrm{U}_{3} \mathrm{O}_{8}$ \\
\hline & $G 5-248$ & $1.36 \mathrm{E}-03$ & $\mathrm{U}_{3} \mathrm{O}_{8}$ \\
\hline & G5-249 & $8.59 E-03$ & $\mathrm{UF}_{4}$ \\
\hline & G5-254 & $1.70 E-03$ & $\mathrm{U}_{3} \mathrm{O}_{8}$ \\
\hline & G2-67 & $3.33 \mathrm{E}-04$ & $\mathrm{U}_{3} \mathrm{O}_{8}$ \\
\hline & G5-256 & $1.27 E-03$ & $\mathrm{U}_{3} \mathrm{O}_{8}$ \\
\hline & $G 5-260$ & $9.29 E-03$ & $\mathrm{U}_{3} \mathrm{O}_{8}$ \\
\hline & G5-261 & $2.11 \mathrm{E}-02$ & $\mathrm{U}_{3} \mathrm{O}_{8}$ \\
\hline & PL-55 & $3.0 \quad E-04$ & $\mathrm{U}_{3} \mathrm{O}_{8}$ \\
\hline & G5A-100 & $8.99 E-04$ & $\mathrm{U}_{3} \mathrm{O}_{8}$ \\
\hline 8 & Scrubbers & $5.33 \quad E-03$ & Various \\
\hline \multicolumn{2}{|c|}{ Incinerator } & $\underline{4.146 E-04}$ & Various \\
\hline & Total & $1.16 \mathrm{E}-01$ & \\
\hline
\end{tabular}

(a) Source: Material provided by the FMPC. Any discrepancies between total plant emissions in Tables 7.1 and 7.7 are due to the assignment of emissions to different dates for accounting purposes.

that a $72 \%$ reduction of emissions from the two largest sources (G4-14 and G5-261) in 1981 would reduce the pulmonary dose from $88 \mathrm{mrem} / \mathrm{yr}$ to $44 \mathrm{mrem} / \mathrm{yr}$, but that no amount of reduction of emissions from these two sources would reduce the pulmonary dose rate to $22 \mathrm{mrem} / \mathrm{yr}$. For this larger reduction, other sources would have to be included. 
TABLE 7.8. Major 1981 Emission Sources at the FMPC

\begin{tabular}{|c|c|c|}
\hline Stack No. & $\begin{array}{c}1981 \text { Emissions } \\
\mathrm{Ci}\end{array}$ & $\begin{array}{c}\text { Pulmonary } \\
\text { Dose Rate } \\
\text { mrem/yr }\end{array}$ \\
\hline G4-5 & $3.83 E-03$ & 3 \\
\hline G4-14 & $5.69 E-02$ & 44 \\
\hline G5-249 & $8.59 \mathrm{E}-03$ & 7 \\
\hline G5-260 & $9.29 E-03$ & 7 \\
\hline G5-261 & $2.11 E-02$ & 17 \\
\hline Scrubbers & $5.33 E-03$ & 4 \\
\hline Other & 8.00 E-03 & 6 \\
\hline Total & $1.13 \mathrm{E}-01$ & 88 \\
\hline
\end{tabular}

TABLE 7.9. Efficiency of Emission Control Technology Needed to Reduce 1981 FMPC Pulmonary Dose Rate by $50 \%$ and $75 \%$

\begin{tabular}{|c|c|c|c|}
\hline & $\begin{array}{l}\text { Combined } \\
\text { Dose }\end{array}$ & $\begin{array}{r}\text { Percen } \\
\text { Needed } \\
\text { Dose }\end{array}$ & $\begin{array}{l}\text { Reduction } \\
\text { to Reduce } \\
\text { Rate }(a)\end{array}$ \\
\hline Source Combination & $\mathrm{mrem} / \mathrm{yr}$ & $50 \%$ & $75 \%$ \\
\hline G4-14, G5-261 & 61 & 72 & NA \\
\hline $\begin{array}{l}\text { G4-14, G5-261, } \\
\text { G5-249, G5-260 }\end{array}$ & 74 & 59 & 89 \\
\hline $\begin{array}{l}\text { G4-14, G5-261, G5-249, } \\
\text { G5-260, Scrubbers }\end{array}$ & 78 & 56 & 85 \\
\hline
\end{tabular}
(a) A $50 \%$ dose rate reduction would reduce the total pulmonary dose rate from FMPC to $44 \mathrm{mrem} / \mathrm{yr}$ from $88 \mathrm{mrem} / \mathrm{yr}$, and a $75 \%$ dose rate reduction would reduce the total pulmonary dose rate to $22 \mathrm{mrem} / \mathrm{yr}$.

In addition, it should be noted that although the major emission sources (stacks) differ each year, Plants 4,5 , and 8 are the greatest source of emissions. 


\subsection{COST ESTIMATES FOR ADDITIONAL EMISSION CONTROL}

The FMPC has over 50 dust collection stacks in either full or part-time operation. The operating stacks already utilize very efficient dust collection systems. Additional improvement in reducing operational releases is expected by using Goretex ${ }^{\circledR}$ fabric bags rather than wool bags and by using administrative controls in conjunction with the continuous stack monitor. Approximately 20 additional stacks have either been abandoned or placed on standby status. Extensive repair and refurbishment would be needed to return the abandoned and standby dust collection stacks to operation.

However, neither the use of improved fabric bags in the existing baghouses, nor installation of continuous radionuclide stack monitors will insure reductions in uranium particulate emissions at the FMPC. Reductions in emissions to lower levels will require the installation of secondary air cleaning systems on the primary emission sources located in Plants 4, 5, and 8 .

The primary particulate emission sources at the FMPC are given in Table 7.10. Each of the stacks listed in Table 7.10 had a measured emission level $\geqslant 5 \mathrm{~kg}$ of uranium during either 1981, 1982, or 1983. Conceptual design and cost estimates for the installation of secondary air cleaning systems have been prepared for these particular stacks.

\subsubsection{Proposed Emission Control Equipment}

The stacks listed in Table 7.10 are the primary particulate emission sources at the FMPC for the 1981-1983 time period. It is expected that these stacks will continue to be the primary particulate emission sources at the FMPC. Table 7.11 was provided by the FMPC and reports the existing exhaust duct diameter, flowrate, and the direction and distance from the dust collector/scrubber to the nearest wall. Each existing dust collector is a baghouse; no additional particulate technology is used on the scrubbers.

It is proposed that High-Efficiency Particulate Air (HEPA) filter systems be installed in addition to the existing emission control technology on each of

${ }^{\circledR}$ Gorete ${ }^{\circledR}$ is a registered trademark of W. L. Gore \& Associates, Inc. 
TABLE 7.10. Emissions from the Primary Particulate Emission Sources During 1981-1983

\begin{tabular}{|c|c|c|c|c|}
\hline \multirow[b]{2}{*}{ Plant } & \multirow{2}{*}{$\begin{array}{c}\text { Collector }(c) / \\
\text { Scrubber }(s)\end{array}$} & \multicolumn{3}{|c|}{ Emissions, $\mathrm{kg} \mathrm{U}$} \\
\hline & & 1981 & 1982 & 1983 \\
\hline 4 & $\begin{array}{l}\mathrm{G} 4-2(\mathrm{C}) \\
\mathrm{G} 4-5(\mathrm{C}) \\
\mathrm{G} 4-7(\mathrm{C}) \\
\mathrm{G} 4-14 \text { (c) }\end{array}$ & $\begin{array}{r}--(a) \\
11.5 \\
6.0 \\
170.8\end{array}$ & $\begin{array}{l}3.2 \\
1.5 \\
5.6 \\
7.3\end{array}$ & $\begin{array}{r}18.5 \\
20.9 \\
2.5 \\
--\left(\begin{array}{l}a \\
a\end{array}\right)\end{array}$ \\
\hline 5 & $\begin{array}{l}\text { G5-249 (c) } \\
G 5-254 \text { (c) } \\
G 5-256 \text { (c) } \\
\text { G5-260 (c) } \\
\text { G5-261 (c) } \\
\text { Plant } 55 \text { (c) }\end{array}$ & $\begin{array}{r}25.8 \\
5.1 \\
3.8 \\
27.9 \\
63.5 \\
0.9\end{array}$ & $\begin{array}{r}-.(a) \\
6.9 \\
2.0 \\
105.6 \\
52.8 \\
14.4\end{array}$ & $\begin{array}{r}0.9 \\
2.6 \\
5.3 \\
4.4 \\
16.1 \\
5.7\end{array}$ \\
\hline 8 & $\begin{array}{l}\text { G43-27 (c) } \\
8024 \text { (c) } \\
\text { Rotary Kiln(s) } \\
\text { Plus 0xidation \#1(s) }\end{array}$ & $\begin{array}{c}-(a) \\
--(a) \\
-16^{(b)}\end{array}$ & $\begin{array}{l}\left.80, \frac{1}{a}\right) \\
--7^{(b)}\end{array}$ & $\begin{array}{l}10.3 \\
14.4 \\
48.7(b)\end{array}$ \\
\hline
\end{tabular}

(a) No reportable emissions.

(b) Emission data reported only for sum of four scrubber units; the rotary kiln and oxidation \#l emissions are included in the totals given.

the emission sources listed in Table 7.10 to reduce their particulate emissions. By definition, each individual HEPA filter must have a minimum particle removal efficiency $>99.97 \%$ for particles $0.3 \mu \mathrm{m}$ diameter ${ }^{(6)}$. At present we must assume the HEPA filter systems will be required to meet the following criteria:

- Each dust collector/scrubber listed will be treated individually, i.e., existing exhaust streams will not be combined.

- The HEPA filter system must be "testable" in-place using the dioctyl phthalate test (DOP test).

- No process at the FMPC can be "shut down" for change-out of the filters. 
TABLE 7.11. Dust Collectors and Scrubbers with Annual Emissions $\geqslant 5 \mathrm{~kg} \mathrm{U}$ During the Period 1981-1983(a)

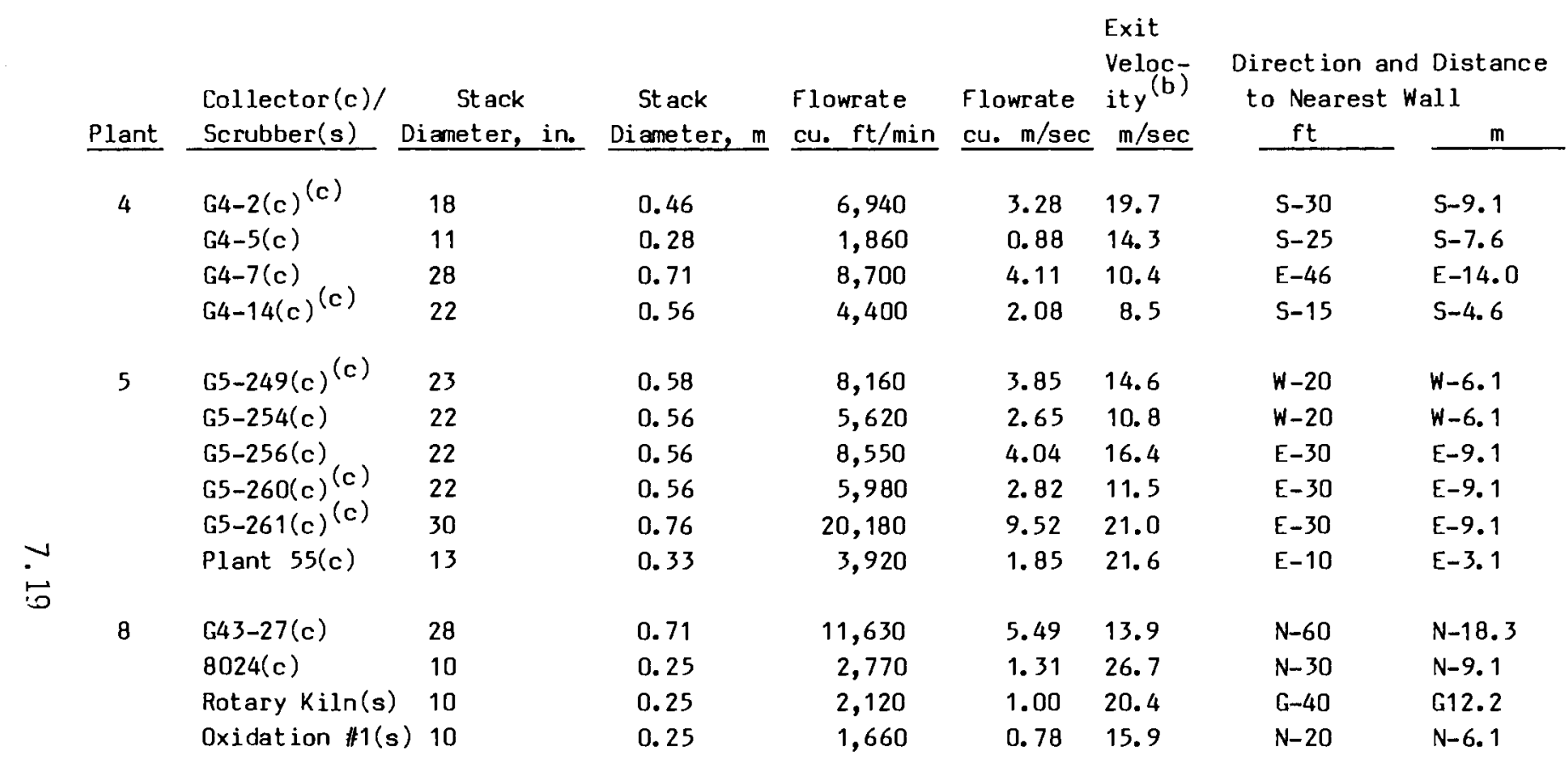

(a) Source: Material provided by the FMPC. Data provided in English units; conversion to metric units is also shown.

(b) Exit velocity calculated as: Exit Velocity = Flow rate/Cross-Sectional area.

(c) Information provided by the FMPC differs from that obtained from available blueprints (also provided by the FMPC). 
- Maintenance and filter change-out should be as "simple" as possible but within accepted practices.

The conceptual design must:

- Determine the applicability of both single-use and cleanable HEPAs.

- Determine equipment, material, and facility needs for the various HEPA filter systems considered.

- Determine the approximate frequency of filter change-out required for each HEPA fiiter system proposed using the largest single-year emission value listed in Table 7.10.

- Determine approximate size (dimensions) required for installation and maintenance, and weight of each HEPA fiiter system considered.

- Determine if existing structures will support the added weight of the proposed HEPA fiiter systems.

- Provide a cost estimate for each of the HEPA filter systems proposed. The cost estimate includes those categories normally provided.

The proposed conceptual design is based on the information given in Tables 7.10 and 7.11. As noted in Table 7.11, not all the information provided by the FMPC corresponds to values obtained from available blueprints (also provided by the FMPC). Table 7.12 presents the information obtained from the available blueprints. In general, differences between the two sources of information are small and are expected to have little or no impact on the conceptual design.

Single-use HEPAs were selected for the conceptual design. Cleanable HEPAs are available from at least two commercial manufacturers. (a) However, cleanable HEPAs were not considered because: 1) it is unknown if cleanable HEPAs

(a) Multi-Fab, Inc., 726 Wilhelm St., Harrison, NJ 07029-2094; and Kermatrol, 5720 Ralston St., Suite 300, Ventura, CA 93003. 
TABLE 7.12. Stack Information Obtained from Blueprints(a)

\begin{tabular}{|c|c|c|c|c|c|c|c|}
\hline Plant & $\begin{array}{c}\text { Stack } \\
\text { Identi- } \\
\text { fication }\end{array}$ & $\begin{array}{c}\text { Stack } \\
\text { Diameter, in. }\end{array}$ & $\begin{array}{c}\text { Stack } \\
\text { Diameter, } m\end{array}$ & $\begin{array}{l}\text { Flowrate } \\
\mathrm{cu} \mathrm{ft} / \mathrm{min}\end{array}$ & $\begin{array}{l}\text { Flowrate } \\
\text { cu } \mathrm{m} / \mathrm{sec}\end{array}$ & $\begin{array}{r}\text { Exit } \\
\text { Veloc- } \\
\text { ity, } \\
\mathrm{ft} / \mathrm{min} \\
\end{array}$ & $\begin{array}{r}\text { Exit } \\
\text { veloc- } \\
\text { ity, } \\
\mathrm{m} / \mathrm{sec} \\
\end{array}$ \\
\hline \multirow[t]{4}{*}{4} & G4 -2 & 20 & 0.51 & 7,900 & 3.73 & 3,625 & 18.4 \\
\hline & G4 -5 & -- & -- & -- & -- & -- & -- \\
\hline & G4-7 & -- & -- & - & -- & -- & -- \\
\hline & G4-14 & 24 & 0.61 & -- & -- & -- & -- \\
\hline \multirow[t]{6}{*}{5} & G5-249 & 23 & 0.58 & 9,200 & 4.34 & 3,170 & 16.1 \\
\hline & G5-254 & 22 & 0.56 & -- & -- & -- & - \\
\hline & G5-256 & -- & -- & -- & -- & -- & -- \\
\hline & G5-260 & 22 & 0.56 & 5,260 & 2.48 & 1,820 & 9.2 \\
\hline & G5-261 & 30 & 0.76 & 22,335 & 10.54 & 4,550 & 23.1 \\
\hline & PTL -55 & -- & -- & -- & -- & -- & -- \\
\hline \multirow[t]{4}{*}{8} & G43-27 & -- & -- & -- & -- & -- & -- \\
\hline & 8024 & -- & -- & -- & -- & -- & -- \\
\hline & Rotary Ki ln & -- & -- & -- & -- & -- & -- \\
\hline & Oxidation \# & -- & - & -- & -- & - & -- \\
\hline
\end{tabular}

(a) Dash indicates information not listed on available blueprints. Data provided in English units; conversion to metric units is also shown.

would be acceptable to DOE for use as the final filter on radioactive systems; and 2) it is not clear that such systems can be DOP tested in-place per ANSI N510 on a periodic basis.

A conceptual HEPA filter system design was prepared for each of the fourteen primary emission stacks given in Table 7.10. Each system possesses redundant filter capacity in order that the individual process and existing baghouse or scrubber will not have to be shut down during periodic filter change-out. Filter change-out is by standard bagout procedures.

Figures 7.3 through 7.16 represent the conceptual designs for each of the fourteen stacks given in Table 7.10. It has been assumed each system will utilize redundant HEPAs, each sized for the stated airflow. Filter housings 


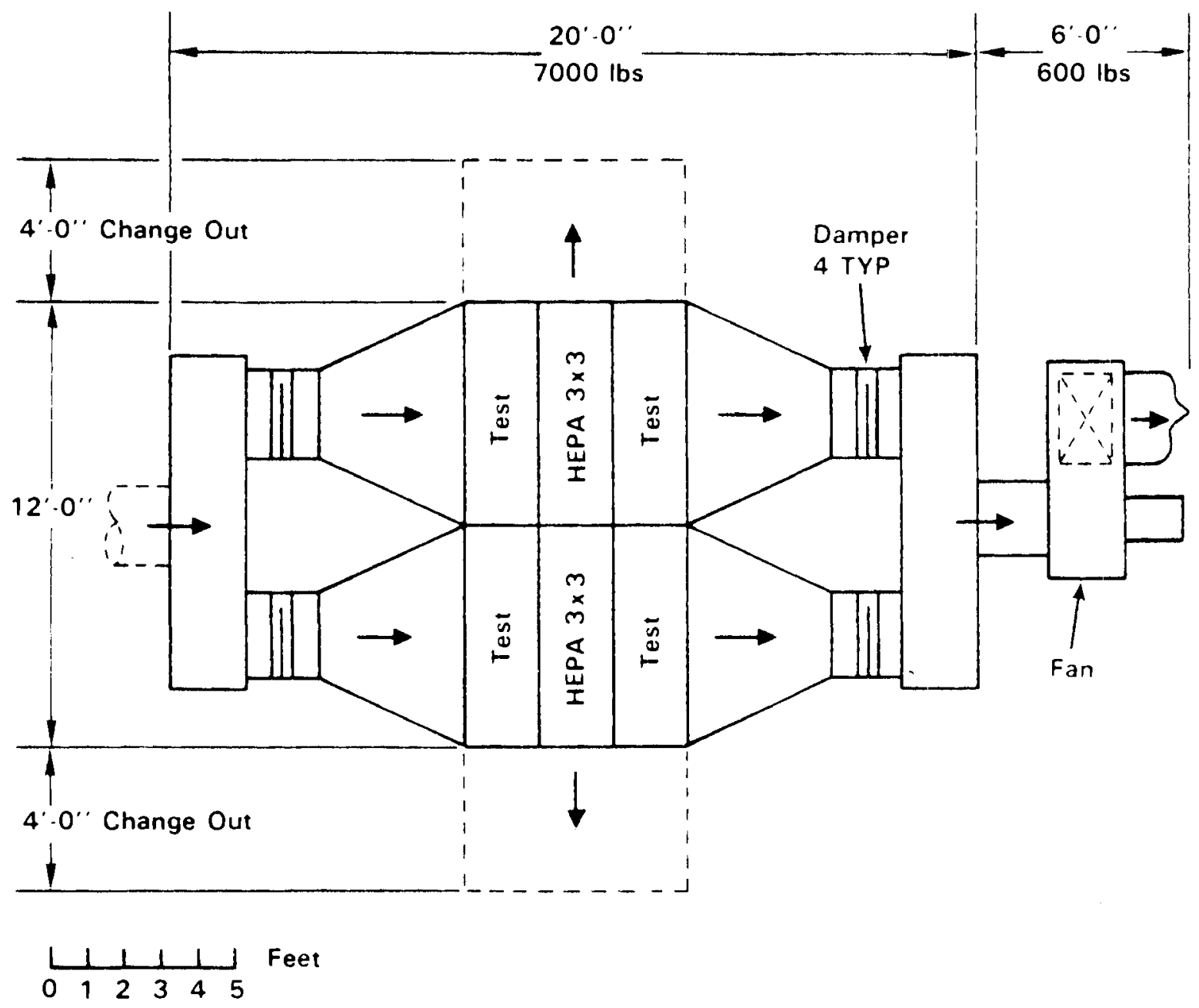

Project: Feed Materials Production Center

System: Plant 4 G4-2 (c)

Airflow: $6.940 \mathrm{CFM}$

Fan - Aerovent BI-450 10" S.P.

Filter: Flanders E.4 ( $3 \times 3)$ GG.F $(304)$

Size - $(3 \times 3) 8^{\prime}-0^{\prime \prime} \mathrm{H} \times 6^{\prime}-4^{\prime \prime} \mathrm{W}$

Weight: Filter and Test 6.000

Fan 600

Duct and Access 1,000

Total

$$
\overline{7.600} \mathrm{lbs}
$$

FIGURE 7.3. Conceptual Design, FMPC, Plant 4, G4-2(c). 


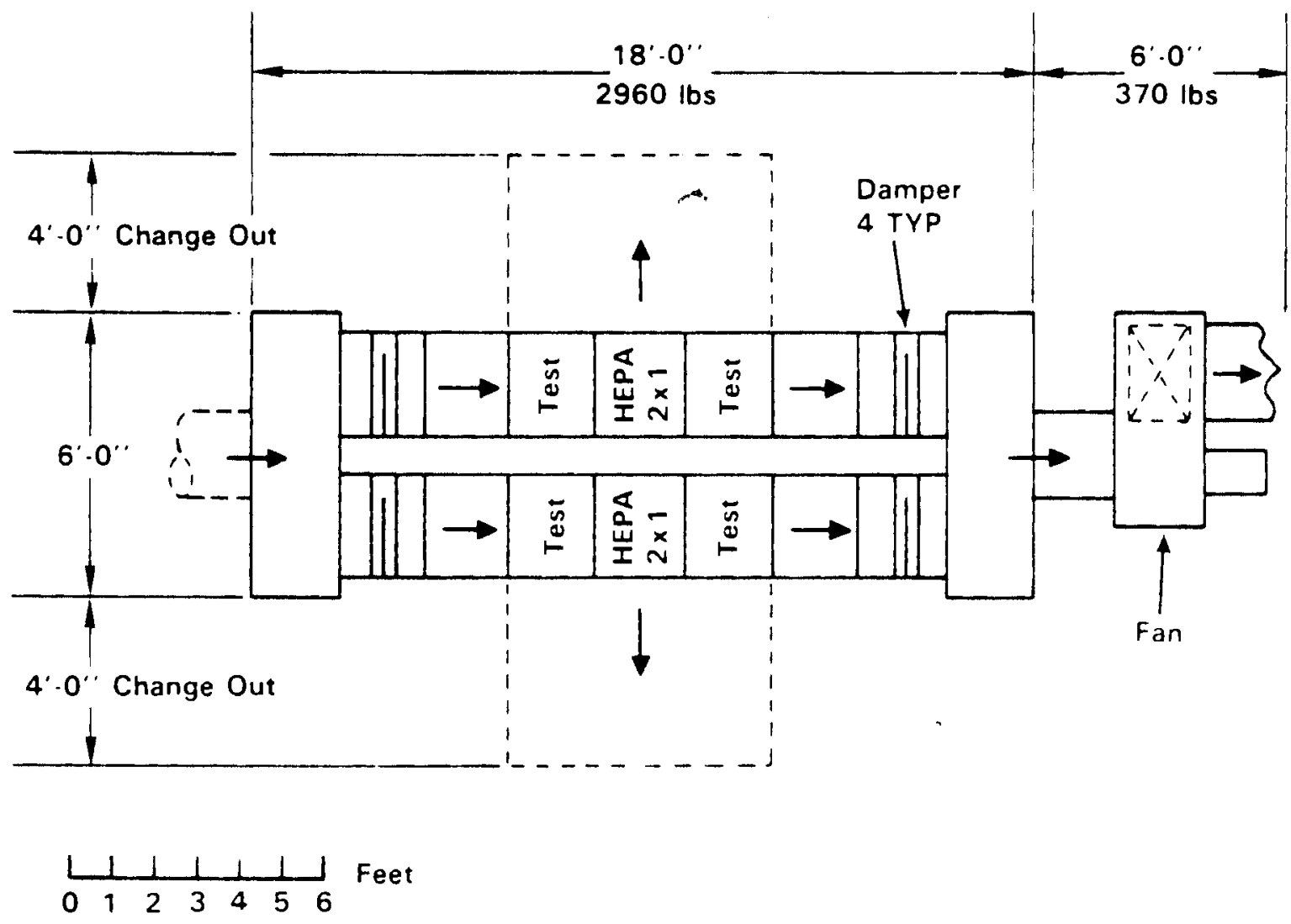

Project: Feed Materials Production Center

System: Plant 4 G4-5 (c)

Airflow: $1.860 \mathrm{CFM}$

Fan - Aerovent Bl-315 10" S.P.

Filter: Flanders E-4 $(2 \times 1)$ GG-F (304)

Size - $(2 \times 1) 5^{\prime}-0^{\prime \prime} \mathrm{H} \times 2^{\prime}-4^{\prime \prime} \mathrm{W}$

Weight: Filter and Test 2.160

Fan $\quad 370$

Duct and Access $\frac{800}{3,330 \mathrm{lbs}}$
Total

FIGURE 7.4. Conceptual Design, FMPC, Plant 4, G4-5(c). 


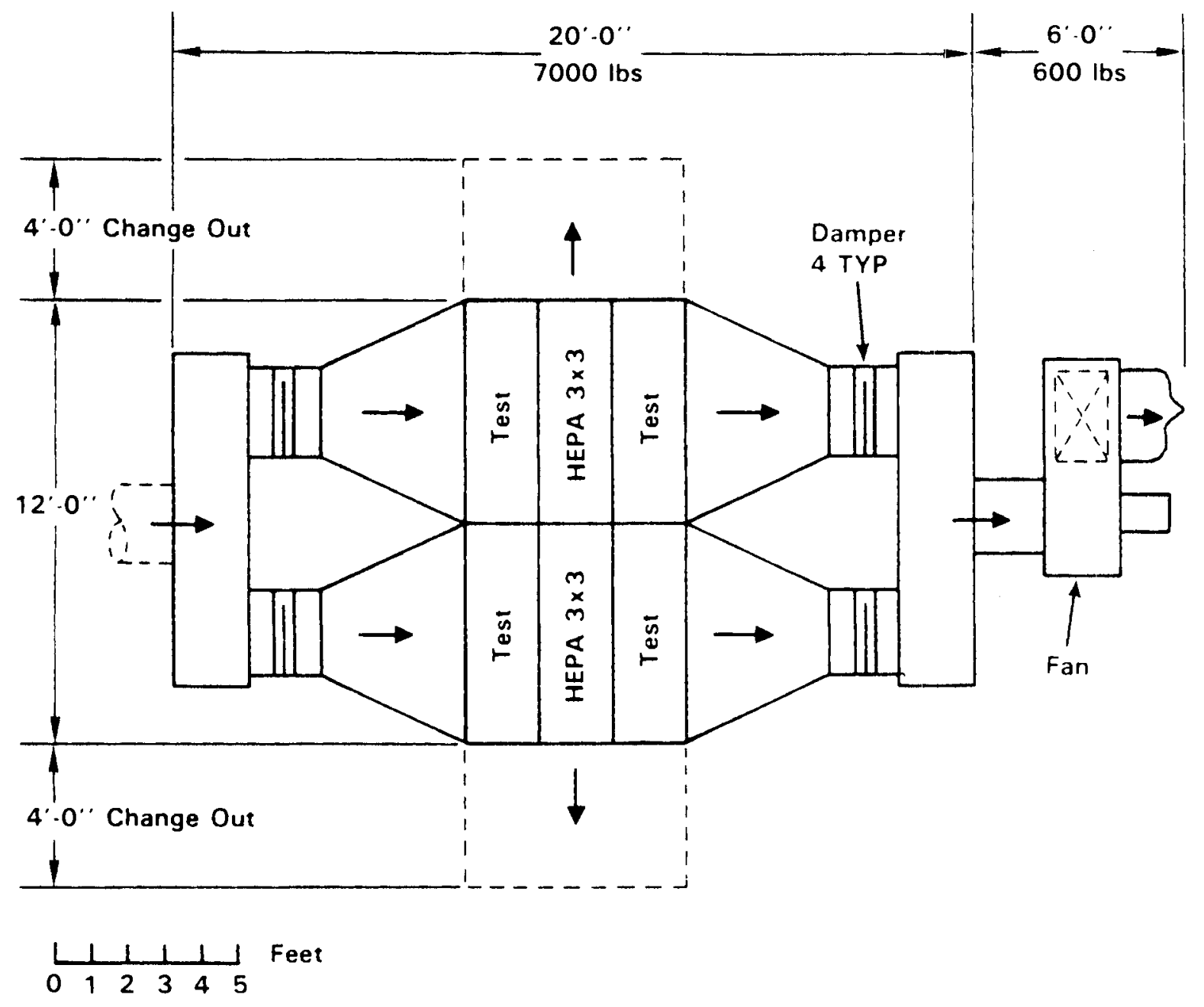

Project: Feed Materials Production Center

System: Plant 4 G4-7 (c)

Airflow: 8,700 CFM

Fan - Aerovent BI-500 10" S.P.

Filter: Flanders E-4 (3 3 3) GG-F (304)

Size - $(3 \times 3) 8^{\prime}-0^{\prime \prime} \mathrm{H} \times 6^{\prime}-4^{\prime \prime} \mathrm{W}$

Weight: Filter and Test 6,000

Fan 600

Duct and Access 1,000

Total $\quad 7,600 \mathrm{lbs}$

FIGURE 7.5. Conceptual Design, FMPC, Plant 4, G4-7(c). 


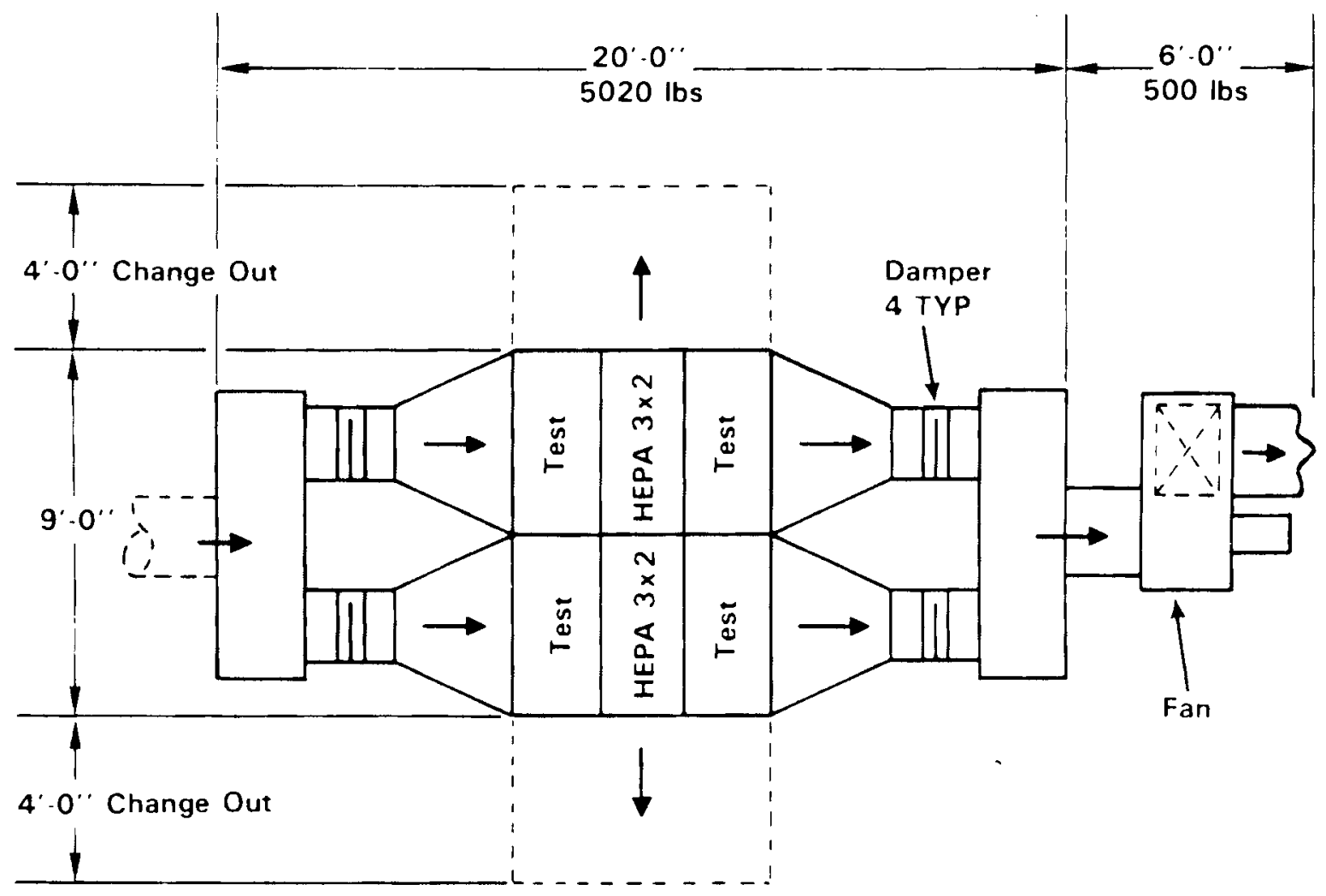

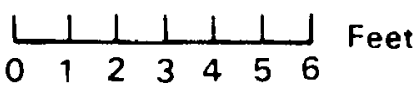

Project: Feed Materials Production Center

System: Plant 4 G4-14 (c)

Airflow: 4,400 CFM

Fan - Aerovent BI-450 10" S.P.

Filter: Flanders E-4 (3×2) GG-F (304)

Size - $(3 \times 2) 8^{\prime}-0^{\prime \prime} \mathrm{H} \times 2^{\prime}-4^{\prime \prime} \mathrm{W}$

Weight: Filter and Test 4,020

Fan 500

Duct and Access 1,000

Total $\overline{5,520} \mathrm{lbs}$

FIGURE 7.6. Conceptual Design, FMPC, Plant 4, G4-14(c). 


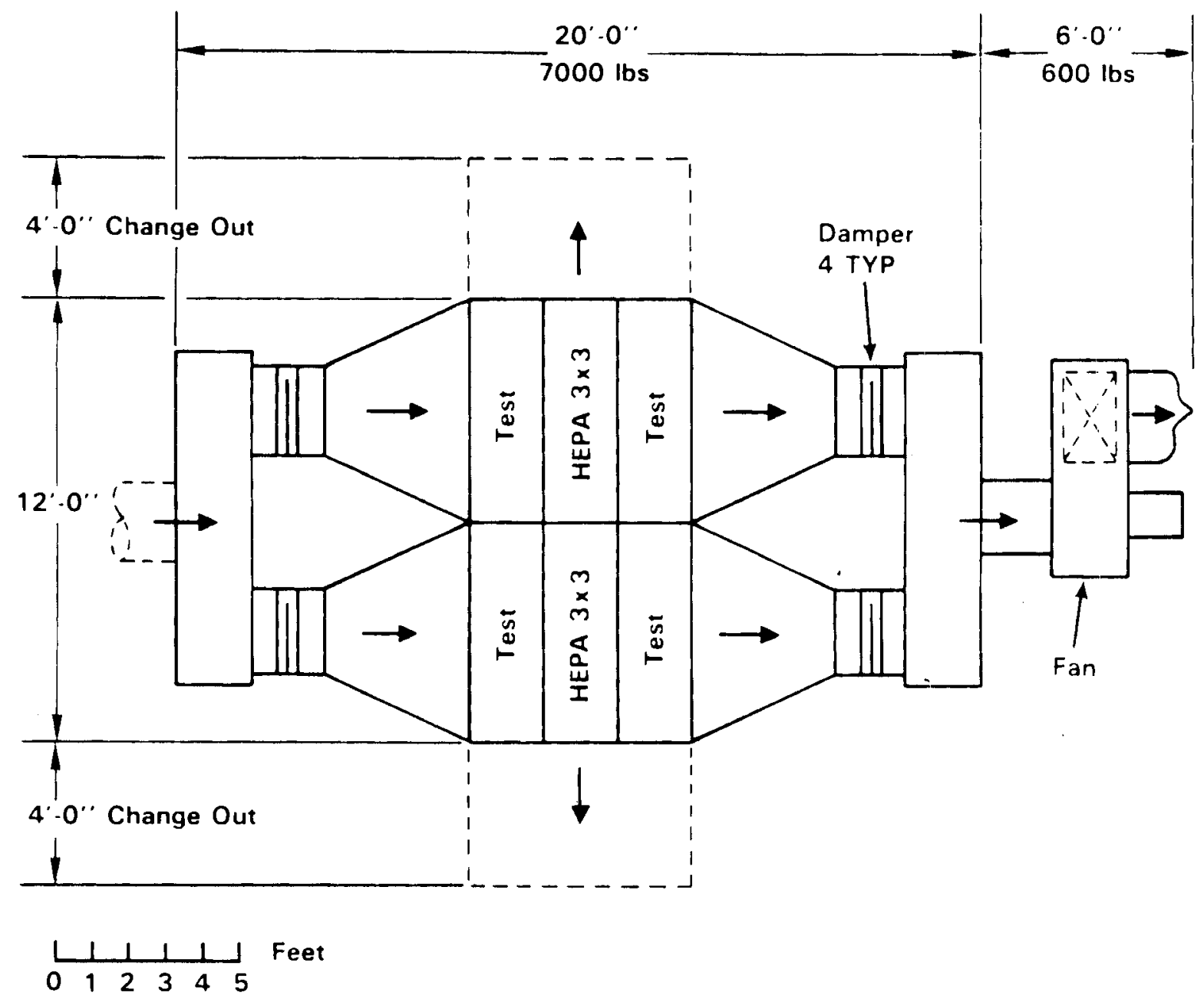

Project: Feed Materials Production Center

System: Plant 5 G5-249 (c)

Airflow: 8.160 CFM

Fan - Aerovent BI-500 10" S.P.

Filter: Flanders E-4 (3×3) GG-F (304)

Size - $(3 \times 3) 8^{\circ}-0^{\prime \prime} \mathrm{H} \times 6^{\prime} .4^{\prime \prime} \mathrm{W}$

Weight: Filter and Test 6,000

Fan 600

Duct and Access 1,000

Total $\overline{7,600} \mathrm{lbs}$

FIGURE 7.7. Conceptual Design, FMPC, Plant 5, G5-249(c). 


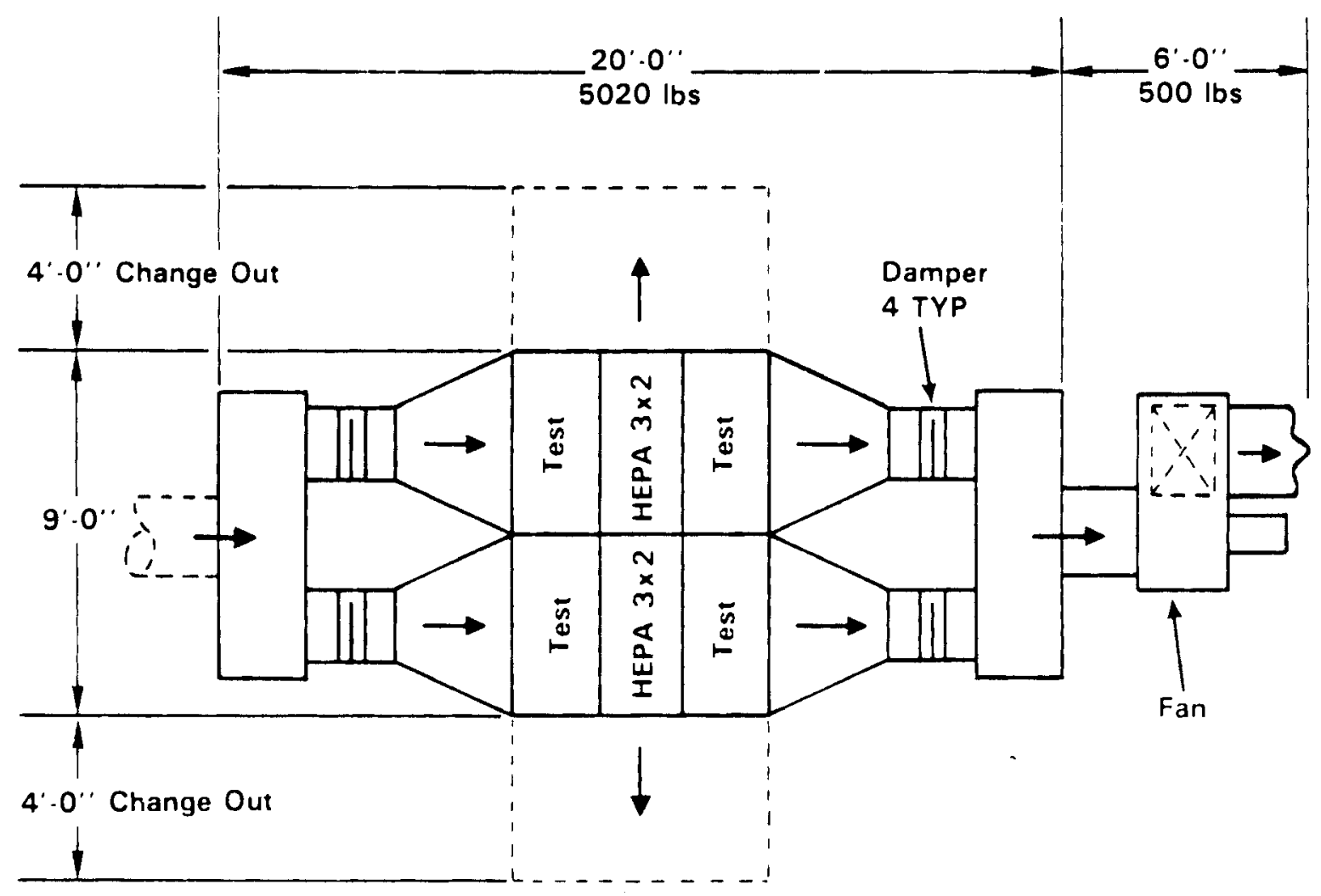

$\begin{array}{llllllll}1 & 1 & 1 & 1 & 1 & 1 & 1 & 1 \\ 0 & 1 & 2 & 3 & 4 & 5 & 6\end{array}$ Feet

Project: Feed Materials Production Center

System: Plant 5 G5-254 (c)

Airflow: 5,620 CFM

Fan - Aerovent B1-450 10" S.P.

Filter: Flanders E-4 (3×2) GG-F (304)

Size - $(3 \times 2) 8^{\prime}-0^{\prime \prime} \mathrm{H} \times 2^{\prime}-4^{\prime \prime} \mathrm{W}$

Weight: Filter and Test 4,020

Fan 500

Duct and Access 1,000

Total $\overline{5,520} \mathrm{lbs}$

FIGURE 7.8. Conceptual Design, FMPC, Plant 5, G5-254(c). 


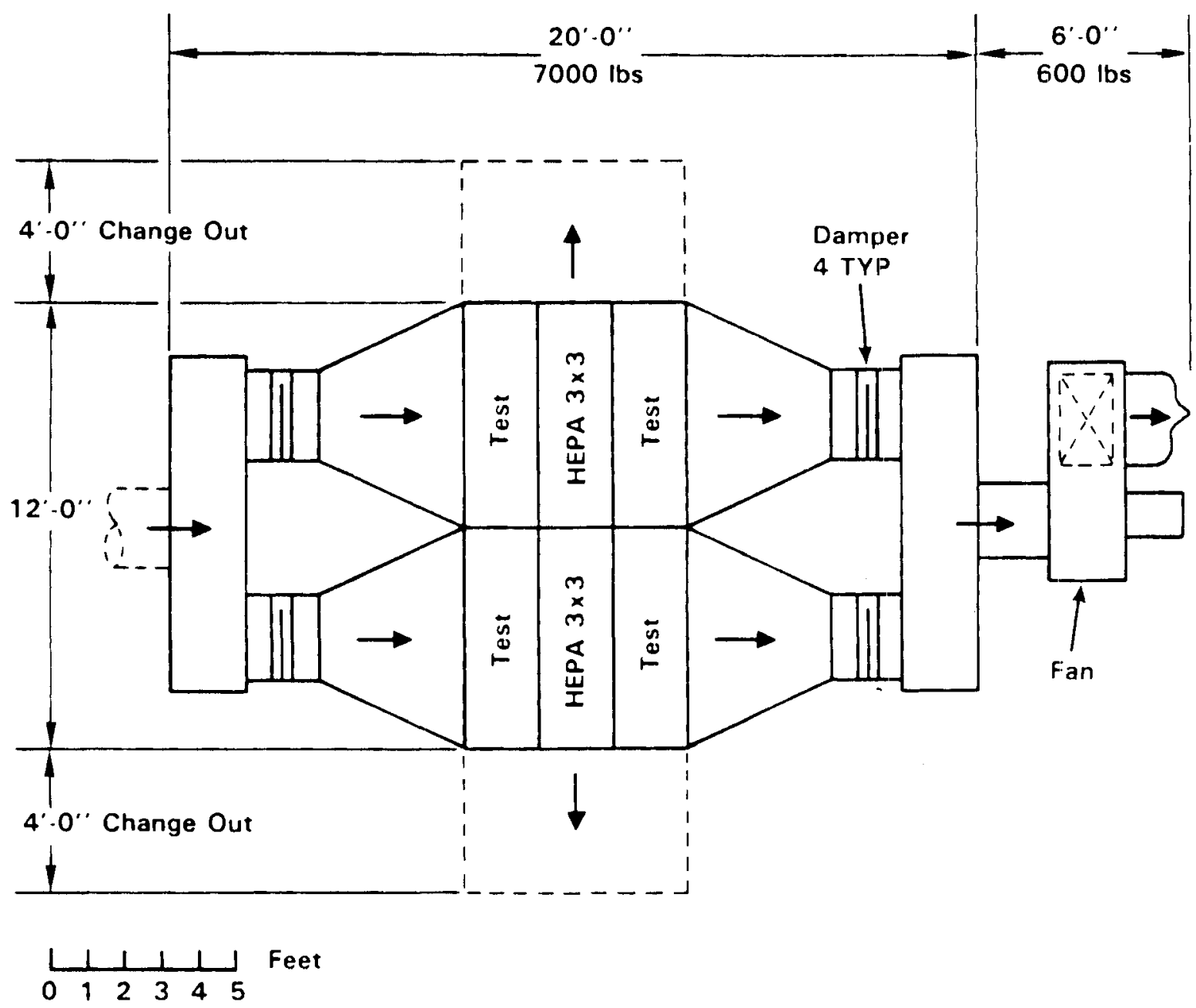

Project: Feed Materials Production Center

System: Plant 5 G5-256 (c)

Airflow: 8.550 CFM

Fan - Aerovent B1-500 10" S.P.

Filter: Flanders E-4 (3×3) GG-F (304)

Size - $(3 \times 3) 8^{\prime}-0^{\prime \prime} \mathrm{H} \times 6^{\prime} .4^{\prime \prime} \mathrm{W}$

Weight: Filter and Test 6.000

Fan 600

Duct and Access 1,000

Total $\quad \overline{7.600} \mathrm{lbs}$

FIGURE 7.9. Conceptual Design, FMPC, Plant 5, G5-256(c). 


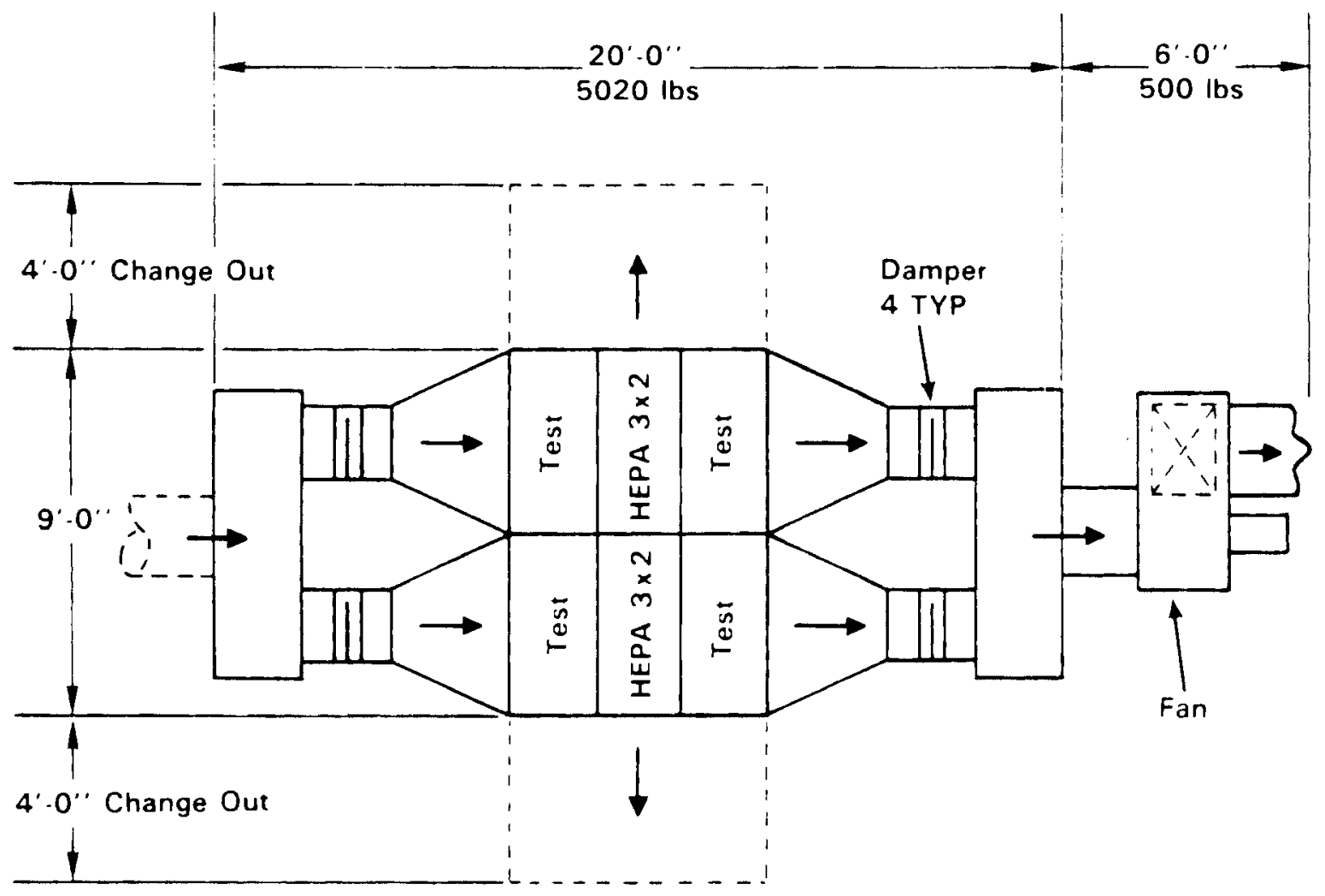

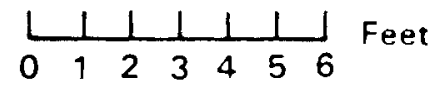

Project: Feed Materials Production Center

System: Plant 5 G5-260 (c)

Airflow: 5,980 CFM

Fan - Aerovent Bl-450 10" S.P.

Filter: Flanders E-4 $(3 \times 2)$ GG-F (304)

Size - $(3 \times 2) 8^{\prime}-0^{\prime \prime} \mathrm{H} \times 2^{\prime}-4^{\prime \prime} \mathrm{W}$

Weight: Filter and Test 4,020

Fan $\quad 500$

Duct and Access 1,000

Total $\quad \overline{5,520} \mathrm{lbs}$

FIGURE 7.10. Conceptual Design, FMPC, Plant 5, G5-260(c). 


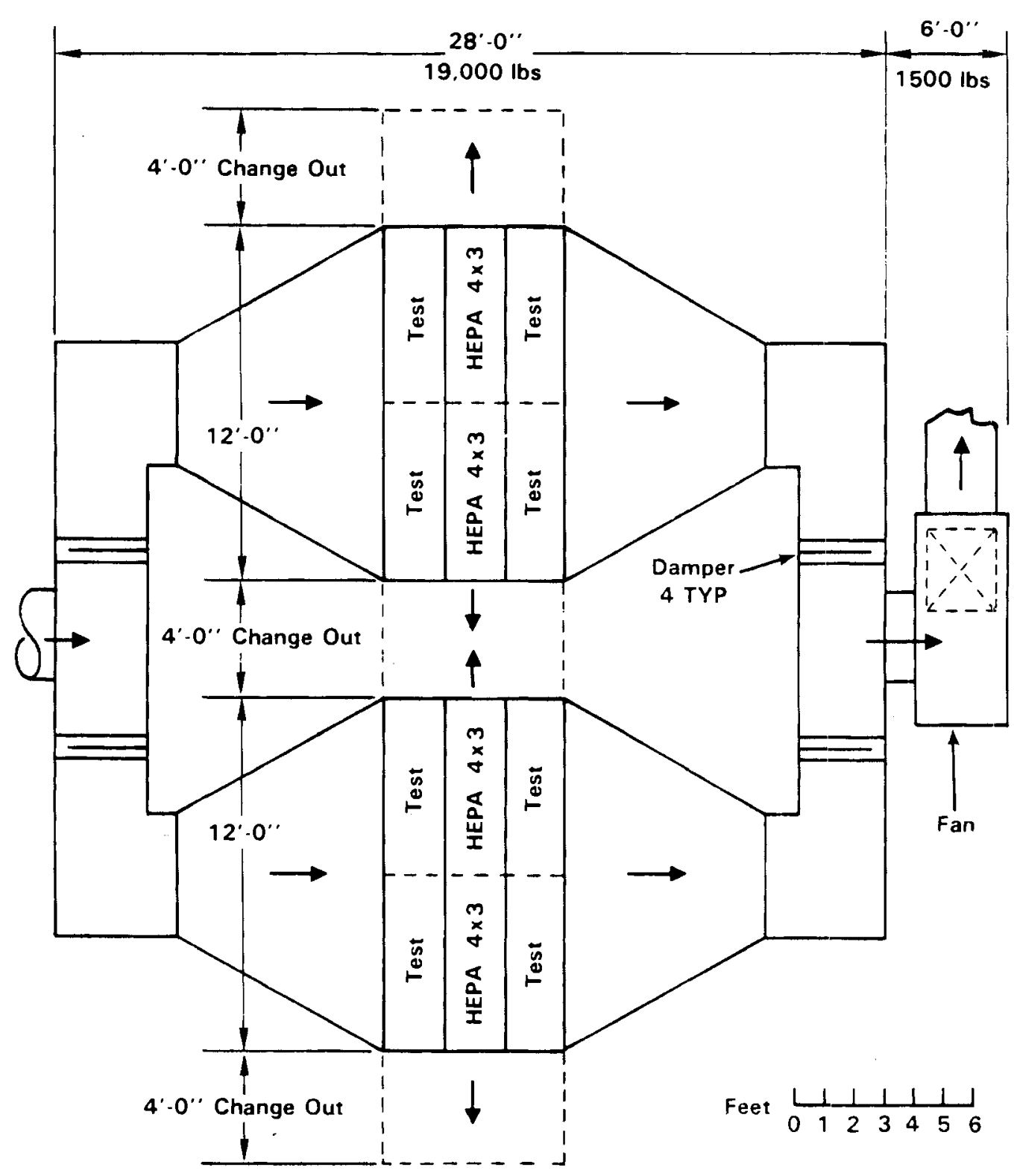

Project: Feed Materials Production Center

System: Plant 5 G5.261 (c)

Airflow: 20,180 CFM

Fan - Aerovent BI-800 10" S.P.

Filter: Flanders E-4 (2 [4×3]) GG-F (304)

Size - $2(4 \times 3) 10^{\prime}-0^{\prime \prime} \mathrm{H} \times 2 \approx 6^{\prime}-4^{\prime \prime} \mathrm{W}$

Weight: Filter and Test 16,000

Fan $\quad 1,500$

Duct and Access 3,000

Total $\overline{20,500} \mathrm{lbs}$

FIGURE 7.11. Conceptual Design, FMPC, Plant 5, G4-261(c). 

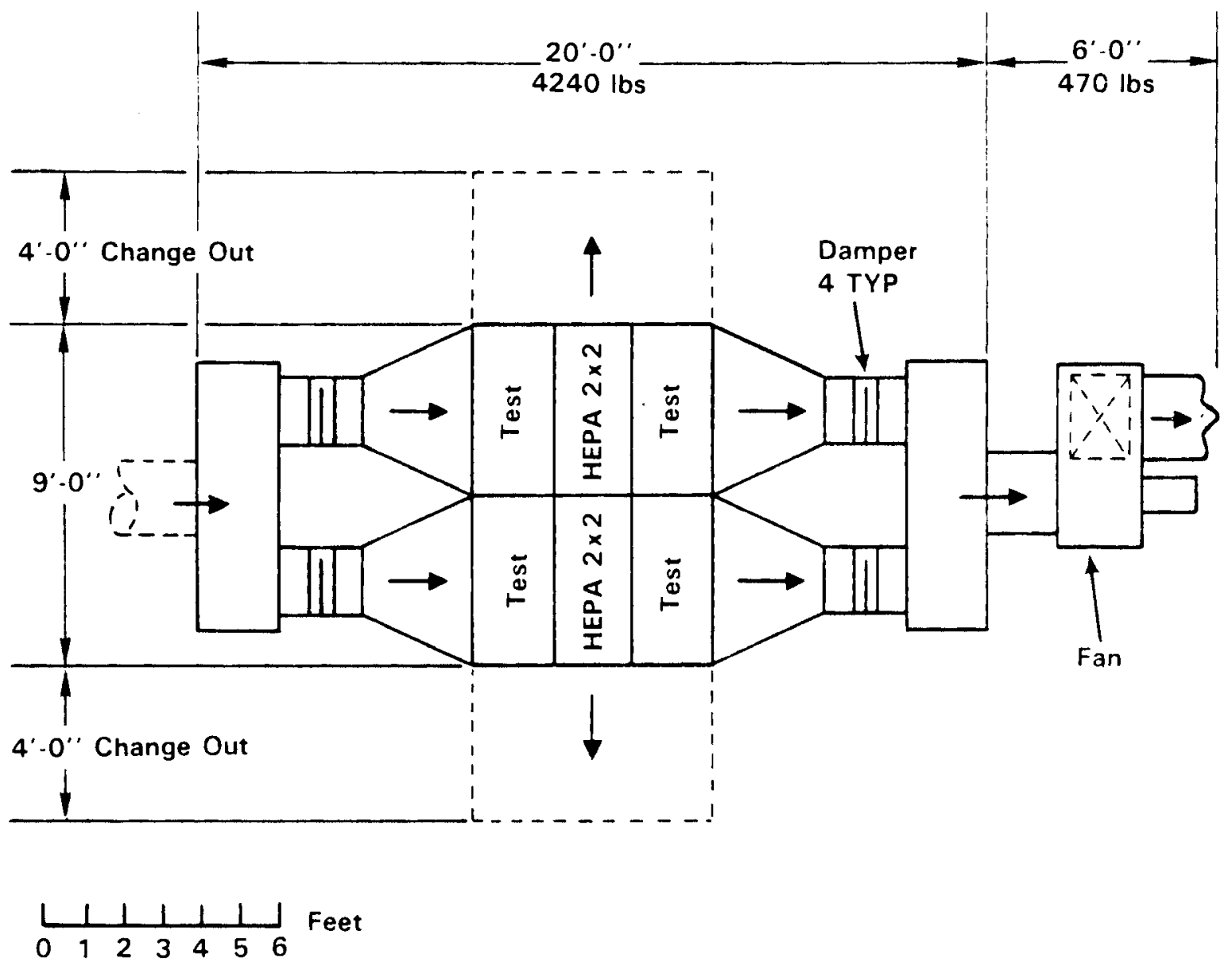

Project: Feed Materials Production Center

System: Plant 5 Plant 55 (c)

Airflow: $3.920 \mathrm{CFM}$

Fan - Aerovent B1-400 10" S.P.

Filter: Flanders E-4 $(2 \times 2)$ GG.F (304)

Size - $(2 \times 2) 5^{\circ} \cdot 0^{\prime \prime} \mathrm{H} \times 4^{\prime} .4^{\prime \prime} \mathrm{W}$

Weight: Filter and Test 3,240

Fan 470

Duct and Access 1,000

Total $\quad \overline{4,710} \mathrm{lbs}$

FIGURE 7.12. Conceptual Design, FMPC, Plant 5, 55(c). 


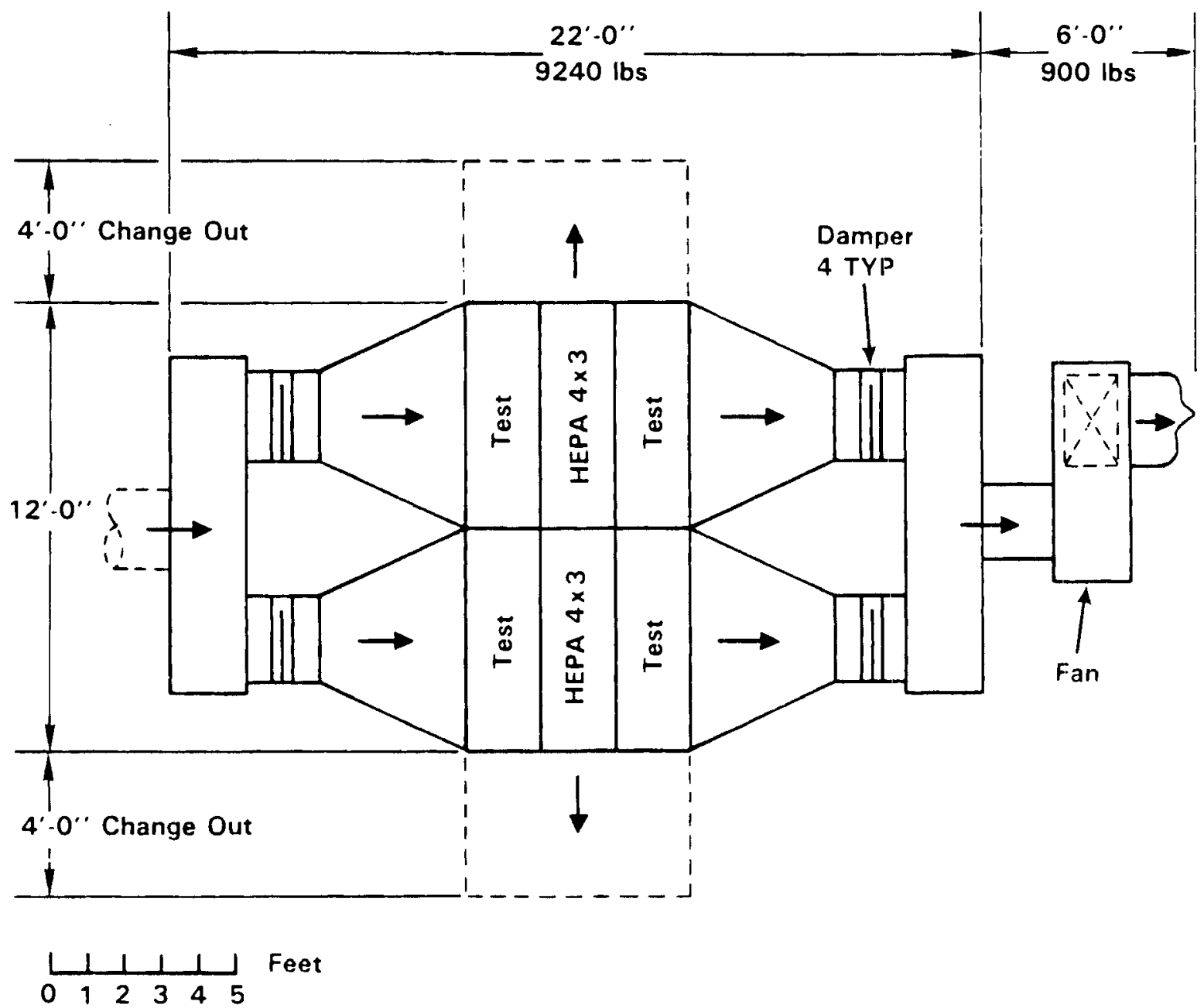

Project: Feed Materials Production Center

System: Plant 8 G43-27 (c)

Airflow: 11,630 CFM

Fan - Aerovent BI-630 10" S.P.

Filter: Flanders E-4 (4×3) GG-F (304)

Size - $(4 \times 3) 10^{\prime}-0^{\prime \prime} \mathrm{H} \times 6^{\prime}-4^{\prime \prime} \mathrm{W}$

Weight: Filter and Test 8.040

Fan

900

Duct and Access 1,200

Total $\overline{10.140}$ lbs

FIGURE 7.13. Conceptual Design, FMPC, Plant 8, G43-27(c). 


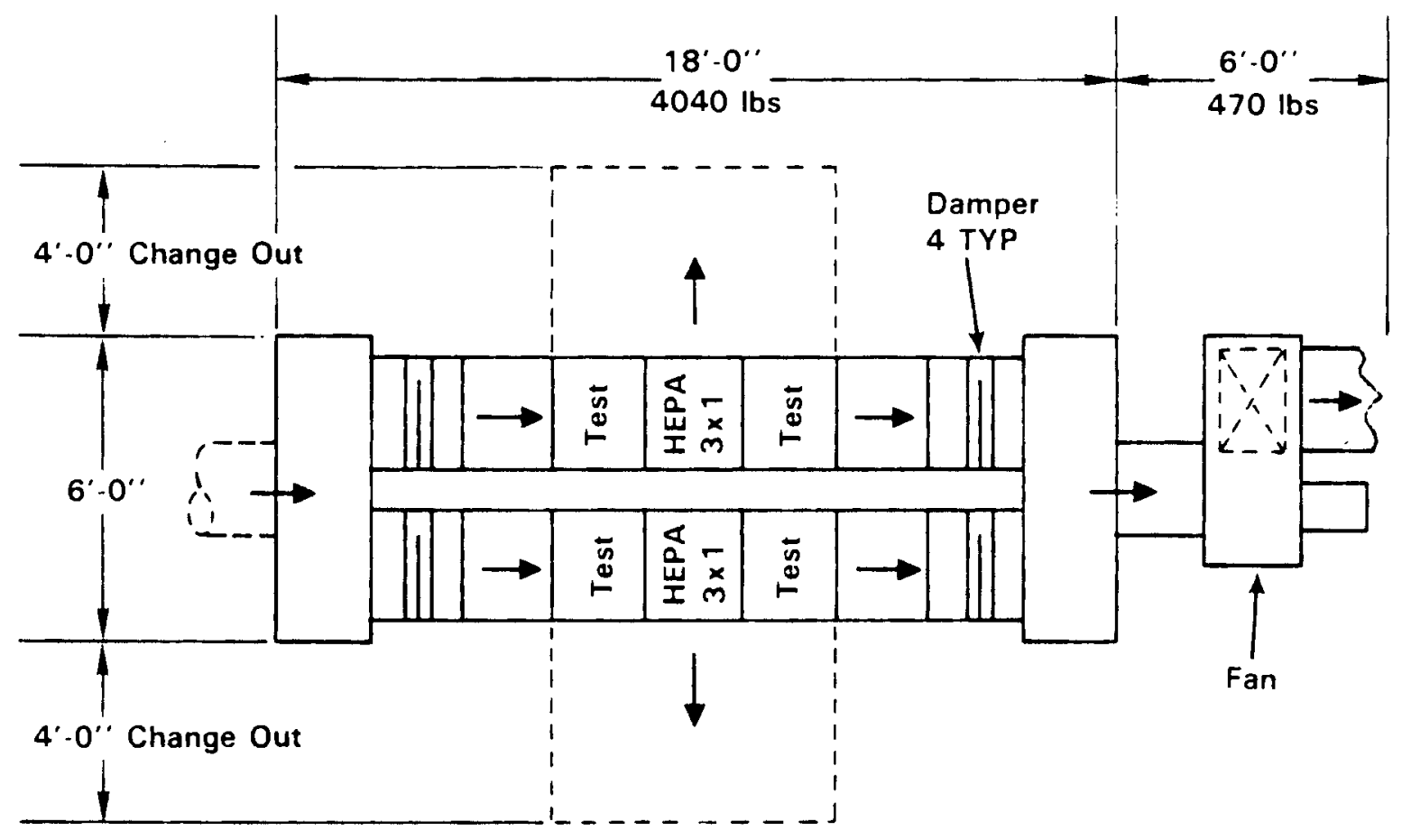

$\begin{array}{llllllll}1 & 1 & 1 & 1 & 1 & 1 & 1 & 1 \\ 0 & 1 & 2 & 3 & 4 & 5 & 6\end{array}$ Feet

Project: Feed Materials Production Center

System: Plant 88024 (c)

Airflow: 2,770 CFM

Fan - Aerovent BI-400 10" S.P.

Filter: Flanders E-4 ( $3 \times 1)$ GG-F (304)

Size - $(3 \times 1) 8^{\prime}-0^{\prime \prime} \mathrm{H} \times 2^{\prime}-4^{\prime \prime} \mathrm{W}$

Weight: Filter and Test $\quad 3.240$

Fan 470

Duct and Access $\frac{800}{4,510} \mathrm{lbs}$
Total

FIGURE 7.14. Conceptual Design, FMPC, Plant 8, 8024(c). 


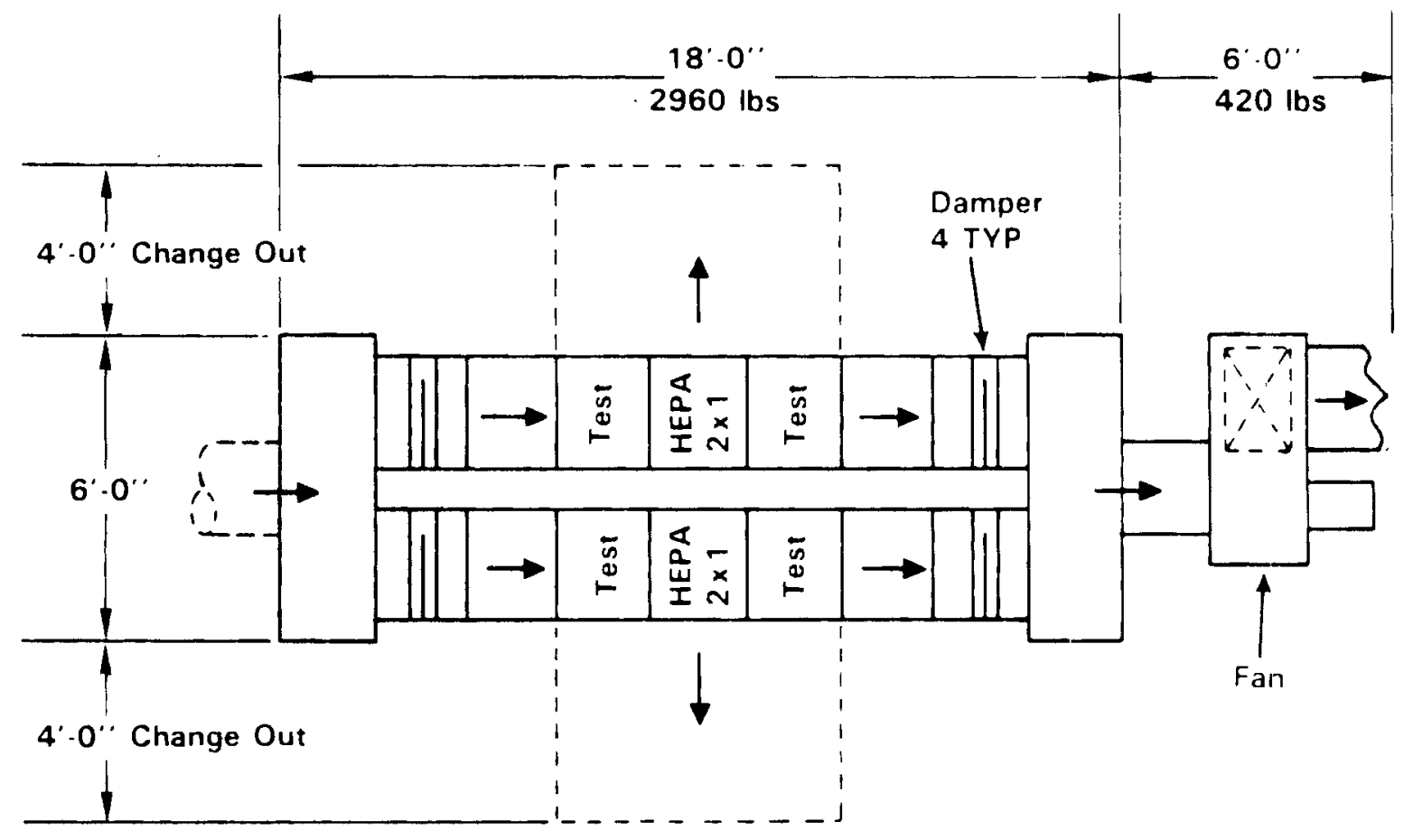

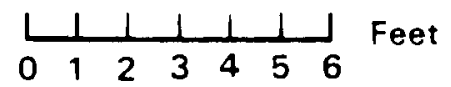

Project: Feed Materials Production Center

System: Plant 8 Rotary Kiln (s)

Airflow: 2,120 CFM

Fan - Aerovent BI-335 10" S.P.

Filter: Flanders E-4 (3x 1$)$ GG-F (304)

Size - $(3 \times 1) 8^{\prime}-0^{\prime \prime} \mathrm{H} \times 2^{\prime} .4^{\prime \prime} \mathrm{W}$

Weight: Filter and Test 2,160

Fan 420

Duct and Access $\frac{800}{3.380}$

Total

$3.380 \mathrm{lbs}$

FIGURE 7.15. Conceptual Design, FMPC, Plant 8, Rotary Kiln(s) 


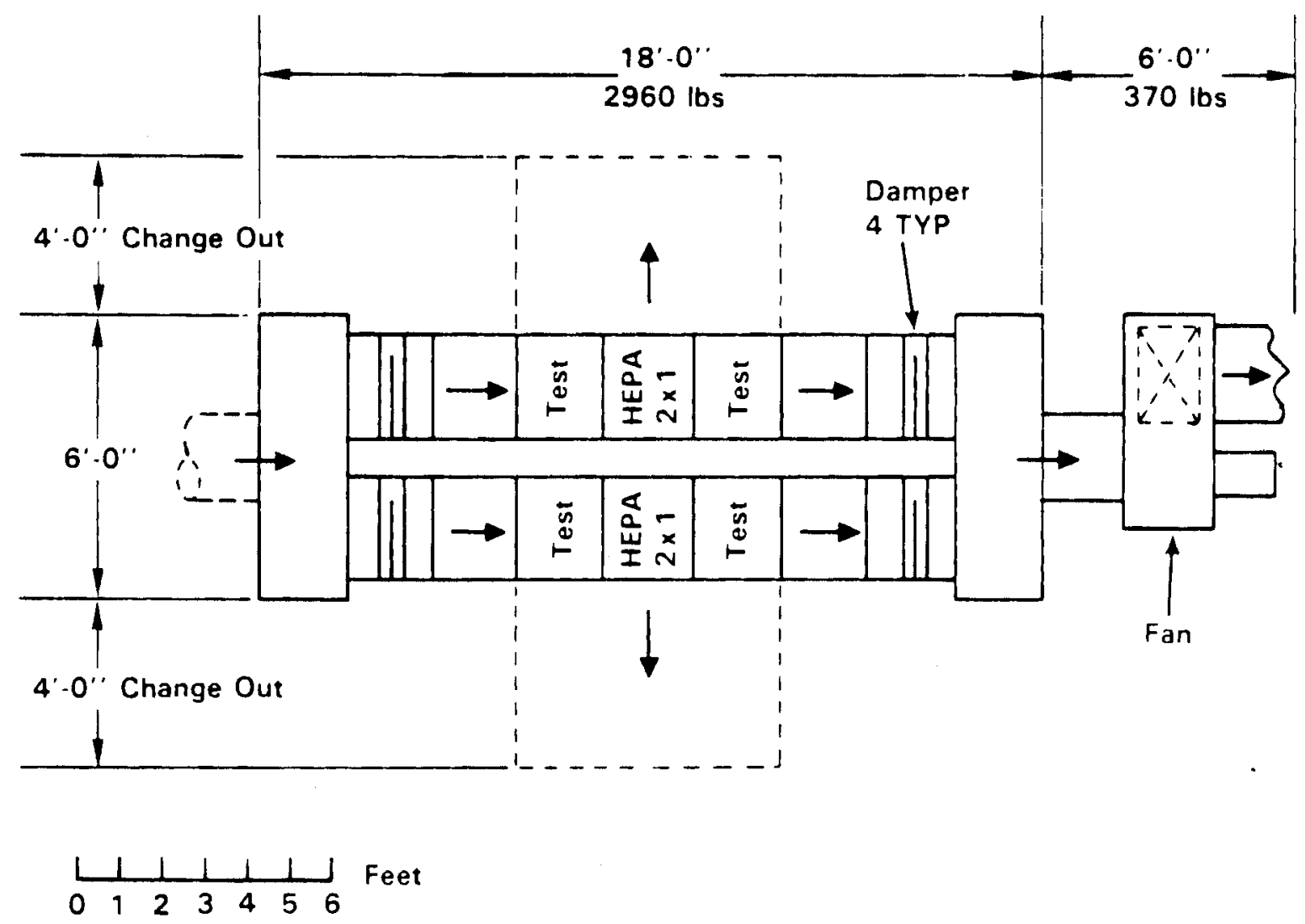

Project: Feed Materials Production Center

System: Plant 8 Oxidation \#1 (s)

Airflow: 1,660 CFM

Fan - Aerovent BI-315 10" S.P.

Filter: Flanders E-4 (2x1) GG-F (304)

Size - $(2 \times 1) 5^{\prime}-0^{\prime \prime} \mathrm{H} \times 2^{\prime}-4^{\prime \prime} \mathrm{W}$

Weight: Filter and Test 2,160

Fan $\quad 370$

Duct and Access

Total $\quad \overline{3.330} \mathrm{lbs}$

FIGURE 7.16. Conceptual Design, FMPC, Plant 8, Oxidation No. 1(s) 
and ductwork are stainless steel. Inlets to the HEPA systems are from existing baghouses or scrubbers. Dimensions required for the filter system, access for maintenance, and space requirements for filter change-out are given for each system. Estimated weights for the major components of each system and the total system weight are also given in each figure.

The conceptual designs for the scrubbers in Plant 8 do not include any reduction in moisture content of the scrubber exhaust prior to the HEPA filter system. Data on moisture content and exhaust temperature for these streams were not available and precluded this analysis. However, it should be noted that moisture reduction devices prior to the HEPA filter systems may be required. Standard practices normally include a demister and/or heaters to prevent a buildup of moisture on the HEPA filters resulting in too great a pressure differential across the filters.

Approximate change-out frequencies for the HEPAs in each system are given in Table 7.13. The change-out frequency is based on the maximum single-year emission experienced per stack during the 1981-1983 annual time period, the design capacity per filter, and the number of filters per system. None of the change-out frequencies is considered excessive.

Placement of the proposed HEPA filter systems is dependent on: 1) available existing space in Plants 4,5 , and 8 ; 2) space that could be made available by removal of obsolete and unneeded existing emission controls; and 3 ) allowable floor or roof $(a)$ live loads at the locations proposed for installation of the HEPA filter systems. The floor loading attributed to the proposed systems is very light and for most of the filter systems would require only the addition of minor secondary steel for support. However, the Plant 5 perimeterappears heavily loaded and may require the additional filter systems to be located outside the existing structure, i.e., a new structure or structures may be required for the filter systems installed in Plant 5 .

(a) Roof allowable live loads are not required if the HEPA filter system is not supported from the roof structure. 
TABLE 7.13. Dust Holding Capacity (a)

Plant \#4

\begin{tabular}{|c|c|c|c|c|c|}
\hline System No. & CFM & Ka Loading ${ }^{(b)}$ & Lbs & $\begin{array}{c}\text { Total Loading(c) } \\
\text { Lbs } \\
\end{array}$ & $\begin{array}{l}\text { Approximate Changeout } \\
\text { Frequency in "Months" (d) } \\
\end{array}$ \\
\hline $64-2(c)$ & 6940 & 18.5 & 40 & 36 & 11 \\
\hline G4-5(c) & 1860 & 20.9 & 46 & 8 & 2 \\
\hline G4-7(c) & 8700 & 6.0 & 13 & 36 & 36 \\
\hline$G 4-14(c)$ & 4400 & 170.8 & 376 & 24 & .875 ( 3.5 weeks) \\
\hline \multicolumn{6}{|c|}{ Plant \#5 } \\
\hline$G 5-249(c)$ & 8160 & 25.8 & 56 & 36 & 8 \\
\hline G5-254(c) & 5620 & 6.9 & 15 & 24 & 20 \\
\hline$G 5-256(c)$ & 8550 & 5.3 & 12 & 36 & 38 \\
\hline$G 5-260(c)$ & 5980 & 105.6 & 233 & 24 & 1.2 \\
\hline$G 5-261(c)$ & 20,180 & 63.5 & 140 & 96 & 8 \\
\hline Plant $55(\mathrm{c})$ & 3920 & 14.4 & 32 & 16 & 6 \\
\hline \multicolumn{6}{|c|}{ Plant \#8 } \\
\hline $643-27(c)$ & 11,630 & 80.1 & 177 & 48 & 3.2 \\
\hline $8024(c)$ & 2770 & 14.4 & 32 & 12 & 4.6 \\
\hline $\begin{array}{l}\text { \{Rotary Kiln(s)t } \\
\text { Oxidation } \# 1(s)\}\end{array}$ & 3780 & 48.7 & 107 & 20 & 1.8 \\
\hline
\end{tabular}

(a) C. A. Burchsted, A. B. Fuller, and J. E. Kahn, ERDA 76-21, 1976. Chapter 3, paragraph 3.2.1 (4 lbs/1000 CFM).

(b) Maximum sinale-year loadina experienced during 1981-1983.

(c) Based on the number of filters in the system.

(d) Chanqeout frequency calculated as: I(Total loading in lbs. permitted for each system, based on the number of filters in the system times 4 lbs loading Der filter) / (Maximum single-year emissions in lbs experienced durina 1981-1983)] $[12$ months]. 


\subsubsection{Existing and Proposed Stack Monitoring Systems}

Radionuclude emissions at the FMPC are essentially all natural uranium in the form of particulates. Various chemical forms are emitted and these have been identified in Table 7.2. Emission particle sizes and particle densities have not been reported.

Each stack at the FMPC has an in-stack sampler to determine the quantity of particulates emitted. The sampler collects particulates on a filter paper which is periodically removed and the quantity of uranium collected determined by chemical analyses. Each stack sampler is operated under isokinetic conditions so that total stack emissions can be determined from the quantity of material collected by the stack sampler.

Emissions determined from a given stack sampler are usually not directly relatable to either a given calendar year or a given fiscal year because the filter paper collectors are not removed for analysis on a regular time interval. A given analysis may represent a several month time period of collection; this time period may span portions of two calendar years or two fiscal years. The stack samplers provide valuable information for uranium inventory control but are deficient as emission detection devices.

The FMPC has installed new, continuous stack monitors on the following stacks: Plant 4, Stacks G4-2, G4-12, and G4-14; Plant 5, Stacks G5-250, G5260, and G5-261; Plant 8, Stack G43-27; and Plant 9, Stack G9N1-1039. The continuous stack monitors are pancake-type Geiger-Müler probes installed to monitor the back side of the filter paper used in the in-stack particulate sampler. The continuous stack monitors provide information in "real-time" on stack emissions. The new monitors can be alarmed for rate-of-rise of radioactivity detected, and coupled to automatic shutoff of the process equipment. The rate-of-rise alarm on the continuous stack monitor indicates the failure of the existing primary emission control device (baghouse or scrubber) to adequately control emissions. The usual cause of alarms for existing baghouses is a break or tear in a bag. The new continuous stack monitors have shown they can detect small leaks in bags that would have gone unnoticed until a buildup of material on the in-stack sampler was observed. 
Thus, engineered controls to shut down a given process as a result of using the continuous stack monitor are possible. The FMPC already has administrative controls to shut down processes in order to replace leaking bags in the existing baghouses. However, the reliability of coupling process shut down to the continuous stack monitors is presently unknown. In addition, the FMPC has stated that some processes cannot be shut down during certain operational phases.

The use of the continuous stack monitor is highly recommended as a method to detect leaks in bags or excessive emissions from either the baghouses or scrubbers. However, installation of the continuous stack monitor cannot insure reductions in emissions; secondary particulate emission control devices are also required.

The continuous stack monitors are best used in their existing configuration,i.e., real-time detection of emissions prior to the secondary particulate emission control devices. This configuration allows rapid detection and repair of deficiencies in the primary emission control devices and should reduce the rate of particulate loading on the HEPA filter systems proposed as the secondary emission controls.

A second in-stack sampler (filter paper collector) downstream of the final emission control device is also recommended for uranium inventory control and determination of actual emissions to the environment. If possible, this in-stack sampler should be analyzed to correlate with annual reporting requirements.

\subsubsection{Estimated Cost of Proposed Equipment}

The FMPC has plans to obtain and install 14 additional continuous stack monitors. They have estimated a cost of $\$ 105 \mathrm{~K}(\$ 7.5 \mathrm{~K}$ per continuous stack monitor) for this additional monitoring technology. The acquisition of fourteen additional continuous stack monitors would allow installation of a continuous stack monitor on each of the stacks listed in Table 7.10 that currently do not have the continuous stack monitor, plus other selected stacks.

Cost estimates for the acquisition and installation of the conceptual design HEPA filter systems for each of the stacks having emissions $\geqslant 5 \mathrm{~kg}$ of natural uranium during 1981-1983 are presented in Tables 7.14 to 7.27. Labor 
costs have been adjusted to those representative of the Cincinnati area. A summary of these total costs is given in Table 7.28.

7.4.4 Effect of Proposed Equipment

Reductions in emissions from the existing emission control devices based on the installation of continuous stack monitors and coupled to either engineered and/or administrative controls are not known at present. The effectiveness of these measures in reducing emissions is dependent both upon the increased sensitivity of detection and the implementation of both effective engineered and administrative controls.

Installation of HEPA filter systems as secondary air cleaning systems is estimated to achieve at least a $90 \%$ reduction in emissions. The total emissions from the FMPC will vary as a function of its utilization. As stated previously, DOE forecasts increased use of the FMPC in the future; ${ }^{(4)}$ a doubling of the 1981 level of usage is a reasonable estimate. Consequently, the reduced stack emissions that would result from the installation of additional emission control technologies are not absolute values, but will reflect the usage of the FMPC.

The minimum number of HEPA filter systems that would have been required to control the 1981 emissions to levels equal to $50 \%$ and $25 \%$ of the 1981 emissions is indicated in Tables 7.8 and 7.9 .

Some uncertainty results in designating only the scrubbers for the rotary kiln and oxidation furnace \#1 in Plant 8 as needing secondary emission control technology because there are a total of four scrubbers in Plant 8. No data were available for the other two scrubbers and the mass of material emitted from the scrubbers is the sum of the four units.

The cost estimates given in the second column of Table 7.28 for acquisition and installation of the conceptual design HEPA filter systems do not include costs associated with removal and disposal of obsolete and unused emission control systems (may be required to obtain space for HEPA system installation), costs for new structures (in the event the HEPA systems must be 
TABLE 7.14 Conceptual Design Cost Estimate - Plant 4, G4-2

\begin{tabular}{|c|c|c|c|c|c|c|c|c|c|}
\hline \multirow[b]{2}{*}{ Description } & \multirow[b]{2}{*}{ Quant ity } & \multirow[b]{2}{*}{ Unit } & \multicolumn{3}{|c|}{ Manhours } & \multirow{2}{*}{$\begin{array}{l}\text { Unit } \\
\text { Cost } \\
\end{array}$} & \multirow[b]{2}{*}{ Labor } & \multirow[b]{2}{*}{ Material } & \multirow[b]{2}{*}{ Total } \\
\hline & & & Unit MH & Total & $\$ / M H$ & & & & \\
\hline $\begin{array}{l}\text { HEPA Filter E-4 }(3 \times 3) \text { GG-F }(304 L) \text {, Jest } \\
\text { Section Inlet and Outlet (Flanders) }\end{array}$ & 2 & ea & 40 & 80 & 21.56 & 40000 & 1725 & 80000 & 81725 \\
\hline Isolation valves $18 " \emptyset$, Manual Operated & 4 & ea & 12 & 48 & 21.56 & 1300 & 1035 & 5200 & 6235 \\
\hline $\begin{array}{l}\text { Exhaust fan } 6940 \mathrm{cfm} \text { Aerovent }{ }^{(b)} \text { BI- } 450 \text {, } \\
10 " \text { S.P. }\end{array}$ & 1 & ea & 16 & 16 & 21.56 & 3303 & 345 & 3303 & 3648 \\
\hline Duct System SST & 1000 & lb & 0.20 & 200 & 21.56 & 1.25 & 4312 & 1250 & 5562 \\
\hline Instrument at ion/Elect* & 1 & ea & 40 & 40 & 21.56 & 5000 & 862 & 5000 & 5862 \\
\hline Test System & 1 & ea & 40 & 40 & 21.56 & -- & 862 & -- & 862 \\
\hline & & & & & & & 9141 & 94753 & 103894 \\
\hline & & & & Over & head an & d Profit & $25 \%$ & & 25974 \\
\hline & & & & TOTA & & & & & 129868 \\
\hline & & & & ROUN & DED OFF & TOTAL & & & 129900 \\
\hline
\end{tabular}

*NOTE: Local readout on DPI only - elec.

allowance due to potential motor h.p. increase

(a) Flanders Filters, Inc., P. O. Box 1708-TR, Washington, NC 27889

(b) Aerovent, Inc., Ash \& Bauer St. , Piqua, OH 45356 
TABLE 7.15. Conceptual Design Cost Estimate - Plant 4, G4-5

\begin{tabular}{|c|c|c|c|c|c|c|c|c|c|}
\hline \multirow[b]{2}{*}{ Description } & \multirow[b]{2}{*}{ Quant ity } & \multirow[b]{2}{*}{ Unit } & \multicolumn{3}{|c|}{ Manhours } & \multirow{2}{*}{$\begin{array}{l}\text { Unit } \\
\text { Cost } \\
\end{array}$} & \multirow[b]{2}{*}{ Labor } & \multirow[b]{2}{*}{ Material } & \multirow[b]{2}{*}{ Total } \\
\hline & & & Unit MH & Total & $\$ / M H$ & & & & \\
\hline $\begin{array}{l}\text { HEPA Filter E-4 }(2 \times 1) \text { GG-F }(304) \text {, Test } \\
\text { Sect ion Inlet and Outlet (Flanders) (a) }\end{array}$ & 2 & ea & 40 & 80 & 21.56 & 12500 & 1725 & 25000 & 26725 \\
\hline Isolation valves $12^{\prime \prime} \emptyset$, Manual Operated & 4 & ea & 6 & 56 & 21.56 & 1100 & 517 & 4400 & 4917 \\
\hline $\begin{array}{l}\text { Exhaust fan } 1860 \mathrm{cfm} \text { Aerovent }{ }^{(\mathrm{b})} \text { BI- } 315 \text {, } \\
10^{\prime \prime} \text { S.P. }\end{array}$ & 1 & ea & 16 & 16 & 21.56 & 2572 & 345 & 2572 & 2917 \\
\hline Duct System-SST & 800 & $1 \mathrm{~b}$ & 0.20 & 200 & 21.56 & 1.25 & 3450 & 1000 & 4450 \\
\hline Instrumentat ion/Elect* & 1 & ea & 40 & 40 & 21.56 & 5000 & 862 & 5000 & 5862 \\
\hline Test System & 1 & ea & 40 & 40 & 21.56 & -- & 862 & -- & 862 \\
\hline & & & & & & & 7761 & 37972 & 45733 \\
\hline & & & & Over & eead an & d Profit & 25\% & & 11433 \\
\hline & & & & TOTA & & & & & 57166 \\
\hline & & & & ROUA & DED OFf & TOTAL & & & 57200 \\
\hline
\end{tabular}

*NOTE: Local readout on DPI only - elec.

allowance due to potential motor h.p. increase

(a) Flanders Filters, Inc., P. 0. Box 1708-TR, Washingt on, NC 27889

(b) Aerovent, Inc., Ash \& Bauer St., Piqua, OH 45356 
TABLE 7.16 Conceptual Design Cost Estimate - Plant 4, 64-7

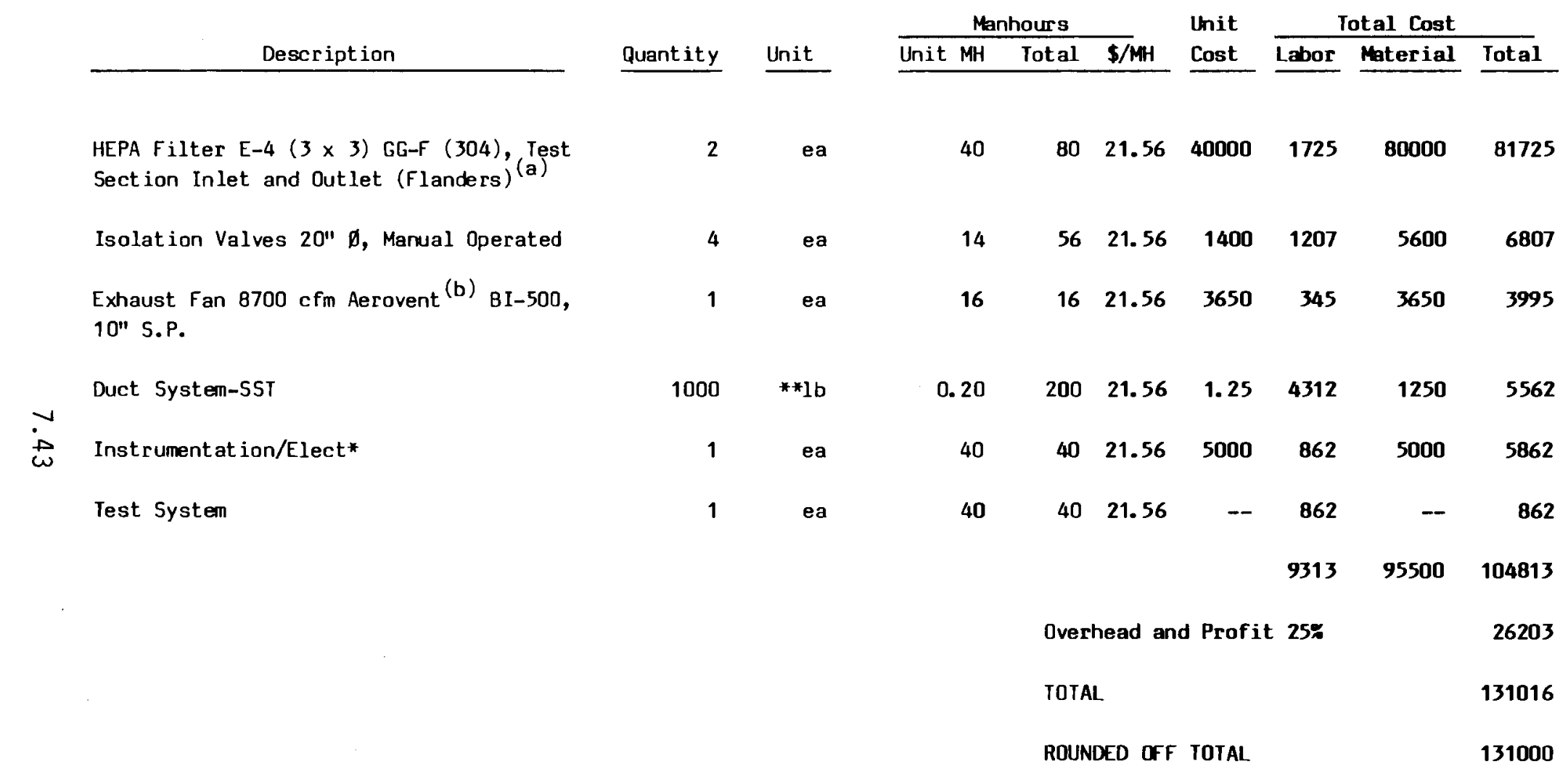

*NOTE: Local readout on DPI only - elec.

allowance due to potential motor h. p. increase

(a) Flanders Filters, Inc., P. 0. Box 1708-TR, Washingt on, NC 27889

(b) Aerovent, Inc., Ash \& Bauer St., Piqua, OH 45356 
TABLE 7.17 Conceptual Design Cost Estimate - Plant 4, G4-14

\begin{tabular}{|c|c|c|c|c|c|c|c|c|c|}
\hline \multirow[b]{2}{*}{ Description } & \multirow[b]{2}{*}{ Quantity } & \multirow[b]{2}{*}{ Unit } & \multicolumn{3}{|c|}{ Manhours } & \multirow{2}{*}{$\begin{array}{l}\text { Unit } \\
\text { Cost } \\
\end{array}$} & \multicolumn{3}{|c|}{ Total Cost } \\
\hline & & & Unit MH & Total & $\$ / \mathrm{MH}$ & & Labor & Material & Total \\
\hline $\begin{array}{l}\text { HEPA Filter E-4 }(3 \times 2) \text { GG-F (304), Test } \\
\text { Sect ion Inlet and Outlet (Flanders) }(a)\end{array}$ & 2 & ea & 40 & 80 & 21.56 & 29000 & 1725 & 58000 & 59725 \\
\hline Isolation Valves $16^{\prime \prime} \emptyset$, Manual Operated & 4 & ea & 9 & 36 & 21.56 & 1200 & 776 & 4800 & 5576 \\
\hline $\begin{array}{l}\text { Exhaust Fan } 4400 \mathrm{cfm} \text { Aerovent BI- } 450 \text {, } \\
10 " \text { 5.P. }\end{array}$ & 1 & ea & 16 & 16 & 21.56 & 2986 & 345 & 2986 & 3331 \\
\hline Duct System-SST & 1000 & 10 & 0.20 & 200 & 21.56 & 1.25 & 4312 & 1250 & 5562 \\
\hline Instrument at ion/Elect* & 1 & ea & 40 & 40 & 21.56 & 5000 & 862 & 5000 & 5862 \\
\hline Test System & 1 & ea & 40 & 40 & 21.56 & -- & 862 & -- & 862 \\
\hline & & & & & & & 8882 & 72036 & 80918 \\
\hline & & & & Over & head an & Profit & 25\% & & 20230 \\
\hline & & & & TOTA & & & & & 101148 \\
\hline & & & & ROUN & $D E D$ DFF & rOTAL & & & 101100 \\
\hline
\end{tabular}

*NOTE: Local readout on DPI only - elec.

allowance due to potential motor h.p. increase

(a) Flanders Filters, Inc., P. O. Box 1708-TR, Washingt on, NC 27889

(b) Aerovent, Inc., Ash \& Bauer St., Piqua, OH 45356 
TABLE 7.18. Conceptual Design Cost Estimate - Plant 5, G5-249

\begin{tabular}{|c|c|c|c|c|c|c|c|c|c|}
\hline \multirow[b]{2}{*}{ Description } & \multirow[b]{2}{*}{ Quantity } & \multirow[b]{2}{*}{ Unit } & \multicolumn{3}{|c|}{ Manhours } & \multirow{2}{*}{$\begin{array}{l}\text { Unit } \\
\text { Cost }\end{array}$} & \multicolumn{3}{|c|}{ Total Cost } \\
\hline & & & Unit MH & Total & $\$ / M H$ & & Labor & Material & Total \\
\hline $\begin{array}{l}\text { HEPA Filter E-4 }(3 \times 3) \text { GG-F }(304) \text {, Test } \\
\text { Section Inlet and Out let (Flanders) (a) }\end{array}$ & 2 & ea & 40 & 80 & 21.56 & 40000 & 1725 & 80000 & 81725 \\
\hline Isolation Valves $20 " \emptyset$, Manual Operated & 4 & ea & 14 & 56 & 21.56 & 1400 & 1207 & 5600 & 6807 \\
\hline $\begin{array}{l}\text { Exhaust Fan } 8160 \mathrm{cfm} \text { Aerovent }{ }^{(\mathrm{b})} \text { BI-500, } \\
10^{\prime \prime} \text { S.P. }\end{array}$ & 1 & ea & 16 & 16 & 21.56 & 3650 & 345 & 3650 & 3995 \\
\hline Duct System-SST & 1000 & $1 \mathrm{~b}$ & 0.20 & 200 & 21.56 & 1.25 & 4312 & 1250 & 5562 \\
\hline Instrument at ion/E lect* & 1 & ea & 40 & 40 & 21.56 & 5000 & 862 & 5000 & 5862 \\
\hline Test System & 1 & ea & 40 & 40 & 21.56 & -- & 862 & -- & 862 \\
\hline & & & & & & & 9313 & 95500 & 104813 \\
\hline & & & & Over & eead an & $d$ Profit & $25 \%$ & & 26203 \\
\hline & & & & TOTA & & & & & 131016 \\
\hline & & & & ROUN & EED OFf & TOTAL & & & 131000 \\
\hline
\end{tabular}

*NOTE: Local readout on DPI only - elec.

allowance due to potential motor h.p. increase

(a) Flanders Filters, Inc., P. O. Box 1708-TR, Washingt on, NC 27889

(b) Aerovent, Inc., Ash \& Bauer St., Piqua, OH 45356 
TABLE 7.19. Conceptual Design Cost Estimate - Plant 5, G5-254

\begin{tabular}{|c|c|c|c|c|c|c|c|c|c|}
\hline \multirow[b]{2}{*}{ Description } & \multirow[b]{2}{*}{ Quantity } & \multirow[b]{2}{*}{ Unit } & \multicolumn{3}{|c|}{ Manhours } & \multirow{2}{*}{$\begin{array}{l}\text { Unit } \\
\text { Cost }\end{array}$} & \multicolumn{3}{|c|}{ Total Cost } \\
\hline & & & Unit MH & Total & $\$ / \mathrm{MH}$ & & Labor & Material & Total \\
\hline $\begin{array}{l}\text { HEPA Filter E-4 }(3 \times 2) \text { GG-F }(304) \text {, Test } \\
\text { Sect ion Inlet and Outlet (Flanders) }\end{array}$ & 2 & ea & 40 & 80 & 21.56 & 29000 & 1725 & 58000 & 59725 \\
\hline Isolation Valves $18^{\prime \prime} \emptyset$, Manual Operated & 4 & ea & 12 & 48 & 21.56 & 1300 & 1035 & 5200 & 6235 \\
\hline $\begin{array}{l}\text { Exhaust Fan } 5620 \mathrm{cfm} \text { Aerovent }{ }^{(\mathrm{b})} \text { BI- } 450 \text {, } \\
\text { 10" S.P. }\end{array}$ & 1 & ea & 16 & 16 & 21.56 & 3114 & 345 & 3114 & 3459 \\
\hline Duct System-SST & 1000 & LB & 0.20 & 200 & 21.56 & 1.25 & 4312 & 1250 & 5562 \\
\hline Instrument at ion/Elect* & 1 & ea & 40 & 40 & 21.56 & 5000 & 862 & 5000 & 5862 \\
\hline Test System & 1 & ea & 40 & 40 & 21.56 & -- & 862 & -- & 862 \\
\hline & & & & & & & 9141 & 72564 & 81705 \\
\hline & & & & Over & read an & Profit & $25 \%$ & & 20426 \\
\hline & & & & TOTA & & & & & 102131 \\
\hline & & & & ROUUN & DEO OFF & TOTAL & & & 102100 \\
\hline
\end{tabular}

*NOTE: Local readout on DPI only - elec.

allowance due to potential motor h.p. increase

(a) Flanders Filters, Inc., P. O. Box 1708-TR, Washingt on, NC 27889

(b) Aerovent, Inc., Ash \& Bauer St., Piqua, $\mathrm{OH} 45356$ 
TABLE 7.20. Conceptual Design Cost Estimate - Plant 5, G5-256

\begin{tabular}{|c|c|c|c|c|c|c|c|c|c|}
\hline \multirow[b]{2}{*}{ Description } & \multirow[b]{2}{*}{ Quantity } & \multirow[b]{2}{*}{ Unit } & \multicolumn{3}{|c|}{ Manhours } & \multirow{2}{*}{$\begin{array}{l}\text { Unit } \\
\text { Cost } \\
\end{array}$} & \multicolumn{3}{|c|}{ Total Cost } \\
\hline & & & Unit MH & Total & $\$ / \mathrm{MH}$ & & Labor & Material & Total \\
\hline $\begin{array}{l}\text { HEPA Filter E-4 }(3 \times 3) \text { GG-F (304), Test } \\
\text { Sect ion Inlet and Outlet (Flanders) (a) }\end{array}$ & 2 & ea & 40 & 80 & 21.56 & 40000 & 1725 & 80000 & 81725 \\
\hline Isolation Valves $20 " \emptyset$, Manual Operated & 4 & ea & 14 & 56 & 21.56 & 1400 & 1207 & 5600 & 6807 \\
\hline $\begin{array}{l}\text { Exhaust Fan } 8500 \mathrm{cfm} \text {, Aerovent }{ }^{(\mathrm{b})} \text { BI-500, } \\
10 \text { " S.P. }\end{array}$ & 1 & ea & 16 & 16 & 21.56 & 3650 & 345 & 3650 & 3995 \\
\hline Duct System-SST & 1000 & $1 \mathrm{~b}$ & 0.20 & 200 & 21.56 & 1.25 & 4312 & 1250 & 5562 \\
\hline Inst r ument at ion/Elect* & 1 & ea & 40 & 40 & 21.56 & 5000 & 862 & 5000 & 5862 \\
\hline Test System & 1 & ea & 40 & 40 & 21.56 & -- & 862 & -- & 862 \\
\hline & & & & & & & 9313 & 95500 & 104813 \\
\hline & & & & Over & lead an & 1 Profit & $25 \%$ & & 26203 \\
\hline & & & & TOTA & & & & & 131016 \\
\hline & & & & ROUN & DED OF & TOTAL & & & 131000 \\
\hline
\end{tabular}

*NOTE: Local readout on DPI only - elec.

allowance due to potential motor h. p. increase

(a) Flanders Filters, Inc., P. 0. Box 1708-TR, Washington, NC 27889

(b) Aerovent, Inc., Ash \& Bauer St., Piqua, $\mathrm{OH} 45356$ 
TABLE 7.21. Conceptual Design Cost Estimate - Plant 5, G5-260

\begin{tabular}{|c|c|c|c|c|c|c|c|c|c|}
\hline \multirow[b]{2}{*}{ Description } & \multirow[b]{2}{*}{ Quant ity } & \multirow[b]{2}{*}{ Unit } & \multicolumn{3}{|c|}{ Manhours } & \multirow{2}{*}{$\begin{array}{l}\text { Unit } \\
\text { Cost }\end{array}$} & \multicolumn{3}{|c|}{ Total Cost } \\
\hline & & & Unit MH & Total & $\$ / \mathrm{MH}$ & & Labor & Material & Total \\
\hline $\begin{array}{l}\text { HEPA Filter E-4 }(3 \times 2) \text { GG-F }(304) \text {, Test } \\
\text { Section Inlet and Outlet (Flanders) }\end{array}$ & 2 & ea & 40 & 80 & 21.56 & 29000 & 1725 & 58000 & 59725 \\
\hline Isolation Valves $18 " \emptyset$, Manual Operated & 4 & ea & 12 & 48 & 21.56 & 1300 & 1035 & 5200 & 6235 \\
\hline $\begin{array}{l}\text { Exhaust Fan } 5980 \mathrm{cfm} \text { Aerovent }{ }^{(b)} \text { BI- } 450 \text {, } \\
10 " \text { S.P. }\end{array}$ & 1 & ea & 16 & 16 & 21.56 & 3303 & 345 & 3303 & 3648 \\
\hline Duct System-SST & 1000 & $1 b$ & 0.20 & 200 & 21.56 & 1.25 & 4312 & 1250 & 5562 \\
\hline Inst r ument at ion/Elect* & 1 & ea & 40 & 40 & 21.56 & 5000 & 862 & 5000 & 5862 \\
\hline Test System & 1 & ea & 40 & 40 & 21.56 & -- & 862 & -- & 862 \\
\hline & & & & & & & 9141 & 72753 & 81894 \\
\hline & & & & Over & head an & Profit & $25 \%$ & & 20473 \\
\hline & & & & TOTA & & & & & 102367 \\
\hline & & & & ROUN & DED OFF & TOTAL & & & 102400 \\
\hline
\end{tabular}

*NOTE: Local readout on DPI only - elec.

allowance due to potential motor h.p. increase

(a) Flanders Filters, Inc., P. O. Box 1708-TR, Washington, NC 27889

(b) Aerovent, Inc., Ash \& Bauer St., Piqua, OH 45356 
TABLE 7.22. Conceptual Design Cost Estimate - Plant 5, G5-261

\begin{tabular}{|c|c|c|c|c|c|c|c|c|c|}
\hline \multirow[b]{2}{*}{ Description } & \multirow[b]{2}{*}{ Quant ity } & \multirow[b]{2}{*}{ Unit } & \multicolumn{3}{|c|}{ Manhours } & \multirow{2}{*}{$\begin{array}{l}\text { Unit } \\
\text { Cost }\end{array}$} & \multicolumn{3}{|c|}{ Total Cost } \\
\hline & & & Unit MH & Total & \$/MH & & Labor & Material & Total \\
\hline $\begin{array}{l}\text { HEPA Filter E-4 }[2(4 \times 3)] \text { GG-F (304) }) \text { Test } \\
\text { Sect ion Inlet and Outlet (Flanders) }(a)\end{array}$ & 4 & ea & 40 & 160 & 21.56 & 54000 & 3450 & 216000 & 219450 \\
\hline Isolation Valves $30^{\prime \prime} \emptyset$, Manual Operated & 4 & ea & 24 & 96 & 21.56 & 3400 & 2070 & 13600 & 15670 \\
\hline $\begin{array}{l}\text { Exhaust fan } 20,180 \mathrm{cfm} \text { Aerovent }{ }^{(\mathrm{b})} \text { BI-800, } \\
10^{\prime \prime} \text { S.P. }\end{array}$ & 1 & ea & 32 & 32 & 21.56 & 6570 & 690 & 6570 & 7260 \\
\hline Duct System-SST & 3000 & $1 \mathrm{~b}$ & 0.20 & 600 & 21.56 & 1.25 & 12936 & 3750 & 16686 \\
\hline Inst rument at ion/Elect* & 1 & ea & 40 & 40 & 21.56 & 5000 & 862 & 5000 & 5862 \\
\hline Test System & 1 & ea & 40 & 40 & 21.56 & -- & 862 & -- & 862 \\
\hline & & & & & & & 20870 & 244920 & 265790 \\
\hline & & & & Over & read an & Profit & $=25 \%$ & & 66447 \\
\hline & & & & TOTA & & & & & 332237 \\
\hline & & & & ROUN & DED OFF & TOTAL & & & 332200 \\
\hline
\end{tabular}

*NOTE: Local readout on DPI only - elec.

allowance due to potential motor $h . p$. increase

(a) Flanders Filters, Inc., P. 0. Box 1708-TR, Washingt on, NC 27889

(b) Aerovent, Inc., Ash \& Bauer St., Piqua, OH 45356 
TABLE 7.23. Conceptual Design Cost Estimate - Plant 5, 55

\begin{tabular}{|c|c|c|c|c|c|c|c|c|c|}
\hline \multirow[b]{2}{*}{ Description } & \multirow[b]{2}{*}{ Quantity } & \multirow[b]{2}{*}{ Unit } & \multicolumn{3}{|c|}{ Manhours } & \multirow{2}{*}{$\begin{array}{l}\text { Unit } \\
\text { Cost }\end{array}$} & \multicolumn{3}{|c|}{ Total Cost } \\
\hline & & & Unit $M H$ & Total & $\$ / M H$ & & Labor & Material & Total \\
\hline $\begin{array}{l}\text { HEPA Filter E-4 }(2 \times 2) \text { GG-F }(304) \text {, Test } \\
\text { Sect ion Inlet and Out let }(F l \text { anders })\end{array}$ & 2 & ea & 40 & 80 & 21.56 & 19000 & 1725 & 38000 & 39725 \\
\hline Isolation Valves $16^{\prime \prime} \not$, Manual Operated & 4 & ea & 9 & 36 & 21.56 & 1200 & 776 & 4800 & 5576 \\
\hline $\begin{array}{l}\text { Exhaust Fan } 3920 \mathrm{cfm} \text { Aerovent }{ }^{(\mathrm{b})} \text { BI-400, } \\
10^{\prime \prime} \text { S.P. }\end{array}$ & 1 & ea & 16 & 16 & 21.56 & 3114 & 345 & 3114 & 3459 \\
\hline Duct System-SST & 1000 & lb & 0.20 & 200 & 21.56 & 1.25 & 4312 & 1250 & 5562 \\
\hline Inst rument at ion/Elect* & 1 & ea & 40 & 40 & 21.56 & 5000 & 862 & 5000 & 5862 \\
\hline Test System & 1 & ea & 40 & 40 & 21.56 & -- & 862 & -- & 862 \\
\hline & & & & & & & 8882 & 52164 & 61046 \\
\hline & & & & Over & head anc & Profit & $25 \%$ & & 15261 \\
\hline & & & & TOTA & & & & & 76307 \\
\hline & & & & ROUUN & DED OFF & IOTAL & & & 76300 \\
\hline
\end{tabular}

*NOTE: Local readout on DPI only - elec.

allowance due to potential motor h.p. increase

(a) Flanders Filters, Inc., P. D. Box 1708-TR, Washingt on, NC 27889

(b) Aerovent, Inc., Ash \& Bauer St., Piqua, OH 45356 
TABLE 7.24. Conceptual Design Cost Estimate - Plant 8, G43-27

\begin{tabular}{|c|c|c|c|c|c|c|c|c|c|}
\hline \multirow[b]{2}{*}{ Description } & \multirow[b]{2}{*}{ Quant ity } & \multirow[b]{2}{*}{ Unit } & \multicolumn{3}{|c|}{ Manhours } & \multirow{2}{*}{$\begin{array}{l}\text { Unit } \\
\text { Cost }\end{array}$} & \multicolumn{3}{|c|}{ Total Cost } \\
\hline & & & Unit $M H$ & Total & $\$ / M H$ & & Labor & Material & Total \\
\hline $\begin{array}{l}\text { HEPA Filter E-4 ( } 4 \times 3) \text { GG-F (304), Test } \\
\text { Sect ion Inlet and Outlet (Flanders) (a) }\end{array}$ & 2 & ea & 40 & 80 & 21.56 & 54000 & 1725 & 108000 & 109725 \\
\hline Isolation Valves $24 " \emptyset$, Manual Operated & 4 & ea & 20 & 80 & 21.56 & 3200 & 1725 & 12800 & 14525 \\
\hline $\begin{array}{l}\text { Exhaust Fan } 11,630 \mathrm{cfm} \text { Aerovent }{ }^{(b)} \text { BI-630, } \\
10^{\prime \prime} \text { S.P. }\end{array}$ & 1 & ea & 32 & 32 & 21.56 & 4646 & 690 & 4646 & 5336 \\
\hline Duct System-SST & 1200 & lb & 0.20 & 240 & 21.56 & 1.25 & 5174 & 1500 & 6674 \\
\hline Inst rument at ion/Elect* & 1 & ea & 40 & 40 & 21.56 & 5000 & 862 & 5000 & 5862 \\
\hline Test System & 1 & ea & 40 & 40 & 21.56 & -- & 862 & -- & 862 \\
\hline & & & & & & & 11038 & 131946 & 142984 \\
\hline & & & & Over & head an & d Profi & $25 \%$ & & 35746 \\
\hline & & & & TOTA & & & & & 178730 \\
\hline & & & & ROUN & DED OFF & TOTAL & & & 178700 \\
\hline
\end{tabular}

*NOTE: Local readout on DPI only - elec.

allowance due to potential motor h.p. increase

(a) Flanders Filters, Inc., P. 0. Box 1708-TR, Washingt on, NC 27889

(b) Aerovent, Inc., Ash \& Bauer St., Piqua, OH 45356 
TABLE 7.25. Conceptual Design Cost Estimate - Plant 8, 8024

\begin{tabular}{|c|c|c|c|c|c|c|c|c|c|}
\hline \multirow[b]{2}{*}{ Description } & \multirow[b]{2}{*}{ Quantity } & \multirow[b]{2}{*}{ Unit } & \multicolumn{3}{|c|}{ Manhours } & \multirow{2}{*}{$\begin{array}{l}\text { Unit } \\
\text { Cost } \\
\end{array}$} & \multicolumn{3}{|c|}{ Total Cost } \\
\hline & & & Unit MH & Total & $\$ / M H$ & & Labor & Material & Total \\
\hline $\begin{array}{l}\text { HEPA Filter E-4 }(3 \times 1) \text { GG-F (304), Test } \\
\text { Sect ion Inlet and Outlet (Flanders) (a) }\end{array}$ & 2 & ea & 40 & 80 & 21.56 & 19000 & 1725 & 38000 & 39725 \\
\hline Isolation Valves $14^{\prime \prime} \emptyset$, Manual Operated & 4 & ea & 8 & 32 & 21.56 & 1100 & 690 & 4400 & 5090 \\
\hline $\begin{array}{l}\text { Exhaust Fan } 2770 \mathrm{cfm} \text { Aerovent }{ }^{(\mathrm{b})} \text { BI- } 400 \text {, } \\
10^{\prime \prime} \text { S.P. }\end{array}$ & 1 & ea & 16 & 16 & 21.56 & 2417 & 345 & 2417 & 2762 \\
\hline Duct System-SST & 800 & $1 \mathrm{~b}$ & 0.20 & 160 & 21.56 & 1.25 & 3450 & 1000 & 4450 \\
\hline Inst rument at ion/Elect* & 1 & ea & 40 & 40 & 21.56 & 5000 & 862 & 5000 & 5862 \\
\hline Test System & 1 & ea & 40 & 40 & 21.56 & -- & 862 & -- & 862 \\
\hline & & & & & & & 7934 & 50817 & 58751 \\
\hline & & & & Over & head an & Profit & $25 \%$ & & 14688 \\
\hline & & & & TOTA & & & & & 73439 \\
\hline & & & & rotit & DED OFF & TOTAL & & & 73400 \\
\hline
\end{tabular}

*NOTE: Local readout on DPI only - elec.

allowance due to potential motor h.p. increase

(a) Flanders Filters, Inc., P. O. Box 1708-TR, Washington, NC 27889

(b) Aerovent, Inc., Ash \& Bauer St., Piqua, $\mathrm{OH} 45356$ 
TABLE 7.26. Conceptual Design Cost Estimate - Plant 8, Rotary Ki In(s)

\begin{tabular}{|c|c|c|c|c|c|c|c|c|c|}
\hline \multirow[b]{2}{*}{ Description } & \multirow[b]{2}{*}{ Quantity } & \multirow[b]{2}{*}{ Unit } & \multicolumn{3}{|c|}{ Manhours } & \multirow{2}{*}{$\begin{array}{l}\text { Unit } \\
\text { Cost }\end{array}$} & \multicolumn{3}{|c|}{ Total Cost } \\
\hline & & & Unit MH & Total & $\$ / M H$ & & Labor & Material & Total \\
\hline $\begin{array}{l}\text { HEPA Filter E-4 }(3 \times 1) \text { GG-F (304) Test } \\
\text { Sect ion Inlet and Outlet (Flanders) }\end{array}$ & 2 & ea & 40 & BO & 21.56 & 19000 & 1725 & 38000 & 39725 \\
\hline Isolation Valves $12^{\prime \prime} \emptyset$, Manual Operated & 4 & ea & 6 & 24 & 21.56 & 1100 & 517 & 4400 & 4917 \\
\hline $\begin{array}{l}\text { Exhaust Fan } 2120 \mathrm{cfm} \text { Aerovent }{ }^{(\mathrm{b})} \text { BI- } 335 \text {, } \\
10^{\prime \prime} \text { S.P. }\end{array}$ & 1 & ea & 16 & 16 & 21.56 & 2634 & 345 & 2634 & 2979 \\
\hline Duct System-SST & 800 & $1 b$ & 0.20 & 160 & 21.56 & 1.25 & 3450 & 1000 & 4450 \\
\hline Inst r ument at ion/Elect* & 1 & ea & 40 & 40 & 21.56 & 5000 & 862 & 5000 & 5862 \\
\hline Test System & 1 & ea & 40 & 40 & 21.56 & -- & 862 & -- & 862 \\
\hline & & & & & & & 7761 & 51034 & 58795 \\
\hline & & & & Over & head an & d Profit & $25 \%$ & & 14700 \\
\hline & & & & TOT & & & & & 73495 \\
\hline & & & & ROUN & DED OFF & TOTAL & & & 73500 \\
\hline
\end{tabular}

*NOTE: Local readout on DPI only - elec.

allowance due to potential motor h.p. increase

(a) Flanders Filters, Inc., P. O. Box 1708-TR, Washingt on, NC 27889

(b) Aerovent, Inc., Ash \& Bauer St., Piqua, OH 45356 
TABLE 7.27. Conceptual Design Cost Estimate - Plant 8, 0xidation \#1(s)

\begin{tabular}{|c|c|c|c|c|c|c|c|c|c|}
\hline \multirow[b]{2}{*}{ Description } & \multirow[b]{2}{*}{ Quant ity } & \multirow[b]{2}{*}{ Unit } & \multicolumn{3}{|c|}{ Manhours } & \multirow{2}{*}{$\begin{array}{l}\text { Unit } \\
\text { Cost }\end{array}$} & \multicolumn{3}{|c|}{ Total Cost } \\
\hline & & & Unit MH & Total & $\$ / M H$ & & Labor & Material & Total \\
\hline $\begin{array}{l}\text { HEPA Filter E-4 }(2 \times 1) \text { GG-F (304) Test } \\
\text { Sect ion Inlet and Dut let (Flanders) }(a)\end{array}$ & 2 & ea & 40 & 80 & 21.56 & 12500 & 1725 & 25000 & 26725 \\
\hline Isolation Valves $12 " \emptyset$, Manual Operated & 4 & ea & 6 & 24 & 21.56 & 1100 & 517 & 4400 & 4917 \\
\hline $\begin{array}{l}\text { Exhaust Fan } 1660 \mathrm{cfm}^{\text {Aerovent }}{ }^{(\mathrm{b})} \text { BI-315, } \\
10^{\prime \prime} \text { S.P. }\end{array}$ & 1 & ea & 16 & 16 & 21.56 & 2572 & 345 & 2572 & 2917 \\
\hline Duct System-SST & 800 & $1 b$ & 0.20 & 160 & 21.56 & 1.25 & 3450 & 1000 & 4450 \\
\hline Instr ument at ion/Elect* & 1 & ea & 40 & 40 & 21.56 & 5000 & 862 & 5000 & 5862 \\
\hline Test System & 1 & ea & 40 & 40 & 21.56 & -- & 862 & - & 862 \\
\hline & & & & & & & 7761 & 35400 & 45733 \\
\hline & & & & Over & lead and & Profit & $25 \%$ & & 11433 \\
\hline & & & & TOTA & & & & & 57166 \\
\hline & & & & ROUN & ED OFF & TOTAL & & & 57200 \\
\hline
\end{tabular}

*NOTE: Local readout on DPI only - elec.

allowance due to potential motor h.p. increase

(a) Flanders Filters, Inc., P. O. Box 1708-TR, Washingt on, NC 27889

(b) Aerovent, Inc., Ash \& Bauer St., Piqua, $\mathrm{OH} 45356$ 
TABLE 7.28. Cost Estimates for Acquisition and Installation of HEPA Filter Systems on Stacks Having Emissions $>5 \mathrm{~kg}$ Uranium During 1981-1983; in 1984 Dollars

\begin{tabular}{|c|c|c|}
\hline Stack No. & $\begin{array}{c}\text { HEPA Filter } \\
\text { Installation } \\
\text { Cost (\$ Thousands) } \\
\end{array}$ & $\begin{array}{l}\text { Total Cost }(b) \\
\text { ( } \$ \text { Thousands) }\end{array}$ \\
\hline G4-2 & 129.9 & 324.8 \\
\hline G4-5 (a) & 57.2 & 143.0 \\
\hline G4-7 & 131.0 & 327.5 \\
\hline$G 4-14(a)$ & 101.1 & 252.8 \\
\hline G5-249 & 131.0 & 327.5 \\
\hline G5-254 & 102.1 & 255.3 \\
\hline G5-256 & 131.0 & 327.5 \\
\hline G5-260 (a) & 102.4 & 256.0 \\
\hline$G 5-261(a)$ & 332.2 & 830.5 \\
\hline Plant 55 & 76.3 & 190.8 \\
\hline G43-27(a) & 178.7 & 446.8 \\
\hline 8024 & 73.4 & 183.5 \\
\hline Rotary $\operatorname{Ki}_{\mathrm{ln}}(\mathrm{a})$ & 73.5 & 183.8 \\
\hline Oxidation \#1 (a) & 57.2 & 143.0 \\
\hline Total & 1677.0 & 4192.8 \\
\hline
\end{tabular}

(a) Stacks where 90\% reduction in 1981-1983 emissions is sufficient to reduce emissions to $25 \%$ of the 1981 emissions at the FMPC. Cost = \$902.3K for HEPA filter installation; $2.3 \mathrm{mi} 1$ lion total.

(b) Includes A-E fee, allowance for removal of existing systems, and allowance for additional structural supports.

located outside a given plant), or costs for Architect-Engineering (A-E) Services. Costs associated with the removal and disposal of obsolete equipment, site preparation, and construction of any needed additional structural supports or structures are difficult to predict without a more comprehensive study. However, these additional costs may reasonably be expected to not exceed those associated with the acquisition and installation of the proposed 
HEPA systems. Architect-Engineer services are typically about $25 \%$ of all other costs. Thus, total costs for the proposed secondary emission controls may be expected to be about $2-1 / 2$ times greater than the costs shown in Table 7.28 .

A total secondary emission control cost estimate for the seven stacks identified in Table 7.28 as requiring a 90\% reduction in their 1981-1983 emissions to reduce emissions to $25 \%$ of the 1981 emissions is $\sim \$ 2.3 M$. This estimate is less than half the estimate provided by the FMPC for the six stacks having the greatest emissions in 1981. Direct comparison of the present cost estimates for a specific stack to those of the FMPC is not possible because no details were provided by the FMPC for their estimates. The total cost estimate for the fourteen major emission sources (emissions $\geqslant 5 \mathrm{~kg}$ uranium) during 19811983 is $\sim \$ 4.2 M$. The FMPC has estimated a cost of $\sim \$ 14 M$ to install secondary emission controls on all presently operating stacks. In either case, the cost estimates are approximate values, subject to revision based on additional details and information.

\subsection{OPERATION AND MAINTENANCE COSTS}

Addition of continuous stack monitors, as planned by the FMPC, will result in the need for their periodic maintenance. These maintenance needs are not expected to be excessive, although the addition of one full-time-equivalent instrument technician may be required. It is also expected that normal operations personnel will be responsible for standard operation of the monitors. No unusual operating or maintenance costs are predicted as a result of the installation of additional continuous stack monitors.

Operation of the proposed secondary emission controls is expected to have no impact on normal operations staffing. Personnel requirements for the periodic change-out of the HEPA filters and DOP testing are based on the following assumptions:

- 2 decontamination/radwaste handling personnel will be required to prepare the surrounding area prior to filter change-out and for cleanup following the operation. 
- 2 people will be required to change a filter (each person limited to less than 2 hours continuous mask use).

- 2 radiation monitoring personnel are required.

- 3 air balance personnel are present to perform DOP testing on each new filter installed.

Estimated time requirements are based on the following assumptions:

- 2 hours are required for area preparation and cleanup.

- 0.3 hour is required per filter replacement and DOP testing.

Total man-hours required to change all the HEPA filters in a given secondary emission control device are based on the following assumptions:

- All personnel are present for the total time (total time = preparation and cleanup plus 0.3 hour $x$ number of filters changed).

- 2 people are required for the actual filter change if the total filter change-out time is less than 1 hour; 4 people are required if the total filter change-out time is greater than 1 hour but less than 3 hours; 6 people are required if the total filter change-out time is greater than 3 hours.

HEPA filter replacement costs have been estimated to be $\$ 94 \mathrm{~K} / \mathrm{yr}$ for the seven stacks having the greatest emissions during 1981-1983, and $\$ 111 \mathrm{~K} / \mathrm{yr}$ for all fourteen stacks listed in Table 7.28. The filter replacement cost estimate is based on an average cost of $\$ 350$ per filter (stainless steel housing), and the total number of filters to be replaced per year, as estimated by the change-out frequency listed in Table 7.13 .

The FMPC currently has no facilities to process uranium-loaded HEPA filters of the size and quantity proposed in order to recover the uranium. Additional costs for this operation have not been estimated.

If the HEPA filters are discarded, they would have to be disposed as lowspecific-activity radioactive waste, i.e. sent to a low-level radioactive waste burial ground. Costs for the packaging, transport, and burial of discarded HEPA filters have not been estimated. 


\subsection{SUMMARY AND CONCLUSIONS}

A summary of 1981 pulmonary dose rates, expected dose rates following installation of the proposed additional emission control technology, capital costs of installation, and annual operating and maintenance costs is presented in Table 7.29. Installation of the proposed emission control technology on four stacks at the FMPC would reduce 1981 pulmonary dose rates from the FMPC by $75 \%$. It should be recognized, however, that the major emission sources may vary each year. Installation of additional emission control technology on more than the four stacks listed in Table 7.29 would be required to insure a $75 \%$ pulmonary dose rate reduction in any given year.

TABLE 7.29. Summary of Estimated Cost of and Expected Pulmonary Dose Resulting from Installation of Proposed Emission Control Technology at the FMPC (a)

\begin{tabular}{|c|c|c|c|c|c|}
\hline Stack No. & $\begin{array}{c}1981 \text { Pulmonary } \\
\text { Dose Rate } \\
\text { (mrem/yr) } \\
\end{array}$ & $\begin{array}{c}\text { Estimated Pul- } \\
\text { monary Dose Rate } \\
\text { with New ECT } \\
\text { (mrem/yr) } \\
\end{array}$ & $\begin{array}{l}\text { Capit } \\
\mathrm{ECT} \\
(\$ \mathrm{~K}) \\
\end{array}$ & $\begin{array}{l}\text { tal Cost } \\
\text { Monitoring } \\
\quad(\$ K) \\
\end{array}$ & $\begin{array}{c}\text { Annual } \\
0 \& M \text { Cost } \\
(\$ K) \\
\end{array}$ \\
\hline G4 -14 & 44 & 4 & 253 & 7.5 & 46.9 \\
\hline G5-249 & 7 & 1 & 328 & 7.5 & 14.0 \\
\hline$G 5-260$ & 7 & 1 & 256 & 7.5 & 37.7 \\
\hline G5-261 & 17 & 2 & 831 & 7.5 & 36.9 \\
\hline \multirow[t]{2}{*}{ Other } & 13 & 13 & -- & & \\
\hline & 88 & 21 & 1668 & 30 & 135.5 \\
\hline
\end{tabular}

(a) To achieve $75 \%$ reduction of pulmonary dose based on 1981 emissions. 


\section{REFERENCES}

1. D. A. Fleming, M. W. Boback, and K. N. Ross, Feed Materials Production Center Environmental Monitoring Annual Report for 1981, NLCO-1180, May 1982.

2. D. A. Fleming and K. N. Ross, Feed Materials Production Center Environmental Monitoring Annual Report for 1982, NLCO-1187, May 1983.

3. U.S. Department of Energy, Order 5480.1A, Environmental Protection, Safety and Health Protection Program for DOE Operations, Chapter XI Requirments for Radiation Protection, August 13, 1981.

4. Environmental Report, Feed Materials Production Center, U.S. Department of Energy, January 1981.

5. Background Information Document, Proposed Standards for Radionuclides (Draft), EPA 520/1-83-001, U.S. Environmental Protection Agency, Washington, D.C., March 1983.

6. C. A. Burchsted, A. B. Fuller and J. E. Kahn, Nuclear Air Cleaning Handbook, ERDA 76-21, NTIS, Springfield, Virginia, 1976.

7. U. S. Department of Energy, Effluent Information System, EPA Release Point Analysis Report for Calendar Year 1981, July 17, 1982.

8. U. S. Department of Energy, Effluent Information System, Nuclide Database Master List for Calendar Year 1982, April 24, 1984. 


\subsection{ARGONNE NATIONAL LABORATORY}

This section contains information concerning the site and facilities at Argonne National Laboratory, including the major sources of airborne radioactive emissions, a brief description of other sources at the site, and a discussion of the technology utilized for control of emissions.

\subsection{SITE AND MAJOR SOURCE DESCRIPTIONS}

Argonne is an energy research and development laboratory with several principal objectives. It conducts a broad program of research in the basic energy and related sciences (physical, chemical, material, nuclear, biomedical, and environmental), and serves as an important engineering center for the study of nuclear and non-nuclear energy sources. A significant portion of these laboratory studies requires the use of radioactive substances.

\subsubsection{Location of Site and Description of Facilities}

Argonne National Laboratory (ANL) occupies the central 688 hectares of a 1514 hectare tract in DuPage County, $43 \mathrm{~km}$ southwest of downtown Chicago, and $39 \mathrm{~km}$ due west of Lake Michigan. It lies in the Des Plaines River Valley (Figure 8.1).

The terrain is gently rolling, partially wooded, former prairie and farm land. Sawmill Creek runs through the site in a southerly direction and enters the Des Plaines River, a tributary of the Illinois River, about $2.1 \mathrm{~km}$ southeast of the center of the site.

The Targest topographical feature is the Des Plaines River channel, about $1.6 \mathrm{~km}$ wide. The elevation of the channel surface is $180 \mathrm{~m}$ above sea level. Bluffs, which comprise the southern border of the site, rise a few tens of meters from the elevation of the channel.

Important sources of radioactive emissions are described in the next two sections. 


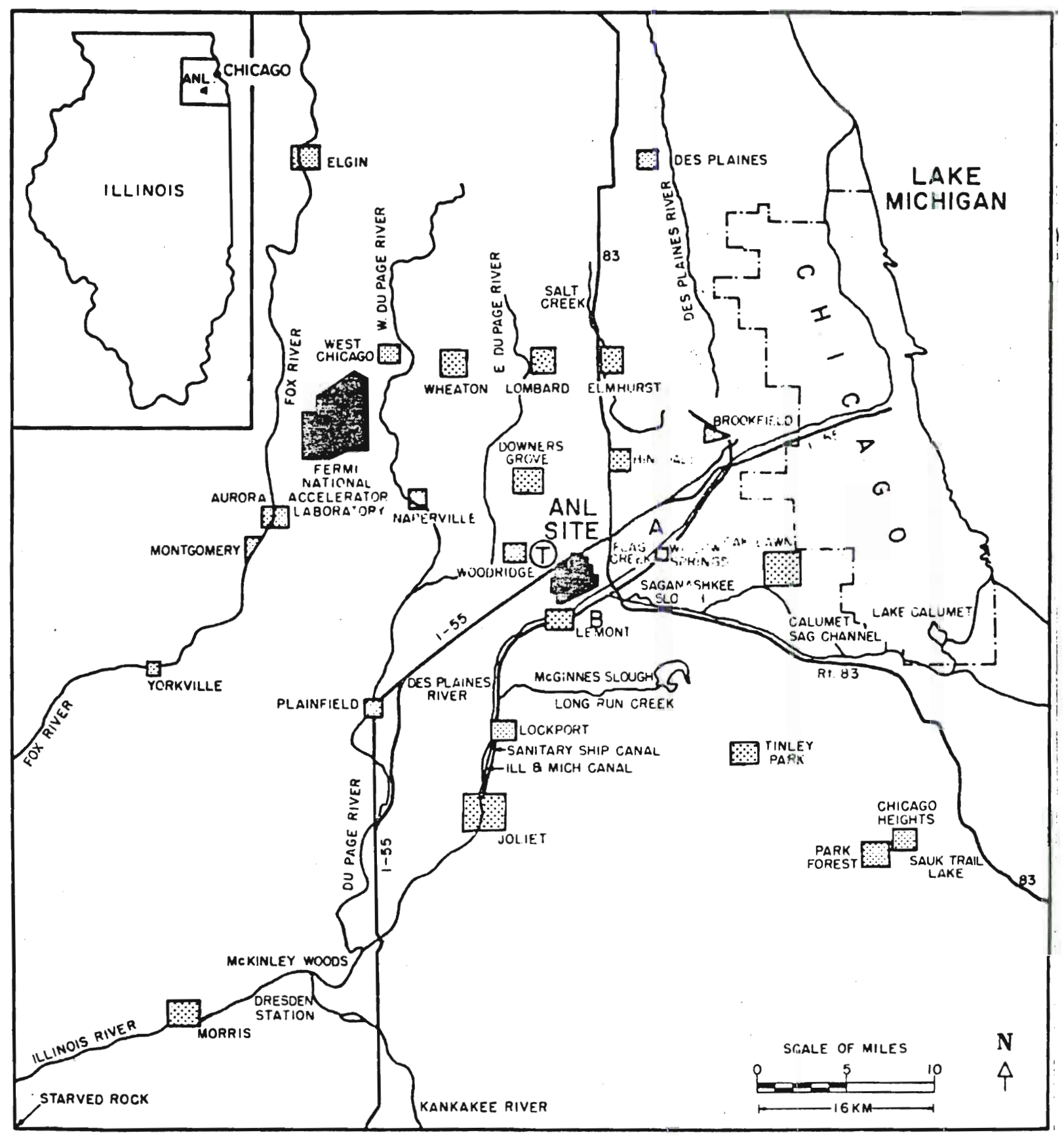

FIGURE 8.1. Location of Argonne National Laboratory 


\subsubsection{Identification and Location of Major Sources}

The methodology used to select the major sources of airborne radioactive emission is discussed in Section 1.4 of this report. Those sources that represent approximately $95 \%$ of the hypothetical risk from the site were selected for inclusion as major sources. There are two major sources of gaseous radioactive emissions from ANL. The locations of the sources are shown in Figure 8.2 and identified below. They are associated with a specific building exhaust, building stack, or reactor.

Hot Cells

The irradiated materials examination facility contains hot cells where examination of nuclear reactor materials is conducted. These are located in the Material Sciences Building 212, F-wing. The alpha-gamma hot cell generates most of the airborne radioactive emissions that evolve from this facility.

\section{Janus Reactor}

The Janus reactor is a 200-kWth light water research reactor designed for animal radiation studies. It is fueled with enriched uranium. The reactor is controlled from the ground floor control room. On the same level there is an area above the reactor for maintenance and refueling. Two neutron fluxes are produced on opposite sides of the reactor. The off-center location of the core allows a neutron flux on the near side that is $10^{4}$ times greater than on the far side. Adjacent to the reactor are high-level and low-level dose rooms for specimen irradiation. Neutron activation of the atmosphere in the high dose room is the source of radioactive emissions from this facility. The equipment for the primary and secondary circulation systems and the helium blanket system are located in the equipment room. An evaporative cooling tower is used to cool the secondary system water. This facility is located in the Biological and Medical Research Building (Building 202). 


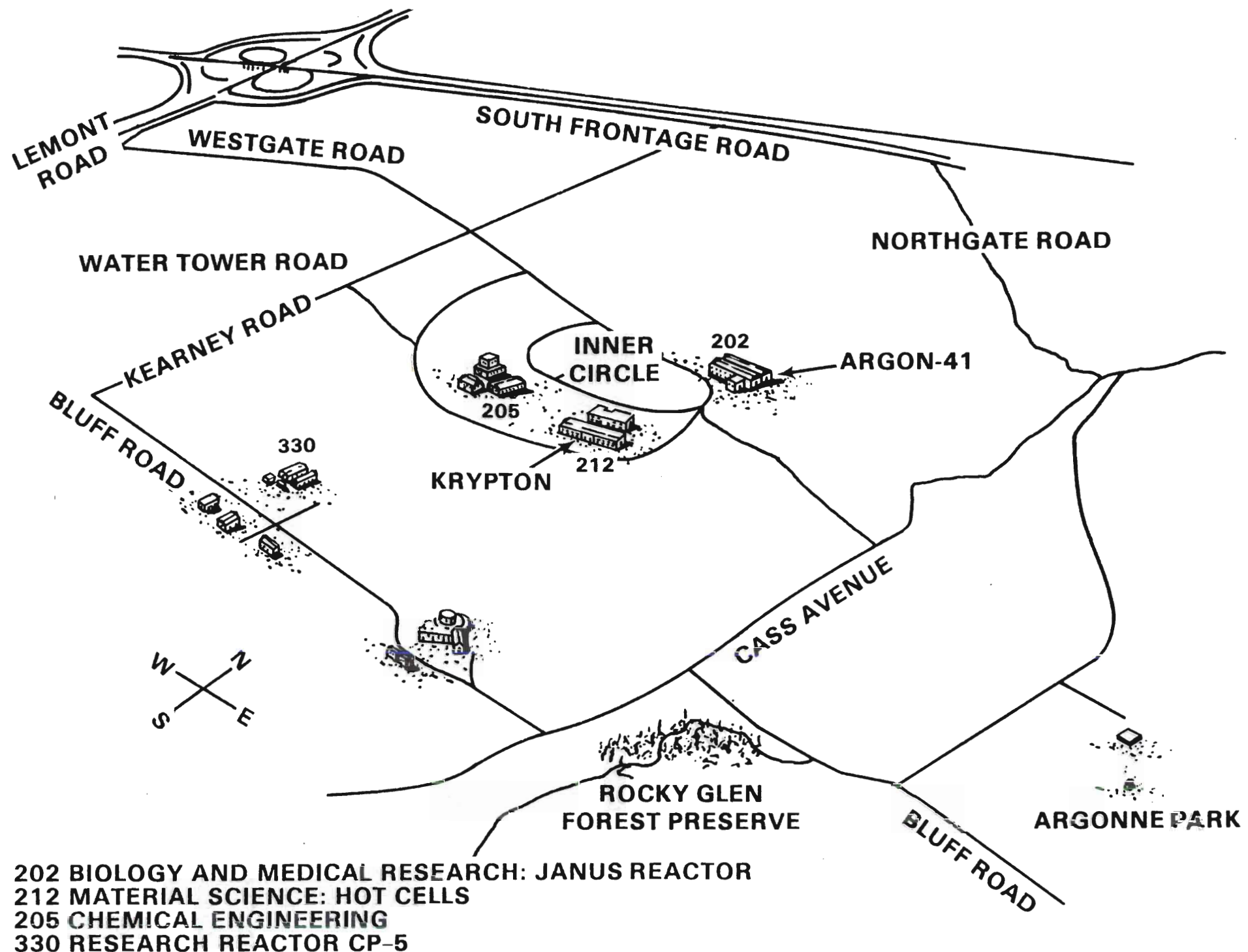

FIGURE 8.2. Locations of Atmospheric Release Points at Argonne National Laboratory 


\subsubsection{Non-Specific and Minor Sources}

There are a number of facilities and laboratories designed for work with radioactive materials which have produced emissions from operations and material processing in the past or that represent only a small contribution to present emissions. These include:

Chemical Engineering Building, 205

In the past, tritium emissions have been observed in laboratory emissions vented to the exhaust stack $(\mathrm{J}-102)$ for this building. No tritium releases were reported for 1981 .

Uranium Activities Building

In the past, uranium machining activities, where airborne emissions contributed $238 U$ to the environment, were conducted in this separate building. The facility has been shut down.

\section{CP-5 Reactor}

The CP-5 reactor was a 5-MWth heavy-water-cooled and moderated research reactor fueled with enriched uranium. It used a helium cover gas system to provide an inert atmosphere for the reactor and to maintain isotopic purity of the $\mathrm{D}_{2} \mathrm{O}$ in the primary system. Neutron activation of room cooling air and tritium leaks were the main sources of effluents. The reactor, located near the southwestern corner of the site, is presently shut down. During operation (1977), argon-41 and tritium were reported in emissions from the reactor stack. No radioactive emissions were reported for 1981.

Other shut down nuclear facilities at ANL include a Zero Power Reactor, the Argonne Thermal Source Reactor, the Zero Gradient Synchrotron, lesser accelerators, and a 60-inch cyclotron.

\subsection{EMISSION CONTROL TECHNOLOGY AT ARGONNE NATIONAL LABORATORY}

A considerable portion of the information presented in this section was obtained from the Chicago Operations Office of the Department of Energy. (a)

(a) Dr. Jerry Nelson, Operational and Environmental Safety Division, Department of Energy, Chicago Operations Office, 9800 South Cass Avenue, Argonne, Illinois 60439. 
In general, radioactive particulate removal devices are installed at locations where the potential exists for particulate emissions to occur. Only limited gaseous air pollution control devices are installed at any of the facilities. The emission control technology at each source location is described below.

\subsubsection{Specific Source 1: Hot Cells}

This section contains information concerning present hot cell emission control technology and radioisotopic discharge rate, potential additional emission control technology and anticipated lower discharge rate, and the estimated cost of additional emission control technology.

\subsubsection{Description of Existing Emission Control Technology}

The hot cells in Building 212, where nuclear reactor material examinations are conducted, are equipped with two stages of HEPA filters and roomtemperature charcoal traps. The HEPA filters efficiently collect particulate emissions. The activated charcoal filters adsorb antimony-125 but do not provide significant hold-up of noble gases (krypton-85). The hot cell emission control system is shown in Figure 8.3. A small stack is located on the roof from which air is exhausted $10.7 \mathrm{~m}(35 \mathrm{ft})$ above ground level.

\subsubsection{Current Discharge Rate}

Radioactive airborne emissions during 1981 from the hot cells include $6.65 \mathrm{Ci}$ of krypton-85 and a minor contribution of about $1.7 \times 10^{-5} \mathrm{Ci}$ of antimony- 125 .

\subsubsection{Potential Additional Emission Control Technology}

At this time, it is not practical to remove krypton gas emissions from the large gaseous flow stream emanating from Building 212. It is possible, however, that the actual source of these emissions could be isolated upstream (before mixing with the general air ventilation system) where the flow rates are quite small. A reduction in the offsite dose from the hot cell emissions could be accomplished by passing the exhaust gases over cooled $\left(-80^{\circ} \mathrm{C}\right)$ charcoal to remove krypton. 


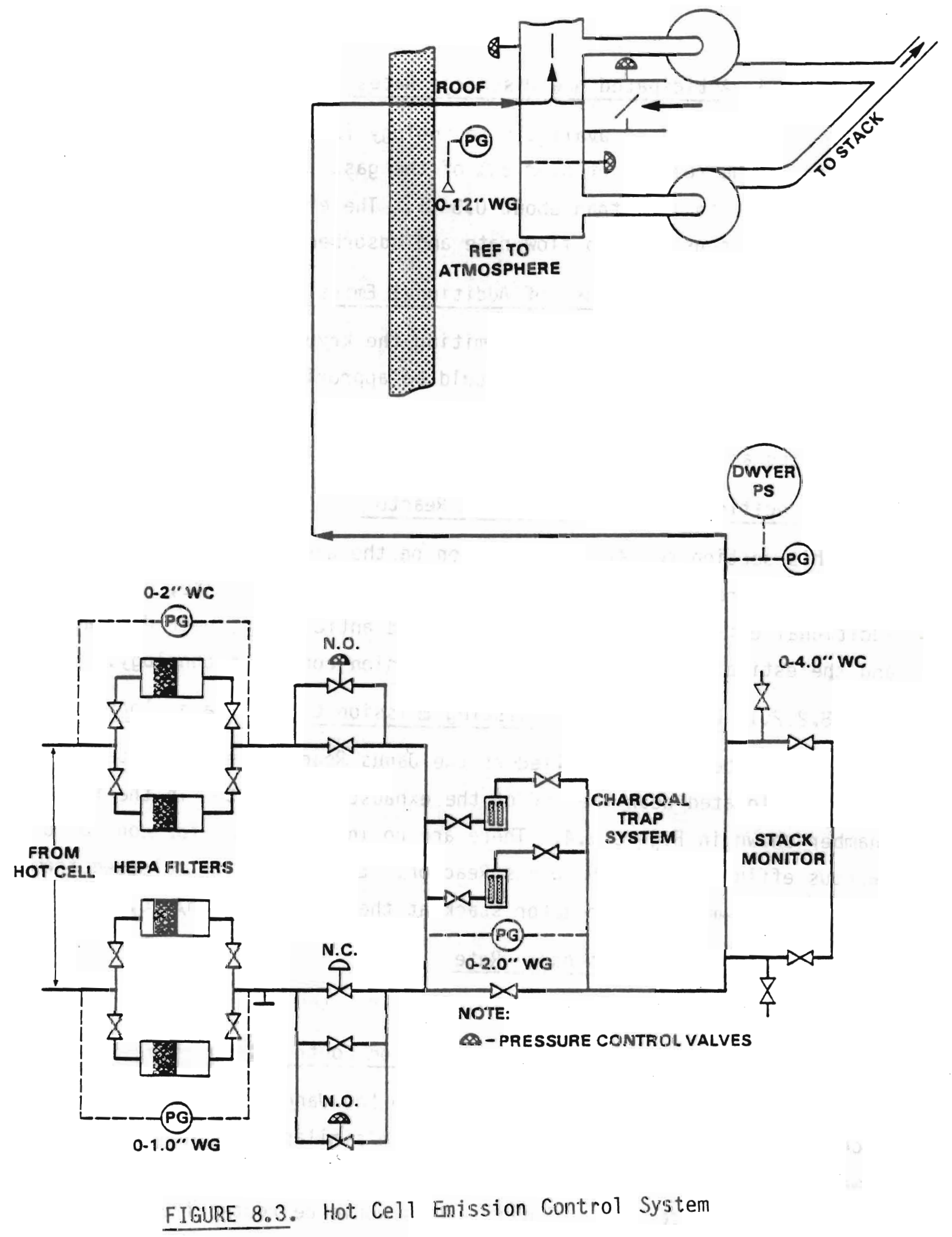

8.7 


\subsubsection{Anticipated New Discharge Rates}

The application of available technology for krypton adsorption would provide for the removal of over $50 \%$ of the gas. This would reduce the annual discharge rate to less than about $0.3 \mathrm{Ci}$. The effectiveness of this technology is sensitive to flow rate and adsorber size (gas residence time).

8.2.1.5 Estimated Cost of Additional Emission Control Technology

The cost of a facility for limiting the krypton emissions from a low flow rate source stream $(0.05 \mathrm{~m} / \mathrm{sec})$ would be approximately $\$ 4.6 \mathrm{million}$ (1983 dollars). This includes $\$ 2.5$ million for construction, $\$ 0.88 \mathrm{million}$ for engineering and a $\$ 1.26$ million contingency.

\subsubsection{Specific Source 2: The Janus Reactor}

This section contains information on the Janus Reactor concerning present emission control technology and radioisotope discharge rate, possible additional emission control technology and anticipated lower discharge rate, and the estimated cost of additional emission control technology.

\subsubsection{Description of Existing Emission Control Technology}

HEPA filters are installed at the Janus Reactor to remove particulates. These are located near the end of the exhaust duct system in the final filter chamber shown in Figure 8.4. There are no installations for control of gaseous effluents from the Janus Reactor. Exhaust air is released from the top of the $23-\mathrm{m}(75-\mathrm{ft})$ reactor stack at the rate of $1.6 \mathrm{~m} / \mathrm{sec}$.

\subsubsection{Current Discharge Rate}

About $0.38 \mathrm{Ci}$ of $41_{\mathrm{Ar}}$ were released from the Janus Reactor in 1981.

\subsubsection{Potential Additional Emission Control Technology}

A reduction in the offsite dose from the Janus reactor emissions could be accomplished by using a gas hold-up system similar to that used in commercial power reactors. The system would consist of four large steel tanks mounted on individual concrete pads. Exhaust gases would be routed from tank to tank, in series, and then to the stack. 


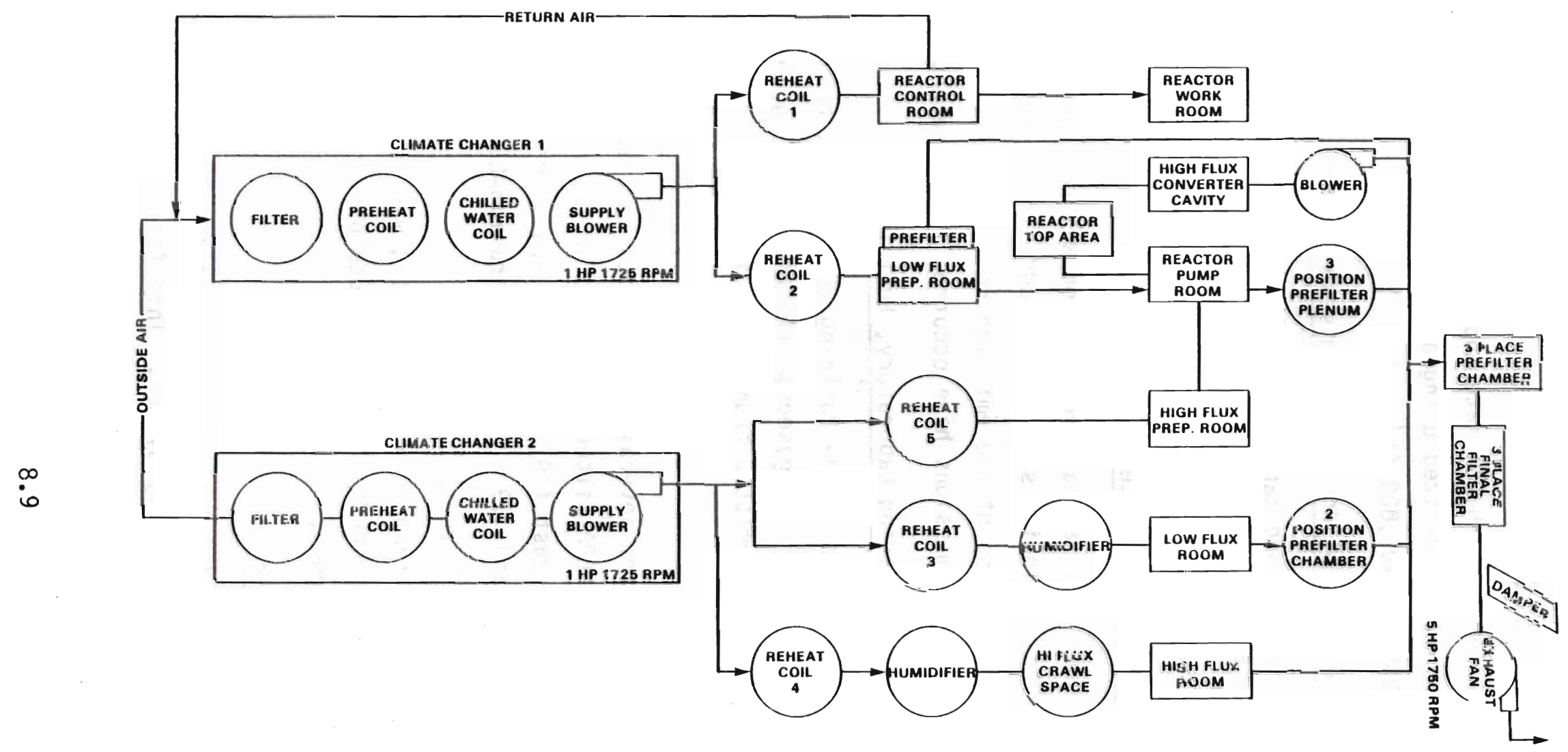

FIGURE 8.4. Building 202 Ventilation System 


\subsubsection{Anticipated New Discharge Rates}

Based on the present air exhaust rate and the $1.8 \mathrm{hr}{ }^{41} \mathrm{Ar}$ decay rate, a $75 \%$ curie reduction could be realized using a gas nold-up system capable of containing about $20,000 \mathrm{~m}^{3}\left(700,000 \mathrm{ft}^{3}\right)$.

\subsubsection{Estimated Cost of Additional Emission Control Technology}

The cost of the four holdup tanks, each containing a volume of $5000 \mathrm{~m}^{3}$, is estimated to be $\$ 7.5 \mathrm{milli}$ ion. This includes $\$ 4.73 \mathrm{million}$ for construction, $\$ 0.71$ million for engineering and a $\$ 2.1 \mathrm{million}$ contingency.

\subsubsection{Non-Specific and Minor Sources}

Only one minor source of radioactive emission was reported during 1981 . This is described in the following section. In addition, a brief description is given in subsequent sections of the emission control technology at locations where radioactive emissions have occurred in the recent past.

8.2.3.1 Chemical Engineering Laboratory, Building 205

HEPA filters are installed in the Building 205 exhaust; however, there are no installations for control of gaseous effluents. During 1981, only $6.9 \times 10^{-7} \mathrm{Ci}$ of tritium were emitted from this building.

\subsubsection{Laboratories}

Particulate emissions from several laboratories handling radioactive materials are controlled by HEPA filters installed in their exhaust stacks. Radioactive emissions in the past (1977) included $6.5 \times 10^{-1} \mathrm{Ci}$ of tritium, $2.0 \times 10^{-1} \mathrm{Ci}$ of krypton-85 and $1.9 \times 10^{-7} \mathrm{Ci}$ of uranium-238.

\subsubsection{Uranium Machining Building}

The airborne effluent stream from this building was treated with a wet scrubber and an electrostatic precipitator to reduce particulate emissions. This facility has been shut down.

\subsubsection{The CP-5 Reactor}

The CP-5 Reactor had HEPA filtration of its reactor thimble exhaust system and an argon-41 exhaust delay system. This facility has been shut down. 


\subsection{BROOKHAVEN NATIONAL LABORATORY}

Brookhaven National Laboratory (BNL) is a multidisciplinary scientific research center operated under contract between the Department of Energy and Associated Universities Incorporated. BNL was founded in 1947 to create research capabilities to supplement existing capabilities of local academic institutions. The original research emphasis at BNL was on nuclear science; however, environmental studies and energy development have since become important areas of concentration.

\subsection{SITE AND MAJOR SOURCE DESCRIPTIONS}

The following discussion of BNL includes a description of the site and its facilities, major sources of radioactive airborne emissions on the site, emission control technology (ECT) in use at specific stacks, and a discussion of possible additional emission control technology.

\subsubsection{Location of Site and Description of Facilities}

BNL is located in Upton, Brookhaven Township, Suffolk County, New York, approximately at the geographical center of Long Island and about 97 kilometers east of New York City (see Figure 9.1). About 1.2 million people live in Suffolk County. Several villages and towns are within a 24-kilometer radius of BNL.

The principal facilities are located near the center of the 2130-hectare site. These facilities occupy an area of about 283 hectares. Among the major facilities (Figure 9.2) at BNL are the High Flux Beam Reactor (HFBR), the Hot Laboratory, the Research Van de Graaff Accelerator, the Alternating Gradient Synchrotron (AGS), the Brookhaven Medical Research Reactor (BMRR), the Chemistry Building, the Brookhaven LINAC Isotope Producer Facility (BLIP), and the Hazardous Waste Management Area. Outlying facilities, occupying about 182 hectares, include the apartment area, ecology forest, gamma field, biology farm, landfill and waste management areas, and the sewage disposal plant. The balance of the site (nearly $80 \%$ ) is mostly wooded. $(1,2)$ 


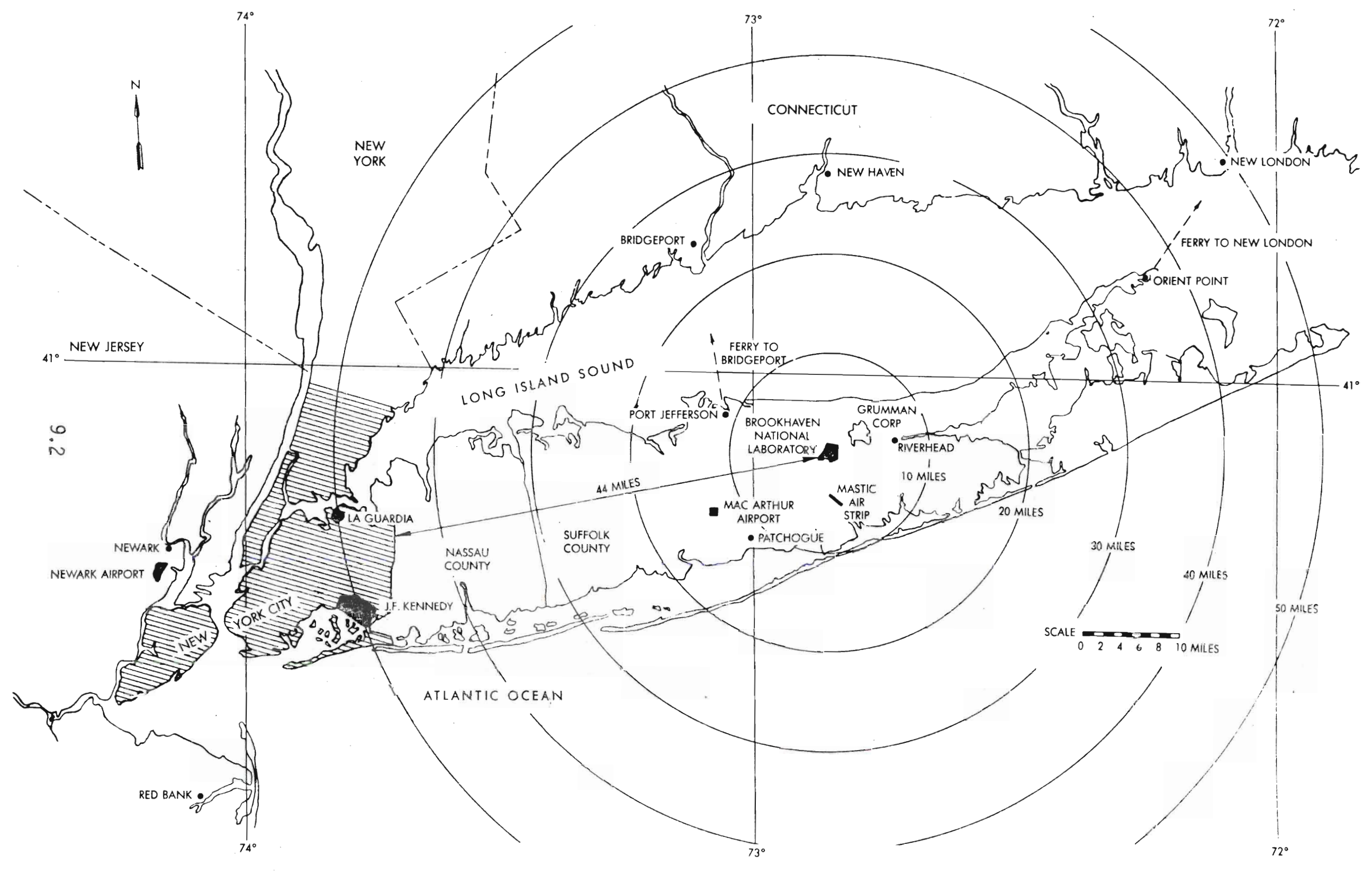

FIGURE 9.1. Regional Map Showing Location of BNL 


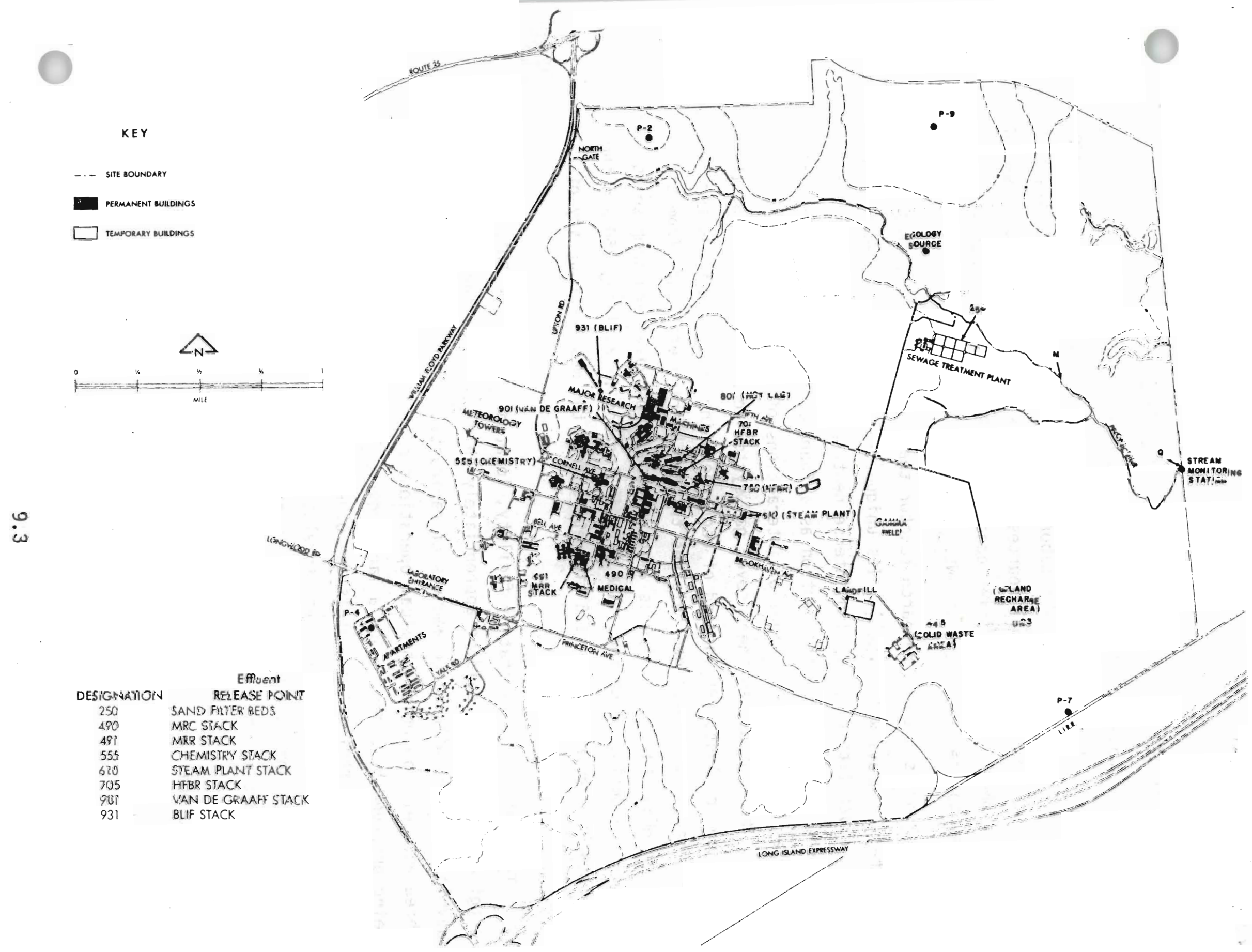

FIGURE 9.2. BNL Site Map 


\subsubsection{Identification and Location of Specific Sources}

Using the analytical technique described previously in Section 1.4, we determined that stacks for the Research Van de Graaff Accelerator, the HFBR (with contributions from the Hot Laboratory), the Medical Research Reactor, and the BLIP are the principal sources of radioactive airborne emissions of concern at BNL. These facilities account for $99 \%$ of the radioactive discharges to the atmosphere at BNL.

The HFBR is a 60-MW research reactor that is moderated, cooled, and reflected by heavy water $\left(\mathrm{D}_{2} \mathrm{O}\right)$. Its unique design gives this reactor the special capability of providing intense neutron beams that are useful to scientists interested in the neutron as a fundamental constituent of matter, as well as in the several kinds of interactions of neutrons with other matter. The HFBR has an inert cover gas system to maintain purity of the heavy water coolant. At the end of each operating cycle (10 times per year), the purging of the cover gas releases tritium-bearing effluents from the 98-meter HFBR stack. Tritium is also released from valve and pump seals from evaporation during refueling. The HFBR is located in Building 750 and the HFBR stack is approximately 1.6 kilometers from the western boundary of BNL. $(1,2)$

The central Hot Laboratory facility, located in Building 801, had the original purpose of providing appropriately shielded areas for research and development work with large amounts of radioactive material. It includes three hot cells in which chemical operations can be performed remotely while being observed by a periscope, a large hot cell for complete physical examination of radioactive metals and other materials, and several totally sealed systems, some of which are shielded, to provide the capability for working with alpha emitters alone or in the presence of gamma radiation. These cells are maintained at a negative pressure with respect to their surroundings to minimize the possibility of radioactivity escaping into other parts of the building. Each cell is provided with individual exhaust air 
filters as well as a backup filter preceding discharge to a common duct leading to the 98-m stack that serves both the HFBR and the Hot Laboratory. $(1,2)$

The BLIP was set up to utilize the excess capacity of the Brookhaven linear accelerator to produce significant quantities of radionuclides that can be made in no other way. For this reason, the BLIP Facility is not competitive with private industry. The entire BLIP and all of its products are dedicated to the development of new radiopharmaceuticals (mostly for diagnostic purposes) and other medical applications of radionuclides. The aim is to provide better diagnostic information with a lower radiation dose to the patient. The principal component of the BLIP is a 10.4-m deep, 2.4-m diameter, water-filled tank into the bottom of which the 200-MeV proton beam is directed horizontally. A series of ten $J$-shaped guide tubes attached to an $20.3 \mathrm{~cm}$ diameter irradiation chamber filled with helium at 2 atmospheres pressure allows the lowering of targets from the operating level at the top of the tank down into the proton beam by motor-driven continuous cables and provides for accurate positioning. Each target is individually jacketed and cooled with a high-velocity thin film of water. The tank shielding water is separate from the cooling-water system, which is recycled continuously. The facility was designed to keep the environmental impact as low as feasible, and the small amounts of radioactive effluents are controlled and monitored. The BLIP is located in Building 931B, which is about 1 kilometer from the BNL western boundary. $(1,2)$

The BMRR is a 5-MW modified tank-type reactor that is devoted primarily to medical and biological studies. The BMRR is located in Building 491, which is about 1.4 kilometers from the west boundary of BNL. The building has four levels, three of which are within the building containment. The basement area contains the primary pumps, heat exchangers and other auxiliary equipment, the building air conditioning, as well as the building inlet air filters. The sub-basement level, with access only from outside the containment, houses the building exhaust air filters and fans. The experimental level provides access to all of the experimental facilities except for those facilities installed in 
the reactor core. The operations level has the control room and also provides access to the top of the reactor shield where all in-core work is done. $(1,2)$

The Research Van de Graaff Accelerator is located in Building 901. At its nearest site boundary proximity, it is approximately $1.5 \mathrm{kilometers}$ from the BNL western boundary that paraltels the William Floyd Parkway. This accelerator is a 3.5-MeV machine used mostly for low energy physics programs, solid state studies and applications to environmental and biomedical studies. It is capable of accelerating protons, deuterons, and tritium ions. When tritium ions are being accelerated, about $200 \mathrm{Ci} / \mathrm{month}$ of tritium gas is used. $(1,2)$

\subsection{EMISSION CONTROL TECHNOLOGY AT BROOKHAVEN NATIONAL LABORATORY}

In this section, the points of discharge that contribute most to the radiological impact from airborne emissions at the BNL site are discussed. These facilities were described in Section 9.1.2. Some information in this section was furnished by Jerry Nelson of DOE's Chicago Operations Office.

\subsubsection{Specific Source 1: HFBR Stack}

The following is a description of emission control technology now in use to minimize radionuclide releases to the air from the HFBR stack that receives effluents from the HFBR and the Hot Laboratory.

\subsubsection{Description of Existing Emission Control Technology}

The principal radionuclides discharged from the HFBR stack are tritium, from the HFBR, and xenon-127 and small amounts of unidentified radionuclides that emtt beta and gamma radiation, from the Hot Laboratory. Tritium is the most prevalent radionuclide discharged. (3) Following is a description of ECT currently in use at the HFBR and Hot Laboratory facilities.

HFBR

The HFBR facility (Building 750) is ventilated by about $566 \mathrm{~m}^{3} / \mathrm{min}$ $(20,000)$ cfm of air, all of which is filtered through absolute High-Efficiency Particulate Air (HEPA) filters to remove particulates and radioactivity before being discharged from the $98-\mathrm{m}$ stack. $(1,2)$ In addition, procedural and administrative controls have been implemented to detect tritium, prevent its 
leakage and reduce the release of tritiated water vapor from the HFBR stack. Since 1977, yearly replacement of a portion of the heavy water (moderator and coolant) has reduced the annual tritiated water vapor released from the HFBR by approximately $50 \%$.

Hot Laboratory

The hot area of the Hot Laboratory (Building 801) consists of five semihot cells, three chemical processing hot cells and three high-level hot cells for handling multicurie amounts of radioactive materials. Each cell is equipped with its own roughing exhaust air filter as well as a backup HEPA filter in the exhaust line leading to the stack. The three chemical process cells have a separate exhaust air system that uses a $\mathrm{NaOH}$ scrubber and charcoal filter to remove radioiodines. The small amount of xenon-127 released is diluted after release from the stack. All effluents from the Hot Laboratory are exhausted to the $98-m$ HFBR stack. $(1,2)$

The block diagram in Figure 9.3 graphically depicts ECT in use at the HFBR and the Hot Laboratory.

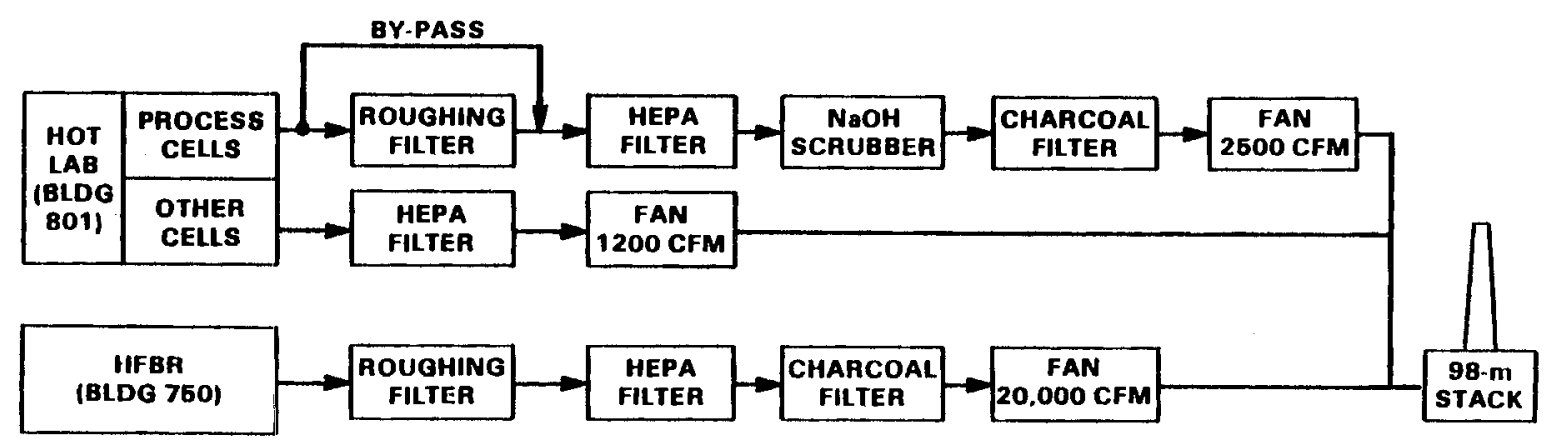

FIGURE 9.3. Block Diagram of Emission Control Technology in Use at the HFBR and the Hot Laboratory

\subsubsection{Current Discharge Rate}

The latest information available indicates that about $240 \mathrm{Ci}$ of tritium was released from the HFBR stack in 1981. This tritium was formed during operation of the HFBR. (3) In addition, about $1.8 \times 1 \mathrm{n}^{-4} \mathrm{Ci}$ of unidentified 
beta and gamma emitting radionuclides and $2.3 \mathrm{Ci}$ of xenon-127 were released from the HFBR stack in 1981. These releases resulted from activities in the Hot Laboratory. (3)

\subsubsection{Potential Additional Emission Control Technology}

The primary radiation dose to offsite populations from the HFBR is due to tritiated water vapor releases. Discussions with DOE personnel indicate that no further treatment of the tritium resulting from HFBR operations is considered to be necessary since the dose rate at the site boundary from this source in 1981 was estimated by DOE to be about $0.02 \mathrm{mrem} / \mathrm{yr}$. Since this dose equivalent rate is al ready so $10 \mathrm{w}$, it is evident that costs associated with additional ECT would outweigh the small benefits of further dose reductions.

The amounts of unidentified radionuclides emitting beta and gamma radiation and xenon-127 contributed by the Hot Laboratory annually are so small that additional treatment of these sources of radiation is also considered unnecessary.

\subsubsection{Specific Source 2: Brookhaven LINAC Isotope Production Facility}

The following is a detailed description of ECT now in use to minimize radioactive releases to the air from the Brookhaven LINAC Isotope Production Facility (BLIP).

\subsubsection{Description of Existing Emission Control Technology}

The targets used for the production of desired radionuclides in the BLIP facility are sealed so that no radioactivity can escape from them during normal operation. However oxygen-15 and tritium are formed by the incident protons in the target cooling water. Larger release rates of oxygen-15 in relation to the other gases result because it is swept out with absorbed oxygen in the cooling water. The absorbed oxygen is formed by the radiolytic formation of stable oxygen. The airborne effluents from the BLIP facility undergo HEPA filtration to remove any particulates prior to monitoring and release from an $18-m$ stack. $(1,2)$ The oxygen-15 and tritium currently receive no treatment prior to discharge from the stack. 
Currently installed ECT at the BLIP facility is graphically presented in Figure 9.4.

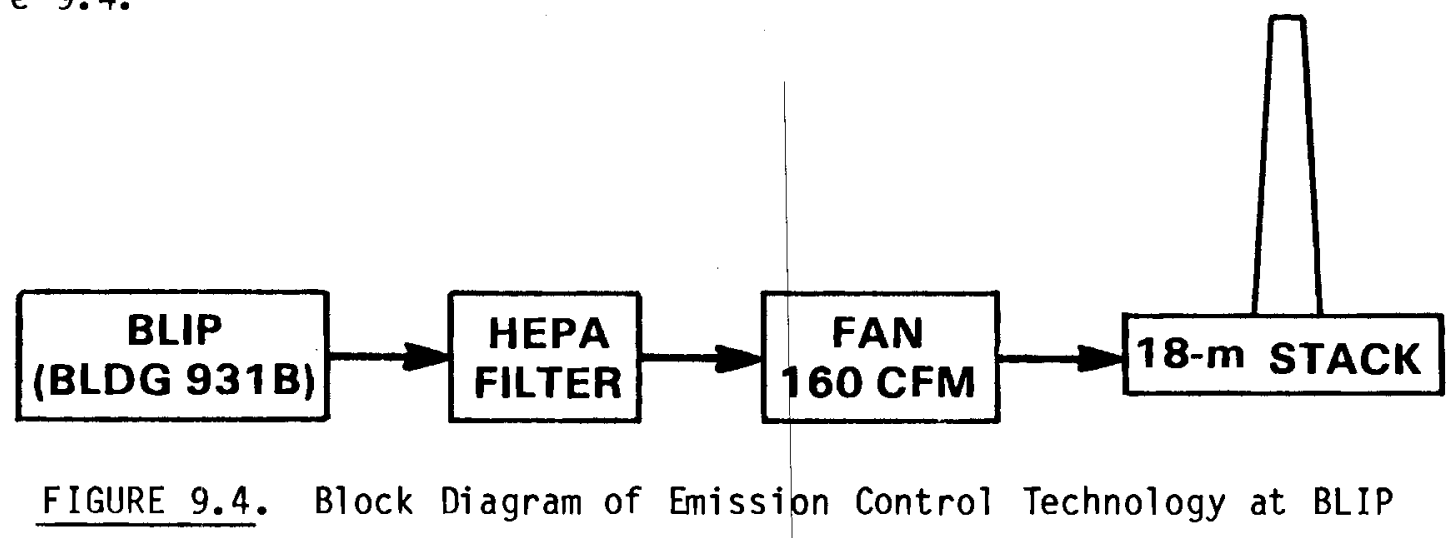

\subsubsection{Current Discharge Rate}

The latest available information indicates that about $36,000 \mathrm{Ci}$ of 122 second half-life oxygen-15 and $6.6 \times 10^{-2} \mathrm{Ci}$ of tritium were discharged from the BLIP facility stack in 1981.(3)

\subsubsection{Potential Additional Emission Control Technology}

The oxygen-15 is characterized by its relatively short half-life. Radioactive decay decreases the air activity concentration of this radionuclide during the transit time between the source and site boundary. Representatives at BNL report that, after release and dilution with ambient combined with decay, radiation from this source was reduced to such a level that it produced no detectable increase in the offsite dose equivalent rate during 1981. For this reason, it has been determined that no additional ECT is necessary at this specific source.

\subsubsection{Specific Source 3: Brookhaven Medical Research Reactor}

The following is a detailed description of ECT now in use to minimize radionuclide releases to the air from the Brookhaven Medical Research Reactor $(B M R R)$ •

\subsubsection{Description of Existing Emission Control Technology}

The principal radioactive gas discharged during routine operations of the BMRR is 110-minute half-1 ife argon-41, which is produced in the cooling air in the reactor's graphite reflectors. At a full power level of $3 \mathrm{MW}$, a release 
rate of about $3 \mathrm{Ci} / \mathrm{hr}$ has been established by direct measurements. The operation of the BMRR is administratively controlled to a daily limit of $24 \mathrm{MWhr}$. Currently, it is operated intermittently for short-lived activation irradiation. The BMRR is enclosed in a containment building that is maintained under negative pressure to prevent inadvertent releases to the outside. Air flow from the building is passed through HEPA and charcoal filters to remove particulates before being vented to the atmosphere via a 45m stack. $(1,2)$ Figure 9.5 shows the currently installed emission control technology.

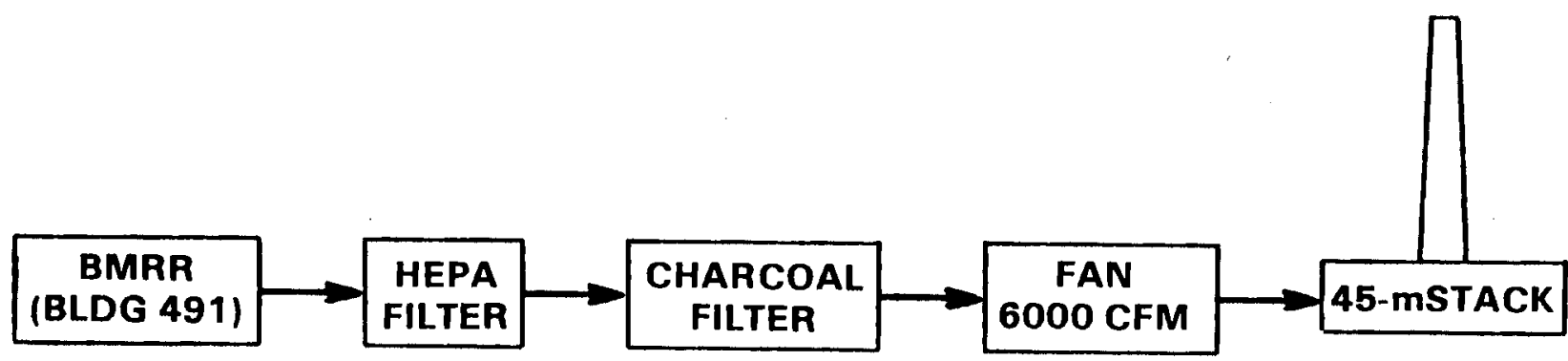

FIGURE 9.5. Block Diagram of Emission Control Technology at BMRR

\subsubsection{Current Discharge Rate}

The latest available information indicates that about $170 \mathrm{Ci}$ of argon-41 were discharged from the BMRR stack in 1981. (3)

\subsubsection{Potential Additional Emission Control Technology}

The argon-41 produced by the BMRR is characterized by a relatively short half-life (approximately $1.8 \mathrm{hr}$ ). Radioactive decay decreases the air activity concentration of the argon-41 during the transit time between the source and the site boundary. Discussions with DOE personnel indicate that after dilution with ambient air following release from the stack, concentrations of this source of radiation were reduced to such low levels 
that they produced no detectable increase in the offsite dose equivalent rate in 1981. For this reason, no treatment is being considered for the argon-41 released from the BMRR stack.

\subsubsection{Specific Source 4: Research Van de Graaff Accelerator}

The following is a description of emission control technology now in use to minimize radionuclide releases to the air from the Research Van de Graaff Accelerator.

\subsubsection{Description of Existing Emission Control Technology}

The principal radionuclide discharged to the atmosphere from the Research Van de Graaff Accelerator is tritium. Currently, about 95\% of the release is in the gaseous form and about $5 \%$ is tritiated water vapor. The air control system in this facility is designed to function as a closed system. During normal operation, a low-pressure pump is used to maintain negative pressure on the system. The output of this pump is routed through a catalytic recombiner where the tritium gas is converted to tritiated water vapor that is passed through a dessicant for removal. Spent dessicants are periodically removed and transported offsite for disposal with other low-level solid waste. When the accelerator is shut down for maintenance, the negative pressure is removed and air at atmospheric pressure is allowed to fill the system. Upon completion of maintenance, the system is pumped down to a negative pressure. During these times, the flow exceeds the capacity of the recombiner and the excess flows are routed directly to the stack via a by-pass 1 ine. When tritium ions are being accelerated, about $200 \mathrm{Ci} /$ month of tritium gas is used. Of the total tritium used, about $50 \%$ is trapped by the dessicant and about $50 \%$ is released from the $18-m$ stack attached to Building $901 .(1,2)$

Figure 9.6 shows a simple block diagram of the ECT currently in use at the Research Van de Graaff Accelerator.

\subsubsection{Current Discharge Rate}

The latest information available indicates that $410 \mathrm{Ci}$ of airborne tritium were discharged from the Research Van de Graaff Accelerator in 1981. (3) 


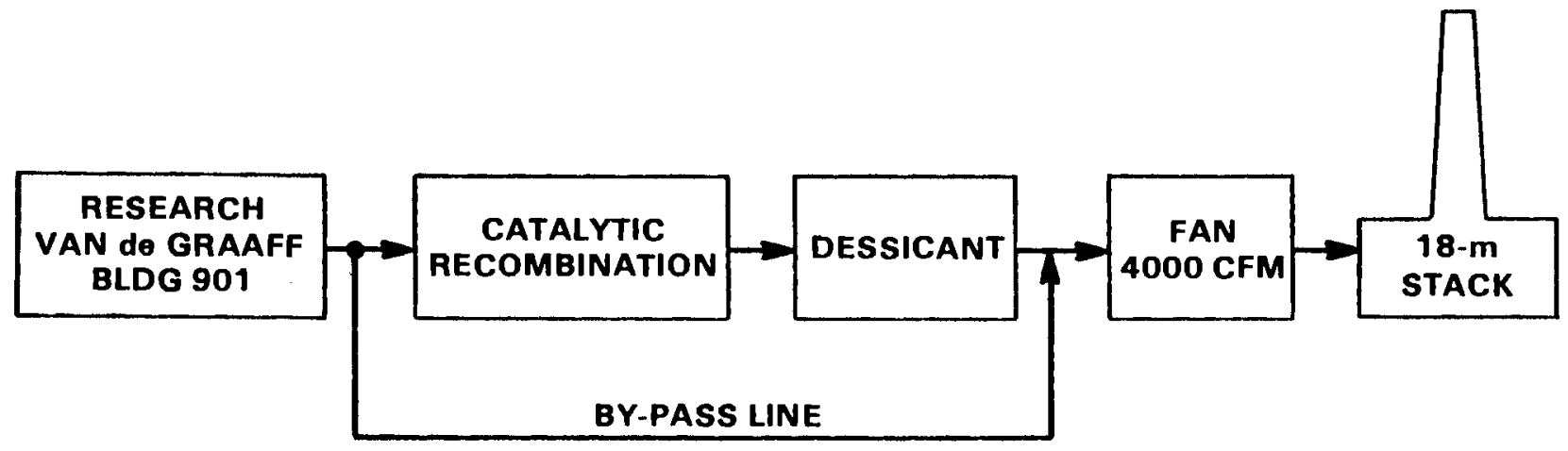

FIGURE 9.6. Block Diagram of Emission Control Technology at Research Van de Graaff Accelerator

\subsubsection{Potential Additional Emission Control Technology}

No changes in the tritium treatment process currently in use at the Research Van de Graaff Accelerator are under consideration. If further reductions in the amount of tritium being released from the stack were determined to be necessary, a process using more efficient catalytic recombination and dessicants or molecular sieves could possibly be used. Of the total amount of tritium, $50 \%$ is currently trapped on the dessicant. (1) Available information indicates that the dessicant system currently used recovers most of the tritiated water vapor received from the catalytic recombiner. (1) Based on this information, it appears that the catalytic recombination step is currently governing the amount of tritium removed from this effluent. Overall process effectiveness could possibly be improved by installing a more efficient catalytic recombination step followed by removal of the resulting tritiated water vapor by use of dessicants or molecular sieves. This process change could possibly improve tritium removal efficiencies from the presently attained 50\% to about 99\%. However, the costs of this additional treatment would have to be balanced against the degree of benefit it would bring to public health. 


\section{REFERENCES}

1. Final Environmental Impact Statement: Brookhaven National Laboratory, ERDA-1540, Energy, Research and Development Administration, Washington, D.C., 1977.

2. Radiological Impact Caused by Emissions of Radionuclides into Air in the United States, EPA 520/7-79-006, Environmental Protection Agency, Washington, D.C., 1980.

3. U.S. Department of Energy Effluent Information System, U.S. Department of Energy, Washington, D.C., 1981. 



\subsection{FERMI NATIONAL ACCELERATOR LABORATORY}

The Fermi National Accelerator Laboratory (FNAL) was authorized in 1968. Construction was completed and operations began in 1972. The primary mission of the laboratory is fundamental research in high-energy elementary particle physics using a proton synchrotron. In addition, cancer patients are treated with neutrons released by proton-target interactions.

\subsection{SITE AND MAJOR SOURCE DESCRIPTIONS}

The major activity at FNAL is operation of the proton synchrotron. The synchrotron can operate at energies up to $500 \mathrm{GeV}$ and operates routinely at $400 \mathrm{GeV}$. The proton beam is extracted from the main accelerator of the synchrotron and routed to three different experimental areas for the research studies.

\subsubsection{Location of Site and Description of Facilities}

The Fermi National Accelerator Laboratory is located on a 2,750-hectare site in the greater Chicago area just east of Batavia, Illinois. Figure 10.1 shows a map of the region, and Figure 10.2 shows the laboratory site. Approximately 1,930 persons are employed at the laboratory. About eight million people live within $80 \mathrm{~km}$ of the site. The laboratory site is open to the public. No hunting is allowed on the site, but fishing is permitted in some ponds and lakes. Other recreational activities such as hiking and baseball are also allowed on site.

Earth shielding has been used to eliminate radiation hazards in most places. Fences and interlocked enclosures are used wherever access still needs to be controlled.

The accelerator system consists of four accelerators: a Cockcroft-Walton preaccelerator, a linear accelerator, a booster synchrotron, and a main ring accelerator. The proton beam is extracted from the main ring accelerator and sent to three target and experimental areas: the Neutrino area, the Meson Area, and the Proton Area (see Figures 10.2 and 10.3). 


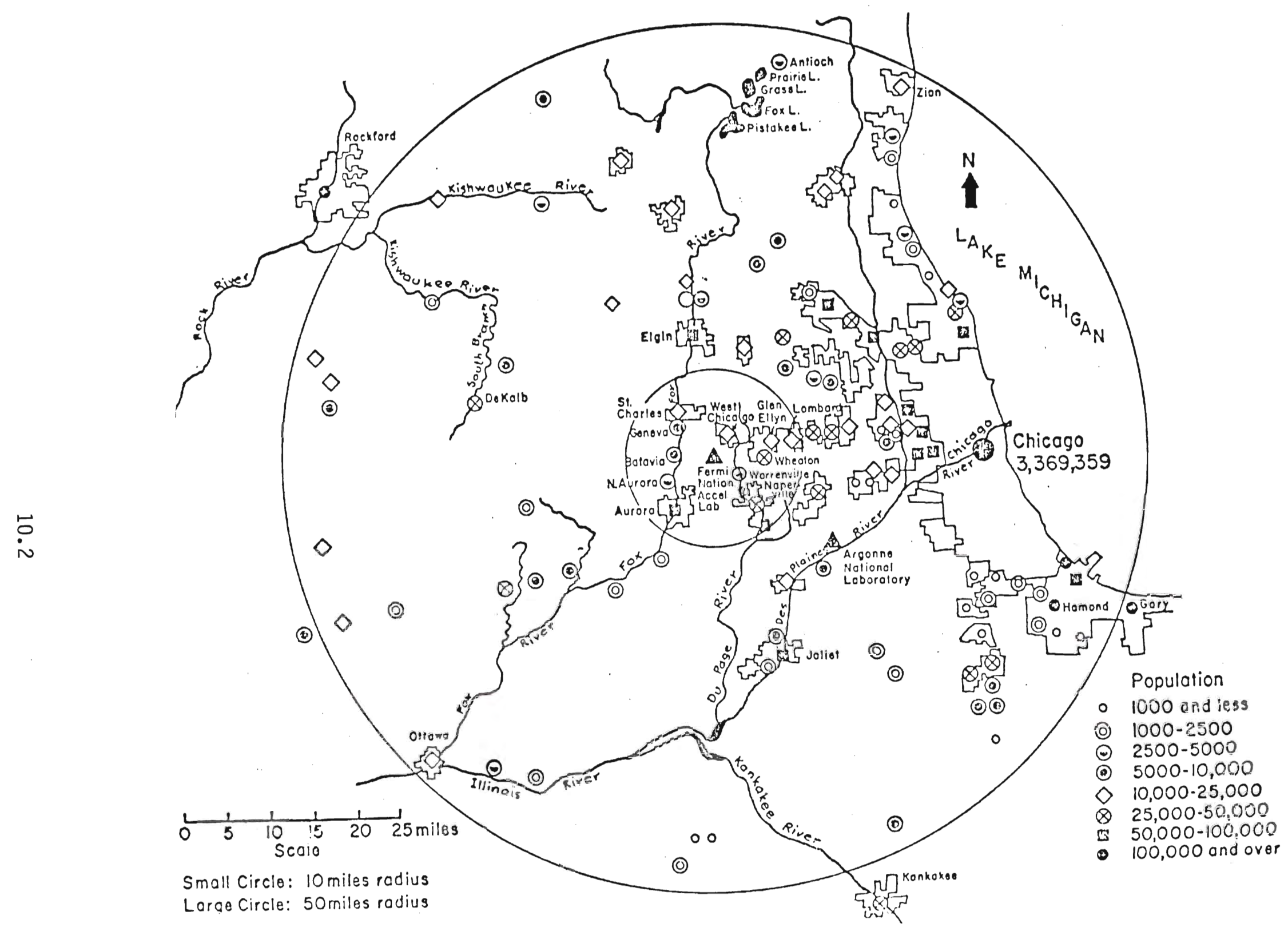

FIGURE 10.1. Location of the Fermi National Accelerator Laboratory and Population Concentrations Within $80 \mathrm{~km}$ (50 mi) 


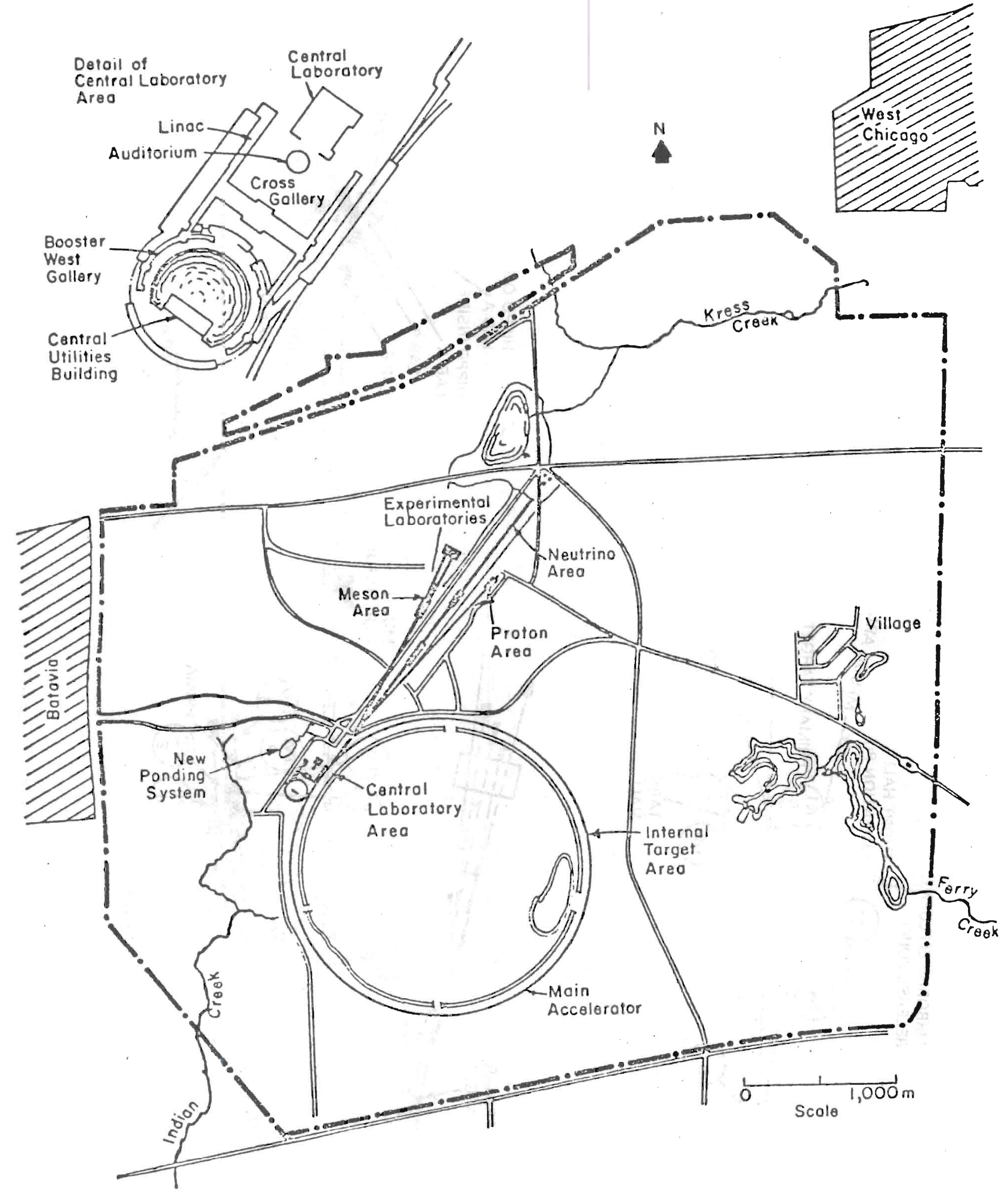

FIGURE 10.2. Map of the Fermi National Accelerator Laboratory. Site 


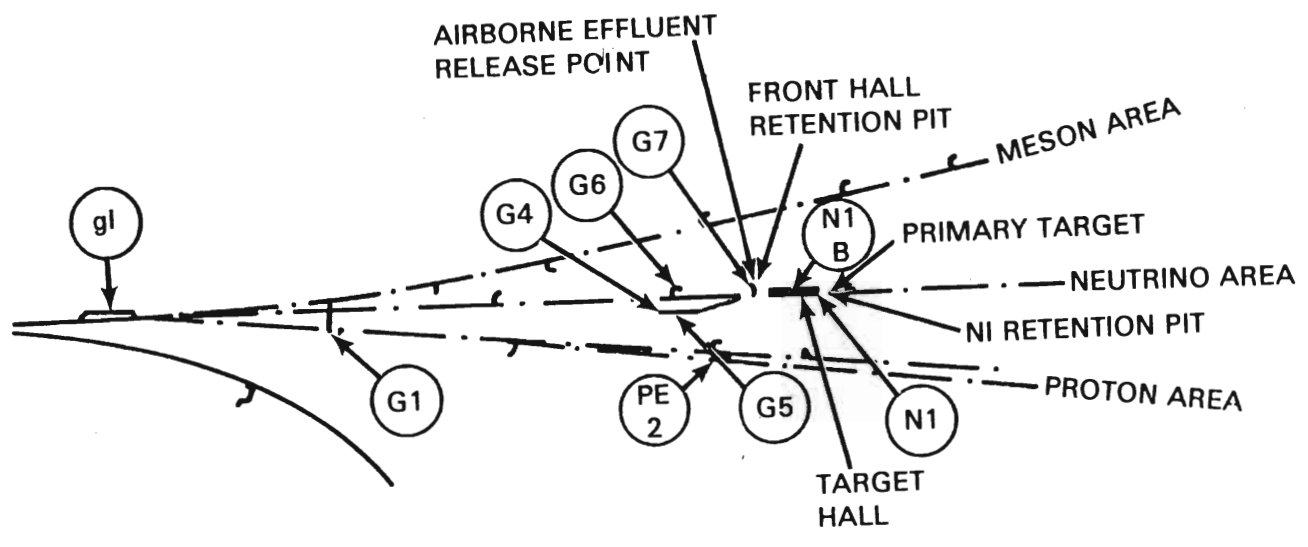

$\stackrel{5}{\circ}$

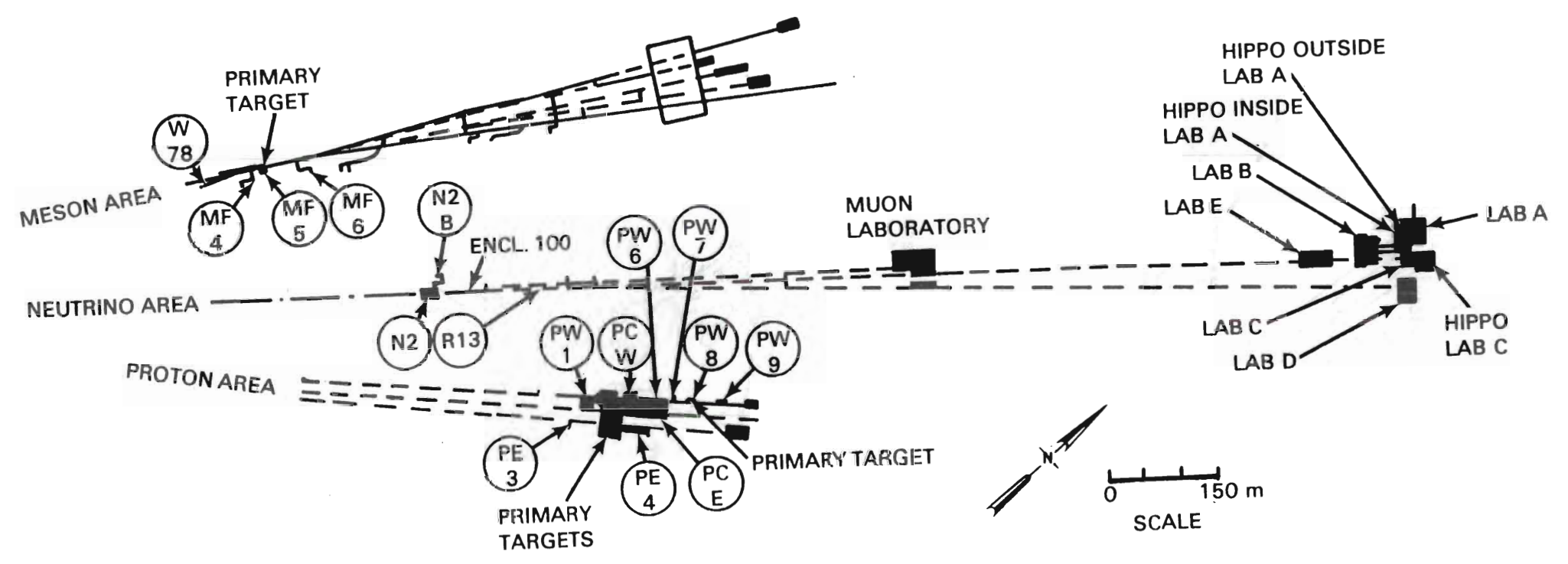

FIGURE 10.3. Map of the Target Experimental Areas at the FNAL 
The booster accelerator and the main ring accelerator are located below ground in concrete tunnel enclosures. The Cockcroft-Walton preaccelerator and the linac are housed in structures that are below ground but extend one story above ground. The proton beam is conducted to the experimental areas in concrete tunnels. The experimental apparatus is contained in high-bay industrial-type buildings. All facilities are provided with adequate shielding to contain secondary particles generated by the primary proton beam.

Support facilities include a central laboratory, office building, central utility plant, electrical power substation, and industrial buildings.

\subsubsection{Identification and Location of Specific Sources}

Operation of the proton synchrotron produces airborne radioactivity and penetrating radiation. (1) Radioactivation of air occurs when the proton beam, and secondary particles resulting from the proton beam's interaction with matter, pass through air. Since the proton beam travels for the most part inside evacuated tubes, radioactivation of air is usually caused by the secondary particles. Operation of the accelerator at high energies and beam intensities also results in the production of some penetrating radiation, primarily muons and neutrons, outside the protective shielding. Although the penetrating radiation contributes to the offsite exposure, it is not within the scope of this study.

Carbon-11 produced by the interaction of secondary particles with air accounts for almost all of the radioactivity released to the atmosphere at FNAL in 1981. (1) Essentially all of the carbon-11 release occurred from the labyrinth stack, which is used to ventilate a Neutrino Area enclosure where the proton beam strikes a target (see Figure 10.3).

Tritium in millicurie quantities was the only other radionuclide released to the atmosphere in detectable quantities in 1981.(1) The tritium was discharged from several locations.

Calculations by FNAL personnel, based on a Gaussian plume diffusion model, showed the expected dose at the site boundary for 1981 due to the 
carbon-11 released to the atmosphere was 0.3 mrem. (1) The site boundary dose resulting from the tritium releases was determined to be negligible using the same diffusion mode1. From the procedure described in Section 1.4 , it was determined that the carbon-11 released from the labyrinth stack accounts for about $99.6 \%$ of the hypothetical risk, while the tritium released accounts for the remaining $0.4 \%$ of the risk. Based on these calculations, it was decided that the labyrinth stack is the only discharge point releasing radionuclides to the atmosphere which would be evaluated in detail.

\subsubsection{Nonspecific and Minor Sources}

As mentioned in the previous section, very small amounts of tritium are released to the atmosphere from several sources at FNAL. The two principal release points in 1981 were: 1) a tritium evaporator in the boneyard where tritiated water is evaporated to the atmosphere, and 2) a debonding oven used to debond failed radioactive magnets by decomposing at high temperatures the epoxy adhesive in the magnets. The tritium release accounts for only a very small fraction of the offsite exposure and can be considered to be negligible in comparison to the exposure resulting from the carbon-11 release.

No radionuclides, other than carbon-11 and tritium, were released to the atmosphere in detectable quantities at FNAL in 1981.

\subsection{EMISSION CONTROL TECHNOLOGY AT FERMI NATIONAL ACCELERATOR LABORATORY}

The following sections describe the emission control technology currently in use at FNAL to reduce atmospheric releases of radionuclides. Potential application of additional control technology, the effects of such improvements on atmospheric discharge rates, and the costs of such improvements are also discussed. Some information in Sections 10.2.1 and 10.2.1.1 was obtained from J. J. Nelson of the DOE Chicago Operations Office.

10.2.1 Specific Source 1: Labyrinth Stack (1)

In the Neutrino Area, carbon-11 is released to the atmosphere from the labyrinth stack. The stack is used to ventilate an enclosure where the proton 
beam from the accelerator strikes a target. Carbon-11 is produced by the interaction of secondary particles with air. The secondary particles result from the interaction of protons from the beam with matter. The target area and its enclosure are located below grade. The air from the enclosure flows through an underground duct to the labyrinth stack which is located approximately $30 \mathrm{~m}$ from the enclosure area. Air flow to the stack is a nominal $3700 \mathrm{~m}^{3} / \mathrm{hr}(2175 \mathrm{cfm})$. The stack has a height of three meters and is located approximately $1600 \mathrm{~m}$ from the site boundary. The location of the labryinth stack within the FNAL site is shown in Figure 10.3.

Carbon-11 is present in the air stream primarily in the form of carbon dioxide and carbon monoxide. A small fraction of the carbon-11 is also present in unidentified organic molecules. It is reported that the carbon-11 present in organic molecules can be removed from the air stream by filtration.

10.2.1.1 Description of Existing Emission Control Technology(1)

Holdup of the air prior to release is the emission control technology in place to remove the carbon-11 from the air stream discharged from the labyrinth stack. Carbon-11 has a half-life of 20.4 minutes and decays by positron emission to boron-11. The residence time of the air in the target area enclosure and duct leading to the stack is such that a significant fraction of the carbon-11 generated in the target area decays before it is released from the stack. The average holdup time will depend on the air flow through the target area enclosure. At a nominal flow rate of $3700 \mathrm{~m}^{3} \mathrm{hr}$, the holdup would allow something less then $50 \%$ of the carbon-11 generated to decay prior to discharge from the stack.

Plans are currently underway at FNAL to modify the operating characteristics of the accelerator. This will decrease the rate of carbon-11 formation in the target area enclosure. Plans are also underway to change the air flow to the stack. The overall effect of the planned changes will be to reduce the carbon-11 released from the labyrinth stack by approximately 50\%, assuming an accelerator operating level equivalent to that of $\mathrm{Cr} 1981$. 


\subsubsection{Current Discharge Rate}

The carbon-11 released to the atmosphere from the labyrinth stack in $\mathrm{CY}$ 1981 amounted to $1450 \mathrm{Ci} .{ }^{(1)}$ The yearly release can vary significantly depending on the level of accelerator operation during a given year.

Using measurements made at the labyrinth stack and calculations based on a Gaussian plume diffusion model, FNAL personnel determined that the expected dose due to carbon-11 at the site boundary for CY 1981 was $0.3 \mathrm{mrem} .{ }^{\text {(1) If }}$ the planned changes in the accelerator operation characteristics and labyrinth stack operations produce the estimated 50\% reduction in carbon-11 release from the stack (to $725 \mathrm{Ci} / \mathrm{yr}$ ), the site boundary dose would be reduced accordingly.

\subsubsection{Potential Additional Emission Control Technology}

Three options are available for reducing carbon-11 emission from the labyrinth stack:

- Reduce the air flow from the target area enclosure to the stack, thus providing additional holdup time for radioactive decay to occur,

- Provide additional holdup space between the carbon-11 source and the stack to allow additional holdup time for decay, and

- Install equipment to remove the carbon-11 before venting the air stream to the atmosphere.

An additional option which has been used in the past to reduce the carbon-11 release is to halt the air flow through the target area enclosure during accelerator operation. The air flow is not started until a finite time after accelerator operation is stopped. This allows a substantial time for the carbon-11 produced during accelerator operation to decay. This option is no longer considered feasible.

Some reduction in carbon-11 release could be achieved by reducing the air flow to the labyrinth stack. Even a 50\% reduction in the air flow, however, 
would only reduce carbon-11 emissions by a small fraction and would adversely affect ventilation of the target enclosure area.

Additional holdup time for decay could be obtained by providing atmospheric or pressurized air storage tanks. The atmospheric pressure storage volumes required to obtain various reductions in the carbon-11 release at a nominal air flow of $3700 \mathrm{~m}^{3} / \mathrm{hr}(\sim 2175 \mathrm{cfm})$ are given in Table 10.1. Use of a pressurized system would reduce the storage volume required but would probably increase the overall capital cost of the system.

TABLE 10.1. Reduction in Carbon-11 Emissions as a Function of Air Storage Volume - Assuming a Nominal Air Flow of $3700 \mathrm{~m}^{3} / \mathrm{hr}$

\begin{tabular}{|c|c|c|}
\hline Air Storage $\mathrm{m}_{3}$ Volume, $(\mathrm{a})$ & $\begin{array}{l}\text { Holdup time, } \\
\text { minutes } \\
\end{array}$ & $\begin{array}{c}\text { Estimated }{ }^{11_{C}} \text { Release } \\
\mathrm{C} i / y r\end{array}$ \\
\hline 0 & 0 & $725^{(b)}$ \\
\hline 1,000 & 16 & 421 \\
\hline 2,500 & 41 & 180 \\
\hline 5,000 & 81 & 46 \\
\hline 7,500 & 130 & 8.8 \\
\hline 10,000 & 162 & 2.9 \\
\hline
\end{tabular}

(a) Air is stored at atmospheric pressure.

(b) Assumes the accelerator operates at the same level of activity as in CY 1981, and the planned changes discussed in 10.2.1.1 are carried out.

Removal of the carbon-11 from the air stream by chemical means would provide an effective method for reducing carbon emissions. Techniques developed for removing ${ }^{14} \mathrm{CO}_{2}$ from air streams should be directly applicable to removal of ${ }^{11} \mathrm{CO}_{2}$ from the air flowing to the labyrinth stack. The removal of

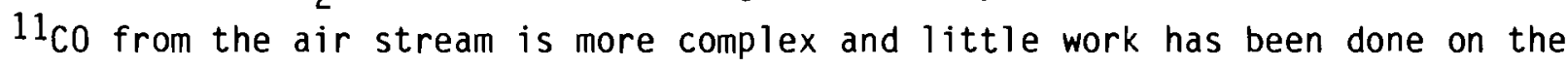

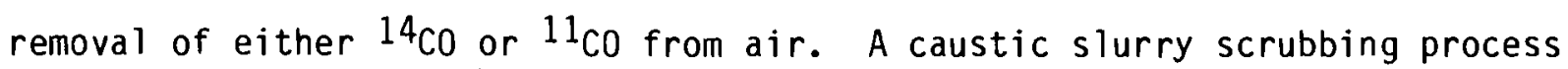
would be the preferred method for removing the ${ }^{11} \mathrm{CO}_{2}$ from the air. The process was developed at $\mathrm{ORNL}$ and has been demonstrated on a laboratory 
scale. (2) Any ${ }^{11_{\mathrm{CO}}}$ in the air stream could probably be converted to ${ }^{11_{\mathrm{CO}}}$ by passing the air stream through a bed of Hopcalite ${ }^{\circledR}$ prior to the scrubbing step. The $\mathrm{CO} / \mathrm{CO}_{2}$ conversion step would require experimental verification. Carbon-11 present as organic molecules could be removed by filtration. Overall, it appears that a filter-caustic slurry scrubbing process should be able to provide a carbon-11 decontamination factor (DF) in the range of 20-50.

If one assumes that the caustic slurry scrubbing process provides a maximum DF of 50, an atmospheric pressure air storage volume of about $7100 \mathrm{~m}^{3}$ $\left(250,000 \mathrm{ft}^{3}\right)$ would be required to give an equivalent reduction in the carbon-11 release. Considering the uncertainties associated with the caustic slurry scrubbing process and its relatively high capital and operating costs, the preferred method for reducing carbon-11 emissions from the labyrinth stack is to provide additional holdup volume.

A nonpressurized air storage tank located above grade would be utilized to provide the required holdup. The air from the target area enclosure would flow through the underground duct to the storage tank which would be located where the labyrinth stack is now sited. The air from the tank would be vented directly to the atmosphere. Tank size would depend on the DF reqired. The air storage system could probably be installed without affecting day-to-day accelerator operation.

To provide a DF of 100 , the air storage system would require a storage volume of about $8360 \mathrm{~m}^{3}$ at a nominal air flow of $3700 \mathrm{~m}^{3} / \mathrm{hr}$. This would require a storage tank which is $30 \mathrm{~m}$ in diameter by about $12 \mathrm{~m}$ high. The tank would be carbon steel and placed on a concrete pad. The air compressor needed to maintain the air flow could be located in the underground duct or a small building adjacent to the storage tank (see figure 10.4). The estimated capital cost for the air storage facility is given in Table 10.2, while estimated operating costs are given in Table 10.3.

The capital costs for atmospheric pressure air storage systems of varying size would vary approximately as the eight-tenths power of the size ratio.

(8) Trademark of Mine Safety Appliances Corp. 


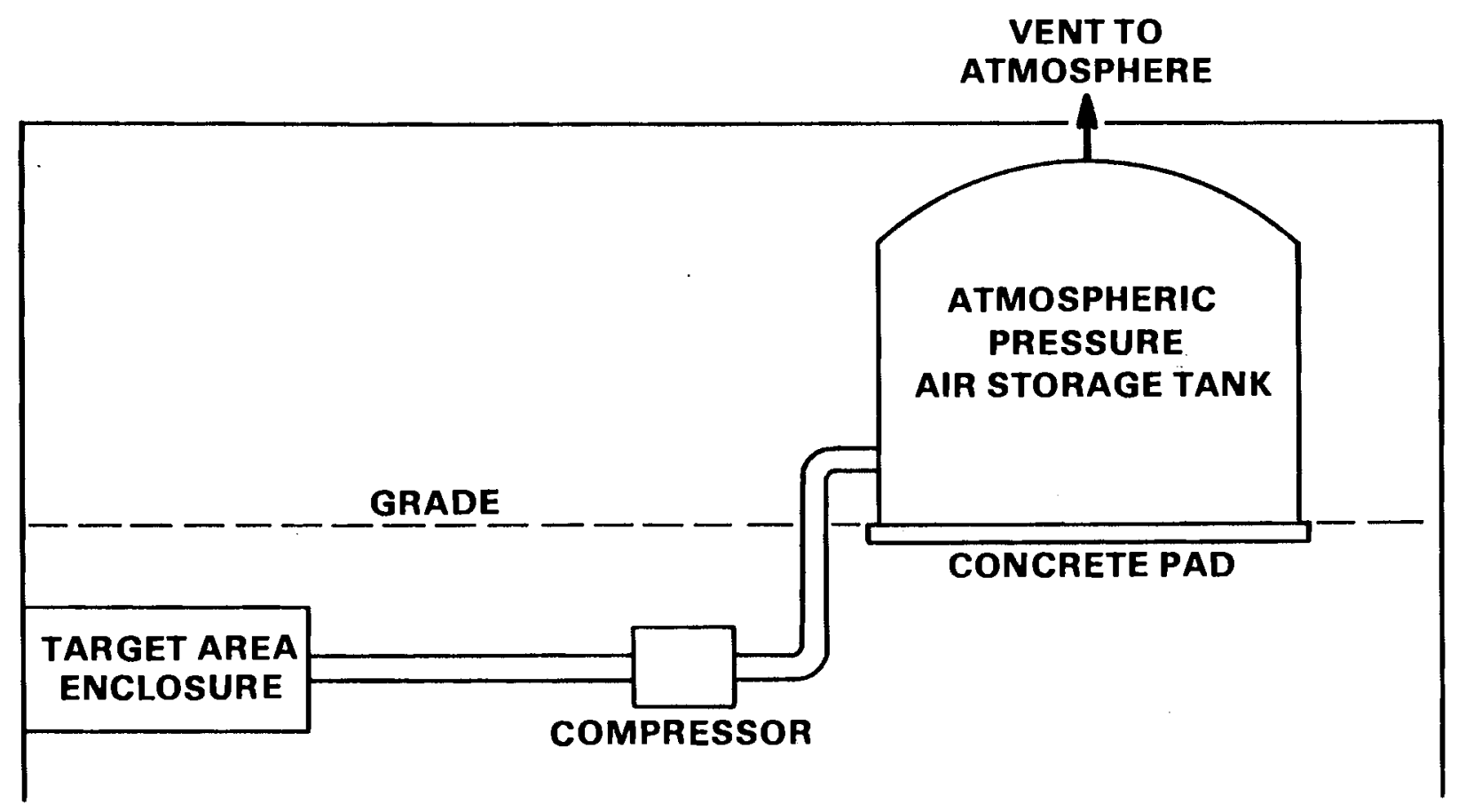

FIGURE 10.4. Air Storage System for Reducing Carbon-11 Emissions

TABLE 10.2. Capital Cost Estimate for an Air Storage Tank System to Provide a Carbon-11 Decontamination Factor of 100 - in 1983 Dollars

\begin{tabular}{|c|c|}
\hline Item & Cost, $\$$ thousands \\
\hline Carbon Steel Tank - Installed (Vol. $8360 \mathrm{~m}^{3}$ ) & 1,600 \\
\hline Compressor, Piping, Instrumentaion, Building & 600 \\
\hline Concrete Pad & 250 \\
\hline Site Preparation & 40 \\
\hline Subtotal Direct Construction Costs & 2,490 \\
\hline Architect-Engineering Services $(\sim 15 \%)$ & 400 \\
\hline Subtotal & 2,890 \\
\hline Contingency $(40 \%)$ & 1,160 \\
\hline Total Facility Cost & 4,050 \\
\hline
\end{tabular}

Table 10.4 shows how the capital costs would vary with the carbon-11 DF required. Annual operating costs for the system would be almost independent of system size. 
TABLE 10.3. Operating Cost Estimates for an Air Storage System to Provide a Carbon-11 Decontamination Factor of 100 - in 1983 Dollars

\begin{tabular}{lc}
\multicolumn{1}{c}{ Item } & Annual Cost, $\$$ \\
Operator (0.25 man-yr/yr) & 7,500 \\
Maintenance (0.25 man-yr/yr) & 7,500 \\
Utilities & 20,000 \\
Maintenance Materials & 20,000 \\
Overhead & 15,000 \\
Miscellaneous & 5,000 \\
Total & $\$ 75,000$
\end{tabular}

TABLE 10.4. Estimated Capital Costs for Air Storage Systems as a Function of the Carbon-11 Decontamination Factor Required - in 1982 Dollars

\begin{tabular}{|c|c|c|c|}
\hline $\begin{array}{l}{ }^{11}{ }_{C} \text { DF } \\
\text { Required } \\
\end{array}$ & $\begin{aligned} & \text { Estimated }{ }^{11_{C}} \\
& \text { Release, } \mathrm{Ci} / \mathrm{yr} \\
&\end{aligned}$ & $\begin{array}{c}\text { Air Storage } V_{Q} l . \\
\text { Required, } \mathrm{m}^{3} \\
\end{array}$ & $\begin{array}{c}\text { Cost, } \\
\$ \text { thousands }\end{array}$ \\
\hline 2 & 363 & 1,225 & 870 \\
\hline 10 & 73 & 4,140 & 2,310 \\
\hline 50 & 15 & 7,050 & 3,530 \\
\hline 100 & 7 & 8,360 & 4,050 \\
\hline 500 & 1.5 & 11,200 & 5,120 \\
\hline
\end{tabular}

(a) Assumes accelerator operating level similar to 1981 and that currently planned changes are instituted.

Assuming the level of accelerator operation is similar to CY 1981 and currently planned changes are instituted, an air storage system which provides a DF of 100 would reduce the carbon-11 emissions to about $7 \mathrm{Ci} / \mathrm{yr}$.

Considering the large capital cost of an air storage system, an additional effort should be made to find a more cost-effective alternative for reducing carbon-11 emissions, if such reductions become necessary. 


\subsubsection{Minor Sources}

The bulk of the tritium discharged to the atmosphere in 1981 was released from two evaporators located in the boneyard. The tritium was released in the form of tritiated water. In prior years the tritiated water was converted into solid waste and buried in a low-level waste burial ground. Evaporation as a means of disposal was used for the first time in 1981.

Tritium in measurable amounts was also released from the debonding oven. The oven is used to debond magnets which have failed. Most of the magnets are radioactive, having been subjected to accelerator operations. The failed magnets were heated to high temperatures to decompose the epoxy adhesives used in the magnet fabrication. Small quantities of tritium are released each time a radioactive magnet is processed.

In previous years very small amounts of tritium were released from a Meson Area Target Box ventilation system. In 1980, the ventilation system was changed to a flow-through system using air instead of helium. The air flow is much greater than the helium flow that was used in past years. The air is vented into the enclosure rather than being released directly to the atmosphere through a small-diameter stack. These changes have resulted in reductions of the tritium concentration in the air stream to levels too low to detect by the analytical techniques used.

\subsubsection{Description of Existing Emission Control Technology}

There is no control technology in place to reduce tritium releases from the boneyard evaporators. Air from the evaporators, which contains the tritiated water, is released directly to the atmosphere.

There is no control technology in place to reduce tritium releases from the debonding oven. Air containing the tritium from the oven is vented directly to the atmosphere from a stack approximately $10 \mathrm{~m}$ high. Air flow to the stack is $2000 \mathrm{~m}^{3} / \mathrm{hr}(\sim 1177 \mathrm{cfm})$. 


\subsubsection{Current Discharge Rate}

A total of $0.42 \mathrm{Ci}$ of tritium as tritiated water was released to the atmosphere from the boneyard evaporators in 1981. Five millicuries of tritium were released to the atmosphere from the stack serving the debonding oven.

Calculations by FNAL personnel show that the contribution of the tritium release to the total offsite exposure was negligible.(1)

\subsubsection{Potential Additional Emission Control Technology}

Based on the small quantities of tritium released to the atmosphere from the various sources, and their minimal effect on offsite exposure, installation of additional control technology to reduce tritium releases does not appear to be justified. If necessary, evaporation of tritiated water in the boneyard evaporators could be stopped. The tritiated water could be converted into solid waste and disposed of in a low-level waste burial ground as was done in previous years. 


\section{REFERENCES}

1. S. I. Baker, Environmental Monitoring Report for Calendar Year 1981, FERM/LAB 82/22 (1104.100), Fermi National Accelerator Laboratory, Batania, Illinois, 1982.

2. K. J. Notz, et al., Processes for the Control of ${ }^{14} \mathrm{CO}_{2}$ During Reprocessing, ORNL/TM7338, Oak Ridge National Laboratory, Oak Ridge, Tennessee, 1980. 



\subsection{HANFORD SITE}

The Hanford site was established in 1943 to produce plutonium for nuclear weapons. Diversification started in the late 1940s with the construction of research and development facilities to support the production facilities. Further diversification occurred in 1965 when a single prime operating contractor was replaced by a number of contractors. Since that time, many of the production facilities have been shut down, converted to other uses, or replaced; and a number of major research and development facilities have been built to support nonweapons nuclear activities.

\subsection{SITE AND MAJOR SOURCE DESCRIPTIONS}

This section provides brief descriptions of the Hanford site, its major U.S. government facilities, and the major sources of airborne radioactive emissions existing in 1981 or expected in 1983-1984.

\subsubsection{Location of Site and Description of Facilities}

The $1500-\mathrm{km}^{2}\left(570-\mathrm{mi}^{2}\right)$ Hanford site is located in southeast Washington, $270 \mathrm{~km}$ southeast of Seattle and $200 \mathrm{~km}$ southwest of Spokane, Washington. It is in a semi-arid region. The 1980 population within an 80-km (50-mi) radius of the site is about 341,000. The Columbia River flows through the site and forms part of its eastern border.

The Hanford site is divided into four major limited access operating areas identified by area numbers. Figure 11.1 shows the location of the site and of the several areas within the site.

100 Area. Nine plutonium production reactors are located in the 100 Area in the northern part of the site along the Columbia River. The eight older reactors were shut down between 1964 and 1971. The ninth reactor, which was completed in 1963, is still operating. This reactor, the $\mathrm{N}$-Reactor, is the first, and to date, the only, dual-purpose reactor built in the United States. It produces plutonium and also by-product steam that has been used since 1966 by the Washington Public Power Supply System (WPPSS) to generate electricity for commercial use. 


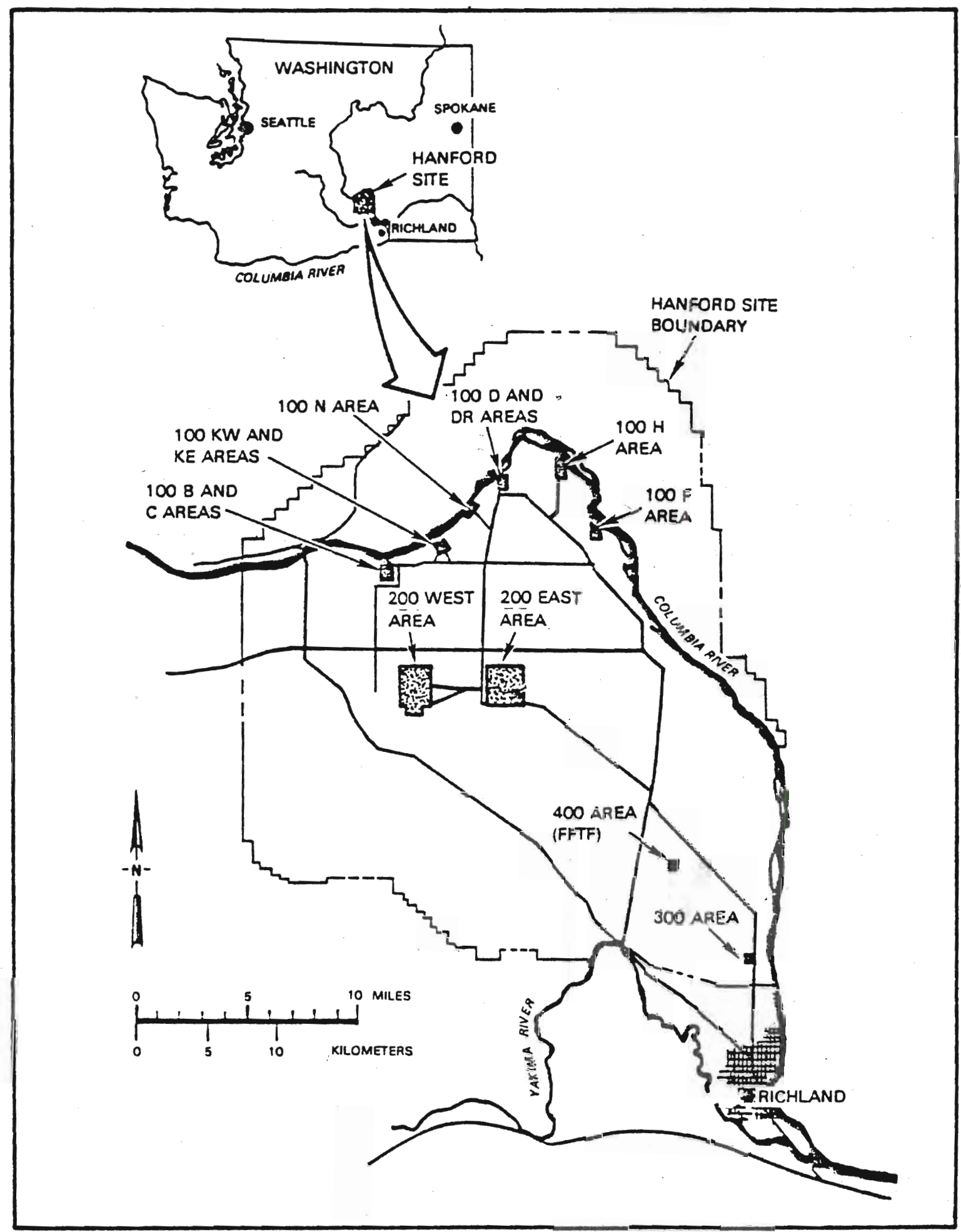

FIGURE 11.1. Hanford Site 
The 1706 laboratory is located in the 100-K Area. Studies of water quality, filtration and corrosion in support of $\mathrm{N}$-Reactor operations are conducted here, along with small-scale decontamination studies.

200 Area. The 200 East and 200 west Areas are located in the center of the Hanford site on an elevated plateau. Facilities supporting irradiated fuel processing are located here. These facilities include several fuel processing plants, tank farms for high-level waste management and storage, waste fractionation plants, plutonium and uranium processing plants, research laboratories, the Critical Mass Laboratory, and burial grounds for radioactive waste. The fuel processing plants have all been shut down except for the PUREX facility, which has been on "wet standby" since 1972. PUREX is expected to come back on line in 1984 .

300 Area. The 300 area is located about $1.7 \mathrm{~km}$ north of Richland. Most of the research and development facilities for the Hanford site are located here, including laboratories and test facilities in support of peaceful utilization of plutonium, in support of the Fast Flux Test Facility, and in support of liquid metal technology. Additional facilities include a metal fabrication laboratory in which studies of metallurgical techniques are performed, a fuel fabrication facility for making fuel elements for $\mathrm{N}$-Reactor, a fuel fabrication facility for making fast flux test reactor fuel elements, laboratories for the development of advanced waste management techniques, and a life sciences laboratory for biophysical and biomedical research.

400 Area. The 400 Area is the location of the Fast Flux Test Facility (FFTF). The area is about $19.5 \mathrm{~km}$ northwest of Richland and $6.5 \mathrm{~km}$ west of the Columbia River. The FFTF is a nuclear reactor complex designed for irradiation testing of fuels and materials to be used for future sodium-cooled fast breeder power reactors. The facility includes a fast flux test reactor and associated heat removal systems, coolant servicing systems, fuel handling systems, control systems, waste disposal facilities, post-irradiation examination facilities, maintenance facilities and administrative offices. 
Other. Other nongovernment facilities have been or are being built on the Hanford site. These include three commercial nuclear power reactors and one commercial burial ground for low-level radioactive waste. These facilities are on land leased from the U.S. Government and are not part of this study.

\subsubsection{Identification and Location of Specific Sources:}

As stated in Section 11.1.1, the PUREX Plant is expected to come back on line in 1984. Because of this, the expected releases from PUREX are added to the emission data for 1981, which appear in Appendix A. PUREX can be operated in its present configuration at a processing rate of $2100 \mathrm{MT} / \mathrm{yr}$. Table 11.1 shows the estimated releases(1) from PUREX at an operating rate of $1050 \mathrm{MT} / \mathrm{yr}$

TABLE 11.1. Estimated Annual Airborne Radionuclide Releases from PUREX

\begin{tabular}{|c|c|c|c|}
\hline Facility/Release Point & Nuclide & $\begin{array}{l}\quad \text { Curies } \\
\text { at } 1050 \text { MT/yr } \\
\text { Processing Rate } \\
\end{array}$ & $\begin{array}{l}\text { Curies (a) } \\
\text { at } 2100 \mathrm{MT} / \mathrm{yr} \\
\text { Processing Rate }\end{array}$ \\
\hline \multirow[t]{7}{*}{$\begin{array}{l}\text { Building 202-A PUREX } \\
\text { Main Stack 291-A-1 }\end{array}$} & ${ }^{239} \mathrm{Pu}$ & $3.1 \mathrm{E}-3$ & $6.3 \mathrm{E}-3$ \\
\hline & ${ }^{90} \mathrm{Sr}$ & $2.7 \mathrm{E}-1$ & $4.6 \mathrm{E}-1$ \\
\hline & ${ }^{129} \mathrm{I}$ & 2. $0 \mathrm{E}-2$ & 4. $0 \mathrm{E}-2$ \\
\hline & ${ }^{131_{\mathrm{I}}}$ & $2.9 \mathrm{E}-1$ & $2.9 E-1$ \\
\hline & $85_{K r}$ & $1.0 E+6$ & $1.3 E+6$ \\
\hline & $3_{H}$ & $1.3 E+3$ & $2.2 E+3$ \\
\hline & ${ }^{14} \mathrm{C}$ & $3.5 \mathrm{E}+0$ & $6.9 \mathrm{E}+0$ \\
\hline \multirow[t]{2}{*}{ All other PUREX Stacks } & ${ }^{239} \mathrm{Pu}$ & $7.2 E-5$ & $1.5 E-4$ \\
\hline & ${ }^{90} \mathrm{Sr}$ & 3. $7 \mathrm{E}-3$ & $6.3 E-3$ \\
\hline
\end{tabular}

(a) Note: The emissions for a processing rate of $2100 \mathrm{MT} / \mathrm{yr}$ are not double the emissions for a processing rate of $1050 \mathrm{MT} / \mathrm{yr}$ because a different mix of aged fuel is assumed for processing at $2100 \mathrm{MT} / \mathrm{yr}$ than is assumed for processing at $1050 \mathrm{MT} / \mathrm{yr}$. 
and at $2100 \mathrm{MT} / \mathrm{yr}$. At the operating rate of $1050 \mathrm{MT} / \mathrm{yr}$, the PUREX main stack contributes about $99.8 \%$ of the emissions of concern for the 200 Area (as determined by the selection method discussed in Section 1.4). Increased activity at other facilities in the 200 Area due to the operation of PUREX would contribute insignificant additional airborne radionuclide emissions to the area.

The 300 Area and the 400 Area are close to each other. They were combined for the determination of significant release points from these areas. Only the 400 Area releases are significant for these combined areas.

There are other Hanford facilities that may be coming on line in the foreseeable future. They include the Fuels Materials Examination Facility (FMEF), the Fusion Materials Irradiation Test Facility (FMIT), and a highlevel waste vitrification hot demonstration. The possible increased airborne radionuclide releases from these facilities have not been included in this study. There also may be increased activity at FFTF. FFTF stacks are included in this study based on their 1981 emission data.

The significant stacks and release points are listed in Table 11.2.

\subsubsection{Nonspecific and Minor Sources}

Nonspecific sources are listed with the emission data in Appendix A. In the 200 Area they are mainly related to waste storage operations and to laboratories. The 300 Area release points and stacks are all considered to be nonspecific sources.

\subsection{EMISSION CONTROL TECHNOLOGY AT HANFORD}

This section describes existing emission control technology at Hanford. Some information in this section was supplied by Don Elle of the DOE's Richland Operations Office.

\subsubsection{Specific Source 1: Stack 116-N Serving the 105-N Reactor Building}

Information for specific source 1 was obtained from Reference 2 and from Larry P. Diediker, Safety and Environmental Engineering, United Nuclear Industries, P.0. Box 490, Richland, Washington. 
TABLE 11.2. Major Release Points at Hanford

\begin{tabular}{|c|c|c|c|c|}
\hline Stack Number & $\begin{array}{r}\text { Building } \\
\text { Served } \\
\end{array}$ & $\begin{array}{l}\text { Location } \\
\text { of Building }\end{array}$ & $\begin{array}{l}\% \text { of Total } \\
\text { Risk } \\
\text { for Area (a) } \\
\end{array}$ & $\begin{array}{l}\text { Radionuclide } \\
\text { of Greatest } \\
\text { Concern (a) }\end{array}$ \\
\hline $116-N$ & $\overline{105-N-R e a c t o r}$ & 100 Area & 95.6 & $41_{\mathrm{Ar}}$ \\
\hline 291-A-1 & 202-A PUREX & 200 Area & 99.8 & $85_{\mathrm{Kr}}$ \\
\hline $\begin{array}{l}\text { Combined } \\
\text { exhaust } \\
\text { Bldgs } 405,(b) \\
4621,4717 \text { (b) }\end{array}$ & FFTF & 400 Area & 59.4 & $88 \mathrm{kr}$ \\
\hline $\begin{array}{l}\text { Bldg } 491-S \\
H \text { and } V \\
\text { Exhaust }(b)\end{array}$ & FFTF & 400 Area & 12.2 & $88 \mathrm{kr}$ \\
\hline $\begin{array}{l}\text { Bldg } 4717 \\
\text { Lower Area } \\
H \text { and V } \\
\text { Exhaust (b) }\end{array}$ & FFTF & 400 Area & 28.4 & $88_{K r}$ \\
\hline
\end{tabular}

(a) See Section 1.4.

(b) Because they are interrelated (as explained in Section 11.2.3), these are considered as one specific source.

Argon-41, which consititues the primary airborne radioactive emission from $\mathrm{N}$-Reactor, is produced from the leakage of air into the reactor system and subsequent activation of the stable argon in the air. Noble gases and volatile fission products, such as xenon-133 and iodine-131, come from leaks in fuel element claddings. Nonvolatile particulate fission and activation products, such as cobalt-60, europium-154 and molybdenum-99, become airborne as a result of the primary coolant contacting exposed surfaces, then drying and becoming suspended in air currents.

\subsubsection{Description of Existing Emission Control Technology}

The ventilation systems in $105-\mathrm{N}$ are separated into five zones based on their potential for contamination with airborne radioactive material. The 116-N stack is the main discharge point for airborne radioactive material from $\mathrm{N}$-Reactor. Immediately preceding the $116-\mathrm{N}$ stack is the $117-\mathrm{N}$ filter and 
diversion facility through which the exhaust air is routed prior to release to the stack. The stack exhausts to the atmosphere $61 \mathrm{~m}(200 \mathrm{ft})$ above ground level.

The 117-N facility contains four separate air filtration cells. Figure 11.2 is a block diagram of the filtration system. The air from Zones I, II and III of the $105-N$ building enters through three separate ducts. Air from Zone I passes through two filtration cells, air from Zone II passes through a third filtration cell and air from Zone III normally bypasses the filter cells as it is routed through the facility. In the event of an emergency, however, Zone III exhaust can be combined with Zone II exhaust to provide filtration for Zone III exhaust. The fourth filtration cell is on standby for emergency backup.

The first, second and fourth filtration cells are composed of a series of three filter bank stages. The first stage is an aluminum mesh screen used as a moisture separator to protect the remaining filters in the event of entrained moisture in the air stream. The second stage is a high-efficiency particulate air (HEPA) filter. Minimum efficiency for removal of particulate matter larger than 0.3 microns is $99.97 \%$. These filters are routinely tested for efficiency. The third stage contains granular activated charcoal that removes $95 \%$ of the inorganic halogen gases in the air stream.

The third filtration cell contains two stages, a HEPA filter and an activated charcoal absorber.

Zones IV and $V$ serve offices, administration areas and the reactor control room. Ventilation air from these areas is exhausted through roof exhausters without treatment.

11.2.1.2 Current Discharge Rate

Over $5660 \mathrm{~m}^{3} / \mathrm{min}(200,000 \mathrm{cfm})$ of air (and other gases) is moved through the 117-N filter and diversion facility and the 116-N stack. This air contains radioactive nuclides as listed in Table 11.3. 


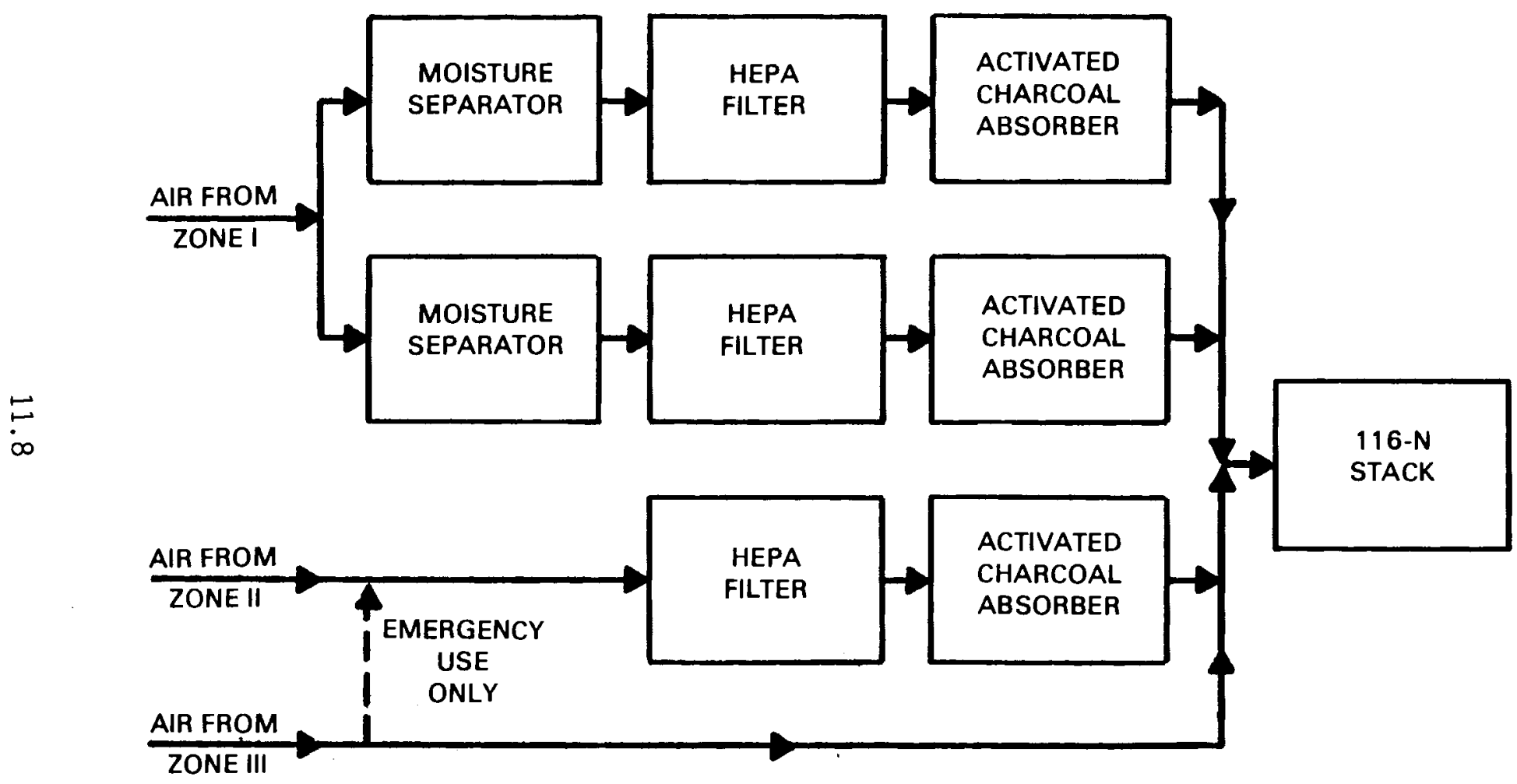

FIGURE 11.2. 117-N Filter and Diversion Facility 
TABLE 11.3. Airborne Releases in 1981 from the N-Reactor 105-N Ventilation Stack

\begin{tabular}{|c|c|}
\hline Nuclide & $\begin{array}{c}\text { Total Curies } \\
\text { for } 1981 \\
\end{array}$ \\
\hline $41_{\mathrm{Ar}}$ & $6.300 E+04$ \\
\hline${ }^{76}$ As & $3.400 \mathrm{E}-01$ \\
\hline${ }^{14} \mathrm{C}$ & $3.200 E+00$ \\
\hline${ }^{58} \mathrm{Co}$ & $6.600 \mathrm{E}-03$ \\
\hline${ }^{60} \mathrm{Co}$ & $5.100 E-03$ \\
\hline${ }^{137} \mathrm{Cs}$ & $8.300 E-03$ \\
\hline${ }^{138} \mathrm{Cs}$ & $4.900 E+03$ \\
\hline${ }^{154} \mathrm{Eu}$ & $1.500 \mathrm{E}-01$ \\
\hline $155_{\mathrm{Eu}}$ & $2.400 E-02$ \\
\hline $3_{H}$ & $1.800 E+01$ \\
\hline${ }^{129}$ I & $8.700 E-09$ \\
\hline $131_{I}$ & $1.500 \mathrm{E}-02$ \\
\hline 132 I & $6.000 \mathrm{E}-01$ \\
\hline${ }^{133} \mathrm{I}$ & $1.200 \mathrm{E}-01$ \\
\hline $135 \mathrm{I}$ & $8.100 \mathrm{E}-01$ \\
\hline${ }^{88} \mathrm{Kr}-88_{\mathrm{Rb}}$ & $4.300 E+02$ \\
\hline $85 m_{K r}$ & $1.900 \mathrm{E}+02$ \\
\hline${ }^{87} \mathrm{Kr}$ & $1.800 E+02$ \\
\hline${ }^{99 m_{M o}-{ }^{9} m_{T c}}$ & 3. $900 \mathrm{E}-02$ \\
\hline${ }^{238} \mathrm{Pu}$ & $4.500 \mathrm{E}-07$ \\
\hline${ }^{239} \mathrm{Pu}$ & $1.700 \mathrm{E}-06$ \\
\hline${ }^{89} \mathrm{Sr}$ & $7.400 \mathrm{E}-05$ \\
\hline${ }^{90} \mathrm{Sr}$ & $1.200 \mathrm{E}-04$ \\
\hline $135 x e$ & $3.400 E+02$ \\
\hline Total & $6.906 E+04$ \\
\hline
\end{tabular}

11.2.1.3 Potential Additional Emission Control Technology

As mentioned in Section 11.2.1, the argon-41 in the emissions from the $\mathrm{N}$ Reactor stack is produced by activation of stable argon in ambient air that has 
leaked into the reactor system. Because of the large flow rate of air, the argon-41 is very dilute in the stack gases.

Possible techniques that have been considered for argon-41 removal include absorption into halogenated solvents, cryogenic separation, chromatographic separation, selective absorption into molecular sieves or activated carbon, diffusion through permselective membranes or metals, and rare-gas clathrates (imprisonment in a crystalline structure). Because of the difficulty of removing a dilute noble gas from a very large air stream, the cost for any of these treatment systems would be in the tens of millions of dollars.

An alternative to the removal of argon-41 from the stack gases would be to reduce its formation by reducing air leaks into the reactor gas system. Some air in-leaks will always exist but efforts will continue to repair such leaks.

\subsubsection{Specific Source 2: PUREX Main Stack No. 291-A-1}

Information for specific source 2 was obtained from References 1 and 2 and from Ronald M. Orme, Process Design, Rockwell Hanford Operations, Energy Systems Group, P.0. Box 800, Richland, Washington, as well as from D0E-RL.

There are four sources of gases that exhaust through the 61-m- (200-ft- ) high 291-A-1 main stack of the Hanford PUREX facility. They are: the declad and dissolver off-gas system, the process off-gas system, the plutonium oxide conversion facility off-gas system, and the canyon ventilation system.

11.2.2.1 Description of Existing Emission Control Technology

Existing ECT on the PUREX 291-A-1 main stack is described below.

Declad and Dissolver Off-Gas System. Figure 11.3 shows the declad and dissolver off-gas cleanup system. The PUREX facility has the capability to process irradiated fuel to separate and recover plutonium, uranium and neptunium. In the head-end of the process, the cladding is chemically removed from the fuel elements and the fuel is then dissolved in the same vessel. The decladding and dissolving are accomplished in three dissolver vessels. The dissolvers have parallel systems for treatment of the declad and dissolver off-gases. 


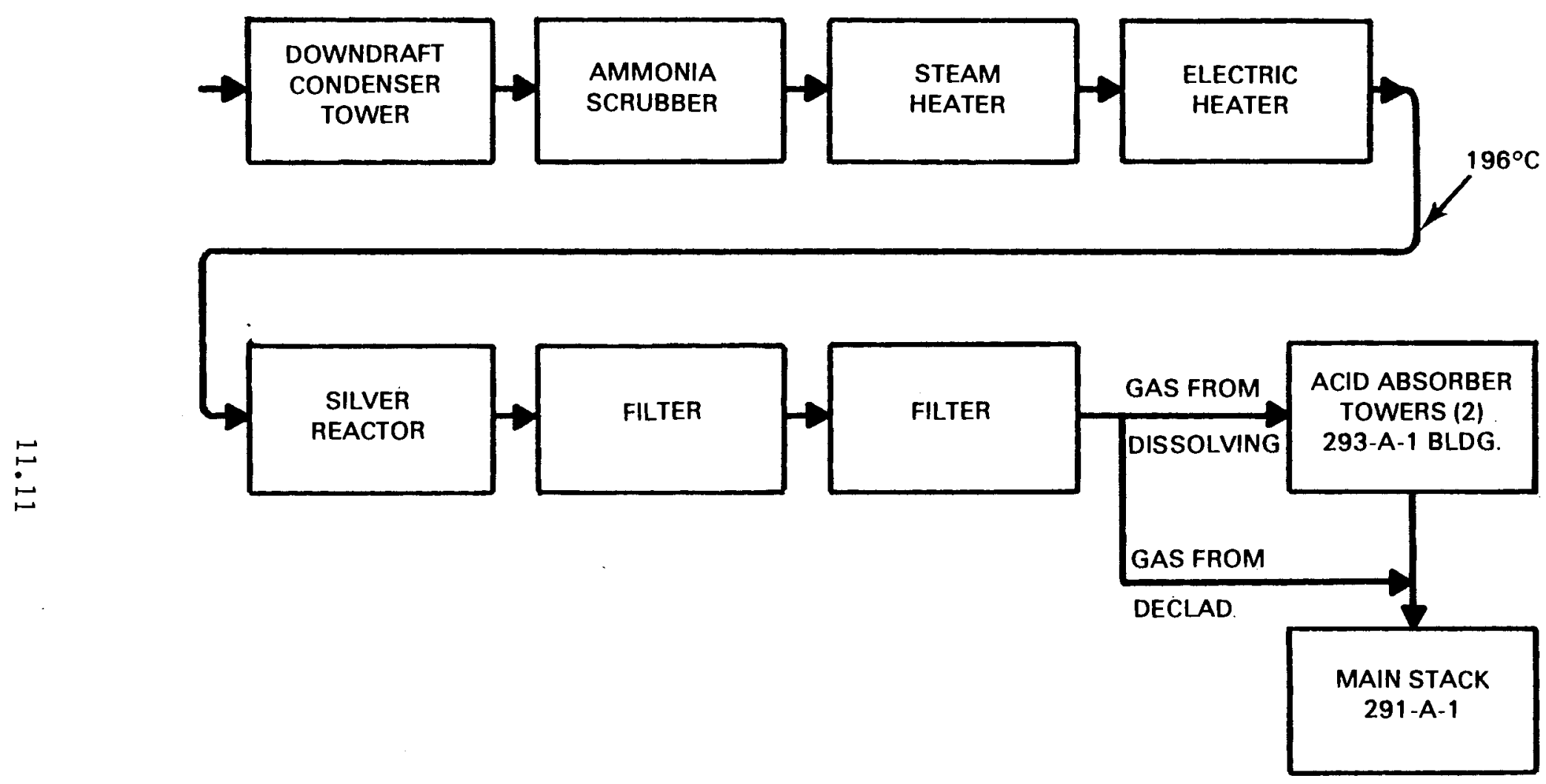

FIGURE 11.3. Declad-Dissolver Off-Gas System 
The declad off-gases first go through a downdraft condenser tower that condenses moisture and removes part of the nitrogen oxides as nitric acid. The gases pass through an ammonia scrubber and then through a steam heater and an electric heater. The gases are heated to $196^{\circ} \mathrm{C}$ before passing into the silver reactor.

The DF for the silver reactor averages 100 . The cell $B$ silver reactor has a 2.44-m- (8-ft-) deep packing bed of $1.3 \mathrm{~cm}-(0.5-\mathrm{in}$.$) ceramic saddles,$ while the cells $A$ and $C$ silver reactors have a $0.88-m-(34-i n .-)$ deep bed of 1.3-cm (0.5-in.) saddles on top of a 0.30-m- (12-in.-) deep bed of 2.5-cm (1.0-in.) saddles. The saddles are coated with silver nitrate. Iodine-129 and -131 are removed in the silver reactor. When the efficiency falls, the silver reactor bed is regenerated with fresh silver nitrate solution that is then baked on the packing. When a reactor becomes plugged, it is replaced and sent to a low-level waste burial ground.

From the silver reactor, the declad gases pass through two deep-bed glass fiber filters in series. The gases are then exhausted through the main stack, 291-A-1.

During the dissolution step, the gases follow a similar path. The ammonia scrubber does not operate during dissolution. The gases exiting the second glass fiber filter are routed to the 293-A Building in which two acid absorbers in series remove $90 \%$ of the remaining iodine and $90-92 \%$ of the remaining nitrogen oxides. The gases are then sent to the main stack, $291-A-1$.

A major radionuclide that is released during the declad and dissolving processes is krypton-85. There is no cleanup of krypton-85 at PUREX.

Process Off-Gas System. Figure 11.4 is a diagram of the process off-gas system. The PUREX process produces off-gases from condensers and other process equipment. These are combined and routed through the process off-gas cleanup system.

The gases go through a condenser to remove the condensable vapors. Then the noncondensable gases are heated in a steam heater to $160^{\circ} \mathrm{C}$ and pass 


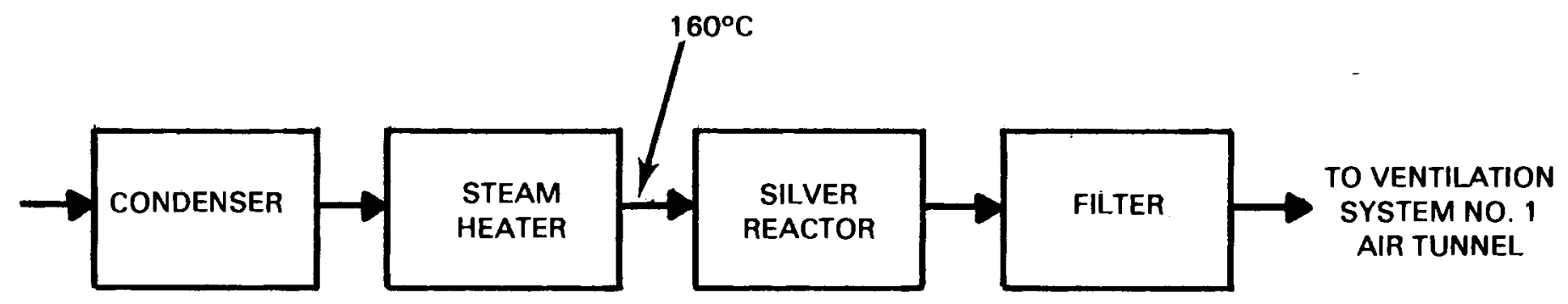

FIGURE 11.4. Process Off-Gas System 
through a silver reactor that removes radioactive iodine that remained in solution during the fuel dissolving process and that evolves during processing steps. This silver reactor has a very low efficiency. From the silver reactor the gases pass through a deep-bed glass fiber filter and from there to the ventilation system No. 1 air tunnel.

Plutonium Oxide Conversion Facility off-Gas System. During the time the PUREX plant has been on standby, a plutonium oxide facility has been added to the plant. Figure 11.5 shows the off-gas treatment system for this facility.

Off-gases from the plutonium nitrate storage vessels and the prereduction tank pass through a heater and then through two stages of HEPA filtration. There is a combined flow of about $1,583 \mathrm{l} / \mathrm{min}$ at $60^{\circ} \mathrm{C}$. Blowers deliver these gases to the ventilation system No. 1 air tunnel.

Off-gases from the calciner pass through a porous stainless steel filter at a flow rate of about $186 \mathrm{l} / \mathrm{min}$ at $157^{\circ} \mathrm{C}$ to remove plutonium oxide particles. These gases, along with the off-gases from the filtrate concentrator and the vessel vent gases from the oxide rework facility, are fed to a scrubber to remove nitric acid. The off-gases from the vacuum header pass through a vacuum tank and are combined with the scrubber off-gases. The combined gases then pass through two vacuum dropout tanks in series to remove entrained liquids. The combined gas flow of about $400 \mathrm{l} / \mathrm{min}$ then goes through a heater and two stages of HEPA filtration in series. A vacuum pump delivers the gases to the blowers that exhaust to the ventilation system No. 1 air tunnel.

Canyon Ventilation System. Ventilation system No. 1 provides ventilation air for the process cells in the PUREX canyon. Added to this air are the gases from the process off-gas cleanup system and from the plutonium oxide conversion facility off-gas treatment system. The treatment of these combined gases is shown in Figure 11.6.

The combined gases are exhausted through filters at a flow rate of $3570 \mathrm{~m}^{3} / \mathrm{min}\left(126,000 \mathrm{ft}^{3} / \mathrm{min}\right)$. Two glass fiber filters and one HEPA filter are installed in parallel. Each unit is designed to handle the full canyon ventilation air flow. Unit one, which was installed in 1955, now has marginal 
FROM PLUTONIUM NITRATE STORAGE

VESSELS AND

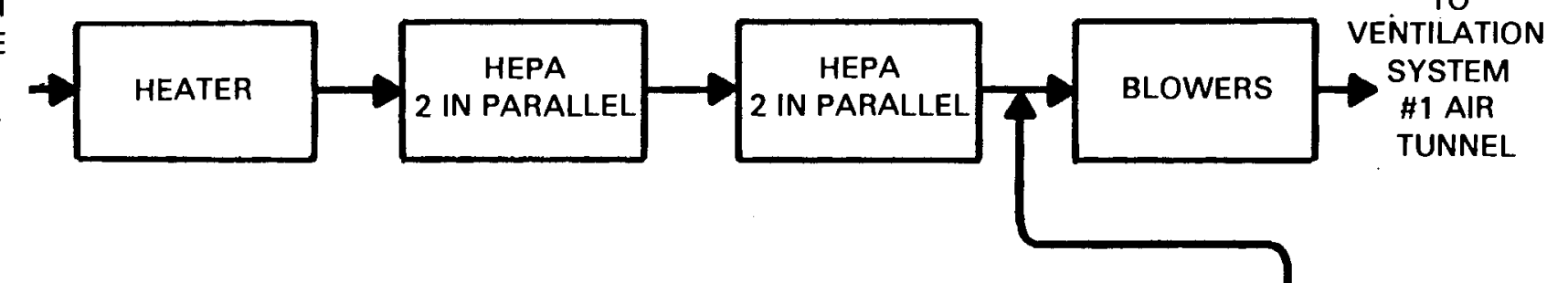

FROM PREREDUC

TION TANK

NTILATION

TUNNEL

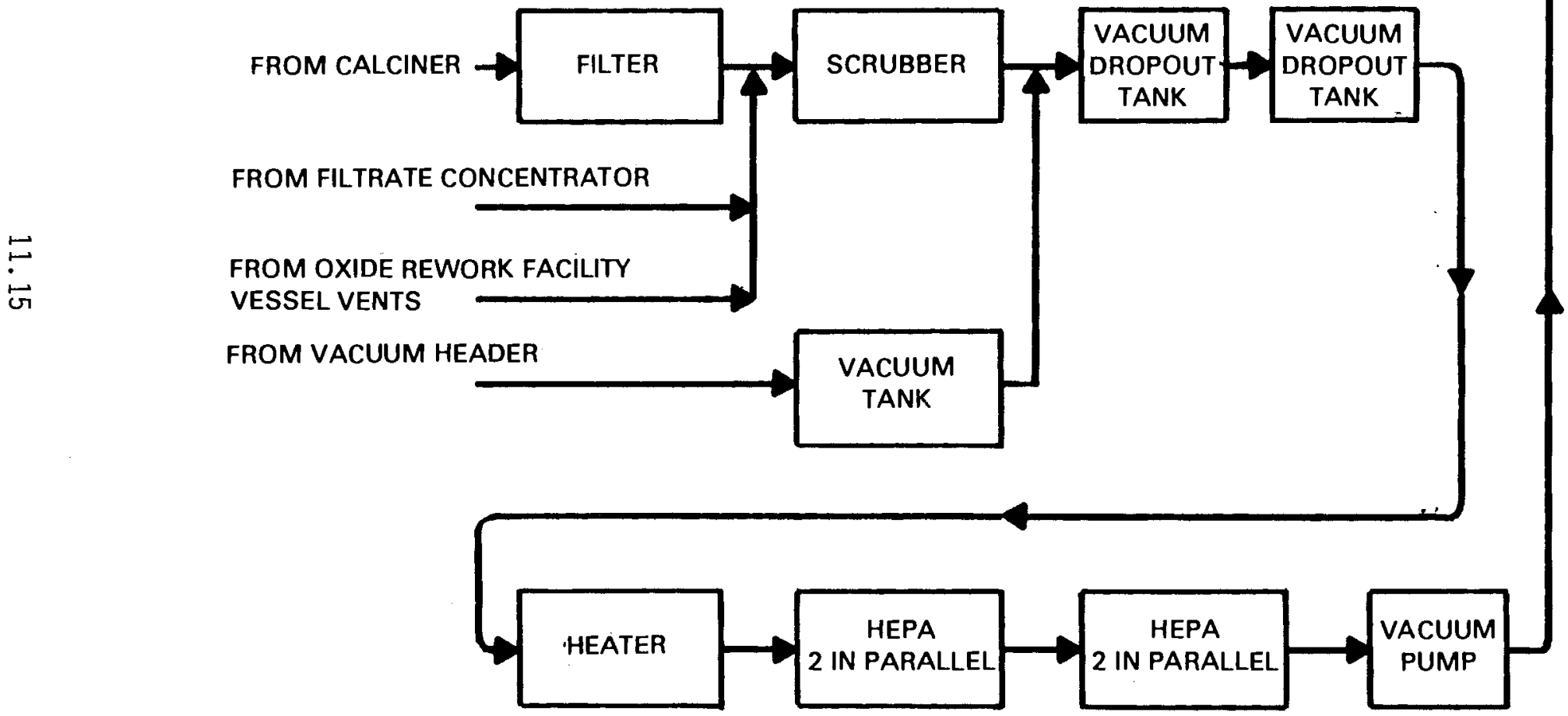

FIGURE 11.5. Plutonium 0xide Conversion Facility Off-Gas System 


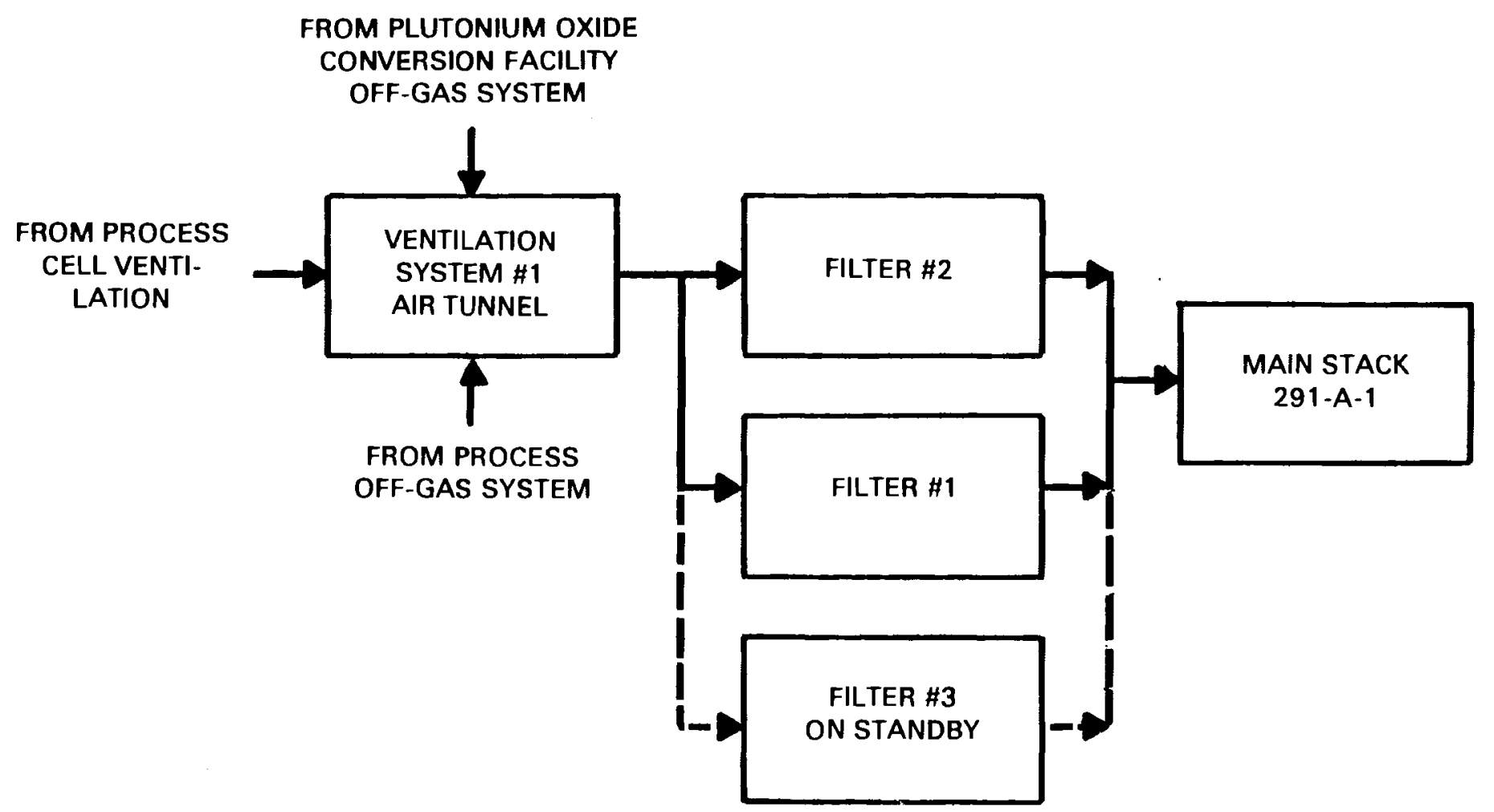

FIGURE 11.6. Canyon Ventilation System 
capacity because of the accumulation of solids. Unit two is run in parallel with unit one. Unit three is on standby. The filters are installed underground. When they are no longer usable, they will be sealed and left in place. Recent tests have shown the two fiberglass filters to have efficiencies greater than $99.95 \%$ for 0.3 micron particles. Unit three is designed to remove $99.97 \%$ of the 0.3 micron particles from the ventilation air. Fans deliver the filtered gases to the PUREX main stack, 291-A-1.

\subsubsection{Current Discharge Rate}

Discharge rates have been estimated for the PUREX main stack when PUREX comes back on line in 1984. They are listed in Table 11.1 in Section 11.1.2.

\subsubsection{Potential Additional Emission Control Technology}

Radionuclides of concern that are emitted from the Hanford PUREX stack are krypton-85 and iodine-129 and -131. Descriptions of potential removal of krypton and iodine and the problems associated with their removal follow.

Removal of Krypton. Potential recovery of krypton involves processing the off-gas stream generated during the uranium dissolution step. In the normal operation of the dissolvers, large volumes of air are used to sparge and sweep the dissolvers during dissolution of the uranium fuel. The atmospheric (non-radioactive) krypton contained in the air sparge will therefore have to be recovered along with the krypton in the fuel. (The nonradioactive krypton in the fuel would also be recovered with the radioactive krypton-85.)

A generic description of krypton-85 recovery by cryogenic distillation is given in Section 4 of this report. Despite the relatively advanced state of technology for krypton recovery by cryogenic distillation, krypton recovery at the Hanford PUREX Plant would require considerable development activities.

A preliminary conceptual study of krypton-xenon recovery from Hanford's PUREX Plant was recently performed by the Ceramics and Polymer Development Section of the Materials Department of the Pacific Northwest Laboratory (PNL). (Note: the xenon is liquefied along with the krypton in the cryogenic process. The cryogenic distillation of the liquid does not give complete 
separation of these elements.) In the PNL study, it was assumed that the processing rate was 2100 MT of $\mathrm{N}$-Reactor fuel per year and that the fuel had been aged 1 year prior to processing, so that all the radioactive krypton and xenon isotopes except krypton-85 would have decayed to negligible levels. It was estimated that $80 \%$ of the krypton and xenon in the $\mathrm{N}$-Reactor fuel would be recovered.

The gaseous feed stream to the krypton-xenon recovery system from the second acid absorber in Building 293-A would require extensive pretreatment to remove impurities before the krypton and xenon could be recovered by cryogenic distillation. The pretreatment must provide for removal of residual ruthenium and iodine, oxides of nitrogen, oxygen, tritium, water (including tritiated water), and carbon dioxide (including ${ }^{14} \mathrm{C}$ ). The sequence of the pretreatment steps can vary depending on the process selected for contaminant removal. Processes available for removing some of the contaminants from the gas stream have not been adequately demonstrated using radioactive gases, and considerable development effort would be required regardless of the pretreatment process selected. Figure 11.7 shows the pretreatment scheme selected for the PNL study.

Based on the PNL study, an order-of-magnitude estimate(a) of the capital costs for the krypton-xenon recovery facility was made by Kaiser Engineers Hanford. About $\$ 160$ million (in 1988 dollars) would be required. The recovered krypton-xenon would need to be stored. One storage method is in pressurized cylinders in a storage facility. Capital costs for a storage facility for a 2100 MT/yr processing plant have been estimated $(3)$ to be in excess of $\$ 150$ million (in 1976 dollars). Operating and maintenance costs must be added to the capital costs when considering costs.

At an assumed processing rate of $2100 \mathrm{MT} / \mathrm{yr}$, the krypton-85 available for recovery is estimated to be $1.3 E+6$ curies/year. An $80 \%$ recovery rate of this krypton gives an annual remaining discharge rate for krypton-85 of $2.6 \mathrm{E}+5$ curies from $\mathrm{N}$-Reactor fuel.

(a) An order-of-magnitude estimate is defined as an approximation made without detailed engineering data. This type of estimate is used as an early aid in evaluating the potential of a project. 


\section{DISSOLVER OFF-GAS}

FROM THE SECOND

ACID ABSORBER TOWER

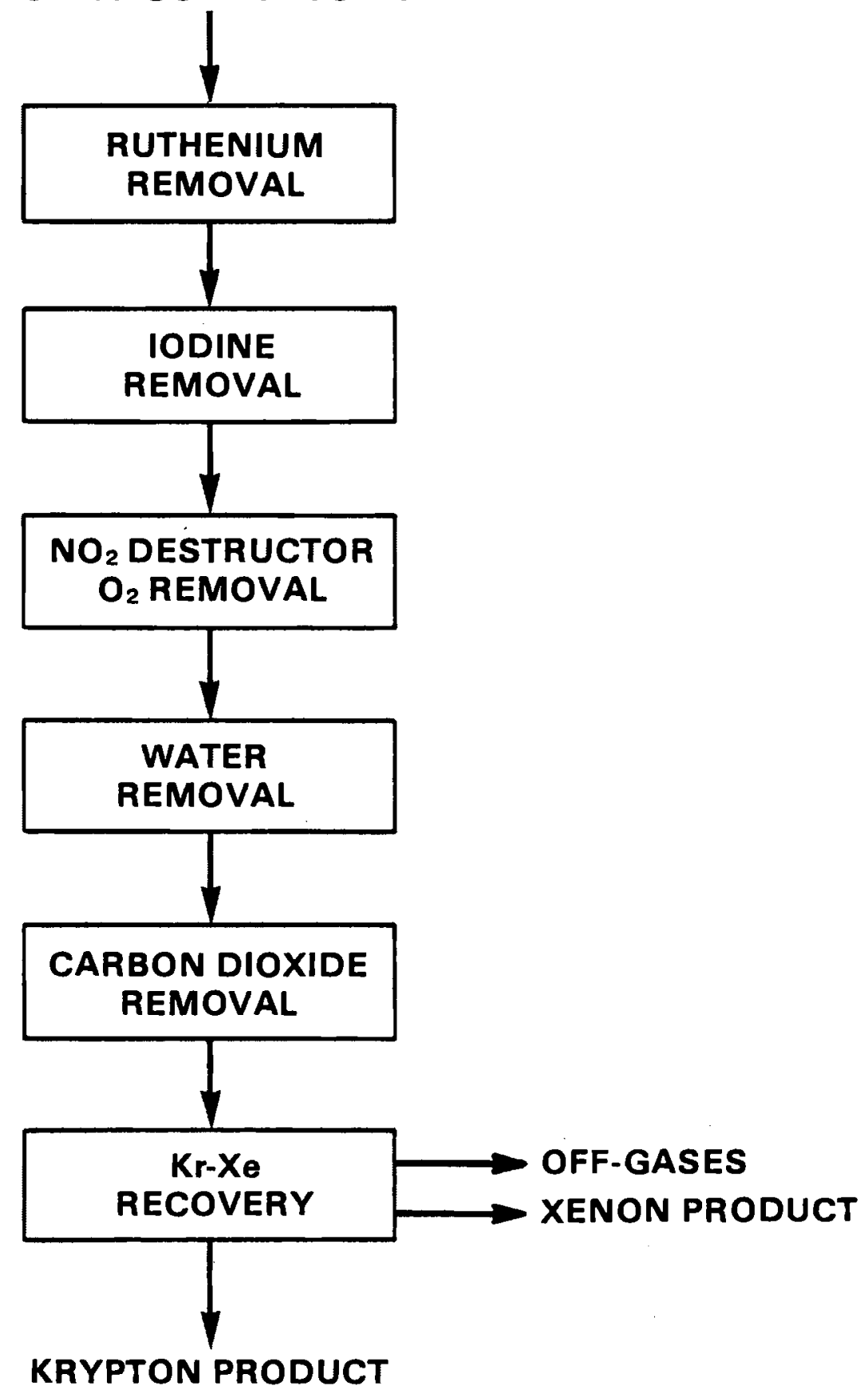

FIGURE 11.7. Pretreatment Sequence for Removing Contaminants from the Dissolver Off-Gas Prior to Krypton-Xenon Recovery 
Removal of Iodine. Iodine removal from the dissolver off-gases is very effective. The $D F$ for the dissolver silver reactors averages 100 , while the DF for iodine for the acid absorbers in the 293-A Building (in series with the silver reactors) is about 10 . With an overall DF of 1000 , very little iodine is exhausted to the stack with the gases from the dissolvers.

About $35 \%$ of the initial iodine charge leaves the dissolvers in the solution. This solution is then processed by solvent extraction. About 1 to $5 \%$ of the initial iodine is released with the process off-gases; the rest remains in solution. The silver reactor for the process off-gases has a very low efficiency; hence, essentially all of the iodine released in the process off-gases through the vessel vent system is delivered to the stack. About 95\% of the iodine in the stack gases is from the process off-gases.

There are several reasons for the inefficient performance of the vessel vent silver reactor. The PUREX process produces a considerable volume of gases. Because of this, the iodine is so dilute in the gases that very little driving force exists for the chemical reaction of iodine with silver nitrate. In addition, the reaction with silver nitrate appears to be temperature dependent. The silver reactors for the dissolver off-gases operate at $196^{\circ} \mathrm{C}$. However, the available steam for heating the vessel vent gases is at $1241 \mathrm{kPa}(180 \mathrm{psia})$ and $188^{\circ} \mathrm{C}$. This limits the operating temperature of the vessel vent silver reactor to $160^{\circ} \mathrm{C}$. Significant modifications would be necessary to increase the steam pressure and/or temperature; and a larger heat exchanger would be necessary for heating the vessel vent gases to the more optimum temperature of $196^{\circ} \mathrm{C}$. The feasibility and cost of these kinds of modifications to an existing system have not been studied. An alternative modification would be to install an electric heating system. The costs of such a system have not been estimated but could be large and the system also could pose a safety hazard. The presence of organic vapors in the vessel vent gases, plus a spark from a malfunction of the electric heaters, could cause an explosion.

Replacing the present vessel vent silver reactor with an absorbing tower might be technically feasible; but may not be physically possible because of 
limited space and possible other physical constraints. No other methods for removing the dilute iodine have been proposed.

Assuming that $95 \%$ of the released iodine comes from the process off-gases and that an absorbing tower or some other scheme with a DF of 10 can be used in place of the silver reactor, the new discharge rates for iodine for a processing rate of $2100 \mathrm{MT} / \mathrm{yr}$ would be: ${ }^{129} \mathrm{I}, 3.8 \mathrm{E}-3$; and ${ }^{131} \mathrm{I}, 2.8 \mathrm{E}-2$. 11.2.3 Specific Source 3: Combined Exhaust from Buildings 405, 4621E, 4717; Building 491-S Heating and Ventilating Discharge; and Building 4717 Lower Area Heating and Ventilating Exhaust, Serving the FFTF

Information for specific source 3 was obtained from References 2, 4 and 5 and from David 0. Hess, Safety, Engineering, Technical Services Department, Hanford Engineering Development Laboratory, Westinghouse Hanford Company, P.0. Box 1970, Richland, Washington.

Radioactive gases generated in the FFTF are a result of neutron activation of the reactor cover gas or are released from the fuel through defective fuel cladding. These gases are processed through the Radioactive Argon Processing System (RAPS) and released to the atmosphere through the combined exhaust. There are about 200-280 $\mathrm{\ell} / \mathrm{min}$ (7-10 cfm) of gases from this source. Effluent from cells and spaces subject to potential contamination is processed through the Cell Atmosphere Processing System (CAPS) before release through the combined exhaust. The CAPS contributes about 1700-2000 $\mathrm{l} / \mathrm{min}$ $(60-70 \mathrm{cfm})$ to the combined exhaust. Other contributions to the combined exhaust are about $100 \mathrm{~m}^{3} / \mathrm{min}(3,600 \mathrm{cfm})$ from the normal heating and ventilating system and about $570 \mathrm{~m}^{3} / \mathrm{min}(20,000 \mathrm{cfm})$ from the containment heating and ventilating system.

Gases from the fission gas monitor and from the argon blower and valve cell exhaust go through the 491-S Building directly to the atmosphere without treatment. Should the monitors on the inlet to Building 491-S show the presence of radionuclides, there is provision to route the gases through the CAPS. If the Building 491-S outlet monitors show contamination, a routing through HEPA filters is available. The Building 4717 lower area heating and ventilating system exhausts directly to the atmosphere. Should the radiation 
monitor detect contamination, the blowers would be shut down until the situation could be evaluated.

\subsubsection{Description of Existing Emission Control Technology}

The RAPS and CAPS are described in this section.

Radioactive Argon Processing System (RAPS). Figure 11.8 is a diagram of the RAPS system. Inputs to the RAPS consist of about $170-200 \mathrm{l} / \mathrm{min}$ (6-7 cfm) of argon reactor cover gas and about $28-57 \mathrm{\ell} / \mathrm{min}(1-2 \mathrm{cfm})$ bleed from the argon atmosphere hot cell. The compressors, one on line and one on standby, draw the gases through a vacuum tank and filters which remove moisture and oils. The gases then pass to a surge and delay tank equipped with baffles, which delays their passage for about 30 hours to provide decay of argon-41. From the surge and delay tank, the gases pass to the cold box, which operates at cryogenic temperatures. Heat exchangers using liquid nitrogen cool four charcoal-delay beds that operate in series. The adsorption of the gases by the charcoal beds provides about 3.25 days of delay for krypton and about 284 days of delay for xenon. This allows for decay of the short-lived radioisotopes. If there has been no failed fuel cladding, the gases would then be routed to the combined exhaust or to the CAPS. If there has been some failed fuel cladding, longer-lived noble gases could be present. In this case, the gases from the charcoal-delay beds would be routed to a liquidnitrogen-cooled fractional distillation column. Here, the liquid portion would contain the longer-lived noble gases. The liquid would be warmed and the noble gases sent to a noble gas storage vessel. The gas portion from the fractional distillation column would be routed to the combined exhaust or to the CAPS.

Cell Atmosphere Processing System (CAPS). Figure 11.9 is a diagram of the CAPS System. Inputs to the CAPS consist of: 1) about $1415 \mathrm{l} / \mathrm{min}$ (50 cfm) of discharge from nitrogen atmosphere cells, 2) about $1-2 \ell / h r$ from the gas chromatograph that samples the argon atmosphere reactor cover gas, 3) about 425-570 $\&\left(15-20 \mathrm{ft}^{3}\right)$ of contaminated argon about once a week from the gas tag sample trap, and 4 ) effluent from the RAPS, if radiation monitors detect 


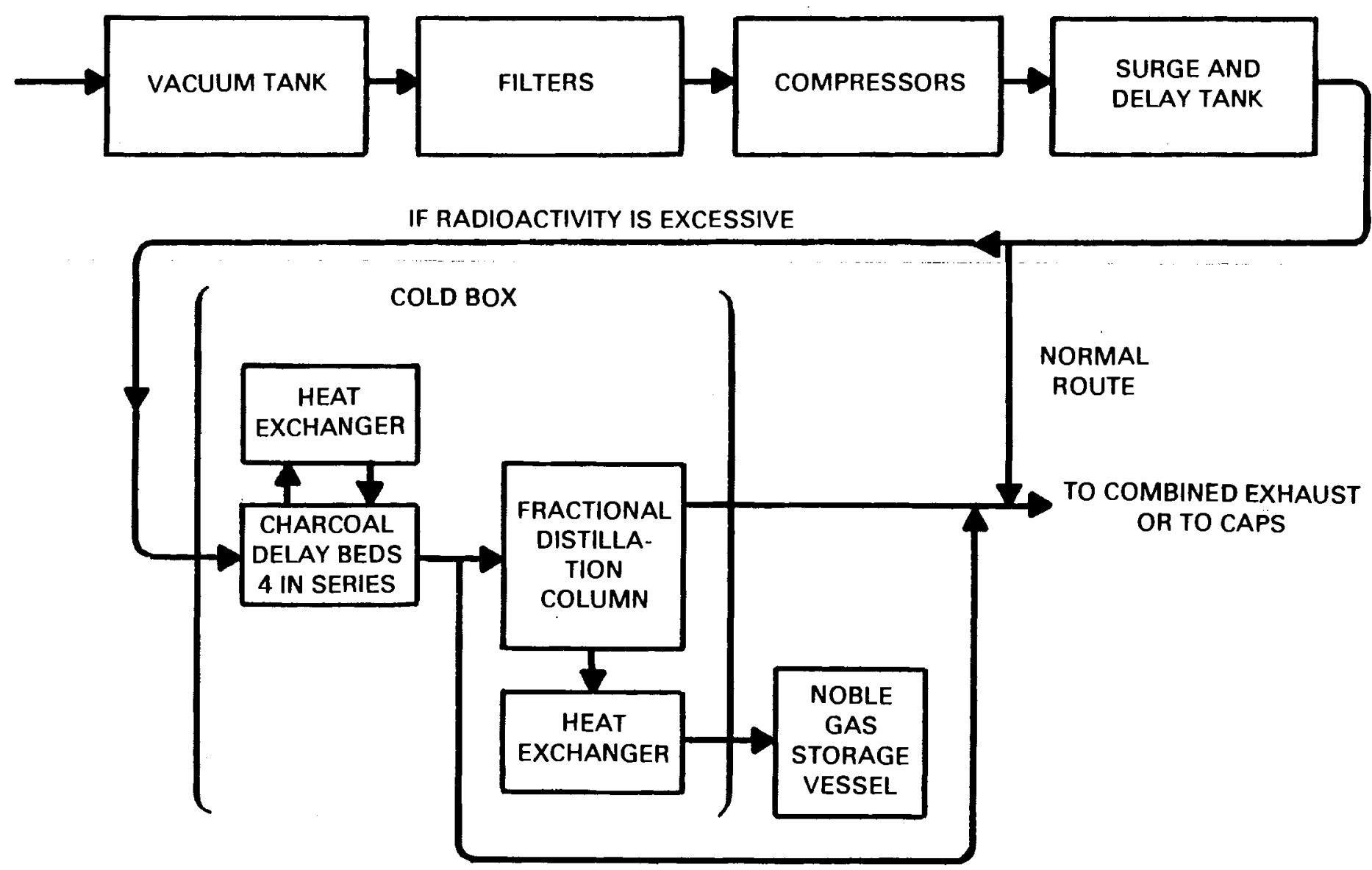

FIGURE 11.8. Diagram of the RAPS System 


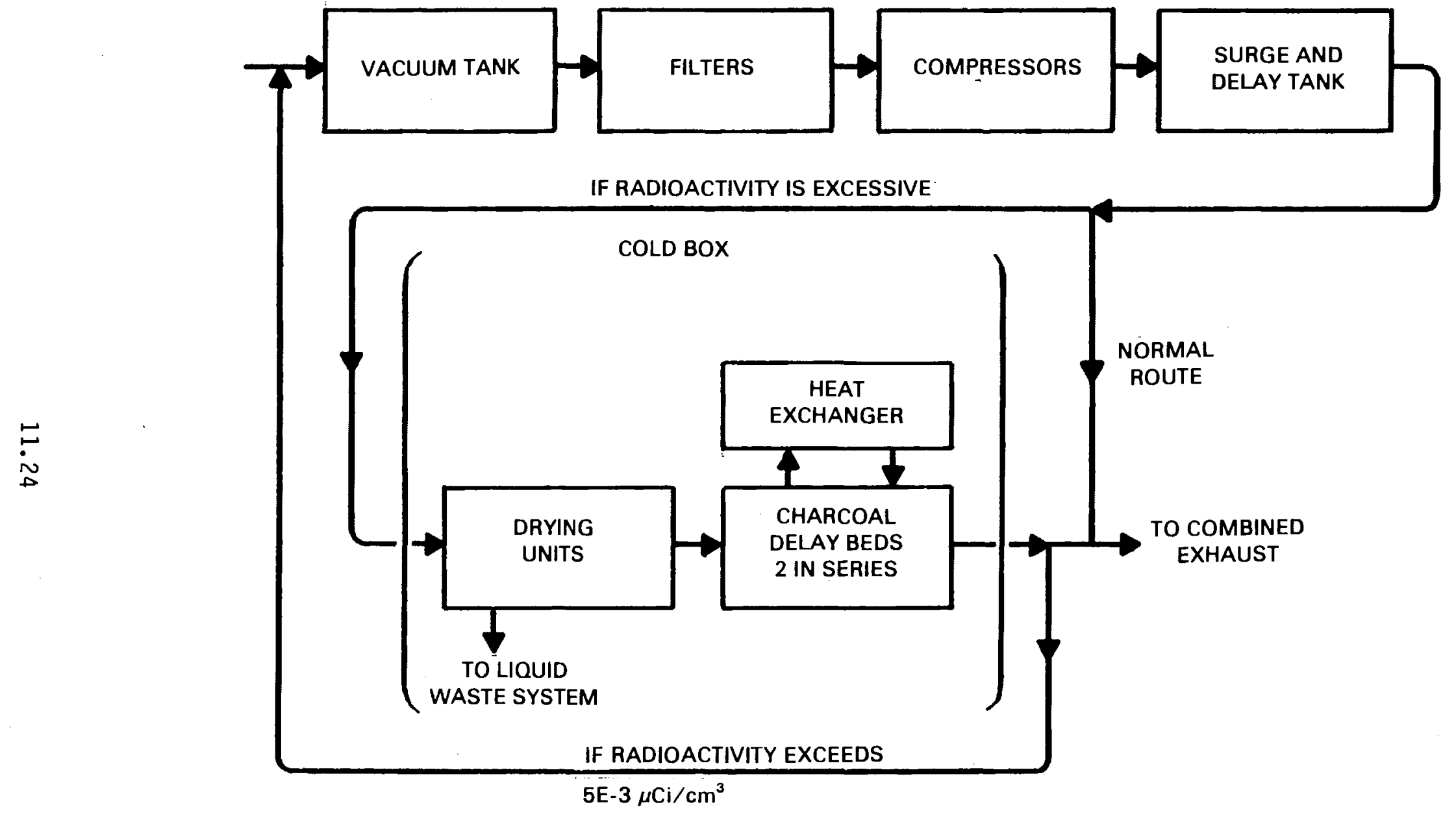

FIGURE 11.9. Diagram of the CAPS System 
radioactivity above $1 \mathrm{E}-3$ microcuries per cubic centimeter. As with the RAPS system, the gases are drawn into a vacuum tank and through filters to remove moisture and oils by two compressers, one on line and one on standby, and thence into a surge and delay tank for decay of argon-41. The CAPS input flow normally has a very low radioactivity level ( $<1 \mathrm{E}-7 \mu \mathrm{Ci} / \mathrm{CC}$ ). In normal operation, the gases from the surge and delay tank are then routed to the combined exhaust. If radiation monitors detect radiation, the gases are routed to the cold box. Two drying units dry the gas to a dewpoint of $-68^{\circ} \mathrm{C}\left(-90^{\circ} \mathrm{F}\right)$ or less. The liquid from the drying unit may contain some tritium and is sent to the liquid waste system. Two liquid-nitrogen-cooled charcoal-delay beds in series provide decay time for short-lived radionuclides. If the gases exiting the charcoal-delay beds have a radioactivity of less than $5 \mathrm{E}-3 \mu \mathrm{Ci} / \mathrm{cm}^{3}$, they are routed to the combined exhaust. If the radioactivity exceeds this limit, the gases are routed back to the CAPS vacuum tank for another pass through the CAPS.

\subsubsection{Current Discharge Rate}

The current radionuclide discharge rates from the FFTF are not known. Numbers that have been reported represent the minimum sensitivity of the monitoring instruments. Responsible personnel at the FFTF project estimate that the current discharge rates are much less than the reported numbers. These "less than" emissions are listed in Table 11.4.

\subsubsection{Potential Additional Emission Control Technology}

The RAPS cyrogenic processing subsystem is designed to process a maximum radioactivity input at the rate of $377 \mathrm{Ci} / \mathrm{min}$ with a flow rate of $710 \mathrm{l} / \mathrm{min}$ $(25 \mathrm{cfm})$. The normal process flow rate is $110 \mathrm{l} / \mathrm{min}(4 \mathrm{cfm})$. If the reactor were operated with $1 \%$ failed fuel (a conservative estimate), the activity level would be $1.35 \mathrm{E}-4 \mathrm{Ci} / \mathrm{min}$. The comparison of the normal operating service demands with the design capability of the subsystem shows the normal demands to be six orders of magnitude below the design capability. For this reason, no additional ECT is suggested for the RAPS system. 
TABLE 11.4. 1981 Emissions from the Fast Flux Test Facility

Release Point/Nuclide

Combined Exhaust (Buildings 405, 4621-E, and 4717)

$131_{\text {I }}$

$88 \mathrm{Kr}$

$239 \mathrm{Pu}$

${ }^{90} \mathrm{Sr}$

Total

Building 491-S $H$ and $V$ Discharge (HTS-South)

${ }^{88} \mathrm{Kr}$

Total

Building 4717 Lower Area $\mathrm{H}$ and $\mathrm{V}$ Exhaust

$131_{\text {I }}$

$88 \mathrm{Kr}$

${ }^{90} \mathrm{Sr}$

Total
Maximum Total Curies for $1981(a)$

1.000E-05

$2.700 \mathrm{E}+02$

$6.300 \mathrm{E}-06$

$3.200 \mathrm{E}-05$

$2.700 \mathrm{E}+02$

$5.000 \mathrm{E}+01$

$1.300 \mathrm{E}-06$

$5.000 E+01$

3.000E-06

$1.300 \mathrm{E}+02$

$7.300 \mathrm{E}-06$

$1.300 \mathrm{E}+02$

(a) Values are the sensitivity limits of the monitoring instruments.

The CAPS cryogenic subsystem is designed so that the processed gas radioisotope concentration is low enough so that DOE requirements for a restricted occupational area are not exceeded upon mixing the processed gas with the $570 \mathrm{~m}^{3} / \mathrm{min}(20,000 \mathrm{cfm})$ of the heating and ventilating system. This design condition is met by a CAPS outlet radiation monitor that will recycle the CAPS effluent should the radiation level exceed $5 E-3 \mu \mathrm{Ci} / \mathrm{cm}^{3}$. Levels to date have never reached this limit. For this reason, no additional ECT is suggested for the CAPS system.

\subsubsection{Nonspecific and Minor Sources}

Reference 2 is the major source of information for this section. 
In the inactive facilities of the 100 Area, very little work with radionuclides is currently in progress. No facilities or equipment for management of airborne radioactivity are needed or are now in service.

Gaseous effluents from the 200 Area facilities, other than PUREX, are limited to airstreams containing relatively low concentrations of radionuclides either in.gaseous or entrained particulate form. Multiple filtration is relied on to remove particulate matter. Where especially toxic or radioactive off-gases from processes are encountered, special off-gas systems with gas treatment and filtering equipment are provided in the cells before the final filtration of the gases. The emissions are negligible compared to those discussed, and thus are not considered further in this study.

The exhaust treatment systems in every facility in the 300 Area, except the 333 Building, use HEPA filters. Where required, a charcoal absorber is used to collect radioactive iodine. The wet uranium fume exhaust from the abrasive cut-off saw in the 333 Building passes through a water scrubber unit before being sampled and discharged to the atmosphere. The emissions from the 300 Area facilities are negligible compared to those discussed, and thus are not considered further in this study. 


\section{REFERENCES}

1. Draft Environmental Impact Statement, Operation of PUREX and Uranium Oxide Plant Facilities, Hanford Site, Richland, Washington, DOE/EIS0089D, May 1982.

2. Final Environmental Statement, Waste Management Operations, Hanford Reservation, Richland, Washington, ERDA-1538, December 1975.

3. P. J. Mellinger, et al. ${ }^{85} \mathrm{Kr}$ Management Trade-0ffs: A Perspective to Total Radiation Dose Commitment, PNL-3176, Pacific Northwest Laboratory, Richland, Washington, January 1980.

4. Environmental Statement, Fast Flux Test Facility, Richland, Washington, WASH-1510, May 1972.

5. Final Safety Analysis Report, Fast Flux Test Facility, ERDA, December 1975. 


\subsection{IDAHO NATIONAL ENGINEERING LABORATORY}

This section describes radionuclide emission control technology at the Idaho National Engineering Laboratory (INEL).

\subsection{SITE AND MAJOR SOURCE DESCRIPTIONS}

The Idaho National Engineering Laboratory is located in southeastern Idaho. It was established as an area where various types of nuclear reactors and their components could be built and tested in relative isolation. The site also includes waste storage, fuel reprocessing, and waste calcination facilities.

\subsubsection{Location of Site and Description of Facilities}

The INEL, formerly known as the National Reactor Testing Station (NRTS), is situated in southeastern Idaho on the upper Snake River Plain at an average elevation of $1,460 \mathrm{~m}$. The site is of an irregular shape, encompasses 231,000 hectares, and is about $63 \mathrm{~km}$ from north to south and $58 \mathrm{~km}$ from east to west. The eastern boundary is $47 \mathrm{~km}$ west of Idaho Falls.

There are four major contractors at the INEL. These contractors and the facilities are listed in Table 12.1. A map of the INEL site showing the location of the facilities is shown in Figure 12.1.(1)

\section{EG\&G Facilities}

The Test Reactor Area (TRA) contains three test reactors and three lowpower reactors. Of the three test reactors, only the ATR (Advanced Test Reactor) is operating. The MTR (Materials Test Reactor) and the ETR (Engineering Test Reactor) are in a stand-by status. The ATR is used to provide engineering and research data on reactor components under high neutron flux conditions.

The Test Area North (TAN) contains the Technical Support Facility (TSF) and is used in support of the Loss of Fluid Test (LOFT) and various other reactor safety studies. Large radioactive components may be remotely disassembled and reassembled in the Hot Shop Area. A Warm Shop is also available for equipment and materials that are only slightly radioactive. 
TABLE 12.1. INEL Major Contractors and Facility Responsibility

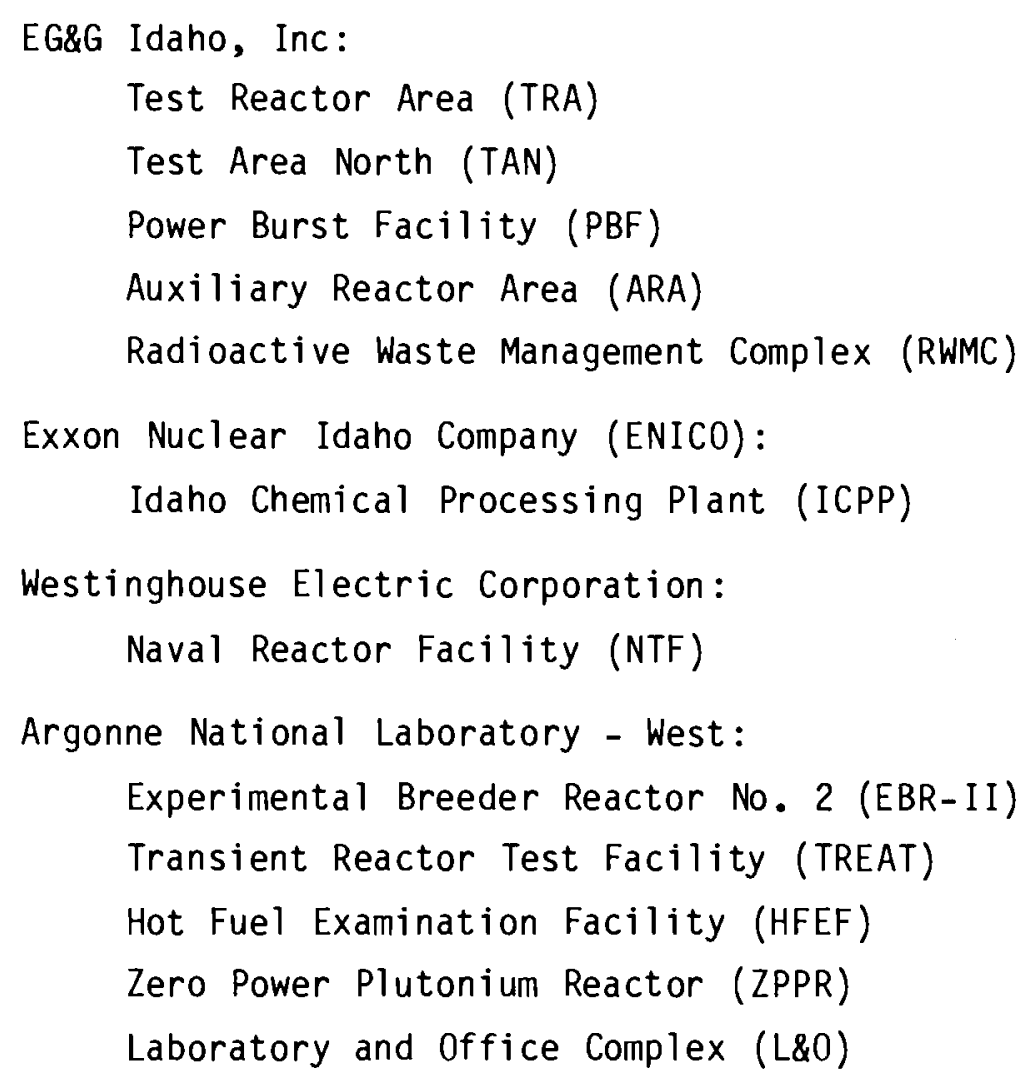

Auxiliary Reactor Area-1 (ARA) is used as a laboratory facility. It contains a hot cell where test specimens for the reactors may be prepared.

The Radioactive Waste Management Complex (RWMC) (one of three located at INEL) packages and stores waste from INEL and other DOE facilities such as Rocky Flats. The other two facilities are the ANL-W Radioactive Scrap and Waste Facility and the ICCP Waste Calcining Facility.

Exxon Nuclear Idaho Company (ENICO)

The Idaho Chemical Processing Plant (ICPP) is comprised of three major activities: 1) irradiated fuel storage; 2) fuel reprocessing; and 3) waste calcination. Spent fuel, sent to the ICCP from INEL reactors and others, may be either stored or chemically processed to convert the uranium to uranium 


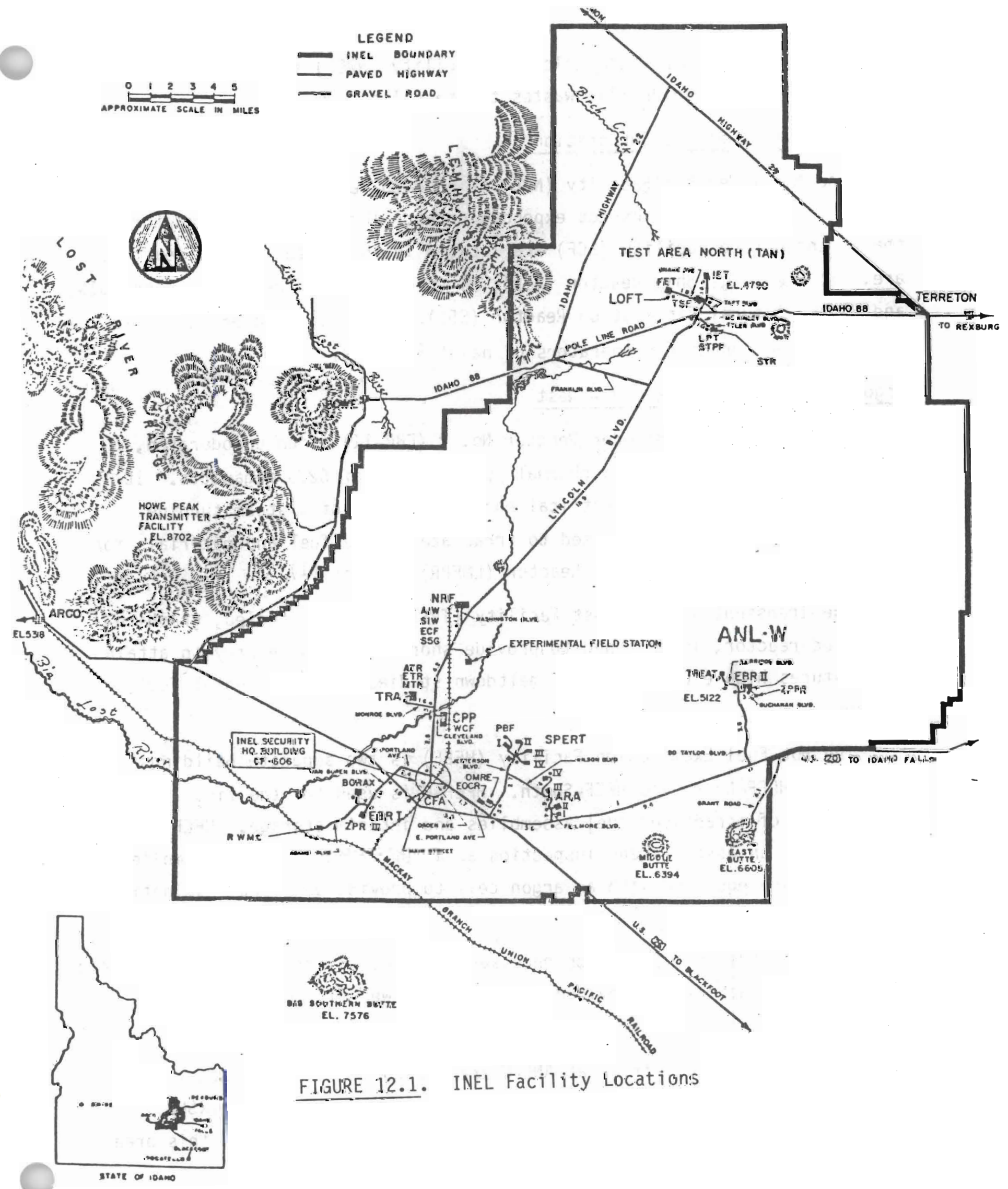


oxide powder. The New Waste Calcining Facility (NWCF) is used to convert high-level liquid radioactive wastes to the solid form.

\section{Westinghouse Electric Corporation}

The Naval Reactor Facility (NRF) is used to test prototype naval reactors and to disassemble and inspect expended cores. Three operating reactors and the Expended Core Facility (ECF) are located in this area. These reactors are: 1) the Large Ship Reactor (AIW); 2) the Submarine Thermal Reactor (SIW); and 3) the Natural Circulation Reactor (S5G).(1) These reactors are also used as a training center for operators of naval reactors. Argonne National Laboratory - West

The Experimental Breeder Reactor No. 2 (EBR-II) is an unmoderated, sodium-cooled reactor with a thermal power output of 62.5 megawatts. It produces 20 megawatts of electrical energy by means of a steam turbine generator. The facility is used to irradiate sample fuel and materials for the Liquid-Metal Fast Breeder Reactor (LMFBR) program.(1)

The Transient Reactor Test Facility (TREAT), an air-cooled, graphitemoderated reactor, is designed to provide short pulses of energy to attain temperatures high enough to allow meltdown studies of experimental fuel elements.

The Hot Fuel Examination Facility (HFEF) is two separate buildings designated HFEF-North and HFEF-South. HFEF-N is used for the final examination of irradiated fuel assemblies and interim storage. HFEF-S functions as an assembly and inspection area for irradiated subassemblies. Both areas are equipped with an argon cell to provide an inert examination atmosphere.

Reactor physics information necessary for design work on plutonium-fueled fast-breeder reactors is provided by the Zero Power Plutonium Reactor (ZPPR). A variety of fuel assembly patterns is possible in this facility.

The remaining facilities at ANL-W are designated the Laboratory and office Complex (L\&O). The Radioactive Scrap and Waste Facility (RSWF), support functions and waste management operations are located in this area. 


\subsubsection{Identification and Location of Specific Sources}

The EPA Release Point Analysis Report for calendar year 1981 (see Appendix A) identifies airborne release points on the site whose emissions range from $2.8 \times 10^{-7}$ to $5.9 \times 10^{4} \mathrm{Ci} / \mathrm{yr}$ (see Table 12.2). The major radioactive species produced from reactor operations are short-lived noble gases. The ICPP differs somewhat in that it is a fuel reprocessing facility and releases of fission products such as iodine, tritium, strontium and longer-lived noble gases occur in addition to activation products.

From Table 12.2 it can be seen that two sources, the ICPP and the ATR, contribute almost $100 \%$ of the curies released at INEL. These two sources are investigated in this section.

\subsubsection{Nonspecific and Minor Sources}

With the exclusion of the sources named for further investigation in Section 12.1.2, all sources listed in the EPA Release Point Analys is Report on the INEL for calendar year 1981 are considered as nonspecific and minor sources.

12.2 EMISSION CONTROL TECHNOLOGY AT THE IDAHO NATIONAL ENGINEERING LABORATORY

Emission control technology (ECT) varies from none at some facilities to elaborate and complex at others. Each facility therefore must be discussed separately. Some of the information in the following sections was furnished by Peter Dirkmaat of the DOE's Idaho Operations Office.

\subsubsection{Specific Source 1: Advanced Test Reactor (ATR)}

The ATR has an operational thermal-power level rating of $250 \mathrm{MW}$. It is designed for use in developing advanced cores and fuel system materials for commercial power programs. The ATR is a light-water-moderated and cooled system that employs the flux concentration principle (flux traps) to achieve higher neutron flux levels. 
TABLE 12.2. INEL Airborne Radioactive Releases for 1981(a)

\begin{tabular}{|c|c|}
\hline Release Point & $\mathrm{Ci} / \mathrm{Mr}$ \\
\hline $\begin{array}{l}\text { Idaho Operations Office } \\
\text { ARA-1 Hot Cell } \\
\text { Loss of Fluid Test } \\
\text { Test Area North } \\
\text { Power Burst Facility } \\
\text { Advanced Test Reactor } \\
\text { Engineering Test Reactor } \\
\text { TRA Hot Cel1 } \\
\text { TRA Alpha and Chem. Lab } \\
\text { Idaho Chem. Process. P1. }\end{array}$ & $\begin{array}{l}2.789 \mathrm{E}-07 \\
3.146 \mathrm{E}-02 \\
5.544 \mathrm{E}-04 \\
2.422 \mathrm{E}-04 \\
8.309 \mathrm{E}+03 \\
2.569 \mathrm{E}+01 \\
1.754 \mathrm{E}-06 \\
5.233 \mathrm{E}-06 \\
5.920 \mathrm{E}+04\end{array}$ \\
\hline $\begin{array}{l}\text { Chicago Operations Office } \\
\text { Lab and Office Bldg. } \\
\text { Power Plut. Reactor }\end{array}$ & $\begin{array}{l}1.489 E+01 \\
3.676 E+00\end{array}$ \\
\hline $\begin{array}{l}\text { EBR-II Hot Cell Exam. } \\
\text { Facility - South }\end{array}$ & $7.822 E+01$ \\
\hline $\begin{array}{l}\text { EBR-II Hot Cell Exam. } \\
\text { Facility - North }\end{array}$ & $3.007 \mathrm{E}-06$ \\
\hline $\begin{array}{l}\text { Fuel Assembly and } \\
\text { Storage Bldg. }\end{array}$ & $2.217 E-06$ \\
\hline $\begin{array}{l}\text { Nondestructive Assay } \\
\text { Laboratory }\end{array}$ & $7.635 E-07$ \\
\hline $\begin{array}{l}\text { Sodium Components Maint. } \\
\text { Shop }\end{array}$ & $1.795 \mathrm{E}-05$ \\
\hline $\begin{array}{l}\text { Transient Reactor Test } \\
\text { Facility }\end{array}$ & $6.351 E+01$ \\
\hline
\end{tabular}

(a) Source: EPA Release Point Analysis Report for calendar year 1981 .

12.2.1.1 Description of Existing Emission Control Technology

Ventilation air from the ATR is discharged from a 76 -meter stack with no waste treatment system employed. The stack is monitored on a continuous basis 
for particle and gaseous activity. Noble gases, such as argon, krypton, and xenon, are released. The airflow rate of the stack is $1275 \mathrm{~m} 3 / \mathrm{min}(45,000 \mathrm{cfm})$.

\subsubsection{Current Discharge Rates}

The EPA Release Point Analysis Report for calendar year 1981 (see Appendix A) indicates a total airborne curie release from the ATR of $8.309 \times$ $10^{3} \mathrm{Ci} / \mathrm{yr}$ made up of the radionuclides shown in Table 12.3.

\section{TABLE 12.3. ATR Waste Gas Stack Airborne Activity}

\begin{tabular}{|c|c|}
\hline Radi onuclide & $\mathrm{Ci} / \mathrm{yr}$ \\
\hline $41 \mathrm{Ar}$ & $2.434 E+03$ \\
\hline${ }^{139} \mathrm{Ba}$ & $1.570 E+02$ \\
\hline${ }^{138} \mathrm{Cs}$ & $1.723 E+01$ \\
\hline $85 m_{k r}$ & $2.162 E+02$ \\
\hline $87 \mathrm{Kr}$ & $8.579 E+02$ \\
\hline $88 \mathrm{Kr}$ & $8.037 E+02$ \\
\hline${ }^{88_{\mathrm{Rb}}}$ & $1.007 E+01$ \\
\hline $133 \times e$ & $1.216 E+02$ \\
\hline $135 x e$ & $7.768 E+02$ \\
\hline${ }^{135 m} \times e$ & 4. $191 E+02$ \\
\hline $138 x \mathrm{e}$ & $2.495 E+03$ \\
\hline Total & $8.309 E+03$ \\
\hline
\end{tabular}

12.2.1.3 Potential Additional Emission Control Technology

At the ATR, about $4.25 \mathrm{~m}^{3} / \mathrm{min}(150 \mathrm{cfm})$ of ventilation air comes from the primary degassing tank of the reactor and is the primary source of activity in the ATR stack effluent.(1) A typical ATR gaseous effluent composition is shown in Table 12.4. If the effluent from the primary degassing tank is delayed for a period of about 10 hours in a holdup tank, the activity in the airstream would be reduced by at least a factor of 10 . This tank(s) would require a volume of $2550 \mathrm{~m}^{3}\left(90,000 \mathrm{ft}^{3}\right)$ if atmospheric pressure within the tank is postulated. 
TABLE 12.4. Typical ATR Gaseous Effluent Composition

\begin{tabular}{lcc}
$\frac{\text { Isotope }}{41 \mathrm{Ar}}$ & $\begin{array}{c}\text { Relative } \\
\text { Percentage }\end{array}$ & $\frac{\text { Half }-\mathrm{Life}}{1.8 \mathrm{hr}}$ \\
\cline { 2 - 3 } & 30 & $4.4 \mathrm{hr}$ \\
${ }^{85 \mathrm{~m}} \mathrm{Kr}$ & 3 & $1.3 \mathrm{hr}$ \\
${ }^{87} \mathrm{Kr}$ & 11 & $2.8 \mathrm{hr}$ \\
$88_{\mathrm{Kr}}$ & 10 & $127.0 \mathrm{hr}$ \\
$133 \mathrm{Xe}$ & 1 & $9.2 \mathrm{hr}$ \\
$135 \mathrm{Xe}$ & 9 & $16.0 \mathrm{~min}$ \\
$135 \mathrm{~m} \mathrm{Xe}$ & 5 & $14.2 \mathrm{~min}$ \\
$138 \mathrm{Xe}$ & 31 &
\end{tabular}

12.2.1.4 Anticipated New Discharge Rates

The stack airflow from the Advanced Test Reactor (ATR) is $1275 \mathrm{~m} 3 / \mathrm{min}$ $(45,000 \mathrm{cfm})$. With the installation of a 10-hour delay in the primary degassing tank, the only radionuclides expected to exceed MPC for an unrestricted area, as listed in $10 \mathrm{CFR} 20$, are $41 \mathrm{Ar}, 88 \mathrm{kr}, 133 \mathrm{Xe}$ and $135 \mathrm{Xe}$ as they exit the stack. All are expected to be a factor of 20 or less above MPC for an unrestricted area.

12.2.1.5 Estimated Cost of Additional Emission Control Technology

The estimated cost to construct a tank(s) to provide a 10-hour delay in the effluent from the primary degassing tank is about $\$ 1,670,000$. This cost is broken down as follows:

\begin{tabular}{|c|c|}
\hline Item & $\begin{array}{c}\text { Cost, } \\
(\$ \text { thousands) }\end{array}$ \\
\hline Carbon Steel Tank - Installed (Vol. $2550 \mathrm{~m}^{3}$ ) & 480 \\
\hline Compresșor, Piping, Instrumentation, $\mathrm{Bl} d \mathrm{~d}$. & 420 \\
\hline Concrete Pad & 80 \\
\hline Site Preparation & 10 \\
\hline Subtotal - Direct Construction Costs & 990 \\
\hline Architect-Engineering Services ( 20\%) & 200 \\
\hline Subtotal & 1,190 \\
\hline Contingency $(\sim 40 \%)$ & 480 \\
\hline Total Facility Cost & 1,670 \\
\hline
\end{tabular}




\subsubsection{Specific Source 2: Idaho Chemical Processing Plant (ICPP)}

The ICCP is used to process highly enriched-irradiated nuclear reactor fuel elements in order to recover uranium. Fuel elements from INEL reactors (test and research), other research reactors (domestic and foreign), and U.S. Navy ship propulsion reactors have been reprocessed.(1) Airborne emissions from the ICPP are largely attributable to off-gases from the process dissolvers, process vessels, analytical facilities, sample stations, waste solvent burner, New Waste Calcining Facility (NWCF) and ventilation air. The New Waste Calcining Facility is used to convert radioactive liquid waste from the ICPP to a solid, using a fluidized bed calcination process.

\subsubsection{Description of Existing Emission Control Technology}

This section discusses the individual gaseous waste handling systems and their functions and includes descriptions of process flows through various pieces of equipment in each system. Figure 12.2 shows the systems that exhaust gaseous waste through the main stack.

The atmospheric protection system (APS) serves as a final cleanup facility for most ventilation systems and the process off-gas systems within the ICPP. The APS is divided into three treatment sections: 1) ventilation air treatment, 2) nitrogen oxide-bearing off-gas treatment (CPM, NWCF and VOG systems), and 3) hydrogen-rich off-gas treatment (E-DOG).

The VOG treatment section of the APS facilitates treatment of the process off-gases from: 1) continuous process modification dissolver of $f$-gas (CPM$D O G), 2$ ) vessel of $f$-gas $(V O G)$, and 3 ) the New Waste Calcining Facility (NWCF). This section of the APS consists of a condenser, demister, superheater, prefilter, final filter, and blowers. The system is constructed of stainless steel for acid resistance.

A single-story $15.8-\times 6.1-\mathrm{m}(52-\times 20-\mathrm{ft})$ building attached to the southeast corner of the HEPA building, CPP-649, contains the APS cleanup system and blowers for the VOG process off-gases. The cleanup portion of the system (condenser, demister, superheater, and prefilter) is in the east 


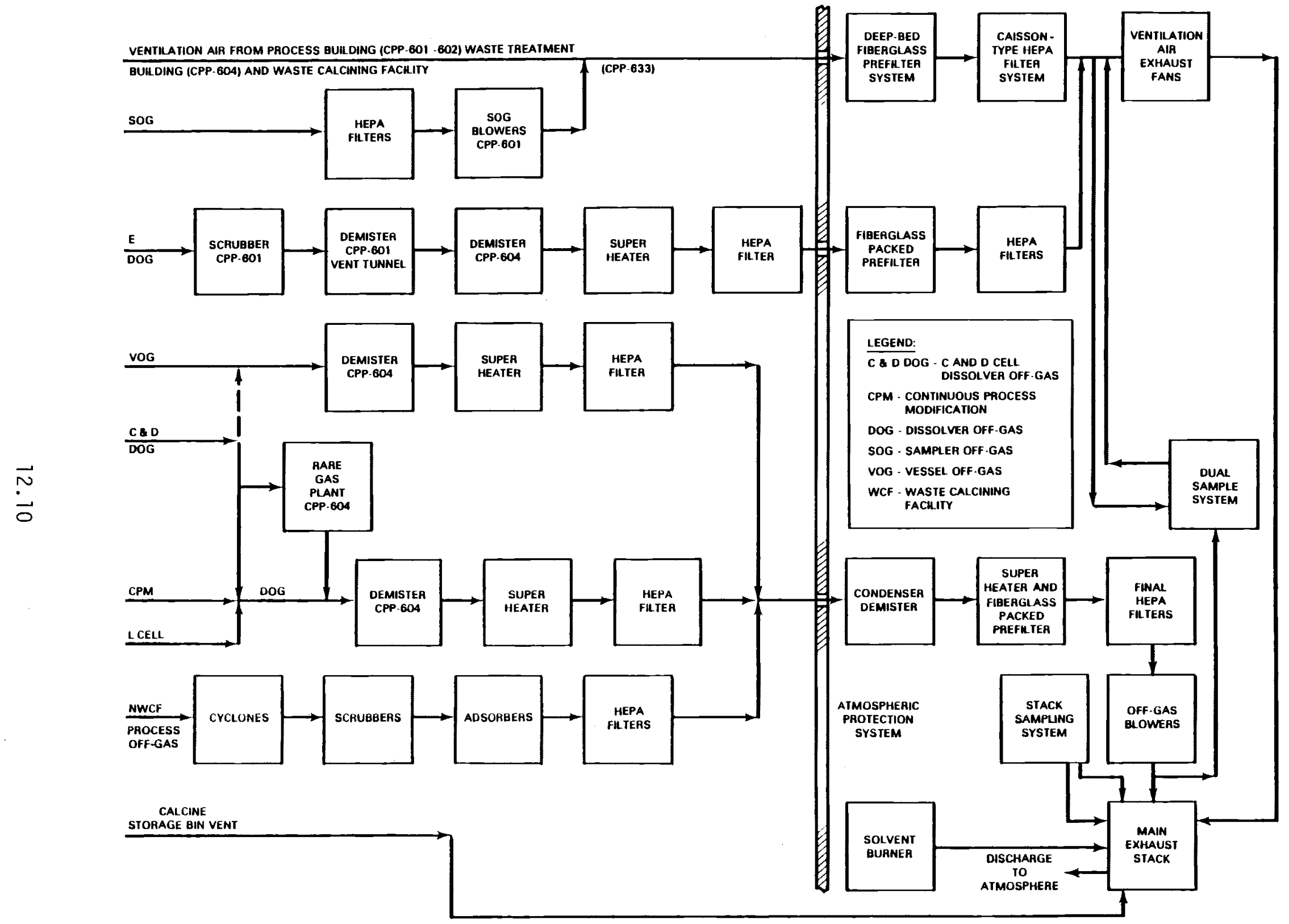

FIGURE 12.2. Gaseous Waste Systems Exhausting to the Main Stack 
portion of the building. Some valves that may require opening or closing during operation are equipped with reach rods that penetrate the shielding wall.

The demister consists of two 10-cm (4-in.)-thick stainless steel mesh elements contained in a stainless steel chamber.

The prefilter is constructed of five separate fiberglass beds supported on stainless steel screens. Contained in a $3.7 \times 2.1 \times 4.0-m(12 \times 7 \times 13-f t)$, stainless steel housing, the prefilter has a water line for flushing the filter medium. The prefilter can be bypassed during flushing. The flush water drains to the process equipment waste (PEW) evaporator feed tank. The three HEPA filters are housed in caissons equipped with dampers for individual filter isolation. The HEPA filters are made of acid-and moisture-resistant materials. The HEPA filters are equipped with knife-edge seals to prevent leakage.

Two stainless steel blowers exhaust the VOG streams to the main stack. Only one blower is required for normal operation. The operating blower is switched automatically to emergency power during commercial power outages; the standby blower starts automatically on failure of the operating blower to maintain necessary vacuum. The blowers are provided with automatic airoperated valves to isolate the unit not in operation.

The ventilation exhaust filter system, a portion of the APS, consists of a deep-bed fiberglass prefilter in series with standard HEPA filters. The prefilter is located in an underground reinforced concrete vault (CPP-756) that is $12.2 \times 27.4 \times 4.3 \mathrm{~m}(40 \times 90 \times 14 \mathrm{ft})$. The vault includes a system for backwashing the prefilter medium. Over-temperature protection for the filters is provided by a fog-spray system located upstream of the prefilter. This system actuates on high-gas temperature in the duct and cools the gas and protects the filters from an in-cell fire. A bypass duct is provided around the prefilter for use during washing of the filter medium.

The ventilation air ducts from the various buildings join before entering the prefilter distribution plenum. The distribution plenum extends the full length of the west side of the vault and distributes air, via flow slots, into each of four bays. 
The floor of the underground vault is sloped to the north; four troughs drain condensate or flush water to the north edge of the vault. From there, another trough carries the water to a 1893-l (500-gal) capacity collection sump located in the northeast corner of the vault. The sump is equipped with a high-level alarm and a sampler. From the sump, the liquid and associated solids are jetted to the process equipment waste (PEW) evaporator feed tank, WL-102.

The south wall of the vault has six viewing ports for inspection of the vault and filters. No lights are provided in the vault; portable lighting is used when needed.

The roof of the vault is $0.3 \mathrm{~m}(1 \mathrm{ft})$ below grade and covered with about $0.6 \mathrm{~m}(2 \mathrm{ft})$ of earth for radiation shielding. The roof and earth cover are sloped to allow proper drainage, and the vault is of leaktight construction. The cracks between the removable interlocking concrete blocks are caulked, and a butyl rubber membrane covers the entire roof of the vault. Insulation board overlays the membrane to prevent damage by the soil.

The prefilter has an area of $279 \mathrm{~m}^{2}$ ( $3000 \mathrm{ft}^{2}$ ) and has a maximum flow rate of $4245 \mathrm{~m}^{3} / \mathrm{min}(150,000 \mathrm{cfm})$. The prefilter is designed for gas upflow through five layers of varying density, separately supported, packed fiberglass. The five individual layers are separated and supported by stainless steel wire screens. The screens are mounted on Amercoat-painted carbon steel frames and wired to support pipes spaced at $0.9-m$ (3-ft) intervals. The prefilter frame is attached to Unistrut embedded in the concrete walls; voids in the Unistrut and other openings are caulked with fiberglass to prevent bypassing of the filter medium.

Water spray systems are provided to flush particulates from the fiberglass deep-bed prefilters if the pressure drop becomes excessive. There are three spray lines, located at different elevations, to provide thorough washing of the filter medium.

Each of the three spray lines consists of five $1.2-\mathrm{cm}(3-\mathrm{in}$.) diameter Type 304 stainless steel pipes; the bottom line is equipped with spray nozzles directed upward and the two upper lines have holes drilled in the lower 
portion of the pipes to supply flush water to the filter. To reduce water supply and removal requirements for flushing the ventilation air prefilter, flushing is done in sections. The spray system piping is stubbed off outside the ventilation air prefilter vault for later connection to a water supply, if required. The fiberglass deep-bed prefilters will not require replacement during the design lifetime of 20 years (from 1975). However, with the estimated dust loading in the ventilation air, the prefilter should last about 75 years without flushing or replacement.

Ventilation air from the prefilter is discharged through a concrete duct to the HEPA filters located in a building adjacent to the prefilter vault. The two-story building is a $23.5 \times 10.1 \times 7.9-\mathrm{m}(77 \times 33 \times 26-\mathrm{ft})$-high reinforced concrete structure. The first story of the structure begins $2.4 \mathrm{~m}$ (8 ft) below grade.

The HEPA filters are $9.4 \times 9.4 \times 4.3-\mathrm{cm}(24 \times 24 \times 11-1 / 2-i n$.$) units,$ each rated at $42.5 \mathrm{~m}^{3} / \mathrm{min}(1500 \mathrm{cfm})$, with an initial pressure drop of $2.5 \mathrm{~cm}$ (1 in.) of water. The filters are housed in caissons for ease of maintenance and filter replacement.

Each of the 26 caissons contains four unseparated filters and is individually dampered to allow changing of the filters without shutting down the remaining system. The caissons are connected to central inlet and discharge manifolds. Thirteen caissons are installed on each of the two building levels.

From the HEPA filters, the ventilation air flows through three ventilation fans and is exhausted to the stack. The ventilation fans are direct drive and installed in parallel to provide the motive force for discharging the ventilation air to the stack. The fans are housed in a $6.6 \mathrm{x}$ 14.6-m (21-ft 9-in. $x$ 47-ft 9-in.) addition on the east side of the existing fan building (CPP-605). The fans are of carbon steel construction with backward airfoil blades.

During normal operation, one or two of the three fans is operated on commercial power. If the operating fan fails during normal operation, the 
second and third fans can be started manually on commercial power. Automatic switching of an operating fan to emergency power, during commercial power outages, is provided by manual preselection. Each fan is provided with a damper that closes automatically if the fan stops. The dampers can be opened either with a wrench or via a pressurized $\mathrm{N}_{2}$ system if the need arises.

\subsubsection{Current Discharge Rates}

The EPA Release Point Analysis Report for calendar year 1981 (see Appendix A) indicates a total airborne release rate from the ICPP of $5.920 E+04$ $\mathrm{Ci} / \mathrm{yr}$ made up of the radionuclides shown in Table 12.5.

\subsubsection{Potential Additional Emission Control Technology}

The noble gas $85 \mathrm{kr}$ is the largest contributor to the airborne emissions from the ICPP stack from both a curie and dose standpoint. As the stack airstream is much too large to make removal of $85 \mathrm{kr}$ reasonable, it must be removed closer to the source; namely the dissolver off-gas streams (E-DOG and C\&D DOG). These streams have a total flow of about $1.7 \mathrm{~m} 3 / \mathrm{min}(60 \mathrm{cfm})$ when in operation.

Several processes have been proposed to recover krypton and xenon during the reprocessing of spent nuclear fuels. Most development work has been directed at three processes:

- cryogenic distillation

- selective adsorption

- selective absorption.

The three processes all require extensive pretreatment of the gas stream to remove harmful contaminates prior to recovery of the noble gases.

The cryogenic distillation process has been more completely developed than either of the other two for krypton-xenon recovery and is used commercially commercially for the recovery of noble gases from the atmosphere. The process has been used periodically to recover krypton at the ICPP. For these reasons, it was chosen as the process that might be considered as potential additional emission control technology for the ICPP. 
TABLE 12.5. ICPP Waste Gas Stack Airborne Activity

\begin{tabular}{|c|c|}
\hline Radionucl ide & $\mathrm{Ci} / \mathrm{yr}$ \\
\hline${ }^{14} \mathrm{C}$ & $1.380 E+00$ \\
\hline${ }^{144} \mathrm{Ce}$ & $3.690 \mathrm{E}-04$ \\
\hline${ }^{60} \mathrm{Co}$ & $7.740 E-06$ \\
\hline${ }^{134} \mathrm{Cs}$ & $5.760 \mathrm{E}-05$ \\
\hline${ }^{137} \mathrm{Cs}$ & $8.800 E-03$ \\
\hline 152Eu & $5.990 E-07$ \\
\hline${ }^{154} \mathrm{Eu}$ & $7.650 \mathrm{E}-06$ \\
\hline $155 \mathrm{Eu}$ & $1.540 \mathrm{E}-06$ \\
\hline $3_{H}$ & $3.950 E+02$ \\
\hline $129_{I}$ & $3.690 E-02$ \\
\hline $131_{\text {I }}$ & $5.440 E-02$ \\
\hline $85 \mathrm{Kr}$ & $5.880 E+04$ \\
\hline${ }^{95} \mathrm{Nb}$ & $1.420 \mathrm{E}-05$ \\
\hline${ }^{144} \mathrm{Pr}$ & $3.690 \mathrm{E}-04$ \\
\hline${ }^{238} \mathrm{Pu}$ & $7.370 E-05$ \\
\hline $239-240 \mathrm{Pu}$ & $1.420 \mathrm{E}-05$ \\
\hline${ }^{106} \mathrm{Rh}$ & $7.740 \mathrm{E}-02$ \\
\hline${ }_{106}^{R u}$ & $7.740 \mathrm{E}-02$ \\
\hline${ }^{125} \mathrm{Sb}$ & $1.870 \mathrm{E}-01$ \\
\hline $90 s r$ & $3.890 \mathrm{E}-03$ \\
\hline $90_{Y}$ & $3.890 \mathrm{E}-03$ \\
\hline $95 \mathrm{Zr}$ & $7.580 E-07$ \\
\hline Total & $5.920 E+04$ \\
\hline
\end{tabular}

Pretreatment of the gaseous feed stream to the krypton-xenon recovery system is necessary to remove impurities before recovery is possible by cryogenic distillation. The pretreatment must provide for the removal of residual ruthenium and iodine, oxides of nitrogen, oxygen, hydrogen, water and carbon dioxide. The sequence of pretreatment steps can vary depending on the process selected for contaminant removal.

Figure 12.3 shows a simplified flow diagram for the recovery of krypton and xenon from purified dissolver off-gas using cryogenic distillation as 


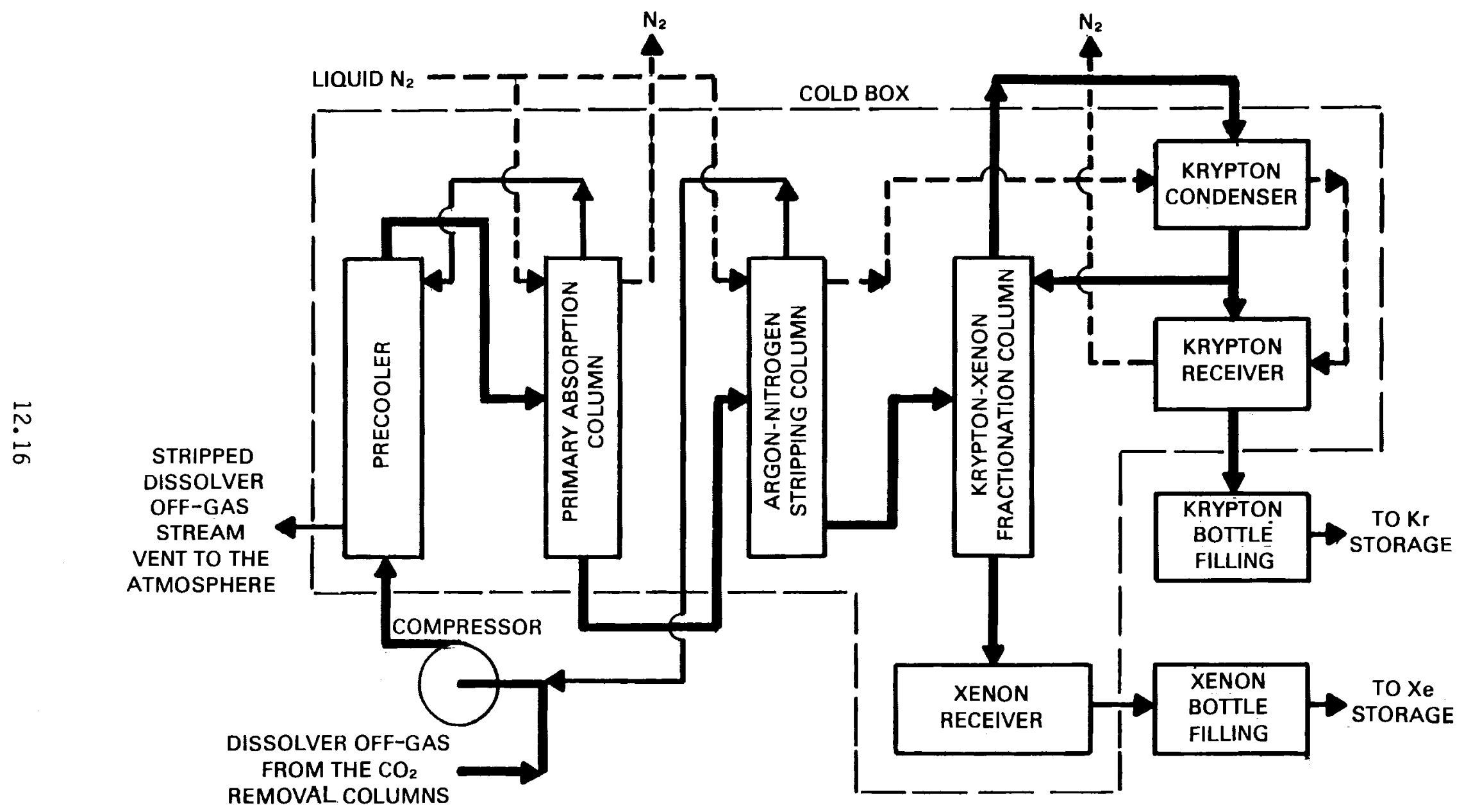

FIGURE 12.3. Simplified Flow Diagram for Recovering Krypton and Xenon from the Purified Dissolver Off-Gas Using Cryogenic Distillation 
suggested for the PUREX process at Hanford, Washington. The flow sheet for recovering the krypton and xenon is comprised of four major components:

- a precooler where the purified gas stream is cooled to about $-160^{\circ} \mathrm{C}$

- a primary absorption column where the krypton, xenon and some argon are separated from the dissolver gas in a liquid nitrogen stream

- an argon-nitrogen stripping column where the argon and nitrogen are removed leaving a liquid krypton-xenon fraction, and

- a krypton-xenon fractionation tower where the krypton and xenon are separated into two product fractions.

The liquid krypton and xenon product from the product receiver are vaporized and stored in cylinders at a pressure of approximately 45 atmospheres. Filling of the storage containers is carried out at a remotely operated filling station.

Waste disposal from the krypton-xenon cryogenic distillation recovery plant will generate a number of waste streams that require disposal, but do not represent major disposal problems. The gaseous waste streams could be released to the atmosphere via the ICPP stack. The aqueous waste could be sent to existing ICPP recovery or disposal systems and the adsorber materials used to remove ruthenium and iodine would go to high-level solid waste. The disposal of the calcium carbonate generated in the $\mathrm{CO}_{2}$ removal unit would probably present the largest waste disposal problem.

\subsubsection{Anticipated New Discharge Rates}

The discharge of ${ }^{85} \mathrm{Kr}$ from the ICPP stack for calendar year 1981, and as shown in Table 12.5 , was $5.880 \times 10^{4} \mathrm{Ci} / \mathrm{yr}$. If an $85 \mathrm{Kr}$ removal of $99 \%$ is achievable with the suggested cryogenic removal system, then the emissions will be reduced to $5.880 \times 10^{2} \mathrm{Ci} / \mathrm{yr}$; however, this efficiency is not expected on a continuous basis and an ${ }^{85} \mathrm{Kr}$ removal of $90 \%$ is considered more reasonable. 


\subsubsection{Estimated Cost of Additional Emission Control Technology}

The estimated cost to install a cryogenic distillation system for the removal and recovery of krypton and xenon is about $\$ 53,000,000$. The cost is broken down as follows:

Item

Equipment

Structure

Indirect Costs

Subtotal

Architect Engineering Services (25\%)

Subtotal

Contingency $(\sim 50 \%)$

Total
Cost $(\$$ thousands)

$$
\begin{array}{r}
3,100 \\
24,000 \\
1,350 \\
\hline 28,450 \\
\frac{7,100}{35,550} \\
\frac{17,450}{53,000}
\end{array}
$$

\subsubsection{Non-Specific and Minor Sources}

All sources listed in the EPA Release Point Analysis Report for the INEL for calendar year 1981 (see Appendix A), with the exclusion of the sources named for further investigation in Section 12.1.2, are considered as non-specific and minor sources. Sources that may have been reported in previous years but not listed in the above-named document are not considered in this report. 


\section{REFERENCES}

1. Waste Management Operations, Idaho National Engineering Laboratory, ERDA1536, U.S. Energy Research and Development Administration, June 1976. 



\subsection{LAWRENCE LIVERMORE NATIONAL LABORATORY/SANDIA NATIONAL}

\section{LABORATORY - LIVERMORE}

The primary mission of Lawrence Livermore National Laboratory (LLNL) is the design of nuclear weapons. However, other programs have been added when the technical expertise and facilities at Livermore seemed appropriate for their undertaking. These additional programs include controlled thermonuclear research, biomedical studies, laser fusion research, and laser isotope separation research.

The principal objective of Sandia National Laboratory - Livermore (SNLL) is research, development, and design of nuclear weapons systems, excluding the nuclear components. Major activities include tritium research; the development of arming, fusing, and firing systems; and the testing of aerodynamic and structural elements used in U.S. nuclear bombs and warheads. Components in these systems include power supplies, timing mechanisms, radars, switches, and other classified elements that make up the intricate actuating and control mechanisms. Energy-related activities are conducted in combustion and solar research. Sandia's responsibilities are carried out jointly between its Livermore and Albuquerque locations.

\subsection{SITE AND MAJOR SOURCE DESCRIPTIONS}

The following discussion of LLNL and SNLL includes descriptions of the sites and their major sources of radioactive airborne emissions, descriptions of emission control technologies (ECT) currently in use at the major source stacks, and a discussion of potential additional ECT.

\subsubsection{Location of Sites and Description of Facilities}

LLNL and SNLL are located about 65 kilometers east of San Francisco at the southeast end of the Livermore Valley in southern Alameda County, California. The city of Livermore is located about 5 kilometers to the west. LLNL occupies about 255 hectares and SNLL occupies about 75 hectares adjacent to and south of the LLNL site. Lands to the north, west, and south 
are zoned for industrial use, although present usage is mostly agricultural. Land immediately to the east is zoned for agricultural use and is currently used as pasture. (1)

The population within 80 kilometers of the LLNL and SNLL sites is about 4.3 million. Figure 13.1 is a regional map showing the location of LLNL and SNLL in relation to major population centers. Figures 13.2 and 13.3 are site maps for LLNL and SNLL, respectively. (1)

There are four principal facilities at LLNL that release radioactivity into the air: the Light Isotope Handling Facility (Buildings 331 and 292 stacks); the Insulated Core Transfer (ICT) Accelerator (Building 212 stack); the 100-MeV Linear Electron Accelerator (LINAC) Facility (Building 194 stack); and the Decontamination Facility (Building 419 stack). At SNLL, radioactive airborne effluents are released from two facilities: the Metallurgy Laboratory (Building 913, stacks 1 and 3) and the Tritium Research Laboratory (Building 968). (1,2)

\subsubsection{Identification and Location of Specific Sources}

Using the analytical technique described previously in Section 1.4, we determined that stacks from three facilities at LLNL and two facilities at SNLL warranted more detailed analysis. These stacks are described below.

$\underline{\text { LLNL }}$

The three facilities at LLNL that contribute most significantly to radioactive airborne emissions are the Tritium Research Facility, the Rotating Target Neutron Source and the 100-MeV LINAC Facility. These three facilities account for $99 \%$ of the hypothetical risk from radioactive discharges to the atmosphere at LLNL.

The principal radionuclide discharged from the Tritium Research Facility is tritium, which is released from two 30 -meter stacks at Building 331. (3) The Tritium Research Facility is designed for experimental work with radioactive gases and their compounds. Normal operations involve the use of multigram quantities of tritium in a variety of forms. Building ventilation is designed to maintain air flow toward zones of higher hazard. The building 


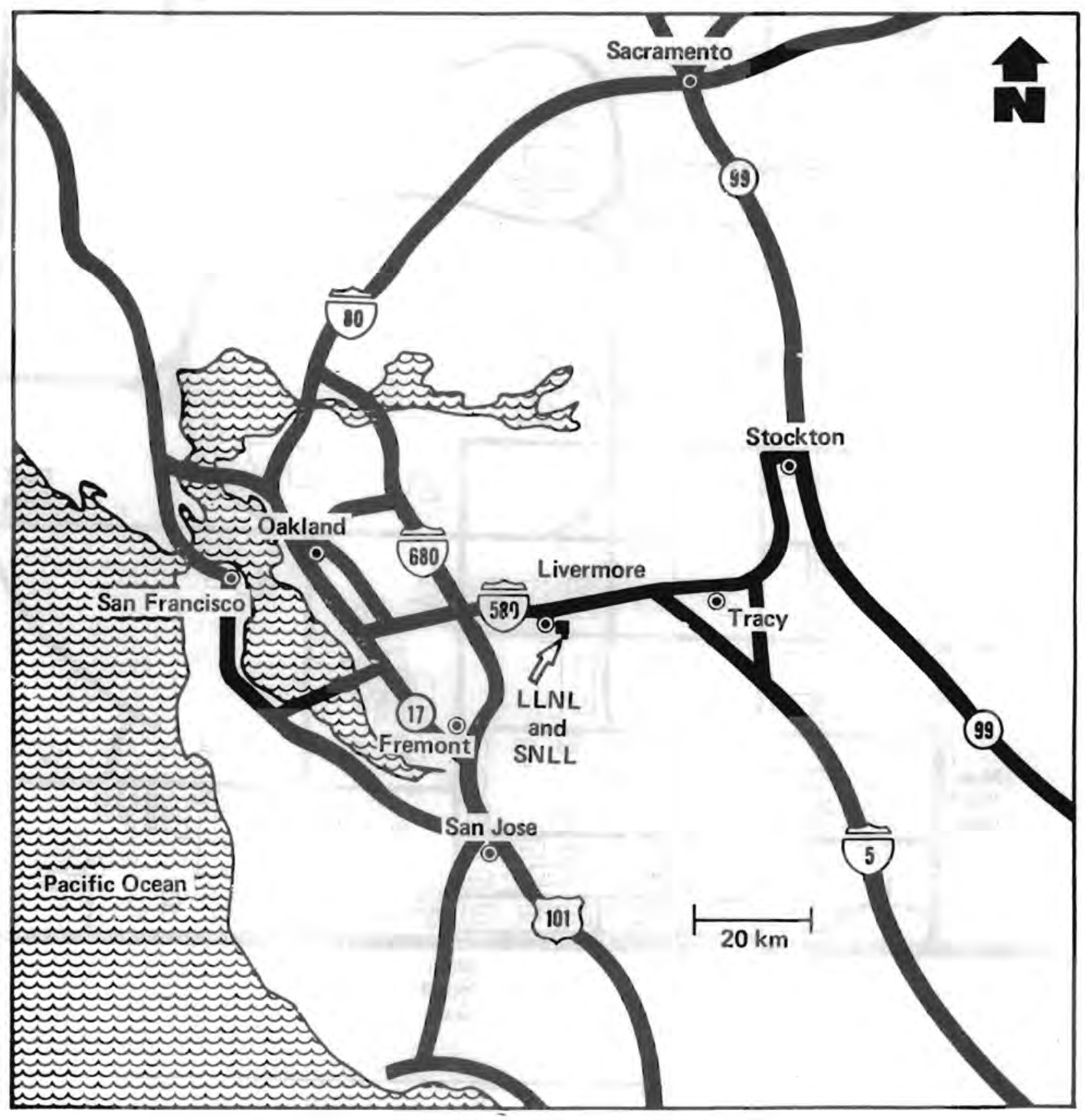

FIGURE 13.1. Regional Map Showing Location of LLNL and SNLL(1) 


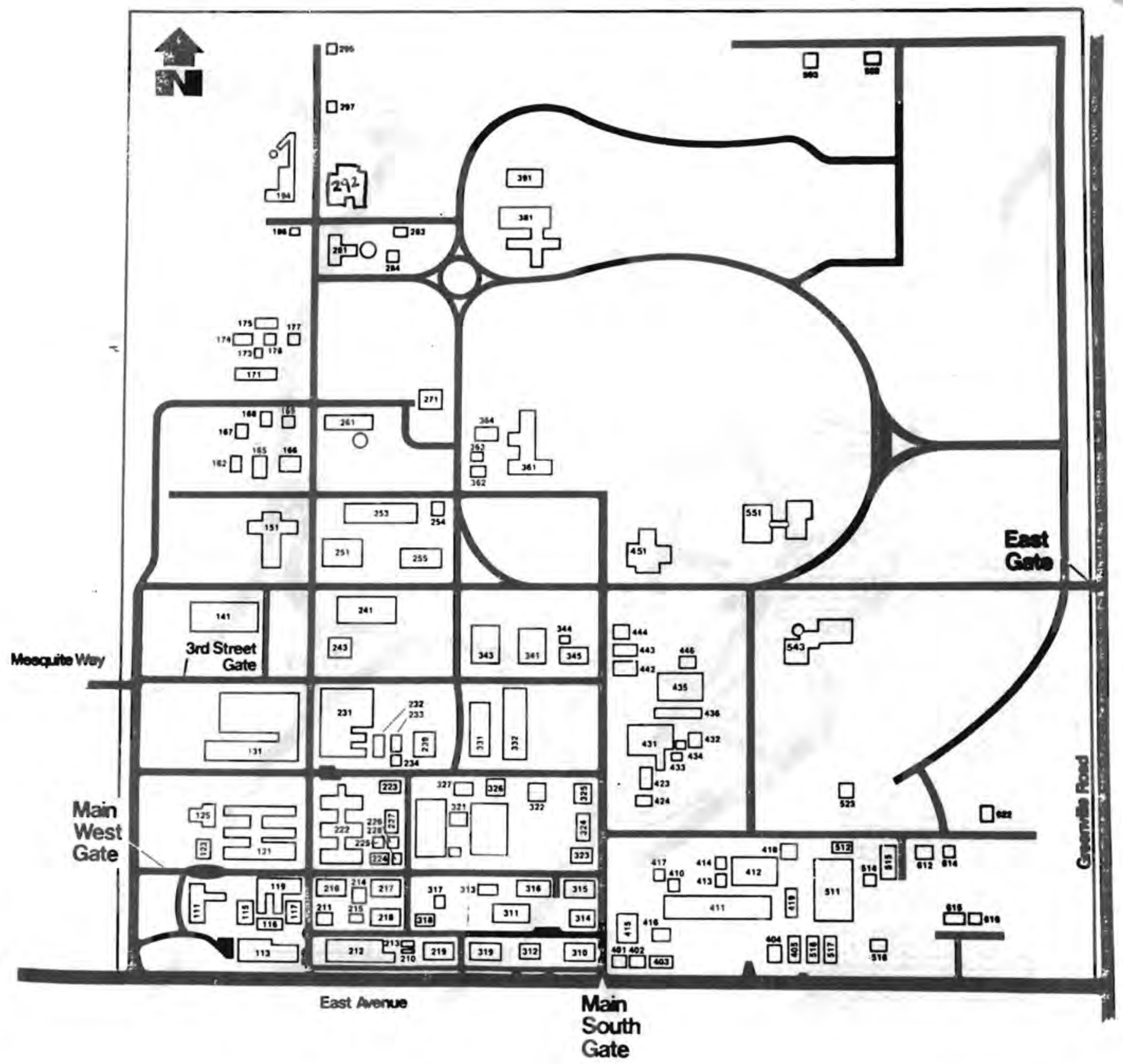

$1 \mathrm{~km}$

FIGURE 13.2. Site Map of LLNL(1) 


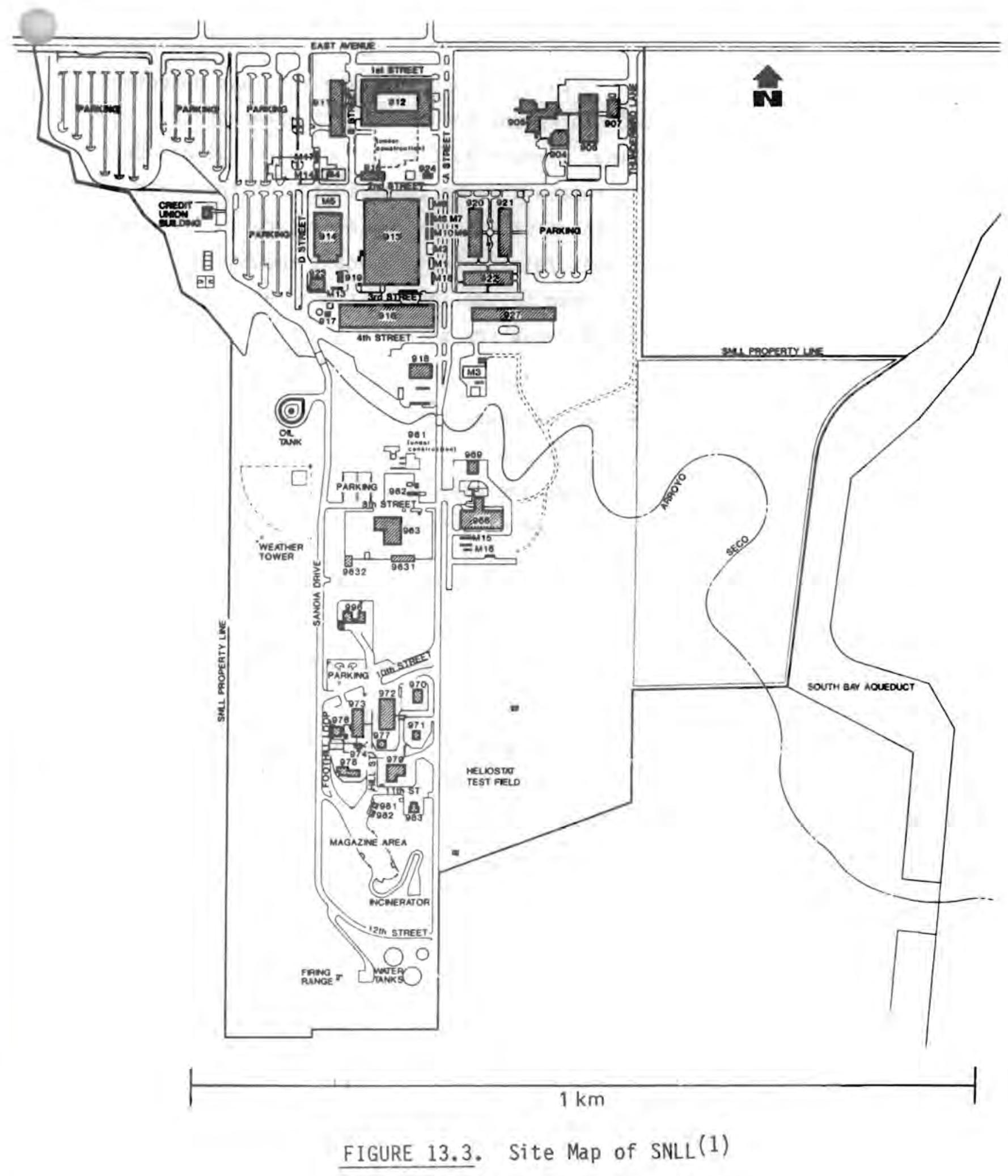


was constructed in two increments; each increment is monitored by a separate set of room air monitors, stack-effluent monitors, ventilation-loss detectors, and associated alarm panels. Each increment has its own 30-meter stack. Due to a change in programmatic funding, a major portion of Building 331 has been decommissioned. Those operations remaining were consolidated in the north end (Increment II) of the building. Decommissioned laboratory space in Increment I is used by other LLNL programs that release insignificant amounts of radionuclides. Building 331 is located in the southwest quadrant of the LLNL site and is about 290 meters from the southern boundary. $(1,2)$

The Rotating Target Neutron Source (RTNS-2) is located in Building 292. The RTNS-2 accelerates deuterons down an evacuated beam line that has a rotating titanium tritide target at the end. This machine utilizes a fusion process to produce 14-MeV neutrons that are used in neutron activation and neutron damage studies. Sma 11 amounts of oxygen-15 and nitrogen-13 are produced as a byproduct of accelerator operations. Small amounts of unidentified alpha, beta, and gamma emitting radionuclides are also produced. (3) Effluents from Building 292 are released to the atmosphere through a 16 -m stack located about 320 meters from the western boundary.

The 100-MeV LINAC facility is located in Building 194 in the northwest quarter of the LLNL site. The-100 MeV LINAC is a significant tool in neutron physics research and in LLNL's work involving photo nuclear cross-section and activation measurements. The facility is located approximately 230 meters equidistant from LLNL's western and northern boundaries. $(1,2)$

SNLL

At SNLL, radionuclides are released to the atmosphere from the Metallurgy Laboratory (Building 913) and the Tritium Research Laboratory (Building 968). The two stacks at these facilities account for $99 \%$ of the radionuclides discharged to the atmosphere at SNLL.

In the Metallurgy Laboratory, assembly and disassembly of radioactive materials are conducted along with cutting and polishing operations. Radioactive effluents reach the atmosphere via a 12-m stack located at the 
Metallurgy Laboratory. This stack discharges small amounts of unidentified alpha, beta and gamma emitting radionuclides. Prior to 1982, some tritium research was carried out in Room $128 \mathrm{G}$ of the Metallurgy Laboratory. Waste tritium was vented to the atmosphere through stack 3 located at Building 913. However, in 1982 this tritium research was moved to the Tritium Research Laboratory (Building 968) and stack 3 at the Metallurgy Laboratory was decommissioned. The Metallurgy Laboratory is located in the northern half of the SNLL site and is about 155 meters from the northern site boundary. (2)

The Tritium Research Laboratory is designed for research experiments involving more than 0.1 gram of tritium. The maximum quantity of tritium allowed in an experiment is 120 grams ( $1.2 \mathrm{MCi}$ ). These experiments are performed in sealed glove boxes. Automatic decontamination systems remove tritium from glove boxes and vacuum pumps. Residual tritium is exhausted to the atmosphere via a 30-m stack. The Tritium Research Laboratory is located in about the center of the SNLL site and is approximately 165 meters from the eastern boundary. $(1,2)$

\subsection{EMISSION CONTROL TECHNOLOGY AT LAWRENCE LIVERMORE NATIONAL LABORATORY} AND SANDIA NATIONAL LABORATORY - LIVERMORE

In this section, the points of discharge that contribute most to the radiological impact from airborne emissions at LLNL and SNLL are discussed. The facilities that contribute most to the radiological impact were described in Section 13.1.2. Some information in this section was furnished by $G$. $W$. Luense and W. E. Keheley of DOE's San Francisco Operations Office and by Daryl Mercer and George Werkema of DOE's Albuquerque Operations Office.

\subsubsection{Specific Source 1: Tritium Research Facility} (Building 331) - LLNL

The following is a description of emission control technology now in use to minimize radionuclide releases to the air from the Tritium Research Facility at LLNL. 


\subsubsection{Description of Existing Emission Control Technology}

The principal radionuclide discharged from the Tritium Research Facility stack is tritium. The sources of tritium-bearing effluents are the tritium handling locations within the facility (e.g., laboratories, hoods, glove boxes). Discussions with representatives of LLNL revealed that there is no treatment of a combined effluent stream resulting from these tritium handling locations. However, local treatment of the effluent streams from some of these locations does occur. The type of local treatment varies with the form of tritium present in the effluent. If the tritium exists in the molecular form, it is oxidized by use of catalytic recombination and the resulting tritiated water vapor is removed in a molecular sieve. These processes are considered to approach an efficiency of $99.9 \%$. It should be noted that such local treatment systems are not currently used at all sources of tritium bearing effluents; however, definite plans do exist to upgrade and extend the treatment system for the Tritium Research Facility (see Section 13.2.1.3).

Figure 13.4 is a block diagram that provides a conceptual view of the type of treatment system currently in use at the Tritium Research Facility.

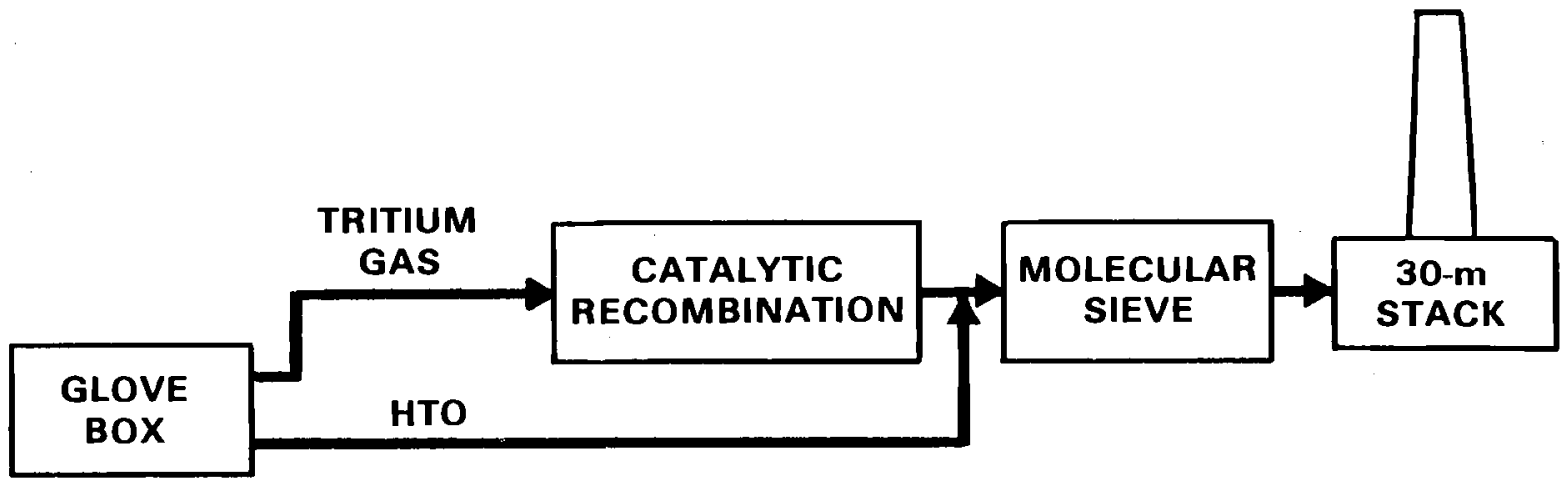

FIGURE 13.4. Block Diagram of ECT in use at the Tritium Research Facility (LLNL) 


\subsubsection{Current Discharge Rate}

The latest information indicates that about $2552 \mathrm{Ci}$ of tritium was discharged from the Building 331 stacks in 1981.(3)

\subsubsection{Potential Additional Emission Control Technology}

Representatives of LLNL indicated that a major upgrade of the Tritium Research Facility ventilation system is planned for FY 1984. This upgrade will improve upon the current system by adding local treatment of effluents from tritium-use locations not presently covered. Also to be included in this upgrade will be the installation of an emergency system to handle unexpected annual releases of up to $45 \mathrm{~g}$ of tritium (approximately $436,000 \mathrm{Ci}$ ). With this system, unexpected releases of tritium would by-pass the normal treatment systems and would be diverted to a separate treatment process consisting of catalytic recombination with removal in a molecular sieve. These planned upgrades should reduce the amount of tritium being released from the Tritium Research Facility to about $1 \%$ of the current amount.

\subsubsection{Anticipated New Discharge Rates}

The improved treatment resulting from the system upgrades discussed in Section 13.2.1.3 should reduce tritium discharges from the Tritium Research Facility to less than $50 \mathrm{Ci}$ per year.

\subsubsection{Estimated Cost of Additional Emission Control Technology}

The system upgrades discussed above are currently budgeted at $\$ 7$ million.

\subsubsection{Specific Source 2: Rotating Target Neutron Source} (Building 202) - LLNL

The following is a description of ECT now in use to minimize radionuclide releases to the air from the Rotating Target Neutron Source at LLNL.

\subsubsection{Description of Existing Emission Control Technology}

The principal radionuclide discharged to the air from the Rotating Target Neutron Source is tritium in the form of tritiated water vapor which is formed in the accelerator beam line. The air from the beam line is exhausted through a vacuum pump and then passed through a molecular sieve where the tritiated 
water vapor is removed. This process approaches $99.9 \%$ efficiency. Figure 13.5 is a simple block diagram of the existing ECT at the Rotating Target Neutron Source.

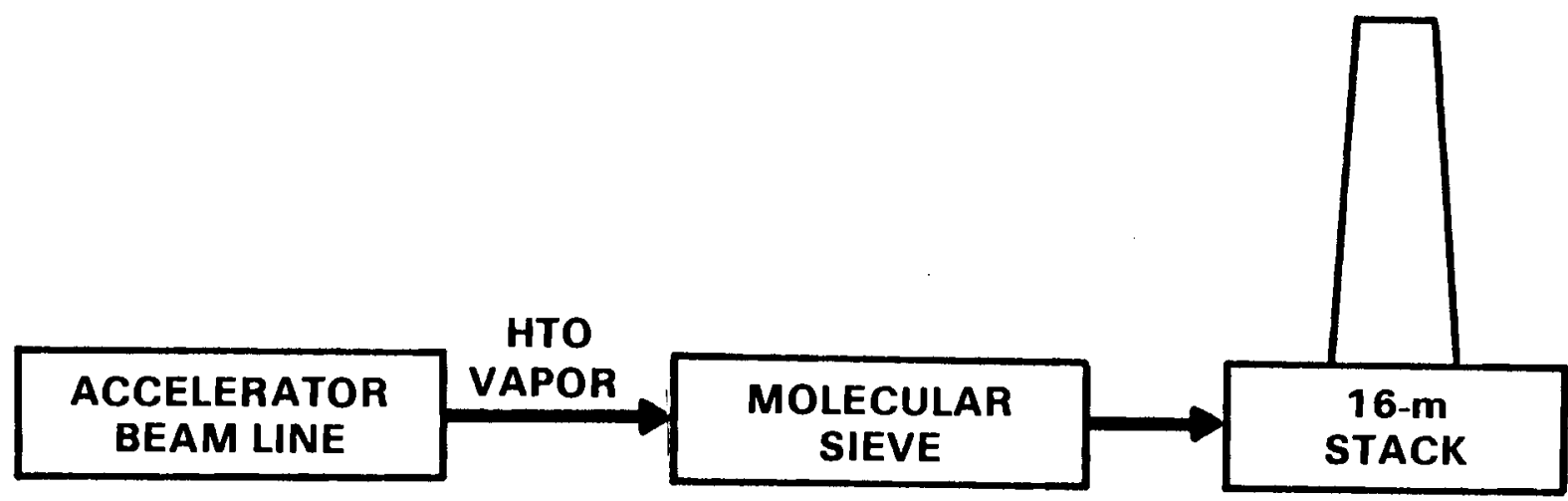

FIGURE 13.5. Block Diagram of the ECT in Use at the Rotating Target Neutron Source

\subsubsection{Current Discharge Rate}

The latest information indicates that about $44 \mathrm{Ci}$ of tritium was discharged from the Building 292 stack in 1981.(3)

13.2.2.3 Potential Additional Emission Control Technology

Since the current total annual amount of tritium discharged from the Rotating Target Neutron Source stack is so low compared to the tritium discharged from the Tritium Research Facility, additional emission control technology is not considered.

13.2.3 Specific Source 3: 100-MeV Linear Accelerator Facility. (Building 194) - LLNL

The following is a description of emission control technology now in use to minimize radionuclide releases to the air from the $100-M e V$ Linear Accelerator Facility.

\subsubsection{Description of Existing Emission Control Technology}

The principal radionuclides discharged from the 100-MeV Linear Accelerator Facility are nitrogen-13, oxygen-15, and particulates containing 
unidentified radionuclides that emit alpha, beta, and gamma radiation. Nitrogen-13 and oxygen-15 are radioactive gases with relatively short halflives (approximatey 10 minutes and 2 minutes, respectively). No ECT is installed to treat these gases. Hold-up time in the facility ventilation system and stack, and dilution after release are estimated to reduce the radiation dose to the offsite population to insignificant levels. HEPA filters are used to reduce the particulate radioactivity. Figure 13.6 is a block diagram of the ECT currently installed at the 100-MeV Linear Accelerator Facility. $(1,2)$

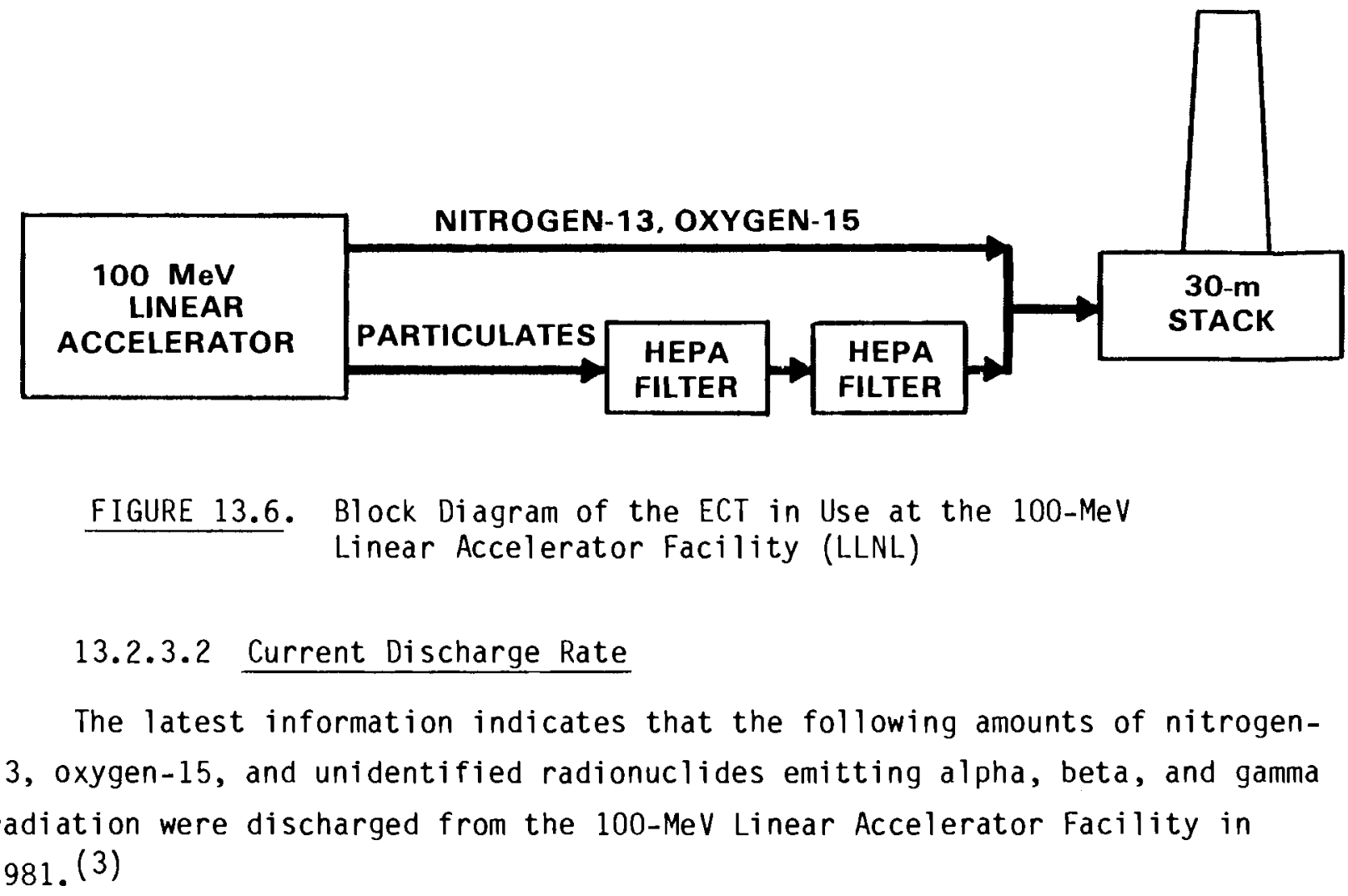

Nitrogen-13

0xygen-15

Unidentified alpha emitters

Unidentified beta and gamma emitters
$172 \mathrm{Ci}$

$172 \mathrm{Ci}$

$4.2 \times 10^{-6} \mathrm{Ci}$

$5.5 \times 10^{-5} \mathrm{Ci}$ 


\subsubsection{Potential Additional Emission Control Technology}

Because of the small amounts of radionuclides currently released from this facility, no additional ECT is considered. Additional holdup time could be considered for nitrogen-13 and oxygen-15, if necessary.

\subsubsection{Specific Source 4: Tritium Research Laboratory (Building 968) - SNLL}

Following is a detailed description of emission control technology now in use to minimize radionuclide releases to the air from the Tritium Research Laboratory.

\subsubsection{Description of Existing Emission Control Technology}

The principal radionuclide discharged from the Tritium Research Facility is tritium. (3) The sources of tritium-bearing effluents are the tritium handling locations within the facility (e.g., laboratories, hoods, glove boxes). Discussions with representatives of SNLL revealed that waste streams from these sources are passed to either the gas purification system or the vacuum effluent recovery system for treatment. Both systems use catalytic recombination to convert molecular tritium to tritiated water vapor, which is removed from the effluent stream by use of dessicants. The vacuum effluent recovery system handles low flow rates, so holding capacity totalling about 12 $\mathrm{m}^{3}$ is included in that system. Treated effluent is vented to the atmosphere through a $30-m$ stack.

SNLL representatives also stated that in 1982, tritium research which had previously been conducted in Room $128 \mathrm{G}$ of the Metallurgy Laboratory was transferred to labs in the Tritium Research Laboratory. Waste tritium resulting from this research previously had received no treatment prior to release from the Building 913 stack 3. Now that this work has been transferred to the Tritium Research Laboratory, waste tritium will receive treatment in the processes described above.

Figures 13.7 and 13.8 are simple block diagrams of the gas purification system and the vacuum effluent recovery system, respectively. 


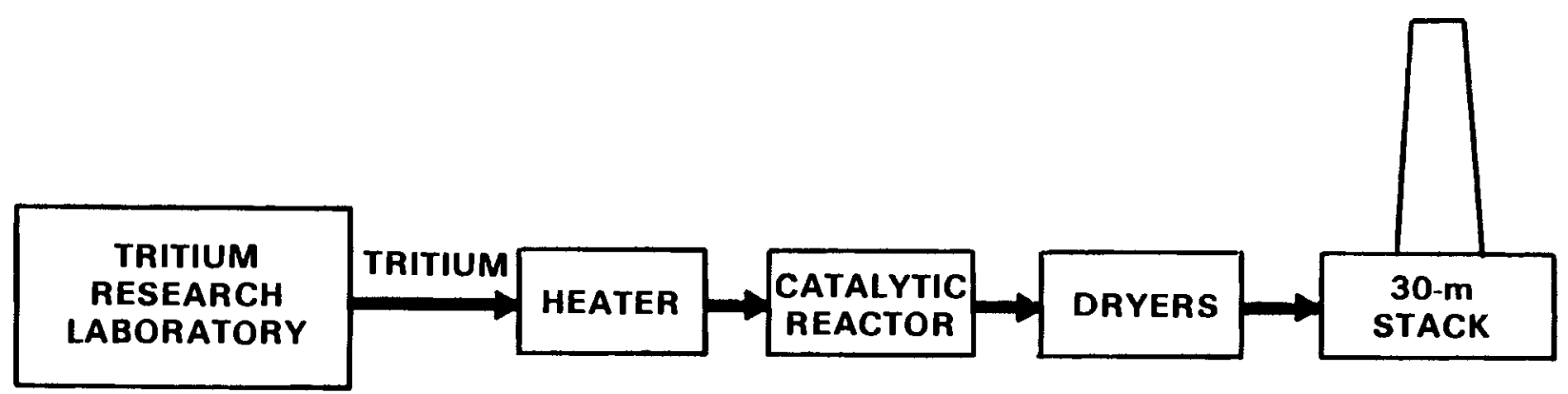

FIGURE 13.7. Block Diagram of the Gas Purification System at the Tritium Research Laboratory (SNLL)

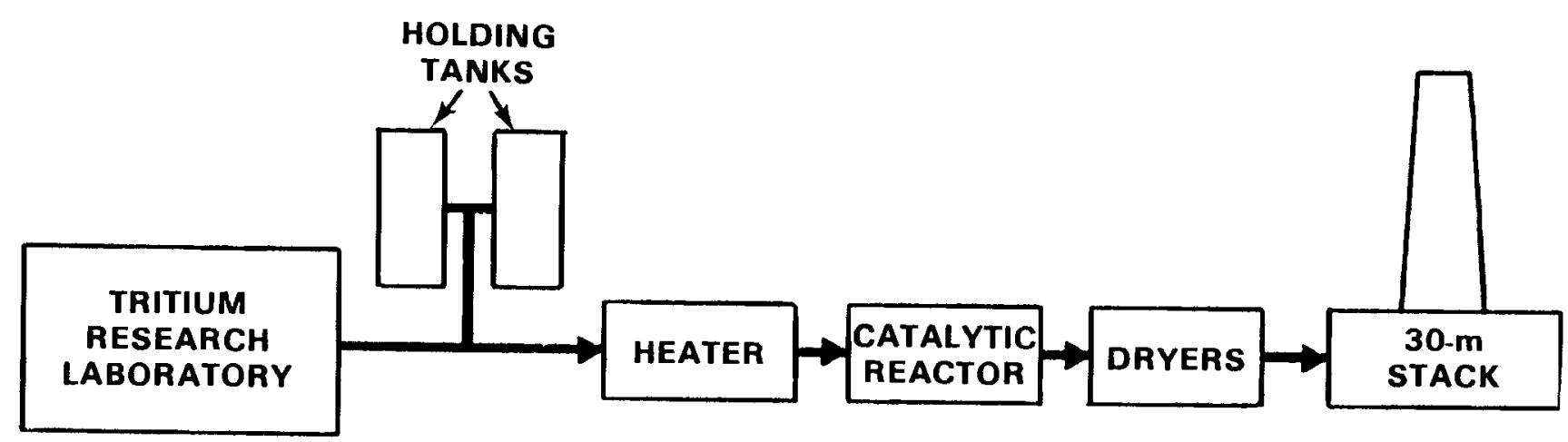

FIGURE 13.8. Block Diagram of the Vacuum Effluent Recovery System at the Tritium Research Facility (SNLL)

\subsubsection{Current Discharge Rate}

Discussions with personnel at SNLL indicate that in 1982 approximately $280 \mathrm{Ci}$ of tritium was discharged from the Building 968 stack. This $280 \mathrm{Ci}$ total ouput for 1982 reflects two unusual situations: 1) the transfer of research from Room $128 \mathrm{G}$ of the Metallurgy Laboratory, and 2) a one-time release of about $175 \mathrm{Ci}$ of tritium following cleanup of a lab facility in the Tritium Research Laboratory. These two unusual occurrences make it difficult to estimate the annual amount of tritium that may be released from this facility under more normal circumstances. In 1981, only about $38 \mathrm{Ci}$ of tritium was released to the atmosphere from the Tritium Research Laboratory. It seems reasonable to expect that, under normal operating conditions and with 
the ECT currently in use, airborne releases from the Tritium Research Laboratory can be maintained at low levels. However, until data that more accurately represent the annual tritium output from this facility are available, consideration of potential additional ECT should be deferred.

\subsubsection{Specific Source 5: Metallurgy Laboratory (Building 913) - SNLL}

Following is a description of emission control technology now in use to minimize radionuclide releases to the air from the Metallurgy Laboratory.

\subsubsection{Description of Existing Emission Control Technology}

The principal sources of airborne radiation released from the Metallurgy Laboratory are unidentified radionulcides that emit alpha, beta, and gamma radiation. (3) These radionuclides result from operations involving assembly and disassembly of radioactive materials along with cutting and polishing operations. The process air from these operations is passed through HEPA filters before being released to the air through a 12-m stack. (2)

Figure 13.9 is a block diagram of the emission control technology currently in use at the Metallurgy Laboratory.

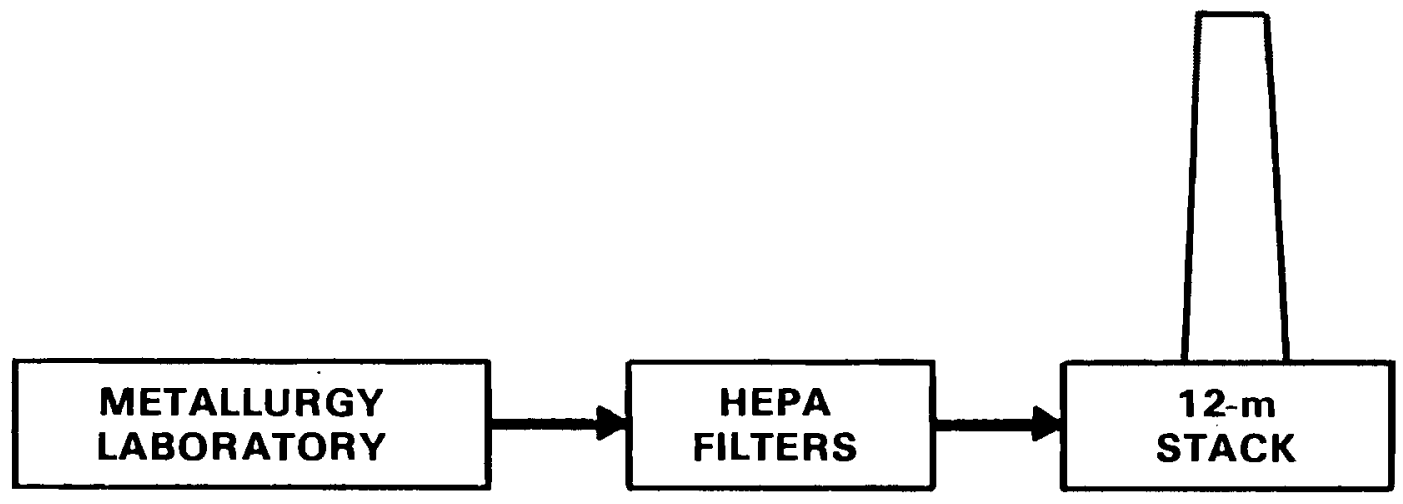

FIGURE 13.9. Block Diagram of the Emission Control Technology in Use at the Metallurgy Laboratory

\subsubsection{Current Discharge Rate}

Current information indicates that in 1981 the following radiation was discharged from stack 1 at Building 913. (3) 


$\begin{array}{ll}\text { Unidentified alpha emitters } & 4.815 \times 10^{-6} \mathrm{Ci} \\ \text { Unidentified beta and gamma emitters } & 8.071 \times 10^{-5} \mathrm{Ci}\end{array}$

13.2.4.3 Potential Additional Emission Control Technology

Because of the small amounts of radiation currently released from this facility annually, no additional ECT is considered. 


\section{REFERENCES}

1. Final Environmental Impact Statement: Lawrence Livermore National Laboratory and Sandia National Laboratories - Livermore Sites, DOE/EIS0028, U.S. Department of Energy, Washington, D.C., 1982.

2. Radiological Impact Caused by Emissions of Radionuclides with Air in the United States, EPA 520/7-79-006, U.S. Environmental Protection Agency, Washington, D.C., 1980.

3. U.S. Department of Energy Effluent Information System, U.S. Department of Energy, Washington, D.C., 1981. 


\subsection{LOS ALAMOS NATIONAL LABORATORY}

The Los Alamos National Laboratory (LANL), formerly the Los Alamos Scientific Laboratory (LASL), was established in 1943 as part of the Manhattan Project. The initial mission of LASL was the design and assembly of the first nuclear fission bomb. Since the 1950s, work has continued at LANL on the design and development of nuclear weapons systems, but the production of weapons has been taken over by other DOE facilities.

\subsection{SITE AND MAJOR SOURCE DESCRIPTIONS}

LANL is a multidisciplinary laboratory facility, with activities currently divided into four major program areas:

- National Security Program - Weapons research is a major mission of LANL; the primary emphasis is on research, development and testing activities related to the production of nuclear weapons.

- Energy Programs - Emphasis is on research and development activities on energy resources and applied energy technology, including fission, fusion, solar, geothermal, coal and shale oil. Advanced isotope separations studies represent a major research area.

- Biomedical and Environmental Projects - The three major program areas are biomedical and environmental research, waste management, and operational health and safety as they relate to various aspects of nuclear research and development. The LANL reservation has been designated a National Environmental Research Park.

- Physical Research Programs - Most of the physical research activities at LANL are related to the operation of the C. P. Anderson Los Alamos Meson Physics Facility (LAMPF) and associated accelerator research studies. The LAMPF consists of a linear proton accelerator designed to produce an $800 \mathrm{MeV}$ proton beam, which is used to generate pi mesons for various nuclear physics studies. 
In addition to the four major program areas, LANL provides all of the general support functions required for the operation of a major national laboratory.

\subsubsection{Location of Site and Description of Facilities}

LANL occupies a 11,100-hectare site located in north-central New Mexico about $97 \mathrm{~km}$ north-northeast of Albuquerque and $40 \mathrm{~km}$ northwest of Santa Fe (Figure 14.1). The work force at LANL in 1981 was approximately 8,600.

Activities at LANL are carried out in about 125 major structures located in 32 technical areas widely dispersed throughout the site. Figure 14.2 shows the locations of the technical areas, while Table 14.1 provides brief descriptions of the active technical areas and their associated programs. South Mesa (TA-3), the main technical area, contains 36 buildings with more than half of the usable space and almost $60 \%$ of the laboratory staff.

According to the EPA Release Point Analysis for 1981 (Appendix A), routine atmospheric releases of radionuclides at LANL occurred from 77 discharge points located in thirteen of the technical areas. (a) The routine discharge points, typically ventilation stacks, are continuously monitored with particulate and/or gas samplers. Atmospheric emissions were reported from a number of other locations in previous years, but not in 1981 . These discharge points are not considered in this study.

Except for tritium and air activation products, (b) routine releases of radionuclides to the atmosphere at LANL have continued to decline in recent years as a result of continuing efforts to reduce such emissions. The release of activation products has increased somewhat in recent years because of the increasing work load at the LAMPF and its associated facilities.

(a) The LANL environmental surveillance report for $1981^{(1)}$ shows radioactive airborne emissions as being monitored at 86 stacks in 1981.

(b) ${ }^{7} \mathrm{Be},{ }^{1} 1_{\mathrm{C}},{ }^{13_{\mathrm{N}}},{ }^{15_{\mathrm{O}}},{ }^{4} 1_{\mathrm{Ar}}$. 


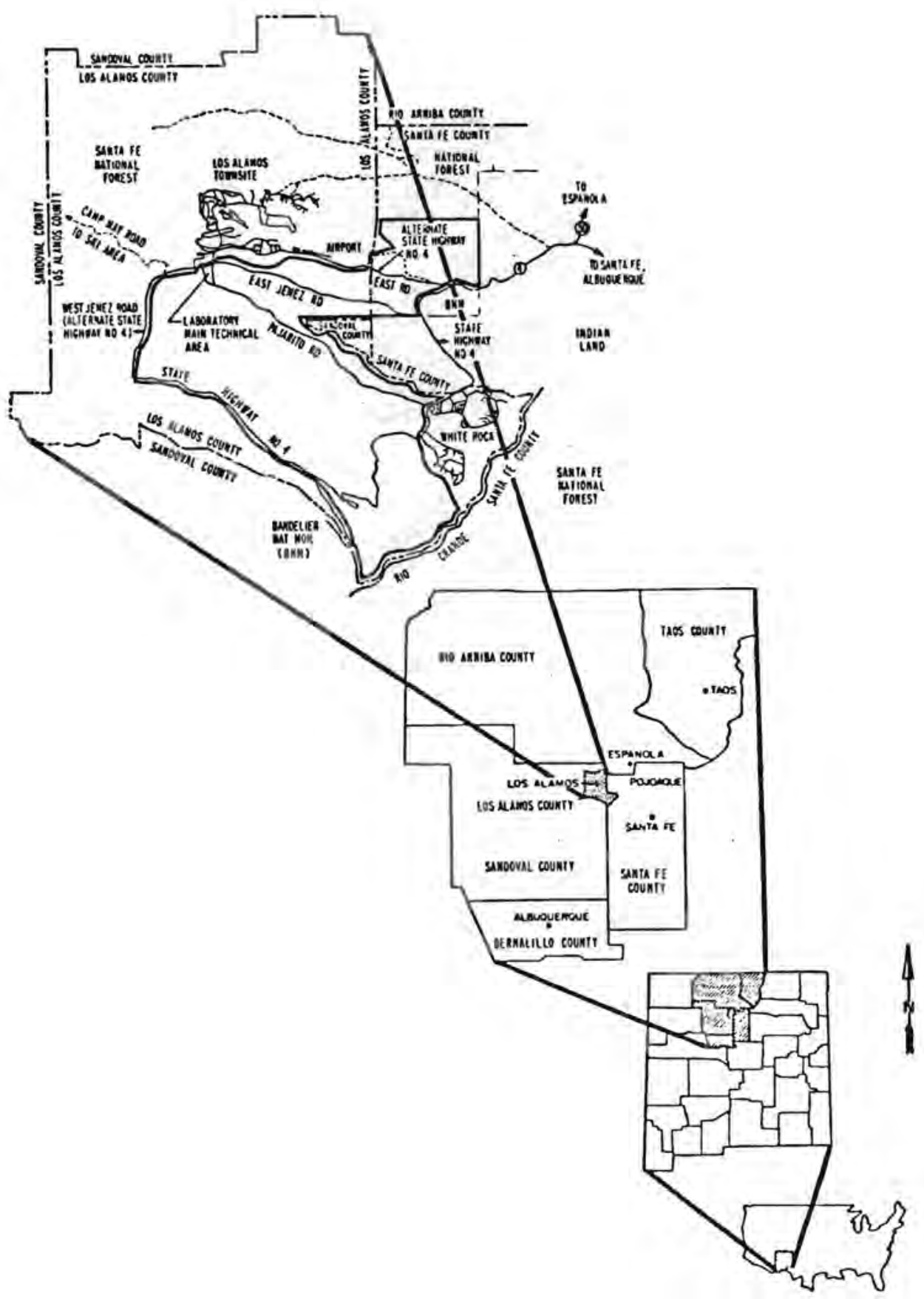

FIGURE 14.1. Location of the Los Alamos National Laboratory 


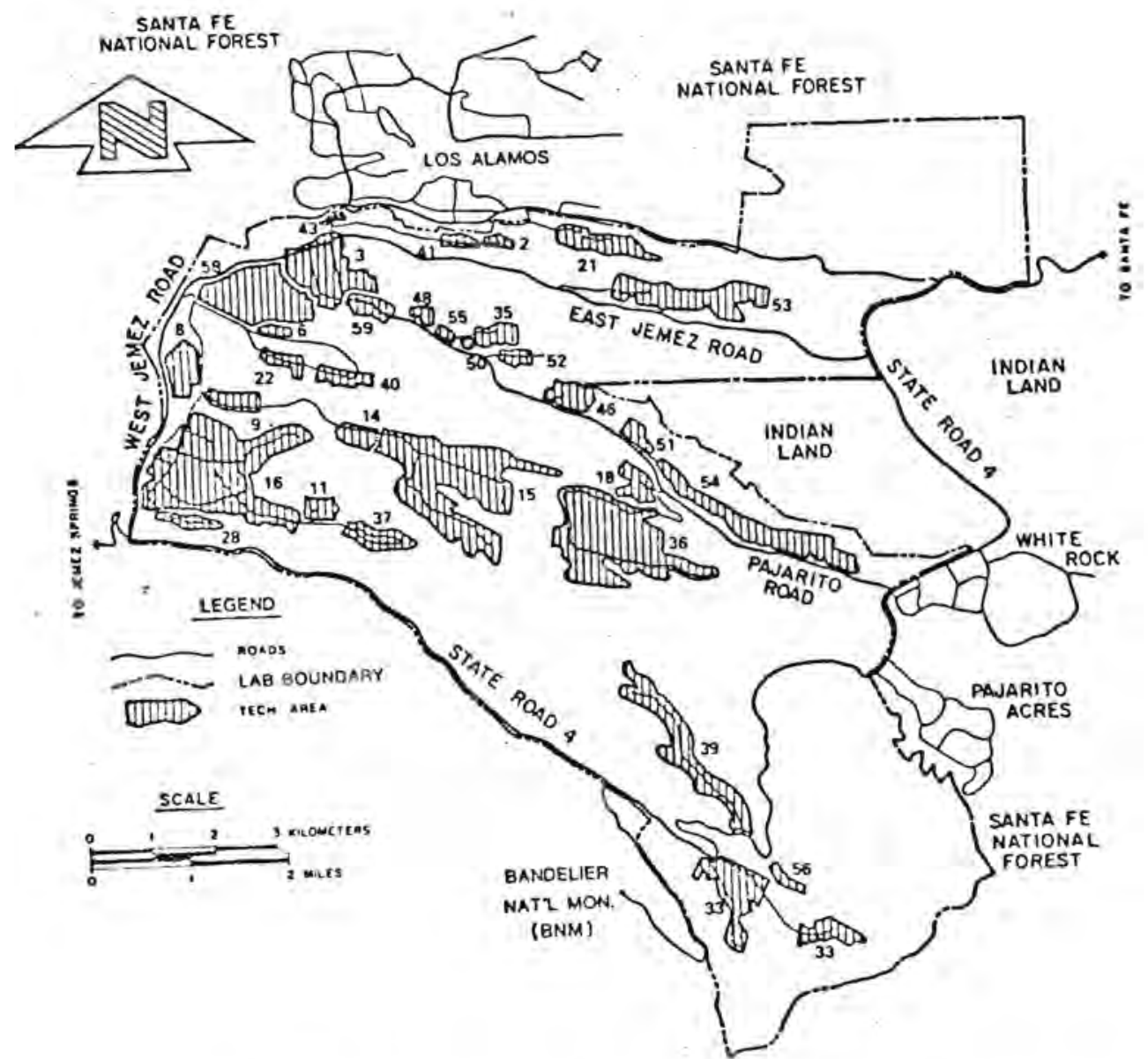

FIGURE 14.2. Los Alamos National Laboratory's Technical Areas and Adjacent Communities 


\section{TABLE 14.1. Descriptions of the Active Technical Areas at the Los Alamos National Laboratory and Their Associated Programs (a)}

TA-2, Omega Sile: Omega West Reactor, an 8 megawatt nuclear research reactor, is located here. It serves as a research tool in providing a source of neutrons for fundamental studies in nuclear physics and associated fields.

TA-3, South Mesa Site: In this main technical area of the Laboratory is the Administration Building that contains the Director's office and administrative offices and laboratories for several divisions. Other buildings house the Central Computing Facility, Personnel Administration Department offices, Materials Department, the science museum, Chemistry and Metallurgy Division, Physics Division, technical shops, cryogenics laboratories, a Van de Graaff accelerator, and cafeteria.

TA-6, Two Mile Mesa Site: This is one of three sites (TA-22 and 'TA-40 are the other two sites) used in development of special detonators for initiation of high explosive systems. Fundamental and applied research in support of this activity includes investigation of ptrenomena associated with initiation of high explosives, and research in rapid shock-induced reactions with shock tubes.

TA-8, GT Site (or Anchor Site West): This is a nondestructive testing site operated as a service facility for the entire Laboratory, It maintains capability in all modern nondestructive testing techniques for insuring quality of materials, ranging from test weapon components to checking of high pressure dies and molds. Principal tools include radiographic techniques ( $x$-ray machines to 1 million volts, a $24-\mathrm{MeV}$ betatron), radioactive isotopes, ultrasonic testing, penctrant testing, and electromagnetic methods.

TA-9. Anchor Site East: At this site fabrication feasibility and physical propertics of explosives are explored. New organic compounds are investigated for possible use as explosives. Storage and stability problems are also studied.

$T A-11, K$-Site: Facilitics are located here for testing explosive components and systems under a varicty of extreme physical environments. The facilities are arranged so testing may be controlled and observed remotely, and so devices containing explosives or radioactive materiais, as well as those containing nonhazardous materials, may be tested.
TA-14, Q-Site: This firing site is used for running various tests on relatively small explosive charges and for fragment impact tests.

$T A-15, R$-Site: This is the home of PHERMEX-a multiple cavity electron accelerator capable of producing a very large flux of $x$-rays for certain weapons development problems and tests. This site is also used for the investigation of weapon functioning and weapon system behavior in nonnuclear tests, principally by electronic recording means.

$T A-16, S$-Site: Investigations at this site include development, engineering design, pilot manufacture, environmental testing, and stockpile production liaison for nuclear weapon warhead systems. Development and testing of high explosives, plastics and adhesives, and process development for manufacture of items using these and other materials are accomplished in extensive facilities.

TA-18, Pajarito Laboratory Site: The fundamental behavior of nuclear chain reactions with simple, lowpower reactors called "critical assemblies" is studied here. Experiments are operated by remote control and observed by closed circuit television. The machines are housed in buildings known as "kivas" and are used primarily to provide a controlled means of assembling a critical amount of fissionable materials. This is done to study the effects of various shapes, sizes, and configurations. These machines are also used as sources of fission ncutrons in large quantities for experimental purposes.

TA-21, DP-Site: This site has two primary research areas, DP West and DP East. DP West is concerned with tritium research. DP East is the high temperature chemistry site where studies are conducted on the chemical stability and interaction of materials at temperatures up to and exceeding $3300^{\circ} \mathrm{C}$.

TA-22, TD Site: Sce TA-6.

TA-28, Magazine Area " $A$ ": Explosives storage area.

TA-33, HP-Site: Design and devclopment of nuclear and other components of weapon systems are conducted here. A major tritium handling facility is located here. Laboratory and office space for Geosciences Division related to the Hot Dry Rock Geothermal Project are also here. 
TA-35, Ten Site: Nuclear safeguards research and development, which is conducted here, is concerned with techniques for nondestructive detection, identification, and analysis of fissionable isotopes. Research in reactor safety and laser fusion is also done here.

TA-36, Kappa Site: Various explosive phenomena, such as detonation velocity, are investigated here.

TA-37, Magazine Area " C": Explosives storage area.

TA-39, Ancho Canyon Site: Nonnuclear weapon behavior is studied here, primarily by photographic techniques. Investigations are also made into various phenomenological aspects of explosives, interaction of explosives, and explosions with other materials.

TA-40, DF-Site: See TA-6.

$T A-41, W$-Site: Personnel at this site are engaged primarily in engineering design and development of nuclear components, including fabrication and evaluation of test materials for weapons. Also located here is an underground laboratory that is used for physics experiments.

TA 43, Health Research Laboratory: The Biomedical Research Group does research here in cellular radiobiology, molecular radiobiology, biophysics, mammalian radiobiology, and mammalian metabolism. A large medical library, special counters used to measure radioactivity in humans and animals, and animal quarters for dogs, mice and monkeys are also located in this building.

TA 46, WA Site: Here applied photochemistry, which includes development of technology for laser isotope separation and laser-enchancement of chemical processes, is investigated. Solar energy research, particularly in the area of passive solar heating for residences, is done.

$T A-48$, Radiochemistry Site: Laboratory scientists and technicians at this site study nuclear properties of radioactive materials by using analytical and physical chemistry. Measurcments of radioactive substances are made and "hot cells" are used for remote handling of radioactive materials.
TA-50, Waste Management Site: Personnel at this site have responsibility for treating and disposing of most contaminated liquid waste received from Laboratory technical areas, for development of improved methods of waste treatment, and for containment of radioactivity removed by treatment. Radioactive waste is piped to this site for treatment from many of the technical areas.

-TA-51, Radiation Exposure Facility: Here animals are irradiated to determine biological effects of high and low exposures.

TA-52, Reactor Development Site: A wide variety of activities related to nuclear reactor performance and safety are done here.

TA-53, Meson Physics Facility: The Los Alamos Meson Physics Facility (LAMPF), a linear particle accelerator, is used to conduct research in the areas of basic physics, cancer treatment, materials studies, and isotope production.

TA-54, Waste Disposal Site: This is a disposal area for radioactive and toxic wastes.

TA-55, Plutonium Processing Facilities: Processing of plutonium and research in plutonium metallurgy are done here.

TA-57, Fenton Hill Site: This is the location of the Laboratory's Hot Dry Rock gecthermal project. Here scientists are studying the possibility of producing energy by circulating water through hot, dry rock located hundreds of meters below the earth's surface. The water is heated and then brought to the surface to drive electric generators.

TA-58, Two Mile Mesa. Undeveloped technical area.

TA-59, Occupational Hcalth Site: Occupational health and environmental science activities arc conducted here.

\section{(a) Environmental Surveillance at Los Alamos During 1980, LA-8810-ENV, Los Alamos National Laboratory, 1981.}




\subsubsection{Identification and Location of Specific Sources}

Table 14.2 summarizes the routine releases of radionuclides to the atmosphere at LANL in 1981. The individual release point data are given in Appendix A. Data in Appendix A were originally in error for argon and tritium, but have since been corrected by DOE in Appendix $A$ to agree with data in Reference 1. The releases shown in Tables 14.2 and 14.3 also agree with the corrected data.

TABLE 14.2. Radionuclides Routinely Released to the Atmosphere at the Los Alamos National Laboratory in 1981(1)

\begin{tabular}{lccc} 
Radionuclide & $\begin{array}{c}\text { Number of } \\
\text { Discharge Points }(a)\end{array}$ & $\begin{array}{c}\text { Release, } \\
\text { Ci/yr }\end{array}$ \\
${$\cline { 2 - 2 }$} }$ & 2 & & 1,360 \\
MAP(b) & 1 & 352,300 \\
Tritium & 8 & 7,225 \\
Uranium(c) & 23 & 0.0013 \\
Plutonium (d) & 42 & 0.000057 \\
MFP(e) & 13 & 0.0015 \\
Americium-241 & 1 & 0.00000003 \\
Iodine-131 & 1 & 0.000044 \\
Phosphorus-32 & 1 & 0.00002
\end{tabular}

(a) Discharge points where routine atmospheric releases are continuously monitored; typically building ventilation stacks.

(b) Mixed Activation Products $\left({ }^{7} \mathrm{Be},{ }^{11} \mathrm{C}, 13 \mathrm{~N}\right.$, and 150$)$

(c) $235 U+238 u$.

(d) $238 \mathrm{pu}+{ }^{239} \mathrm{pu}$.

(e) Mixed Fission Products - Assumed to be all ${ }^{90} \mathrm{Sr}$ for calculational purposes.

The calculations described in Section 1.4 show that activation products, including ${ }^{41} \mathrm{Ar}$, account for greater than $80 \%$ of the hypothetical risk resulting from atmospheric releases of radionuclides, while tritium accounts 
TABLE 14.3. The Major Atmospheric Discharge Points at LANL to be Evaluated in Detail Based on 1981 Release Data

\begin{tabular}{|c|c|c|c|}
\hline Discharge Point & $\begin{array}{l}\text { Technical } \\
\text { Area }\end{array}$ & $\begin{array}{l}\text { Radionuclides } \\
\text { Released }\end{array}$ & $\begin{array}{l}\text { Release, } \\
\text { Ci/yr }\end{array}$ \\
\hline 1. Omega West Reactor Stack & TA-2 & Argon-41 & 300 \\
\hline 2. LAMPF Main Stack TA-53 & & $\begin{array}{l}\text { Argon-41 } \\
\text { Tritium } \\
\text { Beryl lium-7 } \\
\text { Carbon-11 } \\
\text { Nitrogen-13 } \\
\text { Oxygen-15 }\end{array}$ & $\begin{array}{c}1,060 \\
6.5 \\
38.6 \\
352,340\end{array}$ \\
\hline
\end{tabular}

4. South Stack-Wing 3, Chemistry Metal lurgy Research Building (CMR)

5. Main Stack FE-1, Building 3 - D P Site

$\begin{array}{lll}\text { TA-21 } & \text { Uranium-235 } & 6.6 \times 10^{-4} \\ \text { TA-48 } & \text { MFP(d) } & 6.4 \times 10^{-4}\end{array}$

6. CORE Wing Stack - Building RC-1 Radiochemistry
(a) Appendix A.
(b) Reference 1 shows the release of ${ }^{7} \mathrm{Be}$ to be $0.014 \mathrm{Ci}$ in 1981.
(c) $238 \mathrm{Pu}+239_{\mathrm{Pu}}$.
(d) Mixed Fission Products - Assumed to be all ${ }^{90} \mathrm{Sr}$ for the dose calculations. 
for more than 19\%. Particulate emissions (i.e., Pu, U, fission products) account for less than $1.0 \%$ of the hypothetical risk. All of the activation products released to the atmosphere at LANL in 1981 were discharged from two stacks. More than $84 \%$ of the tritium was discharged from one stack. All three stacks are evaluated in detail in the following sections. In addition, three other stacks listed in Table 14.3 are evaluated in some detail even though they do not contribute substantially to the total hypothetical risk. For example, the south stack in Wing 3 of the Chemistry Metallurgy Research Laboratory is responsible for about $58 \%$ of the plutonium released to the atmosphere at LANL. It is evaluated as typical of plutonium release points. Similarly, the two stacks responsible for the bulk of the uranium and mixed fission products (MFP) released to the atmosphere are evaluated.

\subsubsection{Nonspecific and Minor Sources}

Radioactive particulates ( $P u, U, A m$, MFP) were released routinely to the atmosphere from 68 points in 1981.(a) The total activity associated with the particulate discharges amounts to slightly less than three millicuries, of which about $45 \%$ was released from the three stacks listed in Table 14.3. The remaining $55 \%$ of the radioactive particulates ( $1.5 \mathrm{millicuries)}$ were released from the other 65 discharge points.

Tritium was released from eight discharge points at LANL in 1981. About $84 \%$ of the total tritium release was from the HP site stack No. FE-6 and the LAMPF stack, as shown in Table 14.3; the remainder of the tritium was released from the other six stacks in amounts varying from 0.05 to $575 \mathrm{ci} / \mathrm{yr}$.

Emission control technology for the 65 stacks discharging particulates and six stacks discharging tritium in minor amounts is discussed generically in Section 14.2.7.

\subsection{EMISSION CONTROL TECHNOLOGY AT LOS ALAMOS NATIONAL LABORATORY}

The following sections describe the emission control technology currently in use at the six sources being evaluated. Possible application of additional

(a) Based on the release data given in Appendix A. 
control technology, the effects of such improvements on discharge rates, and the costs of such improvements are also discussed. Generic information on the emission control technology for the nonspecific or minor sources is also provided.

Information on emission control technology currently in use at LANL was supplied by T.C. Gunderson of the Environmental Surveillance Group at LANL.

\subsubsection{Specific Source 1: Omega West Reactor Stack}

The Omega West research reactor is located in TA-2. The reactor is a heterogeneous water-cooled tank-type reactor. The maximum power level is 8 MWth. The reactor is used for a wide variety of experimental programs. The reactor is under DOE jurisdiction and meets DOE standards for research reactors which are equivalent to NRC standards for research reactors.

Argon-41 (t $1 / 2 \sim 1.8 \mathrm{hr}$ ) was the only radionuclide above limits of detectibility released to the atmosphere from the Omega West reactor stack in CY 1981. The argon-41 is produced by neutron activation of the natural argon in air. Process air streams and part of the building ventilation exhaust are discharged to the atmosphere from the reactor stack, which is located about 300 meters from the reactor. The total air flow to the stack is about 28.3 $\mathrm{m}^{3} / \mathrm{min}$. The stack is approximately 0.2 meters in diameter, and its height is approximately 46 meters above ground level. The stack is continuously monitored.

\subsubsection{Description of Existing Emission Control Technology}

Charcoal cartridges are installed in the process air stream to remove any radioiodine present. There is no technology in place to remove argon-41 from the air stream flowing to the stack. Some reduction in the argon-41 level is provided by delay (approximately $1 \mathrm{hr}$ ) as the air flows from the reactor building to the stack. Figure 14.3 shows a block diagram of the existing emission control technology.

\subsubsection{Current Discharge Rate}

A total of $300 \mathrm{Ci}$ of argon-41 was released to the atmosphere from the Omega West Reactor stack in 1981. Assuming the argon-41 was released 


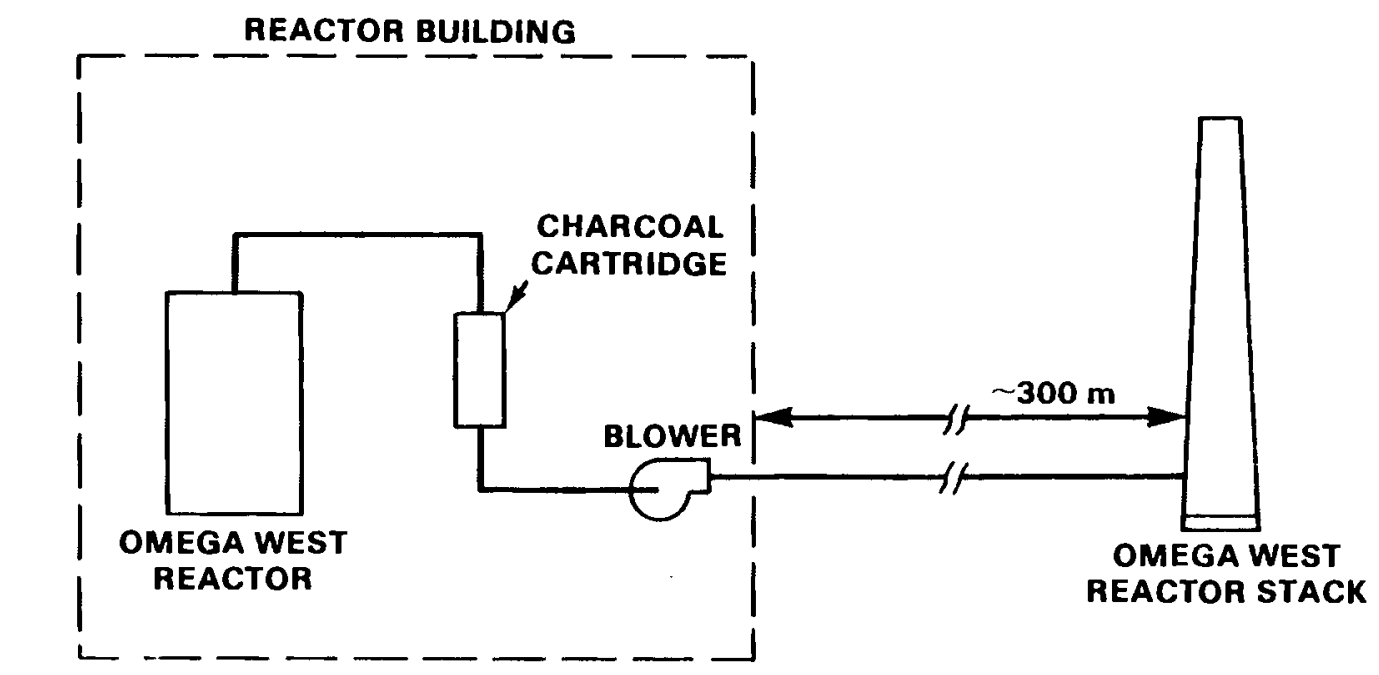

FIGURE 14.3. Block Diagram of Existing Emission Control Technology At the Omega West Reactor

uniformly from the stack throughout the year, the average concentration of argon-41 in the air exiting the stack was about $2.0 \times 10^{-5} \mu \mathrm{Ci} / \mathrm{ml}$. This is approximately 500 times greater than the concentration guide for uncontrolled areas $\left(4 \times 10^{-8} \mu \mathrm{Ci} / \mathrm{m} \ell\right)$.

\subsubsection{Potential Additional Emission Control Technology}

A reduction in the argon-41 released from the reactor stack can be obtained by providing additional holdup time to allow the argon-41 to decay. An atmospheric pressure or pressurized air storage system could be used to provide the holdup time. The atmospheric pressure storage volumes required to obtain various reductions in the argon-41 emissions at a normal airflow of $28.3 \mathrm{~m}^{3} / \mathrm{min}$ are given in Table 14.4 . The use of a pressurized air storage system would reduce the storage volume required for a given decontamination factor (DF), but would probably increase the overall cost of the system.

To provide a DF of 8 , the argon-41 emissions would require a holdup volume of about $9300 \mathrm{~m}^{3}$ at atmospheric pressure. For reactor operating levels equivalent to those of $C Y$ 1981, this would reduce stack emissions from 300 $\mathrm{Ci} / \mathrm{yr}$ to about $38 \mathrm{Ci} / \mathrm{yr}$. 
TABLE 14.4. The Estimated Reductions in the Argon-41 Released From the Omega West Reactor Stack as a Function of the Air Storage Volume Provided (Assuming a nominal air flow of $28.3 \mathrm{~m}^{3} / \mathrm{min}$ ).

\begin{tabular}{|c|c|c|c|}
\hline $\begin{array}{l}\text { Air Stora̧ge } \\
\text { Volume, m } 3(a)\end{array}$ & $\begin{array}{l}\text { Additional } \\
\text { Holdup Time } \\
\text { min } \\
\end{array}$ & $\begin{array}{c}\text { Approximate } \\
\text { DF } \\
\end{array}$ & $\begin{array}{l}\text { Estimated } \\
41_{\mathrm{Ar} \text { Release, }} \text { (b) } \\
\text { Ci/yr } \\
\end{array}$ \\
\hline 0 & 0 & 0 & 300 \\
\hline 3100 & 110 & 2 & 150 \\
\hline 6200 & 220 & 4 & 75 \\
\hline 9300 & 330 & 8 & 38 \\
\hline
\end{tabular}

(a) Assumes an atmospheric pressure storage system.

(b) Assumes the reactor operating level is equivalent to that of CY 1981.

A tank $30 \mathrm{~m}$ in diameter by about $13.2 \mathrm{~m}$ high would be needed to give the required storage volume. The air storage tank could be carbon steel and would be located on a concrete pad adjacent to the reactor building. Figure 14.4 shows a block diagram of the air storage system.

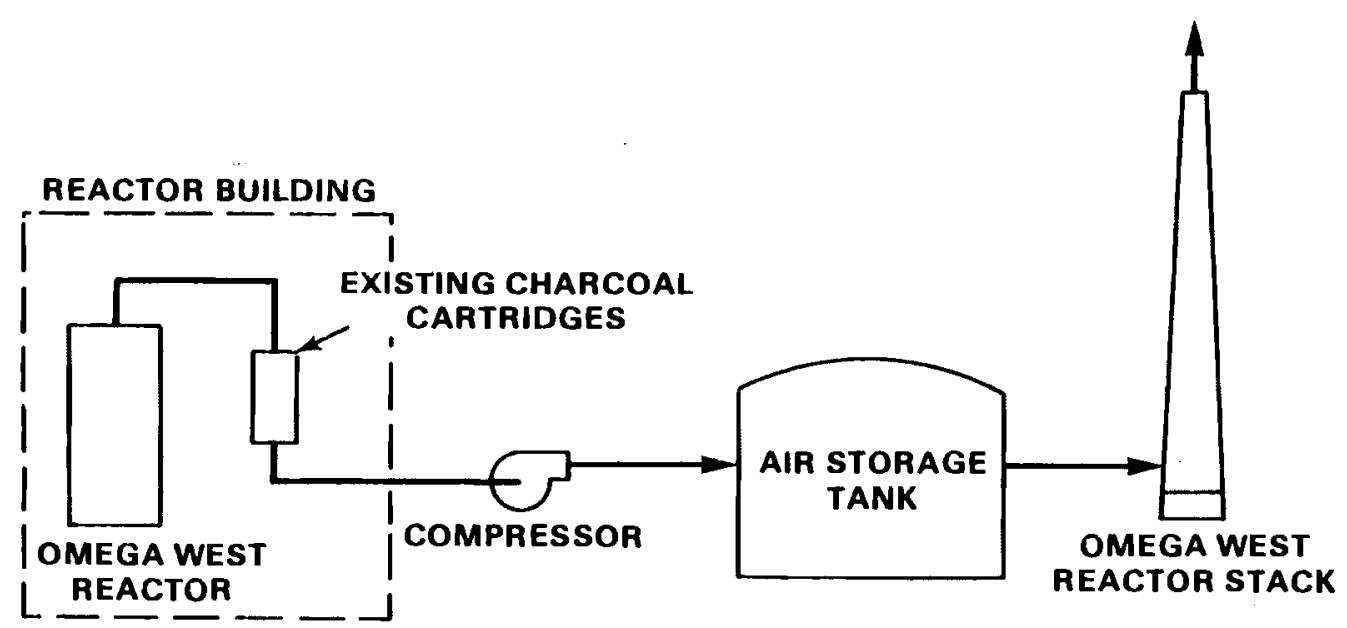

FIGURE 14.4. Block Diagram of an Atmospheric Pressure Air Storage System to Reduce Argon-41 Emissions from the Omega West Reactor Stack

The estimated capital costs for an atmospheric pressure air storage system capable of providing an argon-41 DF of 8 are given in Table 14.5, while the estimated operating costs are given in Table 14.6. 
TABLE 14.5. Capital Cost Estimate for An Atmospheric Pressure Air Storage Tank System to Provide an Argon-41 Decontamination Factor of Eight for Air Flowing to the Omega West Reactor Stack--in 1983 Dollars

\begin{tabular}{lr}
\multicolumn{1}{c}{ Item } & Cost, $\$$ thousands \\
\hline Carbon Steel Tank - installed (Vol. $\left.9300 \mathrm{~m}^{3}\right)$ & 1,700 \\
Compressor, Piping, Instrumentation, Building & 650 \\
Concrete Pad & 250 \\
Site Preparation & $\frac{40}{2,600}$ \\
Subtotal - Direct Construction Costs & $\frac{400}{3,040}$ \\
Architect-Engineering Services (15\%) & 1,210 \\
Subtotal & $\frac{4,250}{\text { Contingency (40\%) }}$ \\
Total Facility Cost &
\end{tabular}

TABLE 14.6. Operating Cost Estimate for an Atmospheric Pressure Air Storage System Providing an Argon-41 Decontamination Factor of Eight--in 1983 Dollars

\begin{tabular}{|c|c|}
\hline Item & Annual Cost (\$) \\
\hline Operator $(0.25 \operatorname{man}-y r / y r)$ & 8,800 \\
\hline Maintenance $(0.3 \mathrm{man}-\mathrm{y} / \mathrm{yr})$ & 10,500 \\
\hline Utilities & 12,000 \\
\hline Maintenance Materials & 22,000 \\
\hline Overhead & 19,300 \\
\hline Miscellaneous & 5,000 \\
\hline Total & 77,600 \\
\hline
\end{tabular}

The capital costs for atmospheric pressure air storage systems of varying size would vary approximately as the eight-tenths power of the size ratio. Table 14.7 shows how the capital cost would vary with the argon-41 DF required. Annual operating costs for the air storage system would be almost independent of system size. 
TABLE 14.7. Estimated Capital Cost for Air Storage Systems as a Function of the Argon-41 Decontamination Factor Required--in 1983 Dollars

\begin{tabular}{|c|c|c|c|c|}
\hline $\begin{array}{l}41_{\text {Ar DF }} \\
\text { Required }\end{array}$ & $\begin{array}{r}\text { Estimated } \\
\text { Release, } \\
\end{array}$ & $\begin{array}{l}41_{\mathrm{Ar}} \\
\mathrm{Ci} / \mathrm{yr}\end{array}$ & $\begin{array}{l}\text { Air Storage, Vol. } \\
\text { Required, }(5)^{3}\end{array}$ & $\begin{array}{c}\text { Cost, } \\
\$ \text { thousands }\end{array}$ \\
\hline 2 & 150 & & 3,100 & 1,760 \\
\hline 4 & 75 & & 6,200 & 3,070 \\
\hline 8 & 38 & & 9,300 & 4,250 \\
\hline 16 & 19 & & 12,400 & 5,350 \\
\hline
\end{tabular}

(a) Assumes that reactor operating levels are the same as CY 1981. (b) Assumes an atmospheric pressure storage system.

Installation of the air storage system should have little effect on the operation of the reactor during the construction period.

\subsubsection{Specific Source 2: LAMPF Main Stack}

The $\mathrm{Clinton} P$. Anderson Los Alamos Meson Physics Facility (LAMPF) in TA53 consists primarily of a linear proton accelerator approximately $800 \mathrm{~m}$ long designed to produce an 800 MeV proton beam with an average intensity of one milliampere. The proton beam, and secondary particles produced when the energetic protons strike a target, are used in a wide variety of experimental programs. Fields of investigation include medium energy nuclear physics, biophysics, radiochemistry, and cancer therapy.

Interaction of the proton beam and secondary particles with air produce several activation products. These activation products, which include beryllium-7, carbon-11, nitrogen-13, oxygen-15, argon-41, and tritium, were the only radionuclides released to the atmosphere from the LAMPF facility in CY 1981. The activation products are discharged to the atmosphere from the LAMPF main stack. The main stack receives the air flow from a single fanexhaust system. Air flow to the main stack is about $480 \mathrm{~m} / \mathrm{min}$. The stack has a diameter which varies from about $1.5 \mathrm{~m}$ to $0.9 \mathrm{~m}$ at the top. The stack height is about $30.5 \mathrm{~m}$ above ground level. 


\subsubsection{Description of Existing Emission Control Technology}

Air flowing to the LAMPF stack is passed through a single stage of HEPA filtration to remove particulates. There is no technology in place to remove gaseous radionuclides from the air stream. Areas where the air activation products are produced are continuously ventilated to remove the radionuclides as they are formed. Due to the short half-lives of some of the activation products formed, some reduction in the radionuclide release is obtained by decay due to holdup as the air flows from the various source points to the stack. The extent of the reduction will depend on the radionuclides. In the case of oxygen-15 ( $t / 2=2.0 \mathrm{~min}$ ), the holdup could reduce the release significantly. In the case of tritium ( $t 1 / 2=12.3 \mathrm{yr}$ ) and beryllium-7 ( $1 / 2=$ 53.3d) the holdup would have essentially no effect on the releases.

Figure 14.5 shows a block diagram of the existing system.

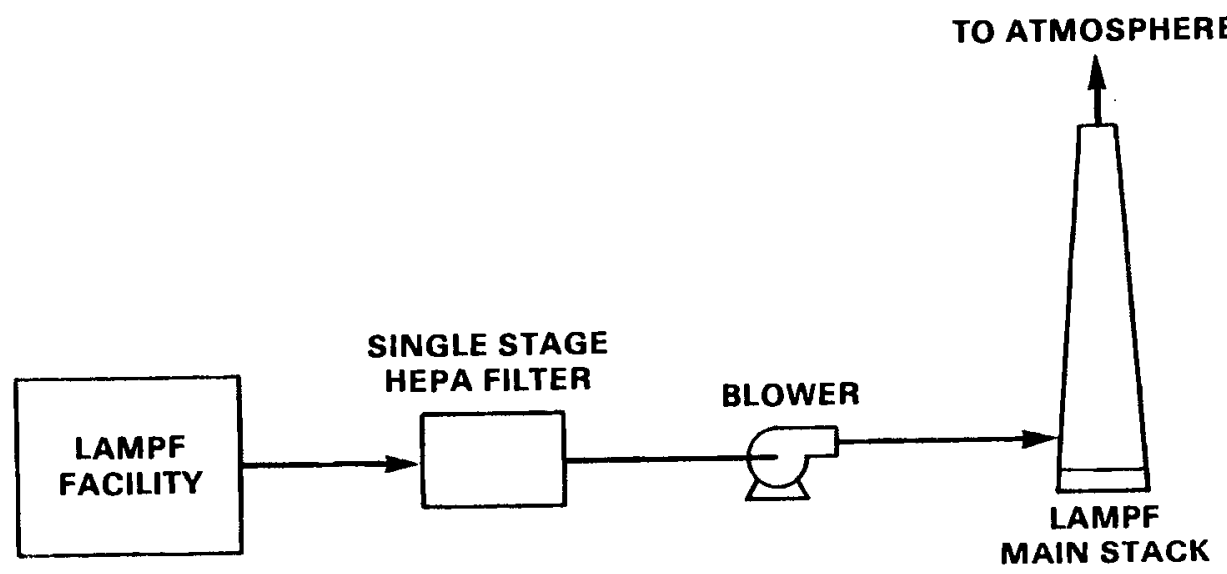

FIGURE 14.5. Block Diagram of the LAMPF Ventilation System

\subsubsection{Current Discharge Rates}

The release of air activation products from the LAMPF main stack has increased in recent years as programmatic activities and beam intensities have increased. Discharge rates from this stack for CY 1981 are shown in Table 14.8. The average concentrations of the radionuclides in the air 
TABLE 14.8. Atmospheric Emissions from the LAMPF Main Stack in CY 1981

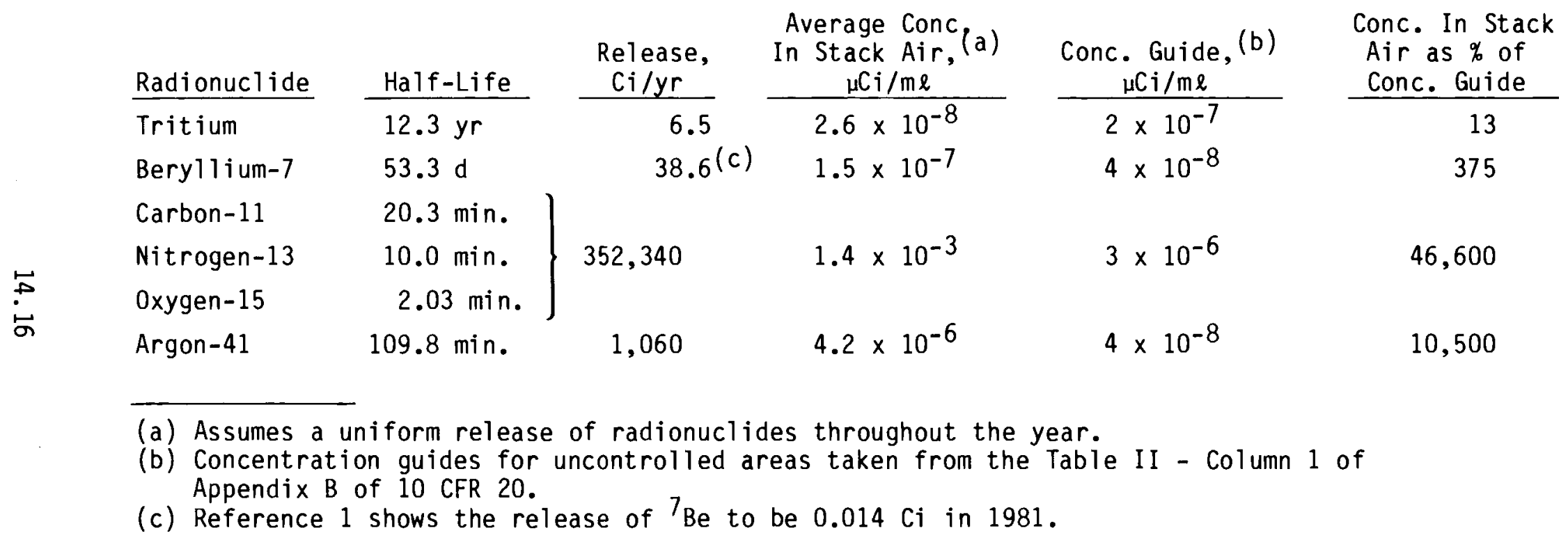


leaving the stack, assuming uniform release throughout the year, are also shown in Table 14.8. Except for tritium, the concentrations of the radionuclides in the air leaving the stack are much higher than the concentration guides for uncontrolled areas.

\subsubsection{Potential Additional Emission Control Technology}

A permanent committee was formed at LANL several years ago to review LAMPF operations. One objective of the committee is to evaluate potential methods for reducing releases of airborne radioactivity from LAMPF operations. One plan currently under consideration is to enclose one of the primary beam stop areas, which is a major producer of air activation products. The enclosed area would not be vented during accelerator operation. Venting would only be done after the accelerator shuts down and the short-lived radioisotopes have had a chance to decay. The overall effectiveness of the proposed modification for reducing airborne emissions from LAMPF has not been determined. If implemented construction of the enclosure will start within 2 years.

Initial release data for 1982 show that the release of airborne radionuclides from the LAMPF stack was decreased from about 353,000 Ci in 1981 to about $250,000 \mathrm{Ci}$ in 1982 . The reduction was accomplished by a series of facility modifications to correct water leaks, but without decreasing the beam intensity or overall operational activity levels at the facility.

The large air flow to the LAMPF main stack $\left(\sim 480 \mathrm{~m}^{3} / \mathrm{min}\right)$ makes it very difficult to utilize any existing technology to remove the gaseous activation products from the air stream. The most realistic approach would be to provide additional holdup time to allow some decay of the short half-lived radionuclides, as indicated above. Extremely large air storage volumes would be required to obtain significant reductions in the radionuclide releases. For example, if an atmospheric pressure air storage system having a storage volume of $9300 \mathrm{~m}^{3}$ (similar to the one discussed in Section 14.2.1.3) were applied to the air flowing to the LAMPF stack, the additional holdup time provided would 
be about 19.4 minutes. With this holdup time, the following reductions in radionuclide emissions would be obtained (assuming programmatic activities similar to CY 1981):

\begin{tabular}{|c|c|c|c|}
\hline Radionuclide & $\begin{array}{l}\text { Holdup } \\
\text { Time in } \\
\text { Half-Lives } \\
\end{array}$ & $\begin{array}{c}\text { Estimated } \\
\text { Decon. Factor } \\
\end{array}$ & $\begin{array}{c}\text { Estimated Release, } \\
\mathrm{C} i / \mathrm{yr}\end{array}$ \\
\hline Tritium & 0 & $\cong 1$ & 6.5 \\
\hline Beryllium-7 & 0.0018 & $\cong 1$ & 38.6 \\
\hline Carbon-11 & 0.95 & 1.94 & 65,600 \\
\hline Nitrogen-13 & 1.94 & 3.81 & 6,500 \\
\hline 0xygen- 15 & 9.56 & 753 & 270 \\
\hline Argon-41 & 0.177 & 1.13 & 940 \\
\hline
\end{tabular}

As a result, total emissions from the stack would be reduced from about $353,300 \mathrm{Ci} / \mathrm{yr}$ to about $73,300 \mathrm{Ci} / \mathrm{yr}$ at the same level of programmatic activities.

The air storage tank would be of carbon steel construction and located on a concrete pad adjacent to the LAMPF stack, assuming adequate space is available. A tank with a storage volume of $9300 \mathrm{~m}^{3}$ would be $30 \mathrm{~m}$ in diameter by about $13.2 \mathrm{~m}$ high. A block diagram of the system is shown in Figure 14.6.

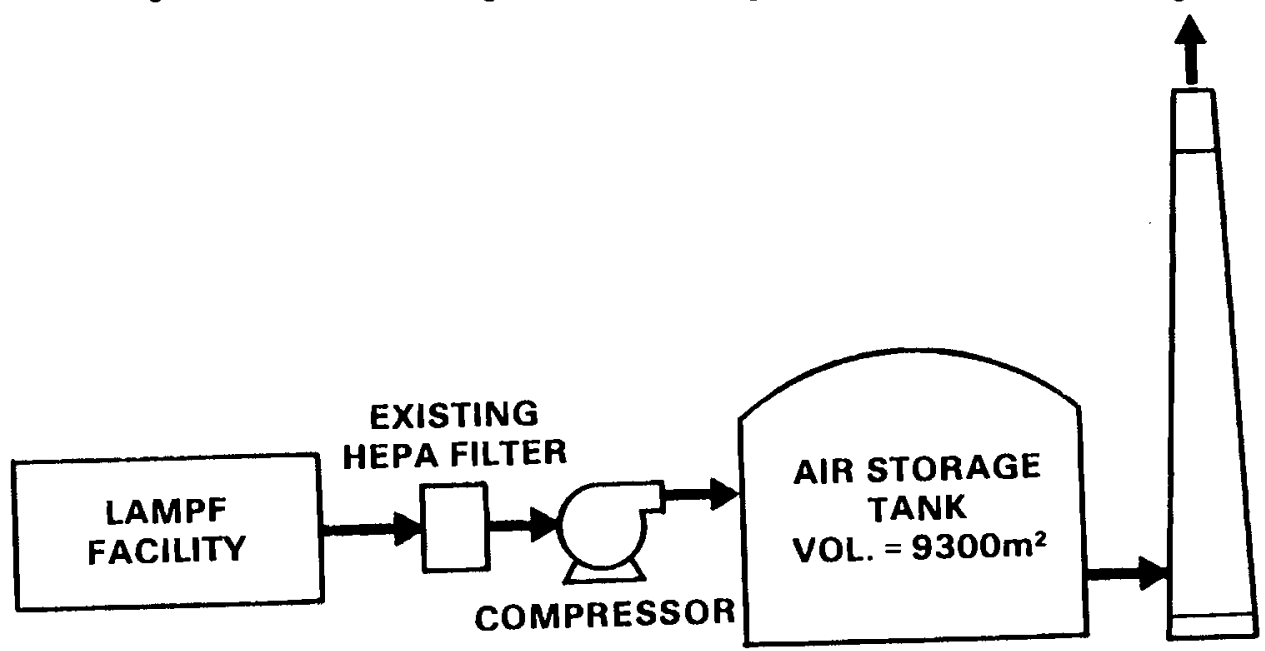

FIGURE 14.6. Block Diagram of an Air Storage System for the Air Flowing to the LAMPF Main Stack 
The estimated capital cost for an atmospheric pressure air storage system, with a storage volume of $9300 \mathrm{~m}^{3}$, would be about $\$ 4,300,000$. The cost would be slightly higher than the cost of a similar size system for the Omega West reactor (see Table 14.6) because a larger blower would be required to handle the air flow. The estimated operating costs would be about $\$ 90,000 / y r$. The capital cost of air storage systems of varying size would vary approximately as the eight-tenths power of the size ratio. Annual operating costs would be almost independent of the size ratio.

\subsubsection{Specific Source 3: Stack FE-6-HP Site}

The tritium handling facility is located at the HP site (TA-33). A wide variety of experimental programs involving the use of tritium is carried out at the facility. Large amounts of tritium are released to the atmosphere from the facility stack (FE-6). A single fan-exhaust system is used to ventilate the facility and feeds to the FE- 6 stack. More than $84 \%$ of the tritium discharged to the atmosphere at LANL is released from Stack FE-6.

The average air flow to the stack is about $200 \mathrm{~m}^{3} / \mathrm{min}$. The stack is $0.61 \mathrm{~m}$ in diameter and the height above ground level is about $23 \mathrm{~m}$.

The tritium handling facility is scheduled to be replaced in several years.

14.2.3.1 Description of Existing Emission Control Technology

Physical containment of the tritium during experimental activities is the principal method for controlling tritium emissions from the tritium handling facility stack. Adequate ventilation of work areas is provided to maintain the tritium concentration, due to leaks, below the concentration guide for controlled areas. A dryer system is used to remove tritiated water from the air flowing to the stack. A block diagram of the system is shown in Figure 14.7.

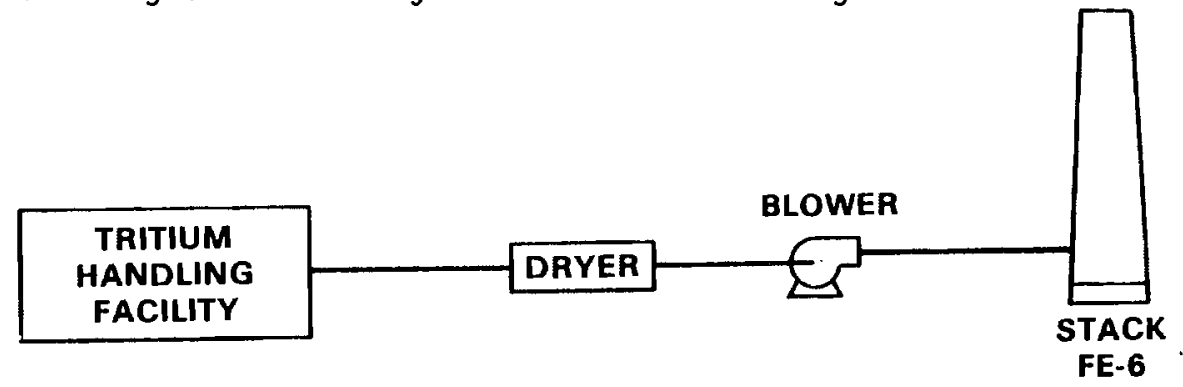

FIGURE 14.7. Block Diagram of Existing Emission Control Technology 14.19 


\subsubsection{Current Discharge Rate}

A total of $6085 \mathrm{Ci}$ of tritium was released to the atmosphere from stack FE-6 at the tritium handling facility in CY 1981. The chemical form of the tritium is unknown, but since any tritiated water should be removed by the dryer, the tritium is probably present as molecular hydrogen.

Assuming the tritium is uniformly released throughout the year, the average tritium concentration in the air leaving the stack is about $5.7 \times$ $10^{-5} \mu \mathrm{Ci} / \mathrm{m} \ell$. This is about 285 times the concentration guide for uncontrolled areas.

\subsubsection{Potential Additional Emission Control Technology}

The large volume of air flowing to Stack FE-6 and the very low concentration of tritium in the air make effective reduction of the tritium released from the stack both difficult and costly. In addition, the fact that the tritium handling facility is to be replaced in a few years makes it more difficult to justify large expenditures for additional emission control technology.

Assuming the tritium is present in the air stream primarily as molecular hydrogen, adequate removal of the tritium from the air would require its conversion to water. A drying step would then be required to remove the tritiated water from the air prior to discharge. Subsequent recovery of the tritiated water from the dryer and its final disposal would present additional problems. A risk analyses would have to be carried out to determine if disposal of the tritiated water would present less of a risk then release of the tritium, as molecular hydrogen, to the atmosphere.

If removal of tritium from the air flowing to Stack FE- 6 becomes necessary, a recovery system similar to the emergency tritium cleanup system (ETC) which is used at the Tritium Systems Test Assembly (TSTA) at LANL could probably be used. (2) The ETC system is designed to process air at the rate of about $39 \mathrm{~m}^{3} / \mathrm{min}$. Therefore, a similar system for Stack FE- 6 would have to be designed for air flow about five times as large $\left(200 \mathrm{~m}^{3} / \mathrm{min}\right)$. The ETC system 
was not intended for continuous operations, but only for emergency use. However, the system could probably be designed for continuous use.

A block diagram of a potential tritium recovery system based on the ETC concept is shown in Figure 14.8. First, dry air from the tritium handling facility containing about $0.022 \mathrm{ppb}{ }^{3} \mathrm{H}_{2}$ (by volume) would be adiabatically compressed to about 3.5 atmospheres and $175^{\circ} \mathrm{C}$. Hydrogen, diluted with an inert gas would be added to the compressed air to raise the hydrogen concentration to about $100 \mathrm{ppm}$. The air would then be sent to the recombiner where most of the hydrogen would be converted to water using a precious metal catalyst. The hydrogen concentration in the air would be reduced to about 1 $\mathrm{ppb}$. Air from the recombiner would flow to a shell and tube cooler which would reduce the air temperature to about $22^{\circ} \mathrm{C}$. The next step would be a refrigerated condenser designed to reduce the air temperature to about 2 to $3^{\circ} \mathrm{C}$. Some of the water in the air would condense. The condensed water would be collected in a tritiated water storage tank.

Air leaving the condenser would be heated to about 12 to $13^{\circ} \mathrm{C}$. A heat recovery unit on the refrigerated condenser would be used to reheat the air. The reheated air would flow to a first-stage molecular sieve dryer which would reduce the water content to about $1 \mathrm{ppm}$. The dryer would require at least two molecular sieve columns in parallel to permit regeneration of a column as needed. Steam would be added to the air leaving the first-stage dryer to raise the water content to about $100 \mathrm{ppm}$. The moist air would then flow to a second-stage molecular sieve dryer which would again reduce the water content of the air to about $1 \mathrm{ppm}$. Again, at least two molecular sieve columns in parallel would be needed to permit regeneration of a column as required. Air from the second-stage dryer would flow to the stack and be discharged to the atmosphere. Tritiated water collected from the regeneration of the molecular sieve drying columns would be collected in the tritiated water storage tank for subsequent waste disposal.

Regeneration of the molecular sieve drying columns would probably require heating the column to about $200^{\circ} \mathrm{C}$. Hot air would be used to heat the column and supply the heat of sorption required to remove the water from the 


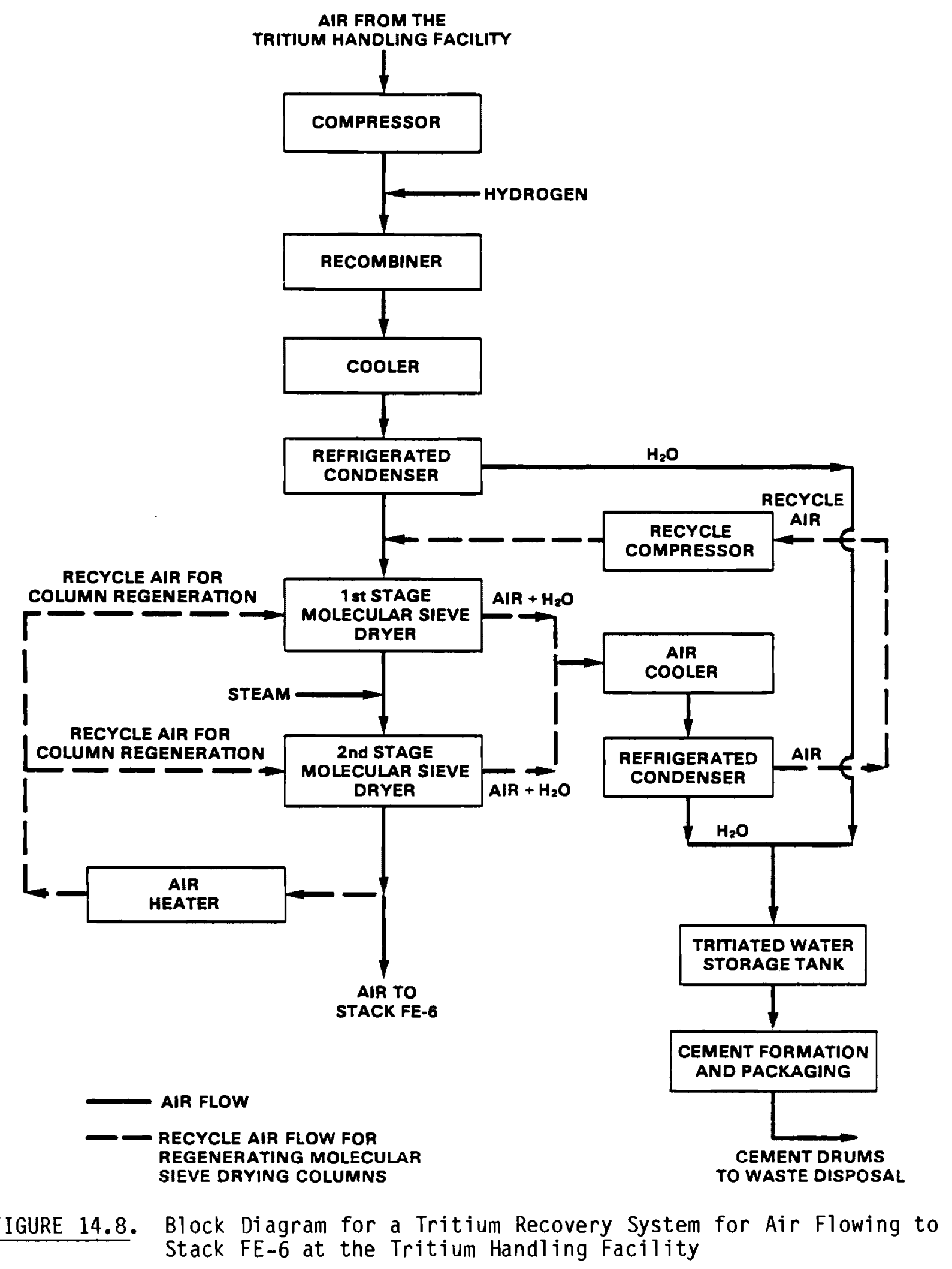


molecular sieves. A portion of the air leaving the second-stage dryer would be recycled for the column regeneration step. An electric heater would be used to reheat the recycled air for regeneration. The recycled air leaving the the molecular sieve column, containing the tritiated water, would flow to an air cooler and then to a refrigerated condenser where the bulk of the water would be condensed. The partially dried air leaving the condenser would be compressed and recycled back to the first-stage molecular sieve dryer. Water from the condenser would be collected in the tritiated water storage tank. As an alternative to regeneration, the molecular sieves could be replaced as needed and the spent molecular sieves, saturated with tritiated water, sent to waste disposal.

The tritium removal system described should be capable of providing a tritium DF of at least $10^{4}$. This would reduce the tritium released from Stack FE-6 to about $0.6 \mathrm{Ci} / \mathrm{yr}$. Most of the tritium released would be in the form of tritiated water.

A higher tritium DF could be achieved by increasing the hydrogen addition ahead of the recombiner and/or increasing the steam addition ahead of the second-stage dryer. This would decrease the cycle time for the two drying stages and increase the volume of tritiated water requiring disposal. Conversely, decreasing the hydrogen and/or steam additions would decrease the DF, lengthen the dryer cycle and decrease the volume of tritiated water requiring disposal. At a DF of $10^{4}$ it is estimated that each molecular sieve column could operate for about 30 days before requiring regeneration.

Even though the system proposed is similar to the ETC system used with the TSTA at LANL, additional development work would be required to demonstrate the feasibility of the system for continuous operation. Demonstrating the technical feasibility of regenerating the molecular sieve drying columns would be especially critical.

Because of the large-size equipment required, it is unlikely that space would be available in the tritium handling facility to house the equipment. Therefore, a structure would probably have to be provided to contain the 
tritium removal system. Table 14.9 provides a capital cost estimate for the facility, including a structure to house the equipment.

TABLE 14.9. Estimated Capital Cost for a Tritium Removal System, Including Waste Handling--in 1983 Dollars

\section{Item}

Major Equipment, Installed

Electrical

Instrumentation

Structure

Site Preparation

Subtotal - Direct Construction Costs

Indirect Construction Costs

Subtotal - Total Field Costs

Architect-Engineering Services

Subtotal

Contingency $(\sim 50 \%)$

Total Facility Cost
Cost (\$ thousands) 830

6,400

1,500

9,250

450

9,700

1,940

11,640

5,860

17,500

At a DF of $10^{4}$ approximately 17,000 liters of tritiated water $(\sim 0.36 \mathrm{Ci} / \ell)$ would be generated per year. There are several methods which could be used to dispose of the tritiated water. The best method would probably be to contain it in cement for subsequent burial. Typically, the cement containing the tritiated water would be triple-contained in a polyethylene inner drum, an asphalt-coated steel secondary drum, and a steel outer drum. With a 100-liter inner drum, each container would accommodate about 27 liters of tritiated water ( $10 \mathrm{Ci}$ of tritium). Approximately 630 drums of cement waste would be generated per year. The drums would have to be buried in an approved land burial facility which should be available at LANL. Adequate containment of the tritiated water would have to be provided during cement manufacture and packaging.

Assuming a tritium DF of $10^{4}$, the tritium removal system would require about $950 \mathrm{~kg} /$ year of hydrogen. The hydrogen could be supplied in gas bottles, 
or it could be produced onsite using an electrolytic hydrogen generator. The latter approach is preferred.

The estimated annual operating costs for the tritium removal facility, including waste disposal, are summarized in Table 14.10. The operating costs for the facility are high because of the need for continuous operation, utility requirements, and the costs associated with waste disposal.

TABLE 14.10. Estimated Operating Costs for a Tritium Removal System, Including Waste Disposal--in 1983 Dollars

\begin{tabular}{lcc}
\multicolumn{1}{c}{ Item } & $\begin{array}{c}\text { Cost } \\
\text { (\$thousands) }\end{array}$ \\
\hline Operators (6 man-yr/yr) & & 170 \\
Maintenance (2 man-yr/yr) & 400 \\
Utilities & 150 \\
Maintenance Materials & 300 \\
Supplies (drum, molecular sieves, H2, etc.) & 630 \\
Drum Burial & 380 \\
Overhead (100\% of labor) & 100 \\
Miscellaneous & 2,340 \\
Total Annual Costs &
\end{tabular}

\subsubsection{Specific Source 4: South Stack-Wing 3-CMR}

The Chemistry Metallurgy Research Building (CMR) located in TA-3 is a large multiwinged building in which a wide variety of research programs is carried out. Each wing of the facility is equipped with one or two stacks to handle the wing air flow. Small amounts of radionuclides are discharged to the atmosphere from most of the building stacks. Wing 3 houses a variety of analytical chemistry groups which provide services for the entire laboratory. Approximately $60 \%$ of the plutonium released to the atmosphere at LANL in CY 1981 was discharged from the south stack of Wing 3 of the facility. No other radionuclides were detected in the stack air flow in CY 1981. The air flow to the stack comes from a single fan and exhaust system 
(FE-19) serving a number of laboratories. The air flow to the stack is about $1400 \mathrm{~m}^{3} / \mathrm{min}$. The stack has a diameter of about one meter and the height above ground level is about 17 meters.

\subsubsection{Description of Existing Emission Control Technology}

The air flowing to the south stack of Wing 3 of the Chemistry Metallurgy Research Building is passed through a two-stage prefilter and a single-stage bag filter prior to discharge from the stack. It is estimated that 90 to $95 \%$ of the particulates are removed by the filter system. Figure 14.9 shows a block diagram of the filtration system.

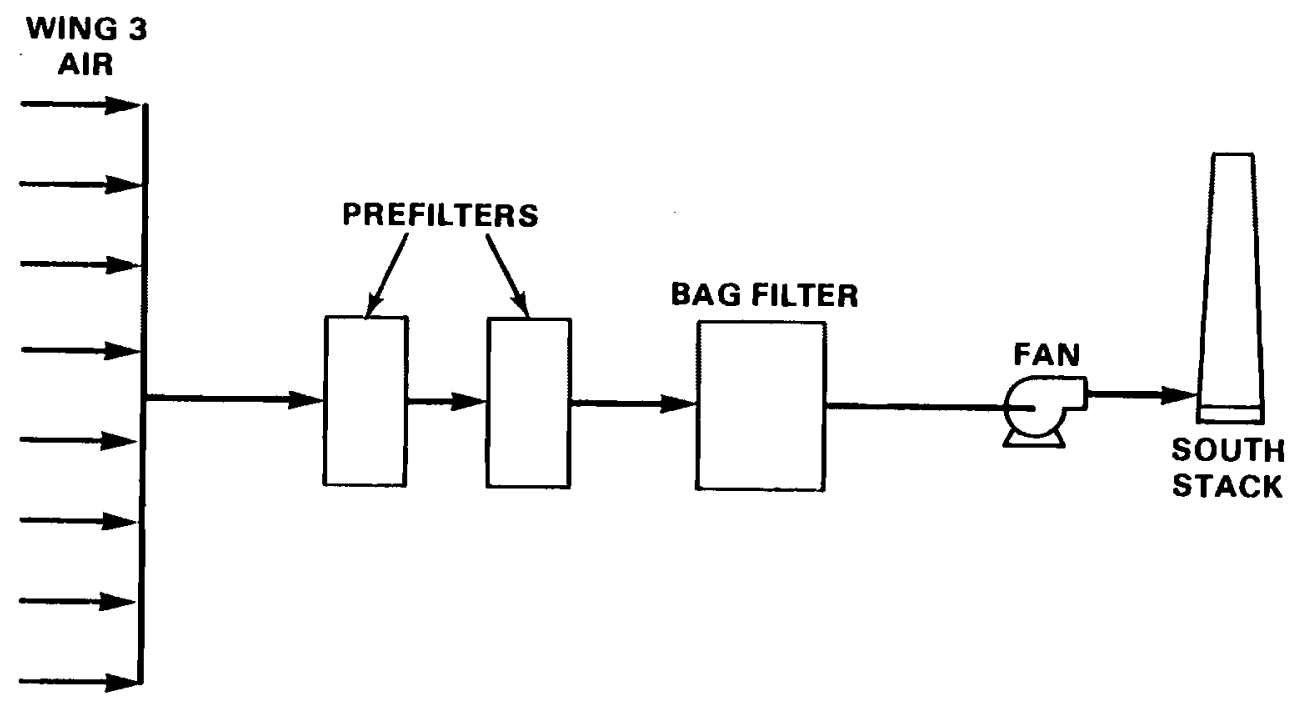

FIGURE 14.9. Block Diagram of the Filtration System For the South Stack Serving Wing 3 of the Chemistry Metallurgy Research Building

\subsubsection{Current Discharge Rate}

Approximately $3.3 \times 10^{-5} \mathrm{Ci}$ of plutonium were released to the atmosphere from the stack in question in CY 1981. The chemical form and isotopic composition of the plutonium discharged are unknown. Assuming the plutonium was dispersed uniformly throughout the year, the average plutonium concentration in the air leaving the south stack was about $4.4 \times 10^{-14} \mu \mathrm{Ci} / \mathrm{ml}$. This is about $73 \%$ of the concentration guide for uncontrolled areas.

Measurements obtained at eleven site perimeter monitoring stations showed that the mean atmospheric plutonium concentrations for $C Y 1981$ at the site 
boundary ranged from 8 to $24 \times 10^{-18} \mu \mathrm{Ci} / \mathrm{ml}$, with an overall average value of $13 \times 10^{-18} \mu \mathrm{Ci} / \mathrm{ml}$. (1) The overall average concentration amounts to only $0.02 \%$ of the concentration guide for plutonium in uncontrolled areas.

\subsubsection{Potential Additional Emission Control Technology}

The plutonium released from the stack in question, and its effect on the environment, are already very low, and it is difficult to consider installation of additional equipment to reduce the plutonium release. If additional reductions are necessary, however, they could be attained by installing a HEPA filter system in addition to or in place of the existing bag filter system. A bank of at least forty-eight $61 \mathrm{~cm} \times 61 \mathrm{~cm} \times 30 \mathrm{~cm}(24$ in. $x 24$ in. $x$ 12 in.) HEPA filters would be needed to handle the air flow. Installation of the HEPA filter system would provide at least a $99 \%$ reduction in the plutonium release from the stack to about $3.3 \times 10^{-7} \mathrm{Ci} / \mathrm{yr}$ or less.

A block diagram of the HEPA filter system is shown in Figure 14.10. The system would be composed of four modules, each rated at $465 \mathrm{~m}^{3} / \mathrm{min}$, with three modules in operation and one module on standby and/or undergoing maintenance. Each module would consist of 16 HEPA filters, two dampers and one 600 $\mathrm{m}^{3} / \mathrm{min}$ blower. It appears that sufficient space exists in the facility to install the HEPA filter system, even if the bag filter system is not removed.

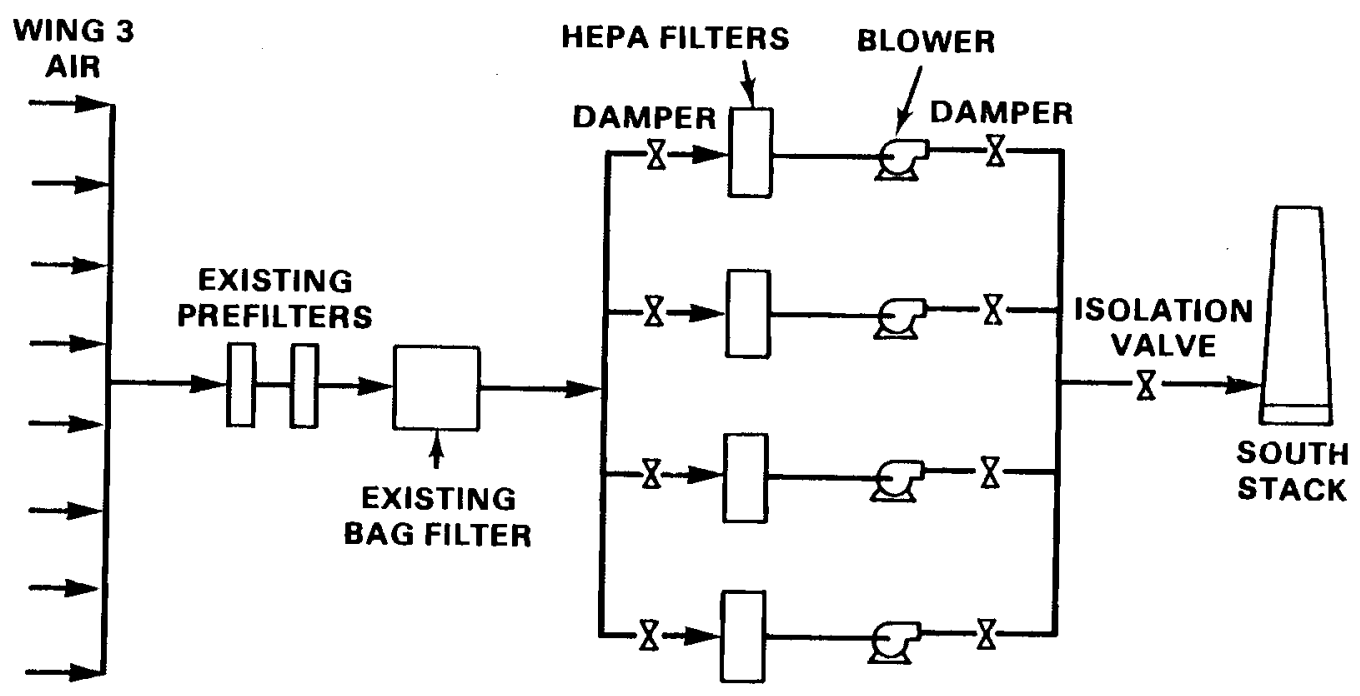

FIGURE 14.10. Block Diagram of a HEPA Filter System to Process the Air Flowing to the South Stack of Wing 3 of the Chemistry Metallurgy Research Laboratory 
The estimated capital cost for the HEPA filter system is given in Table 14.11. The estimated annual operating costs for the HEPA filter system are as follows, based on published cost data:(3)

$\begin{array}{ll}\text { Maintenance } & \$ 20,000 \\ \text { Electrical } & \$ 20,000 \\ \text { Testing } & \$ 10,000 \\ \text { Total } & \$ 50,000\end{array}$

TABLE 14.11. Capital Cost Estimate for HEPA Filter System for the Air Flowing to the South Stack of Wing 3 of the Chemistry Metallurgy Research Building--in 1983 Dollars

\begin{tabular}{lr}
\multicolumn{1}{c}{ Item } & Cost (\$) \\
\hline HEPA Filters - Installed (64) & 350,000 \\
Dampers - Installed (8) & 80,000 \\
Blowers - Installed (4) & 100,000 \\
Ductwork & \\
Electrical and Instrumentation & 70,000 \\
Subtotal, Direct Construction Costs & 785,000 \\
Indirect Construction Costs & 40,000 \\
$\quad$ Subtotal, Total Field Costs & 825,000 \\
Architect-Engineering Services ( 25\%) & 205,000 \\
Subtotal & $1,030,000$ \\
Contingency (35\%) & 360,000 \\
Other Costs & 60,000 \\
Total Project Cost & $\$ 1,450,000$
\end{tabular}

\subsubsection{Specific Source 5: Main Stack - Building 3-DP Site}

Building 3 at the DP site (TA-21) is a facility used for enriched uranium recovery operations. Small amounts of uranium are discharged to the atmosphere from several stacks used to ventilate the building. $235 \mathrm{U}$ released from the main stack of the building accounted for about $47 \%$ of the total uranium released to the atmosphere at LANL in $\mathrm{CY}$ 1981. The chemical form of the 
uranium released from the stack is unknown. No other radionuclides were detected in the air leaving the stack.

The main building stack serves to ventilate building work areas using a single fan-exhaust system (FE-1). Air flow to the stack is $480 \mathrm{~m}^{3} / \mathrm{min}$. The stack is about 1 meter in diameter, and the height of the stack is about 15 meters above ground leve1.

\subsubsection{Description of Existing Emission Control Technology}

There is no equipment in place to reduce emissions from the main stack of Building 3 except for local HEPA filters in gloveboxes.

\subsubsection{Current Discharge Rate}

Approximately $6.6 \times 10^{-4} \mathrm{Ci}$ of ${ }^{235} \mathrm{U}$ were released from the stack in question in CY 1981. Assuming the uranium was dispersed uniformly throughout the year, the average ${ }^{235} U$ concentration in the air exiting the stack was about $2.6 \times 10^{-12} \mu \mathrm{Ci} / \mathrm{ml}$. this amounts to about $65 \%$ of the concentration guide for $235 \mathrm{U}$ in uncontrolled areas.

\subsubsection{Potential Additional Emission Control Technology}

The amount of uranium released from the main stack of Building 3 is already very low and its effect on the environment is minimal. Therefore, it is unrealistic to consider the installation of additional equipment to reduce the emissions. If such reductions become necessary however, a filter system could probably be installed. A HEPA filter system would be preferred. A bank of at least eighteen $61 \mathrm{~cm} \times 61 \mathrm{~cm} \times 30 \mathrm{~cm}$ (24 in. $\times 24 \mathrm{in}$. $\times 12$ in.) HEPA filters would be required to handle the air flow to the stack.

Installation of a HEPA filter system would provide at least a $99.9 \%$ reduction in the uranium release from the stack. This would decrease the annual discharge of $235 \mathrm{U}$ from the stack to about $6.6 \times 10^{-7} \mathrm{Ci}$. Assuming that uranium is released uniformly throughout the year, the average concentration of uranium in the air exiting the stack would be reduced to about $2.6 \mathrm{x}$ $10^{-15} \mu \mathrm{Ci} / \mathrm{m} \ell$.

A block diagram of a HEPA filter system for the stack air is shown in Figure 14.11. The system would be comprised of three modules, each rated at 


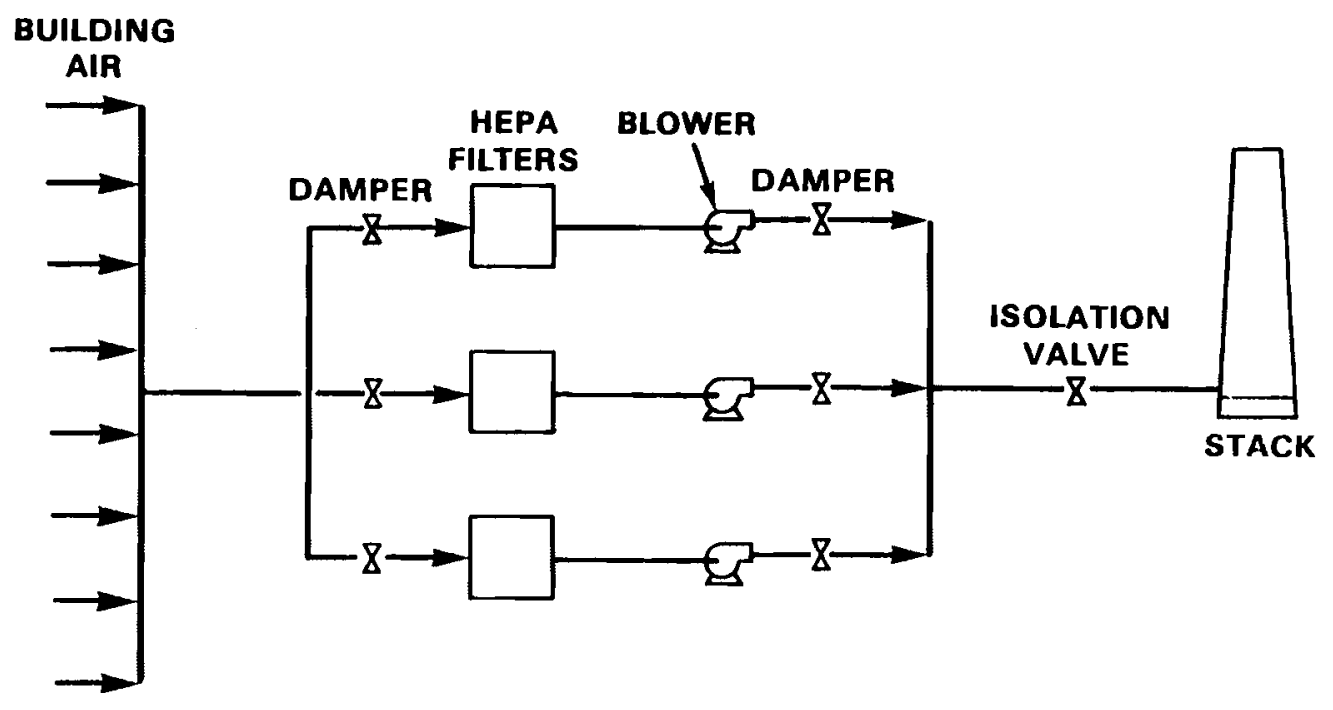

\section{FIGURE 14.11. Block Diagram of a HEPA Filter System to Treat Air Flowing to the Main Stack of Building 3 at the DP Site}

$250 \mathrm{~m}^{3} / \mathrm{min}$, with two modules in operation and one module in standby. Each module would consist of nine HEPA filters, two dampers and one $300 \mathrm{~m}^{3} / \mathrm{min}$ blower.

Availability of space for installing a HEPA filter system in the facility is not known. If adequate space does not exist, an auxillary structure would have to be provided to house the filter system. This would add substantially to the capital cost for the system. The estimated capital cost for a HEPA filter system to handle the stack air flow, exclusive of any costs associated with a structure to house the system, is $\$ 880,000$. The estimated annual operating cost for the system is $\$ 30,000$. The capital and operating costs were developed as shown in Section 14.2.4.3 after allowing for the differences in the size of the two filter systems.

\subsubsection{Specific Source 6: Core Wing Stack-Building RC-1-Radiochemistry Site}

The radiochemistry site in TA-48 is a facility used for a variety of programs involving radioactive materials. Laboratory hoods, glove boxes and "hot 
cells" are used to contain the radioactive materials. Small quantities of radioactive materials are released to the atmosphere from several stacks at the facility. About $46 \%$ of the mixed fission products (MFP) released to the atmosphere at LANL in CY 1981 were released from the Core Wing Stack, which is one of the stacks used to ventilate the radiochemistry facility. A very small amount of plutonium-239 was also released from the stack in CY 1981.

Two fan-exhaust systems (FE-45 and FE-46) discharge into the Core Wing Stack. A number of glove boxes are serviced by the two fan-exhaust systems. Total air flow to the stack is about $1400 \mathrm{~m}^{3} / \mathrm{min}$, with the air flow almost equally divided between the two fan-exhaust systems. The Core Wing stack has a diameter of about $1.5 \mathrm{~m}$ and a height of approximately $21.3 \mathrm{~m}$ above ground level.

\subsubsection{Description of Existing Emission Control Technology}

The glove boxes which discharge to the two fan-exhaust systems serving the Core Wing Stack are each provided with a single stage of HEPA filters. No other control technology is provided to reduce emissions from the Core Wing Stack. Figure 14.12 shows a block diagram of the existing control technology.

\subsubsection{Current Discharge Rates}

Approximately $6.4 \times 10^{-4} \mathrm{Ci}$ of MFPs were released to the atmosphere from the Core Wing Stack in Cy 1981. About $2.1 \times 10^{-8} \mathrm{Ci}$ of plutonium-239 were also released from the stack in CY 1981.

Assuming the MFPs were released uniformly throughout the year, the average MFP concentration in the air leaving the Core Wing Stack in CY 1981 was only about $8.8 \times 10^{-13} \mathrm{\mu Ci} / \mathrm{ml}$. This amounts to only about $3 \%$ of the concentration guide for uncontrolled areas, assuming the MFPs were all strontium-90. The average plutonium concentration in the air leaving the stack in $\mathrm{CY} 1981$ was about $2.9 \times 10^{-17} \mathrm{\mu Ci} / \mathrm{ml}$, which is about $0.05 \%$ of the concentration guide for uncontrolled areas. 


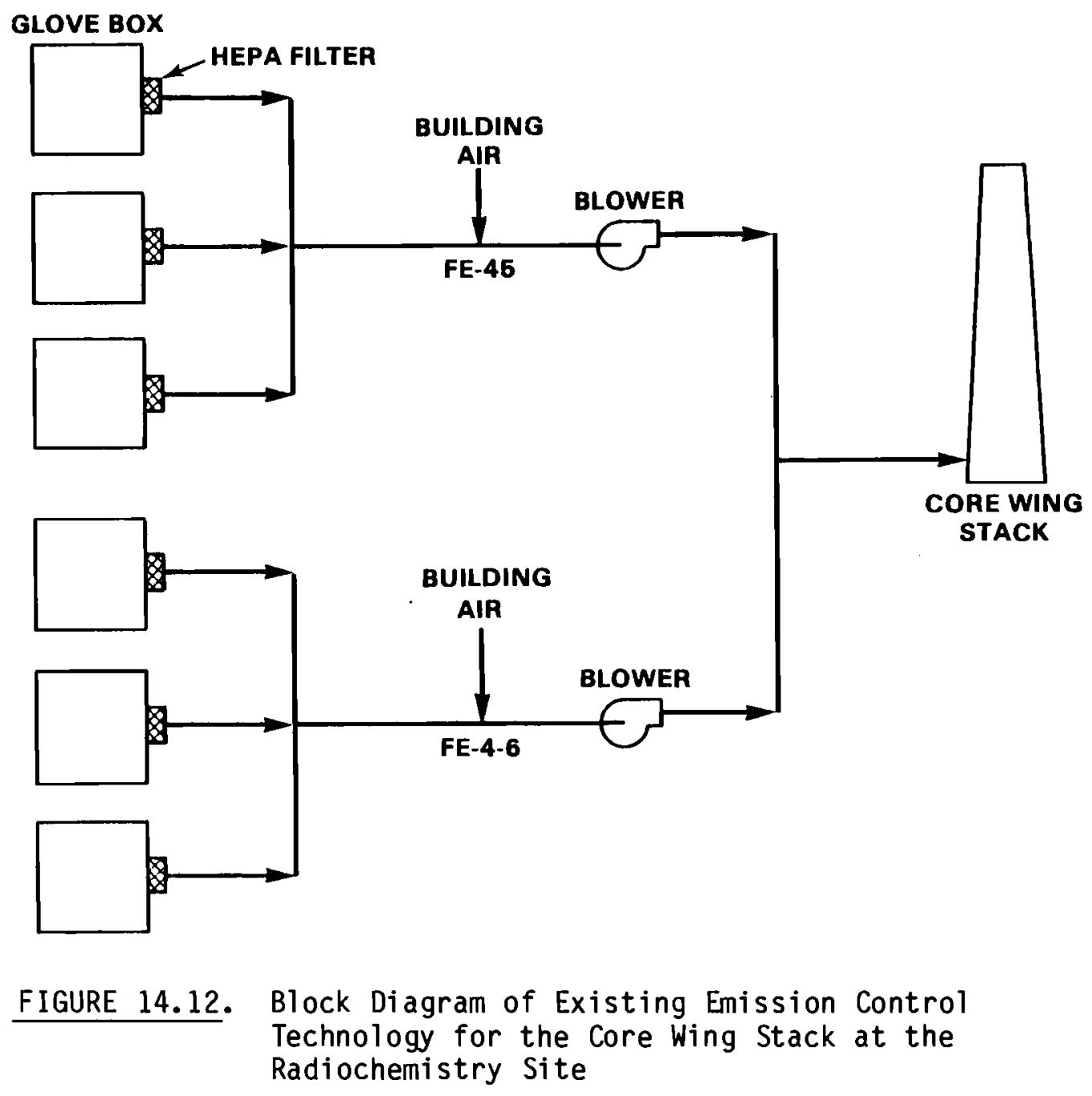

\subsubsection{Potential Additional Emission Control Technology}

Since the radionuclide content of the air leaving the Core Wing Stack is already far below the concentration guides for uncontrolled areas, it is unrealistic to consider the installation of additional equipment to reduce the emissions. If it should become necessary, however, to reduce the stack emissions a HEPA filter system could probably be installed to treat the air flowing to the stack. A single filter system to treat the combined air flow from the two fan-exhaust systems would be the preferred approach. It is not known 
if sufficient space exists in the facility to install the filter system, or if an additional structure would have to be provided to house the filter system. Installation of a HEPA filter system should reduce emissions from the Core Wing Stack by at least $99 \%$. Assuming the same level of facility activities as in CY 1981, this should reduce MFP releases from the Core Wing Stack to less than $6.4 \times 10^{-6} \mathrm{Ci} / \mathrm{yr}$. The plutonium released from the stack should be reduced to less than $2.1 \times 10^{-10} \mathrm{Ci} / \mathrm{yr}$.

Since the air flows to be treated are about the same, the HEPA filter system discussed in Section 14.2.4.3 could be used to filter the air flow to the Core Wing Stack with a minimum of modification. The filter system would be composed of four modules, each rated at $465 \mathrm{~m}^{3} / \mathrm{min}$. Three modules would be in operation, while one module would be in standby and/or undergoing maintenance. Each module would consist of 16 HEPA filters $(61 \mathrm{~cm} \times 61 \mathrm{~cm} \times$ $30 \mathrm{~cm}$ ), two dampers, and one $600 \mathrm{~m}^{3} / \mathrm{min}$ blower. Figure 14.13 shows a block diagram of the filter system.

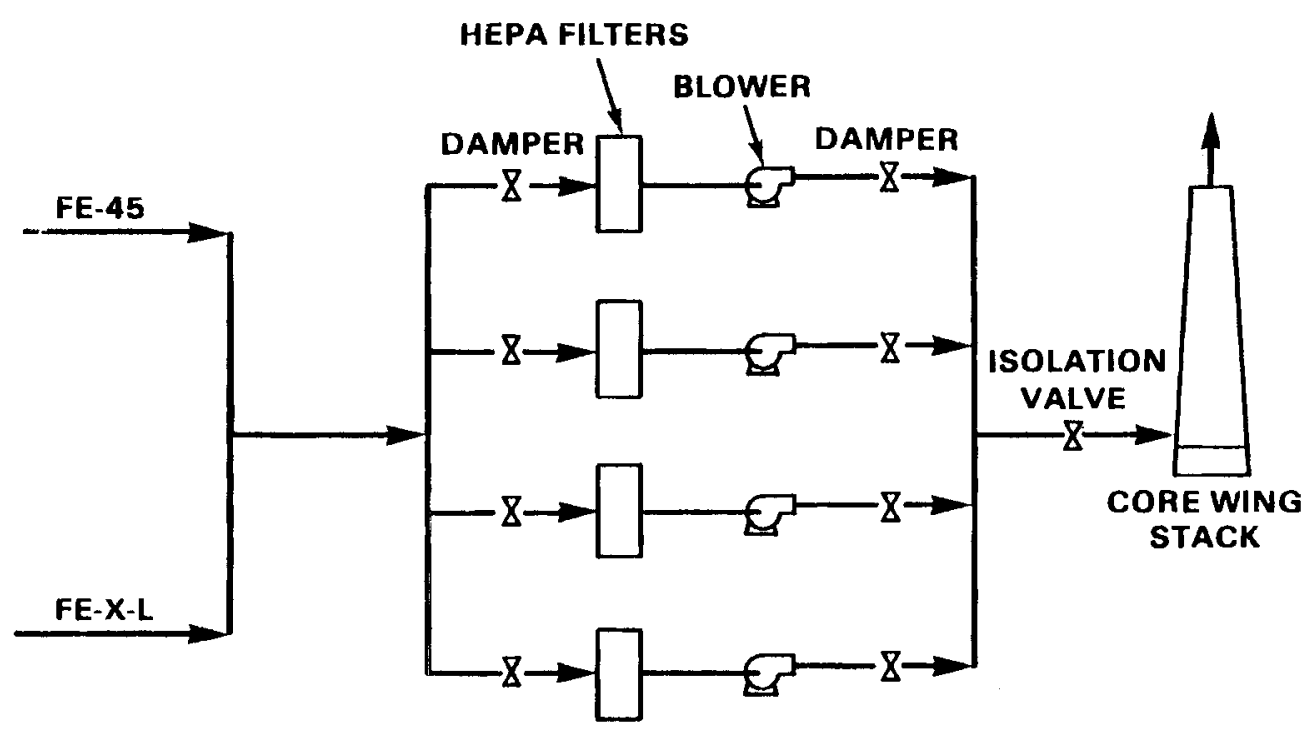

FIGURE 14.13. Block Diagram of a HEPA Filter System to Remove Plutonium from the Air Flowing to the Core Wing Stack at the Radiochemistry Site 
The estimated capital cost for the HEPA filter system, exclusive of any costs associated with providing a structure to house the system, in 1982 dollars, is approximately $\$ 1,450,000$ (see Table 14.11 for a breakdown of the capital costs). The estimated annual operating cost of the system is about $\$ 50,000$ (see Section 14.2.4.3 for a breakdown of the operating costs). The capital cost for the system would be increased substantially if an additional structure must be provided to house the filter system.

\subsubsection{Nonspecific or Minor Sources}

As mentioned previously, radionuclides were routinely released to the atmosphere from 77 of 86 potential discharge points in 1981. The six major discharge points are discussed in the previous sections. The remaining 71 discharge points contributed only a small fraction of the total offsite exposure. Of the 71 discharge points, tritium was released from six of the locations and radioactive particulates from 65 of the locations.

\subsubsection{Description of Existing Emission Control Technology}

In each location where radioactive particulates are released, the exhaust systems are equipped with suitable air filtration systems to remove the particles. Many of the systems have HEPA filters which remove at least $99.97 \%$ of the particulates from the air stream. (1) Ventilation exhausts from facilities such as glove boxes, which handle substantial quantities of plutonium and other transuranics, are provided with three or more stages of HEPA filtration. Gaseous tritium or tritiated water vapor from tritium handling facilities are controlled by containment and operating procedures to the extent that concentrations are below DOE concentration guides for breathing air. Recovery systems are employed to recycle the tritium where possible. An oxidizing microsieve tritium recovery system is also in use at some locations to reduce atmospheric tritium releases.

\subsubsection{Current Discharge Rates}

In 1981, the total tritium released from the six minor discharge points under consideration amounted to $1134 \mathrm{Ci}$. The radioactive particulates 
released to the atmosphere in 1981 from the 65 minor locations amounted to a total of about $1.5 \mathrm{millicuries,} \mathrm{with} \mathrm{the} \mathrm{largest} \mathrm{single} \mathrm{release} \mathrm{being} \mathrm{about}$ 0.4 millicuries of ${ }^{235} \mathrm{U}$.

\subsubsection{Potential Additional Emission Control Technology}

The releases of radioactive particulates from the discharge points under consideration are so low that no additional control technology to reduce the emissions appears to be justified.

Tritium releases from the six minor locations are significant when taken as a group. Additional control technology, similar to that discussed in Section 14.2.3, would have to be installed individually, and would probably not be cost effective on that basis, except possibly for the largest emitter. 


\section{REFERENCES}

1. Environmental Surveillance at Los Alamos During 1981, LA-9349-ENV, Los Alamos National Laboratory, Los Alamos, New Mexico, 1982.

2. Preliminary Safety Analysis Report for the Tritium Systems Test Assembly, Los Alamos Scientific Laboratory, Los Alamos, New Mexico, 1979.

3. L. Skoski, et a1. Airborne Radioactive Emission Control Technology Volume II, Dames and Moore, White Plains, New York. 


\subsection{OAK RIDGE}

This section contains information on the site and facilities at 0ak Ridge, including major sources of airborne radioactive emissions, other sources at the site, and emission control technology used to control the emissions.

\subsection{SITE AND MAJOR SOURCE DESCRIPTIONS}

Oak Ridge is a multipurpose complex that includes a research laboratory involved in basic and applied research; a nuclear weapons design, production, and fabrication area; a complex of production research, development and support facilities for the purpose of producing enriched uranium-235; and a number of other smaller facilities devoted to biological and chemical pursuits.

\subsubsection{Location of Site and Major Areas}

The 0ak Ridge Reservation is located in the west central portion of eastern Tennessee, as shown in Figure 15.1. The Reservation is located in a valley between the Cumberland and Great Smokey Mountains and consists of approximately 15,000 hectares of government-owned land. It is bounded on the northeast, southeast, and southwest by the $\mathrm{Cl}$ inch River and on the northwest by Black Oak Ridge. The surrounding area is rural with the largest population center, Knoxville, Tennessee, about 24 kilometers to the east.

The three major areas at the U.S. Department of Energy Reservation at Dak Ridge are the Oak Ridge National Laboratory (ORNL), the Oak Ridge Gaseous Diffusion Plant (ORGDP) and the $Y-12$ Plant. Each of these is located in a different portion of the reservation. ORNL is also known as the $X-10$ area and ORGDP is also known as the $k-25$ area.

A smaller research facility, the Comparative Animal Research Laboratory, operated by the Dak Ridge Associated Universities, is also located on the reservation. 


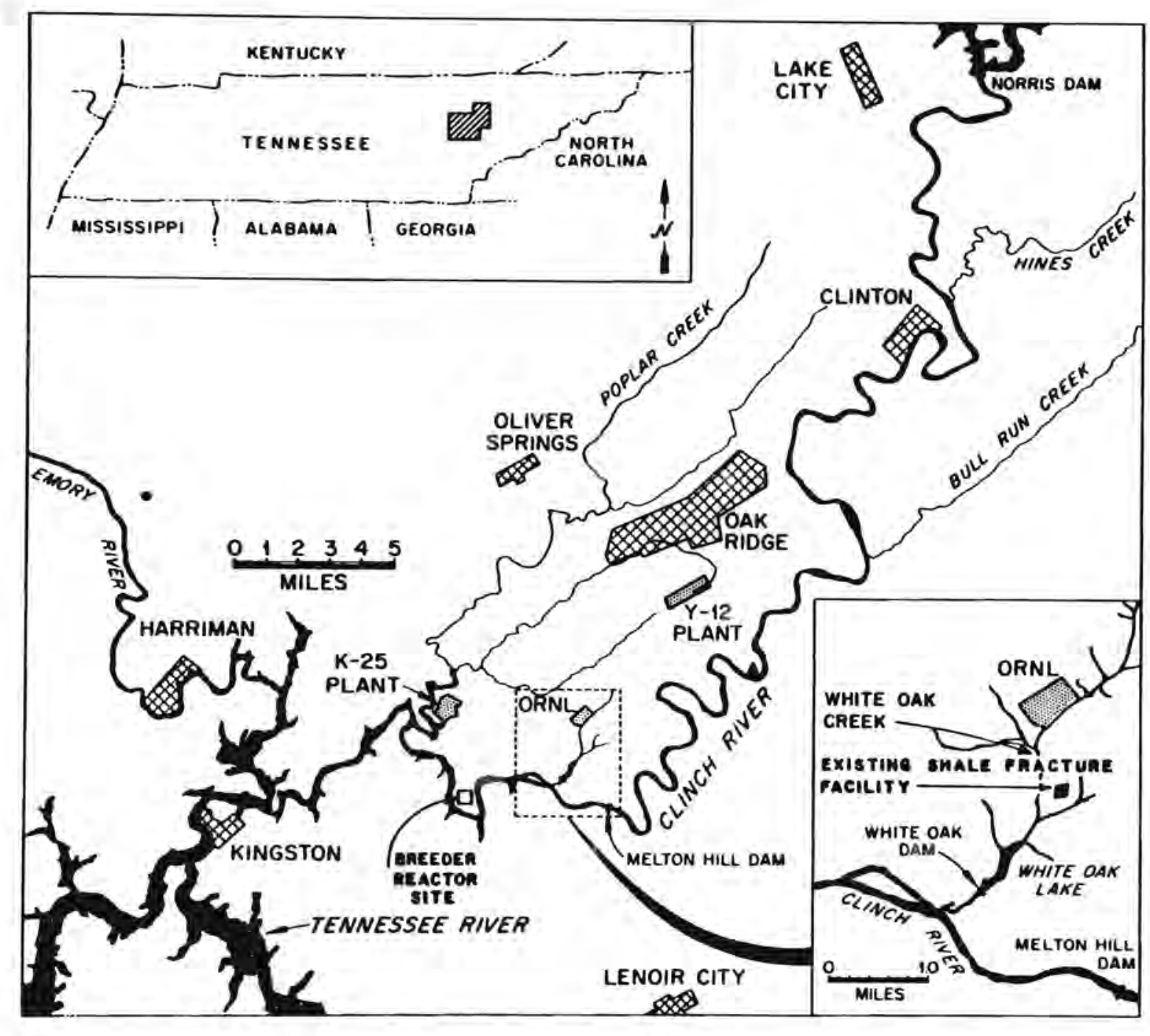

FIGURE 15.1. Location of Oak Ridge

\subsubsection{Identification and Location of Specific Sources}

The methodology used to select the major sources of airborne radioactive emission is discussed in Section 1.4 of this report. Those sources that 
represent $95 \%$ of the hypothetical risk from the site were selected for inclusion as major sources. Sources are identified in each of the major areas found at Oak Ridge.

\section{Oak Ridge National Laboratory}

The Oak Ridge National Laboratory contains nuclear energy research facilities consisting of nuclear reactors, chemical pilot plants, research laboratories, radioisotope production laboratories and support facilities. The location of the facilities on the site is shown in Figure 15.2.

The central radioactive gas disposal facilities release tritium, iodine131, and noble gases, Krypton and xenon are also released from radioisotope separations, reactor operations, and radioactive material handling operations in hot laboratories and chemistry laboratories.

The stack servicing the High Flux Isotope Reactor and the Transuranic Processing Plant releases fission product gases resulting from the chemical separation of curium and californium, and from reactor operations.

Isotope separations and chemistry laboratory operations are sources of effluents. Uranium and plutonium are present in airborne effluent from the electromagnetic isotope separations facility, although radiological operations in this facility have been shut down since 1979. There are 14 exhaust points from this facility.

A tritium target fabrication building releases small amounts of tritium from target preparation operations.

Oak Ridge Gaseous Diffusion Plant (ORGDP)

The ORGDP is located on a level 256-hectare tract of land near the junction of Poplar Creek and the CTinch River on the Oak Ridge Reservation in Roane County, Tennessee. The location of facilities on the site is shown in Figure 15.3. The only thoroughfares providing access to the plant site are Blair Road from the north and Tennessee Highway 58 from the northeast and southwest. 


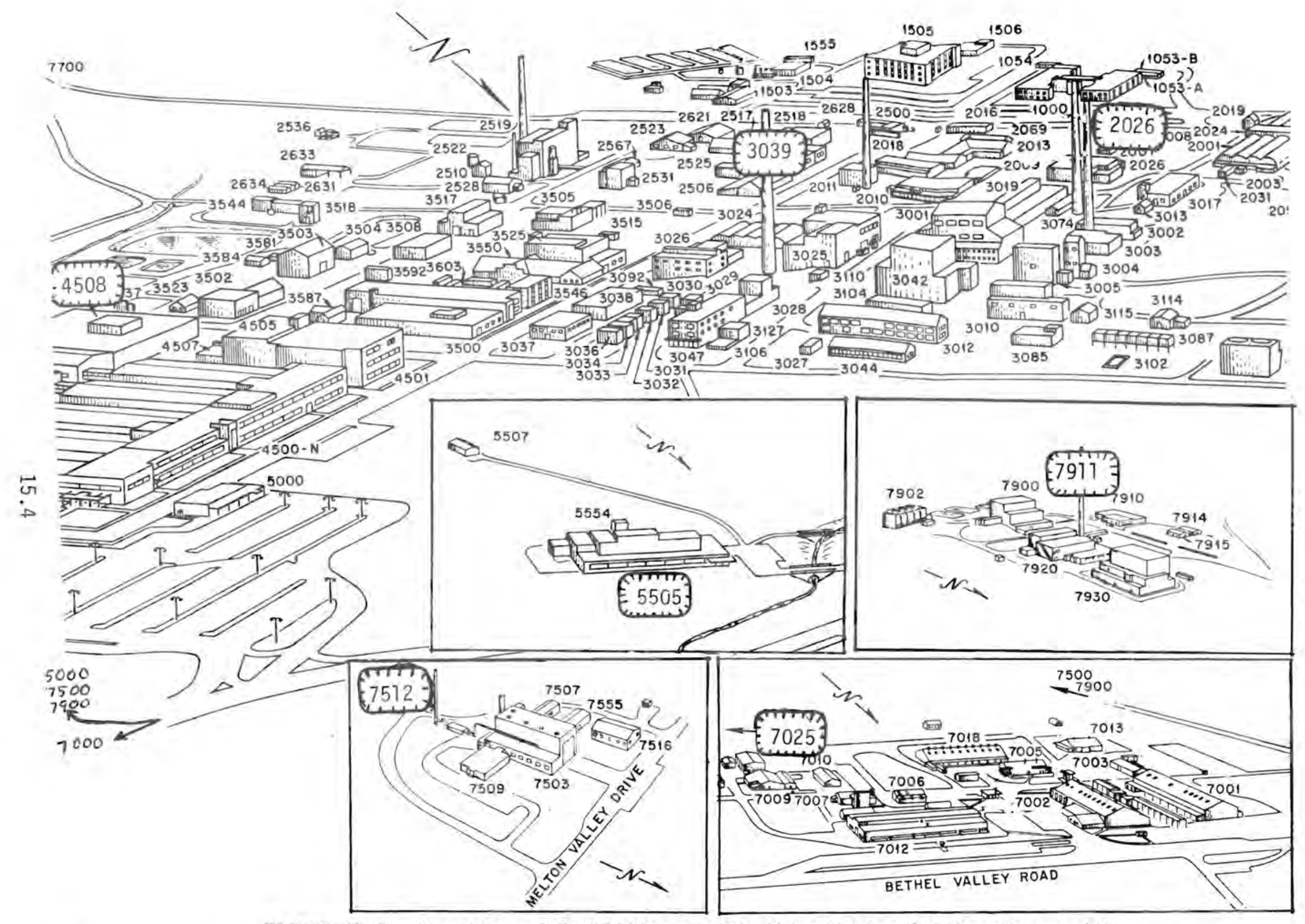

FIGURE 15.2. Location of Facilities at Oak Ridge National Laboratory, with Major Sources Hightighted 


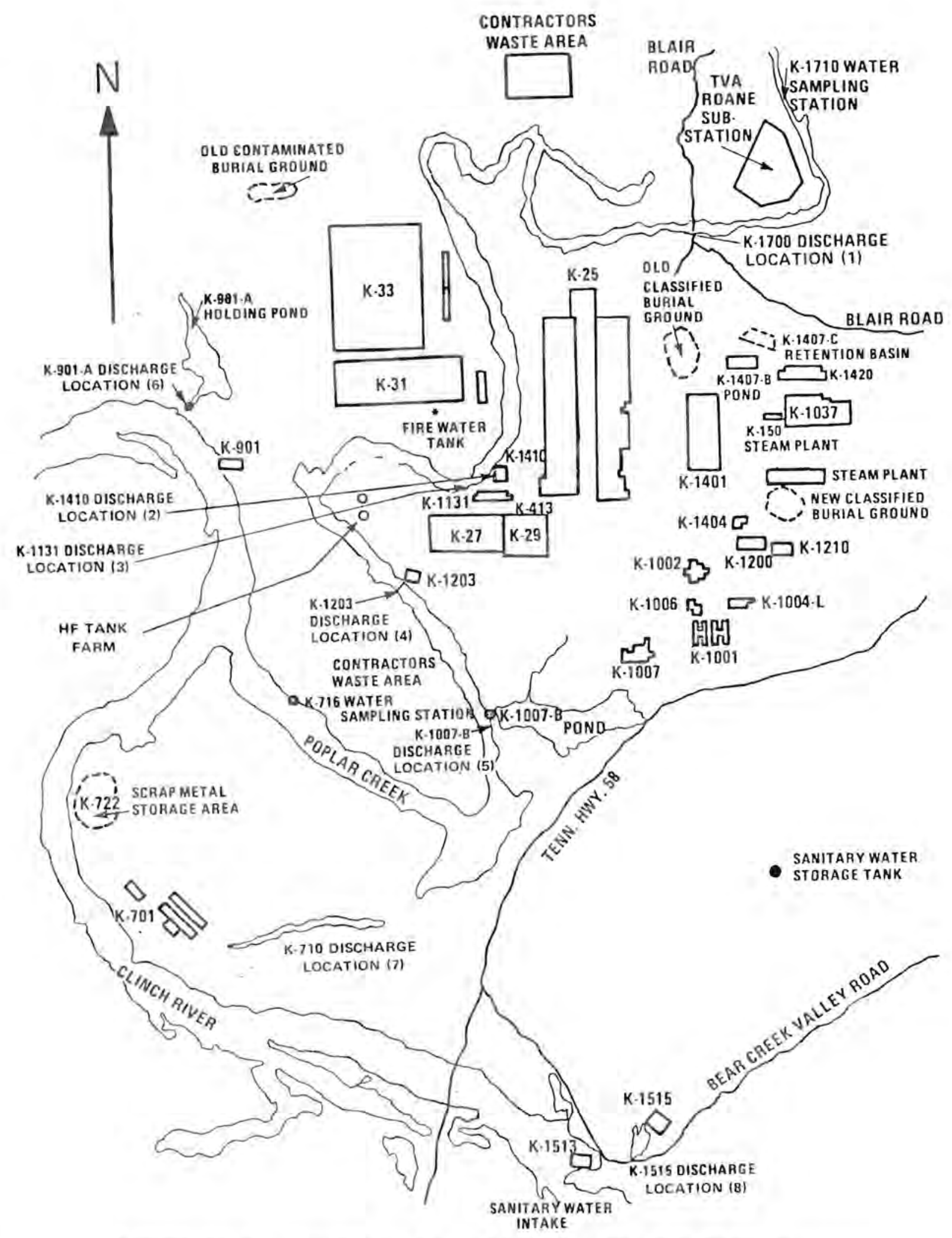

FIGURE 15.3. Location of Facilities at the Oak Ridge Gaseous Diffusion Plant 
The ORGDP is a complex of production, research, development and support facilities and has the primary function to enrich uranium hexafluoride (UF 6 ) in the uranium-235 isotope.

The five largest buildings are the diffusion-process facilities: K-25, $\mathrm{K}-27, \mathrm{~K}-29, \mathrm{~K}-31$, and $\mathrm{K}-33$. Most of the $\mathrm{K}-27$ building is in standby condition, with only a small section serving as a purge cascade for the diffusion process. The $\mathrm{K}-25$ building is used only as a warehouse and thus is not involved in the enrichment process. Other buildings house administration, data processing, and laboratory personnel and equipment; fabrication and maintenance facilities; utilities equipment; a fossil-fueled steam plant; supply stores; gas centrifuge and laser isotope separation development facilities; and various other support facilities. Large mechanical-draft cooling towers provide a means for dissipating waste heat from the gaseous diffusion process, and the vapor plumes are visible for a distance of several miles during the cooler months of the year.

Sources of airborne releases of radioactivity from the ORGDP include the decontamination facilities, the diffusion purge cascade, and the Centrifuge Plant Demonstration Facility (CPDF). Advanced isotope separation development facilities are planned for the future. If these facilities are constructed, they will constitute additional radioactive airborne emission sources.

\section{Y-12 Plant}

The Oak Ridge Y-12 Plant is located at the northeast corner of the Reservation (see Figure 15.4). It was built to perform four primary functions: 1) production of nuclear weapons components, 2) fabrication support for weapons design, 3) support for the Oak Ridge National Laboratory, and 4) support and assistance to other government agencies. The Y-12 Plant conducts activities which include production of lithium compounds, recovery of enriched uranium from scrap material and fabrication of uranium into finished parts and assemblies. Fabrication operations include vacuum casting, arc melting, powder compaction, rolling, forming, heat treating, machining, inspection, and testing. Many of these procedures release particulate activity into the room exhaust air. 


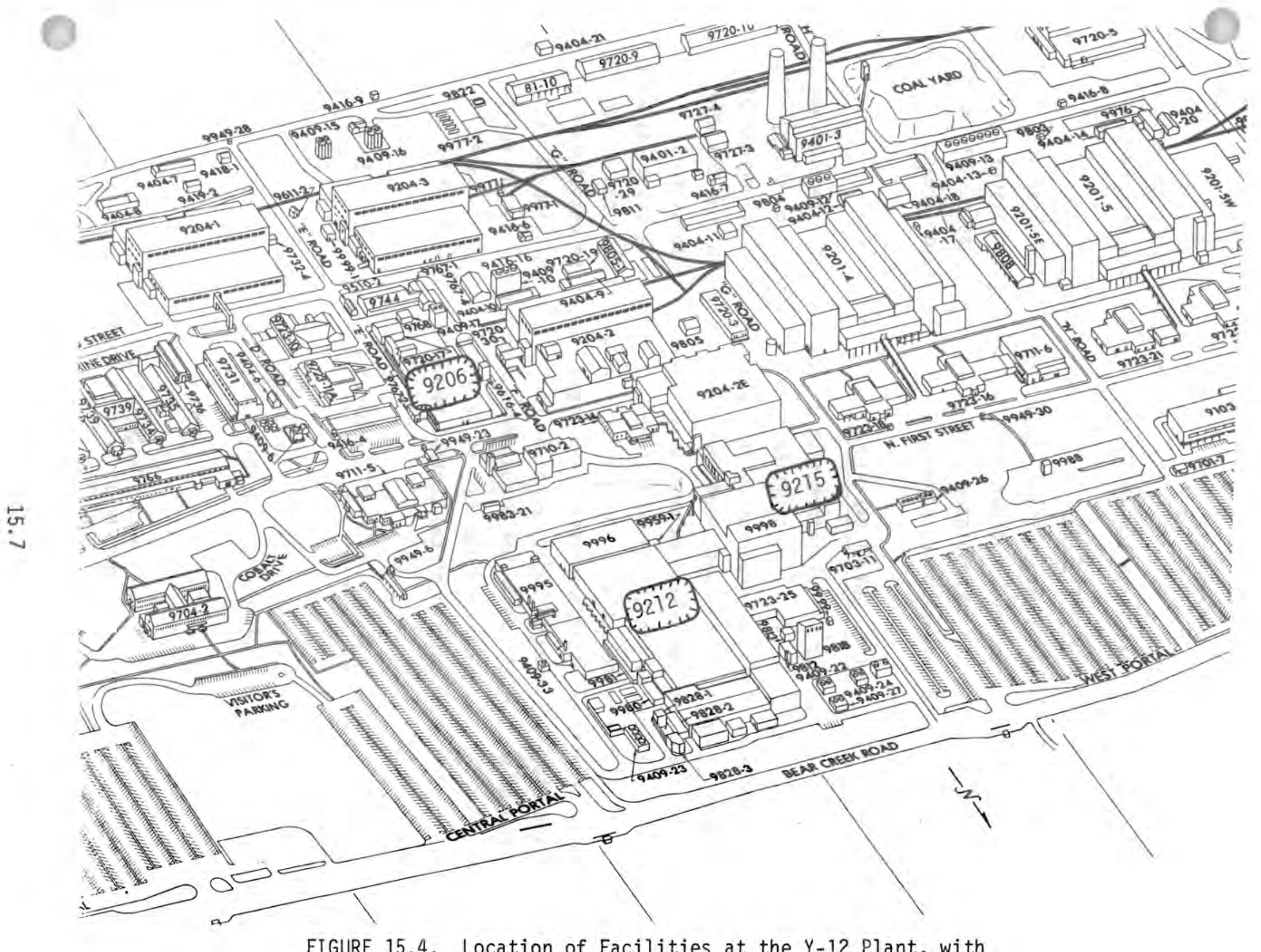

FIGURE 15.4. Location of Facilities at the $Y-12$ Plant, with Major Sources Highlighted 


\subsubsection{Non-Specific and Minor Sources}

There are a number of minor sources of radioactive emissions at each of the three major areas at Oak Ridge and at Oak Ridge Associated Universities.

Oak Ridge Associated Universities

The Oak Ridge Associated Universities conduct research in areas such as biological chemistry, immunology, nuclear medicine, and radiochemistry. Radionuclides are handled in encapsulated or liquid form and gaseous effluents are relatively small in comparison to sources in the three major areas.

\subsection{EMISSION CONTROL TECHNOLOGY AT OAK RIDGE}

A considerable portion of the information presented in this section was obtained from the Oak Ridge Operations Office of the Department of Energy. (a) At the present time, plans are underway by the DOE for Y-12 Plant upgrade of emission control devices at the West Head House exhaust system, the C-1 Wing ventilation system, and the C-Wing exhaust stack system. These systems include the major sources identified in this report at the Y-12 Plant, as well as other systems that interact with these major sources and that can be conveniently incorporated into a comprehensive upgrade plan. The emission control technology utilized to reduce airborne radioactive emission at facilities located at each of the major 0ak Ridge areas is presented in the following sections. The control technology used at major sources is discussed first, followed by a discussion of the control technology used at other, minor sources.

\subsubsection{ORNL, Specific Source 1: Central Radioactive Gas Disposal}

Facility (CRGDF)

Gaseous emissions from the central disposal facility emanate from the 3039 source stack. There are three internal sources of radioactive exhaust

(a) Dr. J. F. Wing, Chief Environmental Protection Branch, Safety and Environmental Control Division, Department of Energy, Oak Ridge Operations, P.0. Box E, Dak Ridge, Tennessee 37830 
gas, each with its own emission control technology (ECT) system that contributes effluents to the stack. Information pertinent to these sources is presented in the following subsections.

\subsubsection{Description of Existing Emission Control Technology}

There are three ECT systems at this facility. They include: 1) roughing filter, HEPA filter, charcoal filter bed followed by another HEPA filter; 2) roughing filter, wet scrubber, HEPA filter followed by a final HEPA filter; and 3 ) roughing filter followed by two HEPA filters in series. The stack that serves these systems is $61 \mathrm{~m}$ high, $2.44 \mathrm{~m}$ in diameter. Air is exhausted through the stack at the rate of $63.7 \mathrm{~m}^{3} / \mathrm{sec}$.

\subsubsection{Current Discharge Rate}

During $1981,2.47 \times 10^{4} \mathrm{Ci}$ of xenon-133, $5.05 \times 10^{3} \mathrm{Ci}$ of krypton-85, $9.77 \times 10^{3} \mathrm{Ci}$ of tritium and less than $1.2 \times 10^{-1} \mathrm{Ci}$ of iodine-131 were released from the facility. This source represents about $71 \%$ of the hypothetical airborne risk from effluents at Oak Ridge, based upon the annual output expressed in MPC's for radioactive species identified in the exhaust (Section 1.4).

\subsubsection{Potential Additional Emission Control Technology}

The major portion of the radiological hazard from the gas disposal facility is due to the emission of xenon-133 and tritium. Practical control technology exists for removal of these materials from low flow rate air streams only. Because of the high rate of emission $\left(64 \mathrm{~m}^{3} / \mathrm{sec}\right)$ from the stack of this facility, additional control technology must be implemented before the individual source stream is diluted with ventilation air or other gas streams.

A considerable portion of the tritium emissions is in the form of tritiated water. (1) This portion can be removed by passing the source stream through a dryer containing molecular sieve materials for water removal and then regenerating the adsorber material with heat. A pair of such driers, operated alternately, will provide for the continuous removal of tritiated water from the source. 
Xenon gas can be removed from gas streams by adsorption as the gas passes through a cooled $\left(-80^{\circ} \mathrm{C}\right)$ bed of charcoal. A demonstration of this technology in plant operations was conducted at the Idaho Chemical Reprocessing Plant for recovery of both xenon and krypton. Once the gas has passed through the charcoal bed, the xenon is desorbed by heating and the recovered gas is stored for 60 days to allow for xenon decay. A pair of such beds, operated alternately, will provide for the continuous removal of xenon from the source. Depending upon the flow rate and the rate of bed changeover, this method may remove over $80 \%$ of the xenon-133 and a portion (20\%) of the krypton-85 also present in the emissions. The krypton and xenon gases may be further purified by processing in existing facilities at 0ak Ridge.

Although impregnated charcoal traps ( $K I$ and TEDA) are installed to remove iodine-131, small amounts of this material are found in the emissions from the facility. Since such traps are known to remove essentially all iodine gas present, other organic species of iodine may be escaping and contributing to the emissions. Improvement in the removal capability of charcoal for these organic species is possible by using additional depths of impregnated charcoal (including the use of alkyl TEDA) in the adsorbers and slowing the flow through the adsorber beds as much as possible. The cost for such a modification is not addressed in this report.

\subsubsection{Anticipated New Discharge Rate}

Based upon the discussions in Section 15.2.1.3 concerning the possible additional ECT that could be implemented, Table 15.1 presents the anticipated new discharge rates for the radioisotopes presently contributing to the environmental emissions from the central radioactive gas disposal facility.

TABLE 15.1. Anticipated New Discharge Rates for Radioactivity at CRGDF

\begin{tabular}{ccccc} 
Radioisotope & $\begin{array}{c}\text { Present Discharge } \\
\text { Rate }(\mathrm{Ci} / \mathrm{yr})\end{array}$ & $\begin{array}{c}\text { Postulated ECT } \\
\text { Removal Efficiency }\end{array}$ & $\begin{array}{c}\text { New Discharge } \\
\text { Rate (Ci/yr) }\end{array}$ \\
\cline { 2 - 2 }${ }^{3} \mathrm{H}$ & $9.77 \times 10^{3}$ & & $90 \%$ & $9.77 \times 10^{2}$ \\
$133_{\mathrm{Xe}}$ & $2.47 \times 10^{4}$ & & $80 \%$ & $4.94 \times 10^{3}$ \\
$85 \mathrm{Kr}$ & $5.05 \times 10^{3}$ & $20 \%$ & $4.04 \times 10^{3}$ \\
$131_{\mathrm{I}}$ & $<1.2 \times 10^{-1}$ & $90 \%$ & $<1.2 \times 10^{-2}$
\end{tabular}




\subsubsection{Estimated Cost of Additional Emission Control Technology}

At this time it is not practical to remove xenon and krypton gas from the large gaseous flow stream $\left(63.7 \mathrm{~m}^{3} / \mathrm{sec}\right)$ emanating from the CRGDF. It is postulated, however, that the actual source of these emissions can be isolated upstream (before mixing with the general air ventilation system) where the flow rates are considerably smaller. The cost of a facility that would remove xenon and reduce krypton from a source stream whose flow rate is about $0.1-0.2 \mathrm{~m}^{3} / \mathrm{sec}$ is $\$ 7.6 \mathrm{million}$ (1983 dollars). This includes $\$ 4.4 \mathrm{million}$ for construction, $\$ 1.1 \mathrm{million}$ for engineering, and a $\$ 2.1 \mathrm{million}$ contingency. This facility would provide for short-term storage of the collected gas to allow xenon-133 decay and recovery of the krypton and inert xenon in the existing gas purification facility at Oak Ridge.

Recently, more specific information concerning this facility has become available from the DOE office at Oak Ridge. The source of the xenon and krypton gas emissions was found to originate from two source streams, each with an estimated flow rate of $0.25 \mathrm{~m}^{3} / \mathrm{sec}$. Larger costs can be expected for equipment to control flow rates larger than those postulated in this study.

The cost of an emission control system for the removal of tritiated water is estimated at $\$ 1.66$ million. This includes $\$ 1$ million for construction, $\$ 0.2$ million for engineering, and a $\$ 0.46 \mathrm{million}$ contingency.

These cost estimates are highly dependent upon the ease of incorporating the potential controls into the existing gas handling system. It is possible that the existing gas handling system would have to be completely replaced to accommodate more controls.

The cost for removal of iodine species that are not trapped by the existing ECT is not addressed in this report.

\subsubsection{ORNL Specific Source 2: High Flux Isotope Reactor (HFIR) and TRU} Processing Plant

Gaseous emissions from the processing plant emanate from the 7911 source stack. Information pertinent to this facility is discussed in the following subsections. 


\subsubsection{Description of Existing Emission Control Technology}

There is a roughing filter and a HEPA filter followed by a charcoal filter bed installed in the air exhaust system for control of airborne radioactivity at this facility. The stack that serves this facility is $76 \mathrm{~m}$ high and $1.5 \mathrm{~m}$ in diameter. The air control system vents $15.1 \mathrm{~m}^{3} / \mathrm{sec}$ from the stack exhaust.

\subsubsection{Current Discharge Rate}

During $1981,7.71 \times 10^{3} \mathrm{Ci}$ of xenon-133, $1.58 \times 10^{3} \mathrm{Ci}$ of krypton-85 and about $1.2 \times 10^{-1} \mathrm{Ci}$ of iodine-131 were released from this facility. This source represents about $11 \%$ of the hypothetical risk from airborne effluents at 0ak Ridge, based upon the annual output expressed in MPC's for radioactive species identified in the exhaust (Section 1.4).

\subsubsection{Potential Additional Emission Control Technology}

The major portion of the radiological hazard from this facility is due to the emission of xenon-133. The available control technology for this material as well as for krypton-85 and iodine-131 was discussed in Section 15.2.1.3. To be cost effective, application of additional emission control technology must be directed at the originating process stream rather than at the facility stack. This will minimize the quantity of gas that must be treated by the emission control system. In this study, it was postulated that typical flow rates of $0.1 \mathrm{~m}^{3} / \mathrm{sec}$ could be anticipated from dissolver process streams.

\subsubsection{Anticipated New Discharge Rate}

Based upon the discussions in Section 15.2.1.3 concerning the possible additional ECT that could be implemented and the postulated ECT removal efficiency presented in Table 15.1, the following reduced discharge rates are estimated: xenon-133, $1.54 \times 10^{3} \mathrm{Ci} / \mathrm{yr}$; krypton-85, $5.42 \times 10^{2} \mathrm{Ci} / \mathrm{yr}$; iodine$131,<1.2 \times 10^{-2} \mathrm{Ci} / \mathrm{yr}$.

\subsubsection{Estimated Cost of Additional Emission Control Technology}

Based upon the arguments presented in Section 15.2.1.5, the cost of a facility which would continuously remove xenon and reduce krypton from a 
source stream postulated to flow at about 0.05 to $0.1 \mathrm{~m}^{3} / \mathrm{sec}$ is $\$ 4.64 \mathrm{million}$ (1983 dollars). This includes $\$ 2.5$ million for construction, $\$ 0.88$ million for engineering and a $\$ 1.26$ million contingency. The xenon and krypton gases would be recovered as described in Section 15.2.1.3.

Recently, information concerning the size of the source stream has become available from the DOE office at Oak Ridge. Two sources of xenon and krypton gas emissions were identified as potential sources for additional pollutant controls. These included a stream whose flow rate was about $0.5 \mathrm{~m}^{3} / \mathrm{sec}$ and one at $0.35 \mathrm{~m}^{3} / \mathrm{sec}$. Since these flow rates are larger than those postulated in this study, higher costs than those estimated in this section can be anticipated for implementing added emission control to these systems.

The cost for removal of iodine species that are not trapped by the existing ECT is not addressed in this report.

15.2.3 ORNL, Specific Source 3: Tritium Target Fabrication Building

Gaseous emissions from the tritium target fabrication building exit through the 7025 source stack. Information pertinent to this facility is presented in the following subsections.

\subsubsection{Description of Existing Emission Control Technology}

There are no emission control devices installed at this facility except a small elevated stack. It is $3.7 \mathrm{~m} \mathrm{high}$ and $0.5 \mathrm{~m}$ in diameter. The ventilation control system vents $15.1 \mathrm{~m}^{3} / \mathrm{sec}$ of air from the stack exhaust.

\subsubsection{Current Discharge Rate}

During $1981,1.51 \times 10^{3} \mathrm{Ci}$ of tritium were released from this facility. This source represents about $3.5 \%$ of the hypothetical risk from airborne effluents at Oak Ridge, based upon the annual output expressed in MPC's for radioactive species identified in the exhaust (Section 1.4).

\subsubsection{Potential Additional Emission Control Technology}

Tritiated water can be removed from the gaseous exhaust by passing the exhaust air stream through a dryer containing molecular sieve materials for 
water removal and then regenerating the adsorber material by the application of heat. A pair of such driers, operated alternately, will provide for the continuous drying of the exhaust and the collection of tritiated water for storage or further processing.

Analytical information concerning the gases present in the stack exhaust indicates that only about $1 \%$ of the tritium is in the form of tritiated water. At this time it is not practical to remove tritium in the form of hydrogen gas from the large gaseous stream flow emanating from the Tritium Target Fabrication Building.

\subsubsection{Anticipated New Discharge Rate}

It is postulated that over $90 \%$ of the tritiated water would be collected by the application of the additional technology; however, since the tritiated water represents only a small portion of the total tritium from this facility, no significant reduction in the present emissions $\left(1.5 \times 10^{3} \mathrm{Ci} / \mathrm{yr}\right)$ will occur.

\subsubsection{Estimated Cost of Additional Emission Control Technology}

The cost of an emission control system specifically designed for the removal of tritiated water is estimated at $\$ 1.66 \mathrm{million}$. This includes $\$ 1$ million for construction, $\$ 0.2$ million for engineering and a $\$ 0.46$ million contingency.

\subsubsection{Y-12 Plant: Specific Source 4: Uranium Product Recovery}

There are three sources of emission from uranium product recovery. The major source is the West Head House, Building 9212. Information pertinent to this facility is presented in the following subsections.

\subsubsection{Description of Existing Emission Control Technology}

There are roughing filters, prefilters and HEPA filters installed for particulate control at this facility. The stack that serves this facility is $20 \mathrm{~m} \mathrm{high}$ and $0.91 \mathrm{~m} \times 1.22 \mathrm{~m}$ in cross-section. The air control system vents $8.6 \mathrm{~m}^{3} / \mathrm{sec}$ from the stack exhaust. 


\subsubsection{Current Discharge Rate}

During $1981,3.7 \times 10^{-2} \mathrm{Ci}$ of uranium-234 were released from this facility. This source represents about $4.3 \%$ of the hypothetical risk from airborne effluents at Oak Ridge, based upon the annual output expressed in MPC's for radioactive species identified in the exhaust (Section 1.4).

\subsubsection{Potential Additional Emission Control Technology}

Installation of an additional stage of HEPA filters would serve to reduce the amount of particulate emission and uranium-234 that bypasses the present ECT system, if the present ductwork can be adapted or expanded to allow incorporation of more HEPA filters downstream of the existing filter system.

\subsubsection{Anticipated New Discharge Rate}

HEPA filters are estimated to remove at least $99.95 \%$ of particulate materials in a single pass. It has been shown, however, that uncollected materials have a lower collection efficiency when passed through a second HEPA filter stage. Collection efficiency estimates for such a second stage may vary due to the size distribution of the original particulates. It is postulated that a second HEPA filter installed in series will remove $99 \%$ of the remaining particulates and reduce the amount of uranium-234 from $3.7 \times$ $10^{-2} \mathrm{Ci} / \mathrm{yr}$ to $3.7 \times 10^{-4} \mathrm{Ci} / \mathrm{yr}$.

\subsubsection{Estimated Cost of Additional Emission Control Technology}

The cost of the control devices presently installed in the uranium product recovery facility is $\$ 55,000$. The estimated additional cost for installation of backup HEPA filtration within the existing system is an additional $\$ 20,000$. The present annual operating cost is $\$ 14,640$. Based upon the assumption that the air capacity of the system can be maintained by the existing fan system, additional power and HEPA changeout requirements will increase the operating cost about $20 \%$.

If significant structural additions or modifications are necessary in order to properly operate and maintain the expanded air control system, then significant cost increases can be anticipated. In addition to the HEPA filter cost, modifications that include ductwork, blowers, dampers, instrumentation 
and electrical work will increase the cost to about $\$ 455,000$. Engineering costs of about $\$ 115,000$ and a $35 \%$ contingency will raise the total project cost to over $\$ 800,000$. Major structural additions will further increase the cost. Operating costs are expected to double with the implementation of this modified system.

15.2.5. Y-12 Plant: Specific Source 5: Uranium Product Preparation

There are three sources of emission from the uranium product preparation. The major source described in the following subsections is from the $\mathrm{C}-1$ wing of Building 9212.

\subsubsection{Description of Existing Emission Control Technology}

There are roughing filters, prefilters, HEPA filters and a wet scrubber installed for control of particulates at this facility. The stack that serves this facility is $16 \mathrm{~m} \mathrm{high}$ and $0.11 \mathrm{~m}$ in diameter. The air control system vents $1.7 \mathrm{~m}^{3} / \mathrm{sec}$ from the stack exhaust.

15.2.5.2 Current Discharge Rate

During $1981,2.98 \times 10^{-2} \mathrm{Ci}$ of uranium-234 were released from this facility. This source represents about $3.5 \%$ of the hypothetical risk from airborne effluents at Oak Ridge, based upon the annual output expressed in MPC's for radioactive species identified in the exhaust (Section 1.4).

\subsubsection{Potential Additional Emission Control Technology}

Replacement of the existing scrubber with a high-energy venturi scrubber and adding a backup stage of HEPA filtration would reduce the emission of uranium-234 from this facility, if the present ductwork can be modified or expanded to allow incorporation of these changes.

\subsubsection{Anticipated New Discharge Rate}

Based upon the arguments presented in Section 15.2.4.4, about 99\% of the particulate emission will be removed by the addition of a second HEPA filter stage. In addition, the use of a high-energy venturi scrubber will provide a $20 \%$ improvement in the collection efficiency of the scrubber system and will provide higher efficiency (98-99\%) for removal of particulates below 
1 micron.(a) It is postulated that by implementation of the additional ECT the emission of uranium-234 will be reduced from $2.98 \times 10^{-2} \mathrm{Ci} / \mathrm{yr}$ to less than $2.38 \times 10^{-4} \mathrm{Ci} / \mathrm{yr}$.

\subsubsection{Estimated Cost of Additional Emission Control Technology}

The cost of the control devices presently installed in the uranium product preparations $\mathrm{C}-1$ wing building is $\$ 46,300$. The estimated additional cost for adding a high-efficiency scrubber, including demisters, is $\$ 15,000$ ( $\$ 11,000$ capital plus $\$ 4,000$ installation). The estimated additional cost for backup HEPA filtration is $\$ 9,000$. These estimates are based upon the assumption that the existing fan system is capable of maintaining the necessary pressures and flows with the added ECT.

The present annual operating cost is $\$ 6,880$ and is expected to increase $30 \%$ due to the power necessary to maintain high differential pressures in the venturi and provide flow through both HEPA filters.

If significant structural additions or modifications and other equipment such as special nitric acid scrubbers are necessary to properly operate and maintain the expanded air control system, then significant cost increases can be anticipated. In addition to the HEPA filter cost, modifications that include ductwork, blowers, dampers, instrumentation and electrical work will increase the cost to about $\$ 200,000$. Engineering costs of about $\$ 80,000$ and a $35 \%$ contingency will raise the total project cost to about $\$ 400,000$. Major structural additions will further increase the cost. Operating costs are expected to double with the implementation of this modified system. 15.2.6 Y-12 Plant: Specific Source 6: Uranium Fuel Element Fabrication

The fabrication process is located in the C-wing of Building 9212. Information pertinent to this facility is discussed in the following subsections.

(a) Sly Manufacturing Co., Catalog 401A, 21945 Drake Road, Strongsville, Ohio. 


\subsubsection{Description of Existing Emission Control Technology}

Only roughing filters are installed at this facility. The stack that serves this facility is $21 \mathrm{~m} \mathrm{high}$ and $1.37 \mathrm{~m}$ in diameter. The air control system vents $23.6 \mathrm{~m}^{3} / \mathrm{sec}$ from the stack exhaust.

\subsubsection{Current Discharge Rates}

During $1981,1.73 \times 10^{-2} \mathrm{Ci}$ of uranium-234 were released from this facility. This source represents about $2.0 \%$ of the hypothetical risk from airborne effluents at Oak Ridge, based upon the annual output expressed in MPC's for radioactive species identified in the exhaust (Section 1.4).

\subsubsection{Potential Additional Emission Control Technology}

Installation of HEPA filters would significantly reduce the amount of particulate uranium-234 emitted from the uranium fuel element fabrication facility, if the present ventilation system can be modified or expanded to allow installation of HEPA filters downstream of the roughing filters.

\subsubsection{Anticipated New Discharge Rate}

HEPA filters collect almost $100 \%$ of the airborne particulate materials from airstreams containing typical size distributions of suspended materials. It is estimated that $99.95 \%$ of the materials which pass the roughing filters will be removed by a single pass through HEPA filtration. Based upon this assumption, the annual emission of uranium-234 will be reduced from 1.73 $\times 10^{-2} \mathrm{Ci}$ to less than $8.7 \times 10^{-6} \mathrm{Ci}$ by the installation of HEPA filters.

\subsubsection{Estimated Cost of Additional Emission Control Technology}

The uranium fuel element fabrication facility is served by a large ventilation system which exhausts air at the rate of $23.6 \mathrm{~m}^{3} / \mathrm{sec}$. A similar sized system which includes the addition of HEPA filters is installed at the Y-12 plant, uranium denitrator. The difference in cost between these facilities is $\$ 41,400$ and is postulated as the cost to add HEPA filters to the fabrication facility. This is based upon the assumption that the air capacity 
of the system. can be maintained by the existing fan system. The cost of additional power requirements and the cost of HEPA filter replacement will double operating costs to about $\$ 50,000 / \mathrm{yr}$.

If significant structural additions or modifications such as air coolers are necessary in order to properly operate and maintain the expanded air control system, then significant cost increases can be anticipated. In addition to the HEPA filter cost, modifications that include ductwork, blowers, dampers, instrumentation and electrical work will increase the costs to about $\$ 825,000$. Engineering costs of about $\$ 200,000$ and a $35 \%$ contingency will raise the total project cost to $\$ 1,450,000$. Major structural additions will further increase the cost. Operating costs are expected to double with the implementation of this modified system.

15.2.7 Oak Ridge Gaseous Diffusion Plant: Specific Source 7: Purge Cascade

The Purge Cascade is a part of the Oak Ridge Gaseous Diffusion Plant K-27 process area, identified in Figure 15.5. All diffusion plant process buidings are three story, steel frame with $6 \mathrm{~mm}$ transite side panels (preformed concrete).

The Purge Cascade is intended to separate light gases from UF 6 and vent them to the atmosphere through the emission control devices. Emissions from this building represent the largest hypothetical risk (Section 1.4) from the Oak Ridge Gaseous Diffusion Plant. For this reason, the Purge Cascade is presented in the following subsections; however, the E-wing Lab, E-wing east exhaust in the $Y-12$ area (discussed in Section 15.2.8.1) represents a slightly higher individual hypothetical risk.

\subsubsection{Description of Existing Emission Control Technology}

The primary source of airborne radioactive emissions from the ORGDP is the K-402-9 purge cascade. The airborne effluent from this facility is passed through sodium fluoride traps, alumina traps, and a potassium hydroxide scrubber, illustrated in Figure 15.5, prior to being discharged to the atmosphere. The stack that serves this facility is $23 \mathrm{~m}$ high and $0.3 \mathrm{~m}$ in diameter. The air control system vents $0.22 \mathrm{~m}^{3} / \mathrm{sec}$ from the stack exhaust. 


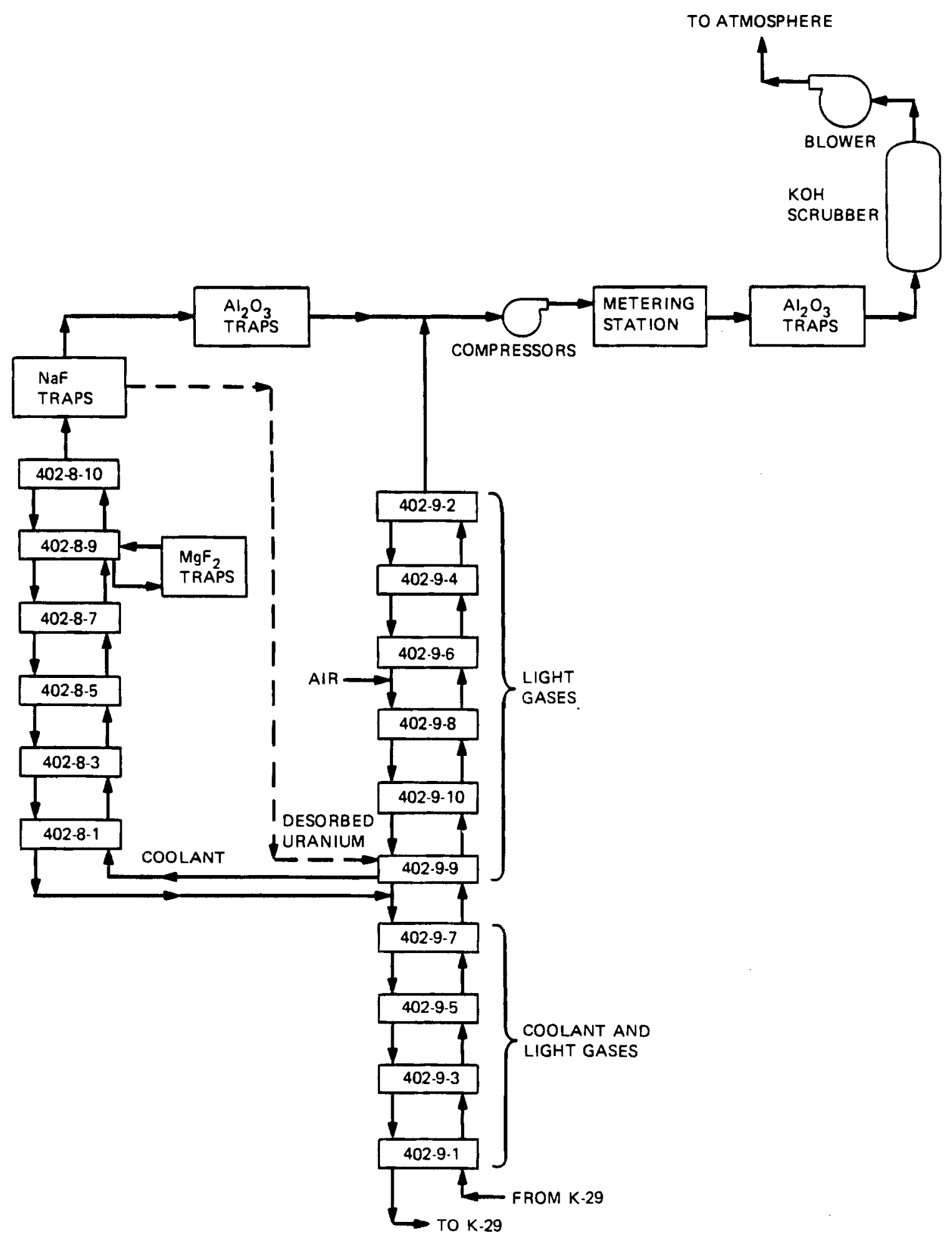

FIGURE 15.5. Flow Diagram of the ORGDP Purge Cascade 
As part of a FY 1981 capital equipment expenditure, the scrubber system is being significantly modified to repair existing corrosion damage and help reduce the chances of similar damage in the future. Specifically, the existing five-stage spray scrubber will be replaced with a new five-stage spray scrubber followed by a low-energy venturi scrubber. While the primary purpose of the venturi scrubber is to remove caustic mist carried over from the spray scrubber and, thus, reduce downstream corrosion problems, it should also result in some additional reduction in radionuclide emissions to the atmosphere. In addition to the scrubber hardware itself, a new sampling system and discharge stack will also be installed. The estimated cost of these modifications is about $\$ 500,000$.

\subsubsection{Current Discharge Rate}

During $1981,3.08 \times 10^{-3} \mathrm{Ci}$ of uranium-234, $1.01 \times 10^{-4} \mathrm{Ci}$ of uranium$235,1.4 \times 10^{-5} \mathrm{Ci}$ of uranium-236, $4.74 \times 10^{-4} \mathrm{Ci}$ of uranium-238 and $3.58 \times$ $10^{-2} \mathrm{Ci}$ of technetium-99 were released from this facility. This source represents about $0.5 \%$ of the hypothetical risk from airborne effluents at 0ak Ridge, based upon the annual output expressed in MPC's for radioactive species identified in the exhaust (Section 1.4). It should be pointed out that the ORGDP operated at about one-third capacity in 1981, and that operations at full capacity would increase the emissions correspondingly.

\subsubsection{Potential Additional Emission Control Technology}

Radioactive emissions from the ORGDP purge cascade consist mainly of gaseous and particulate uranium and technetium fluorides that pass through existing abatement equipment. A new, low-energy venturi scrubber is planned for installation downstream of the existing spray scrubber to reduce mist carry-over and thus help mitigate equipment corrosion problems. This new scrubber should also result in some reduction of airborne emissions.

\subsubsection{Anticipated New Discharge Rate}

Low-energy venturi action would remove more airborne particulate and droplet materials; however, quantification of the scrubbing action is not 
precise. It is dependent upon the gaseous solubility and upon the effectiveness of the mixing and impinging action. Addition of this device is estimated to remove about $50 \%$ of the remaining radioactive emissions.

15.2.7.5 Estimated Cost of Additional Emission Control Technology

The cost of the emission control devices presently installed at the Purge Cascade is $\$ 1.25$ million. The estimated additional cost for purchase of a low-efficiency venturi is $\$ 13,000$. The added annual operating cost for this installation is estimated to be minor $(\$ 1,300)$ compared to the present annual operating cost of $\$ 300,000$. Installation costs are sensitive to the amount of modification necessary to incorporate the added device. No estimate was made for these costs.

\subsubsection{Minor Sources at Oak Ridge}

Minor sources at Oak Ridge are those that contribute between 0.1 and $1.0 \%$ of the hypothetical risk and are not accounted for in the major sources (major sources represent $95 \%$ of the hypothetical risk). They are listed in order of their radiological importance.

\subsubsection{Y-12 Plant: E-Wing Lab}

There are four sources of emission from the E-wing lab. The largest, described below, is from E-wing, east-lab room 1021 - Building 9212.

Description of Existing Emission Control Technology

There are no emission control devices installed at this facility except for the 14-m-high, 0.41-m-diameter stack which exhausts air at the rate of $2.4 \mathrm{~m}^{3} / \mathrm{sec}$.

Current Discharge Rate

During $1981,7.5 \times 10^{-3} \mathrm{Ci}$ of uranium-234 were released from this facility. This source represents about $1 \%$ of the hypothetical risk from airborne effluents at Oak Ridge, based upon the annual output expressed in MPC's for radioactive species identified in the exhaust (Section 1.4). 


\subsubsection{Y-12 Plant: Uranium Product Preparation}

There are three sources of emission from the uranium product preparation facility. The largest was described in Section 15.2.5; next of importance is the C-1 wing-room exhaust - Building 9212. This source is described below.

Description of Existing Emission Control Technology

There are roughing filters, prefilters, HEPA filters and a wet scrubber for control of particulates at this facility. The stack that serves this facility is $16 \mathrm{~m}$ high and $0.11 \mathrm{~m}$ in diameter. The air control system vents $6.4 \mathrm{~m}^{3} / \mathrm{sec}$ from the stack exhaust.

Current Discharge Rate

During $1981,2.99 \times 10^{-3} \mathrm{Ci}$ of uranium-234 were released from this facility. This source represents less than $1 \%$ of the hypothetical risk from airborne effluents at 0ak Ridge, based upon the annual output expressed in MPC's for radioactive species identified in the exhaust (Section 1.4).

15.2.8.3 Y-12 Plant: Uranium Machining

There are three sources of emission from the uranium machining facility. Information pertaining to the largest, M-wing machine shop Building 9215, is presented below.

Description of Existing Emission Control Technology

There are roughing filters, prefilters and a baghouse filter installed for control of particulates at this facility. The stack that serves this facility is $4 \mathrm{~m} \mathrm{high}$ and $1.72 \mathrm{~m}$ in diameter. The air control system vents $25.3 \mathrm{~m}^{3} / \mathrm{sec}$ from the stack exhaust.

Current Discharge Rate

During $1981,2.97 \times 10^{-3} \mathrm{Ci}$ of uranium-234 were released from this facility. 
15.2.8.4. Y-12 Plant: Uranium Chemical Salvage

There are six sources of emission from the uranium chemical salvage processes. Information pertinent to the largest, B-1-wing process exhaust Building 9212, is presented below.

Description of Existing Emission Control Technology

There are roughing filters and a wet scrubber installed for control of particulates at this facility. The stack that serves this facility is $17 \mathrm{~m}$ high and $0.3 \mathrm{~m}$ in diameter. The air control system vents $1.4 \mathrm{~m}^{3} / \mathrm{sec}$ from the stack exhaust.

Current Discharge Rate

During $1981,2.77 \times 10^{-3} \mathrm{Ci}$ of uranium-234 were released from this facility.

\subsubsection{Y-12 Plant: Uranium Chemical Salvage}

There are six sources of emission from the uranium chemical salvage process. Information pertinent to the second largest source, the B-1denitrator room and hood exhaust, is presented below.

Description of Existing Emission Control Technology

There are roughing filters, a baghouse filter and HEPA filters installed for control of particulates at this facility. The stack that serves this facility is $13 \mathrm{~m} \mathrm{high}$ and $0.76 \mathrm{~m}$ in diameter. The air control system vents $1.5 \mathrm{~m}^{3} / \mathrm{sec}$ from the stack exhaust.

Current Discharge Rate

During $1981,2.54 \times 10^{-3} \mathrm{Ci}$ of uranium-234 were released from this facility.

15.2.8.6 Y-12 Plant: Uranium Chemical Salvage

There are six sources of emission from the uranium chemical salvage process. Information pertinent to the third largest source, the B-1-wing-1st floor conversion - Building 9212, is presented below. 


\section{Description of Existing Emission Control Technology}

There are roughing filters, a baghouse filter and HEPA filters installed for particulate control at this facility. The stack that serves this facility is $7 \mathrm{~m} \mathrm{high}$ and $0.56 \mathrm{~m}$ in diameter. The air control system vents $5.9 \mathrm{~m}^{3} / \mathrm{sec}$ from the stack exhaust.

Current Discharge Rate

During $1981,1.91 \times 10^{-3} \mathrm{Ci}$ of uranium-234 were released from this facility.

\subsubsection{Y-12 Plant: Uranium Chip Burning - Building 920}

There are three sources of emission from the uranium chip burning process. Exhaust number 3 is considered a minor source of emission. Information pertinent to this exhaust is presented below.

Description of Existing Emission Control Technology

There are roughing filters and HEPA filters installed for particulate control at this facility. The stack that serves this facility is $24 \mathrm{~m} \mathrm{high}$ and $0.37 \mathrm{~m}$ in diameter. The air control system vents $0.6 \mathrm{~m}^{3} / \mathrm{sec}$ from the stack exhaust.

Current Discharge Rate

During $1981,1.57 \times 10^{-3} \mathrm{Ci}$ of uranium-234 were released from this facility.

15.2.8.8 Y-12 Plant: Uranium Chemical Conversion

This source of emission is located in the D-wing of Building 9212. Information pertinent to this source is given below.

Description of Existing Emission Control Technology

There are prefilters, HEPA filters and a scrubber installed for particulate control at this facility. The stack that serves this facility is $21 \mathrm{~m} \mathrm{high}$ and $1.22 \mathrm{~m}$ in diameter. The air control system vents $22.8 \mathrm{~m}^{3} / \mathrm{sec}$ from the stack exhaust. 
Current Discharge Rate

During $1981,1.38 \times 10^{-3} \mathrm{Ci}$ of uranium-234 were released from this facility.

\subsubsection{Y-12 Plant: Uranium Denitrator}

This source of emission includes the uranium denitrator and room exhaust and denitrator exhaust - Building 9206. Information pertinent to this facility is discussed below.

\section{Description of Existing Emission Control Technology}

There are roughing filters and HEPA filters installed for particulate control at this facility. The stack that serves this facility is $21 \mathrm{~m}$ high and $1.74 \mathrm{~m}$ in diameter. The air control system vents $21.8 \mathrm{~m}^{3} / \mathrm{sec}$ from the stack exhaust.

\section{Current Discharge Rate}

During $1981,1.29 \times 10^{-3} \mathrm{Ci}$ of uranium-234 were released from this facility.

\subsubsection{ORNL: Molten Salt Reactor}

The source of emission is the 7512 stack that serves the molten salt reactor experiment. Although this facility is not in use, a small amount of off-gassing is observed due to the fact that the reactor is still fueled. Information pertinent to this source is presented below.

\section{Description of Existing Emission Control Technology}

There are roughing filters and a HEPA filter preceding a charcoal bed trap. This bed is followed by an additional HEPA filter. The stack that serves this facility is $30.5 \mathrm{~m}$ high and $0.91 \mathrm{~m}$ in diameter. The air control system vents $4.7 \mathrm{~m}^{3} / \mathrm{sec}$ from the stack exhaust.

Current Discharge Rate

During 1981 , less than $1.2 \times 10^{-1} \mathrm{Ci}$ of iodine-131 were released from this facility. 
15.2.8.11 ORNL: High Radiation Level Analytical Laboratory

The source of emission is from the stack located at Building 2026. Information pertinent to this source is given below.

Description of Existing Emission Control Technology

Roughing filters followed by HEPA filters are installed to control particulate emissions at this facility. The stack that serves this facility is $22.9 \mathrm{~m} \mathrm{high}$ and $1.1 \mathrm{~m}$ in diameter. The air control system vents $4.7 \mathrm{~m}^{3} / \mathrm{sec}$ from the stack exhaust.

Current Discharge Rate

During 1981 , less than $1.2 \times 10^{-1} \mathrm{Ci}$ of iodine-131 were released from this source.

15.2.8.12 ORNL: Pilot Plant Operations and Analytical Chemistry Labs

The source of emission is from stack 3020, which serves as an exhaust for pilot plant operations conducted at Building 3019. Information pertinent to this source is given below.

Description of Existing Emission Control Technology

There are two exhaust systems which contribute to the stack emissions. One utilizes a roughing filter and HEPA filters for emission control and the second uses scrubbers and HEPA filters for particulate control. The stack that serves this facility is $76.2 \mathrm{~m} \mathrm{high}$ and $0.91 \mathrm{~m}$ in diameter. The air control system vents $12.3 \mathrm{~m}^{3} / \mathrm{sec}$ from the stack exhaust.

Current Discharge Rate

During 1981, less than $1.2 \times 10^{-1} \mathrm{Ci}$ of iodine-131 were released from this source.

\subsubsection{Y-12 Plant: E-Wing Recovery}

The process is located in Building 9212. Information pertinent to the E-wing recovery exhaust is presented below. 
Description of Existing Emission Control Technology

There are no emission control devices installed at this facility except the $14-\mathrm{m}-\mathrm{high}$ by $0.73-\mathrm{m}$ square stack. The air control system vents $7.1 \mathrm{~m}^{3} / \mathrm{sec}$ from the stack exhaust.

Current Discharge Rate

During $1981,1.14 \times 10^{-3} \mathrm{Ci}$ of uranium-234 were released from this facility.

15.2.8.14 Y-12 Plant: Uranium Foundry

Emissions from the uranium foundry include exhaust ducts from Rooms 20 and 27. Information pertinent to this facility is presented below.

Description of Existing Emission Control Technology

There are no emission control devices installed at this facility except the 24-m-high by $2.84-m-d i a m e t e r ~ s t a c k$. The air control system vents 18 $\mathrm{m}^{3} / \mathrm{sec}$ from the stack exhaust.

Current Discharge Rate

During $1981,1.1 \times 10^{-3}$ of uranium-234 were released from this facility.

15.2.8.15 ORGDP: K-1420 Decontamination Facility

The $\mathrm{K}-1420$ drum dryers are the source of airborne radioactive emissions from the decontamination facility. Information pertinent to this source is given below.

Description of Existing Emission Control Technology

There are no emission control devices installed at this facility.

Current Discharge Rate

During $1981,5.6 \times 10^{-4} \mathrm{Ci}$ of uranium-234, $2.0 \times 10^{-5} \mathrm{Ci}$ of uranium-235, $1.0 \times 1.0^{-5} \mathrm{Ci}$ of uranium-236 and $3.3 \times 10^{-4} \mathrm{Ci}$ of uranium-238 were released from this facility. 
15.2.8.16 Y-12 Plant: Uranium Incinerator

Emissions from the uranium incinerator are directed through an exhaust from Building 9206. Information pertinent to this facility is presented below.

Description of Existing Emission Control Technology

A cyclone separator and a baghouse filter are installed for particulate control at this facility. The stack that serves this facility is $21 \mathrm{~m}$ high and $0.98 \mathrm{~m}$ in diameter. The air control system vents $5.8 \mathrm{~m}^{3} / \mathrm{sec}$ from the stack exhaust.

\section{Current Discharge Rate}

During $1981,9.88 \times 10^{-4} \mathrm{Ci}$ of uranium-234 were released from this facility.

\subsubsection{Y-12 Plant E-Wing Lab}

There are four sources of emission from this facility. One has already been described (Section 15.2.8.1). The second most important is the Room 1022 exhaust from Building 9212. Information pertinent to this facility is given bel ow.

\section{Description of Existing Emission Control Technology}

Roughing filters are installed at the exhaust from a hood at this facility. The stack that serves this facility is $18 \mathrm{~m}$ high and $0.66 \mathrm{~m}$ in diameter. The air control system vents $4.9 \mathrm{~m}^{3} / \mathrm{sec}$ from the stack exhaust.

Current Discharge Rate

During $1981,8.97 \times 10^{-4} \mathrm{Ci}$ of uranium-234 were released from this facility.

15.2.8.18 Y-12 Plant: Uranium Casting Operation

The uranium casting operation is located in the E-wing of Building 9212. Information pertinent to this facility is given below. 


\section{Description of Existing Emission Control Technology}

Particulate releases from this facility are controlled by roughing filters, followed by a baghouse filter and HEPA filters. The stack that serves this facility is $20 \mathrm{~m}$ high and $1.52 \mathrm{~m}$ in diameter. The air control

system vents $28.3 \mathrm{~m}^{3} / \mathrm{sec}$ from the stack exhaust.

Current Discharge Rate

During $1981,8.81 \times 10^{-4} \mathrm{Ci}$ of uranium-234 were released from this facility.

\subsubsection{Other Sources at Oak Ridge}

There are a number of lesser sources of airborne radioactive emissions known to exist at each of the three major areas at Oak Ridge and at the Oak Ridge Associated Universities site. These are summarized in Table 15.2, along with any applicable emission control devices used to control emissions from each source. 
TABLE 15.2. Lesser Sources of Airborne Radioactive Emissions at Oak Ridge

\begin{tabular}{|c|c|c|c|c|}
\hline Location & Description & $\begin{array}{c}1981 \\
\text { Emissions } \\
(\mathrm{C} i / \mathrm{yr}) \\
\end{array}$ & $\begin{array}{c}\text { Type of } \\
\text { Radioactivity }\end{array}$ & $\begin{array}{c}\text { Control }(a) \\
\text { Devices } \\
\end{array}$ \\
\hline \multirow[t]{4}{*}{ ORNL } & Isotope Separations, Stack 9204-3 & $<5 \times 10^{-6}$ & Activated Gases & 1,2 \\
\hline & TRL Hood and Glove Box, Stack 5505 & $<3.89 \times 10^{-8}$ & Alpha & 2,2 \\
\hline & Metals and Ceramics Lab, Stack 4508 & $3.9 \times 10^{-8}$ & Alpha & 1,2 \\
\hline & Linear Accelerator, Stack 6010 & trace & Activated Gases & 1,2 \\
\hline ORGDP & Building K-1413 & $2.5 \times 10^{1}$ & $85_{K r}$ & $N A^{(b)}$ \\
\hline \multirow[t]{15}{*}{ Y-12 Plant } & Uranium Product Recovery (c) & & & \\
\hline & Reduction Area Exhaust & $3.5 \times 10^{-4}$ & ${ }^{234} \mathrm{U}$ & 1,2 \\
\hline & Reactor Hood Exhaust & $7.2 \times 10^{-5}$ & $234 U$ & 1,2 \\
\hline & Uranium Product Preparation (d) & & & \\
\hline & E-Wing Reduction Exhaust & $5.4 \times 10^{-5}$ & $234 U$ & 1,2 \\
\hline & Uranium Chemical Salvage $(c)$ & & & \\
\hline & B-1 Wing Calciner & $3.6 \times 10^{-4}$ & $234 U$ & 1,3 \\
\hline & B-1 Wing Feed Prep. and Filter & $6.3 \times 10^{-5}$ & ${ }^{234} U$ & $1,2,4$ \\
\hline & Room 30, Building 9206 & $2.1 \times 10^{-5}$ & ${ }^{234} \mathrm{U}$ & 1,2 \\
\hline & E-Wing Lab $(c)$ & & & \\
\hline & Room 1021 & $3.9 \times 10^{-4}$ & ${ }^{234} U$ & 1,2 \\
\hline & Room 1021 E-Wing Lab & $3.8 \times 10^{-4}$ & ${ }^{234} U$ & None \\
\hline & Uranium Machining(d) & & & \\
\hline & E-Wing Machine Shop & $1.7 \times 10^{-4}$ & ${ }^{234} U$ & 5,6 \\
\hline & 0-Wing Machine Shop & $5.1 \times 10^{-4}$ & $234 U$ & 4,5 \\
\hline
\end{tabular}


TABLE 15.2. (Contd)

\begin{tabular}{|c|c|c|c|c|}
\hline Location & Description & $\begin{array}{c}1981 \\
\text { Emissions } \\
(\mathrm{Ci} / \mathrm{yr}) \\
\end{array}$ & $\begin{array}{c}\text { Type of } \\
\text { Radioactivity }\end{array}$ & $\begin{array}{c}\text { Control } \\
\text { Devices }\end{array}$ \\
\hline \multirow[t]{7}{*}{ Y-Plant (Contd) } & Uranium Carbon Burner $(\mathrm{e})$ & $3.2 \times 10^{-4}$ & $234 U$ & 2,7 \\
\hline & Room-19, Machine Room & & & \\
\hline & Exhaust 1 & $4.7 \times 10^{-5}$ & $234 U$ & 1,2 \\
\hline & Exhaust 2 & $2.7 \times 10^{-4}$ & $234_{U}$ & 1,2 \\
\hline & Uranium Chip Burning(e) & & & \\
\hline & Exhaust 1 & $8.2 \times 10^{-5}$ & $234 U$ & 1,2 \\
\hline & Exhaust 2 & $3.9 \times 10^{-4}$ & $234 U$ & 1,2 \\
\hline \multirow{4}{*}{$\begin{array}{l}\text { 0ak Ridge Associated } \\
\text { Universities }\end{array}$} & Carl Division & $2.0 \times 10^{-4}$ & ${ }^{14} \mathrm{C}$ & NA \\
\hline & Marmoset Research & $\begin{array}{l}2.0 \times 10^{-4} \\
1.5 \times 10^{-4}\end{array}$ & $\begin{array}{l}14 C_{I} \\
{ }^{125} I\end{array}$ & NA \\
\hline & Medical Division & $\begin{array}{l}1.0 \times 10^{-3} \\
5.0 \times 10^{-3} \\
1.0 \times 10^{-4} \\
1.0 \times 10^{-4} \\
2.0 \times 10^{-3}\end{array}$ & $\begin{array}{l}14 \mathrm{C} \\
3 \mathrm{H}^{12} \\
125 \mathrm{I} \\
131_{\mathrm{I}} \\
133_{\mathrm{Xe}}\end{array}$ & NA \\
\hline & Special Training Division & $1.0 \times 10^{-4}$ & ${ }^{131}$ I & NA \\
\hline
\end{tabular}

\footnotetext{
(a) Type of device: 1) roughing filters, 2) HEPA filters, 3) scrubber, 4) baghouse filter, 5) prefilters, 6) CWS

filters, 7) cyclone separator.

(b) Data not available.

(c) Building 9212 .

(d) Building 9215 .

(e) Building 9206 .
} 


\subsection{OAK RIDGE Y-12 PLANT}

Flow rate, curie emissions of $U-234$ in 1981 as reported by DOE, (2) and pulmonary radiation doses as calculated by EPA (3) from the five largest emitters at the 0ak Ridge Y-12 Plant are shown in Table 15.3. For completeness, the remaining portion of the total pulmonary dose is also reported.

TABLE 15.3. Pulmonary Dose to the Maximum Exposed Individual from Identified Sources at the Oak Ridge Y-12 Plant

\begin{tabular}{|c|c|c|c|c|c|c|}
\hline \multirow{2}{*}{$\begin{array}{l}\text { Source } \\
\text { No. } \\
\end{array}$} & \multirow[b]{2}{*}{ Source } & \multirow{2}{*}{$\begin{array}{l}\text { Stack } \\
\text { Flow Rate } \\
\left(\mathrm{m}^{3} / \mathrm{sec}\right) \\
\end{array}$} & \multirow{2}{*}{$\begin{array}{c}\mathrm{U}-234 \\
\text { Emission } \\
(\mathrm{Ci} / \mathrm{yr}) \\
\end{array}$} & \multicolumn{2}{|c|}{$\begin{array}{l}\text { Pulmonary Dose } \\
\text { (mrem/yr) }\end{array}$} & \multirow[b]{2}{*}{ Total } \\
\hline & & & & $\mathrm{U}-234$ & $\mathrm{U}-238^{(\mathrm{a})}$ & \\
\hline 1 & $\begin{array}{c}\text { West Headhouse, } \\
\text { B1dg. } 9212\end{array}$ & 8.6 & $3.7 \times 10^{-2}$ & 9.1 & 5.2 & 14.3 \\
\hline 2 & $\begin{array}{l}C-1 \text { Wing }(C-1) P V C) \\
\text { B } 1 \mathrm{dg} \cdot 9212(b)\end{array}$ & $6.9(c)$ & $2.98 \times 10^{-2}$ & 7.4 & 4.2 & 11.6 \\
\hline 3 & $\begin{array}{l}\text { C-Wing Process Stack, } \\
\text { B1dg. } 9212\end{array}$ & 23.6 & $1.73 \times 10^{-2}$ & 4.3 & 2.4 & 6.7 \\
\hline 4 & $\begin{array}{l}\text { E-Wing Laboratory, } \\
\text { Bldg. } 9212\end{array}$ & 2.4 & $7.5 \times 10^{-3}$ & 1.8 & 1.1 & 2.9 \\
\hline 5 & $\begin{array}{l}\text { C-1 Wing }(C-2 \text { PVC), } \\
\text { Bldg. } 9212(b)\end{array}$ & $6.9(c)$ & $2.99 \times 10^{-3}$ & 0.7 & 0.4 & 1.1 \\
\hline & Other $Y-12$ Plant Sources & & $2.28 \times 10^{-2}$ & 6.3 & 3.6 & 9.9 \\
\hline & $\begin{array}{l}\text { Other 0ak Ridge Sources } \\
\text { (mostly tritium) }\end{array}$ & & & & & 3.3 \\
\hline & Totals & & $11.74 \times 19^{-2}$ & 29.6 & 16.9 & 49.8 \\
\hline
\end{tabular}

(a) Assumes total U-238 release of $4.0 \times 10^{-2} \mathrm{Ci}(3)$ is emitted in the same proportion from each source as U-234.

(b) Individual processes contributing to the $\mathrm{C}-1$ Wing process stack exhaust.

(c) Estimated at $50 \%$ of the total C-1 Wing Process Stack exhaust of $13.9 \mathrm{~m}^{3} / \mathrm{sec}$.

\subsubsection{Strategies to Reduce Dose Rate by at Least $50 \%$}

Strategies to reduce emissions from the 0ak Ridge $Y-12$ Plant by at least $50 \%$ are suggested by examination of Table 15.3. Elimination of any single source would be inadequate to achieve the desired reductions. However, a $50 \%$ reduction can be obtained in a number of different ways by addition of emission control technology (ECT) to various combinations of the five listed 
sources. Several of the most promising combinations are listed in Table 15.4. At a minimum, additional ECT would have to be applied to the west Headhouse and the $\mathrm{C}-1$ Wing Process Stack. Although strategies which exclude one or the other of these two sources are theoretically possible, it would require very high ECT efficiency on other combinations to produce a dose rate reduction of $50 \%$.

TABLE 15.4. Efficiency of Emission Control Technology Needed to Reduce Oak Ridge Pulmonary Dose by $50 \%$

$\begin{array}{lcccc}\text { Source No. (a) } & \begin{array}{c}\text { Combined Dose } \\ (\mathrm{mrem} / \mathrm{y} r)\end{array} & \begin{array}{c}\text { Reduction Required } \\ \text { (mrem/yr) }\end{array} & \begin{array}{c}\text { \% Reduction } \\ \text { Needed }\end{array} \\ 1,2 & 25.88 & 27.04 & 24.9 & 96 \\ 1,2,5 & 28.79 & 24.9 & 24.9 & 92 \\ 1,2,4 & 32.58 & 24.9 & 86 \\ 1,2,3 & 35.49 & 33.74 & 24.9 & 76 \\ 1,2,3,4 & 36.65 & 24.9 & 70 \\ 1,2,3,5 & & 24.9 & 74 \\ 1,2,3,4,5 & & & & 68\end{array}$

(a) See Table 15.3.

Considering cost versus benefit usually indicates the best way to reduce emissions. The cost to reduce particulate emissions is generally proportional to the effluent flow rate while the benefit (risk reduction) is normally directly proportional to the estimated dose. A comparison of the flow rate/ dose rate for the five major sources at $Y-12$ is shown in Table 15.5. This comparison may be interpreted as a simplified cost/benefit analysis. The conclusion is that additional ECT on the West Headhouse and the $\mathrm{C}-1$ Wing Process Stack is one of the more cost-effective way to reduce emissions.

Recent discussions held with personnel at Oak Ridge who are responsible for operation of the $Y-12$ Plant indicated that there are several projects underway and more planned for the future to help reduce emissions from this facility. One future project is the rerouting of air, now going to the C-Wing 
TABLE 15.5. Simplified Cost/Benefit Analysis(a)

\begin{tabular}{|c|c|c|c|}
\hline $\begin{array}{l}\text { Source } \\
\text { No. } \\
\end{array}$ & $\begin{array}{l}\text { Flow Rate } \\
\left(\mathrm{m}^{3} / \mathrm{sec}\right)\end{array}$ & $\begin{array}{l}1981 \text { Dose Rate } \\
\text { (mrem/yr) }\end{array}$ & Flow Rate/Dose Rate \\
\hline 1 & 8.6 & 14.33 & 0.60 \\
\hline 2 & $6.9^{(b)}$ & 11.55 & 0.60 \\
\hline 3 & 23.6 & 6.70 & 3.52 \\
\hline 4 & 2.4 & 2.91 & 0.82 \\
\hline 5 & 6.4 & 1.16 & 5.52 \\
\hline
\end{tabular}

(a) The flow rate is proportional to the cost to reduce emissions and the dose rate is proportional to the benefit to be achieved.

(b) Estimated at $50 \%$ of the total C-1 Stack flow.

Process Stack from certain Headhouse processes, to the West Headhouse Stack. 0ak Ridge personnel strongly suspect that almost all of the reported C-Wing emissions are the result of this air being pulled from the Headhouse processes to the C-Wing Stack. This project would include sealing of tile ductways beneath the building floor to eliminate flow to the C-Wing, and addition of ducts in the West Headhouse from the originating process to the West Headhouse exhaust plenum.

The estimated air flow involved in rerouting is only $2.4 \mathrm{~m}^{3} / \mathrm{sec}(5000$ $\mathrm{ft}^{3} / \mathrm{min}$ ) and the potential benefit is a reduction of $6.70 \mathrm{mrem} / \mathrm{yr}$. The cost/ benefit (flow rate/benefit) ratio of 0.36 for such an installation is very attractive when compared with the 3.52 reported in Table 15.5 for applying ECT to the system as it is presently operated. For this reason, and the need to take a conservative approach to emissions reduction as discussed later, this project is incorporated into the ECT improvement recommendations made in this report.

Operational requirements at the $\gamma-12$ Plant may change from year to year. These changes contribute to annual variations in emissions from the $Y-12$ Plant, observed in the past, and predicted to take place in the future. Although the need for emission control addressed by this report is based upon 1981 DOE emissions data, it is also necessary to consider the consequences of emission level changes with time. More recent data available from $Y-12$ are those published in 
the DOE Effluent Information System for 1982 emissions. Table 15.6 is a comparison of the 1981 and 1982 emissions data from which it is apparent that $50 \%$ reductions in 1981 emissions, derived from additional ECT postulated for Sources No. 1, 2, and 3, would surpass that possible in 1982 (because Sources No. 2 and 3 exhibited reduced emissions in 1982).

The need for additional ECT to reduce the pulmonary dose based upon 1982 data is dependent upon differing emissions from individual sources. If the total pulmonary dose due to uranium particulates is similar in 1981 and 1982 , then postulated reductions realized by added ECT on Sources No. 2 and 3 in 1981 would be halved in 1982 on the basis of the data presented in Table 15.6. Then the required efficiency of ECT on Sources 1, 2, and 3 to produce a $50 \%$ dose rate reduction in 1982 is greater than 100\% rather than the 76\% estimate that was based on 1981 data. Thus there is a need for conservatism in any additional ECT proposed for the purpose of reducing emissions below specified values, considering all of the various operations likely to take place at the Y-12 Plant.

Based upon the discussions presented, additional ECT in the form of HEPA filtration is proposed for the West Head House, portions of the $C-1$ Wing and the E-Wing in order to reduce emissions by a minimum of $50 \%$.

TABLE 15.6. Comparison of Particulate Emissions from Important Sources at Y-12 for 1981 and 1982

\begin{tabular}{|c|c|c|c|c|}
\hline \multirow{2}{*}{$\begin{array}{c}\text { Source } \\
\text { No. }\end{array}$} & \multicolumn{2}{|c|}{ Emissions ( $\mathrm{C} i / \mathrm{yr}$ ) } & \multicolumn{2}{|c|}{$\begin{array}{c}\text { Rank or } \\
\text { Importance }\end{array}$} \\
\hline & 1981 & 1982 & 1981 & 1982 \\
\hline $1(a)$ & $3.7 \times 10^{-2}$ & $3.74 \times 10^{-2}$ & 1 & 1 \\
\hline $2(\mathrm{a})$ & $2.98 \times 10^{-2}$ & $1.44 \times 10^{-2}$ & 2 & 2 \\
\hline $3(a)$ & $1.73 \times 10^{-2}$ & $8.97 \times 10^{-3}$ & 3 & 5 \\
\hline $4(a)$ & $7.5 \times 10^{-3}$ & $1.21 \times 10^{-2}$ & 4 & 3 \\
\hline $5(a)$ & $2.99 \times 10^{-3}$ & $3.38 \times 10^{-3}$ & 5 & 7 \\
\hline$B(b)$ & $2.97 \times 10^{-3}$ & $1.02 \times 10^{-2}$ & 7 & 4 \\
\hline$c^{(c)}$ & $1.29 \times 10^{-3}$ & $5.13 \times 10^{-3}$ & 13 & 6 \\
\hline
\end{tabular}

(a) See Table 15.3.

(b) M-Wing machine Shop, Bldg. 9215.

(c) Uranium Denitrator and Room Exhaust, B1dg. 9206. 


\subsubsection{Cost Estimates for Additional Emission Control Technology}

Cost estimates presented in the following paragraphs are based upon the general use of 304 stainless steel for most filter enclosures, ducts, and other components that interface with existing systems within Building 9212 at the Y-12 Plant. Cost estimates do not include additional costs for filter disposal because it is assumed that the quantity of uranium removed by the filters at Y-12 would be of sufficient value to make reprocessing economically feasible. Cost estimates also do not include any special provisions for criticality control should the isotopic mixture change in future years. Where necessary, the exact configuration of large HEPA filter systems proposed in this study can be modified to suit existing space requirements. This feature is derived from the modular nature of their construction.

\subsubsection{West Head House}

Proposed Equipment

It is proposed that a new air filtration system shown in Figure 15.6 be installed on grade elevation to replace the existing system. It is also proposed to reroute several headhouse processes, that now exhaust to the C-Wing Stack, to the new filtration system and the West Head House stack. The new air filtration system will include prefilters, HEPA filters, a fan/motor with outlet damper flow control, and a 60 foot stack. The system is designed in a 3-high $\times 8$-wide array of HEPA filters with a capacity of 32,000 cfm. This is sufficient to maintain the present headhouse air flow (approximately 26,000 $\mathrm{cfm}$ ) and the additional rerouted air (about 5,000 $\mathrm{cfm}$ ). Pertinent weight estimates for the components that make up the air filtration system are listed as "Estimated Weights."

\section{Estimated Cost of Proposed Equipment}

Cost estimates for capital expenditures and labor associated with the installation of the air filtration system described in Figure 15.6 are presented in Table 15.7. The total cost is estimated at about $\$ 313,000$. The cost of construction at grade elevation of a building to house the system is included in the total cost estimate. 


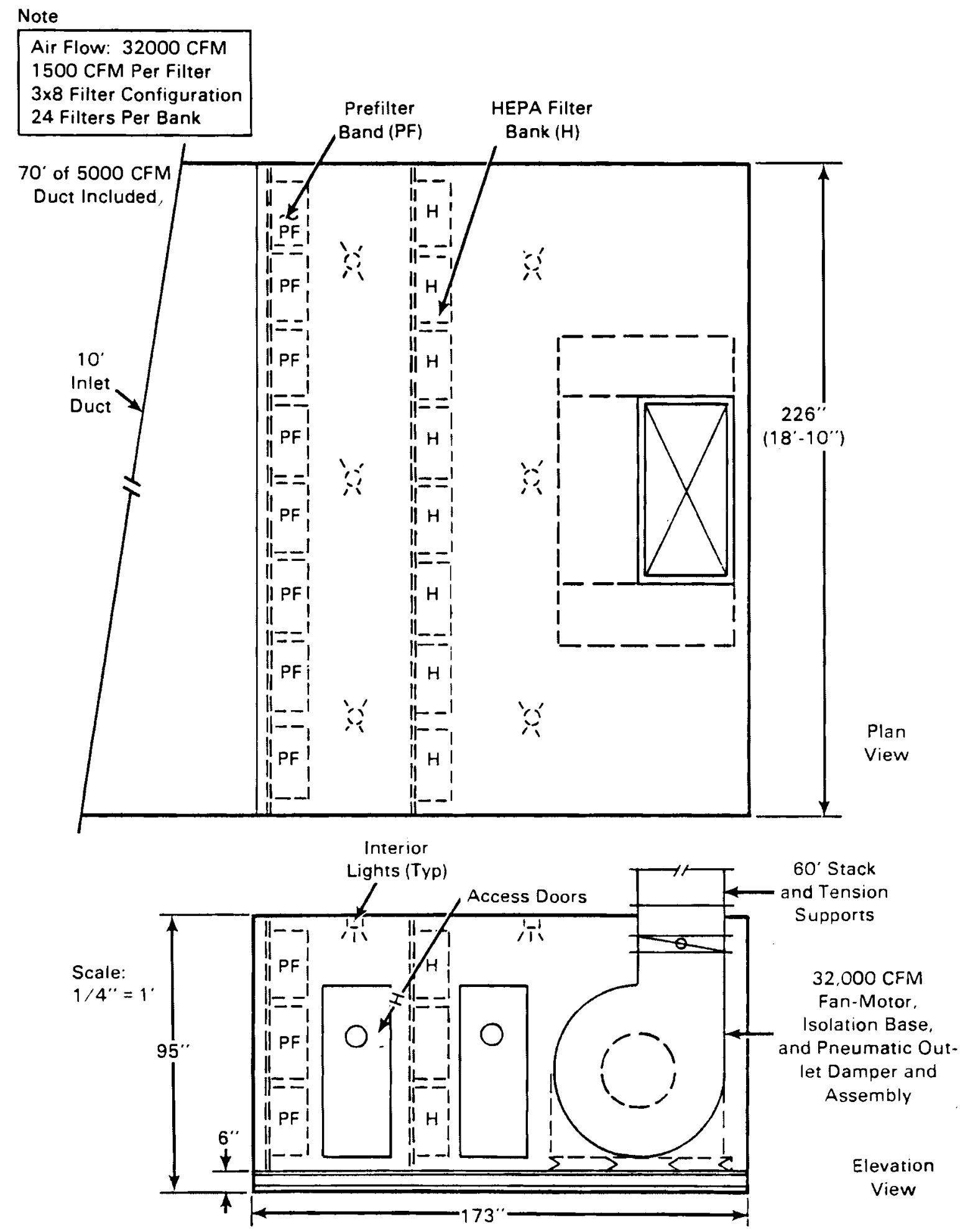

FIGURE 15.6. Proposed Emission Control at West Head House 
TABLE 15.7. Estimated Cost for Emission Control at West Head House

\begin{tabular}{lr}
\multicolumn{1}{c}{ Item } & Cost $(\$ \mathrm{~K})$ \\
\cline { 3 - 3 } Plenum and Duct Rerouting & 85.7 \\
Stack & 6.0 \\
Fan/Motor Assembly & 7.4 \\
Filters and Separators & 12.1 \\
Engineering & 10.0 \\
Installation and Shipping & $\underline{96.0}$ \\
Air Filtration System Subtotal & 217.2 \\
Stack Sampler & \\
Building Enclosure & 61.8 \\
Seal under Tile Ductways to C-Wing & $\underline{10.0}$ \\
Total System Cost & 313.2
\end{tabular}

Estimated Weights: $6.12 \mathrm{lb} / \mathrm{ft}^{2}$ (304 SST Construction)

Front/Back Wall
Roof/Floor
End (Fan)
End Extension
Prefilters
HEPAs
Fan Assembly
Base Channel
Stack

Total System Weight

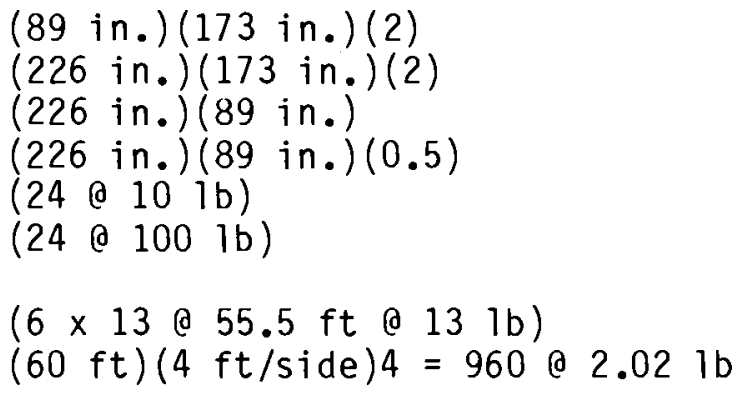

$\begin{array}{cc} & \begin{array}{c}\text { Component weight } \\ (1 \mathrm{~b}, \text { approx })\end{array} \\ = & 1,300 \\ = & 3,300 \\ = & 900 \\ = & 400 \\ = & 200 \\ = & 2,400 \\ = & 2,400 \\ = & 900 \\ = & \frac{1,900}{13,700}\end{array}$

\section{Effect of Proposed Equipment}

Carefully installed and maintained HEPA filter systems generally have an efficiency of greater than $99.9 \%$. The installation proposed here is conservatively estimated to reduce existing emissions from Sources 1 and 3 by $90 \%$.

\subsubsection{C-1 Wing (C-1 PVC)}

Proposed Equipment

It is proposed that a new air filtration system be installed on the roof of the $\mathrm{C}-1$ Wing (or in close proximity to the $\mathrm{C}-1$ Wing) at a location adjacent to $C-1$ PVC exit to the $C-1$ Process Stack. The $C-1$ PVC emissions that are now 
combined with C-2 PVC emissions will be isolated from other building emissions and purified by passing through the new air filtration system. This new system includes acid scrubbers, moisture separators, prefilters, and HEPA filters. The system is sized to allow mounting on the roof area without major additions of structural supports. The structural loading of the system is about $61 \mathrm{~b} / \mathrm{ft}^{2}$ and will be positioned in an area estimated to be capable of supporting $20 \mathrm{lb} / \mathrm{ft}^{2}$ of live load. This system will provide emissions control for the second most significant particulate source (as reported in 1981).

The C-2 PVC emissions (the No. 5 source of importance) have not been included in the proposed system because of the high costs and limited benefits expected. Addition of the C-2 PVC emissions to the proposed system would not only necessitate a larger air filtration system but would include significant costs for additional building support from the roof to the foundation.

The proposed air filtration system is shown in Figure 15.7. Pertinent weight estimates for calculating roof loading are as follows:

\section{Weight Estimates of Components:}

Basis: $11 \mathrm{Ga}: 304 \mathrm{SST}=5 \mathrm{lb} / \mathrm{ft}^{2}$

$1 / 4$ in. $x 2$ in. Strip Stiffeners: $304 \mathrm{SST}=1.7 \mathrm{lb} / \mathrm{ft}$ Total SST $=\left(5.57 \mathrm{lb} / \mathrm{ft}^{2}\right)(1.1)=6.121 \mathrm{~b} / \mathrm{ft}^{2}$ (Safety Factor)

\begin{tabular}{|c|c|c|c|}
\hline & & & \\
\hline Front/Back Wall & $(208$ in.) $(89$ in.)(2) $\times 6.12$ & $=$ & 1,600 \\
\hline Roof/Floor & $(118$ in.)(208 in.)(2) $\times 6.12$ & $=$ & 2,100 \\
\hline End $(\mathrm{Fan})$ & $(89$ in.) $(118$ in.)(1) $\times 6.12$ & $=$ & 400 \\
\hline End (Scrubber & $(89$ in.) $(118$ in.)(3) $\times 6.12$ & $=$ & 1,300 \\
\hline Scrubber: & Pipe, Spray Heads, Pump, Sump & $=$ & 800 \\
\hline Moisture Separators: & & $=$ & 400 \\
\hline Prefilters: & $12 @ 101 b$ & $=$ & 100 \\
\hline HEPAs & $120(37.191 b+601 b)$ & $=$ & 1,200 \\
\hline Fan/Isolator/Motor & Damper: & $=$ & 1,500 \\
\hline Base Channel & $(10.5 \mathrm{lb} / \mathrm{ft})(55 \mathrm{ft})$ & $=$ & 600 \\
\hline Stack & $(40 \mathrm{ft})(3 \mathrm{ft} / \mathrm{side})(4) \times 2.02 \mathrm{lb} / \mathrm{ft}^{2}$ & $=$ & 1,000 \\
\hline Total System Weight & & & 11,000 \\
\hline
\end{tabular}


Estimated Cost of Proposed Equipment

Cost estimates for materials and labor associated with the installation of the air filtration system described in Figure 15.7 are presented in

Table 15.8. The total cost is estimated at about $\$ 217,000$ and includes the cost of a metal building enclosure $(3,5001 \mathrm{~b}$ in addition to the 11,000 1b of equipment), around the exhaust plenum, that may or may not be needed to satisfy radiological requirements.

\section{Effect of Proposed Equipment}

Additional control technology is estimated to result in an efficiency of $95 \%$ for removal of particulates from Source 2 .

15.3.2.3 E-Wing Laboratory (E-Wing, East Laboratory, Room 1021)

The fourth most important source of uranium particulate emissions from $Y-12$ (as reported in 1981) is the east hood located in Room 1021 in the E-Wing (also known as EIS-27). At this time, it is not necessary to make cost estimates for selectively reducing emissions from this individuat source because of a project already underway at $Y-12$ and scheduled for completion by March 1985 . A diagrammatic sketch of the air exhaust pathways that were present in 1981 is shown in Figure 15.8. The project that is underway combines E1S-27 with E1S-26 and creates a new emission source. Air from this new source, shown in Figure 15.9, will be filtered and should contain considerabiy less emissions than from the original unfiltered air from E1S-27 (and E1S-26). The cost of this project was originalTy estimated by DOE at $\$ 400,000$; however, it included a considerable amount of overdesign in order to be compatible with their future plans for the E-Wing. At this time, we are told that many portions of this project have been contracted at less than estimated costs.

\section{Proposed Equipment}

For comparison purposes, in the following paragraphs estimates are made of the materials and labor costs for installing additional emission control technology on each of the four process exhausts that were included in the scope of the project described in the preceding paragraph. No allowance is made, however, for overdesign or for coordinating with additional modifications that are planned for the E-1 Wing in the future. 


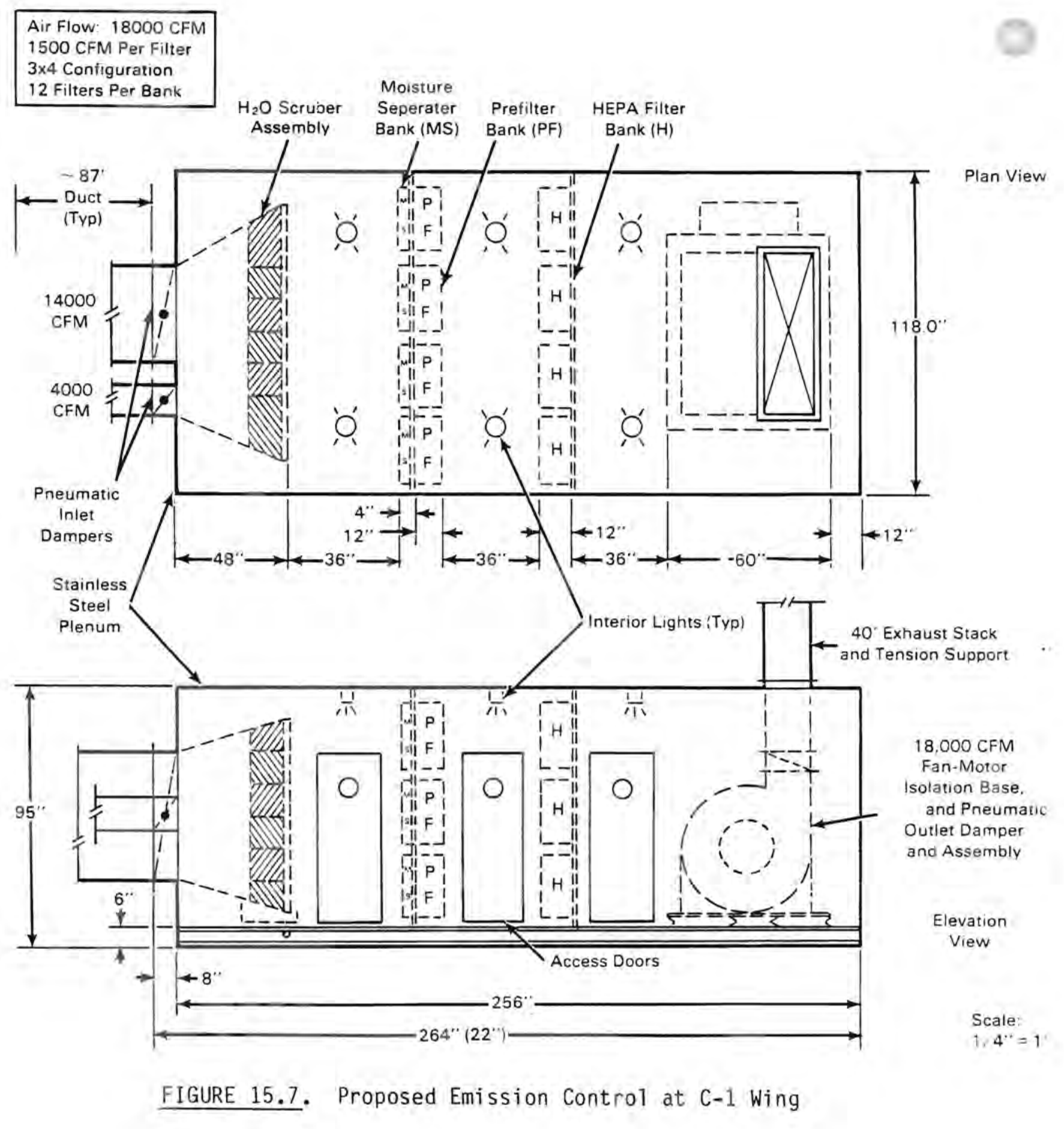


TABLE 15.8. Estimated Cost for Emission Control on C-1 Wing (C-1 PVC)

Item

\begin{tabular}{l}
\hline Plenum \\
Stack \\
Fan/Motor Assembly \\
Filters and Separators \\
Engineering \\
Installation and Shipping \\
Subtotal, Air Filtration System \\
Scrubber Tanks/Equipment \\
Stack Sampler \\
Metal Building Enclosure $\left(\$ 30 / \mathrm{ft}^{2}\right)$ \\
Secondary Support Members and \\
Structural Slab \\
Total System Cost
\end{tabular}

Plenum

Filters and Separators

Engineering

Estallation and sh

Scrubber Tanks/Equipment

Stack Sampler

Metal Building Enclosure $\left(\$ 30 / \mathrm{ft}^{2}\right)$

econdary Support Members and

Total System Cost

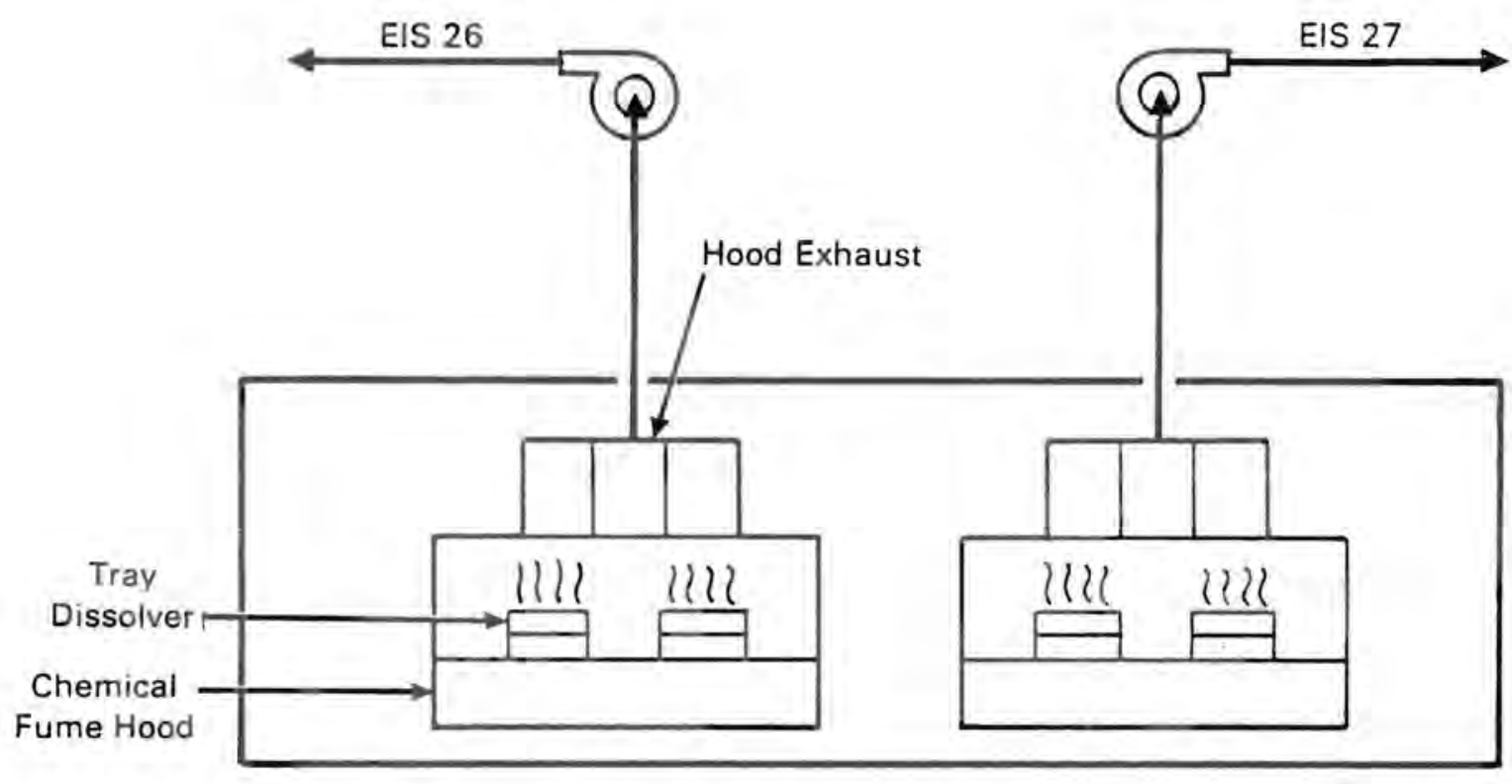

FIGURE 15.8. Air Emission Pathway During 1981
Cost (\$K)

62.0

4.0

6.3

12.1

9.8

74.4

168.6

14.2

21.8

7.0

5.0

$\overline{216.6}$ 
It is proposed that each dissolver shown in Figure 15.9 be equipped with its own filtration system such as the one shown in Figure 15.10.

The system consists of four individual plenums containing acid scrubbers, moisture separators, heaters, and HEPA filters. Depending upon space requirements, they may be stacked verticaliy. Each system is capable of exhausting $200 \mathrm{ft}^{3} /$ min to a central air exhaust and an $11 \mathrm{ft}$ horizontal stack. The central air handling components consist of a fan, motor, base, and outlet damper with 6 in. interconnecting ducts.

Pertinent weight estimates of each system for calculating internal support requirements are as follows:

Estimated Weights $6.12 \mathrm{1b} / \mathrm{ft}^{2}$ (304 SST Construction)

\begin{tabular}{|c|c|c|c|}
\hline \multirow[b]{2}{*}{ Front/Back Wa1I } & \multirow[b]{2}{*}{$(84$ in. $)(18$ in. $)(2) \times 6.12$} & \multicolumn{2}{|c|}{$\begin{array}{c}\text { Component Weight } \\
\text { (1b approx) }\end{array}$} \\
\hline & & $=$ & 130 \\
\hline Roof/Floor & & $=$ & 130 \\
\hline Scrubber: & Pipe/Sprayer/Heads/Pump & $=$ & 100 \\
\hline Moisture Separator: & 1 a $101 \mathrm{~b}$ & $=$ & 10 \\
\hline HEPA Filters & 1010 & $=$ & 10 \\
\hline Base Channel: & $5.4 \mathrm{lb} / \mathrm{ft} @ 14 \mathrm{ft}$ & $=$ & 80 \\
\hline Subtotal & (Each of 4 systems) & & 460 \\
\hline \multirow{2}{*}{\multicolumn{2}{|c|}{$\begin{array}{l}\text { Fan/Isolator/Motor/Damper: } \\
\text { Stack: } \quad(11 \mathrm{ft})(1 \mathrm{ft} / \mathrm{side})(4) \times 2.021 \mathrm{~b} / \mathrm{ft}\end{array}$}} & $=$ & 300 \\
\hline & & $=$ & 90 \\
\hline \multicolumn{2}{|c|}{ Tota1 System Weight ( $4 \times 457$ plus fan and stack) } & $=$ & 2200 \\
\hline
\end{tabular}

\section{Estimated Cost of Proposed Equipment}

Cost estimates are presented in Table 15.9 for materials and labor associated with the installation of the proposed air filtration system described in Figure 15,10. The total cost is $\$ 98,000$.

Effect of Proposed Equipment

Installation of scrubbers and HEPA filters on sources previously both filtered and unfiltered is conservatively estimated to result in a particulate removal efficiency of $90 \%$. 


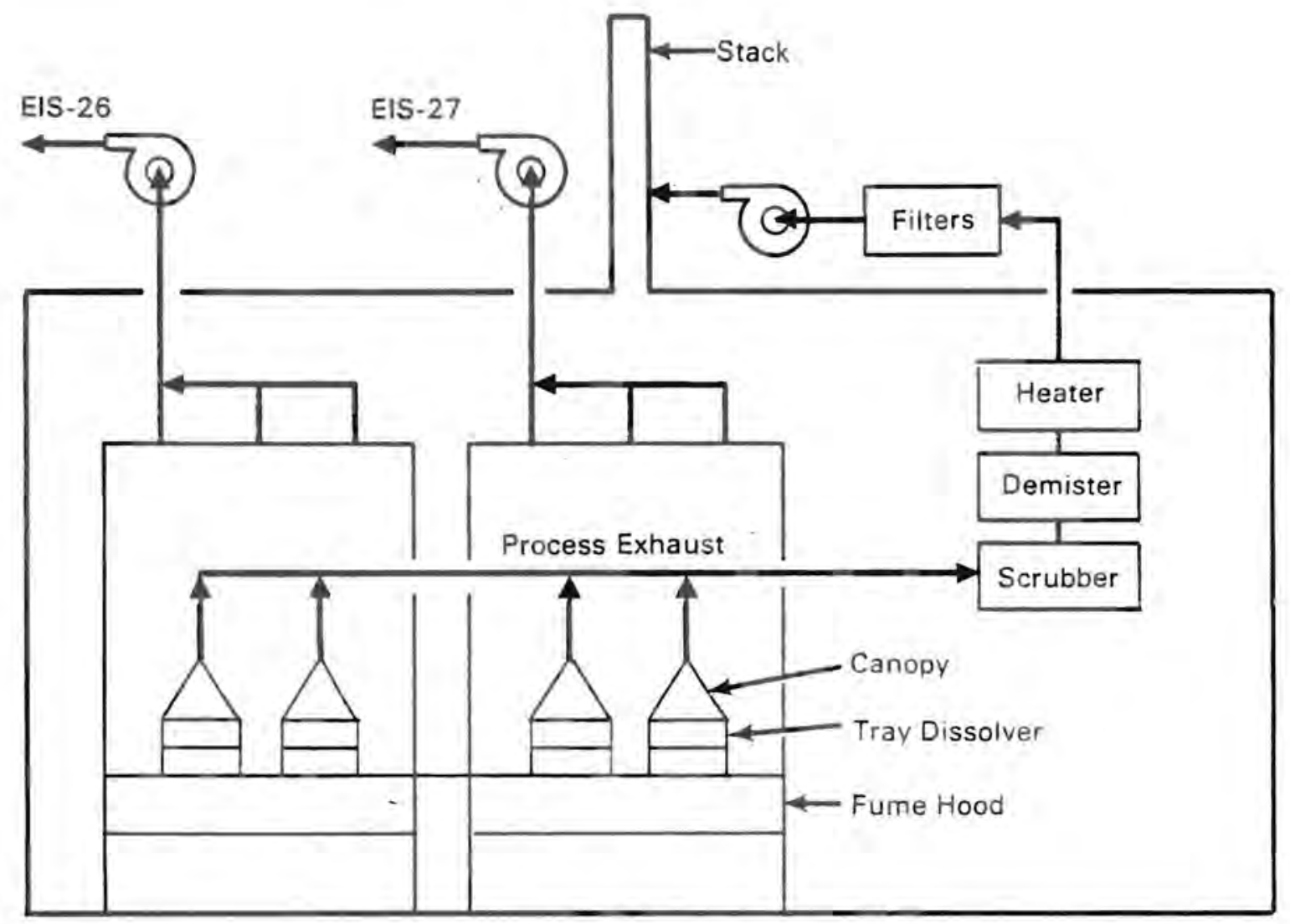

FIGURE 15.9. Emission Pathways Planned by March 1985

\subsubsection{Operation and Maintenance Costs}

Operation and maintenance (0\&M) costs for the three proposed systems are shown in Table 15.10. The annual cost of $\$ 90,000$ will be partially offset by substituting the new 0\&M activities for 0\&M activities that are to be replaced.

\section{3 .4 Summary}

A summary of 1981 pulmonary doses, expected pulmonary doses following installation of the proposed additional ECT at the $Y-12$ PIant, capital costs of installation, and annual 0\&M costs is presented in Table 15.11. The installation cost contains a $25 \%$ allowance for overhead and profit, and the total cost includes a factor of 2.5 to allow for removal and disposal of existing obsolete and unused systems, for additional structural supports and for additional AE fee. Installation of the proposed ECT on the Y-12 plant would reduce 1981 emissions from the Oak Ridge Facility by an estimated $65 \%$. 


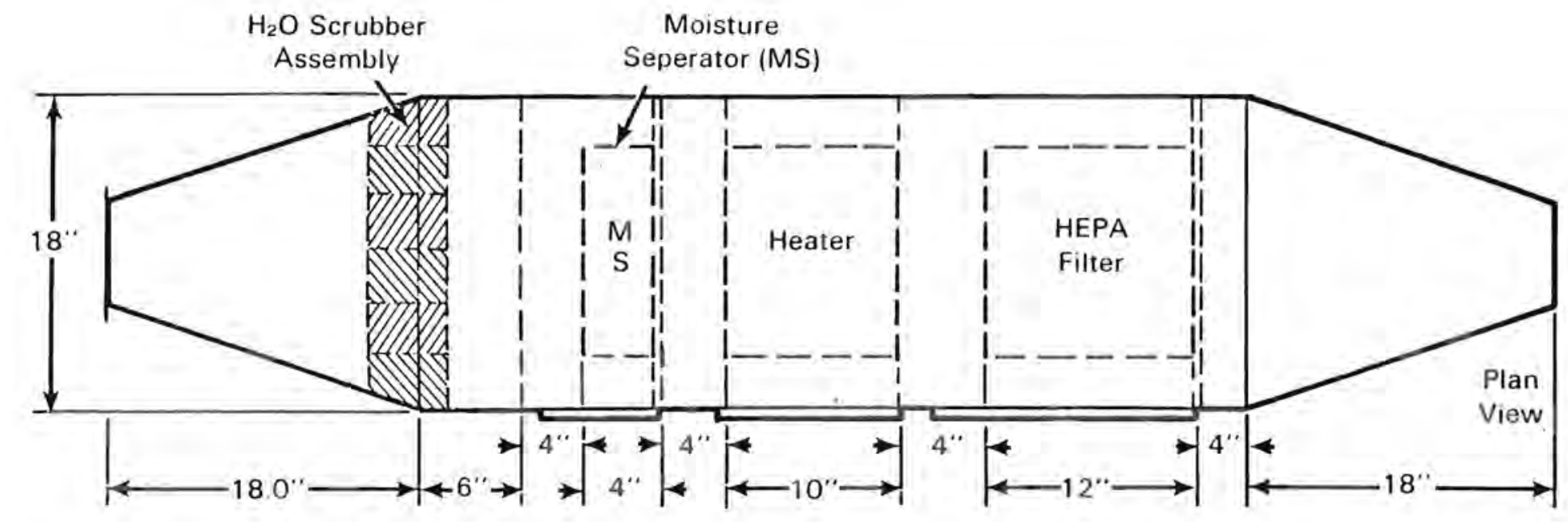

宊

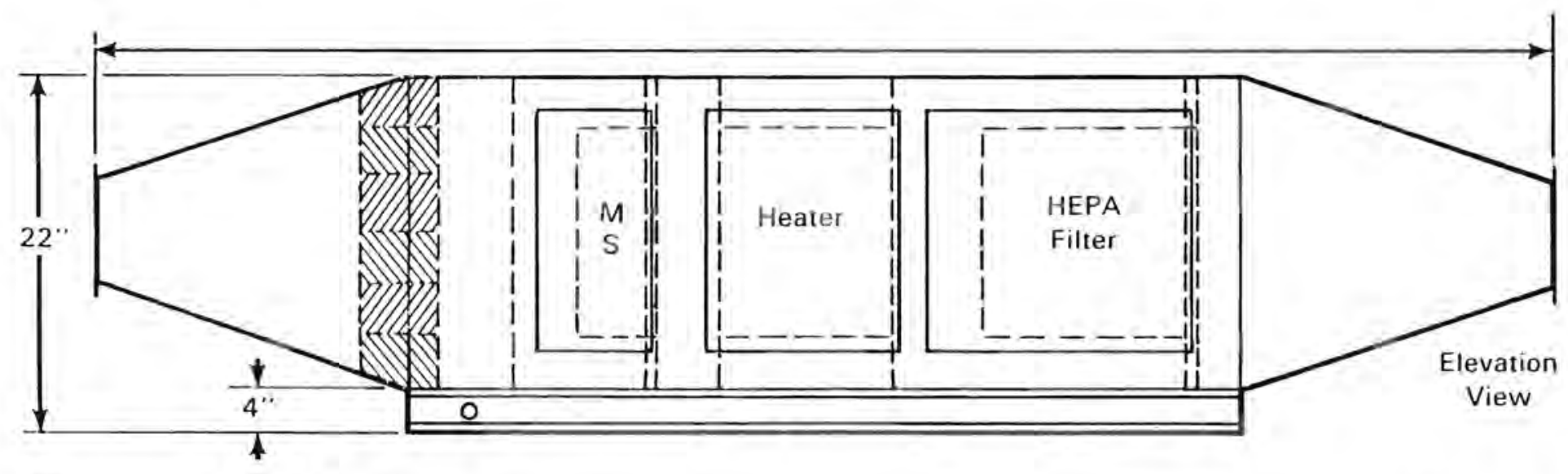

Note

4 Units Required

Each Unit: 200 CFM

1 Filter Per Bank

Each Filter $1^{\prime} \times 1 \times 1$ ' 
TABLE 15.9. Estimated cost for Emission control at E-Wing

\begin{tabular}{lr}
\multicolumn{1}{c}{ Item } & Cost (\$K) \\
Plenums (4) & 21.1 \\
Heaters and Controls (4) & 3.2 \\
Fan Assembly & 2.3 \\
Filters (4 units) & 1.6 \\
Engineering & 7.8 \\
Installation and Shipping & $\underline{29.2}$ \\
Subtotal, Air Filtration System & 65.2 \\
Scrubber Tanks/Equipment & 7.0 \\
Stack Sampler & 21.8 \\
Canopies/Ductwork for Hoods (4) & $\underline{4.0}$ \\
Total System Cost & 98.0
\end{tabular}

TABLE 15.10. Annual Operating Costs for ECT Proposed at $Y-12$

\begin{tabular}{|c|c|c|c|c|c|}
\hline \multirow[b]{2}{*}{ System } & \multirow[b]{2}{*}{ Electrical (a) } & \multicolumn{2}{|c|}{$\begin{array}{l}\text { Filter } \\
\text { Replacement }\end{array}$} & \multirow{2}{*}{$\begin{array}{c}\text { Filter (b) } \\
\text { Testing } \\
\end{array}$} & \multirow[b]{2}{*}{ Totals } \\
\hline & & Parts & Labor & & \\
\hline $\begin{array}{l}\text { West Headhouse } \\
C-1 \text { Wing } \\
\text { E-Wing Lab }\end{array}$ & $\begin{array}{r}23,200 \\
14,900 \\
500\end{array}$ & $\begin{array}{r}24,000 \\
12,000 \\
1,200\end{array}$ & $\begin{array}{l}2,400 \\
2,400 \\
2,400\end{array}$ & $\begin{array}{l}2,400 \\
2,400 \\
2,400\end{array}$ & $\begin{array}{r}52,000 \\
31,700 \\
6,500 \\
\end{array}$ \\
\hline Tota1 & & & & & 90,200 \\
\hline
\end{tabular}

(a) Based upon continuous operation at $\$ 0.05 / \mathrm{kWh}$.

(b) Based upon two filter changeouts annually. 
TABLE 15.11. Summary of Estimated Cost of and Expected Pulmonary Dose Resulting from Installation of Proposed Emission Control Technology at the $\mathrm{Y}-12 \mathrm{Plant}$

\begin{tabular}{|c|c|c|c|c|c|}
\hline Source & $\begin{array}{c}1981 \\
\text { Estimated } \\
\text { Pulmonary } \\
\text { Dose } \\
(\text { mrem/yr) } \\
\end{array}$ & $\begin{array}{c}\text { Estimated } \\
\text { Pulmonary } \\
\text { Dose with } \\
\text { New ECT } \\
\text { (mrem/yr) }\end{array}$ & $\begin{array}{c}\text { Installatjon } \\
\text { Cost a } \\
(\$ K)\end{array}$ & $\begin{array}{l}\text { Total } \\
\text { Cost }(b) \\
(\$ K) \\
\end{array}$ & $\begin{array}{l}\text { Annual } \\
\text { O\&M } \\
\text { Cost } \\
(\$ K) \\
\end{array}$ \\
\hline $\begin{array}{l}\text { West Headhouse } \\
C-1 \text { Wing (C-1 PVC) } \\
\text { C-Wing Process Stack } \\
\text { E-Wing Laboratory } \\
\text { C-1 Wing (C-2 PVC) } \\
\text { Other Y-12 Plant Sources } \\
\text { Other Oak Ridge Sources }\end{array}$ & $\begin{array}{r}14.3 \\
11.6 \\
6.7 \\
2.9 \\
1.1 \\
9.9 \\
3.3 \\
\end{array}$ & $\begin{array}{l}1.4 \\
0.6 \\
0.7 \\
0.3 \\
1.2 \\
9.9 \\
3.3 \\
\end{array}$ & $\begin{array}{r}391.5 \\
270.8 \\
(c) \\
122.5\end{array}$ & $\begin{array}{l}979 \\
677 \\
(c) \\
306\end{array}$ & $\begin{array}{r}52.0 \\
31.7 \\
(c) \\
6.5\end{array}$ \\
\hline Total & 49.8 & 17.4 & $\$ 784.4$ & $\$ 1962$ & $\$ 90.2$ \\
\hline
\end{tabular}

(a) From Tables 15.7, 15.8 and 15.9. Figures here include 25\% allowance for overhead and profit.

(b) Includes factor of 2.5 to allow for removal and disposal of existing obsolete and unused systems, for additional structural supports, and for additional AE fee.

(c) Included in West Headhouse figures. 


\section{REFERENCES}

1. L. E. Trevorrow, et aT., Tritium and Noble Gas Fission Products in the Nuclear Fuel Cycle, Vol. 1, "Reactors," ANL-8102, Argonne National Laboratory, Argonne, IlTinois, October 1974.

2. U.S. Department of Energy, Effluent Information System, EPA Release Point Analysis Report for Calendar Year 1981, July 17, 1982.

3. U.S. Environmental Protection Agency, Background Information Document Proposed Standards for Radionuclides (Draft), EPA-520/1-83-001, March 1983. 


\subsection{PADUCAH GASEOUS DIFFUSION PLANT}

The Paducah Gaseous Diffusion Plant is a government-owned facility constructed for the purpose of enriching the uranium-235 content of uraniium feed material for both government and commercial uses. Paducah is one of three gaseous diffusion plants in the United States, the other two being located at Portsmouth, Ohio, and Oak Ridge, Tennessee. It was the second of the three plants to be built. Construction was started in 1951 and the last of the five cascade buildings was completed in 1954.

\subsection{SITE AND MAJOR SOURCE DESCRIPTIONS}

The site of the plant, the facilities on the site, and the location of major sources of emissions to the atmosphere at the site are described in the next three sections.

\subsubsection{Location of Site and Description of Facilities}

The Padacah Gaseous Diffusion Plant is located in McCracken County, Kentucky, near the town of Paducah. Figure 16.1 shows the plant location with respect to nearby towns. It is $6 \mathrm{kilometers} \mathrm{south} \mathrm{of} \mathrm{the} \mathrm{Ohio} \mathrm{River,} \mathrm{and}$ about 8 kilometers southwest of the town of Metropolis, Illinois. The site is bounded by a buffer zone of government-owned land which, in turn, is surrounded by an extensive wildlife management area. The plant itself is within a 300-hectare fenced area.

The function of the plant is to enrich the fissile ${ }^{235} \mathrm{U}$ content of natural uranium or uranium feed material. The enrichment process is based on the diffusion of gaseous $U F_{6}$ through a porous barrier. A single stage of the process consists of a compressor and a diffusion barrier cell called a converter. Because only a slight separation occurs at each stage, approximately 1812 separation stages are used at Paducah facility. The stages are connected to form a separation cascade. The cascades at Paducah are housed in five buildings, C-310, C-331, C-333, C-335 and C-337. These and other site buildings are shown in Figure 16.2. 


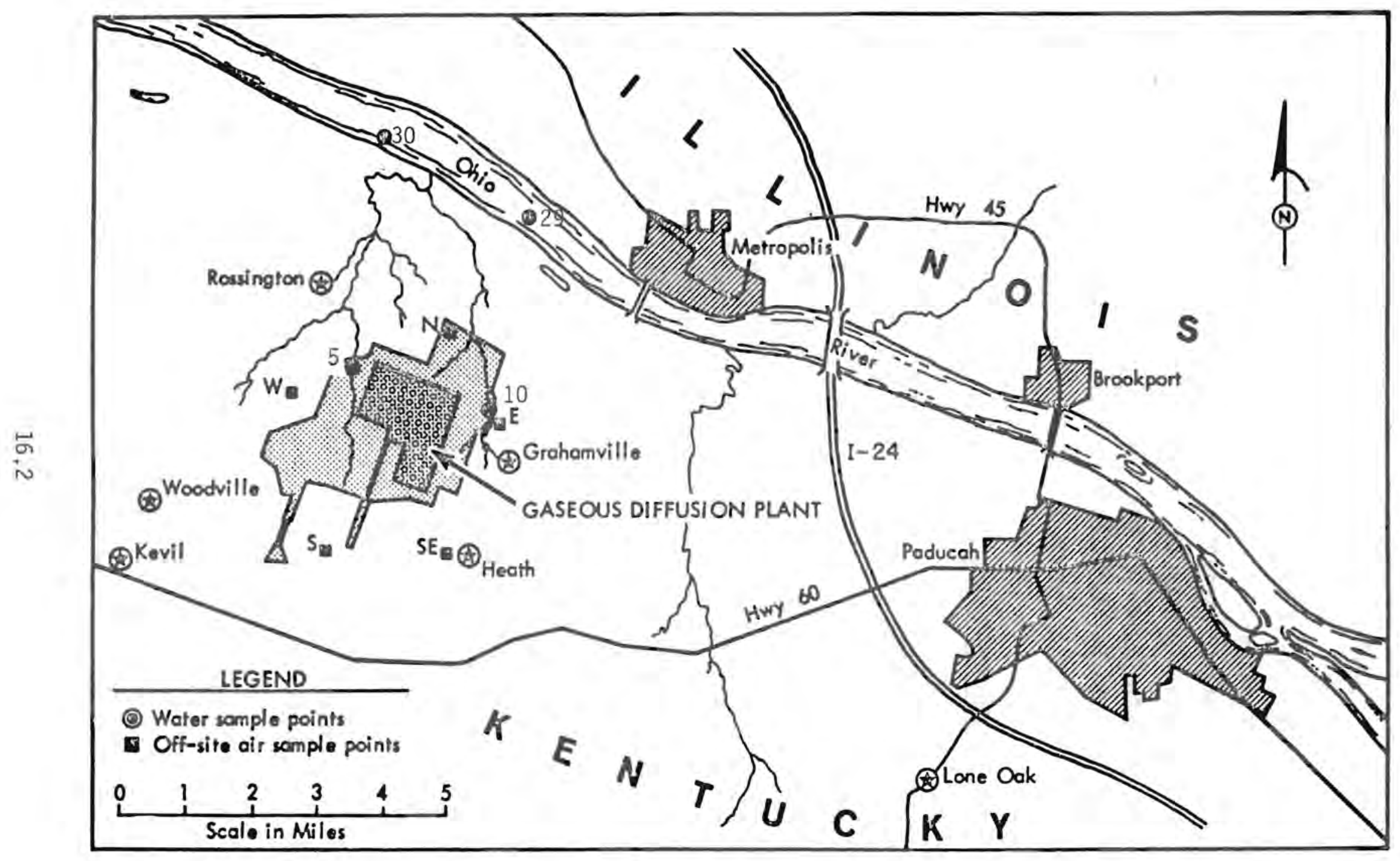

FIGURE 16.1. Paducah Gaseous Diffusion Plant 


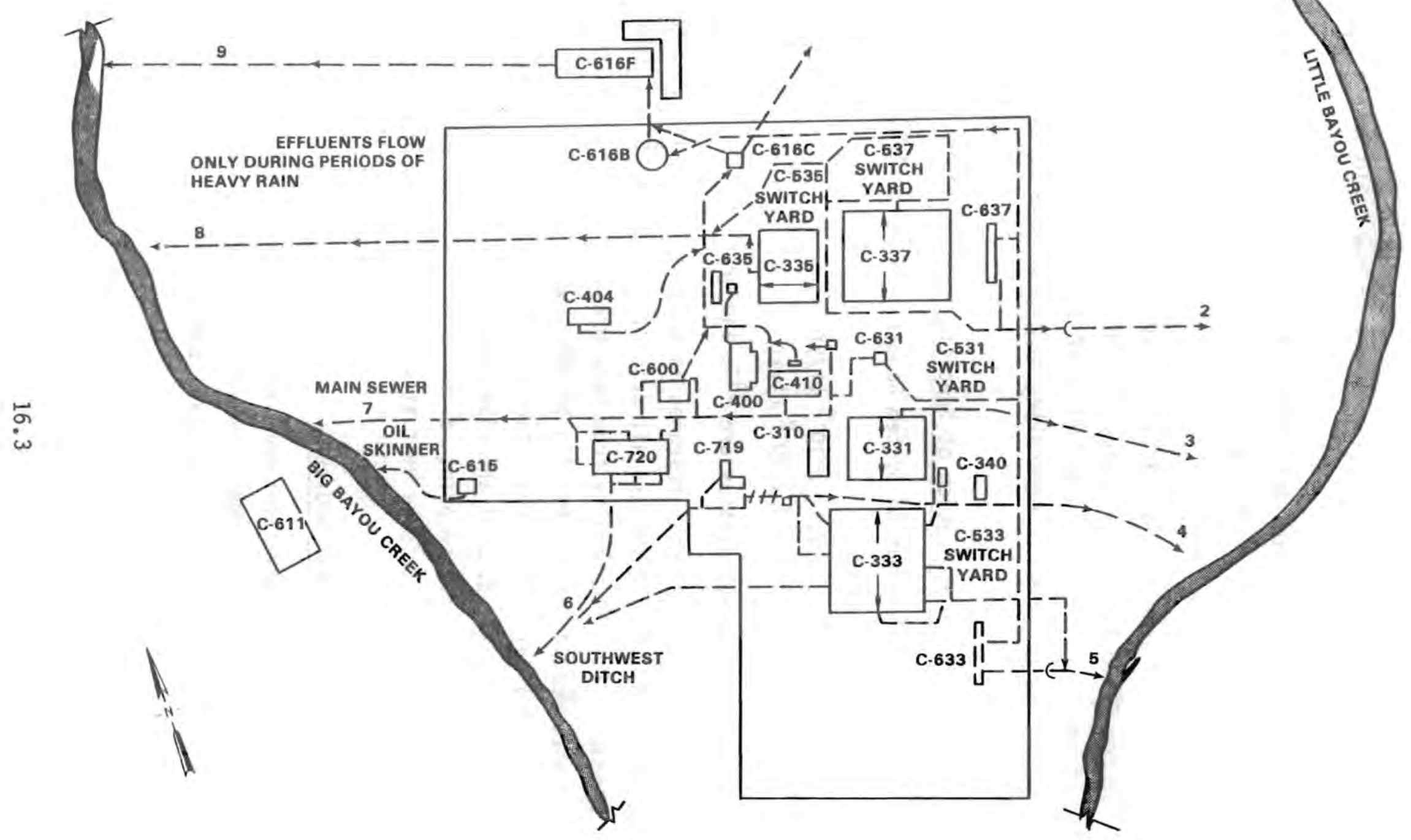

FIGURE 16.2. Paducah Gaseous Diffusion Plant Site Plan 
The major cascade building emission source is the C-310 Building stack. The stack vents light gas contaminants from the purge cascade. These contaminants include uranium and its daughters, and the fission product technetium-99 from previously irradiated uranium feed. The stack is $61 \mathrm{~m}$ high.

Another major source is the Uranium Recovery and Chemical Processing Facility in the $\mathrm{C}-400$ Building. Operations involving pulverizing and screening of uranium salts are conducted in this facility. The particulate emissions from this process are controlled by a removable cartridge filtration process.

\subsubsection{Identification and Location of Specific Sources}

The DOE Effluent Information System Report to EPA for 1981(1) identifies the following major sources:
- C-310 Stack $-7.12 \times 10^{-3} \mathrm{Ci} / \mathrm{yr}$
- C-400 Putverizer Vent - 5.0 × $10^{-2} \mathrm{Ci} / \mathrm{yr}$

The radioisotopes in these releases are ${ }^{99} \mathrm{Tc}$ and uranium.

The isotopic content of the releases is shown in Table 16.1. The radioisotopes in these releases are all uranium isotopes or ${ }^{99} \mathrm{Tc}$, a 1 ong-lived fission product. The ${ }^{99} \mathrm{Tc}$ results from feed uranium that has been recovered from irradiated reactor fuel. Results of the hypothetical risk (or hypothetical dose) calculation described in Section 1.4 and used for stack selection indicate that $98.1 \%$ of the risk comes from the $\mathrm{C}-400$ Building pulverizer vent. This release point is the major emission source at Paducah. The $\mathrm{C}-310$ Purge Cascade vent stack is the next most significant source.

\subsubsection{Nonspecific and Minor Sources}

The $C-400$ Building pulverizer vent and the $C-310$ Building purge vent were the most important sources in 1981. However, facilities that are still intact but present1y inactive have been important sources in the past. They 
TABLE 16.1. Paducah 1981 Releases ( $\mathrm{Ci} / \mathrm{yr}$ )

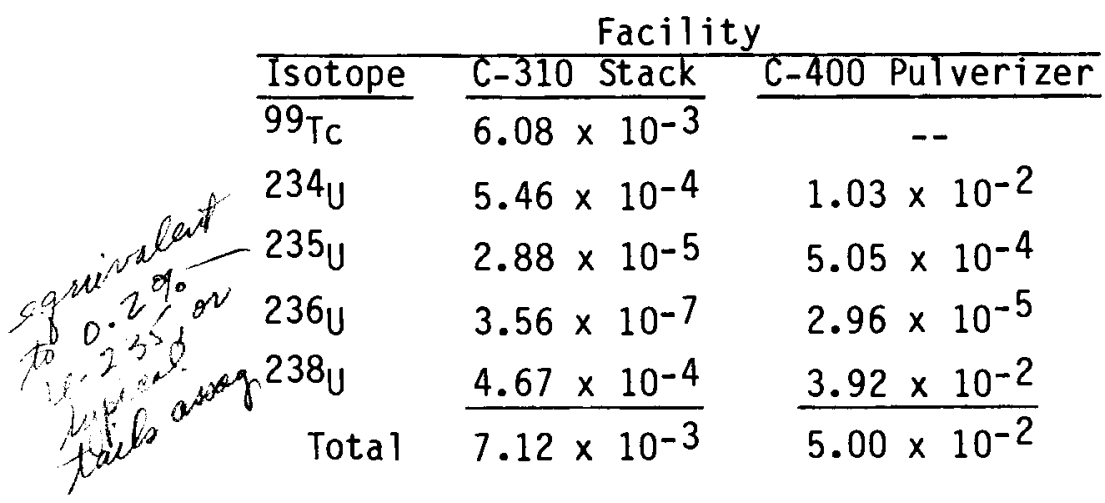

may become important in the future if plant operations are modified to include these process steps. Principal past sources are listed in Table 16.2. This information was supplied by G. J. Marciante of DOE's Oak Ridge Operation. There are no plans to reactivate any of these facilities at present.

\subsection{EMISSION CONTROL TECHNOLOGY AT THE PADUCAH GASEOUS DIFFUSION PLANT}

The primary control technologies presently at Paducah GDP are: HEPA filters, cartridge filters, sodium fluoride absorption traps, and activated alumina absorption traps. These methods are useful in controlling the release of uranium. They are also effective in controlling the fission product isotope ${ }^{99} \mathrm{Tc}$.

\subsubsection{Specific Source 1: C-400 Pulverizer Vent}

The C-400 Building Pulverizer Vent was the major source of emission at Paducah in 1981. The process operation is grinding UF 4 to a fine powder. This activity is not a main process activity and so may fluctuate drastically in the future. It is independent of enrichment plant operations. The following information was furnished by G. J. Marciante of DOE, ORO.

16.2.1.1 Description of Existing Emission Control Technology

The C-400 Pulverizer Vent discharges $17.4 \mathrm{~m}(57 \mathrm{ft})$ above ground level. The discharge flow rate is $2.12 \mathrm{~m}^{3} / \mathrm{sec}(4500 \mathrm{cfm})$ at a temperature less than 
TABLE 16.2. Principal Past Release Points at Paducah

\begin{tabular}{|c|c|c|c|c|c|}
\hline$\underline{B l d g}$ & $\begin{array}{r}\text { Operation } \\
\end{array}$ & Last Year of Operation & $\begin{array}{l}\text { Uranium } \\
\text { Emission Rate } \\
\text { (mCi/yr) } \\
\end{array}$ & Control Device & Efficiency \\
\hline$C-340$ & Slag Mill Derby Line & 1973 & 12.9 & Bag Filter & $99 \%$ \\
\hline$C-340$ & U Metal Derby Cleaning \#8 Blower & 1973 & 11.3 & None & \\
\hline$C-340$ & $\mathrm{UF}_{4}$ to Metal Conversion & 1973 & 24.9 & Bag Filter & $99 \%$ \\
\hline & (3 Roof Vents) & 1973 & 6.5 & Bag Filter & $99 \%$ \\
\hline$C-340$ & $\mathrm{UF}_{6}$ to $\mathrm{UF}_{4}$ Conversion & 1977 & 2.3 & Bag Filter & $99 \%$ \\
\hline & (2 Roof Vents) & 1977 & 2.7 & Bag Filter & $99 \%$ \\
\hline$C-340$ & Slag Recycling and Uranium Casting & 1973 & & & \\
\hline$C-746$ & Storage & 1978 & 11.5 & None & \\
\hline$C-410$ & General $\mathrm{UF}_{4}$ to $\mathrm{UF}_{6}$ Conversion & 1977 & 2.2 & Bag Filter & $99 \%$ \\
\hline$C-410$ & Fume $\mathrm{UF}_{4}$ to $\mathrm{UF}_{6}$ Conversion & 1977 & 13.1 & HEPA Filter & $99 \%$ \\
\hline$C-410$ & Vacuum $\mathrm{UF}_{4}$ to $\mathrm{UF}_{6}$ Conversion & 1977 & 6.4 & $\begin{array}{l}\text { Bag Filter and } \\
\text { Backup Pleated Filter }\end{array}$ & $99+\%$ \\
\hline C -410 & Fluorination & 1977 & 22.5 & $\begin{array}{l}\text { Cold Condenser Fluid } \\
\text { Bed Absorber Sintered } \\
\text { Metal Filters }\end{array}$ & $\sim 99 \%$ \\
\hline
\end{tabular}


$38^{\circ} \mathrm{C}\left(100^{\circ} \mathrm{F}\right)$. The vent has a square cross-sectional area of $37 \mathrm{~cm}(1.2 \mathrm{ft})$ on a side. Removable cartridge filtration is used with a rated overall efficiency of $99.9 \%$.

The removable cartridge filters were installed in 1981, replacing bag filters used previously. The capital costs of the replacement were approximately $\$ 20,000$, with annual operating costs of $\$ 14,000$.

\subsubsection{Current Discharge Rate}

The 1981 discharge rate is listed by Reference 1 as $50 \mathrm{mCi} / \mathrm{yr}$. Table 16.1 displays the isotopic release rates. The entire release is due to isotopes of uranium. The uranium composition is approximately $0.2 \%{ }^{235} \mathrm{U}$, which corresponds to current tails assay. The chemical form of the release is $\mathrm{UF}_{4}$. The 1982 operating experience is $9.2 \mathrm{mCi} / \mathrm{yr}$, a reduction by a factor of 5 due to the cartridge filter installation.

\subsubsection{Potential Additional Emission Control Technology}

A second cartridge filter could be added to the existing cartridge filter. The first cartridge filter would then act as a roughing filter for the second filtration stage. The amount of material deposited in the second filter should be very small, which would mean that replacement of the unit would be infrequent and a stand-by filter should not be required. An additional blower might be required to maintain flow.

\subsubsection{Anticipated New Discharge Rates}

An additional cartridge filter can be expected to operate at $99.9 \%$ efficiency. (2) With allowances for installation leaks and unfavorable particle size distributions, an overall efficiency for the second filter of at least $90 \%$ would appear to be easily achievable. This would reduce the 50 $\mathrm{mCi} / \mathrm{yr}$ rate to $5 \mathrm{mCi} / \mathrm{yr}$. In 1981 the vent was operated at $10 \%$ capacity. Full capacity operation would increase the $5 \mathrm{mCi} / \mathrm{yr}$ to $50 \mathrm{mCi} / \mathrm{yr}$.

16.2.1.5 Estimated Cost of Additional Emission Control Technology

G. J. Marciante of DOE, ORO has provided cost information for varous control devices installed on the Paducah Plant sources. The information is given in 1981 dollars and includes only the capital and operating cost of the device itself and not the capital cost of associated ducts, pipes and blowers. 
Cartridge filters were installed at a cost of $\$ 4 / \mathrm{cfm}$ capital cost and $\$ 3 /$ cfm annual operating cost. Increasing the capital cost by a factor of 3 to account for installation costs, and allowing for a flow rate of $2.12 \mathrm{~m}^{3} / \mathrm{sec}$ (4500 cfm), brings the cost of a second $C-400$ pulverizer vent cartridge filter to $\$ 54,000$ and the operating cost to $\$ 13,500 / y r$. DOE estimates the capital cost to be $\$ 204,000$ on the basis of installation difficulties at this location.

\subsubsection{Specific Source 2: C-310 Purge Vent}

The $\mathrm{C}-310$ purge vent contributes less than $2 \%$ of the hypothetical risk from the whole plant. The chemical processing of feed material, reclamation of product, or tails rework can temporarily overshadow releases from the cascades. However, the purge vent will remain the most significant source from the separations process itself for normal cascade operations. It is included, therefore, as a specific source for the Paducah Plant.

\subsubsection{Description of Existing Emission Control Technology}

The existing control technology is shown in Figure 16.3. (3) An NaF trap is installed on the cylinder burp at the product withdrawal stage of the purge cascade.

The releases prior to 1982 were vented from a $21.3-\mathrm{m}$ (70-ft) stack, 24.4 $\mathrm{cm}$ (9.6 in.) in diameter. A $200-\mathrm{ft}$ stack, $30.5 \mathrm{~cm}$ (1 ft) in diameter was constructed, largely to meet state of Kentucky ambient fluoride regulations. (4) The new stack was connected to the $\mathrm{C}-310$ Vent in 1982 . It will mitigate the dose received from this source by fostering a wider atmospheric dispersion.

\subsubsection{Current Discharge Rate}

The 1981 discharge rate is listed by Reference 1 as $7.12 \mathrm{mCi} / \mathrm{yr}$. Table 16.1 displays the isotopic release rates. The bulk of the release, or 6.08 $\mathrm{mCi}$, comes from ${ }^{99} \mathrm{Tc}$, with the remaining $1.04 \mathrm{mCi}$ coming from the isotopes of uranium. 


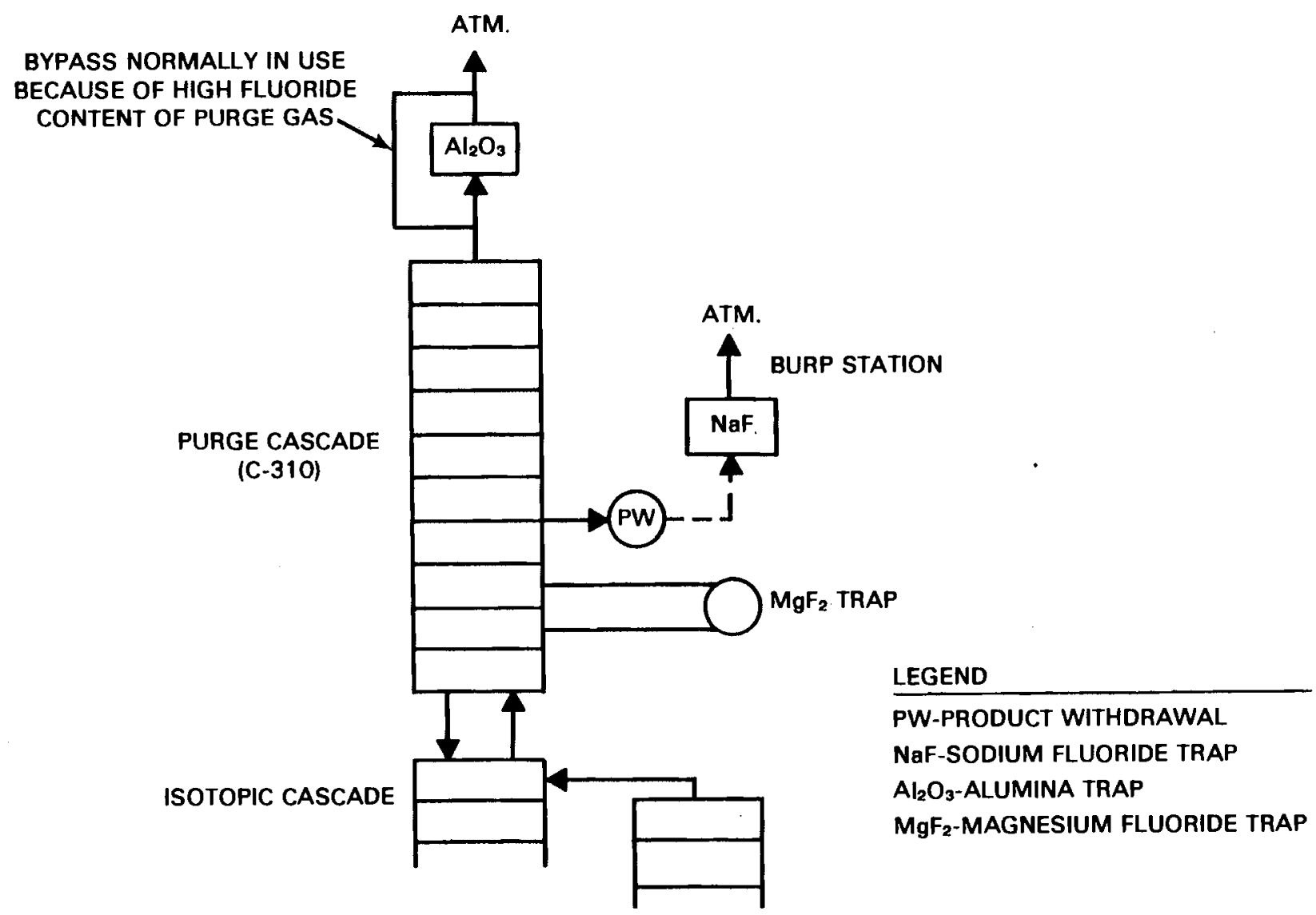

FIGURE 16.3. C-310 Bldg. Top Purge Effluent Treatment System

However, when the hypothetical risk factors as discussed in Section 1.4 are considered, the ${ }^{99}$ Tc contributes less than $1 \%$ to the total. The uranium isotopes are therefore of primary concern.

The ${ }^{99} \mathrm{Tc}$ present in the 1981 release comes from the introduction of previously irradiated uranium recycle material into the cascades. Currently no recycled uranium is being used as feed material. The ${ }^{99}$ Tc concentration in the cascade will decrease with time unless fresh recycle feed is introduced.

\subsubsection{Potential Additional Emission Control Technology}

A potassium hydroxide scrubber could be installed between the activated alumina traps and the stack. This control device is used at the Oak Ridge Gaseous Diffusion Plant on the purge cascade vent. $\mathrm{KOH}$ scrubbers are 
specified at the AGNS fuel reprocessing plant $\mathrm{UF}_{6}$ conversion facility (5) for of $f$-gas scrubbing of the fluorination process. (Since preparation of the first draft of this document, PNL has learned that the potassium hydroxide scrubber at the Oak Ridge Gaseous Diffusion Plant was installed solely for the purpose of removing fluorides, rather than uranium. And while the scrubber has been somewhat effective in removing uranium, perhaps to a lesser extent than the $90 \%$ deduced below, the 0ak Ridge scrubber has also been subject to serious corrosion problems, and is being removed and completely replaced after only 6 years of operation. This suggests that potassium hydroxide scrubbing is something less than a proven technology for UF 6 removal.)

\subsubsection{Anticipated New Discharge Rates}

The $\mathrm{KOH}$ scrubber efficiencies can be deduced by comparing the Portsmouth and Oak Ridge top purge control device efficiencies. Portsmouth, like Paducah, uses only activated alumina traps and has an overall efficiency of $90 \%$ for uranium. Oak Ridge, with the additional $\mathrm{KOH}$ scrubber, reports an efficiency of $99 \%$. This indicates that the $\mathrm{KOH}$ scrubber is $90 \%$ efficient. The predicted discharge rate would be reduced from $1.04 \mathrm{mCi} / \mathrm{yr}$ to $0.104 \mathrm{mCi} / \mathrm{yr}$ for uranium. However, in 1981, the operation of the purge vent was only $3 \%$ of the current capacity. At full capacity, the emission rate would be higher than $0.104 \mathrm{mCi} / \mathrm{yr}$.

The ${ }^{99} \mathrm{Tc}$ reduction to be expected from a $\mathrm{KOH}$ scrubber is not known. Experimental studies $(6)$ have indicated that activated alumina is effective as a trapping agent for technetium. The efficiency falls off with decreasing technetium concentration; however, an average efficiency of $97 \%$ was measured for inlet technetium concentration in the 0 to $1.4 \mathrm{ppm}$ range. Additional activated alumina traps upstream of the $\mathrm{KOH}$ scrubber could be used to reduce the ${ }^{99} \mathrm{Tc}$, if necessary. However, placing $\mathrm{Al}_{2} \mathrm{O}_{3}$ traps in series would quickly reduce the incremental increases in efficiency so that only a very few could be used.

\subsubsection{Estimated Cost of Additional Control Technology}

The capital cost of the ORGDP control system is $\$ 1,250,000$ with $\$ 300,000$ per year operating costs. Increasing the capital cost figures to allow for 
ducts, pipes and blowers by using the factor 1.5, and adjusting for the differences in the flow rates between the Paducah Plant and Oak Ridge, brings the estimated capital cost to $\$ 3.3$ million and the scaled operating cost to $\$ 523,000$ per year. A facility to dispose of the $\mathrm{KOH}$ rad waste would cost an additional $\$ 2.7$ million, for a total capital cost of $\$ 6 \mathrm{million}$. 


\section{REFERENCES}

1. U.S. Department of Energy Effluent Information System, EPA Effluent Analysis Report for Calendar Years 1979 through 1981, D0E EIS-261 (Computer Report), July 12, 1982.

2. Technology of Commercial Radioactive Waste Management, D0E/ET-0028, p. 4.8.5., U.S. Department of Energy, Washington, D.C., May 1979.

3. R. M. Schultz and M. J. Stephenson, "Purge Cascade Uranium Monitoring," Proceedings of the 1980 UCC-ND and GAT Waste Management Seminar, CONF 800416, Apri1 22-23, 1980.

4. L. B. Gibson, "An Alternative Approch for Meeting Ambient Gaseous Fluoride Standards," Proceedings of the 1980 UC-ND and GAT Waste Management Seminar," CONF 800416, ApriT 22-23, 1980.

5. Barnwell Nuclear Fuel Plant Separations Facility Final Safety Analysis Report, AGNS, January 1974.

6. A. J. Saraceno, "Technetium Removal from Plant Vent Streams," Proceedings of the 180 UCC-ND and GAT Waste Management Seminar," CONF 800416, Apri1 22-23, 1980. 


\subsection{PORTSMOUTH GASEOUS DIFFUSION PLANT}

The Portsmouth Gaseous Diffusion Plant was constructed by the federal government between 1952 and 1956 for the purpose of enriching the uranium-235 content of uranium feed material through a process of selective diffusion of $U_{6}$ through porous barriers,

\subsection{SITE AND MAJOR SOURCE DESCRIPTIONS}

The site, facility, and major sources of emissions from the facility are described in the next sections.

\subsubsection{Location of Site and Description of Facilities (1)}

The Portsmouth Gaseous Diffusion Plant is located in southern Ohio in Pike County, near the town of Piketon. Figure 17.1 shows the plant location with respect to nearby towns. It is on a 1600 -hectare federal reservation with a 260-hectare inner security area. The function of the plant is to enrich the fissile ${ }^{235} \mathrm{U}$ content of uranium. The enrichment process is based on the diffusion of gaseous $\mathrm{UF}_{6}$ through a porous barrier. A stage in the process consists of a compressor and a diffusion barrier cell called a converter. Because only a slight separation occurs at each stage, approximately 4000 separation stages are used at the Portsmouth facility. The stages are inter-connected to form a separation cascade. The cascades at Portsmouth are housed in three buildings: $X-326, X-330$ and $X-333$, which cover a total of 38 hectares. These and the other plant buildings are shown in Figure 17.2. The three cascade buildings vent process stream 1ight gas contaminant, and residual $U_{6}$ to the atmosphere.

Ancillary facilities include the following:

Tails Withdrawal Facility

This facility is located in the northeast corner of cascade Building $X-330$. It removes $U_{6}$ depleted in $235 U$ from the cascade for storage in cylinders. 


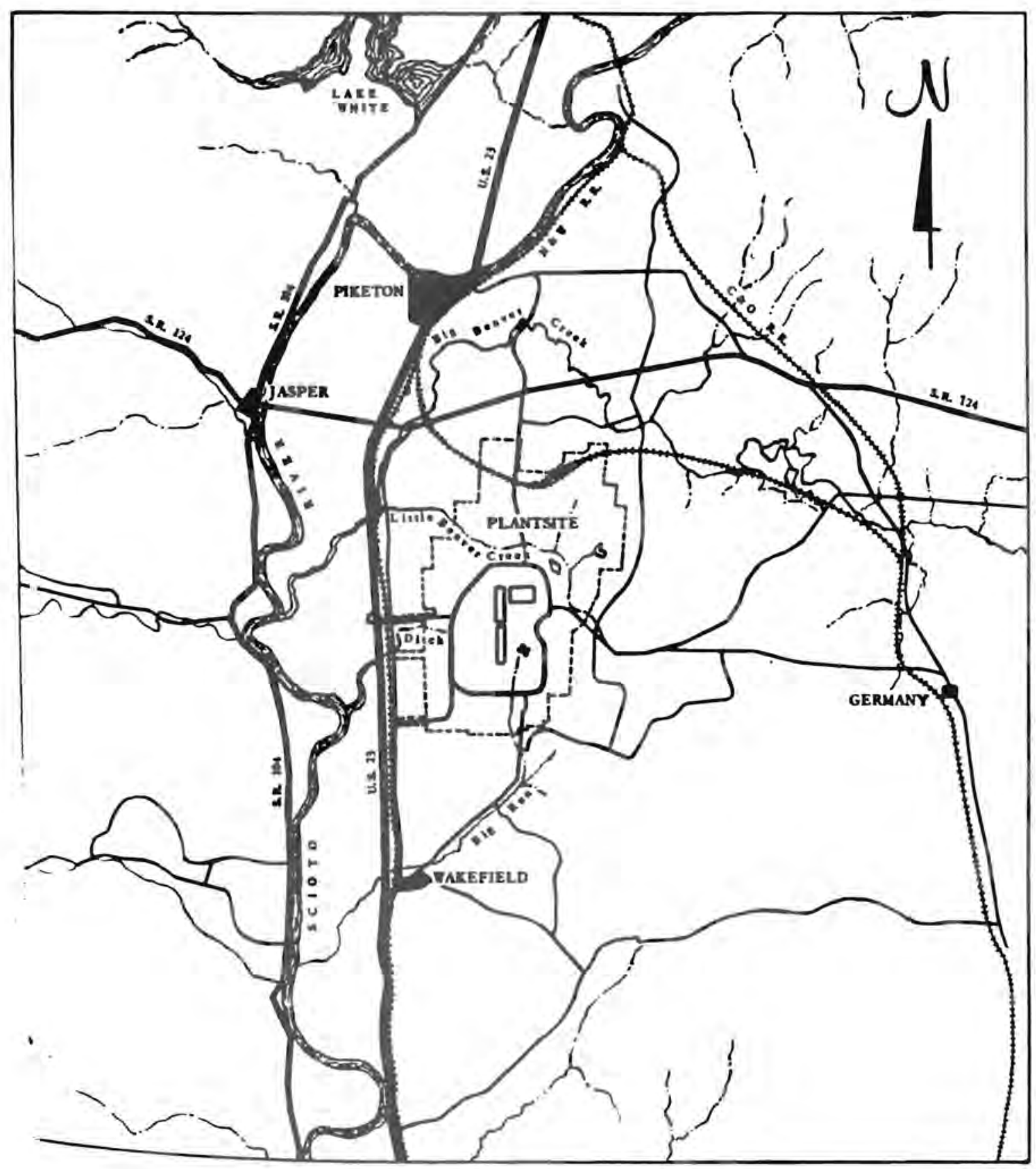

FIGURE 17.1. Map of the Portsmouth Gaseous Diffusion Plant Area 


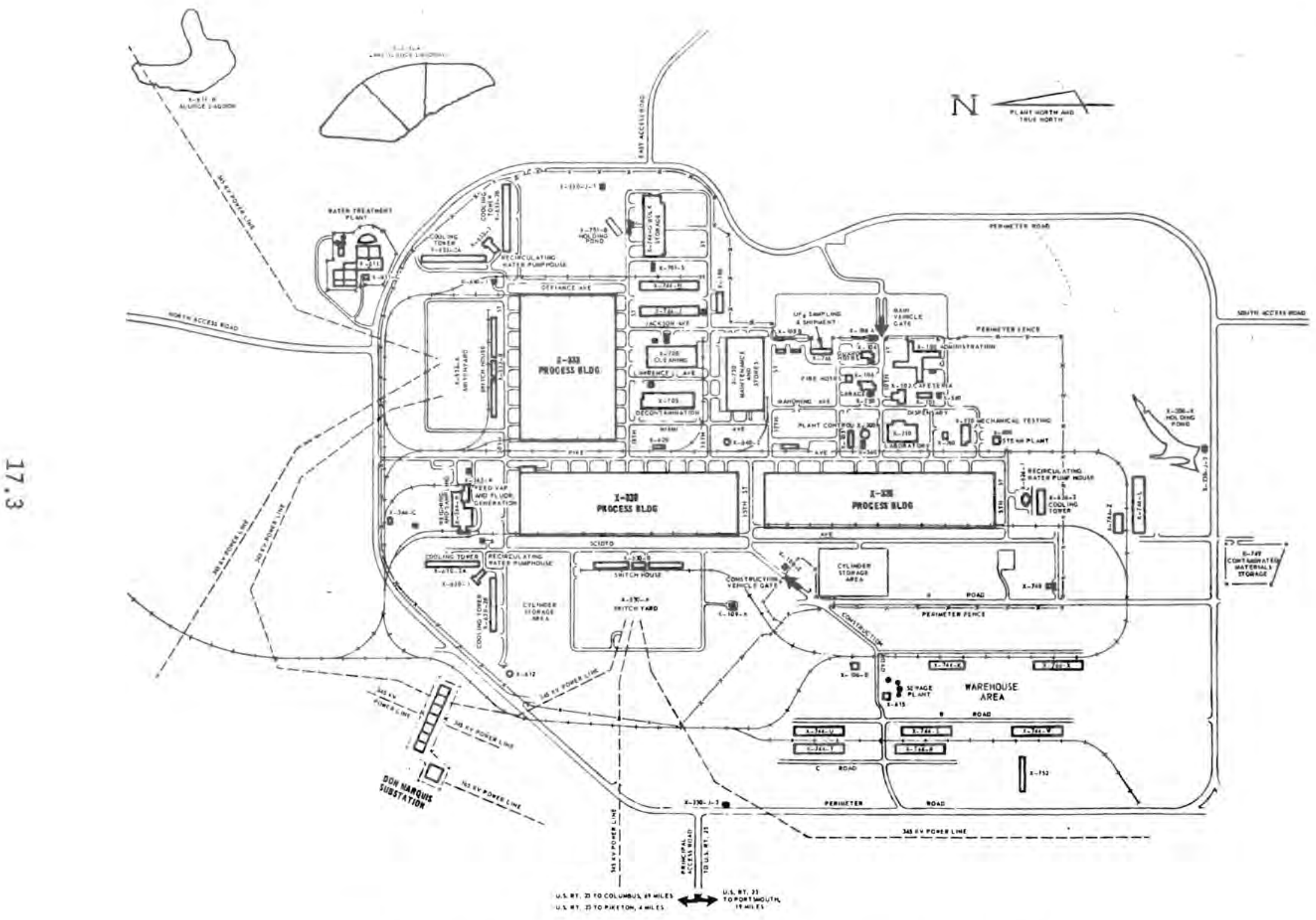

FIGURE 17.2. Portsmouth Gaseous Diffusion Plant Site Plan 
Product Withdrawal Facility

The product withdrawal facility is located in the southwest corner of the $x-326$ cascade building. It is designed to remove high assay UF 6 from the cascade and to store it in shipping cylinders. Product line purges are returned to the cascade.

Purge Cascades

The purge facilities, located in the south end of Building X-326, are used to separate and purge light gases from the process cascade. Two cascade process streams are purged: top purge and side purge. The top purge scrubs the highest assay product gas while the side purge processes the lower assay material. The side purge removes $90 \%$ of the light contaminants. The $10 \%$ spillover combined with equipment in-leakage is removed at the top purge. The purge gases are passed through parallel banks of activated alumina absorption trap before venting to the atmosphere.

\section{X-330 Cold Recovery System}

This facility is used in the recovery of $U_{6}$ from large volumes of purge gases collected throughout the plant. The purge gases are passed through refrigerated cold traps to freeze out $U_{6}$ and then through NaF traps for removal of remaining traces of UF 6 prior to being discharged to the atmosphere by means of air jet exhausts.

\section{$\underline{x-333 \text { Cold Recovery System }}$}

The primary function of this facility is to provide a means of removing $U_{6}$ from a cell or equipment in need of repair and storing it during the repair. The cold-trapping equipment permits separation of UF 6 and light gas in-leakage. The $\mathrm{UF}_{6}$ is returned to the cascade and the light gases are passed through alumina traps to remove traces of $U F_{6}$ and then vented to the atmosphere. 


\subsubsection{Identification and Location of Specific Sources}

The DOE Effluent Information System Report for $1981^{(2)}$ identifies the following major specific sources for the Portsmouth Plant:

- X-326 Building Top and Side Purge Vent - $0.26 \mathrm{Ci} / \mathrm{yr}$

- X-330 Building Cold Recovery Facility - $0.046 \mathrm{Ci} / \mathrm{yr}$

- X-333 Building Cold Recovery Facilty - $0.0043 \mathrm{Ci} / \mathrm{yr}$

The radioisotopes in these releases are uranium and its daughters plus ${ }^{99} \mathrm{Tc}$, a long-lived fission product. The ${ }^{99} \mathrm{Tc}$ results from introducing uranium feed from reprocessed irradiated nuclear reactor fuel.

The isotopic breakdown of 1981 releases is shown in Table 17.1. Over 95\% of the hypothetical risk, as calculated by the method in Section 1.4, originates in the $X-326$ purge vent. The $X-330$ and $X-333$ sources are minor sources.

TABLE 17.1. Portsmouth 1981 Releases (Ci)

Facility

\begin{tabular}{|c|c|c|c|}
\hline Isotope & $x-326$ Purge Vent & $x-330$ Cold Recovery & $x-333$ Cold Recovery \\
\hline$\overline{{ }^{99} \mathrm{Tc}}$ & $1.0 \times 10^{-1}$ & $2.8 \times 10^{-3}$ & $1.2 \times 10^{-3}$ \\
\hline${ }^{234} \mathrm{Th}$ & $3.7 \times 10^{-2}$ & $2.1 \times 10^{-2}$ & $9.9 \times 10^{-4}$ \\
\hline $234 \mathrm{~m} \mathrm{~Pa}$ & $3.7 \times 10^{-2}$ & $2.1 \times 10^{-2}$ & $9.9 \times 10^{-4}$ \\
\hline $234 U$ & $8.5 \times 10^{-2}$ & $1.0 \times 10^{-3}$ & $5.7 \times 10^{-4}$ \\
\hline $235_{u}$ & $2.5 \times 10^{-3}$ & $4.7 \times 10^{-5}$ & $3.3 \times 10^{-5}$ \\
\hline $236_{U}$ & $3.4 \times 10^{-5}$ & $1.1 \times 10^{-6}$ & $1.1 \times 10^{-6}$ \\
\hline $238_{U}$ & $1.4 \times 10^{-4}$ & $5.6 \times 10^{-4}$ & $5.6 \times 10^{-4}$ \\
\hline TOTAL & $\overline{2.6 \times 10^{-1}}$ & $\overline{4.6 \times 10^{-2}}$ & $\overline{4.3 \times 10^{-3}}$ \\
\hline
\end{tabular}

The largest absolute releases are from ${ }^{99} \mathrm{Tc}$. This low energy $\mathrm{B}$ emitter has a relatively high MPC $\left(2.0 \times 10^{-9} \mu \mathrm{Ci} / \mathrm{ml}\right)$, which makes it a less serious emission than the uranium isotopes in 1981. However, its presence depends on the extent to which previously irradiated uranium has been used as a feed material. Currently the recycle of uranium in civilian LWRs is not taking place. If recycled uranium is again introduced, the amount of released ${ }^{99} \mathrm{Tc}$ can be expected to increase and may present a problem in the future. 


\subsubsection{Non-Specific and Minor Sources}

The minor sources are the X-330 Cold Recovery Facility and the X-333 Cold Recovery Facility.

\subsection{EMISSION CONTROL TECHNOLOGY AT THE PORTSMOUTH GASEOUS DIFFUSION PLANT}

The mainline control technologies presently in place at Portsmouth are:

- Cold trapping: the $\mathrm{UF}_{6}$ is removed by freezing

- Sodium fluoride absorption

- Activated alumina absorption

These methods are primarily useful in preventing the release of uranium. They are also effective on uranium decay daughters and on the fission-product isotope ${ }^{99} \mathrm{Tc}$. Some material in this section was supplied by G. J. Marciante of DOE's Oak Ridge Operations Office.

\subsubsection{Specific Source 1: X-326 Top and Side Purge Vent}

The $\mathrm{X}-326$ Purge Vent is the major source of radionuclide emissions to the atmosphere at Portsmouth.

\subsubsection{Description of Existing Emission Control Technology}

The existing control device is the purge cascade itself, which removes the bulk of the $U_{6}$. The remaining light gases are sent through an alumina trap and diluted with an air jet exhauster before venting. Figure 17.3 shows the existing control system.

The schematic arrow to atmosphere shown in Figure 17.3 is a set of four purge vents. Each vent is $23 \mathrm{~m}(76 \mathrm{ft}) \mathrm{high}, 47 \mathrm{~cm}$ (18 in.) apart. The diameter of each vent is $10 \mathrm{~cm}$ ( $4 \mathrm{in}$.). Each vent has a flow rate of $4.72 \times$ $10^{-2} \mathrm{~m}^{3} / \mathrm{s}(100 \mathrm{cfm})$ at ambient temperature.

\subsubsection{Current Discharge Rate (1981)}

$$
\begin{array}{lll}
{ }^{99} \mathrm{Tc} & 1.038 \times 10^{-1} \mathrm{Ci} / \mathrm{yr} \\
\text { Uranium } & 8.8 \times 10^{-2} \mathrm{Ci} / \mathrm{yr} \\
{ }^{234 \mathrm{mPa}} & 3.67 \times 10^{-2} \mathrm{Ci} / \mathrm{yr} \\
{ }^{234} \mathrm{Th} & 3.67 \times 10^{-2} \mathrm{Ci} / \mathrm{yr}
\end{array}
$$

The last two are uranium decay daughters in secular equilibrium. 


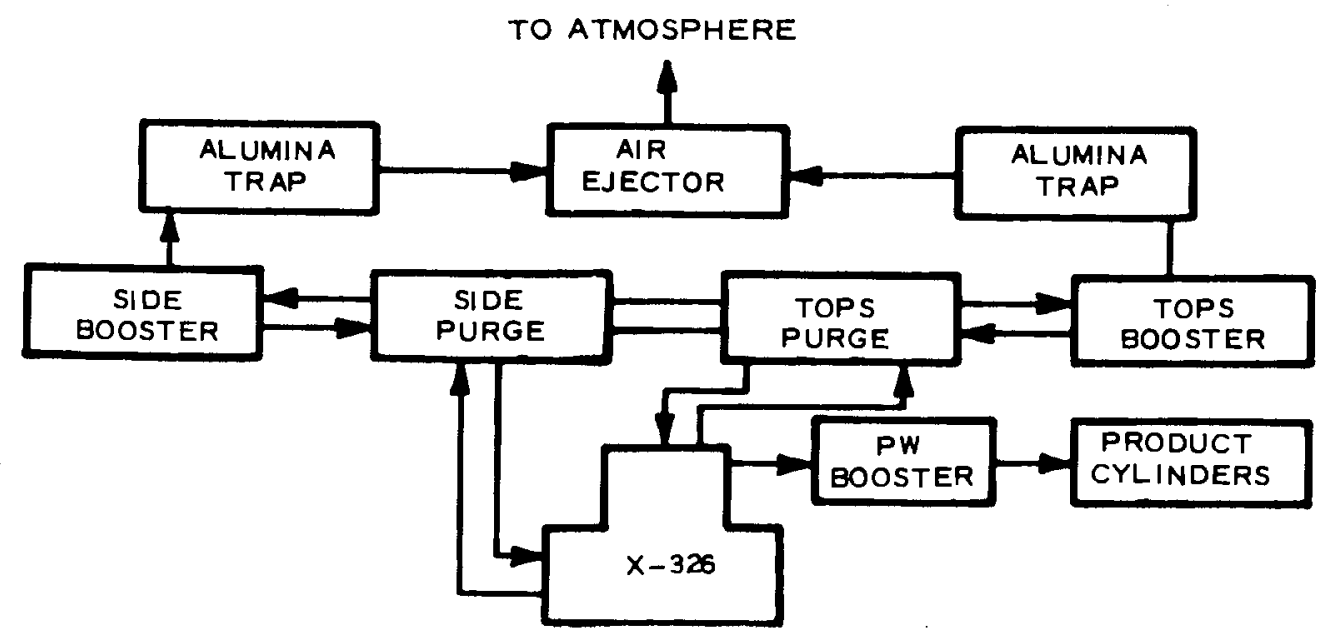

FIGURE 17.3. X-326 Bldg. Top Purge Effluent Treatment System

\subsubsection{Potential Additional Emission Control Technology}

A potassium hydroxide scrubber could be installed between the activated alumina traps and the air ejectors as shown in Figure 17.3. A single scrubber would be supplied from the combined output of the top and side purge alumina traps. This control device is used at the Oak Ridge Gaseous Diffusion Plant to control releases from the purge cascades. $\mathrm{KOH}$ scrubbers are specified at the AGNS reprocessing plant $U_{6}$ conversion facility $(3)$ for of $f$-gas scubbing of the fluorination process. (Since preparation of the working draft of this document, PNL has learned that the potassium hydroxide scrubber at the 0ak Ridge Diffusion Plant was installed solely for the purpose of removing fluorides, rather than uranium. And while the scrubber has been somewhat effective in removing uranium, perhaps to a lesser extent than the $90 \%$ deduced below, the Oak Ridge scrubber has also been subject to serious corrosion problems, and is being removed and completely replaced after only 6 years of operation. This suggests that potassium hydroxide scrubbing is something less than a proven technology for $U_{6}$ removal.)

\subsubsection{Anticipated New Discharge Rates}

The $\mathrm{KOH}$ scrubber efficiency can be deduced by comparing the Portsmouth and Oak Ridge top purge control device efficiencies. Portsmouth uses only 
activated alumina traps. The efficiency is $90 \%$ for uranium. ORGDP with a $\mathrm{KOH}$ scrubber has a 99\% efficiency. This indicates that the $\mathrm{KOH}$ scrubber alone has an efficiency of $90 \%$ when applied to the alumina trap exit gas stream. The emission control efficiencies for the Oak Ridge and Portsmouth plants were supplied by G. J. Marciante of DOE, ORO. With a $\mathrm{KOH}$ scrubber in place, the $88 \mathrm{mCi} / \mathrm{yr}$ uranium discharge rate in 1981 would have been reduced to $8.8 \mathrm{mCi} / \mathrm{yr}$. In 1981, operations were at $52.6 \%$ capacity; therefore, at full capacity with the $\mathrm{KOH}$ scrubber in place about $18 \mathrm{mCi} / \mathrm{yr}$ would be expected.

The reduction in emissions of ${ }^{99} \mathrm{TC}$ is not known because no data are available for $\mathrm{KOH}$ scrubber efficiencies for ${ }^{99} \mathrm{Tc}$ containment.

Additional activated alumina traps might be utilized should ${ }^{99}$ Tc emissions become unacceptable. The efficiency falls off with decreasing technetium concentration, however an average efficiency of $97 \%$ was measured for inlet ${ }^{99} \mathrm{Tc}$ concentrations in the 0 to $1.4 \mathrm{ppm}$ range. (4) Additional alumina traps upstream of the $\mathrm{KOH}$ scrubber could be used with only a very few traps connected in series due to the fall off in efficiency with decreasing concentration.

\subsubsection{Estimated Cost of Additional Control Technology}

The capital cost of the ORGDP control system is $\$ 1,250,000$ with $\$ 300,000$ annual operating cost. These figures do not include an allowance for installation of piping, ducts, valves and blowers. They apply to the control devices alone. Since the product $U_{6}$ is highly enriched in $235 \mathrm{U}$, it would be necessary to put four or five scrubber units in parallel to assure a critically-safe geometry. This would increase the capital costs by a factor of five over the Oak Ridge single unit scrubber. Operating cost would be expected to double. These adjustments result in a $\$ 6,250,000$ capital cost and an annual operating cost of $\$ 520,000$ for the $\mathrm{KOH}$ scrubber. The ORGDP costs were supplied by G. J. Marciante of DOE, ORO. A facility to dispose of the $\mathrm{KOH}$ radwaste would cost an additional $\$ 2.7$ million. 


\section{REFERENCES}

1. Final Environmental Impact Statement, Portsmouth Gaseous Diffusion Plant Site, ERDA-1555, May 1977.

2. U.S. Department of Energy Effluent Information System, EPA Effluent Analysis Report for Calendar Years 1979 through 1981," EIS-261, (Computer Report) U.S. Department of Energy, Washington, D.C., July 1982.

3. Barnwell Nuclear Fuel Plant Separations Facility, Final Safety Analysis Report, AGNS, January 1971.

4. A. J. Saraceno, "Technetium Removal from Plant Vent Streams," In Proceeding of the 1980 UCC-ND and GAT Waste Management Seminar, April 2223, 1980. 



\subsection{ROCKY FLATS PLANT}

This section describes emission control technology at the Rocky Flats Plant.

\subsection{SITE AND MAJNR SOURCE DESCRIPTIONS}

The Rocky Flats Plant (RFP) is located near Denver, Colorado, and is used primarily for production of nuclear weapon components to fulfill the requirements of U.S. defense policy. The manufacturing of these weapon components from plutonium, uranium, and tritium results in some release to the environment of these elements.

\subsubsection{Location of Site and Description of Facilities}

The RFP is located in Jefferson County, Colorado, about $26 \mathrm{~km}$ northwest of Denver. It is bounded on the east by Jefferson County Highway 17, on the south by State Highway 72, and on the west by Highway 128 (Figure 18.1). It covers almost $28 \mathrm{~km}^{2}$ and is situated at an elevation of about $1830 \mathrm{~m}$. The plant is operated by Rockwell International.

The fabrication of nuclear weapon components from both radioactive and nonradioactive materials is the primary function of the RFP. Facilities for the fabrication or recovery of plutonium account for the majority of the buildings located on the site. Radioactive or toxic materials are processed in enclosures within the buildings. Specialized support services include facilities for the recovery of plutonium and americium from wastes, analytical laboratories, waste disposal facilities, and research and development facilities.

In support of the unique facility at Rocky Flats are the usual plant functions, such as health care, safety, quality control, maintenance, and other activities, along with their associated facilities.

18.1.2 Identification and Location of Specific Sources

The EPA Release Point Analysis Report for calendar year 1981 (see Appendix A) identifies 41 airborne release points on the Rocky Flats site 


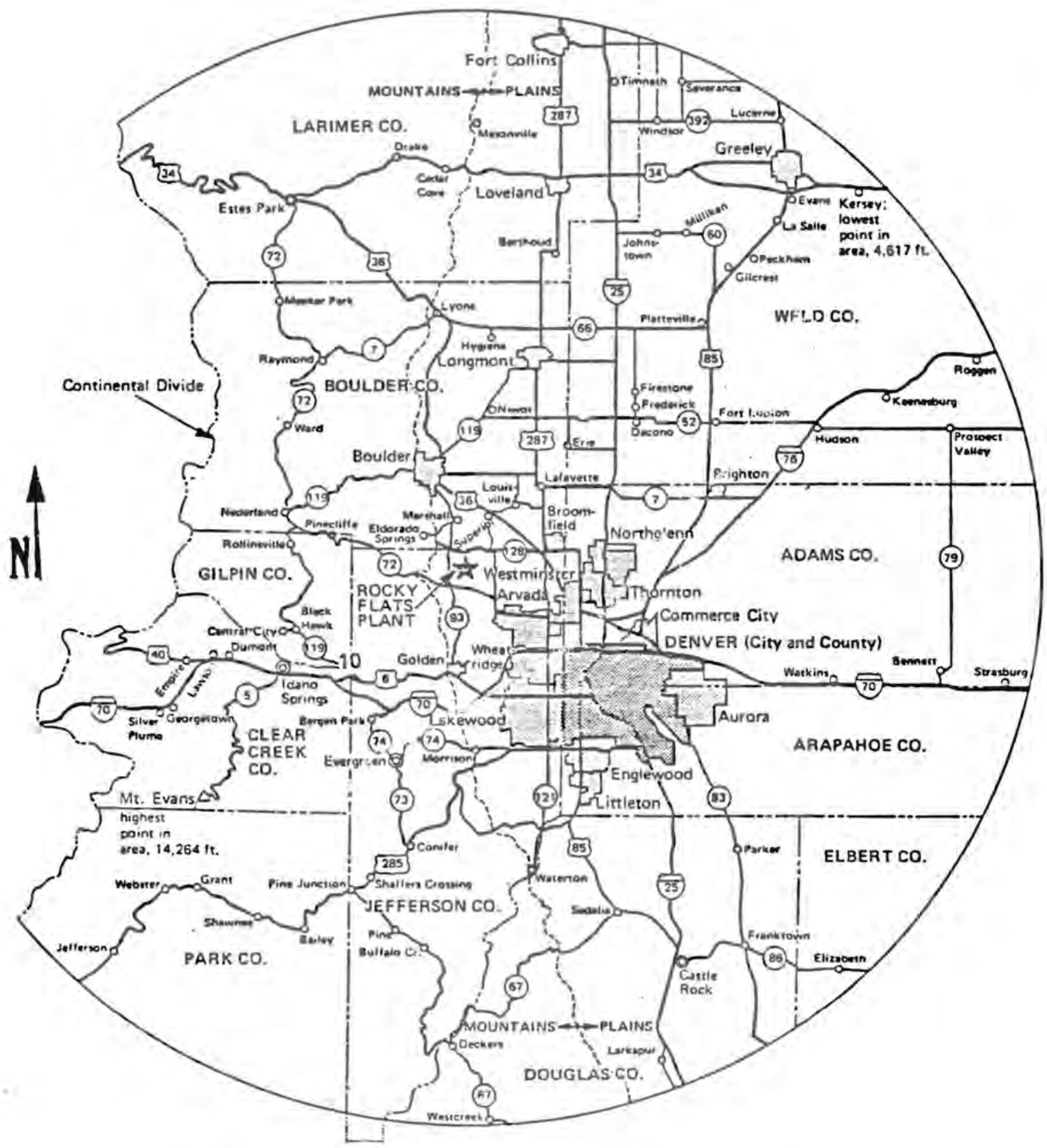

FIGURE 18.1. Genera] Location of the Rocky Flats Plant Within a 50-Mile Radius

whose emissions range from $4.6 \times 10^{-8}$ to $1.2 \times 10^{-1} \mathrm{Ci} / \mathrm{yr}$. The uranium isotopes $233 \mathrm{U}, 234 \mathrm{U}$ and $238 \mathrm{U}$, the plutonium isotopes $239 \mathrm{Pu}$ and $240 \mathrm{Pu}$ and the hydrogen isotope $3 H$ (tritium) are the only ones identified in the report. Total emissions from each release point in 1981 are given in Table 18.1 . 
TABLE 18.1. RFP Airborne Radioactive Releases for 1981(a)

\begin{tabular}{|c|c|}
\hline Release Point & $\begin{array}{l}\mathrm{Pu}, \mathrm{U},{ }^{3} \mathrm{H} \\
(\mathrm{Ci} / \mathrm{Yr})\end{array}$ \\
\hline Plutonium Anal. Lab. & $2.000 E-02$ \\
\hline $\begin{array}{l}\text { Fabrication Assem. Bldg } \\
\text { Bldg } 707-106 \text { Plenum } \\
\text { Bldg } 707-108 \\
\text { Bldg } 707-105 \\
\text { Bldg } 707-107 \\
\text { Bldg } 707-101 / 103 \\
\text { Bldg } 707 \quad 102 / 104\end{array}$ & $\begin{array}{l}3.900 E-03 \\
2.500 E-03 \\
4.600 E-03 \\
1.400 E-02 \\
2.600 E-03 \\
6.400 E-03\end{array}$ \\
\hline $\begin{array}{l}\text { Manufacturing Bldg } \\
371 \text { N1 and N2 } \\
371 \text { South } \\
771-\text { Main Plenum } \\
\text { 771C-Main Plenum } \\
771 \mathrm{C} \text { Room Plenum }\end{array}$ & $\begin{array}{l}4.300 E-03 \\
1.600 E-03 \\
8.001 E-02 \\
4.545 E-05 \\
9.460 E-07\end{array}$ \\
\hline $\begin{array}{l}374 \text { Waste Treat. Facil. } \\
374 \text { Spray Dryer } \\
\text { Bldg 774-202 }\end{array}$ & $\begin{array}{l}7.601 E-04 \\
1.800 E-03\end{array}$ \\
\hline $\begin{array}{ll}\text { Manufacturing } & \text { Bldg } \\
\text { Bldg } & 776-250 \\
\text { Bldg } & 776-206 \\
\text { Bldg } & 776-201 / 203 \\
\text { Bldg } & 776-205 \\
\text { Bldg } & 776-204 \\
\text { Bldg } & 776-251 \\
\text { Bldg } & 776-252 \\
\text { Bldg } & 776-202\end{array}$ & $\begin{array}{l}1.500 E-02 \\
1.200 E-01 \\
8.400 E-04 \\
3.800 E-02 \\
1.500 E-02 \\
8.200 E-08 \\
4.600 E-08 \\
7.000 E-08\end{array}$ \\
\hline $\begin{array}{l}\text { Plut. Devel. Bldg } \\
\text { Bldg 779-729 Plenum } \\
\text { Bldg 779-782 Plenum }\end{array}$ & $\begin{array}{l}2.1 \cap 0 E-03 \\
4.200 E-02\end{array}$ \\
\hline Laundry Bldg 778 & $5.240 \mathrm{E}-07$ \\
\hline $\begin{array}{l}\text { Waste Treat. Facil. } \\
\text { Bldg } 374 \text { Main }\end{array}$ & $1.900 \mathrm{E}-02$ \\
\hline $\begin{array}{l}\text { Manufacturing Bldg } \\
\text { Bldg } 444 \text {-Duct } 2 \text { and } 3 \\
\text { Bldg } 44-\text {-Duct } 1 \\
\text { Bldg } 444-\text { Duct } 5\end{array}$ & $\begin{array}{l}9.200 E-07 \\
1.000 E-06 \\
2.000 E-07\end{array}$ \\
\hline
\end{tabular}


TABLE 18.1. (contd)

\begin{tabular}{|c|c|}
\hline Release Point & $\begin{array}{r}\mathrm{Pu}, \mathrm{U},{ }^{3 \mathrm{H}} \\
(\mathrm{C} i / \mathrm{Yr}) \\
\end{array}$ \\
\hline $\begin{array}{l}\text { Manufacturing Bldg } \\
\text { Bldg } 447 \text { Main }\end{array}$ & $1.200 E-06$ \\
\hline $\begin{array}{l}\text { Materials and Process } \\
\text { Devel. Laboratory } \\
\text { Bldg } 865 \\
\text { Bldg } 865 \text { West }\end{array}$ & $\begin{array}{l}1.800 \mathrm{E}-07 \\
7.000 \mathrm{E}-07\end{array}$ \\
\hline $\begin{array}{l}\text { Manufacturing Bldg } \\
\text { Bldg 881-Ducts } 1-4 \\
\text { Bldg } 881 \text {-Ducts } 5-6 \\
\text { Bldg } 883 \text {-Duct A } \\
\text { Bldg } 883 \text {-Duct B }\end{array}$ & $\begin{array}{l}4.200 E-02 \\
4.430 E-06 \\
7.000 E-06 \\
5.800 E-06\end{array}$ \\
\hline $\begin{array}{l}\text { Nuclear Safety Facil. } \\
\text { Bldg } 886-875\end{array}$ & $2.420 E-07$ \\
\hline $\begin{array}{l}\text { Equip. Decontam. Bldg } \\
\text { Bldg 889-Main }\end{array}$ & $8.905 E-07$ \\
\hline $\begin{array}{l}\text { Assembly Bldg } \\
\text { Bldg 991-985 } \\
\text { 991 Main }\end{array}$ & $\begin{array}{l}1.688 E-07 \\
1.140 E-07\end{array}$ \\
\hline
\end{tabular}

(a) EPA Release Point Analysis Report for Calendar Year 1981.

(b) See Section 1.4 .

Calculations described in Section 1.4 for each release point identify three buildings as major contributors to the overall release of radioactive materials from the plant site: 1) the Plutonium Analytical Laboratory (Building 569), 2) the Manufacturing Building 771-Main Plenum, and 3) the Manufacturing Building 881-Ducts 1,2, 3, and 4.

18.2 EMISSION CONTROL TECHNOLOGY AT THE ROCKY FLATS PLANT

Ventilation systems for the containment of radioactive materials at the RFP are designed to maintain pressure differentials between zones and to 
control the airflow between zones. Negative pressure differentials exist between the outside atmosphere and the building interior as well as between various areas within the building. Thus, should any one zone be breached, the airflow is moved toward a potentially more contaminated zone.

Air supplied to the buildings is filtered, dehumidified, and heated or cooled to meet environmental requirements. The air is transported to the needed areas within the building through ducts in a controlled manner. Highefficiency particulate air (HEPA) filters are provided in a separate exhaust system for room air and glove box (air or inert) enclosures.

The RFP uses a minimum of two stages of HEPA filtration for general building air in buildings that handle plutonium and four stages of filtration from glove boxes used for the handling of plutonium. Examples of these filtration systems are shown in Figures 18.2 and 18.3. Buildings in which uranium is handled have at least one stage of HEPA filtration. (1)

HEPA filters are used exclusively at Rocky Flats for final air filtration. Each new HEPA filter is tested with an aerosol of dioctylphthalate for leakage. Each is also inspected for squareness and damaged gaskets, and tested for total pressure drop. Representative filters from each manufacturer are tested for proper operation under conditions of high humidity. (1)

Newly installed HEPA filter systems are field tested for a system efficiency of $99.95 \%$. Filters are changed on an "as required" basis, which may vary from several days to several years, depending on the loading. Inplace testing of filter banks is performed to assure an efficiency of 99.95\%. Plenums in the newer buildings are designed so that they may be completely isolated during a filter-changing operation. (1)

Although small amounts of tritium are handled at the plant, releases are so low that a tritium removal system is not considered technically or economically practicable. Tritium releases are controlled by a strict limit on the total amount of tritium that can be contained in materials processed at Rocky Flats. Inadvertent processing of special nuclear materials which might contain tritium is prevented by the testing of all nonroutine incoming shipments. 


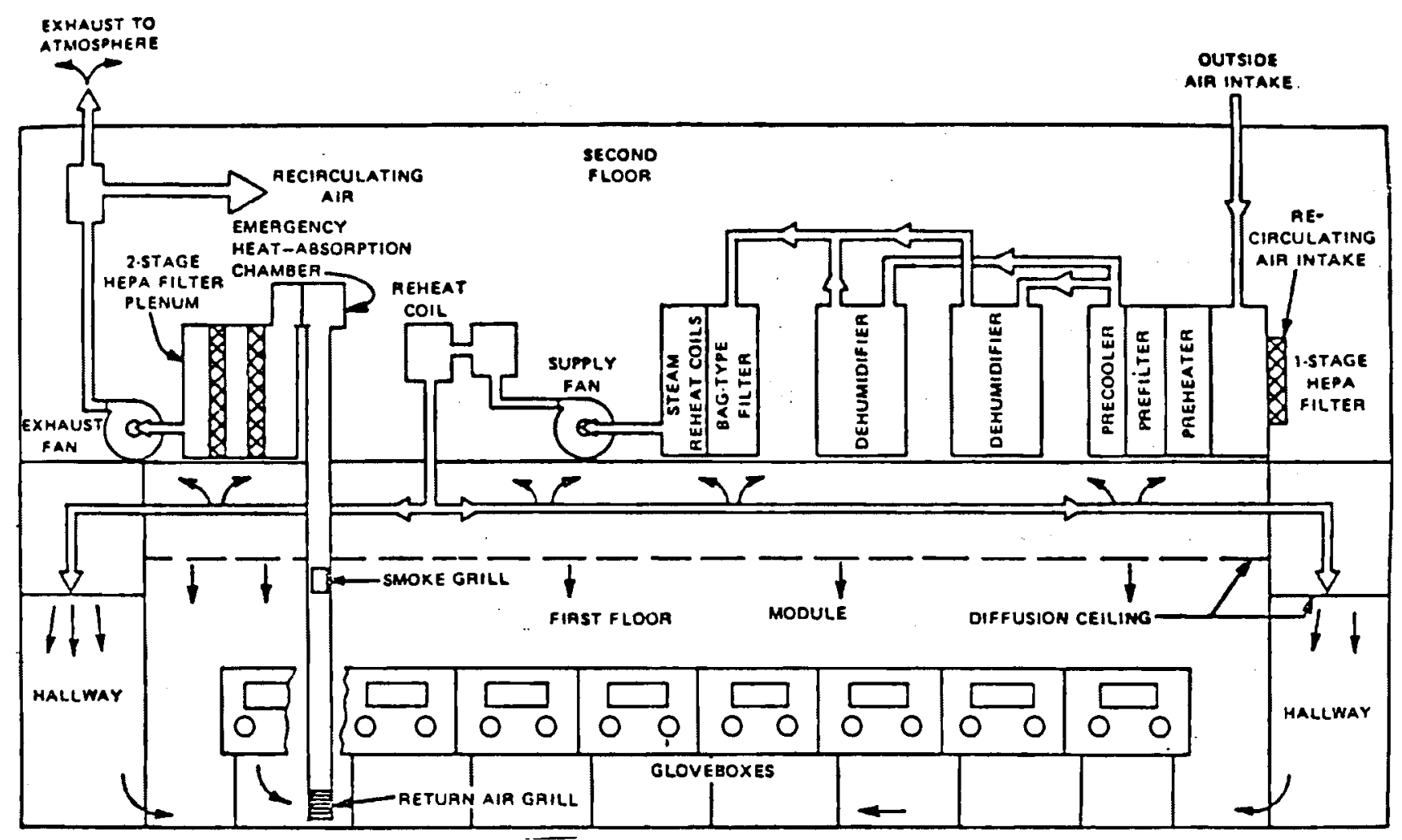

FIGURE 18.2. Typical Building Dry Air Ventilation System

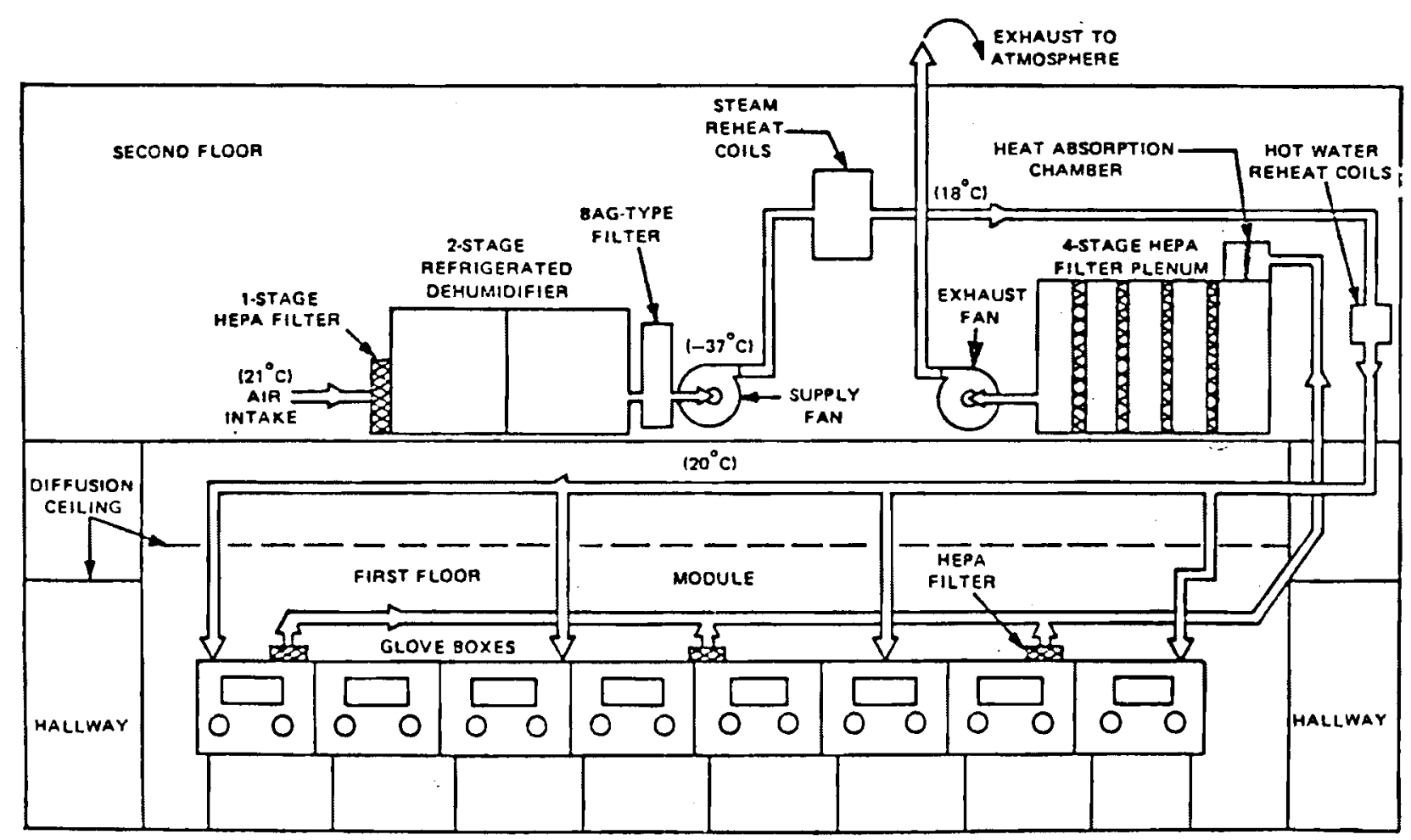

FIGURE 18.3. Typical Glove Box Dry Air Ventilation System 
Some of the information in the following sections was furnished by James Sterns and Bert Crist of the DOE Rocky Flats Field Office.

\subsubsection{Specific Source 1: Building 771 Main Plenum}

The basic mission of the 771 Building is to provide chemical recovery and refining operations. The possibility of removing some of the chemical recovery operations to an alternate onsite location has been studied; however, no firmly committed change in the basic use of Building 771 is anticipated.

\subsubsection{Description of Existing Emission Control Technology}

An airflow diagram for the 771 Building is shown in Figure 18.4. The Glove Box Exhaust System 1-A filter plenum contains 1 stage of demisters, 1 stage of roughing prefilters and 4 stages of HEPA filters having 24 filters per stage. The HEPA stages are arranged as 2 separated banks of 2 stages placed back-to-back. The filtered exhaust from this system is directed to the 771 Main Exhaust system.

Glove Box Exhaust System 2 is an exhaust system composed of three sections. The first $(D C-1)$ is the demister section. The second section (FU-2B) is a plenum containing 4 stages of HEPA filters with 30 filters per stage. These 4 stages are an arrangement of 2 separated banks of 2 stages placed back-to-back. The third section (FU-2A) is a 2-stage plenum having 15 HEPA filters in separated stages. Filtered air from this exhaust system is discharged to the 771 Main Exhaust system. Under emergency conditions, which would result in the loss of the exhaust fans (FN-3, -4), the exhaust from FU$2 B$ would be directed to the 771 Main Exhaust system, bypassing Section FU-2A.

The Incinerator Booster System is a fume scrubber systm that discharges off-gases from an incinerator into a HEPA filter plenum. The scrubber system, not shown in the flow diagram, consists of heat exchangers, off-gas quenching chamber, venturi scrubber and a wet cyclone. The incinerator filter plenum contains 4 stages of HEPA filters having 12 HEPA filters per stage. The 4 HEPA stages are arranged as 2 separated banks of 2 stages placed back-toback. Effluent from this system is directed to the 771 Main Exhaust system. 


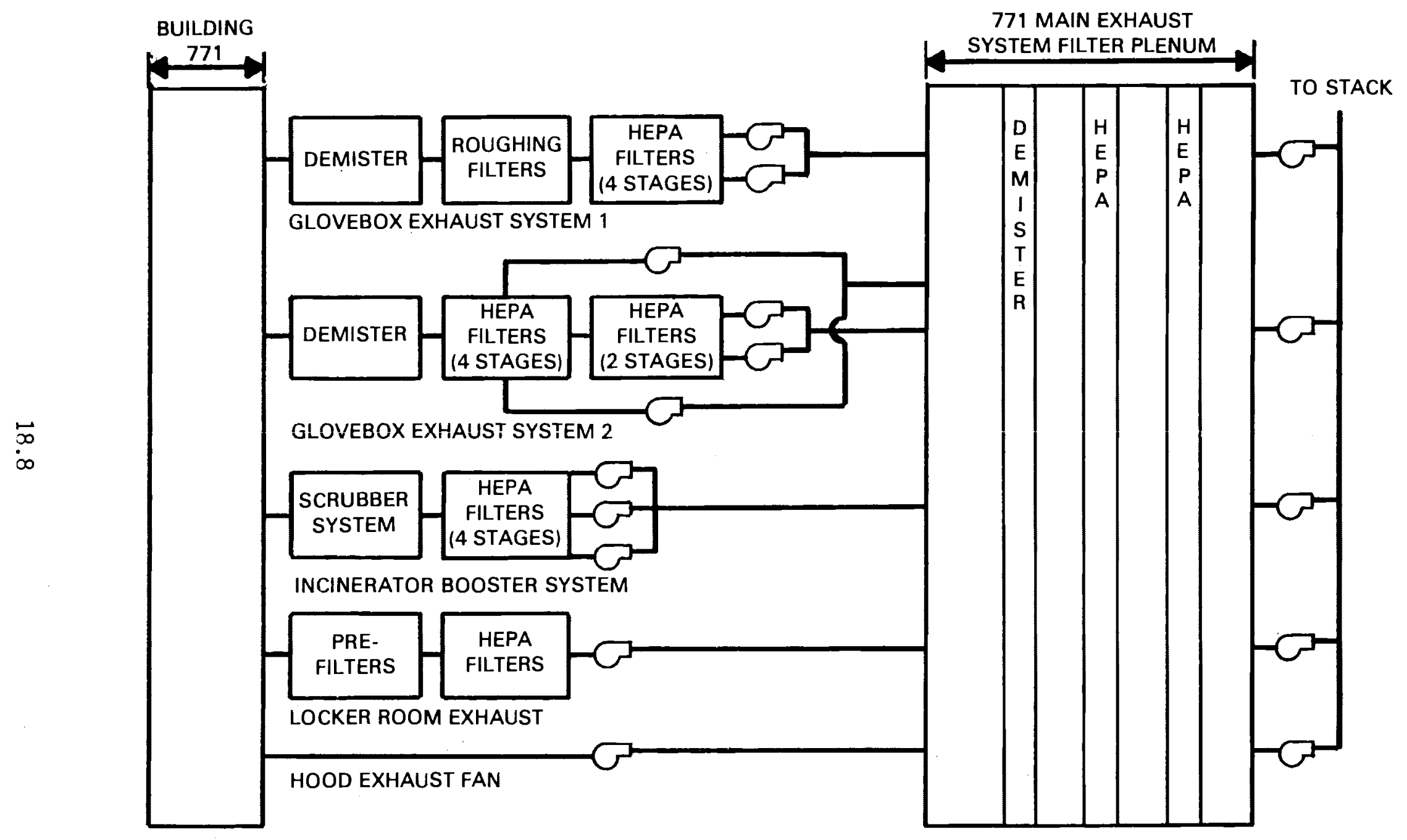

FIGURES 18.4. Air Flow in Building 771 
The FU4 is a single-stage filter plenum containing one stage of furnacetype prefilters and a single stage of 24 HEPA filters. Air from this system is discharged to the 771 Main Exhaust system.

The Tracer Lab Booster System exhaust system (not shown in Figure 18.4) is not currently being used and has been sealed from the atmosphere.

The Main Exhaust System filter plenum contains a demister and 2 stages of HEPA filters. The first stage contains 512 HEPA filters, the second stage contains 525 HEPA filters.

There are no new exhaust systems planned for this building. However, modifications to the downstream portion of the duct work and fan system as well as other modifications upstream may be made sometime in the future. The air is exhausted through a stack having a height of $150 \mathrm{ft}$.

There are no anticipated increases in the discharge rates from 771 Building. The total air exhaust through the Main Exhaust System during 1981 was 3.0E9 cubic meters.

The above-described information was supplied by the Rocky Flats DOE Field Office.

18.?.1.2 Current Discharge Rate

The EPA Release Point Analysis Report for calendar year 1981 (See Appendix A) indicates a total airborne release of $8.001 \mathrm{E}-02 \mathrm{Ci} / \mathrm{yr}$ from the 771 Building Main Plenum.

18.2.1.3 Potential Additional Emission Control Technology

The addition of a third bank of HEPA filters to the 771 Building Main Plenum $(6090 \mathrm{~m} 3 / \mathrm{min}$ or $215,000 \mathrm{cfm})$ is the additional emission control technology that is considered. Theoretically, the decontamination factor (DF) would be increased by a factor of 500 by the addition of a third stage of HEPA filters (99.95\% efficiency for first stage, $99.8 \%$ efficiency for all additional stages).

The estimated capital cost to provide an additional filter bank to the 771 Building Main Plenum, excluding the structure in which it will be enclosed, is shown in Table 18.2. 
TABLE 18.2. Estimated Capital Costs of Providing a Third Stage of HEPA Filters on the 771 Building Main Plenum

\begin{tabular}{|c|c|}
\hline Item & $\begin{array}{c}\text { Cost } \\
\text { (\$Thousands) }\end{array}$ \\
\hline HEPA Filters (252) & 1,380 \\
\hline Dampers (28) & 280 \\
\hline Blowers (14) & 280 \\
\hline Ductwork & 700 \\
\hline Electrical and Instrumentation & 220 \\
\hline Facility & excluded \\
\hline Indirect Construction Costs & $\underline{90}$ \\
\hline Subtotal & $\overline{2,950}$ \\
\hline Architect-Engineering Service $(\sim 25 \%)$ & 730 \\
\hline Subtotal & $\overline{3,680}$ \\
\hline Contingency $(\sim 35 \%)$ & 1,220 \\
\hline Other & 1,000 \\
\hline Total Project Costs & 5,000 \\
\hline
\end{tabular}

The average stack emissions from the 771 Building Main Plenum during 1981 (see Appendix A) were:
1) $239,240 \mathrm{Pu}$
$5.14 \times 10^{-4} \mu \mathrm{Ci} / \mathrm{hr}$
2) $233,234,238 \mathrm{U}$
$1.14 \times 10^{-4} \mu \mathrm{Ci} / \mathrm{hr}$
3) $3 \mathrm{H}$
$9.13 \mu \mathrm{Ci} / \mathrm{hr}$

The average stack air volume for this plenum in 1981 was $3.4 \times 10^{11}$ $\mathrm{m} \ell / \mathrm{hr}$, for an average plutonium concentration of $1.5 \times 10^{-15} \mu \mathrm{Ci} / \mathrm{ml}$. The limiting radionuclide is plutonium, whose concentration is a factor of about 40 below the MPC for unrestricted areas $\left(6 \times 10^{-14} \mu \mathrm{Ci} / \mathrm{ml}\right.$, as listed in $10 \mathrm{CFR}$ 20. Therefore, additional control technology is not suggested on the basis of average concentration of plutonium in the stack.

The DOE has a 771 Main Plenum renovation project in progress. The present plenum was designed about 30 years ago. It is a sealed concrete block construction with steel filter frames bolted and sealed in place. The DOE intends to build a new stainless steel plenum inside the existing one, 
replacing the first-stage filters with steel frames of a more recent design, as used for the existing second-stage filter. These frames and those of the second stage will be welded (sealed) to the steel plenum wall. The plenum, which is presently all one unit, will be divided into three parallel sections such that any two of them could handle the building air flow. This will allow blanking off any one section at a time to reduce the impact of disturbances during filter changes, maintenance or some form of emergency that might give cause to shut down part of the system.

The stainless steel plenum will be installed in four phases. Phases 1 and 2 have been funded. Phases 3 and 4 (removal of a boiler and installation of an exhaust fan) will be requested as budget line items in 1985.

\subsubsection{Specific Source 2: Building 881 - nucts 1, 2, 3 and 4}

All process-related activities involving plutonium and uranium in Building 881 have been relocated. Space formerly devoted to production activities is being converted to additional office space and data processing operations. Expansion of the existing analytical laboratory is planned.

Radioactive releases currently being experienced are due primarily to residual contamination deposited by post-production activities.

18.2.2.1 Description of Existing Emission Control Technology

The flow diagram for Building 881 is shown in the upper portion of Figure 18.5. This exhaust plenum is a single stage containing 712 HEPA filters. An additional recirculating exhaust system is planned to improve the building's energy efficiency. The air is exhausted through a traditional stack having a physical height of $31 \mathrm{~m}(100 \mathrm{ft})$. The total air handled by Building 881 (Ducts 1, 2, 3 and 4) during 1981 was 1.9 E9 cubic meters. The system efficiency is not measured.

\subsubsection{Current Discharge Rate}

The EPA Release Point Analysis Report for calendar year 1981 (see Appendix A) indicates a total airborne release of $4.200 \mathrm{E}-02 \mathrm{Ci} / \mathrm{yr}$ from the 881 Building - Ducts $1,2,3$ and 4. 


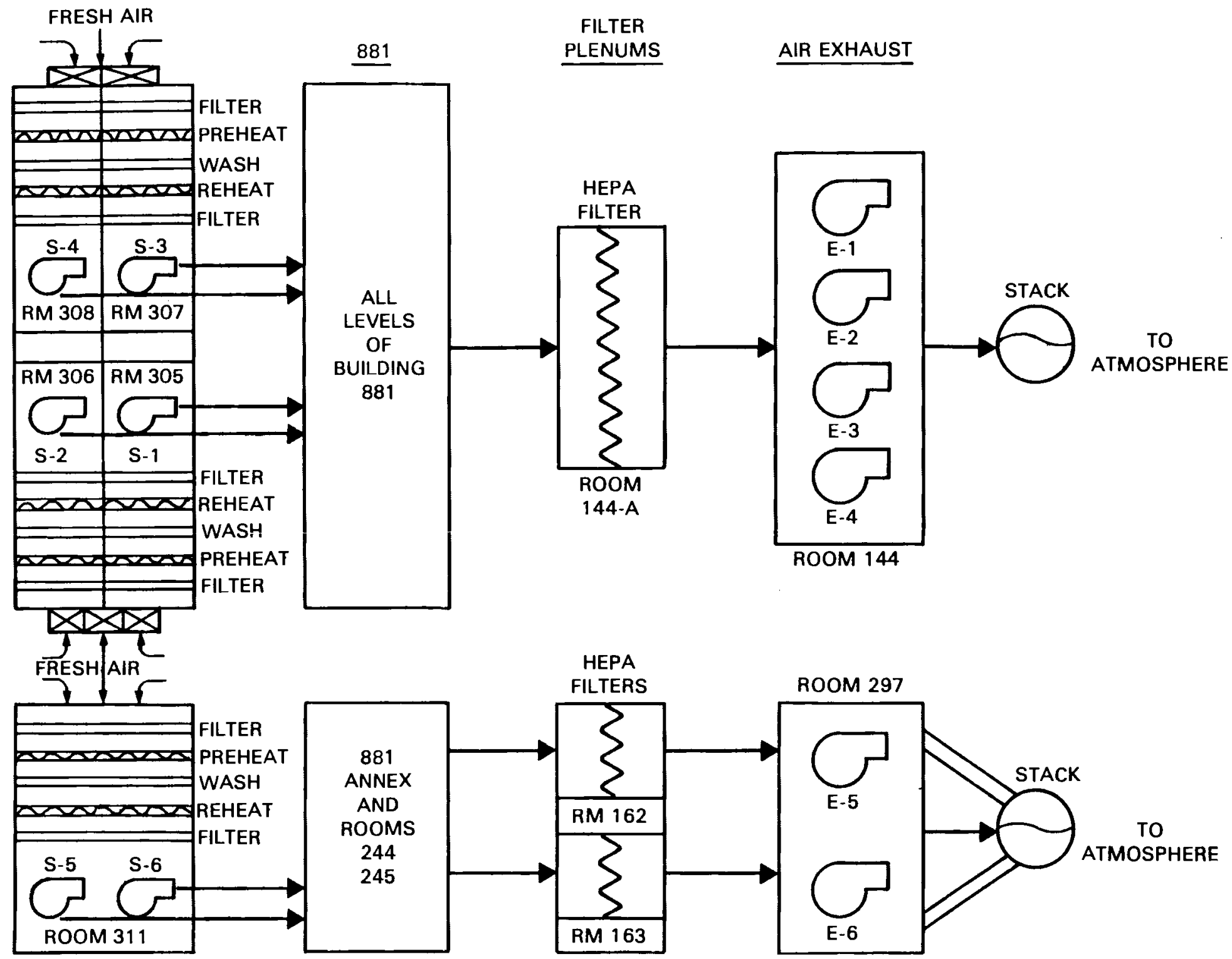

FIGURE 18.5. Air Flow Diagram, Building 881 


\subsubsection{Potential Additional Emission Control Technology}

The average stack emissions from Building 881, Ducts 1, 2, 3 and 4, during 1981 (see Appendix A) were:
1) $239 \mathrm{Pu}$
$4.1 \times 10^{-5} \mu \mathrm{Ci} / \mathrm{hr}$
2) $233,234,238 \mathrm{U}$
$3.0 \times 10^{-4} \mu \mathrm{Ci} / \mathrm{hr}$
3) $3 \mathrm{H}$
$4.8 \mu \mathrm{Ci} / \mathrm{hr}$

The average stack air volume for this building in 1981 was $2.2 \times 1011 \mathrm{~m} \ell / \mathrm{hr}$, for an average plutonium concentration of $1.9 \times 10^{-16} \mu \mathrm{Ci} / \mathrm{ml}$. The limiting radionuclide is plutonium, whose concentration is a factor of 300 or more below the MPC for unrestricted areas $\left(6 \times 10^{-14} \mu \mathrm{Ci} / \mathrm{ml}\right)$, as listed in 10 CFR 20. Thus, additional control technology is not suggested on the basis of average plutonium concentration in the stack.

18.2.3 Specific Source 3: Plutonium Analytical Laboratory (Building 559)

Building 559 is designed and equipped to provide analytical information required for control of the manufacturing and chemical processing of nuclear weapon components at the RFP.

18.2.3.1 Description of Existing Emission Control Technology

Radionuclide emissions from the Plutonium Analytical Laboratory are by way of the building ventilation air system. The total air flow diagrams for Buildings 559 and 561 are shown in Figures 18.6, 18.7, 18.8, and 18.9. FP-300-A is a three-stage filter plenum containing 1 stage of 40 metal impingement filters and 2 stages of 40 HEPA filters per stage. FP-301-A is a five-stage plenum containing 1 stage of 24 metal impingement filters and 4 stages of 24 HEPA filters per stage. FP-302-A is a five-stage plenum containing 1 stage of 20 metal impingement filters and 4 stages of 20 HEPA filters per stage.

The air is exhausted through a stack $6.4 \mathrm{~m}$ in height. No new exhaust systems are planned for this building, and there is no anticipated increase in 


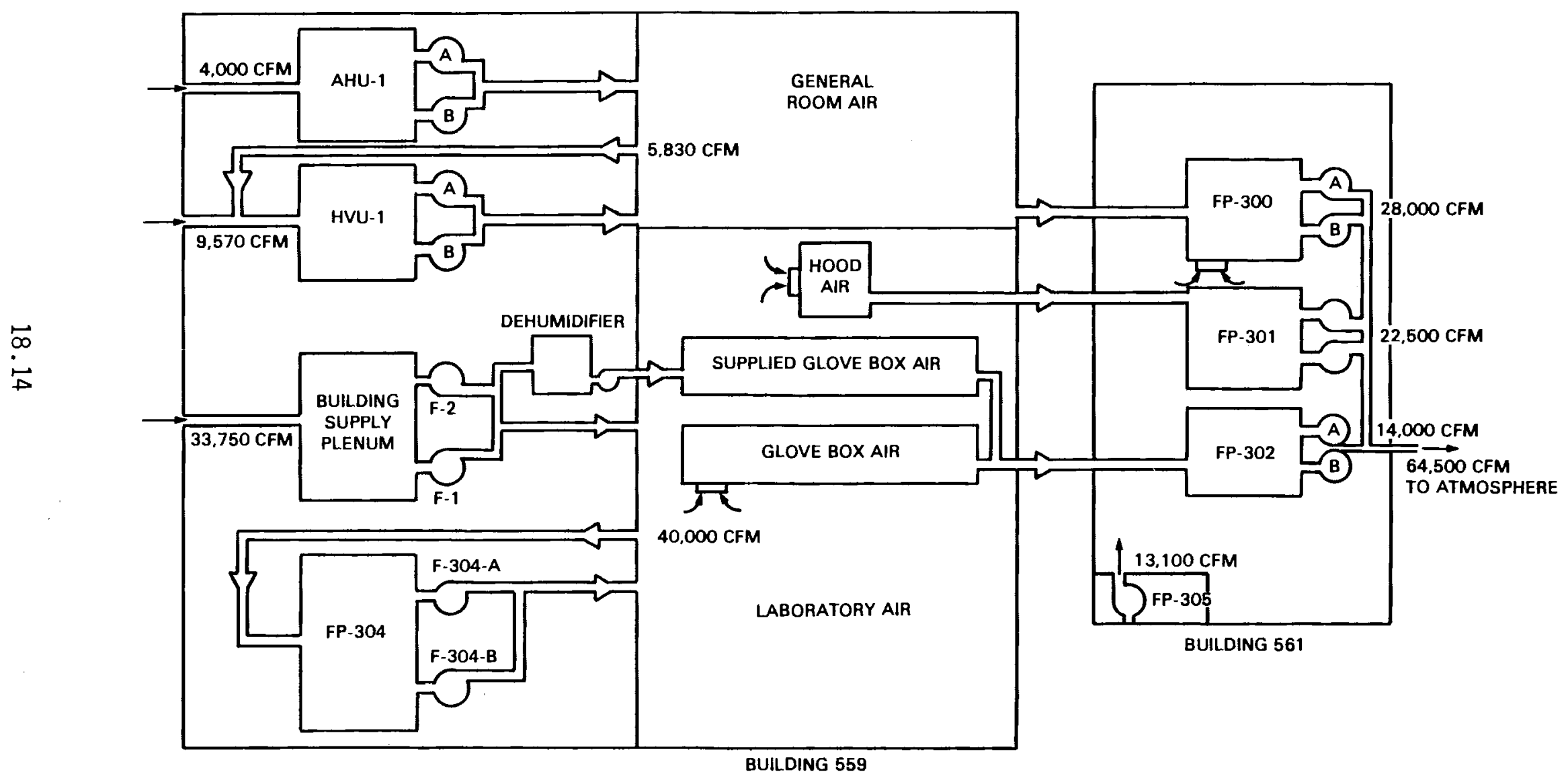

FIGURE 18.6. Air Flow Diagram, Buildings 559 and 561 


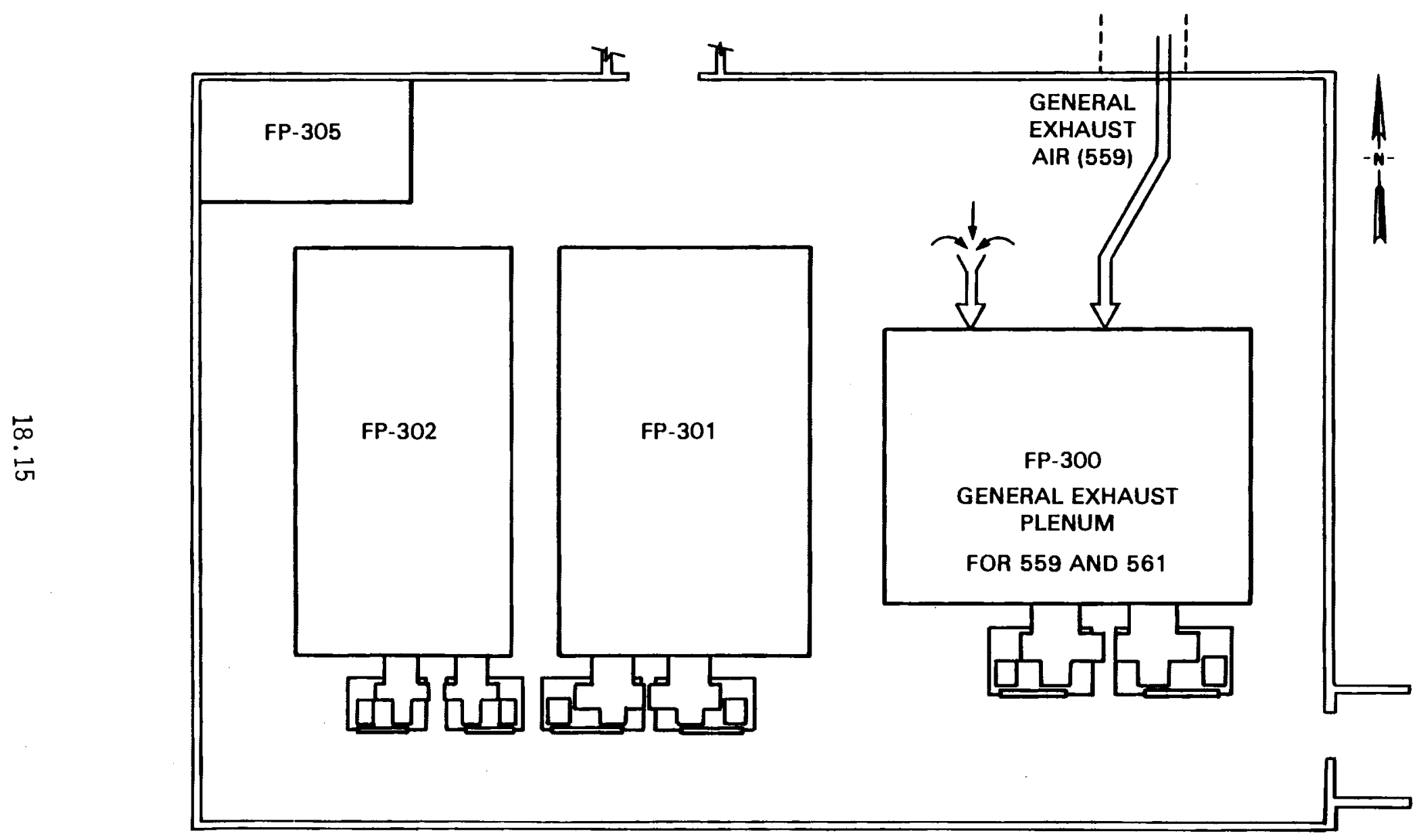

FIGURE 18.7. General Exhaust Air Flow 


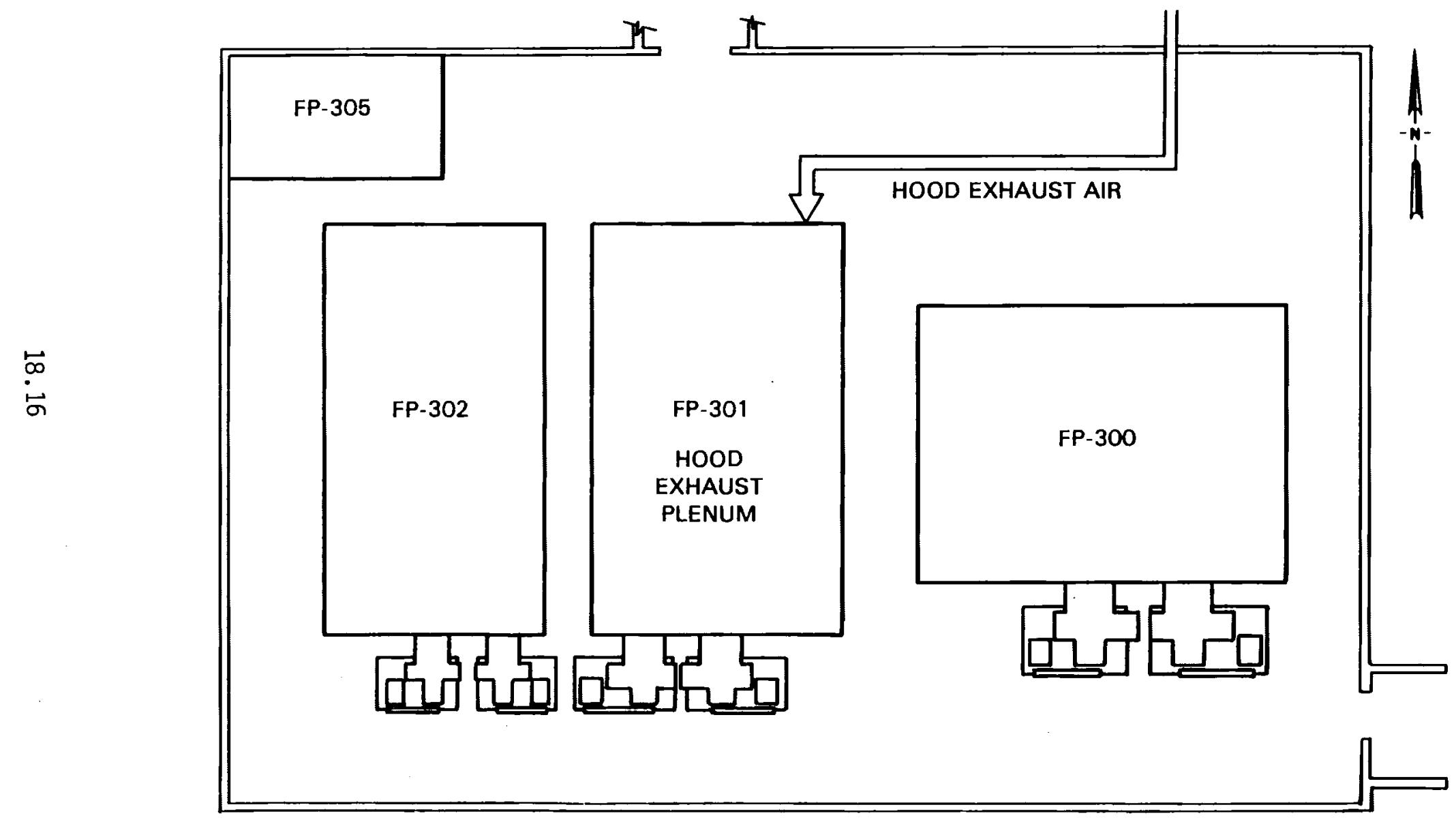

FIGURE 18.8. Hood Exhaust Air Flow 


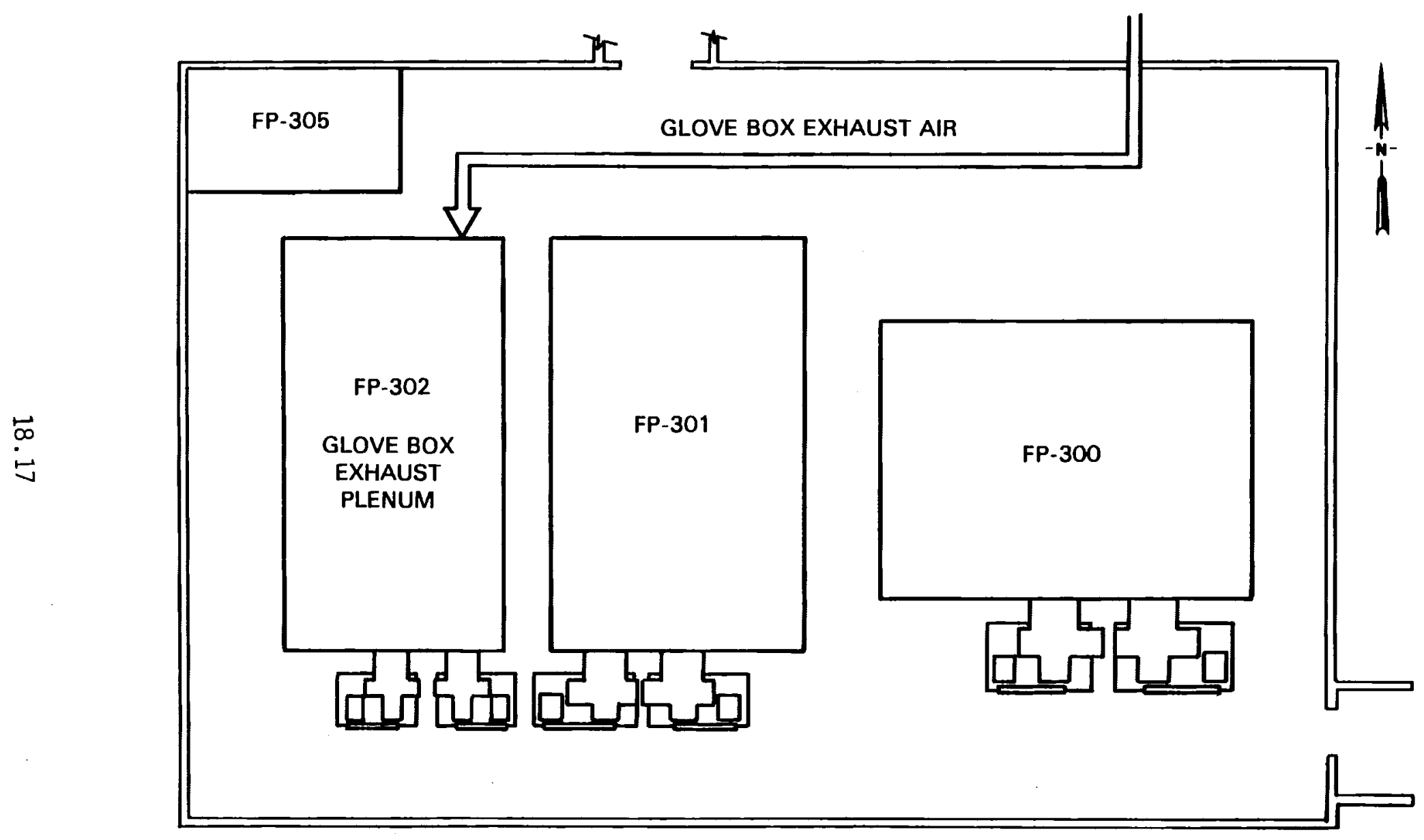

FIGURE 18.9 Glove Box Exhaust Air Flow 
the discharge rates. The total air handled by Building 559 during 1981 was 7.2E8 cubic meters. The system efficiency is not measured.

\subsubsection{Current Discharge Rate}

The EPA Release Point Analysis Report for calendar year 1981 (see Appendix A) indicates a total airborne release of $2.00 \mathrm{E}-2 \mathrm{Ci} / \mathrm{yr}$ from the Plutonium Analytical Laboratory.

\subsubsection{Potential Additional Emission Control Technology}

The average stack emissions from the Plutonium Analytical Laboratory (Building 559) during 1981 (see Appendix A) were:
1) $239,240 \mathrm{Pu}$
$5.0 \times 10^{-5} \mu \mathrm{Ci} / \mathrm{hr}$
2) $233,234,238 \mathrm{U}$
$4.7 \times 10^{-5} \mu \mathrm{Ci} / \mathrm{hr}$
3) $3 \mathrm{H}$
$2.3 \mu \mathrm{Ci} / \mathrm{hr}$

The average stack air volume for this building in 1981 was $8.2 \times 10^{10} \mathrm{ml} / \mathrm{hr}$, for an average plutonium concentration of $6.1 \times 10^{-16} \mu \mathrm{Ci} / \mathrm{m} \ell$. The limiting radionuclide is plutonium, whose concentration is a factor of about 100 below the MPC for unrestricted areas $\left(6 \times 10^{-14} \mu \mathrm{Ci} / \mathrm{ml}\right)$, as 1 isted in $10 \mathrm{CFR} 20$. Thus, no additional control technology is suggested on the basis of average plutonium concentration in the stack.

\subsubsection{Non-Specific and Minor Sources}

All sources listed in the EPA Release Point Analysis Report for calendar year 1981 (see Appendix A), with the exclusion of the three sources named for further investigation in Section 18.1.2, are considered as non-specific or minor sources. Sources that may have been reported in previous years, but not listed in the above-named document are not considered in this report. 


\section{REFERENCES}

1. Rocky Flats Plant Site, DOE/EIS-0064, U.S. Department of Energy, Washington, D.C., Aprii 1980. 



\subsection{SAVANNAH RIVER PLANT}

The Savannah River Plant (SRP) is a government-owned, contractor-operated complex dedicated principally to the production of materials for nuclear weapons. As a result of these operations, radionuclides are released that can cause a small radiation dose to the populace in the surrounding area.

In this section the SRP site and facilities are described, the types and quantities of radionuclides released to the atmosphere and the specific locations of the release points are identified, and the equipment for control of emissions presently installed at the release points is described, together with potential additional control systems for further reduction of releases. In addition, the effectiveness of each potential additional control system is estimated, and the costs for implementing the potential additional control equipment are estimated. The estimated costs are not necessarily of budget quality. Most of the information presented is abstracted from Reference 1.

\subsection{SITE AND MAJOR SOURCE DESCRIPTIONS}

A brief description of the location of the SRP site and of the various operating components on the site is presented in Section 19.1.1. The principal sources of radionuclide releases are identified and their locations on the site are specified in Section 19.1.2.

19.1.1 Location of Site and Description of Facilities

The SRP occupies an approximately circular area of 775 square kilometers (77,500 hectares) in South Carolina, $40 \mathrm{~km}$ southeast of Augusta, Georgia (Figure 19.1). The site borders the Savannah River for approximately $27 \mathrm{~km}$. The plant site is closed to the public except for guided tours, controlled deer hunts, controlled through-traffic along South Carolina Highway 125 (SRP Road A) and along the Seaboard Coast Line Railroad, and traffic on U.S. Highway 278 along the north edge of the site (Figure 19.2). The SRP was designated as the nation's first National Environmental Research Park. 


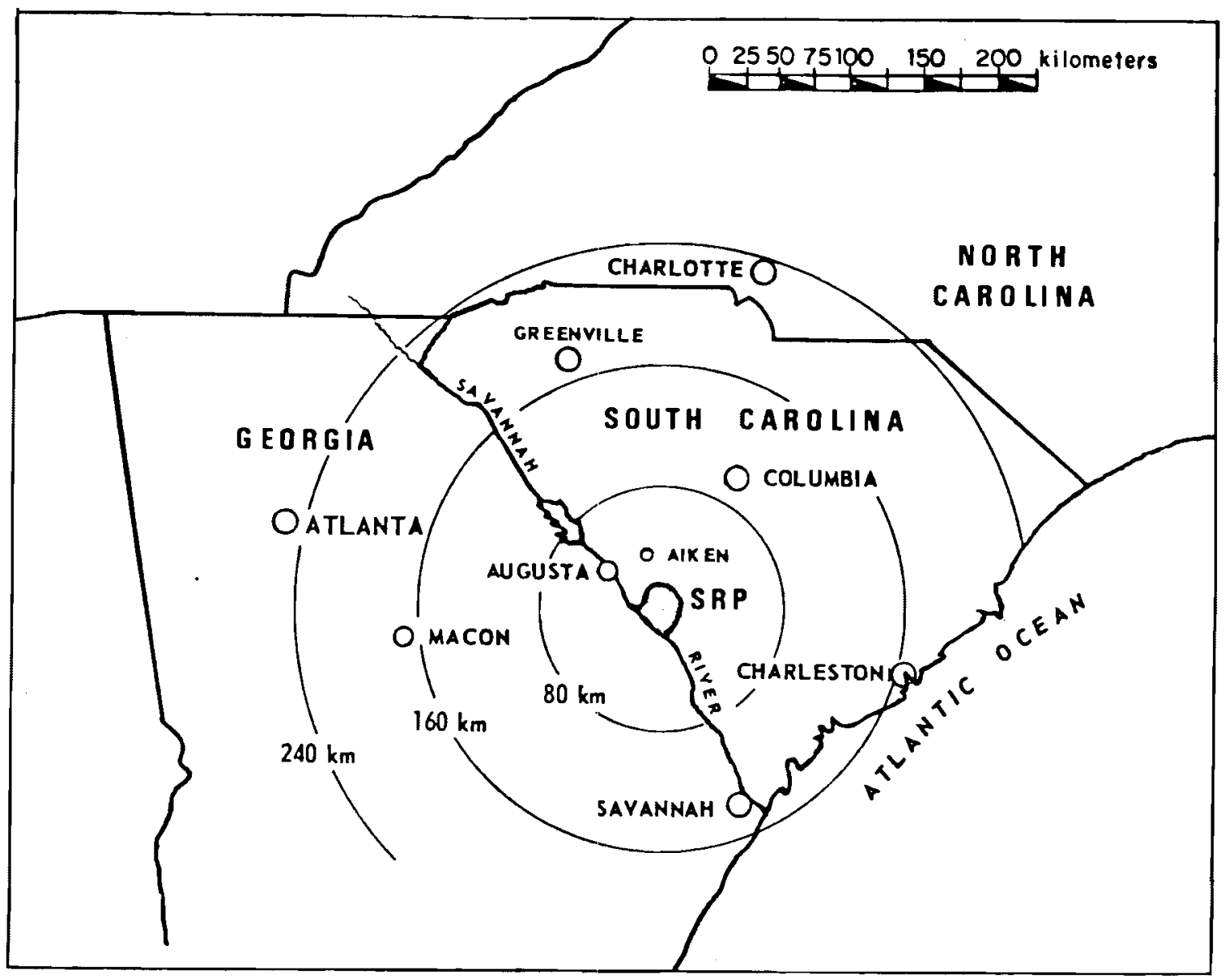

FIGURE 19.1. Location of Savannah River Plant

The SRP was constructed during the 1950s to produce the basic materials, primarily ${ }^{239} \mathrm{Pu}$ and tritium, used in the fabrication of nuclear weapons. The plant facilities (Figure 19.2) consist of three operating nuclear production reactors $(P, K$, and $C)$, two nuclear production reactors in standby condition $(R$ and $L)$, a small test reactor in standby condition (U), two separations areas ( $F$ and $H$ ) for processing irradiated materials, a heavy water rework plant in standby condition (D), a fuel and target fabrication facility (M), the Savannah River Laboratory (a process development laboratory to support production operations), administrative facilities ( $A)$, and the many nonnuclear facilities necessary for plant operations. 


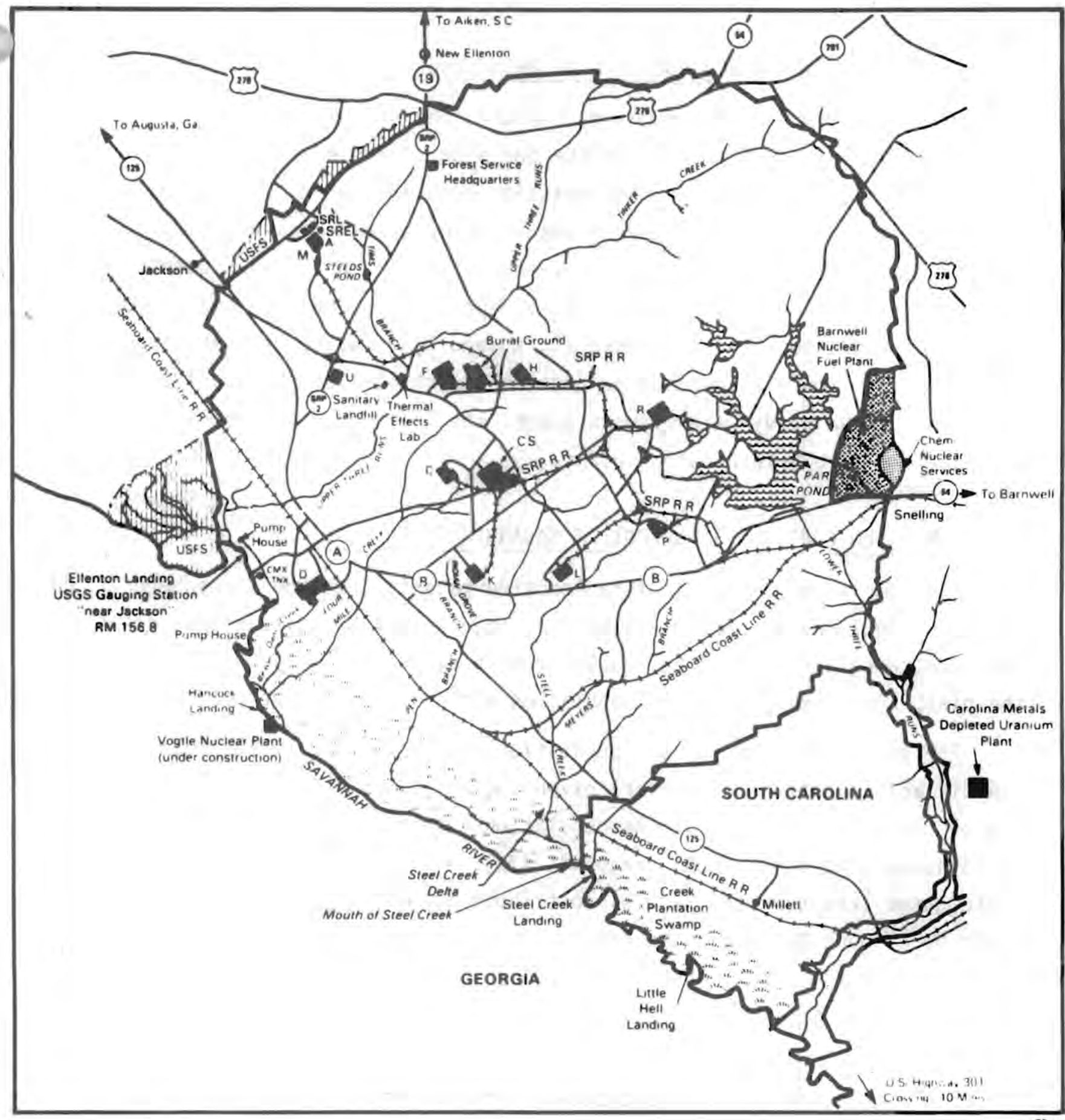

Kar

C. K. A. L. P Reactor Areas IC P K are operatingl Roed A = Highway 125

F. $H$ Separations Areas

M Fuei and Target Fabrication

D Heavy Water Production

A Savannah River Laboratory and Administration Area

CS Central Shop

RM Piver Mile

FIGURE 19.2. Savannah River Plant Site 


\subsubsection{Identification and Location of Major Sources}

Radionuclides are released into the atmosphere from a number of previously described facilities on the SRP site. Each operating area has one or more discharge stacks that have emission control equipment installed. Monitoring systems record data on a real-time or a near real-time basis. All stack release data are reported on an annual basis. The largest quantities of radionuclides are released from the fuel reprocessing areas ( $F$ and $H$ Areas). The three production reactor stacks ( $C, K$, and $P$ ) release the next largest quantities, followed in descending order of quantities of radionuclide emissions by the heavy water rework plant, the Savannah River Laboratory, and the fuel and target fabrication plant.

\subsection{EMISSION CONTROL TECHNOLOGY AT SAVANNAH RIVER PLANT}

The cumulative releases of radioactive materials to the atmosphere at SRP during CY 1981 are listed in Table 19.1, together with the radiation doses that are calculated by SRP to result from those releases to an individual at the plant boundary, and to the population within $80 \mathrm{~km}$ of the plant.

The radiation doses to the population resulting from releases from identifiable locations at SRP are given in Table 19.2. From this table, it can be seen that over $98 \%$ of the population dose results from three radioisotopes, tritium (85\%), argon-41 (7\%), and carbon-14 (6.4\%). Other noble gases (kryptons and xenons) contribute about $1.3 \%$, the iodines contribute about $0.1 \%$, and the particulates contribute less than $0.06 \%$ of the total dose to the offsite population.

Tritium is released from six facilities, with the tritium facilities (232-H, 234-H, 238-H) contributing about $66 \%$ of the total tritium dose; the reactor areas (105-C, 105-K, and 105-P) contributing about 10\%, 16\% and $7 \%$, respectively; the Moderator Rework Unit (420-D) contributing about $0.6 \%$; and the Savannah River Laboratory contributing less than $0.01 \%$.

Argon-41 is released exclusively at the operating reactors in roughly equal proportions. 
TABLE 19.1. Atmospheric Releases and Calculated Dose Commitments -- 1981 (a)

\begin{tabular}{|c|c|c|c|c|c|}
\hline Nuclide & $\begin{array}{l}\text { Curies Released } \\
\text { at Emission } \\
\text { Source } \\
\end{array}$ & $\begin{array}{c}\text { Calculated } \\
\text { Average Conc. } \\
\text { at Plant } \\
\text { Perimeter, } \mu \mathrm{Ci} / \mathrm{cm}^{3} \\
\end{array}$ & \multicolumn{2}{|c|}{$\begin{array}{l}\text { Whole-Body Dose } \\
\text { to Individual at } \\
\text { Plant Perimeter, mrem }\end{array}$} & $\begin{array}{c}\text { Calculated } \\
\text { Population Dose } \\
\text { Commitment, man-rem } \\
\frac{80 \mathrm{~km}}{}\end{array}$ \\
\hline Gases and Vapors & & & & & \\
\hline & $4.0 \times 10^{5}$ & $1.1 \times 10^{-10}$ & 0.65 & 0.88 & 100.3 \\
\hline${ }^{14} \mathrm{C}$ & $6.9 \times 10^{1}$ & $1.9 \times 10^{-14}$ & 0.048 & 0.066 & 7.5 \\
\hline $41_{\mathrm{Ar}}$ & $6.2 \times 10^{4}$ & $8.1 \times 10^{-12}$ & 0.11 & 0.28 & 8.2 \\
\hline $85 m_{K r}$ & $1.3 \times 10^{3}$ & $2.5 \times 10^{-13}$ & 0.00051 & 0.00075 & 0.049 \\
\hline $85_{\mathrm{Kr}}$ & $8.4 \times 10^{5}$ & $2.3 \times 10^{-10}$ & 0.0030 & 0.0041 & 0.52 \\
\hline $87_{\mathrm{Kr}}$ & $8.7 \times 10^{2}$ & $9.6 \times 10^{-14}$ & 0.0016 & 0.0025 & 0.093 \\
\hline${ }^{88} \mathrm{Kr}$ & $1.5 \times 10^{3}$ & $2.4 \times 10^{-13}$ & 0.0063 & 0.0094 & 0.54 \\
\hline $131 m_{x e}$ & $6.4 \times 10^{0}$ & $1.7 \times 10^{-15}$ & $<0.00001$ & $<0.00001$ & 0.00044 \\
\hline $133 \mathrm{xe}$ & $3.9 \times 10^{3}$ & $1.1 \times 10^{-12}$ & 0.00098 & 0.0014 & 0.13 \\
\hline${ }^{135} \mathrm{xe}$ & $2.5 \times 10^{3}$ & $5.5 \times 10^{-13}$ & 0.0017 & 0.0024 & 0.19 \\
\hline${ }^{129} I$ & $1.6 \times 10^{-1}$ & $1.3 \times 10^{-17}$ & 0.0010 & 0.0015 & 0.11 \\
\hline $131_{I}$ & $4.7 \times 10^{-2}$ & $8.5 \times 10^{-18}$ & 0.00001 & 0.00001 & 0.00090 \\
\hline $\begin{array}{l}\text { Particulates } \\
58,60^{\circ} \mathrm{Co}\end{array}$ & $8.9 \times 10^{-5}$ & $5.2 \times 10^{-21}$ & $<0.00001$ & $<0.0001$ & $<0.00001$ \\
\hline $89,90 \mathrm{Sr}$ & $3.0 \times 10^{-3}$ & $1.7 \times 10^{-19}$ & $<0.00001$ & $<0.0001$ & $<0.00001$ \\
\hline $95 \mathrm{Zr}$ & $1.7 \times 10^{-2}$ & $9.9 \times 10^{-9}$ & $<0.00001$ & $<0.00001$ & 0.00001 \\
\hline${ }^{95} \mathrm{Nb}$ & $6.4 \times 10^{-2}$ & $3.7 \times 10^{-18}$ & $<0.00001$ & $<0.00001$ & 0.00001 \\
\hline${ }^{103} \mathrm{Ru}$ & $1.3 \times 10^{-2}$ & $7.5 \times 10^{-19}$ & $<0.00001$ & $<0.00001$ & $<0.00001$ \\
\hline $106_{\mathrm{Ru}}$ & $7.8 \times 10^{-2}$ & $4.5 \times 10^{-18}$ & $<0.00001$ & $<0.00001$ & 0.00001 \\
\hline${ }^{134} \mathrm{Cs}$ & $6.4 \times 10^{-4}$ & $3.7 \times 10^{-20}$ & $<0.00001$ & $<0.00001$ & $<0.00001$ \\
\hline${ }^{137} C_{s}$ & $3.1 \times 10^{-3}$ & $1.8 \times 10^{-19}$ & $<0.00001$ & $<0.00001$ & 0.00001 \\
\hline${ }^{141} \mathrm{Ce}$ & $3.2 \times 10^{-4}$ & $1.9 \times 10^{-20}$ & $<0.00001$ & $<0.00001$ & $<0.00001$ \\
\hline${ }^{144} \mathrm{Ce}$ & $2.7 \times 10^{-2}$ & $1.6 \times 10^{-18}$ & $<0.00001$ & $<0.00001$ & 0.00007 \\
\hline Uranium & $6.1 \times 10^{-3}$ & $3.5 \times 10^{-19}$ & $<0.00001$ & $<0.00001$ & 0.00026 \\
\hline${ }^{238} \mathrm{Pu}$ & $4.6 \times 10^{-3}$ & $2.7 \times 10^{-19}$ & 0.00045 & 0.00045 & 0.031 \\
\hline${ }^{239} \mathrm{pu}_{\mathrm{Pu}}$ & $2.8 \times 10^{-3}$ & $1.6 \times 10^{-19}$ & 0.00034 & 0.00034 & 0.023 \\
\hline $241,243_{\mathrm{Am}}$ & $4.9 \times 10^{-4}$ & $2.8 \times 10^{-20}$ & 0.00004 & 0.00004 & 0.0030 \\
\hline $242,244 \mathrm{Cm}$ & $1.6 \times 10^{-4}$ & $8.3 \times 10^{-21}$ & 0.00001 & 0.00001 & 0.00048 \\
\hline Totals & & & 0.82 & 1.15 & 118.0 \\
\hline
\end{tabular}

(a) Doses calculated by SRP staff members. 
TABLE 19.2. 1981 Dose to Population, by Radionuclide and Source (man-rem) (a)

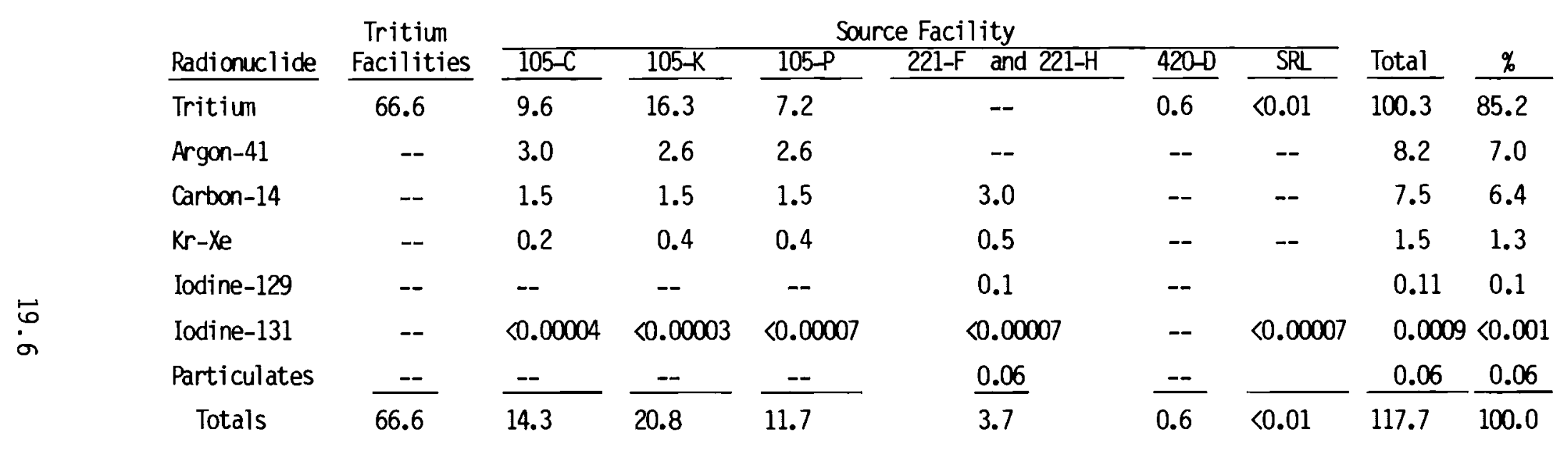

(a) Doses calculated by SRP staff members. 
Carbon-14 is released from the three operating reactors and from the separations plants in $F$ and $H$ Areas in approximately equal proportions.

In terms of radiation dose to the offsite population, the principal sources are the $\mathrm{H}$ Area tritium facilities, followed in order of decreasing contribution by 105-K, 105-C, 105-P and the F and $H$ Areas separations plants. The contributions from other source locations are less than $1 \%$ and are negligible. These specific sources of radionuclide emissions are examined in this section, with descriptions of the existing control systems, and discussions of current discharge rates, suggested additional control equipment and anticipated reduction in emissions, and estimated costs of the suggested additional equipment, for each specific source.

\subsubsection{Specific Source 1: 200-H Area Tritium Facility Stacks}

Releases of tritium from the four stacks associated with the Tritium Facilities in the $200-H$ Area constitute the principal sources of radioactive emissions at SRP resulting in a radiation dose to the offsite population of about 67 man-rem during 1981. This dose represents about 57\% of the total population dose from SRP emissions.

\subsubsection{Existing Emission Control Technology at the 200-H Area Tritium}

\section{Facilities}

The ventilation and monitoring systems associated with the tritium facilities of SRP are illustrated in outline form in Figure 19.3. The systems for reduction of tritium release are shown in Figures 19.4 and 19.5 .

The system shown in Figure 19.4 utilizes a long transit volume (the "Serpentine") as a means to capture and hold air flows from process hoods that contain accidental releases of tritium, so that the contained tritium can be removed from the air before discharge to the stack. A nominal air flow continually passes through the "Serpentine" to the stack line. Air from the process hoods also normally flows to the stack line. When an in-line ion chamber detects a preset level of tritium in the hood outflow, the "Serpentine" inlet from the process hood is opened and the hood flow is diverted to the "Serpentine." The volume of the holdup line is sufficient 


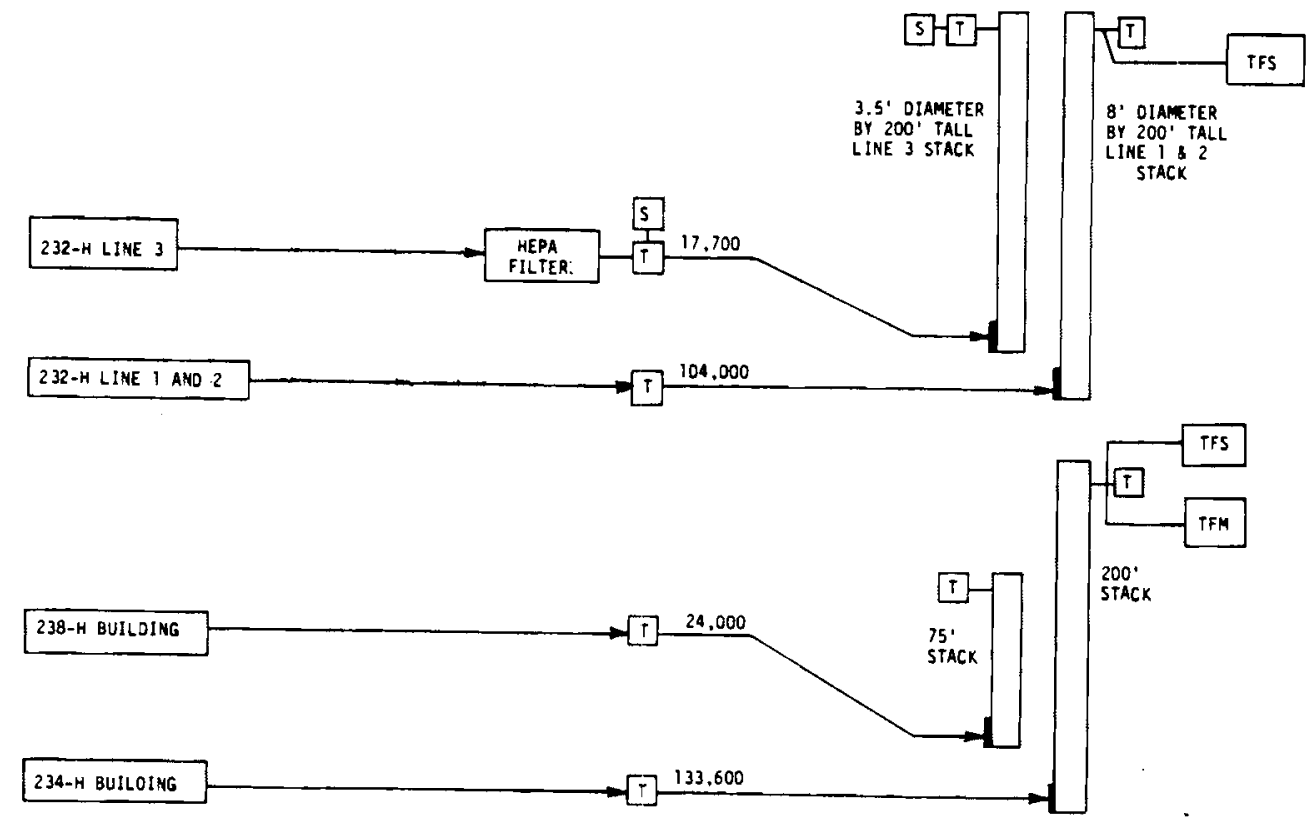

\section{Explanation of Stack Samplers/Monitors:}

$T$ - Kanne Ionization Chambers

All tritium production/processing facilities have continuous on-line Kanne chambers with associated recorder, alarms.

FFS - Tritium Forms Sampler

Building 232-H and 234-H stacks have continuous on-line tritium forms samplers that are molecular sieve collectors. Samples are changed weekly, analyzed, and results used for ratio of elemental to oxide tritium stack release.

TFM - Building 234-H has prototype continuous forms monitor. Two equal samples of stack gas pass through Kanne chambers, one sample having passed through a dryer to remove tritium oxides. The resulting currents are measured under control of a desktop computer which also calculates the elemental and oxide tritium,release rates. Data is output to a local printer.

S - Continuous filter paper sample. The sample is changed daily.

FIGURE 19.3. Tritium Facilities Ventilation Systems 


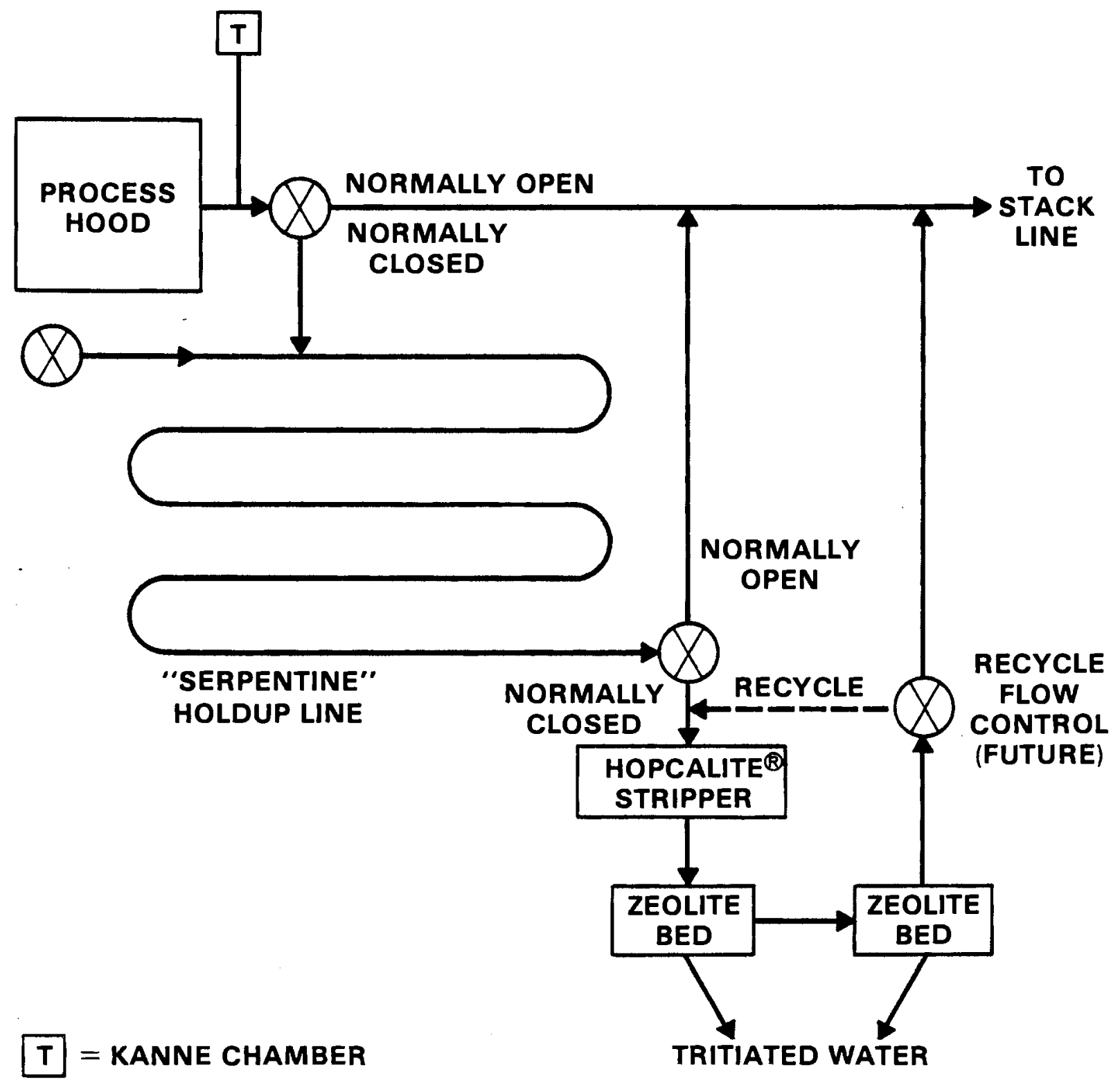

FIGURE 19.4. Hopcalite ${ }^{\circledR}$ Stripper and Zeolite Bed System, with "Serpentine" Holdup Line 


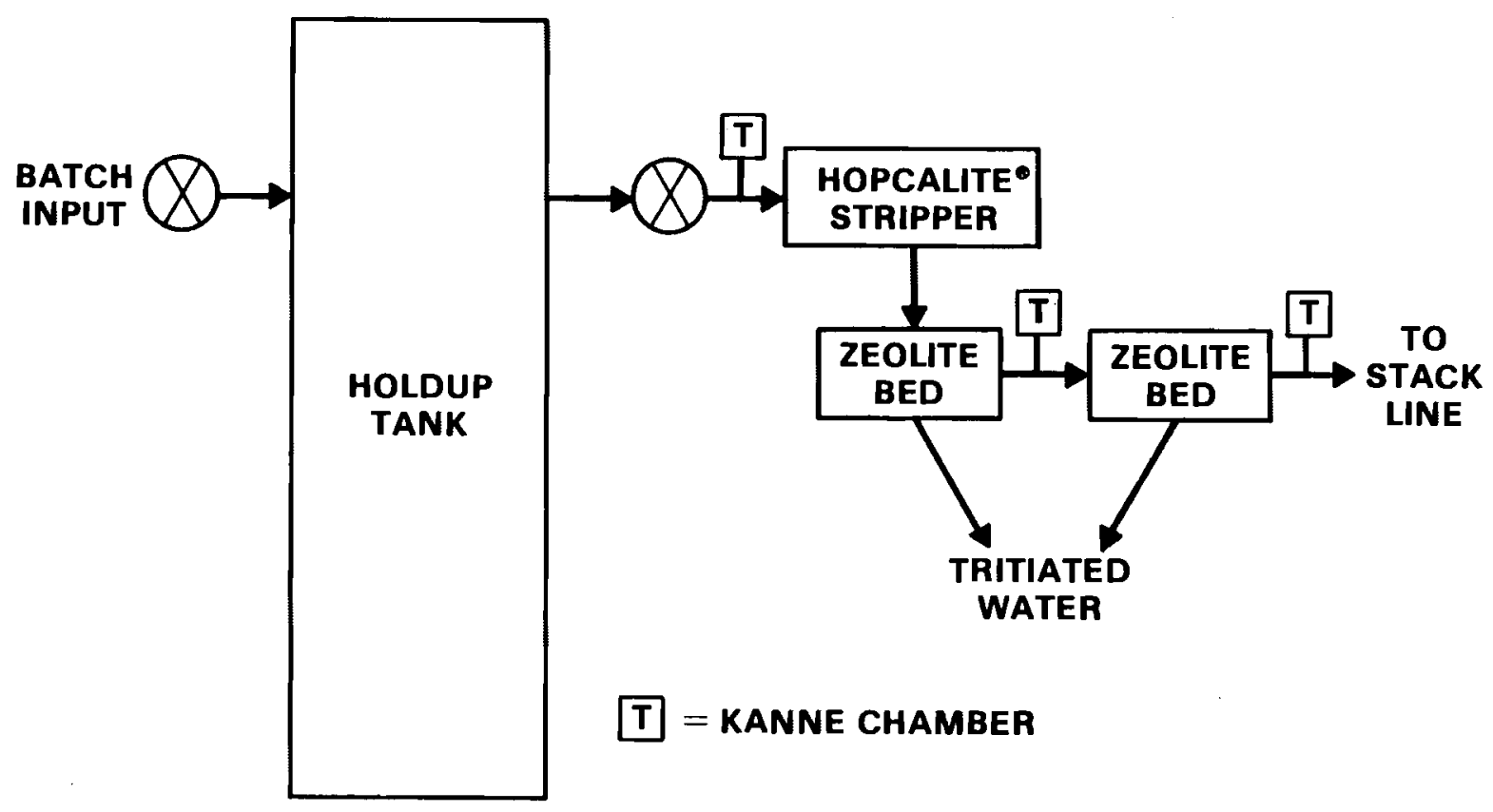

FIGURE 19.5. Holdup Tank System, with Hopcalite ${ }^{\circledR}$

Stripper and Zeolite Bed

to prevent loss of the tritium burst to the stack. An ionization chamber near the end of the "Serpentine" detects the tritium concentration as it exits the "Serpentine." If the concentration is greater than a preset limit, the volume that exceeds the limit is subsequently diverted and processed through the Hopcalite ${ }^{\circledR}$ stripper and zeolite beds to remove the tritium. If the concentration is less than the preset limit, the trapped air volume is discharged to the stack.

The system shown in Figure 19.5 utilizes a holdup tank into which batches of inert gases or air from various operational activities are placed for eventual processing through a Hopcalite ${ }^{\circledR}$ stripper and two zeolite beds.

The Hopcalite ${ }^{\circledR}$ stripper and subsequent zeolite absorption beds shown in Figures 19.4 and 19.5 are described in some detail in Reference 2. The efficiency of the Hopcalite ${ }^{\circledR}$ stripper varies with operating conditions

() Trademark of Mine Safety Appliances Corp. 
(oxidizer bed temperature, oxygen and hydrogen content in the gases to be treated) and can range from a few percent to nearly $100 \%$. The actual average efficiency of the strippers at SRP is classified information and cannot be reported here.

\subsubsection{Current Emission Rates from the Tritium Facilities Stacks}

The total emission of tritium from the $200-H$ Area tritium facilities stacks during 1981 was measured to be $2.31 \times 10^{5}$ curies.

19.2.1.3 Potential Additional Emission Control Technology of the Tritium Facilities

The efficiency of the catalytic oxidizer system might be improved by replacing the Hopcalite ${ }^{\circledR}\left(80 \% \mathrm{MnO}_{2}-20 \%\right.$ CuO $)$ beds with a palladium catalyst. Recycling the effluent gases through the stripper combined with hydrogen swapping will also improve the efficiency of the stripper. The SRP staff has estimated that recycling could reduce normal tritium emissions by $25 \%$. The cost of the system improvements is estimated to be about $\$ 65$ miliion. The system lifetime is estimated to be about 15 years.

\subsubsection{Specific Source 2: Production Reactor Area Stacks}

Releases of radioactivity into the atmosphere at the three production reactors are the next largest contributors to the offsite population dose resulting from operations at the SRP. Actual releases will vary from reactor to reactor, year by year, depending upon operations activities. For 1981, the doses resulting from releases from the $61 \mathrm{~m}, 105-\mathrm{C}, 105-\mathrm{K}$, and 105-P stacks were $14.3,20.8$, and 11.7 man-rem, respectively, with principal contributors being tritium, argon-41, and carbon-14 (see Table 19.2).

19.2.2.1 Existing Emission Control Technology at the Production Reactors

A ventilation system typical of the production reactors is shown in Figure 19.6. The filter system consists of inlet prefilters to remove particulates from incoming air, moisture separators to remove entrained moisture droplets from the outgoing air stream, particulate (HEPA) filters to 


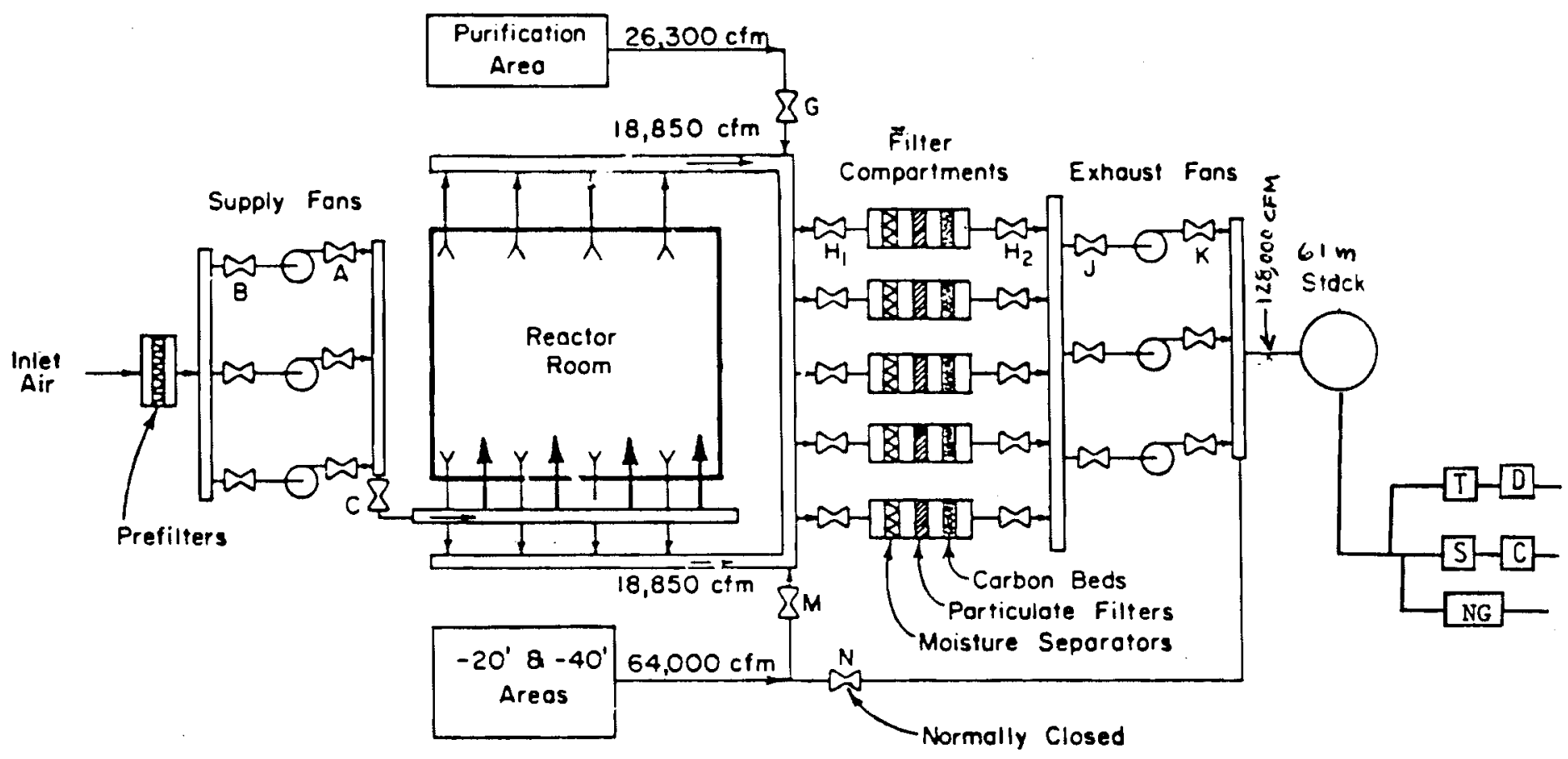

Explanation of 105-P, K, C Stack Samplers/Monitors:

$T$ - Continuous on-line Kanne chambers with recorder, alarms, for tritium monitoring.

D - Continuous dehumidifier samples. Sample collected daily and analyzed for tritium.

NG - Continuous on-line noble gas monitor - GE-Li detector, multichannel analyzer with remote readout. Unit prints results 1 /hour. Releases for $133 \mathrm{Xe}, 85 \mathrm{mKr}, 88 \mathrm{Kr}, 135 \mathrm{Xe}, 87 \mathrm{Kr}$ and $41 \mathrm{Ar}$ are calculated daily.

S - Continuous Gelman (type A-E) filter paper (1-3 cfm). Changed weekly. Counted locally, and forwarded to H.P. H.P. performs gamma PHA on filter, dissolves and does alpha spectroscopy for final release documentation.

C - Continuous charcoal filter (1-3 cfm), changed weekly, analyzed using gamma PHA for radioiodine.

Note: ${ }^{14} \mathrm{C}$ releases from reactor areas are calculated.

FIGURE 19.6. 105-P, K, and C Reactor Airborne Effluents Emission Controls and Measurements 
remove particulate material, and charcoal filters to remove iodines. There are no provisions for reducing the emission of tritium, noble gases, or carbon-14.

Monitoring equipment at the 61-m reactor stacks includes continous Kanne chambers and dehumidifier samplers for monitoring tritium emission, a continuous noble gas monitor utilizing a Ge-Li detector/multichannel analyzer system, a continuous charcoal filter for monitoring radioiodines, and a continuous filter paper sampler for particulate monitoring. Additional details on these monitoring systems are given in Reference 1 .

\subsubsection{Current Emission Rates at the Production Reactors}

The radioactivity releases (in curies) from the production reactors during 1981 are shown in Table 19.3.

TABLE 19.3. Radioactivity Releases from Reactor Areas - 1981 (curies)

\begin{tabular}{|c|c|c|c|}
\hline Radionuclide & 105-C Stack & 105-K Stack & 105-P Stack \\
\hline Tritium & $3.318 \times 10^{4}$ & $5.671 \times 10^{4}$ & $2.513 \times 10^{4}$ \\
\hline Argon-41 & $2.262 \times 10^{4}$ & $1.955 \times 10^{4}$ & $1.969 \times 10^{4}$ \\
\hline Krypton-85M & $2.700 \times 10^{2}$ & $3.300 \times 10^{2}$ & $6.990 \times 10^{2}$ \\
\hline Krypton-87 & $1.870 \times 10^{2}$ & $4.270 \times 10^{2}$ & $2.550 \times 10^{2}$ \\
\hline Krypton-88 & $4.060 \times 10^{2}$ & $6.070 \times 10^{2}$ & $4.630 \times 10^{2}$ \\
\hline Iodine-131 & $2.060 \times 10^{-3}$ & $1.517 \times 10^{-3}$ & $3.408 \times 10^{-3}$ \\
\hline Xenon-133 & $3.860 \times 10^{2}$ & $1.110 \times 10^{3}$ & $2.431 \times 10^{3}$ \\
\hline Xenon-135 & $3.700 \times 10^{2}$ & $9.110 \times 10^{2}$ & $1.251 \times 10^{3}$ \\
\hline Other Beta/Gamma & $3.330 \times 10^{-4}$ & $4.190 \times 10^{-4}$ & $1.530 \times 10^{-4}$ \\
\hline Total Alpha & $3.998 \times 10^{-6}$ & $3.620 \times 10^{-6}$ & $1.070 \times 10^{-6}$ \\
\hline
\end{tabular}

19.2.2.3 Potential Additional Emission Control Technology at the Production Reactors

Reduction of tritium emissions from the heavy water moderated reactors could be accomplished by 1 ) replacing tritiated moderator with fresh moderator, 2) minimizing evaporation losses from the moderator, and 
3) removing tritium from the existing moderator. While none of these approaches is classified as emission control technology, they are operational in that they attempt to prevent the presence of tritium in the ventilation system rather than attempting to remove the tritium from the effluent air stream.

The first approach is not particularly viable. The effect would be only temporary since the tritium levels in the moderator build up with each year's reactor operation.

The second approach is normal operating practice and is carried on to the extent feasible al ready.

The third approach would utilize either vapor phase catalytic exchange with cryogenic distillation (CE-CD) or a thermal cycle absorption process (TCAP). These processes, described in Reference 1, have the potential for reducing tritium emissions at the production reactors by about $90 \%$ once steady-state operation is achieved after about 6 years. Capital costs for a CE-CD system are estimated by SRP staff to be in the $\$ 20-40$ million range. Estimated annual operating cost would be in the $\$ 1.5$ to $2 \mathrm{milli}$ ion range, with an estimated operating life of 30 years.

No estimates are currently available for the cost of a TCAP system.

Releases of argon-41 at the production reactors could be reduced by installing a holdup volume into which the air containing the argon-41 (from the annular cavity around the reactor tank) could be routed, thus allowing the radioactivity to decay to insignificant levels. A possible system would utilize an existing $1893-\mathrm{m}^{3}$ (500,000-gallon) tank in the emergency core cooling system. An air flow of 1.4 to $4.3 \mathrm{~m}^{3} /$ minute into an effective storage volume of $707 \mathrm{~m}^{3}$ is expected to reduce argon-41 emissions by about $60 \%$. The feasibility of utilizing the $1893-\mathrm{m}^{3}$ tank for this purpose is being actively pursued. The capital cost of this proposed system is small, since mostly existing systems and equipment would be utilized.

No other systems for reducing emissions from the production reactors are presently under consideration. 


\subsubsection{Specific Source 3: 200-F and 200-H Area Separation Plants}

Releases of radioactivity to the 291-F and $291-\mathrm{H}$ and associated stacks (221-F and 221-H facilities) are principally carbon-14, noble gases, and small amounts of iodine.

19.2.3.1 Existing Emission Control Technology at the 200-F and 200-H Separations Plants

The ventilation systems at the separations plants are shown in Figures 19.7 and 19.8. Explanations of the monitoring systems shown in both figures are given on page 19.17 .

Effluent control equipment on the 200-F Area ventilation systems consists principally of particulate filters: fiberglass, HEPA, and sand filters. Silver nitrate beds are used for scrubbing iodine from the dissolver offgas stream.

19.2.3.2 Current Release Rates at the 200-F and 200-H Separation Plants

Releases of radioactivity from the separation plants are quite small, resulting in a radiation dose to the population offsite of less than 4 man-rem in 1981. Most of this dose resulted from carbon-14 ( $\sim 3$ man-rem), with the noble gases being the other principal contributor ( 0.5 man-rem).

The measured (or calculated) releases from the 291-F and 291-H stacks during 1981 are given in Table 19.4. For reasons of national security, the releases of iodine-129, krypton-85, and xenon-131m from both $F$ and $H$ Areas are aggregated.

\subsubsection{Potential Additional Emission Control Technology at the Separations Plants}

Carbon-14, the noble gases, and iodine contribute nearly all of the radiation dose from the separations plants. An absorber system utilizing flaked barium hydroxide octahydrate to react with ${ }^{14} \mathrm{CO}_{2}$ to form barium carbonate, thus capturing the carbon-14, could be installed. In addition, one of several techniques for capturing the noble gases (particularly krypton-85) could also be installed. These techniques, cryogenic distillation, 


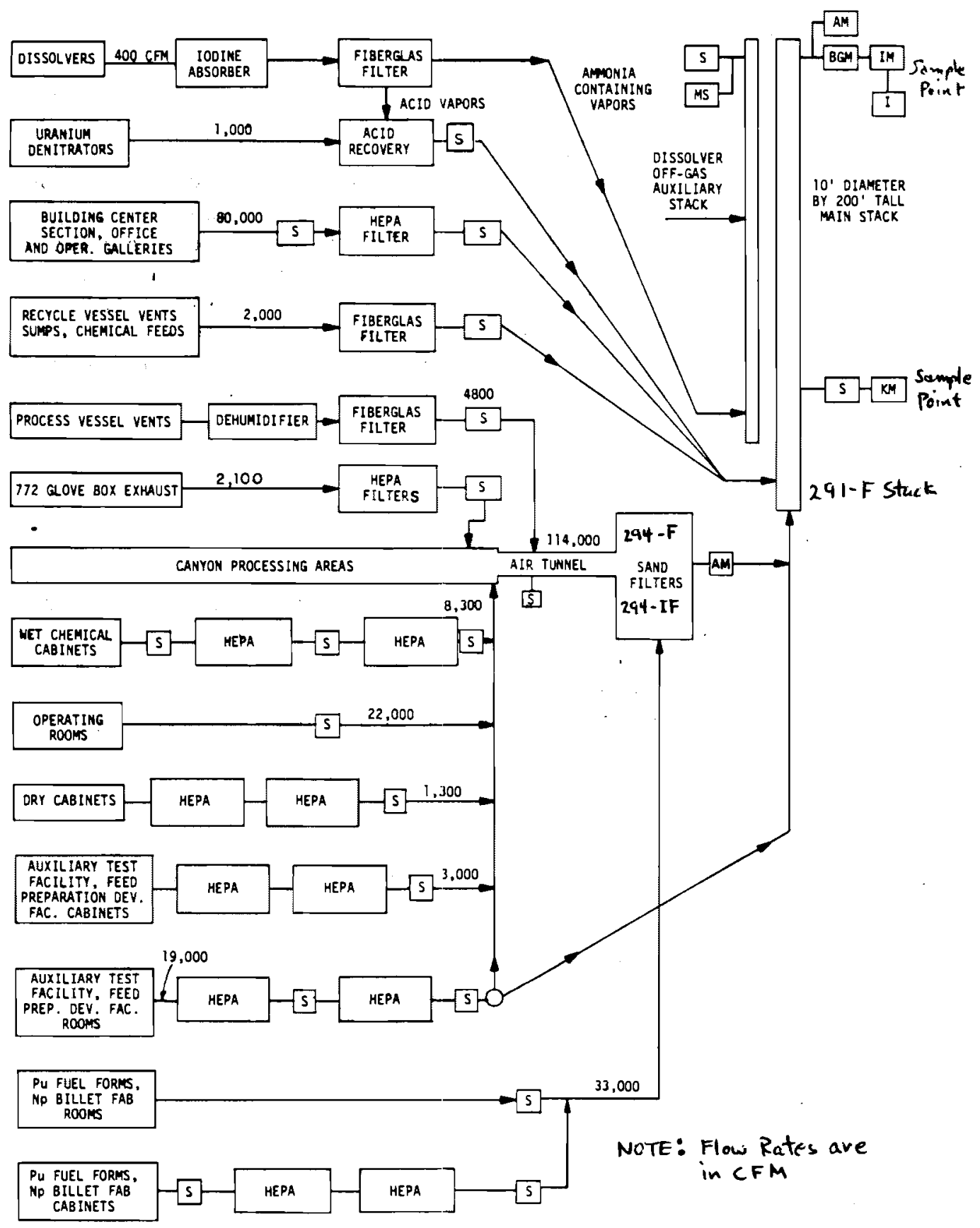

FIGURE 19.7. F-Area Airborne Effluents Emission Controls and Measurements 
(for Figures 19.7 and 19.8)

Explanation of 291-F and 291-H Stack Samplers/Monitors

Continuous filter paper $(3-5 \mathrm{cfm})$ with photomultiplier tube, log ratemeter $\left(10^{6} \mathrm{c} / \mathrm{m}\right)$, recorder, alarms. Alarm point $=\sim 0.25 \mathrm{mCi}$ release. Upper limit $=\sim 200 \mathrm{mCi}$ release. Source checked weekly. Filter paper (Gelman, fiberglass Type A-E $76 \mathrm{~mm}$ ) is changed daily, counted, and analyzed for all particulate radioactivity. The filters are composited for one week and a gamma PHA performed. The weekly composited filters are dissolved and an aliquot taken for alpha spectroscopy. A chemical analysis for $89,90 \mathrm{Sr}$ is also performed.

BGM - Beta-Gamma Monitor

Continuous filter paper ( $5 \mathrm{cfm})$ on hollow cylinder surrounding a G.M. tube, log ratemeter $(106 \mathrm{c} / \mathrm{m})$, recorder, alarms. Alarm point $=230 \mathrm{mCi} \beta_{\lambda}$ release. Upper limit = $\sim 200 \mathrm{Ci}$ release. Source checked weekly; calibrated (Cs 137) monthly.

(Note: Filter is changed weekly but not used for any specific release determination.)

IM - Radiolodine Monitor I - Backup Charcoal Canister

- Two activated charcoal filters (hollow cylinder) in series ( $4 \mathrm{cfm}$ ) downstream of the beta-gamma filter collector. First filter has a G.M. tube (identical to $\beta_{\text {g }}$ above), log ratemeter $(106 \mathrm{c} / \mathrm{m})$, recorder, alarms. Second filter is "backup" - not mortitored. Alarm point - $300 \mathrm{mCl}$ release. Upper limit $300 \mathrm{Ci}$ release. An in-place scaler count is made daily for local area release estimate.

Both filters changed weekly for $\gamma$ scan and calculation.

I monitor source-checked weekly with ${ }^{137} \mathrm{Cs}$, calibrated monthly with ${ }^{137} \mathrm{Cs}$ and calibrated annually with 131 i sources ( 3 ranges).

KM - Krypton-85 Monitor

Continuous intrinsic germanium detector, coupled to a microprocessor based multichannel analyzer (MCA) and a PDT-11 floppy disk system and a DECwriter printer. Continuous sample (2 SCFH) is drawn through sample cell from the stack sample line. Sample passes through filter paper and silica gel trap (to remove moisture, acid, undesirable radioactivity) to sample cell before return to central vacuum header. Analyzer accumulates data for one hour, transmits to floppy disk system which analyzes data per program. Results are printed each hour.

Calibrated monthly with $\mathrm{NBS}{ }^{85} \mathrm{Kr}$ standard $(200 \mu \mathrm{Ci})$. System has upper range to $>36,000 \mathrm{Ci}$.

S - Continuous filter paper sample. The $15-\mathrm{m}$ level sample is changed daily as backup to the $59-m$ stack sample.

S MS - Dissolver Off-Gas (Auxiliary Stack)

The dissolver off-gas system has two separate sampling systems. The off-gas system has continuous (4 cfm) samples through filter paper $[S$ which is changed daily. During dissolving of fuel cladding, a sampling ( $1 \mathrm{cfm}$ ) system which consist of filter paper backed by a three-stage molecular sieve ${ }_{5}$ s silver nitrate impregnated aluminum silicate is also used. The three-stage sample is changed weekly for analysis for radioiodine.

Note: In addition to the measured radioactivity releases described above, calculations are currently made for the following isotopes: $14 \mathrm{C}, 85 \mathrm{Kr}, 129 \mathrm{I}, 131 \mathrm{Xe}$, for both $\mathrm{F}$ and H Areas. 


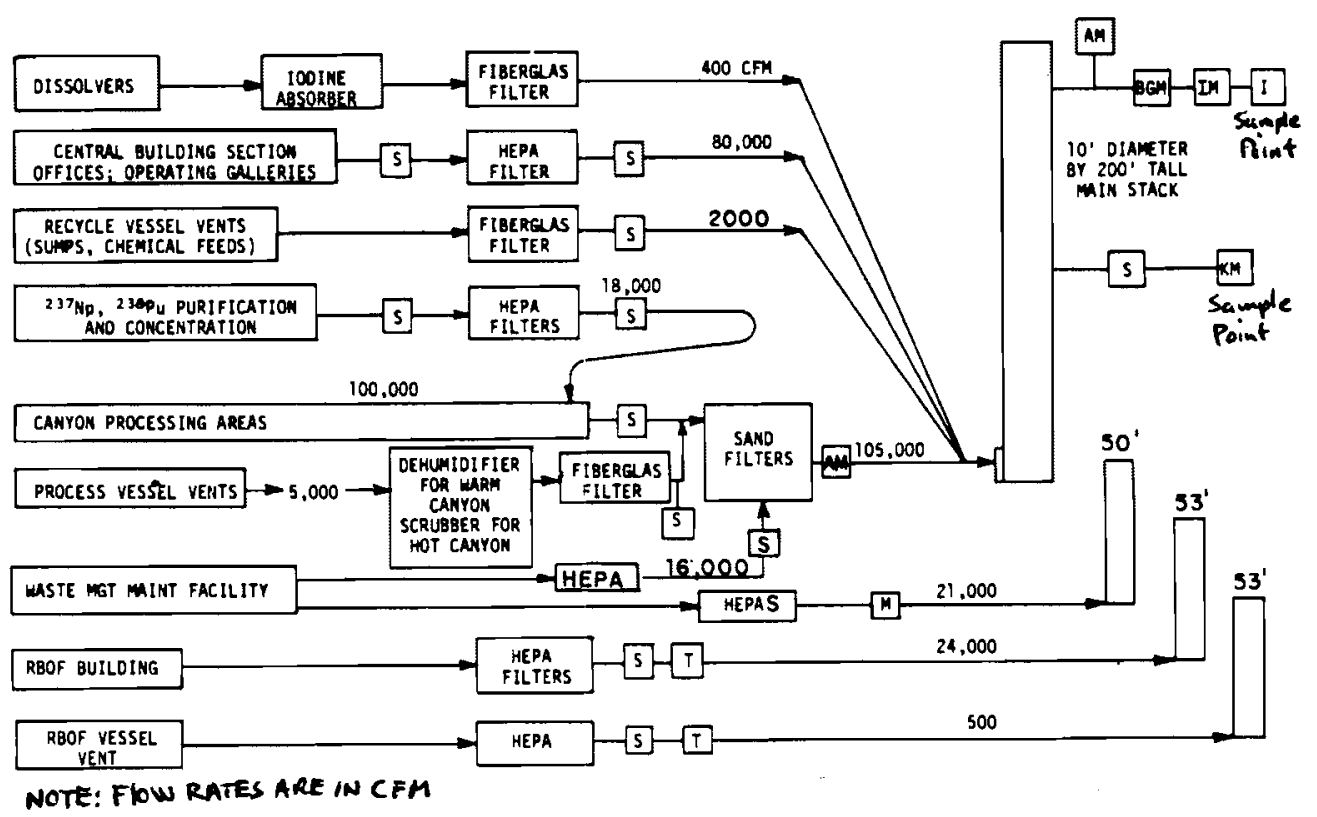

FIGURE 19.8. H-Area Separations Plant Ventilation System and Associated H-Area Ventilation Systems

fluorocarbon absorption, and absorption on mordenite beds, all have decontamination factors of about 100. The existing iodine absorber beds utilizing silver nitrate could exhibit improved iodine removal capabilities if they were converted to silver mordenite and moved from the dissolver off-gas system and installed in the vessel vent system.

It is estimated by SRP staff that an integrated off-gas treatment system, utilizing the above techniques would cost about $\$ 50$ million per plant, and would have annual operating costs of about $\$ 3$ million. 
TABLE 19.4 Radioactivity Releases from Separations Areas - 1981 (curies)

\begin{tabular}{|c|c|c|}
\hline Radionuclide & 291-F Stack & 291-H Stack \\
\hline Carbon-14 & $1.400 \times 10^{1}$ & $1.400 \times 10^{1}$ \\
\hline Strontium-89,90 & $1.573 \times 10^{-3}$ & $1.385 \times 10^{-3}$ \\
\hline Zirconium-95 & $1.317 \times 10^{-2}$ & $3.923 \times 10^{-3}$ \\
\hline Ni obi um-95 & $6.083 \times 10^{-2}$ & $2.811 \times 10^{-3}$ \\
\hline Ruthenium-103 & $2.795 \times 10^{-3}$ & $1.018 \times 10^{-2}$ \\
\hline Ruthen i um-106 & $2.252 \times 10^{-2}$ & $5.578 \times 10^{-2}$ \\
\hline Iodine-131 & $3.264 \times 10^{-2}$ & $4.177 \times 10^{-3}$ \\
\hline Cesium-134 & $2.300 \times 10^{-5}$ & $6.180 \times 10^{-4}$ \\
\hline Cesium-137 & $1.292 \times 10^{-3}$ & $1.773 \times 10^{-3}$ \\
\hline Cesium-141 & $2.560 \times 10^{-4}$ & $5.900 \times 10^{-5}$ \\
\hline Cesium-144 & $1.262 \times 10^{-2}$ & $1.381 \times 10^{-2}$ \\
\hline Americium-241,243 & $2.940 \times 10^{-4}$ & $2.000 \times 10^{-4}$ \\
\hline Curium-242,244 & $9.300 \times 10^{-5}$ & $7.000 \times 10^{-5}$ \\
\hline Urani um-235,238 & $4.303 \times 10^{-3}$ & $1.768 \times 10^{-3}$ \\
\hline Plutoni um-238,239 & $1.220 \times 10^{-3}$ & $6.147 \times 10^{-3}$ \\
\hline Iodine-131 & \multicolumn{2}{|c|}{$1.600 \times 10^{-1}$} \\
\hline Xenon-131m & \multicolumn{2}{|c|}{$6.417 \times 10^{0}$} \\
\hline Krypton-85 & \multicolumn{2}{|c|}{$8.385 \times 10^{5}$} \\
\hline Tritium & \multicolumn{2}{|c|}{$2.31 \times 10^{5}$} \\
\hline
\end{tabular}




\section{REFERENCES}

1. E. K. Dukes and R. W. Benjamin, Savannah River Plant Airborne Emissions and Controls, DPST-82-1054, E. I. du Pont de Nemours \& Co., Savannah River Laboratory, Aiken, South Carolina, December 1982.

2. D. A. Orth and W. J. Jacober, "Trapping and Removal at the Savannah River Plant, in Tritium Control Technology, pp. 240-244, WASH-1269, Prepared by Mound Laboratory for the U.S. AEC, December 1973. 


\subsection{STANFORD LINEAR ACCELERATOR CENTER}

The Stanford Linear Accelerator Center (SLAC) is a large research laboratory devoted to theoretical and experimental research in high-energy physics and to the development of new techniques in high-energy particle detectors. Construction of the center was started in 1962 and completed in 1966. Research activities at the center were started in late 1966.

\subsection{SITE AND MAJOR SOURCE DESCRIPTIONS}

The major activity at SLAC is operation of the $3.2-\mathrm{km}-1$ ong linear accelerator. The accelerator can produce electron beams with energies up to $31 \mathrm{GeV}$ and positron beams with energies up to $20 \mathrm{GeV}$. The beams can be used directly for experiments or they can be sent into either of two storage-ring facilities: SPEAR or PEP. The storage rings are major laboratory facilities where electrons and positrons from the accelerator are stored and circulated continuously in opposite directions. Beam energies for SPEAR and PEP are 4.5 and $18 \mathrm{GeV}$, respectively, giving total collision energies of 9 and $36 \mathrm{GeV}$. SPEAR became operational in 1972 and PEP started operation in 1980.

\subsubsection{Location of Site and Description of Facilities}

The SLAC is located on a 170-hectare site about $3 \mathrm{~km}$ west of the Stanford University campus in San Mateo County, California. The site is about midway between San Francisco and San Jose. Figure 20.1 shows a map of the region, while Figure 20.2 shows a photograph of the SLAC site. Approximately 1300 persons are employed at the center, and about 4.2 million people reside within $80 \mathrm{~km}$ of the site. The linear accelerator is oriented almost eastwest, and the total length of the accelerator and experimental area is about $4.8 \mathrm{~km}$. The experimental area is located at the east end of the 3.2-km-1ong accelerator. The storage-ring facilities, SPEAR and PEP, are located in the experimental area.

\subsubsection{Identification and Location of Specific Sources}

Operation of the linear accelerator and associated equipment produces airborne radioactivity and penetrating radiation. (1) Radioactivation of air 


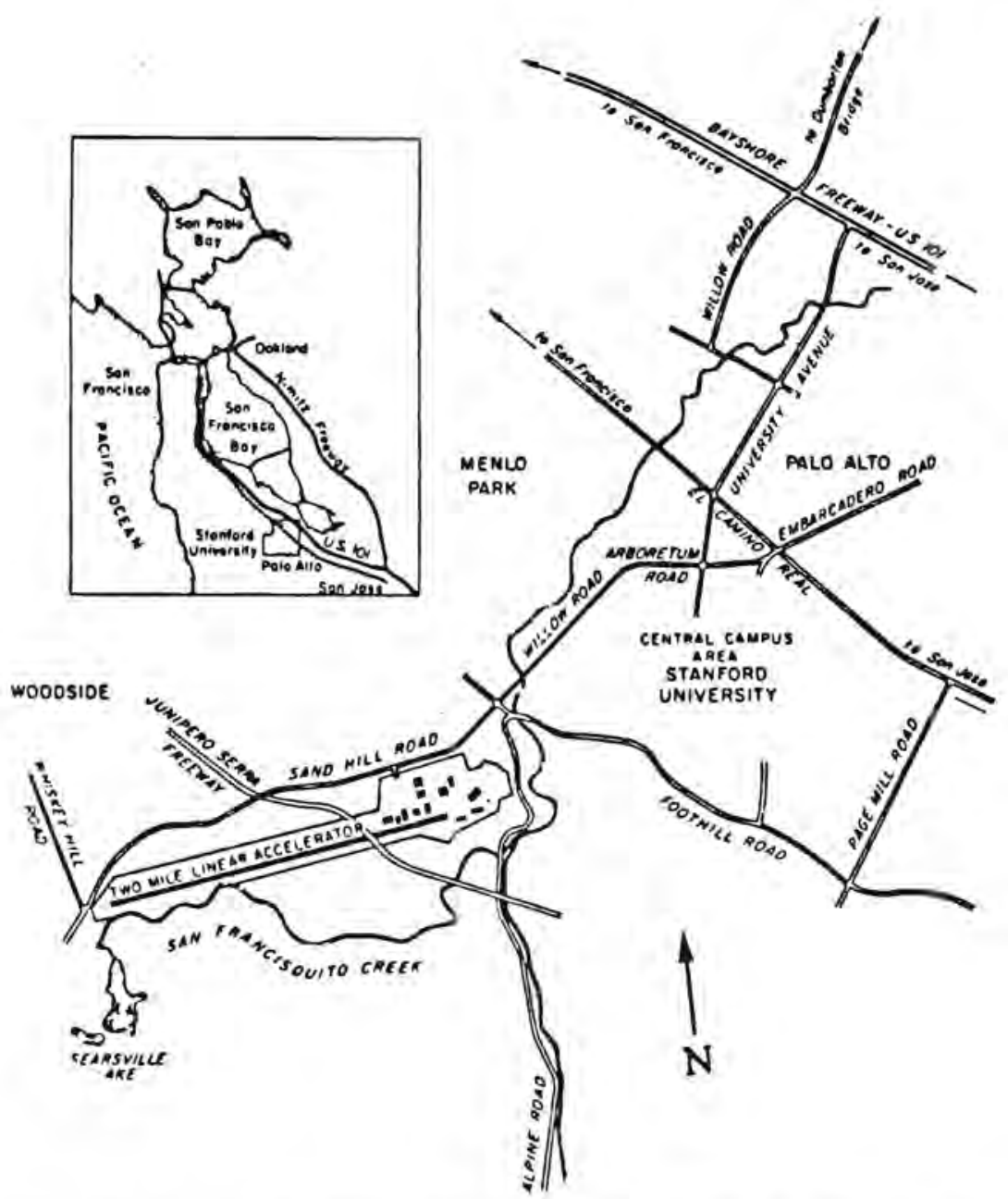

FIGURE 20.1. SLAC Site Location Relative to Stanford University and Surrounding Communities

occurs when the electron or positron beam, or secondary particles resulting from the beam's interaction with matter, passes through air. The airborne radioisotopes produced by accelerator operation all have half-lives of less than 2 hours, as shown in Table 20.1. The radionuclides produced are in gaseous form. Radioactive particulates have not been detected in the atmospheric discharges.

The penetrating radiation resulting from SLAC operation consists of fast neutrons and is characterized as skyshine from the research areas. The neutrons result from absorption of high-energy electrons and photons in the 


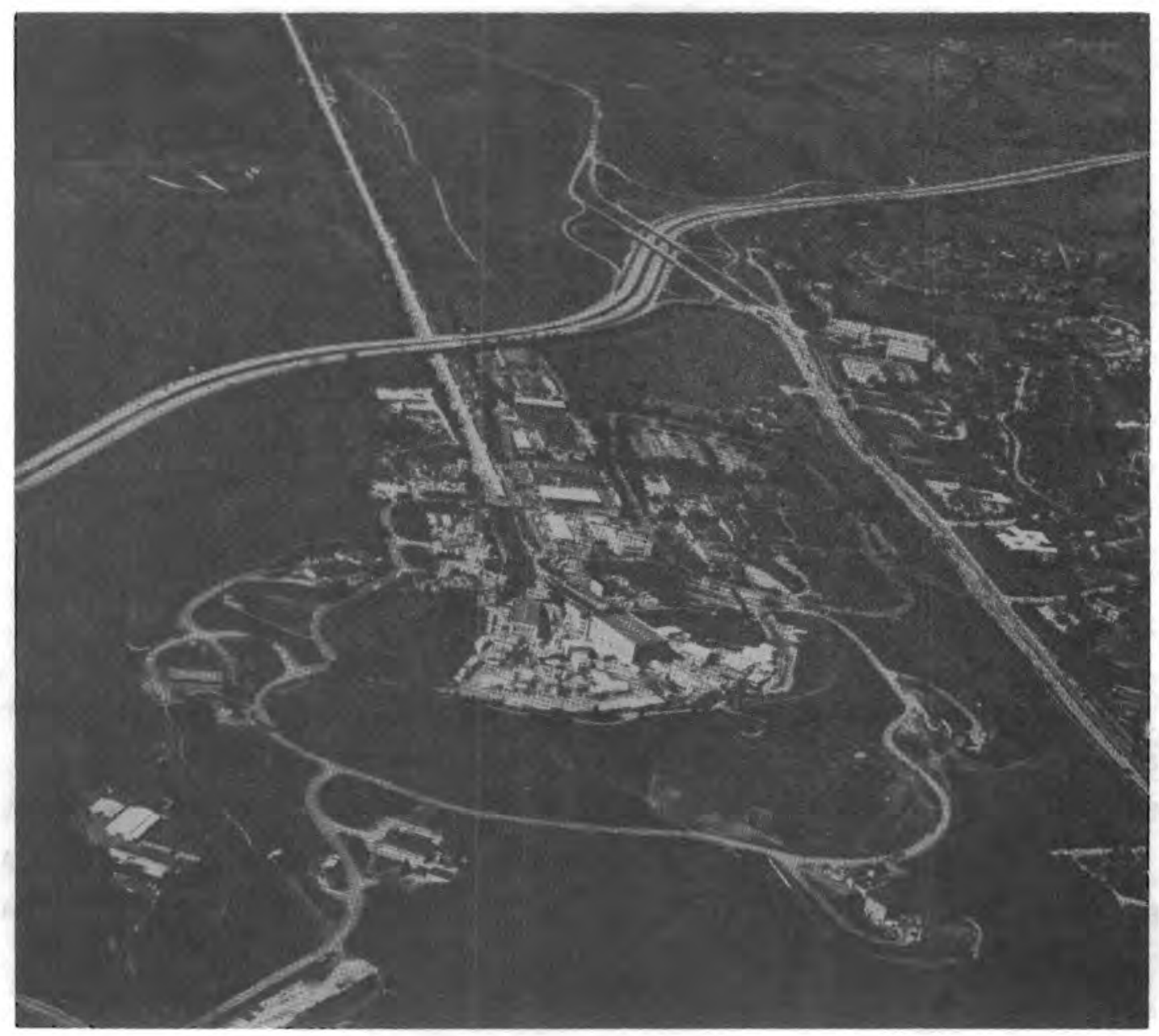

FIGURE 20.2. Air View of the SLAC Site Showing the Accelerator and Research Facility. In the foreground, the PEP interaction regions can be seen, connected by the circumferential road.

experimental area creating energetic particles, some of which escape from the heavily shielded areas. The penetrating radiation accounts for most of the offsite exposure resulting from SLAC operations. The penetrating radiation is not considered in this study, however, and the evaluation here is limited to the airborne radioactivity.

The accelerator, beam switchyard (BSY), storage rings, and interaction areas are vented by a series of exhaust fans. The exhaust fans for the accelerator and BSY discharge at points slightly above roof level. Fans for the storage rings and interaction areas discharge just above grade level. 
TABLE 20.1. Airborne Radioisotopes Produced by Operation of the Linear Accelerator at SLAC

\begin{tabular}{|c|c|c|}
\hline Radioisotope & Half-Life & $\begin{array}{c}\mathrm{CG}^{(\mathrm{a})} \\
\mu \mathrm{Ci} / \mathrm{m \ell} \\
\end{array}$ \\
\hline${ }^{11} \mathrm{C}$ & $20.5 \mathrm{~min}$ & $3 \times 10^{-6}$ \\
\hline $13 \mathrm{~N}$ & $9.9 \mathrm{~min}$ & $3 \times 10^{-6}$ \\
\hline $15_{0}$ & $2.1 \mathrm{~min}$ & $3 \times 10^{-6}$ \\
\hline $41 \mathrm{Ar}$ & $1.8 \mathrm{hr}$ & $4 \times 10^{-8}$ \\
\hline
\end{tabular}

(a) Concentration Guide for uncontrolled
areas. Taken from Table II - Column 1
of Appendix B of 10 CFR 20 (1982). (2)

The accelerator, storage rings, and interaction areas do not represent measurable sources of airborne radioactivity due to low activation potentials. The only potential sources of measurable airborne radioactivity at SLAC are five exhaust fans that serve to ventilate the beam switchyard. The locations of the five fans are shown in Figure 20.3. Each BSY exhaust fan is equipped with gas and particulate monitoring equipment. Monitoring data show that only gaseous radionuclides are discharged from the BSY fans.

In CY 1981, only a single BSY exhaust fan discharged radionuclides to the atmosphere at SLAC. This was the fan that ventilated the B-Target Room area (see Figure 20.3). For this study, only the B-Target Room fan is evaluated in detail. The other fans (BSY exhaust fans with the potential for releasing gaseous radionuclides to the atmosphere) are quite similar to the B-Target Room fan, and comments regarding the latter exhaust fan should be generally applicable to the other four fans as well.

20.2 EMISSION CONTROL TECHNOLOGY AT STANFORD LINEAR ACCELERATOR CENTER

This section describes the emission control technology currently in place at SLAC to reduce atmospheric releases of radionuclides. In addition, 


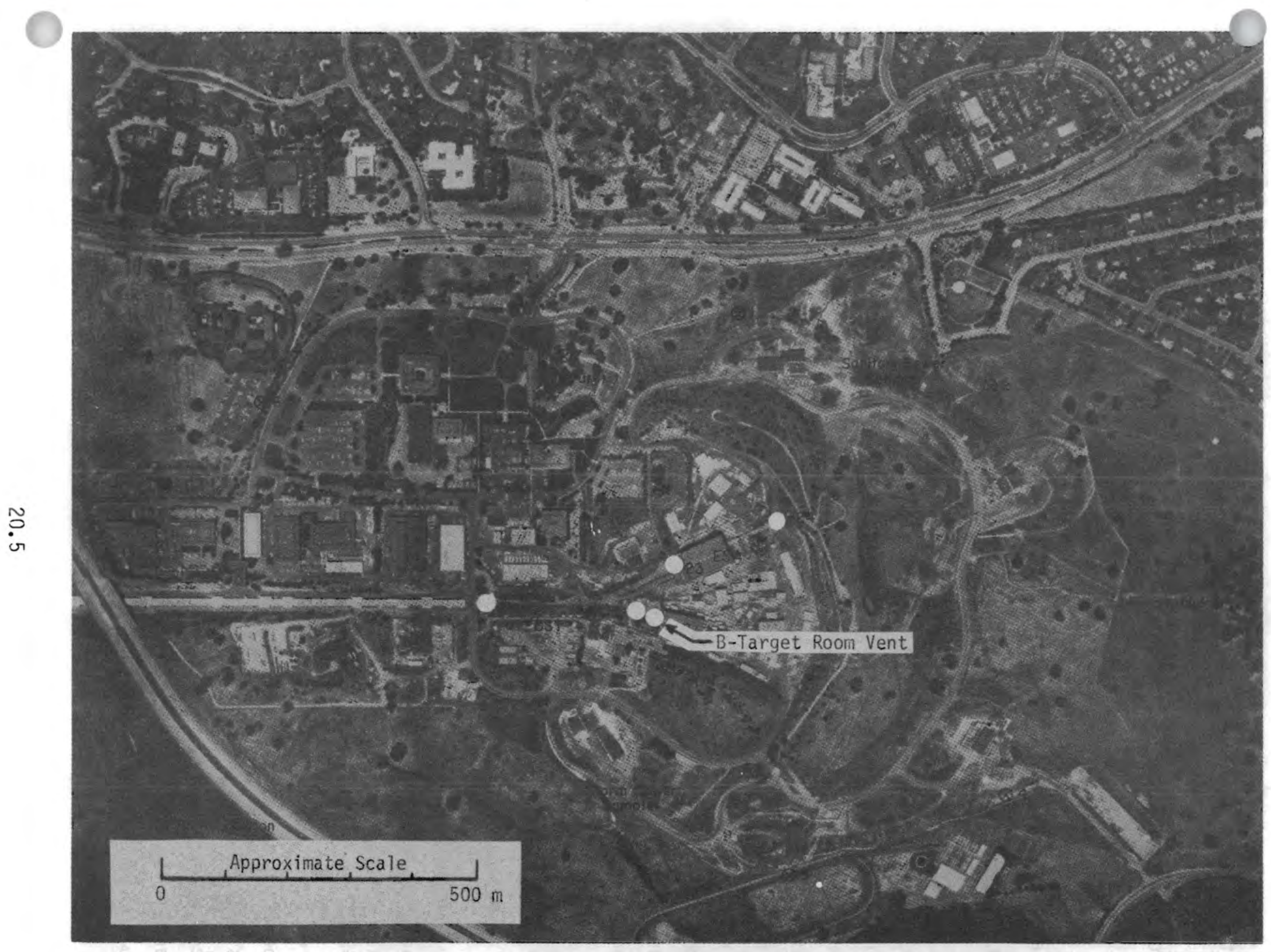

FIGURE 20.3. SLAC Research Area and Surrounding Community. The white dots indicate the five exhaust fans which vent the beam switchyard and have the potential for releasing radionuclides to the atmosphere 
potential application of additional emission control technology, the effects of such additions on atmospheric discharge rates, and the estimated costs of such additions are discussed.

Information on emission control technology at the SLAC was provided by G. W. Luense and W. W. Warner of the Department of Energy's San Francisco Operations office.

\subsubsection{Specific Source 1: B-Target Room Exhaust Fan}

All of the airborne radioactivity released to the atmosphere at SLAC in 1981 was discharged from the exhaust fan that vents the B-Target Room. The fan vents to the atmosphere at a point slightly above roof level. The ventilation fan is interlocked with a radioactive gas detector comprised of a Geiger-Mueller detector, power supply, rate meter, strip chart recorder, and air pumps. The electronics are in continuous operation and the recorder and air pump are interlocked with the ventilation fan so that they only operate when the fan is operating. The gas monitor also collects particulate samples during venting. Results obtained continue to show that no radioactive particulates are released during venting.

The nominal air flow through the B-Target Room exhaust fan during venting is $340 \mathrm{~m}^{3} / \mathrm{min}(12,000 \mathrm{cfm})$.

\subsubsection{Description of Existing Emission Control Technology}

There is no emission control technology in place to remove gaseous radionuclides from the air vented through the B-Target Room exhaust fan. The only control is to provide holdup of the air prior to venting to allow decay of some of the short-lived radionuclides. The accelerator and beam switchyard are not ventilated during accelerator operation. When an accelerator operating cycle is completed, the accelerator is turned off. Sufficient time is then allowed for the short-lived gaseous radionuclides to decay to negligible levels before the exhaust fans are started to ventilate the facilities. As a result, no detectable amounts of radioactivity are released to the atmosphere at the end of an accelerator operating cycle. 
Some airborne radioactivity is released to the atmosphere if personnel entry into the facility has to be made during an operating cycle. If entry is required, the accelerator is shut down. Normally a delay time of 1 hour after accelerator shutdown is provided before venting of the area to be entered is started (the delay time varies depending on operations). The area is vented for 10 minutes prior to entry. Venting only lasts for 30 to 60 minutes. The minimum l-hour delay prior to venting allows most of the short half-lived radionuclides to decay before venting is started.

\subsubsection{Current Discharge Rate ${ }^{(1)}$}

About $1.1 \mathrm{Ci}$ of short-lived radioactivity was released to the atmosphere through the B-Target Room exhaust fan in CY 1981. (1) The activity was essentially all argon-41. No detectable amounts of airborne radioactivity were released to the atmosphere through the other BSY exhaust fans during 1981.

Using the atmospheric dispersion models described in Reference 1, SLAC personnel determined that the average site boundary concentration in 1982 for argon-41 released from the B-Target Room vent was about $1.6 \times 10^{-11} \mu \mathrm{Ci} / \mathrm{m} \ell$. This amounts to only about $0.04 \%$ of the concentration guide. It was also reported that the model used for the calculation is conservative and overestimates the actual site boundary concentration by factors of 2 to 10 . The maximum site boundary annual dose resulting from the argon-41 released from the B-Target Room vent in 1981 was less than 0.3 mrem.

\subsubsection{Potential Additional Emission Control Technology}

The amount of airborne radioactivity released annually through the B-Target Room exhaust fan will vary depending on how often personnel entry is required each year during accelerator operating cycles. This applies to the other BSY exhaust fans as wel1. Past operating experience at SLAC shows that airborne releases can be expected to be relatively low. For example, total annual releases from 1976 to 1980 varied from 0.06 to $1.7 \mathrm{Ci}$ compared to the $1.1 \mathrm{Ci}$ released in 1981 . 
Because the annual airborne releases at SLAC are low, as are the site boundary exposures resulting from the airborne releases, it is difficult to justify additional emission control technology. If reductions in the release of airborne radioactivity (or offsite exposure) become necessary, however, there are several possible options that could be applied to the B-Target Room exhaust fan to reduce airborne emissions and/or offsite exposure, including the following:

- provide additional holdup time before venting, after the accelerator is turned off during an operating cycle,

- discharge the exhaust fan through a tall stack,

- provide a holdup tank to contain the air vented through the exhaust fan,

- provide a sorption system to remove argon from the air vented through the exhaust fan.

These options would apply to the other BSY exhaust fans as well. The simplest and least costly procedure for reducing airborne emissions from the B-Target Room would be to provide additional holdup time before venting the area with the exhaust fan, after the accelerator is turned of $f$. This would allow additional time for decay of the argon-41. How long a holdup time could be provided would probably depend on the experimental programs in progress during a given accelerator operating cycle, and would probably have to be determined on a case-by-case basis. Table 20.2 shows the reduction in argon-41 emissions obtainable as a function of additional holdup time provided.

TABLE 20.2. Reduction in Argon-41 Emissions Obtainable as a Function of Additional Holdup Time

\begin{tabular}{cc}
$\begin{array}{c}\text { Additional } \\
\text { Holdup Time, } \\
\text { hr }\end{array}$ & $\begin{array}{c}\text { \% Reduction in } \\
\text { the Argon-41 } \\
\text { Released }\end{array}$ \\
\hline 0 & 0 \\
1 & 32 \\
2 & 54 \\
4 & 79 \\
8 & 95
\end{tabular}


Consideration could be given to discharging the airflow from the B-Target Room exhaust fan to the atmosphere through a tall stack. Installation of a stack would not have a significant effect on the argon-41 release but could reduce offsite exposure. Effectiveness of the stack in reducing the exposure would depend on stack design and location, as well as on local climatic conditions. Evaluating the effectiveness of a stack in reducing offsite exposure is beyond the scope of this study. If a stack were installed, it could serve only the B-Target Room exhaust fan or all of the BSY fans. If a central stack were used to serve all of the fans, some of the connecting ducts would have to be several hundred meters long.

Use of an air storage system to provide additional holdup time could be considered. Because of the large airflow rate from the B-Target Room during venting, however, a large storage volume would be required to obtain a substantial reduction in the argon-41 release. Since venting of the B-Target Room is intermittent and only lasts for 30 to 60 minutes at one time, the situation is markedly different from a situation where venting is continuous. At the nominal airflow of $340 \mathrm{~m}^{3} / \mathrm{min}$, and assuming venting lasts for a maximum of 60 minutes, the total air displaced during the venting operation would be about $20,400 \mathrm{~m}^{3}$. If the air storage tank had a similar volume, essentially all of the air vented from the B-Target Room would be contained within the storage tank (assuming no intermixing). The argon-41 in the vented air would have more than sufficient time to decay to negligible levels before the next venting cycle occurred. In actual practice, some intermixing would occur during venting, and a small amount of air from the B-Target Room would be released from the storage tank during venting. The amount of argon-41 released would depend on the degree of intermixing, but with proper design, intermixing could be reduced to a fairly low level.

A typical tank with a volume of $20,400 \mathrm{~m}^{3}$ would be about $35 \mathrm{~m}$ in diameter by about $21 \mathrm{~m}$ high. The estimated capital cost for a tank of this volume, in 1983 dollars, is about $\$ 5,800,000$. A breakdown of the capital cost is given in Table 20.3. The estimated operating cost for a storage tank system is about $\$ 70,000 / y r$ (in 1983 dollars). 
TABLE 20.3. Estimated Capital Cost for an Atmospheric Pressure Air Storage Tank for Air Vented Through the B-Target Room Exhaust Fan - in 1983 Dollars

\begin{tabular}{lr} 
Item & Cost, \$ Thousands \\
\cline { 2 - 2 } Carbon Steel Tank - Installed (Vol. 20,400 $\mathrm{m}^{3}$ ) & 2,500 \\
Compressor, Piping, Instrumentation, Building & 750 \\
Concrete Pad & 300 \\
Site Preparation & $\frac{50}{3,600}$ \\
$\quad$ Subtotal - Direct Construction Costs & $\underline{600}$ \\
Architect - Engineering Services & 4,200 \\
$\quad$ Subtotal & $\underline{1,600}$ \\
Contingency & 5,800 \\
$\quad$ Total Facility Cost
\end{tabular}

A number of small tanks, of equivalent total volume, connected in series could be used instead of a single large tank. A pressurized air storage system could be used to reduce the storage volume required, but the overall capital cost would probably be increased. Since the BSY exhaust fans only operate at infrequent intervals and because it is unlikely that two fans would be in operation at one time, a single air storage tank system could probably be used to serve all of the BSY fans.

Argon-41 could be removed from the air vented from the B-Target Room by adsorption on a suitable adsorper such as activated carbon. Effective removal of the argon-41 would require carrying out the adsorption operation at a temperature of $-80^{\circ} \mathrm{C}$ or lower. The air would have to be dried prior to cooling to prevent freezeup of the contained water. Because of the large airflow and the high argon content (due to natural argon in the air), a very large adsorber system would be required. Assuming venting of the B-Target Room lasts 60 minutes, an air volume of $20,400 \mathrm{~m}^{3}$ would have to be processed in a period of 60 minutes each time the area is vented. It is estimated that an adsorber bed volume of at least $150 \mathrm{~m}^{3}$ would be required if the adsorber 
operated at $-80^{\circ} \mathrm{C}$. This would be equivalent to an adsorption column $4 \mathrm{~m}$ in diameter by $12 \mathrm{~m} \mathrm{high}$. The column would contain at least $90,000 \mathrm{~kg}$ of activated carbon. Removal of the water from the air would require a molecular sieve-drying column at least $3 \mathrm{~m}$ in diameter by $3 \mathrm{~m} \mathrm{high}$. The heat load on the refrigeration system to cool the air and adsorption column would be at least $1 \times 10^{6} \mathrm{kcal} / \mathrm{hr}(\sim 1160 \mathrm{~kW})$. The capital and operating costs of such a large adsorption system would be relatively high, and such a system should not be considered for use unless the other options discussed above are unacceptable.

It is impossible to rank the first three options for reducing argon-41 emissions without a detailed analysis, which is beyond the scope of this study. It is likely, however, that if it did become necessary to reduce argon-41 emissions at SLAC, the options would be ranked approximately in the order in which they are discussed above. 


\section{REFERENCES}

1. Annual Environment Monitoring Report January-December 1981, SLAC-249, Stanford Linear Accelerator Center - Stanford University, Stanford, California, 1982.

2. Code of Federal Regulations, Title 10 - Energy, Part 20 - Standards for Protection Against Radiation, Office of the Federal Register, National Archives and Records Service, General Services Administration, 1982. 


\subsection{OTHER DOE SITES}

Emission control technology at 11 Department of Energy (DOE) sites not discussed in Sections 7 through 20 is discussed in this section.

\subsection{AMES LABORATORY (1)}

Ames Laboratory is operated by Iowa State University (ISU) for the DOE. The principal facility was the Ames Laboratory Research Reactor (now decommissioned), located $2.4 \mathrm{~km}$ northwest of the ISU campus and $4.8 \mathrm{~km}$ northwest of Ames, Iowa, in the Applied Science Center. Other facilities include government-owned or leased facilities on the ISU campus: Spedding Hall, the Metals Development Building, the Metallurgy Building, the Office and Lab Building, the Physics Building, and Gilman Hall (Chemistry).

The Ames Laboratory Research Reactor (ALRR) was used until 1978 as a neutron source for the production of byproduct materials and the neutron irradiation of various materials for research. The reactor was fueled with enriched uranium, was moderated and cooled by heavy water $\left(D_{2} 0\right)$, and was operated continuously at 5000 watts thermal. Operation of the ALRR was terminated on December 1, 1977. Decommissioning began January 3, 1978, and was completed on October 31, 1981. Also located at the site is the waste disposal processing facility, serving both the reactor and the research laboratories located on campus.

\subsubsection{Specific Sources of Emissions}

Prior to decommissioning, the major airborne releases were tritium and argon-41 from the ALRR contaiment stack. The major radionuclide released during the CY 1981 decommissioning activities was tritium.

\subsubsection{Emission Control Technology}

Releases of radionuclides are from the 30.5-m-tall reactor stack (still standing), located $215 \mathrm{~m}$ from the nearest boundary. Airborne emissions are filtered and monitored before release. 


\subsubsection{Current Discharge Rate}

The discharge of radionuclides from the containment stack of ALRR in CY 1981 contained 4.49 curies of tritium. Nuclides released from the stack are given in Table 21.1. Since this facility has now been decommissioned, the radionuclide releases are expected to decrease in the future. TABLE 21.1. Atmospheric Emissions of Radionuclides from Ames Laboratory
Research Reactor Containment Stack for CY 1981(a)

\begin{tabular}{|c|c|}
\hline Radionuclide & $\begin{array}{c}\text { Amount } \\
\text { (Ci) }\end{array}$ \\
\hline $3_{H}$ & $4.49 E+00$ \\
\hline unidentified $\alpha$ & $1.59 \mathrm{E}-07$ \\
\hline unidentified $\beta-\gamma$ & $2.74 \mathrm{E}-06$ \\
\hline${ }^{65} \mathrm{Zn}$ & $2.41 E-07$ \\
\hline${ }^{60} \mathrm{Co}_{\mathrm{O}}$ & $2.22 \mathrm{E}-07$ \\
\hline
\end{tabular}

(a) Source: U.S. DOE Effluent Information System EPA Release Point Analysis Report for CY 1981.

\subsection{ATOMICS INTERNATIONAL (2)}

The Energy Systems Group of Rockwell International Corporation has been engaged in research and development of nuclear energy, including design, development, fabrication and testing of systems and components for central station power plants, and fabrication of nuclear fuel for test reactors. Decontamination and disposition of former nuclear facilities is now being carried out by Rockwell.

The Energy Systems Group operates two sites in California: the Canoga Park site, which is licensed by NRC and the state of California, and the Santa Susana Field Laboratories (SSFL), which are shared by DOE and Rockwell. The SSFL site is approximately $48 \mathrm{~km}$ northwest of Los Angeles, California, on a 117-hectare site. Non-DOE activities at SSFL include a hot laboratory, 
nuclear materials development, neutron radiography, and x-radiography. DOE contract activities are conducted within a 33-hectare area at the 117-hectare SSFL site.

DOE operations at SSFL that may release radioactive materials into the atmosphere are conducted at the Radioactive Material Disposal Facility (RMDF), where wastes from decontamination and disposition of DOE facilities are treated. Liquid and dry radioactive waste materials are processed, packaged, and stored temporarily for later disposal by land burial at authorized sites.

\subsubsection{Specific Sources of Emissions}

The radioactive waste handling facility (RMDF) is housed in Buildings 021 and 022 at SSFL.

\subsubsection{Emission Control Technology}

Airborne radioactive emissions from the waste handling facility are controlled by HEPA filtration. The stack associated with this facility is $40 \mathrm{~m}$ tall and is continuously monitored for radioactive levels in the effluent.

\subsubsection{Current Discharge Rate}

Emissions from DOE facilities at SSFL for CY 1981 consisted of $4.1 \mu \mathrm{Ci}$ of mixed fission products (see Appendix A). The CY 1981 environmental monitoring report for this site indicates the concentration of both alpha and beta radiation in effluent air from this facility was less than ambient, as shown Table 21.2.

\subsection{BATTELLE COLUMBUS LABORATORY (3)}

Battelle Columbus Laboratory (BCL) conducts various NRC-licensed activities as well as activities under Department of Energy contracts.

$B C L$ operates two complexes in the Columbus ohio, area. The first site is the King Avenue Site, which consists of four hectares of land near a residential area in Columbus. The Ohio State University intramural sports practice field borders the site to the north. 

TABLE 21.2. Atmospherjc Emissions from DOE Facilities at SSFL for

\begin{tabular}{lccc} 
Source & $\begin{array}{l}\text { Activity } \\
\text { Monitored }\end{array}$ & $\begin{array}{c}\text { Annual } \\
\text { Average Concen- } \\
\text { tration }\left(\mathrm{Ci} / \mathrm{m}^{3}\right)\end{array}$ \\
\hline $\begin{array}{l}\text { Building } \\
021-022 \\
\text { (RMDF) }\end{array}$ & $\alpha$ & & $<2.5 \times 10^{-16}$ \\
ambient & $\beta$ & $1.2 \times 10^{-14}$ \\
air & $\alpha$ & $<6.8 \times 10^{-15}$ \\
& $B$ & $<1.2 \times 10^{-13}$
\end{tabular}

(a) Source: J. D. Moore, Energy Systems Group Environmental Monitoring and Facility Effluent Annual Report 1981, ESG-82-21, Rockwell International, 1982.

The second site is the Nuclear Sciences Area of the West Jefferson site, which is located about $27 \mathrm{~km}$ west of the King Avenue laboratories. This site occupies about four hectares on a 405-hectare tract of land. There are approximately 1.5 million people living within $80 \mathrm{~km}$ of the laboratory.

The King Avenue site has a uranium-235 processing facility located within Building 3. This building also houses the melting facility and powder metallurgy laboratory. The uranium processing facility manages all transactions involving nuclear material at the King Avenue site. However, handling of contract and licensed material has been very limited since 1977 and monitoring of airborne emissions was discontinued in 1975.

At the West Jefferson site, activities at the Nuclear Sciences Area include operations in the $\mathrm{JN}-1$ hot cell (where irradiated reactor fuel elements are studied) and materials accountability and storage operations, conducted at the JN-2 vault. The JN-4 plutonium laboratory, where research was conducted on uranium-235/plutonium-239 nitride reactor fuel, is being decommissioned. 


\subsubsection{Specific Sources of Emissions}

Airborne releases from the BCL facilities in CY 1981 include plutonium and mixed fission products. The most important emission, as defined by the methodology in Section 1.4, was ${ }^{239} \mathrm{Pu}$ from the JN-4 plutonium lab exhaust vents. The JN-4 lab was being decommissioned in 1981 and 1982, and no further emissions were expected after mid-1982. (a) Other sources of radioactive emissions include unidentified alpha and ${ }^{239} \mathrm{Pu}$ from the $\mathrm{JN}-2$ vault; and ${ }^{235} \mathrm{U},{ }^{85} \mathrm{Kr},{ }^{212} \mathrm{~Pb},{ }^{125} \mathrm{Sb}$ and ${ }^{137} \mathrm{Cs}$ from the $\mathrm{JN}-1$ hot cell.

\subsubsection{Emission Control Technology}

Airborne radioactive emissions at $B C L$ are first filtered at the points of operation (i.e., glove boxes, hoods, test cells) and then passed through one or two stages of HEPA filters before release. The hot cell facility JN-1 is continuously monitored for iodine. Exhaust is diverted to a charcoal filter based on an iodine alarm.

\subsubsection{Current Discharge Rate}

The discharge of radionuclides from BCL for CY 1981 included $0.16 \mu C i$ of ${ }^{239} \mathrm{Pu}$ and $1.01 \mu \mathrm{Ci}$ of $235 \mathrm{U}$. A list of major sources and isotopes in effluents from $B C L$ is given in Table 21.3. A more detailed list of sources and emissions may be found in Appendix A.

\subsection{BETTIS ATOMIC POWER LABORATORY (4)}

The Bettis Atomic Power Laboratory (BAPL) is operated by the Westinghouse Electric Corporation for the Naval Reactors Division of the Department of Energy. Operations involve design and development of nuclear fuel materials, as well as radiochemistry and reactor materials examinations.

BAPL occupies about 81 hectares of land in West Mifflin, Pennsylvania, about. $13 \mathrm{~km}$ southwest of Pittsburgh. The total population within $80 \mathrm{~km}$ of the site is about 3.3 million.

(a) Phone conversation with Dr. Jerry Nelson, DOE Chicago Operations Office, January 1983. 
TABLE 21.3. Atmospheric Emissions of Radionuclides from $B C L$ for $C Y 1981(a, b)$

\begin{tabular}{|c|c|c|}
\hline Source & Radionuclide & $\begin{array}{l}\text { Emission } \\
\quad(\mathrm{Ci})\end{array}$ \\
\hline \multicolumn{3}{|l|}{ JN-4 Plutonium Lab } \\
\hline $\begin{array}{l}\text { Rm } 4126 \text { East Exhaust } \\
\text { Rm } 4114 \text { West Exhaust }\end{array}$ & $\begin{array}{l}239 \mathrm{Pu} \\
239 \mathrm{Pu}\end{array}$ & $\begin{array}{l}6.2 E-08 \\
6.4 E-08\end{array}$ \\
\hline \multicolumn{3}{|l|}{$\mathrm{JN}-2$ Vault } \\
\hline $\begin{array}{l}\text { Exhaust Stack } \\
\text { Exhaust Stack }\end{array}$ & $\begin{array}{c}{ }^{239} \mathrm{Pu} \\
\text { unidentified } \alpha \\
\text { unidentified } \beta-\gamma\end{array}$ & $\begin{array}{l}1.4 \mathrm{E}-08 \\
1.4 \mathrm{E}-08 \\
1.1 \mathrm{E}-07\end{array}$ \\
\hline
\end{tabular}

JN-1 Hot Cel1(b)
New Building Exhaust
01d Building Exhaust
01d Building Exhaust

$\begin{array}{ll}235 U & 6.0 E-07 \\ 235 U & 1.0 E-07 \\ 235_{U} & 7.9 E-08\end{array}$

(a) Source: U.S. DOE Effluent Information System EPA Release Point Analysis Report for CY 1981.

(b) For additional detail, refer to Appendix $A$.

\subsubsection{Specific Sources of Emissions}

Emissions from BAPL, according to the 1981 EPA release point analysis report, are from the main $1 a b$ and the northeast area of the site. Fuel development efforts and hot cell chemistry work are the principal operations contributing to radioactive airborne emissions from BAPL.

\subsubsection{Emission Control Technology}

Short-lived isotopes are controlled by delaying the examination of irradiated fuel to allow for decay. Particulate emissions are controlled with HEPA filters. Charcoal filters are used for iodine control. Small amounts of $85 \mathrm{Kr}$ generated by irradiated fuel examinations are released in the exhaust stacks. Air exhausted from the laboratory's fume hoods is treated by filtration or wet scrubbers to minimize emissions. Exhaust stacks that discharge air from areas where radioactive materials are handled are continuously monitored. 


\subsubsection{Current Discharge Rate}

Radioactive airborne emissions from BAPL in CY 1981 include $1.8 \mu \mathrm{Ci}$ of unidentified alpha and $160 \mathrm{mCi}$ of ${ }^{85} \mathrm{Kr}$. Table 21.4 gives a list of radionuclides in airborne effluents from BAPL for CY 1981.

TABLE 21.4. Atmosphere Emissions of Radionuclide from BAPL for CY $1981^{(a)}$

\begin{tabular}{ccc} 
Radionuclide & & $\begin{array}{c}\text { Emission } \\
(\mathrm{Ci})\end{array}$ \\
\cline { 1 - 1 } unidentified $\alpha$ & & $1.8 \mathrm{E}-06$ \\
$85_{\mathrm{Kr}}$ & & $1.6 \mathrm{E}-01$ \\
unidentified $\beta-\gamma$ & & $1.5 \mathrm{E}-05$ \\
$125_{\mathrm{Sb}}$ & & $5.8 \mathrm{E}-05$ \\
$129 \mathrm{I}$ & & $2.5 \mathrm{E}-07$ \\
$131_{\mathrm{I}}$ & & $8.4 \mathrm{E}-07$ \\
$3_{\mathrm{H}}$ & & $3.0 \mathrm{E}-05$
\end{tabular}

(a) Source: U.S. DOE Effluent Information System EPA Release Point Analysis Report for CY 1981.

\subsection{FEED MATERIALS PRODUCTION CENTER}

The Feed Materials Production Center is discussed in Section 7.0.

\subsection{KNOLLS ATOMIC POWER LABORATORY $(5)$}

The Knolls Atomic Power Laboratory (KAPL) consists of three sites: the Knolls site, the Kesselring site, and the Windsor site. At the Knolls site, the principal function is the design and development of naval nuclear power reactors, while at the Kesselring and Windsor sites the principal function is training personnel in the operation of naval nuclear reactors.

The Knolls site is situated on 69 hectares of land along the Mohawk River, about $3 \mathrm{~km}$ east of Schenectady, New York, in a relatively low population, residential area. About $1.23 \mathrm{million}$ people live within $80 \mathrm{~km}$ of Knolls site. 
The Kesselring site, a 1579-hectare site, is located near West Milton, New York, approximately $27 \mathrm{~km}$ north of Schenectady. The surrounding area is rural and sparsely populated; about 1.08 million people live within $80 \mathrm{~km}$.

The Windsor site consists of only 4 hectares of land near Windsor, Connecticut, about $8 \mathrm{~km}$ north of the city of Hartford. The area is a rural farming and industrial region along the Farmington River. Approximately 3.1 million people live within $80 \mathrm{~km}$.

\subsubsection{Specific Sources of Emissions}

The principal radionuclide emitted from the Knolls site is ${ }^{4} 1_{A r}$. Air leakage into the low-power critical facility is the source of ${ }^{41} \mathrm{Ar}$ emissions. Fission product emissions, notably ${ }^{85} \mathrm{Kr}$, are from the hot cells, where irradiated fuel is examined.

The Kesselring site has four pressurized water reactor plants and associated support facilities used for training. The Windsor site contains one pressurized water reactor plant used for training. Particulate and gaseous activity contained in the primary coolant may become airborne from reactor coolant discharges, sampling operations and during laboratory operations.

\subsubsection{Emission Control Technology}

The operations at the Knolls site involving radioactive materials are serviced by controlled exhaust systems that discharge through elevated stacks. Exhaust air is passed through HEPA and carbon filters and is continuously sampled prior to release. Small amounts of $85^{\mathrm{Kr}}$ generated by examination of irradiated fuel are released in the exhaust stacks. Generation of ${ }^{41} \mathrm{Ar}$ is kept to a minimum by controlling air leakage into the low-power critical assembly.

At the Kesselring site, exhaust air from reactor coolant discharges, sampling and laboratory operations is passed through HEPA filters, monitored, and released from elevated stacks. 
At the Windsor site reactor, exhaust air from operations that have the potential for release of airborne radioactivity is passed through HEPA filters, then monitored, and released through elevated stacks.

Additional controls have not been used on the Kesselring and Windsor reactors because the quality of the fuel is excellent; leaking fuel has not been a problem for these naval-type reactors.

\subsubsection{Current Discharge Rate}

Airborne emissions of radionuclides from the Knolls site in CY 1981 included $3.5 \mathrm{Ci}$ of $41_{\mathrm{Ar}}, 138 \mathrm{mCi}$ of $85 \mathrm{Kr}$, and $81 \mu \mathrm{Ci}$ of mixed fission products (MFP). Facilities at the Kesselring and Windsor sites emitted 313 and $96 \mathrm{mCi}$ of ${ }^{41} \mathrm{Ar}$, respectively. A summary of the major emissions of radionuclides from these sites is given in Table 21.6. A more detailed list of emissions is found in Appendix A.

TABLE 21.6. Major Airborne Radionuclide Emissions from KAPL for CY 1981(a)

\begin{tabular}{|c|c|c|c|}
\hline \multirow[b]{2}{*}{ Radionuclide } & \multicolumn{3}{|c|}{ Emission (Ci) by Site } \\
\hline & Knol1s & Kesselring & Windsor \\
\hline $41_{A r}$ & $3.48 E+00$ & $3.13 E-01$ & $9.59 E-02$ \\
\hline${ }^{85} \mathrm{Kr}$ & $1.38 \mathrm{E}-01$ & -- & -- \\
\hline${ }^{14} \mathrm{C}$ & -- & $1.79 E-01$ & -- \\
\hline MFP & $8.08 E-05$ & - & -- \\
\hline $133 m \times e$ & -- & $4.13 E-02$ & -- \\
\hline
\end{tabular}

(a) Source: DOE Effluent Information System EPA Release Point Analysis Report for CY 1981.

\subsection{LAWRENCE BERKELEY LABORATORY (6)}

Lawrence Berkeley Laboratory $(L B L)$ is a large multidisciplinary research institute. The laboratory carries out a wide range of research programs in the fields of physical and biological sciences. The facilities include a number of large accelerators, and various physics, chemistry, biology and medical research laboratories. 
LBL is part of the University of California and is located on the western slope of the hills parallel to the eastern side of San Francisco Bay. Populated residential areas of the cities of Berkeley and 0akland enclose the site to the north and south. The Berkeley Campus of the University of California is on the west of LBL, and an uninhabited regional park is to the east of the site. There are about 4.6 million people residing within $80 \mathrm{~km}$ of LBL.

\subsubsection{Specific Sources of Emissions}

The use of radionuclides in various research laboratories is the principal potential source of leakage of radionuclides into the environment. There are over 100 such exhaust points, located on a number of different buildings throughout the site. Most of these consist of chemical laboratory box or hood exhausts. Each laboratory box or hood has its own locally controlled exhaust, which is appropriately sampled at its point of discharge.

The largest source of radioactivity from the $L B L$, according to the $C Y$ 1981 Emission Report, is the Building 75 stack, which discharges approximately $100 \%$ of the tritium released from LBL. Building 75 houses a tritium-labeling lab designed to handle kilocurie quantities of tritium.

Many labs at LBL use millicurie quantities of a variety of radionuclides. Small amounts of ${ }^{14} \mathrm{C}$ and radioiodine and unidentified alpha and beta emitters are released from LBL facilities.

\subsubsection{Emission Control Technology}

Each laboratory box exhaust system includes a group of HEPA filters and/or gas traps. The tritium facility has a tritium recovery system in which unused tritium gas is circulated over hot copper oxide and the resultant water is trapped in a liquid nitrogen dewar, drained from the system, and packaged for disposal. This recovery system can be isolated from the labeling and storage system and the tritium can be circulated continuously in a closed loop until the tritium concentration has dropped to an acceptable level for discharge to the atmosphere via the laboratory exhaust manifold. Silica gel traps are used to reduce the level of tritium discharged. 
The purge ventilation system of the LBL tritium facility consists of an air evacuation system that draws air through inside filters into a vent pipe to the outside of the facility where it then undergoes mechanical forcing. This forcing vents the air through a vertical exhaust stack elevated $9 \mathrm{~m}$ above a hill directly behind the facility, giving an effective stack height of $18.3 \mathrm{~m}$.

\subsubsection{Current Discharge Rate}

In CY 1981, radioactive emissions from LBL included $70 \mathrm{Ci}$ of $3_{\mathrm{H},} 0.57 \mathrm{mCi}$ of ${ }^{125} \mathrm{I}$, and $36 \mathrm{mCi}$ of ${ }^{14} \mathrm{C}$. A summary of radionuclides discharged to the atmosphere is given in Table 21.7 .

TABLE 21.7. Airborne Radionuclide Emissions from LBL for CY 1981

$\begin{array}{ccc}\text { Radionuclide } & \frac{\begin{array}{c}\text { Quantity } \\ \text { Discharged } \\ (\mathrm{C} i)\end{array}}{7.0 \mathrm{E}+01} \\ 3_{\mathrm{H}} & 3.9 \mathrm{E}-02 \\ 14_{\mathrm{C}}^{125} \mathrm{I} & 5.6 \mathrm{E}-04 \\ \text { unidentified } \alpha & <1.0 \mathrm{E}-06 \\ \text { unidentified } \beta-\gamma & 4.1 \mathrm{E}-05\end{array}$

\subsection{MOUND FACILITY (7)}

The Mound Facility has been in operation since 1949. Its primary functions include research, development, engineering, production and surveillance of components for the DOE weapons program. Other operations involve the separation, purification, and sale of stable noble gas isotopes and the fabrication of radioisotopic heat sources for thermoelectric generators.

The Mound Facility, located in Miamisburg, Ohio, about $16 \mathrm{~km}$ southwest of Dayton, occupies a 73-hectare site in the Great Miami River Valley. This area is highly industrialized. The surrounding region is mostly agricultural with some light industry and scattered residential communities. About $2.8 \mathrm{million}$ people live within $80 \mathrm{~km}$ of the Mound Facility. 


\subsubsection{Specific Sources of Emissions}

Nine buildings at the Mound Facility released radioactivity into the atmosphere in CY 1981. Operations at these facilities resulted in the release of tritium and plutonium-238. Three stacks on the SW building contribute 99\% of the tritium discharge at Mound. Most of the remaining $3_{H}$ release was from the $H H$ building stack. These stacks and their CY 1981 emissions are described in Table 21.8. SW building operations involve disassembly, analysis and development of nuclear components containing tritium, and recovery of tritium wastes. Mound also emits some ${ }^{238} \mathrm{Pu}$, mainly from the SM and PP buildings, via the SM-PP stack.

TABLE 21.8. Sources of Major Tritium Releases from Mound Facility, CY 1981

\begin{tabular}{llccc} 
Building & \multicolumn{1}{c}{ Stack } & & $\begin{array}{c}\text { Height } \\
(\mathrm{m})\end{array}$ & $\begin{array}{c}\text { Discharge } \\
(\mathrm{Ci})(a)\end{array}$ \\
\cline { 2 - 2 } SW Bldg & HEFS Stack & & 45 & 3240 \\
SW Bldg & SW Stack & & 30 & 613 \\
SW Bldg & NCDPF Stack & & 40 & 380 \\
HH Bldg & HH Bldg Stack. & & 23 & 52
\end{tabular}

(a) Source: DOE Effluent Information System EPA Release Point Analysis Report for CY 1981.

\subsubsection{Emission Control Technology}

Tritium in gaseous effluent streams of the SW building is treated before release by the effluent removal system (ERS), which oxidizes elemental tritium and then removes the resulting tritiated water by molecular sieve drying beds. A flow diagram of the ERS is shown in Figure 21.1. The HEFS, SW, and NCDPF stacks, described in Table 21.8, are all connected with the ERS. The efficiency of this tritium removal system is approximately $99.9 \%$, according to Daryl Mercer of DOE Albuquerque operations.

At the facilities where plutonium is processed, particulate radioactivity is removed from the process air streams by HEPA filters. The airborne 


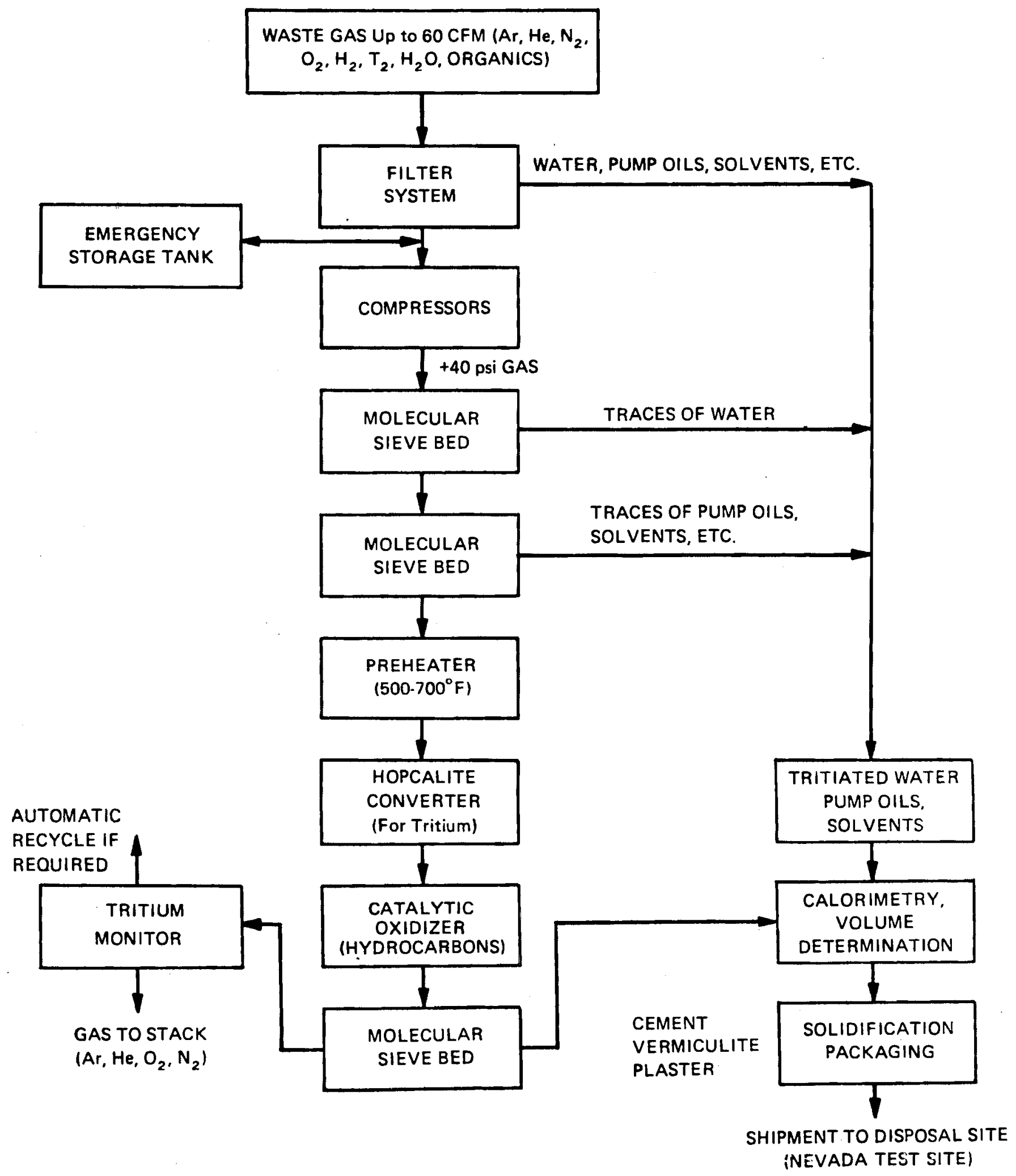

FIGURE 21.1. Flow Diagram of Effluent Removal System at Mound Facility 
effluents undergo filtration at their point of generation and again at the stack just prior to release.

\subsubsection{Current Discharge Rate}

In CY 1981, the radioactive airborne effluent from the Mound Facility consisted of $4286 \mathrm{Ci}$ of $3_{\mathrm{H}}$ and $8.25 \mu \mathrm{Ci}$ of $238 \mathrm{pu}$.

\subsection{NEVADA TEST SITE $(8)$}

The Nevada Test Site (NTS) is a part of the national weapons research and development program. Nuclear weapons testing and experiments on the site are performed in conjunction with weapons systems developed at Lawrence Livermore Laboratory (LLL), the Los Alamos Scientific Laboratory (LASL), and the Sandia Laboratories in response to Department of Defense requirements.

NTS is located in Nye County, Nevada, about $100 \mathrm{~km}$ northwest of Las vegas. It occupies about 349,000 hectares of federally owned land. The Nellis Air Force Base and Tonopah Test Range border NTS on three sides, from the northwest to the east, providing an additional one million hectares of federally owned land as a buffer. With the exception of Las Vegas, the region surrounding the NTS is rural and sparsely populated--only 6,100 people live within $80 \mathrm{~km}$ of NTS. Beatty, with a population of 900, is the largest town nearby.

A1 1 nuclear weapons detonations at the NTS have been conducted underground since the Limited Test Ban Treaty in 1963. Underground detonations create the large amounts of radioactive material contained in the cavity formed by the explosion. Since 1971, there have been no prompt ventings or inadvertent releases of gaseous radioactivity from test explosions. After the test detonations, one or more re-entry holes are drilled back into the radioactive debris for samples to determine the performance of the device.

\subsubsection{Specific Sources of Emissions}

During CY 1981, re-entry drilling operations resulted in occasional lowlevel releases of airborne radioactivity, primarily xenon. There was also some small leakage of tritium to the atmosphere from ventilation of test 
tunnels. Locations with the largest radionuclide discharges in CY 1981 included U3LJ in LASL test area 6 (200 $\mathrm{Ci}$ of $133 \mathrm{Xe}$ ) and three LLNL drilling locations (total $870 \mathrm{Ci}$ of xenon and $270 \mathrm{Ci}$ of tritium.)

The U12G tunnel, a source of tritium, is used in tests conducted in mine shafts in the mountainside at NTS. CY 1981 releases are summarized in Table 21.9.

TABLE 21.9. Airborne Radioactive Effluents from Operations at Nevada Test Site

\begin{tabular}{|c|c|c|c|}
\hline Site & Operation & \multirow{2}{*}{$\frac{\text { Nuclide }}{131_{\mathrm{I}}}$} & $\begin{array}{l}\text { Discharge } \\
\text { (Ci) }\end{array}$ \\
\hline LASL Test Area 6 & U3LJ Post-Shot Drilling Rig & & $5.0 \mathrm{E}-02$ \\
\hline & & ${ }^{133} \times \mathrm{e}$ & $2.0 E+03$ \\
\hline \multirow[t]{4}{*}{ LLNL Post-Shot } & Drilling Rig & ${ }^{133} \times e$ & $7.0 E+02$ \\
\hline & & $133 m_{x e}$ & $2.88 \mathrm{E}+01$ \\
\hline & & ${ }^{135} \times e$ & $1.42 \mathrm{E}+02$ \\
\hline & Drilling Rig & $3_{H}$ & $2.74 E+02$ \\
\hline Area 12 Site U12G & U12G Tunnel Ventilation System & $3_{H}$ & $2.6 \mathrm{E}+02$ \\
\hline
\end{tabular}

\subsubsection{Emission Control Technology}

The drilling rigs of LLNL and LASL use different effluent control systems. The LASL system is designed to force effluent gases back into the drill hole, and filter any escaping gases. The LLNL system passes effluent through prefilters, charcoal filters, and HEPA filters prior to release to the atmosphere.

The tunnel ventilation system has no tritium controls. The ventilation system exits at ground level.

21.9.3 Current Discharge Rate

Annual discharges of radioactivity from NTS in CY 1981 included $2700 \mathrm{Ci}$ of $133 \mathrm{xe}, 270 \mathrm{Ci}$ of $3 \mathrm{H}$, and $50 \mathrm{mCi}$ of $131 \mathrm{I}$ from post-shot drilling and $260 \mathrm{Ci}$ of $3 \mathrm{H}$ from the $\mathrm{U} 12 \mathrm{G}$ Tunnel ventilation. 


\subsection{PANTEX PLANT $(9)$}

The Pantex Plant's mission includes atomic weapons assembly, retirement, and stockpile surveillance. The plant also fabricates and tests chemical explosives.

The Pantex Plant, located on 3683 hectares of land in Carson County, Texas, is in the Panhandle Plains area about $27 \mathrm{~km}$ northeast of Amarillo. The Panhandle is predominately an agricultural area; the population is about 259,000 persons within $80 \mathrm{~km}$.

\subsubsection{Specific Sources of Emissions}

High explosive test firings, which are conducted intermittently, release small quantities of depleted uranium. Disassembly, shipping, and receiving operations within the plant release small amounts of tritium. There are no sources of continuous releases of radioactive material to the atmosphere. With few exceptions, radioactive material is handled in sealed containers. These containers are not opened, thus avoiding the possibility of release during normal operations.

Small quantities of $238_{U}$ are released from firing site No. 5 . The same is true of ${ }^{3} \mathrm{H}$ from the assembly area.

\subsubsection{Emission Control Technology}

There are no systems employed to treat the radioactive emissions to the atmosphere.

\subsubsection{Current Discharge Rate}

Discharge of radionuclides from the Pantex Plant in CY 1981 included $10 \mu \mathrm{Ci}$ of $238 \mathrm{U}$ and $95 \mathrm{mCi}$ of ${ }^{3} \mathrm{H}$.

\subsection{PINELLAS PLANT (10)}

The Pinellas Plant is operated by the Neutron Devices Department of the General Electric Company. Operations involve the design, development, and manufacture of special electronic and mechnical components for nuclear weapons. 
The Pinellas Plant, located on a 39.2-hectare tract in Pinellas County, Florida, is on Florida's west coast, north of St. Petersburg. The county has had a rapid population growth and is the most densely populated county in Florida with about 1.93 million people residing within $80 \mathrm{~km}$ of the plant.

Operations causing atmospheric releases of radioactive materials involve neutron generator development and production, testing, and laboratory operations.

\subsubsection{Specific Sources of Emissions}

Small amounts of tritium gas, tritium oxide, and krypton-85 were released from the stacks at Building 100. Table 21.10 shows the $C Y 1981$ effluent information for the Pinellas Plant. TABLE 21.10. Airborne Radionuclide Releases from
Pinellas Plant for CY 1981(a)

Total

$\frac{\text { Source }}{\text { Building } 100 \text { Main Stack }}$

Lab Stack

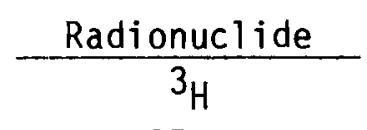

$85_{\mathrm{Kr}}$

$3_{\mathrm{H}}$

${ }^{14} \mathrm{C}$ Discharge $2.44 \mathrm{E}+02$ 3.6 $1.65 \mathrm{E}+02$ $8.5 \mathrm{E}-05$

(a) Source: DOE Effluent Information System EPA Release Point Analysis Report for CY 1981.

\subsubsection{Emission Control Technology}

Areas utilizing radioactive materials are connected to a special exhaust system, shown schematically in Figure 21.2 , that is designed to trap tritium and reduce the amount released to the atmosphere. In this system, tritium gas is converted to the oxide form by passage through heated copper oxide beds. The tritiated water vapor is then absorbed by silica gel. Both the Building 100 main stack (reduced in height from $30.5 \mathrm{~m}$ to $21.3 \mathrm{~m}$ in 1981) and the $1 \mathrm{ab}$ 


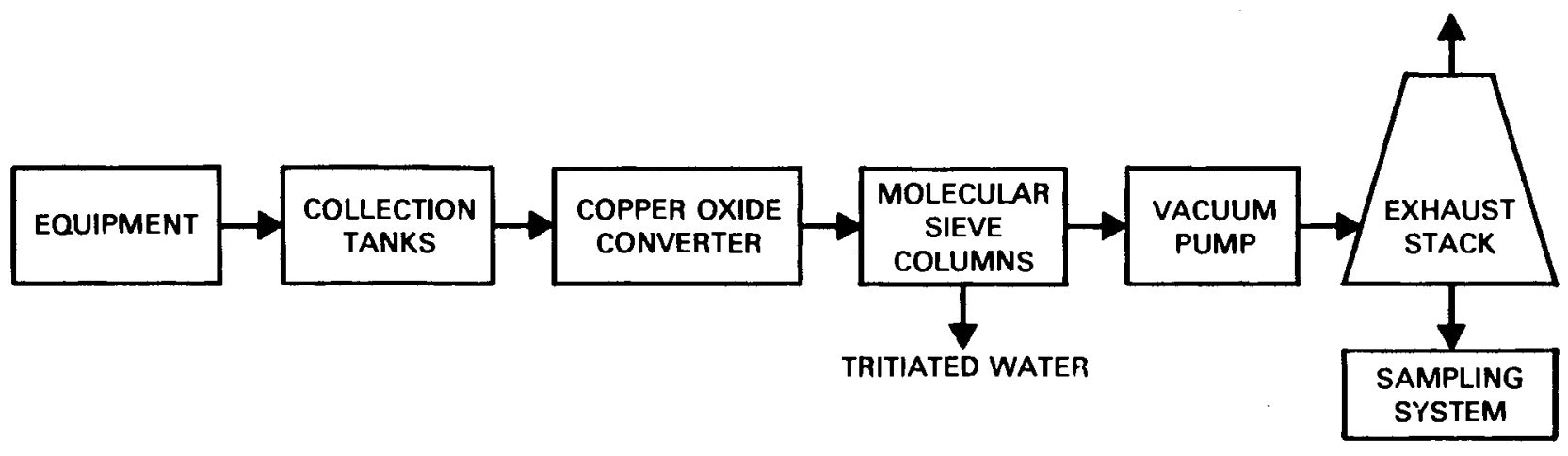

FIGURE 21.2. Schematic of Tritium Recovery System, Pinellas Plant

stack (30.5 $\mathrm{m} \mathrm{high)} \mathrm{are} \mathrm{connected} \mathrm{to} \mathrm{the} \mathrm{tritium} \mathrm{recovery} \mathrm{system.} \mathrm{This} \mathrm{system}$ removes approximately $99 \%$ of the airborne tritium from the respective waste streams.

\subsubsection{Current Discharge Rate}

In $C Y$ 1981, the radioactive airborne effluent from the Pinellas Plant consisted of $416 \mathrm{Ci}$ of tritium, $3.6 \mathrm{Ci}$ of $85 \mathrm{Kr}$, and $84 \mu \mathrm{Ci}$ of ${ }^{14} \mathrm{C}$.

\subsection{SANDIA LABORATORIES, ALBUQUERQUE SITE}

Sandia Laboratories is a nuclear ordnance laboratory that combines nuclear weapons developed by Los Angeles Scientific Laboratory and Lawrence Livermore Laboratory with delivery systems needed by the military services. This responsibility includes performing weapons testing, quality control and assurance, arming and fusing, safety, delivery system modification, and safeguards. Components are tested for proper operation under a variety of environmental conditions involving parameters such as shock, vibration, temperature, moisture and radiation.

The Sandia Laboratories, are located in Albuquerque, New Mexico, and Livermore, California. The Livermore site is covered with Lawrence Livermore Laboratory in Section 13. In Albuquerque, Technical Area $V$ is where much of the radiation testing is performed. Facilities at this site include two research reactors, a relativistic electron beam accelerator facility, and a 
neutron generator. This area is located approximately $10 \mathrm{~km}$ south of the city in a sparsely populated region--about 450,000 people live within $80 \mathrm{~km}$, mostly inside a $20-\mathrm{km}$ radius.

\subsubsection{Specific Sources of Emissions}

Most of the radionuclide emissions at Sandia Laboratories are from two research reactors. The Sandia Pulsed Reactor (SPR) is an unreflected, cylindrical, enriched-uranium assembly. The Annular Core Research Reactor (ACRR) is a modified TRIGA-type reactor. Reactor operations release small amounts of fission and activiation product gases, primarily argon-41. Emissions from ACRR and SPR are given in Table 21.11.

TABLE 21.11. Airborne Radionuclide Emissions from
Sandia Facilities for CY 1981 (a)

\begin{tabular}{|c|c|c|}
\hline Facility & Radionuclide & $\begin{array}{c}\text { Discharge } \\
(\mathrm{Ci})\end{array}$ \\
\hline ACRR & ${ }^{41} \mathrm{Ar}$ & 4.93 \\
\hline SPR & ${ }^{41} \mathrm{Ar}$ & 1.91 \\
\hline
\end{tabular}

(a) Source: DOE Effluent Information System EPA Release Point Analysis Report for CY 1981.

21.12.2 Emission Control Technology

Emission control equipment on ACRR cavity purge (Building 6588 exhaust stack) includes a prefilter, a HEPA filter, two charcoal filters, and another HEPA filter in series. Effluent air is released through a 14-m-high stack. Emission control equipment on SPR (Building 6590 exhaust stack) includes a prefilter, a HEPA filter, and a charcoal filter in series, connected to an 8.5-m-high stack.

\subsubsection{Current Discharge Rate}

Discharge of radionuclides from Sandia in $C Y 1981$ included $6.8 \mathrm{Ci}$ of ${ }^{41}$ Ar from the ACRR and SPR. 


\section{REFERENCES}

1. M. D. Voss, Environmental Monitoring Summary for Ames Laboratory Calendar Year 1981, IS-4798, Prepared for the U.S. DOE by Ames Laboratory, Iowa State University, Ames, Iowa, 1981.

2. J. D. Moore, Energy Systems Group Environmental Monitoring and Facility Effluent Annual Report, ESG-82-21, Rockwell International, Canoga Park, California, 1981.

3. Environmental Report for Calendar Year 1981, Prepared for the U.S. DOE by Battelle Columbus Laboratories, Columbus, Ohi o, 1982.

4. Effluent and Environmental Monitoring Report for Calendar Year 1981, WAPD-RC/E (ESE)-576, Prepared for the U.S. DOE by Westinghouse Electric Corp., Bettis Atomic Power Laboratory, Wes Mifflin, Pennsylvania, 1982.

5. Knolls Atomic Power Laboratory Annual Environmental Monitoring Report Calendar Year 1981, KAPL-4148, Prepared for the U.S. D0E by General Electric Company, Knolls Atomic Power Laboratory, Schenectady, New York, 1982.

6. G. E. Schleimer, ed., Annual Environmental Monitoring Report of the Lawrence Berkeley Laboratory, 1981, LBL-14553 UC-41, June 1982.

7. B. M. Farmer, and D. G. Carfagno, Annual Environmental Monitoring Report: Calendar Year 1981, MLM-2930, Prepared for the U.S. DOE by Monsanto Research Corporation, Mound Facility, Miamisburg, Ohi o, 1982.

8. S. C. Black, et al., Offsite Environmental Monitoring Report - Radiation Monitoring Around United States Nuclear Test Areas, Calendar Year 1981, D0E/DP/00539, Prepared for the U.S. DOE by Environmental Monitoring Systems Laboratory, Office of Research and Development, U.S. EPA, Las Vegas, Nevada, 1982.

9. W. A. Laseter, Environmental Monitoring Report for Pantex Plant Covering 1981, MHSMP-82-14, Prepared for the U.S. DOE by Mason \& Hanger - Silas Mason Co., Inc., Pantex Plant, Amari110, Texas, 1982.

10. Pinellas Plant Environmental Monitoring Report for 1981, GEPP-EM-654, Prepared for the U.S. DOE by General Electric Company, Pinellas Plant, St. Petersburg, Florida, 1982. 


\author{
APPENDIX A \\ U.S. DEPARTMENT OF ENERGY \\ EFFLUENT INFORMATION SYSTEM, \\ EPA RELEASE POINT ANALYSIS REPORT \\ FOR CALENDAR YEAR 1981
}




APPENDIX A
U.S. DEPARTMENT OF ENERGY EFFLUENT
INFORMATION SYSTEM, EPA RELEASE POINT
ANALYSIS REPORT FOR CALENDAR YEAR 1981

The data in this appendix are presented as they appear in the DOE computer printouts. Sites are grouped according to the responsible DOE field office. Effluents are listed by isotope, stack, and building.

Some sites discussed in this document were not included in the 1981 DOE effluent information system report.

A.1 
U.S. TFOART: DF ENFRGY

FFFLUENT INFORMATION SYSTEM

EPA RELEASF POINT ANAI YSIS RFPORT

_.. EOB_CALENDAB_YEAB_1981_...

ALPUCUFROUF OPERATIONS OTFITE

SANDIA CORPIIRATIITN

SANDIA I ARURAIIIRIFS. AL RFOUEROUF

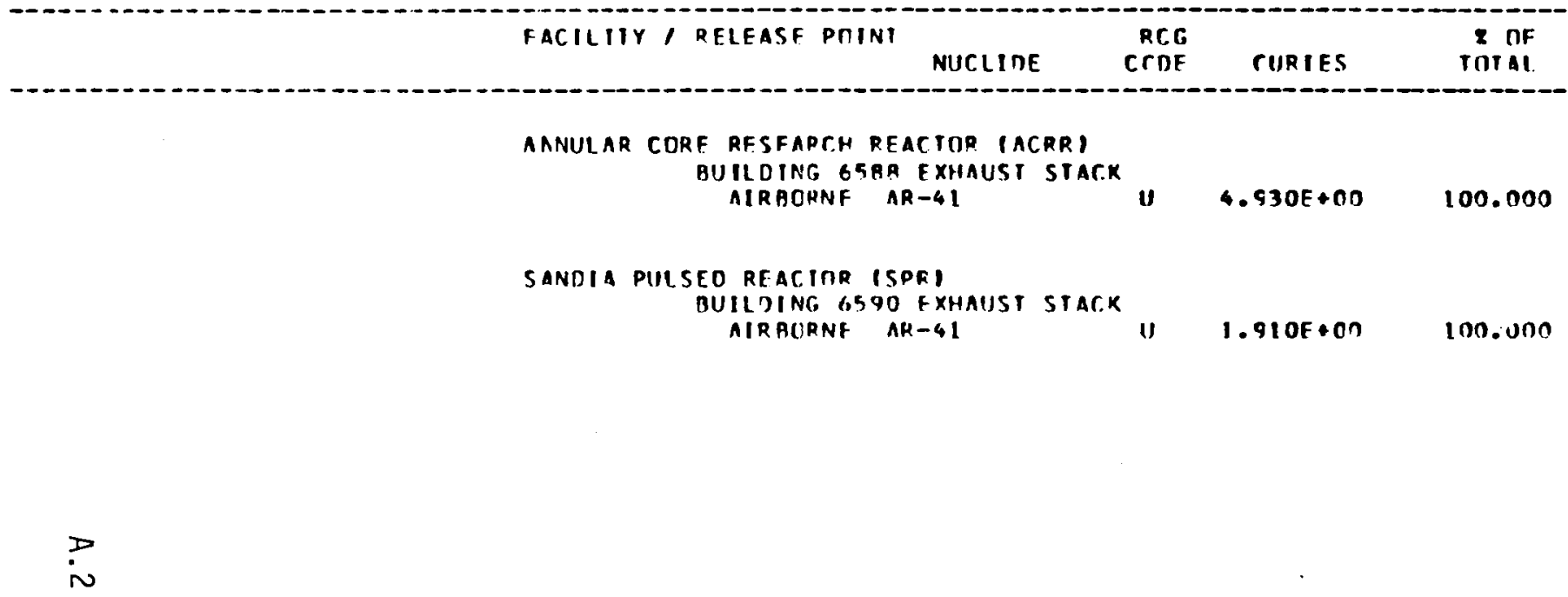


II. S. DFPART YFHT IJF FNFPCIY

FFILUFNT INFIIRMATION SYSIFM

FPA RTIFASF POIVT ANAL YSIS REPORT

-_-ECB_CALENDAB_YEAB_1981_...

AI. BUCUEPDUF DPERATIUNS OFFIT.F

SANDIA CCRPORATION

SANDIA NATIONAL LABORATIIR IES LIVFRMORE

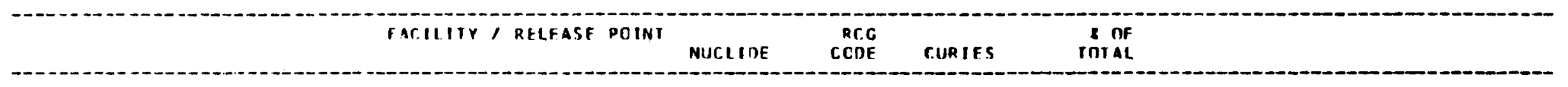

BLIG 913 ME IALLURT,Y LAB

SIACK NH 1 AI DG 913

AIRATRNF UN-III-ALPHA U 4.815E-06 5.679

$\begin{array}{lllr}\text { IN-III-ALPHA } & U & 4.015 E-06 & 5.679 \\ U N-I I-A+G & U & 9.071 F-05 & 94.371\end{array}$

TIIALS ... M.553F-05 100.00

ROCM I PAC, SIACK NO.3

AIRBCPNF $11-3$ S $1.035 E+02 \quad 100.000$

BLDG, 214

RADITLCH LEAX CETECTIOR

AIRPTPNE KRTAL

i

TRITIIIM RESEAPCH I ANORATIIRY AI DS, 968

30 MEIFR STAC.K

AIRATRNE II-3

3.AT3E+CI IOO.ONO 
U.5. OFPART: OF ENEPGY

FFILUENT INFORMATION SYSTFM

EPA RELFASE POINT ANALYSIS RFPORT

_._EOB_CALENDAB_YEAB_1981_.

AL HIOUIFPOUT UPERATIONS BFFICE

LGVEI ATF RICMFI D. FNVIRUNMENTAL RFS INST

LOVELACE FOIINDATION INHIALATISN TOXICOLCGY RFSFARCH INST

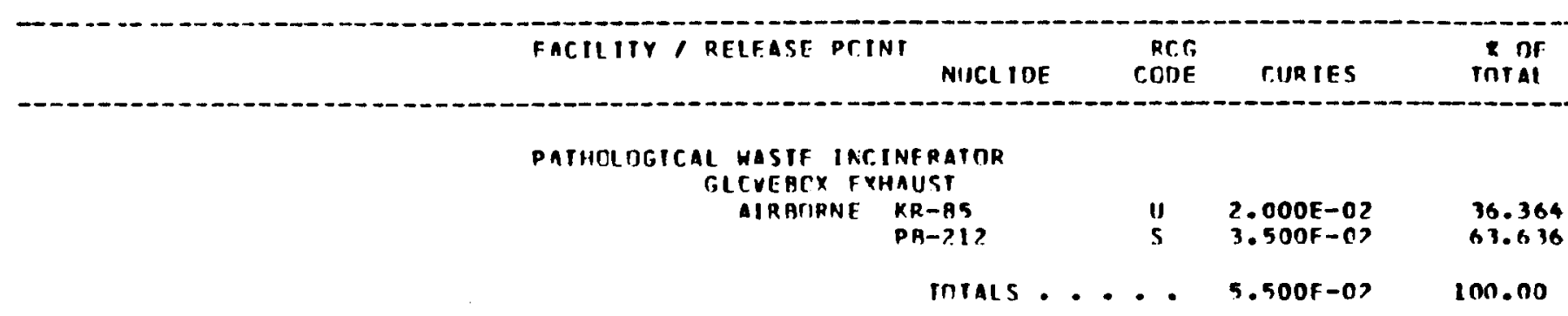


W.S. DEPARTMENT OF ENFP.GY

FTFLUENT INFIJRATION SYSTEM

EPA RFLEASF POINT ANALYSIS RFPIRT

-__EDR_CALENOAB_YEAB_1981_...

AL BUCUTROIIT OPERATIONS RFT ICF

MASON r. HANGER-SILAS MASIIN COMMPANY. INC

PANTFX PI ANT

FACILITY, RLLEASF POINT

NIJCLIDE

RC.r.

CURIES

IIIF

FIRING SI TE

FIRING; SIIT NO 5

AIRAOSNE $11-23$ B

$1.000 F-05$

100.001

ASSEMALY AREA

RUIL DING 12-26 AND $12-42$

AIRACRNF H-3

$9.500 E-02$

100.000

ir 
11.S. DEPART: DF FNFRGY

FFILUENT INTDPMATIUN SYSTEM

FPA PELTASF POINT ANALYSIS RFPORT

-__EUB_CALENDAR_YEAB_1981___

AL RUOUFRDUF TPEPATINNS DFFICF

MONSANTO RFSEARCH CORPORAT ION

MONSANYO RFSEARC

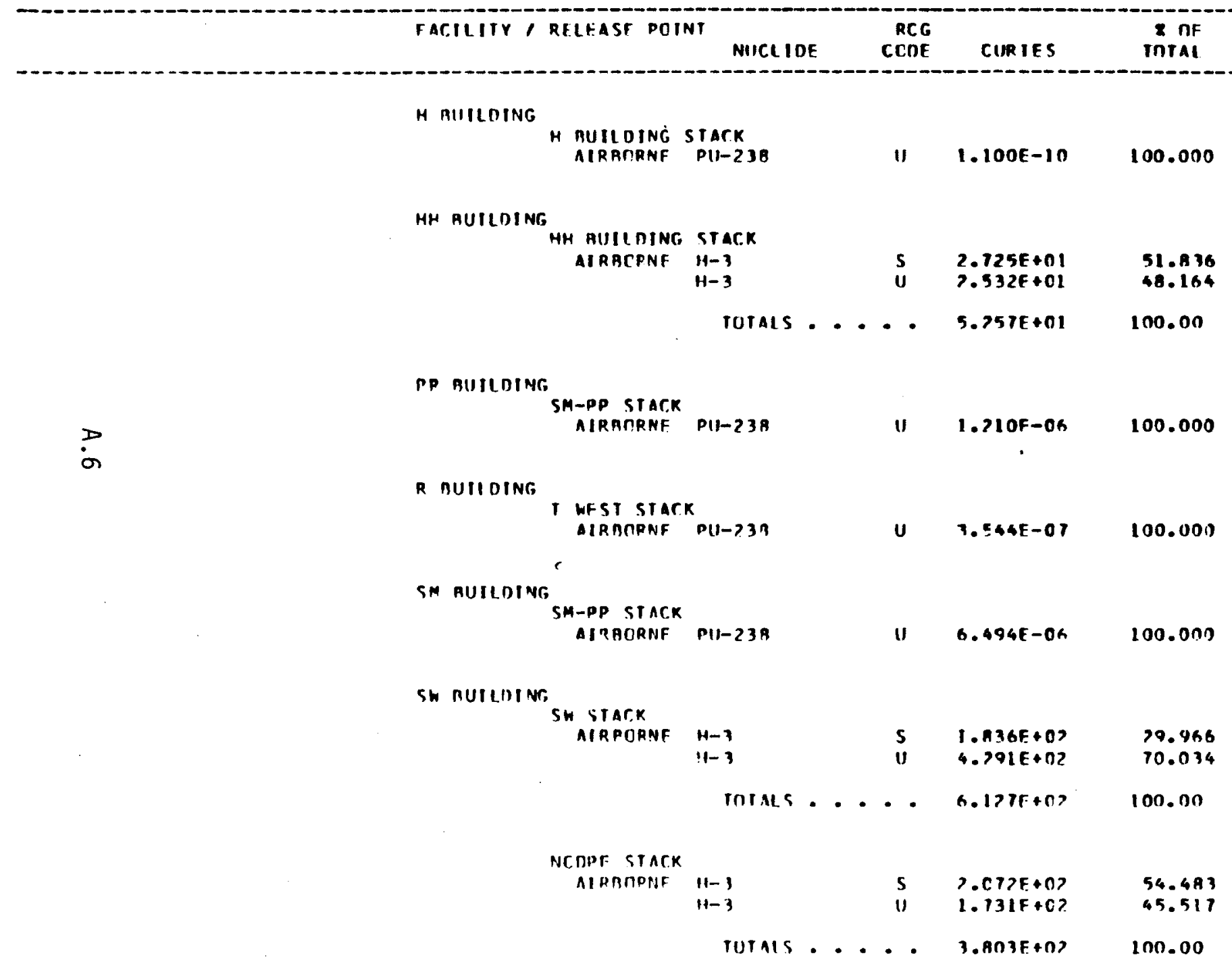


W. S. DEPARTMFNT TF ENFRGY

HFFLUENT IMT:PRAIION SYSTEM

TPA RFLPASE POINT ANALYSIS REPORT

_._EK__CALENDAB_YEAB_1981_...

MLAUOUFROUF OPFRATIONS DFF IT.F

MINSANTIO RFSE ARCH T.ORPORATIITN

MUUNO FASIIIIY

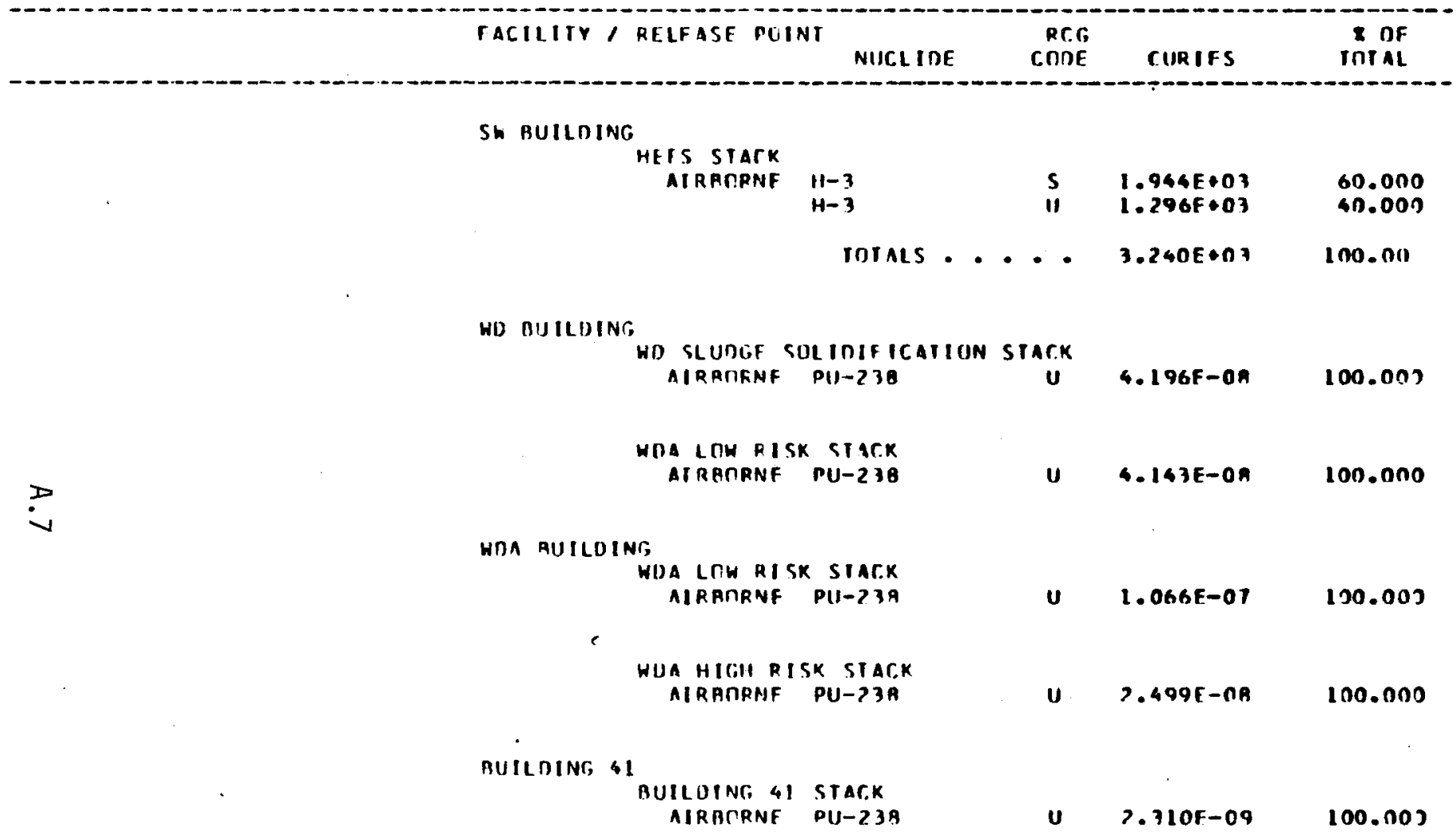


1.5. DEPART, OF ENFRTY

EFFLUFNT INFORMATION SYSTEM

FPA RELFASF POINT ANALYSIS REPTRT

-_EOR_CALENDAB_YEAB_19B1_...

nL RUOLIFRUIIF UPFRATIONS MFFITE

ROCKHTIL INTERNATIONAL

RI)CKY FLATS PLANT

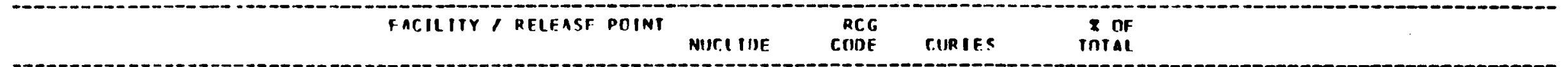

PLUTIINIJM ANALYTICAL LAMORATIORY

BUILDING, 559- MF FXHAUST

AIRAIIPNF H-

$H-3$
PU-239-2.4J
$11-233-234-2.38$

$\begin{array}{rr}2.000 E-07 & 99.996 \\ 4.400 F-07 & 0.013 ? \\ 4.100 E-07 & 0.002\end{array}$

TOTALS.... 2.0JDF-0? 100.00

FAHRICATION ASSEMALY AIIII DING

\begin{tabular}{|c|c|c|c|c|}
\hline \multirow[t]{2}{*}{$\begin{array}{l}\text { AUILDING IN } \\
\text { AIRACKHE }\end{array}$} & $\begin{array}{l}-106 \text { PLENIJM } \\
\text { H-3 } \\
P I I-2.39-2.40 \\
U-2.33-234-2.39\end{array}$ & $\begin{array}{l}\mathbf{u} \\
\mathbf{u} \\
\mathbf{u}\end{array}$ & $\begin{array}{l}3.500 F-07 \\
4.100 F-0 A \\
1.500 F-07\end{array}$ & $\begin{array}{r}99.995 \\
0.0011 \\
0.034\end{array}$ \\
\hline & I DTALS • . & - • & $3.900 \mathrm{~F}-03$ & 100.00 \\
\hline \multicolumn{5}{|c|}{ NUILDINC TnT-IOA } \\
\hline AIRRARNIE & $\begin{array}{l}H-3 \\
\text { PII- 239-243 } \\
11-233-734-718\end{array}$ & $\begin{array}{l}\text { U } \\
\text { 1) } \\
\text { 11 }\end{array}$ & $\begin{array}{l}7.500 F-03 \\
5.500 E-C A \\
9.70 N F-O A\end{array}$ & $\begin{array}{r}99.994 \\
0.012 \\
0.004\end{array}$ \\
\hline
\end{tabular}

AUII.UING 107-105

\begin{tabular}{|c|c|c|c|c|}
\hline AIRATRAIF & $\begin{array}{l}11-3 \\
P \|-23 n-241 \\
(1-233-214-23 A\end{array}$ & $\begin{array}{l}u \\
u \\
u\end{array}$ & $\begin{array}{l}4.600 E-03 \\
1.600 F-07 \\
1.900 F-07\end{array}$ & $\begin{array}{r}99.990 \\
0.003 \\
0.005\end{array}$ \\
\hline & IOTALS. & & $4.600 E-03$ & 100.00 \\
\hline
\end{tabular}

BUII DING ICI-107

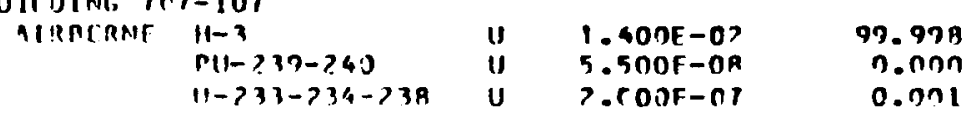

MI115.... 1.400F-0? 100.01 
11. S. DEPARTMENT IIF ENTRGY

TFFIUFNI INFIIRAATION SYSTEM

EPA RFLFASF POINT ANALYSIS RFPORT

-__EUB_CALFNDAB_YEAB_ $1981 \ldots$

AL HUCUFPDIF OPERATIONS DFFICT

RIICKHFLI INTERNATIINAL

RDCKY FLATS PLANT

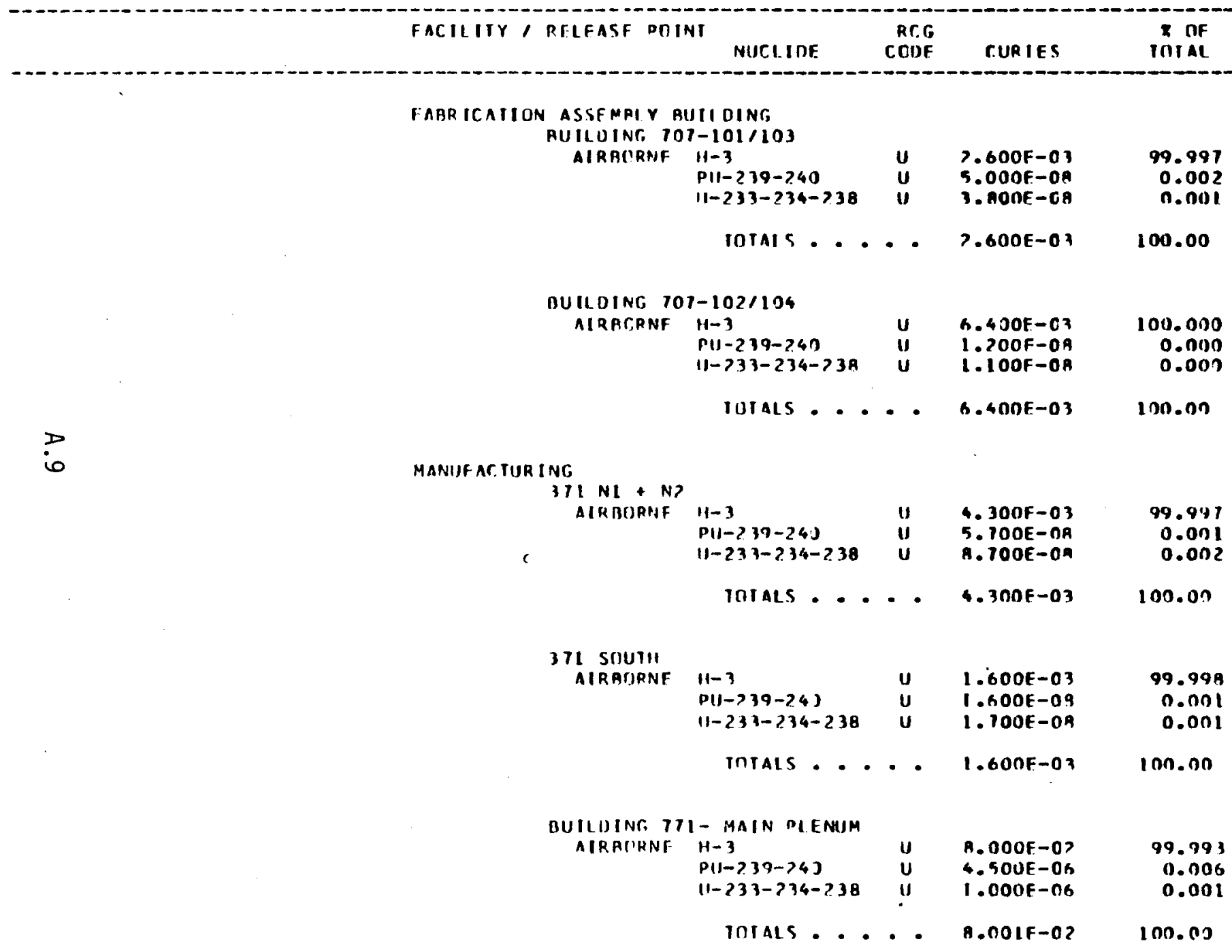


1. S. DFPARTM. DF ENFRTY

FFELUFN IITORAATION SYSITM

FPA RFLFASF POINT ANAL YSIS PEPORT

_ETB_CALFUDAB_YEAB_L_BL__.

ALBUCUFPOUF DPFRATIIINS OFFITF

PICKHTIL INIERNATIIONAL

RUCKY FLATS PLANT

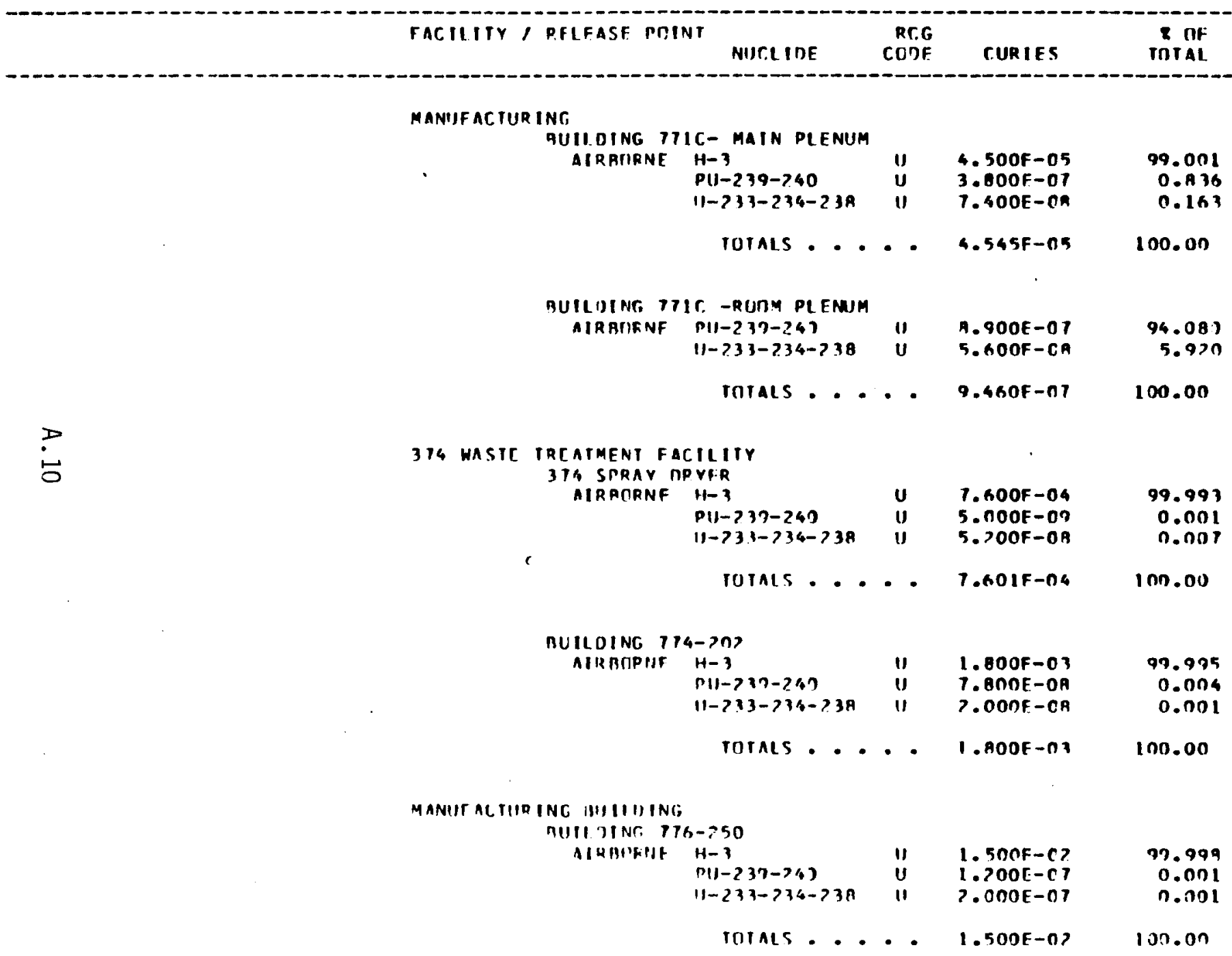


11. S. DFPARIYENT DF FNFRGY

FFFLIIFNI INFIRMATION SYSTEM

FPA KELFASF PUINT ANAL YSIS REPURT

_._LUE_COLENDAB_YEAR_1981_.

AL. RUCUFRDIJE DPERAIIONS IIFIC.E

FUCKWFIL INTFRNATIIINAL

anCKY FIATS PIANT

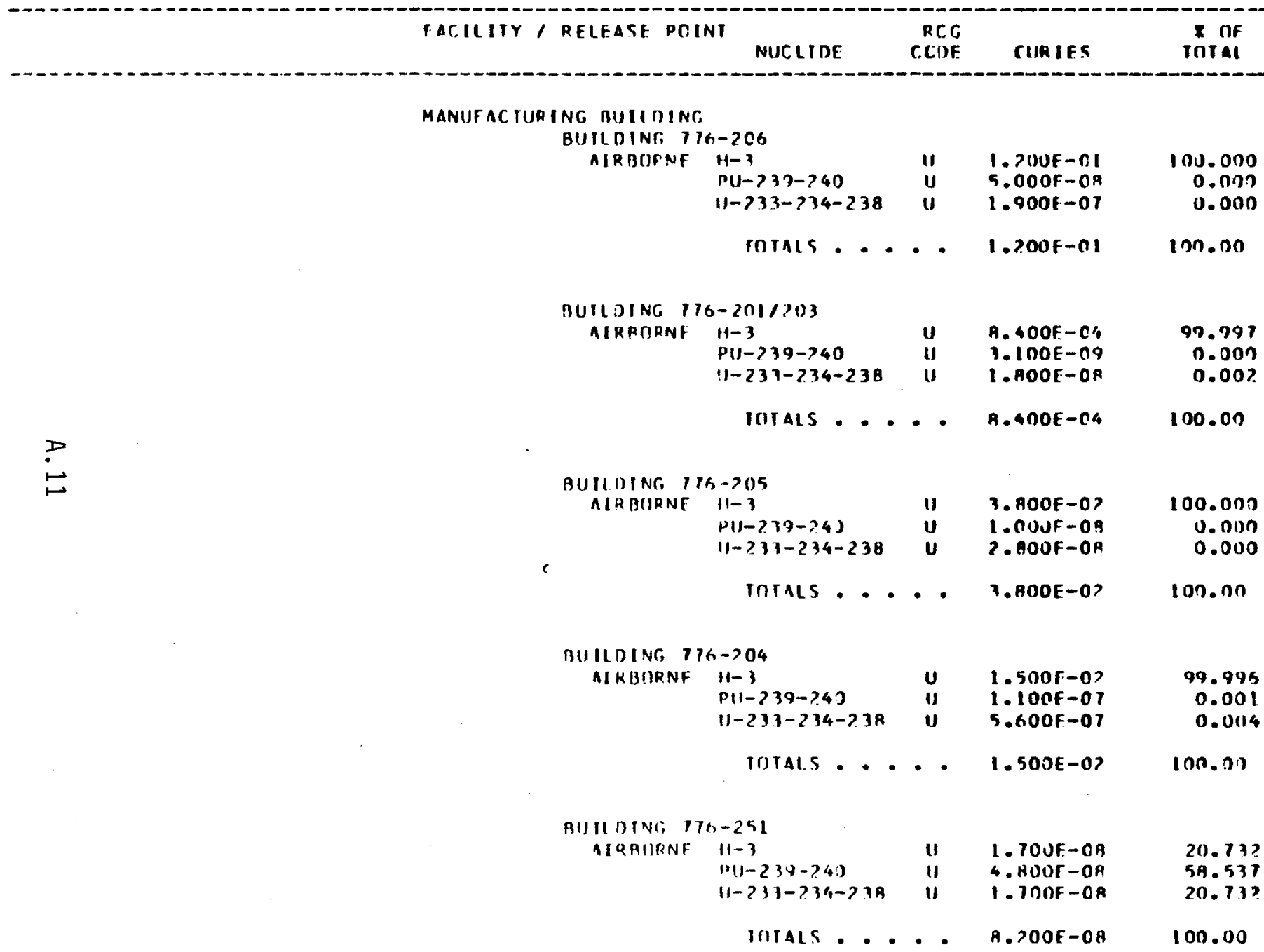




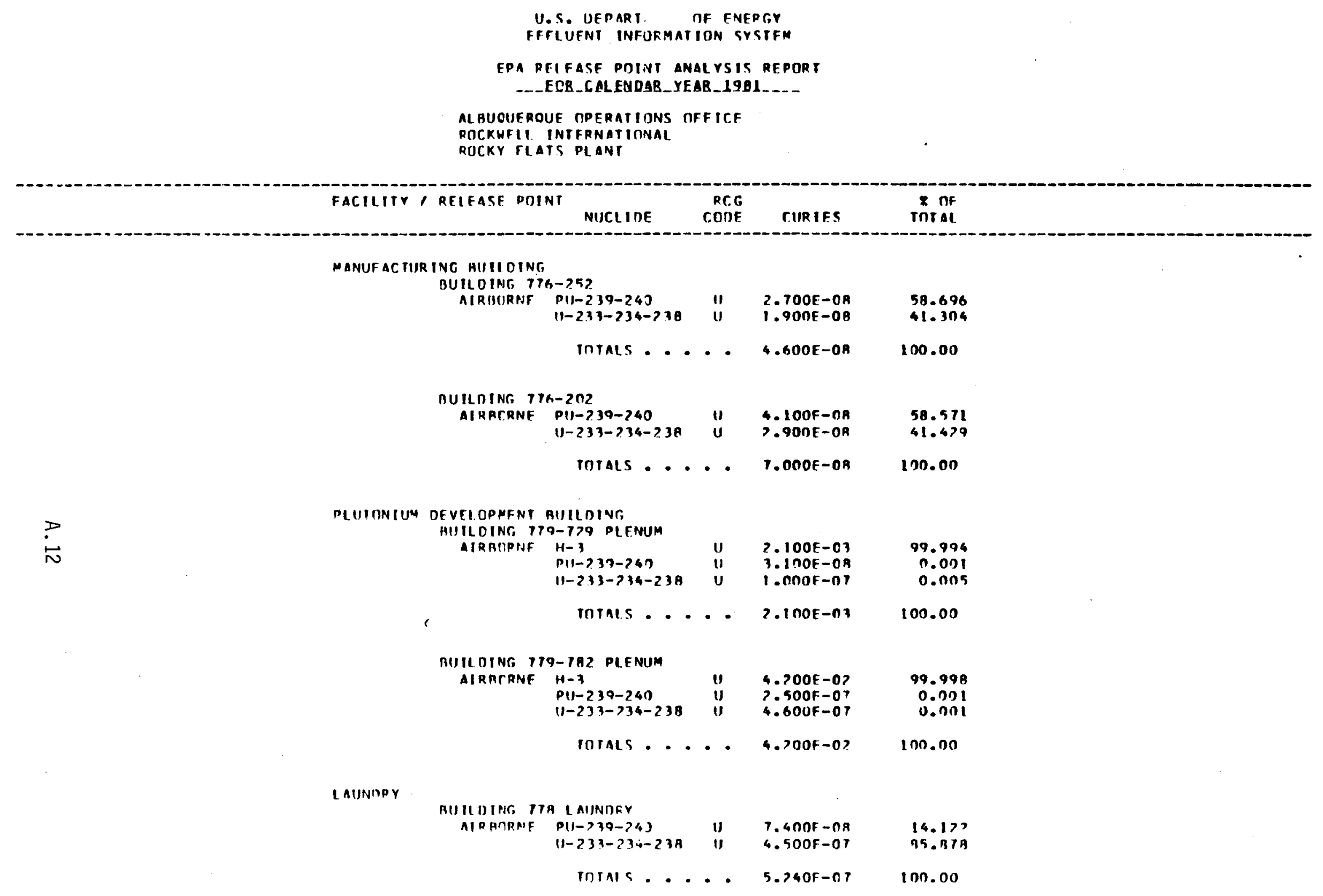


W.S. DTPARTMFNT DF FNFRGY

FRFLUEHT INFORMATION SYSTEM

\section{FPA HFIFASF MIINT ANALYSIS RFPOR}

___EOQ_CALENUAE_YEAB_1.981_._-

ML IUCUITROUE RPFRATIONS OFFICE

ROCKWFII INTERNAIIONAL

RUCKY FLATS PLAVT

PACILIIY, RELEASF POINI

NUCL InE

WASTF IREATMFAT FACILITY

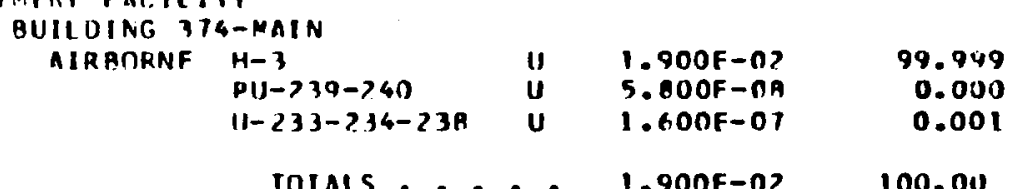

TIIAIS.

MANHIF AC TUR ING MIIIIOING;

\begin{tabular}{|c|c|c|c|}
\hline $\begin{array}{l}\text { BUII DING 444 - DUCIS } 2 \text { ANII } \\
\text { AIRBORNF } 11-273-234-239\end{array}$ & 3 & 9. POOE-07 & 120.000 \\
\hline $\begin{array}{l}\text { BUIL UING, 4A4- DUC.I } 1 \\
\text { AIRACKNF U-233-234-23A }\end{array}$ & 11 & $1.000 F-06$ & 100.000 \\
\hline $\begin{array}{l}\text { RUILUING } 444-\text { DUC. } 5 \\
\text { AIRRORNF } 11->33->34-238\end{array}$ & "1 & $7.000 E-07$ & 100.003 \\
\hline
\end{tabular}

MANUF AC TUP. I MÉ HUIITING

RUILDING 147 MAIN

AIRRTINE $11-233-234-23 A \quad U$.

MAIFRIALS ANO PRECFSS DFVFLIJPMENT LABORATURY

BUIIUING, BKS-EAST

AIRRORNF U-233-234-23A U I.AOOF-C? 100.000

RUII DING, BE5-WESI

AIHACPNF II-733-734-238 U P.000E-07 1n0.000

MANUFAC IUPING HUII DING,

BUILDINF, ABL - DUCTS 1.2 .3 AND 4

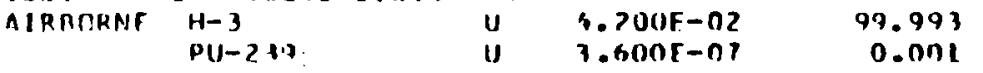


U.S. DFPART. OF FNFRGY

FFFLUENT INFORMATION SYSTFM

EPA RELFASF MTINT ANALYSIS RFPORT

-_-EDB_CALFNDAB_YEAB_1981___

ALBUCUFPOUF DPFRATIONS DFFIT,F

RUCKHFIL INTERNATIONAL

ROCKY FIATS PLANT

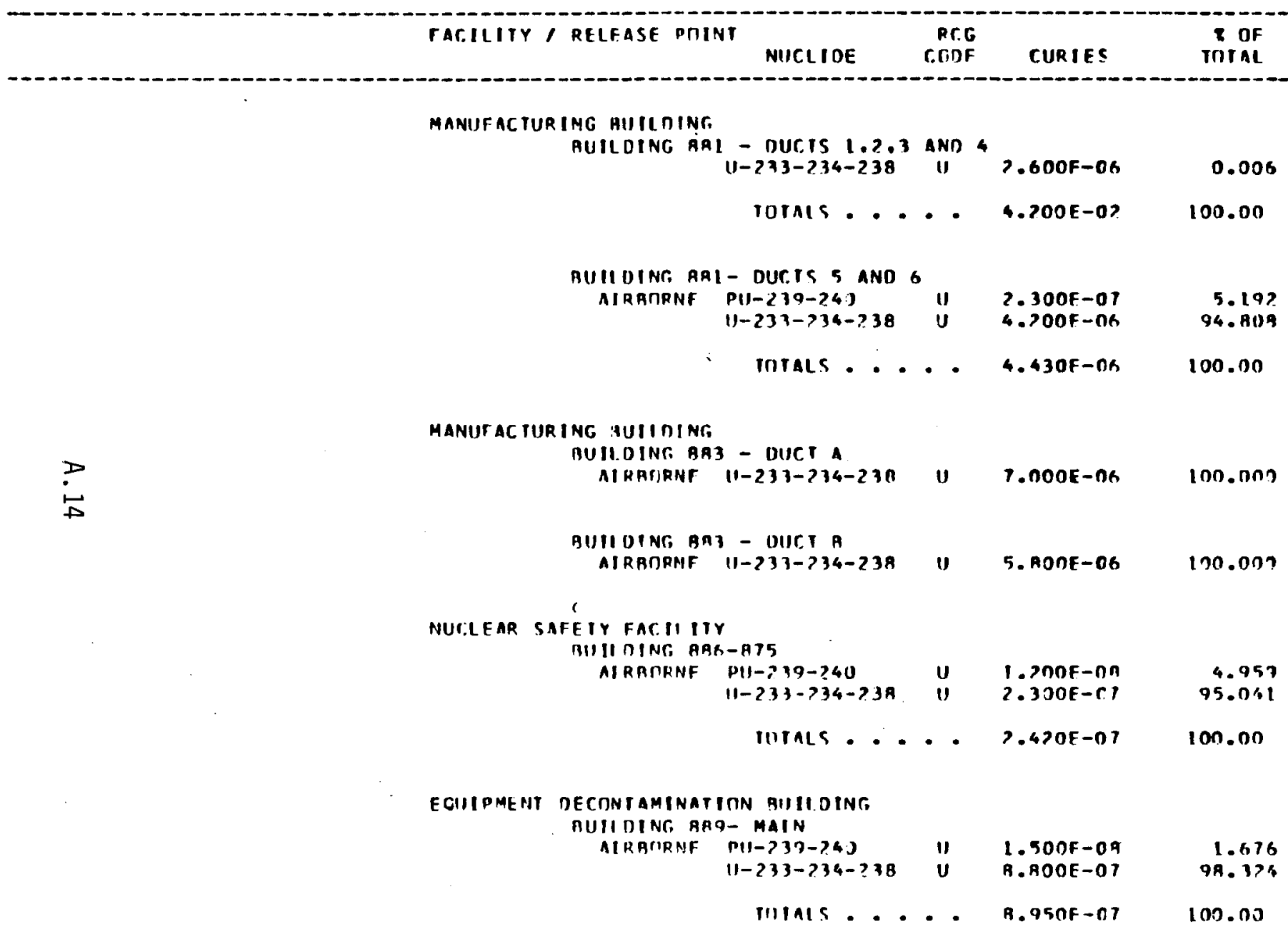


11.S. DFPARTMENT OF ENFRGYY FFFIUENI INTURMATION SYSIEM

FPA RELFASF POINI ANALYSIS RFPOKI

___EUB_CALEEDAB_YEAB_1981

ALRUCUTROUE UPERATIONS GFFIC.

RIICKWFIL INTFRNATIOIVAL

RUC.KY FLATS PLANI

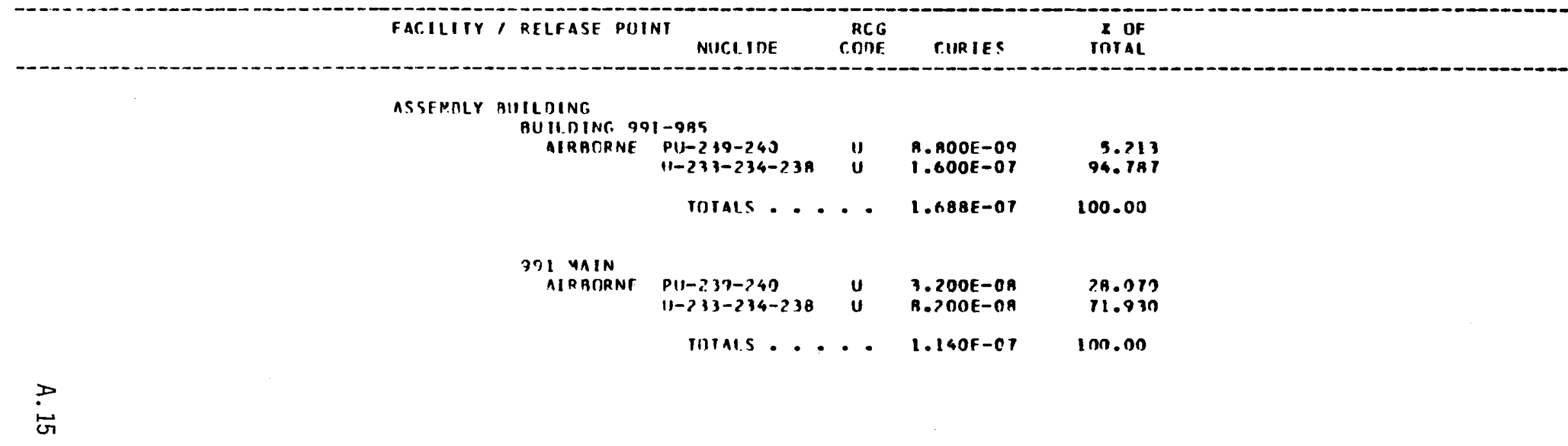




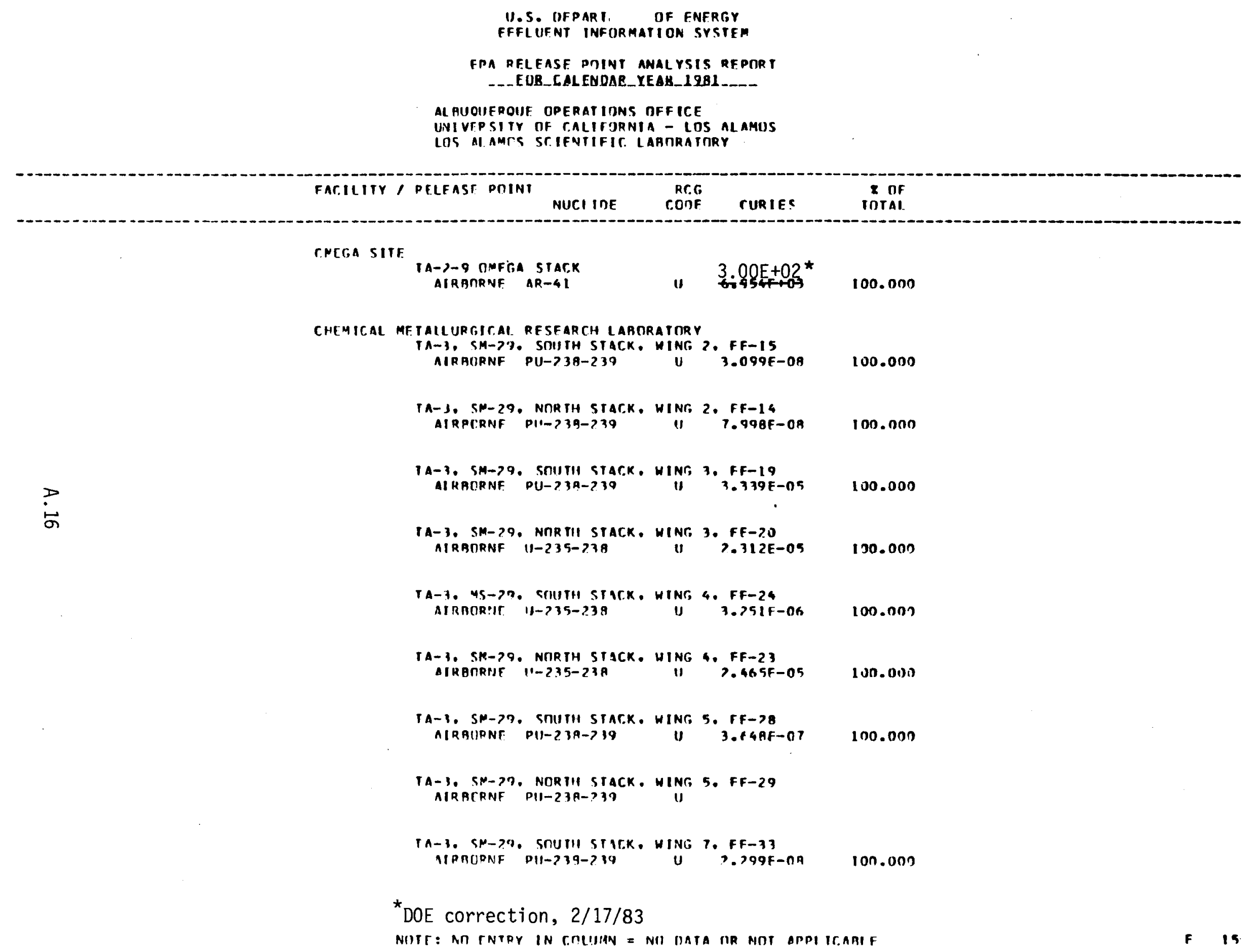


U.S. DFPARTMFHI DF ENFRTY

FFFLUENT INTIJUMATION SYSTEN

\section{EPA PFLEASF ROINT ANALYSIS PFPORT}

___EUR_CALENOAB_YEAB_1981.

AI BUOUFROUF IPERATIONS OFFICF

IVIVFKSIIY OF T.ALIFTRNIA - IOS ALAMOS

LOS ALAMOS SCIENTIFIC IAAORATORY

FACILIIY, RELEASE POINT

NIIC,L INE

RCG

CONF

CURIES

2 of

CHFMIT.AL MFIALLUP, IC.AL FTSFARCH L AGURATGRY

IA-3. SM- 20 . NORIH SIACK WIME 7. FF-32

AIRBTHNF. NUR IH SIAC.K. HING, 7 . FF-32

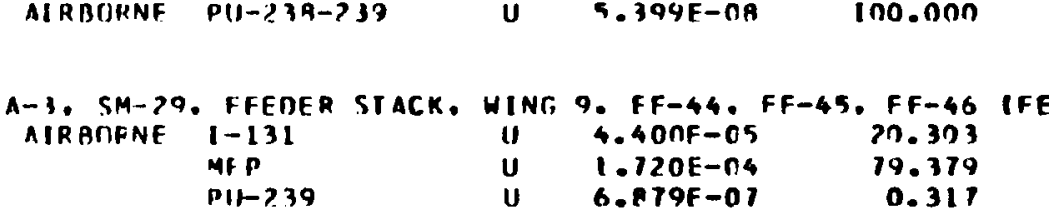

IOIAIS . . ? $2.167 E-04 \quad 100.00$

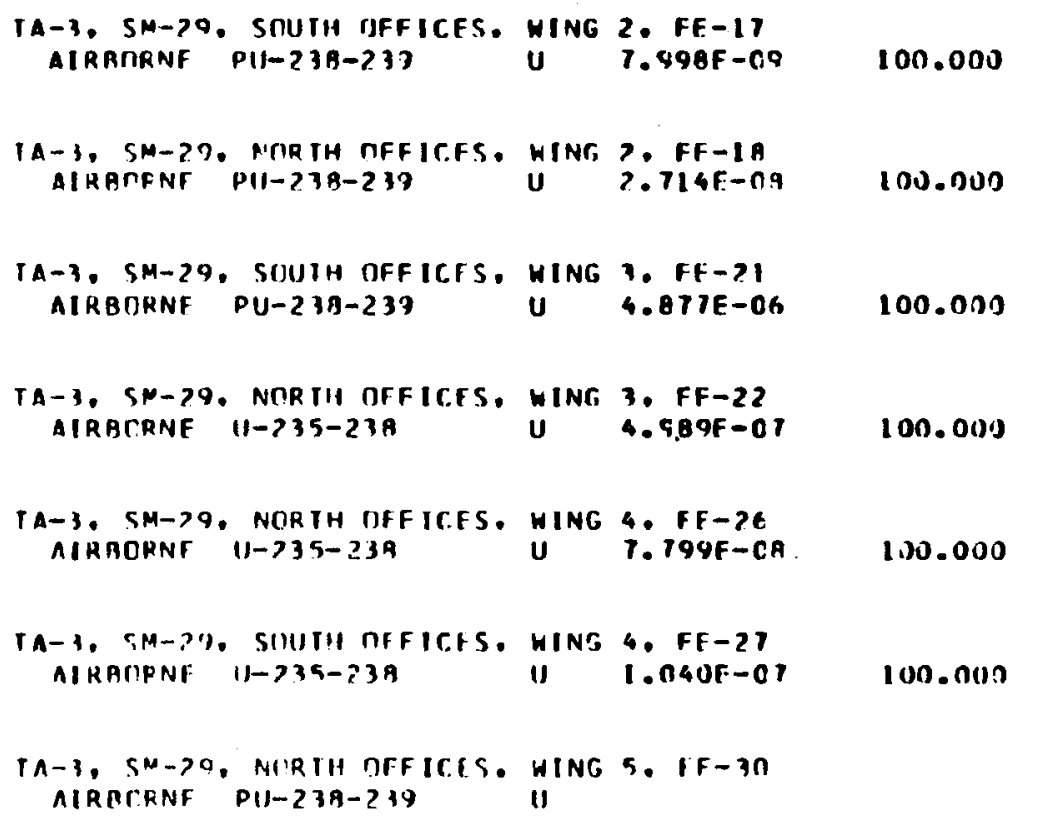




$$
\begin{aligned}
& \text { 11. S. OEPARI OF ENTRGY } \\
& \text { FFFLUFN INFUHMATION SYSTFM }
\end{aligned}
$$

EPA PRLEASF POINT ANAL YSIS REPORT

_._ECP.CALENDAB_YEAB_1981___

AL BUOUFPIIF TPERATIINS DFFIT.E

UNIVERSITY OF CALIFORNIA - LOS AL AMUS

UNIVERSITY OF CALIFORNIA - LOS ALAR

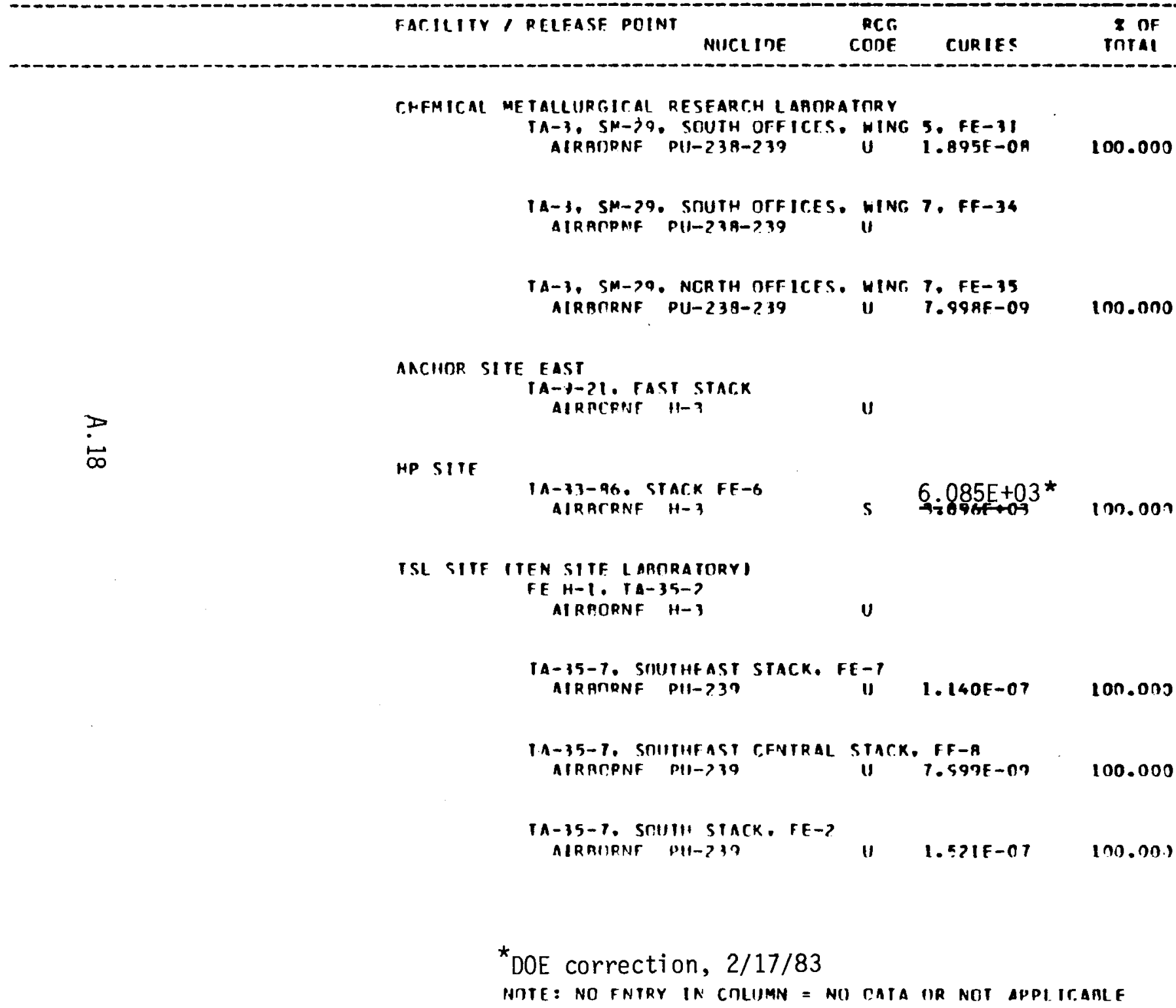


U.S. DFPART AFNT OTF ENFRGY

EFFLUFNT INFORMATION SYSTFM

\section{FHA PEIFASF POINT ANALYSIS REPHRT}

_._EUB_CALENDAR_YEAB_12B1_._-

AL AUOUFROUF TPERAIIUNS DFFICT

UIVIVIPSIIY CF CAI IFORNIA - IOS AL AMUS

LOS ALAMTS ST.IFNTIFIC CABURATORY

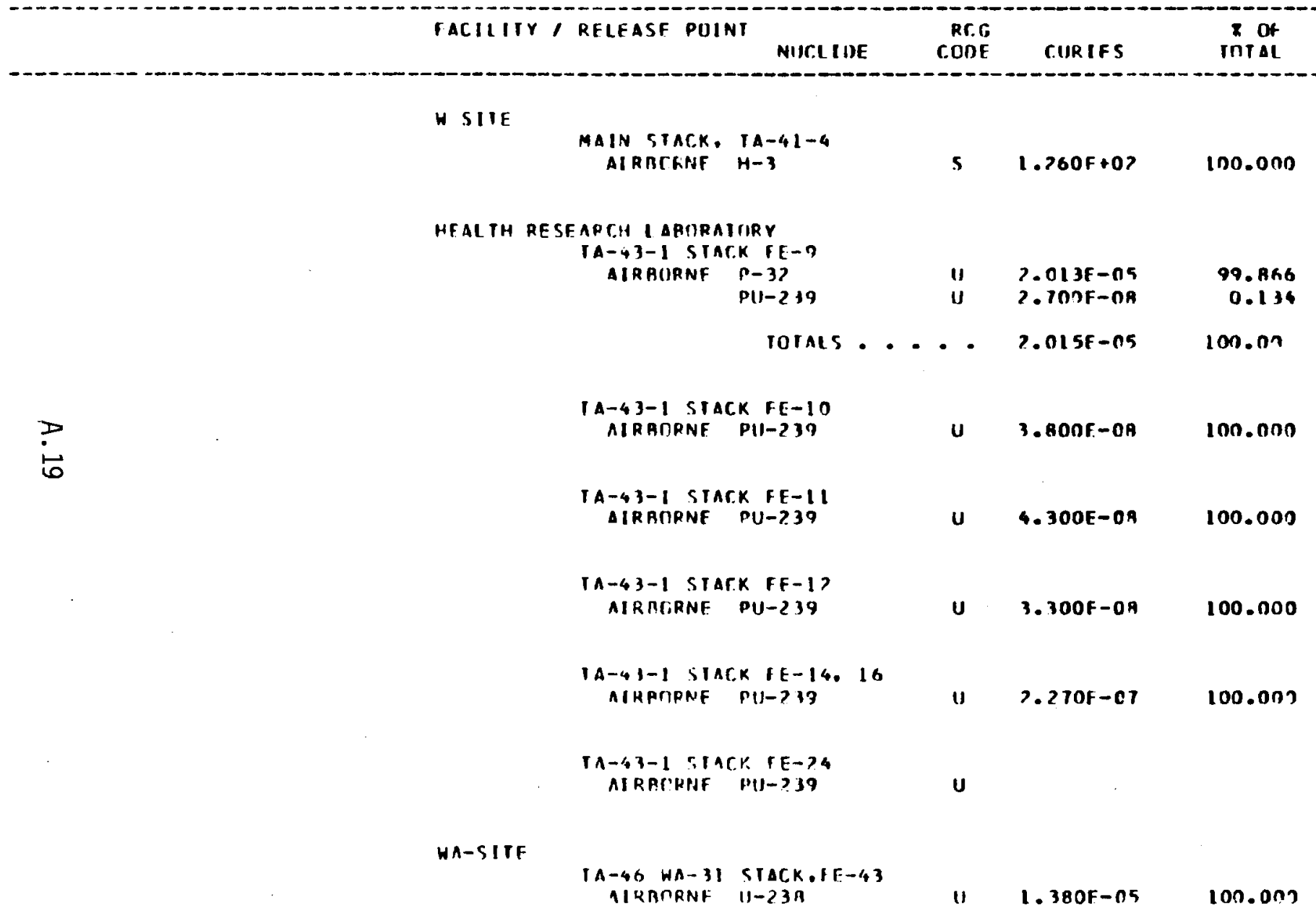


U.S. DFPARTA DF FNFRGY

EFFI.UFN INFORMATION SYSTEM

TPA RFLEASE POINT ANALYSIS REPORT

__EOB_CALENDAB_XEAB_1981.

AL AUCIIFROUF OPERATIONS DFF IC.F

UNIVERSITY OF CALIFORNIA - IOS ALAMOS

LUS AI AMBS ST.IENIIFIC LARTRATCRY

faciliti , Releasf roint

NIJCL IDE

RC,

r.URIES

$x$ of

RADICR,HEMISTRY SIIF

$$
\begin{aligned}
& \text { IA-4B-1 SCUTH STACR, FE-11. FF-12. FE-13 (FFFDFRS) } \\
& \text { AIPBTRNF MFP } 2 \text { II } 2.638 E-04 \text { 99.151 }
\end{aligned}
$$

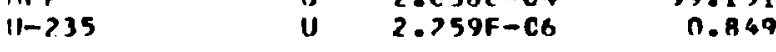

$$
\begin{aligned}
& \text { TOTALS.... 2.661E-04 } 100.00
\end{aligned}
$$

TA-4A. NORT!I STACK. FE-15. FF-16 IFFEDERSI

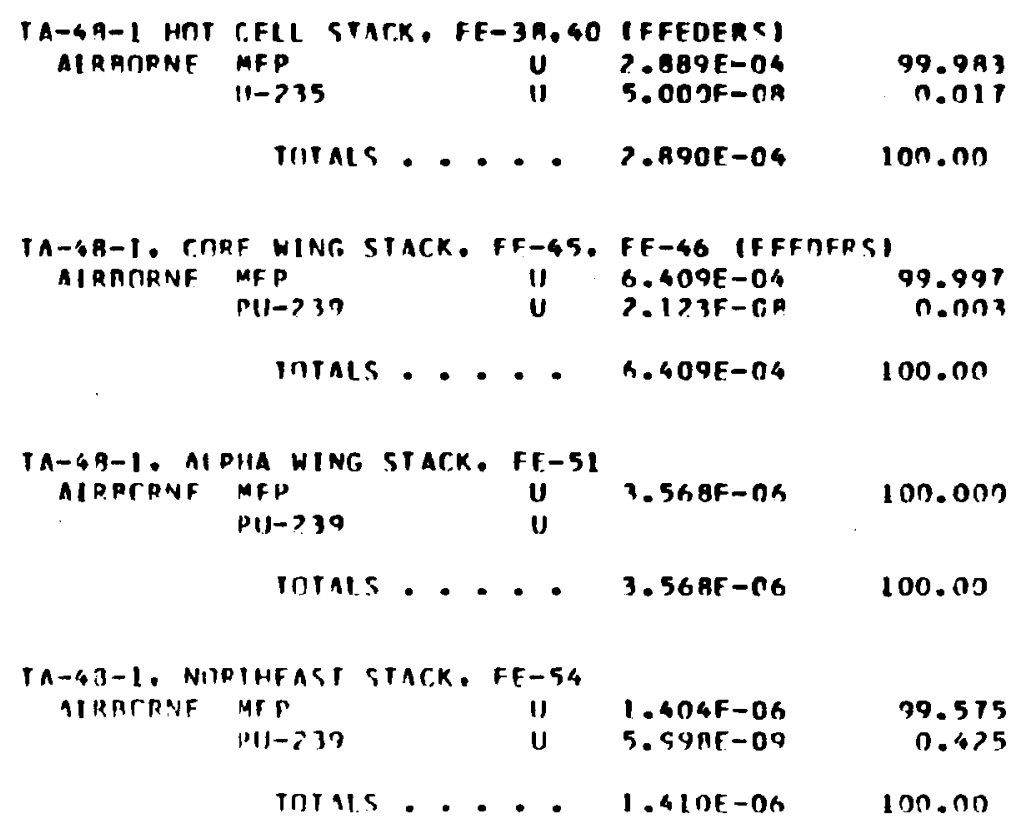


FPA RFITASF PIJINT ANAIYSIS REPORT

-._EDB_CALEYDAK_YEAB__.9B1_._.

AL BUCUEROUE GPTRATIUNS OFFICE

UNIVFRSITY OIF CALIFORNIA - LOSS ALAMOS

UOS ALAMUS SCIEMTIFIC LAHORAIORY

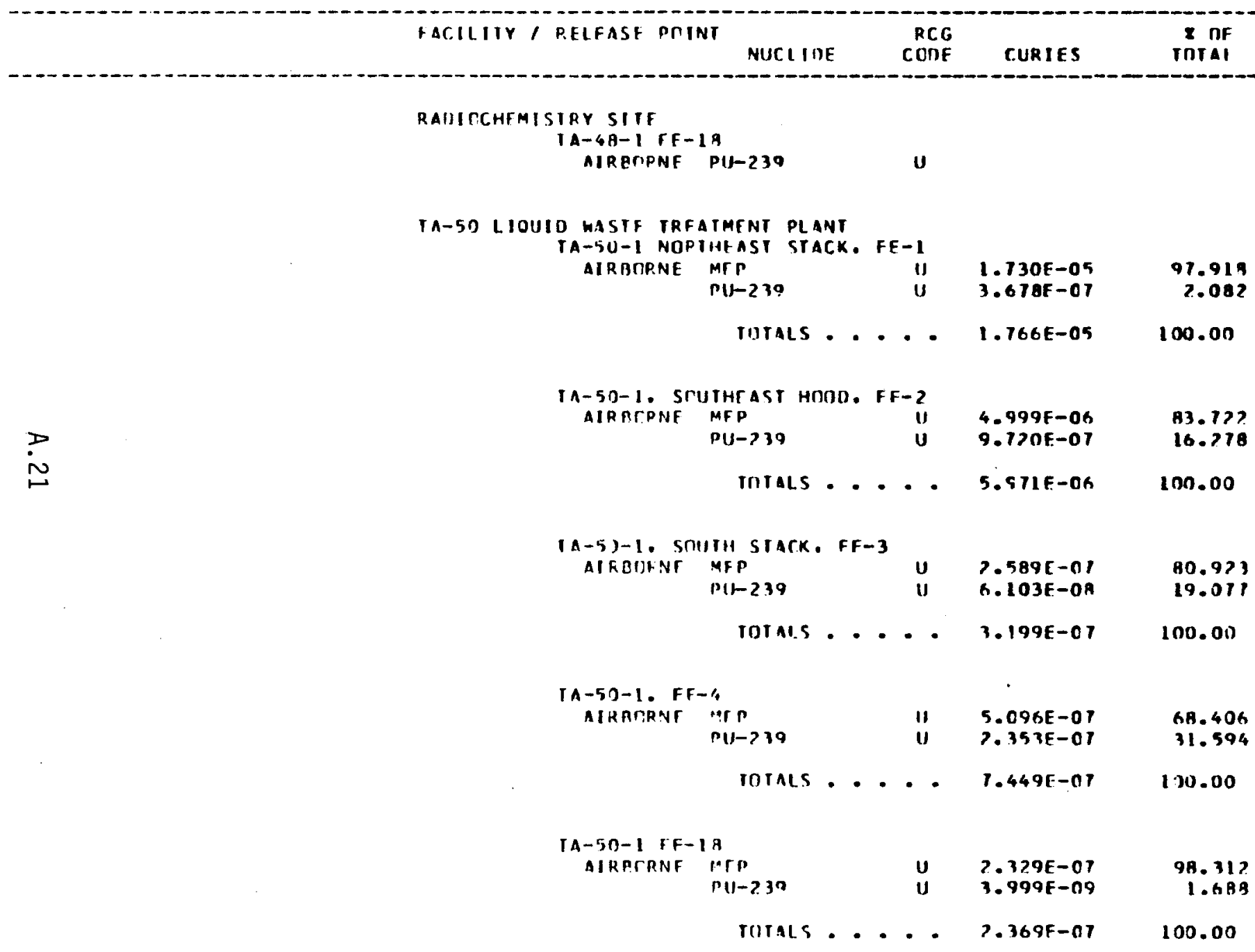


11.5. DFPAR 1 OF ENFRGY

TFILUENT INTORMATION SYSTFM

\section{EPA RELEASE PIINT ANALYSIS RFPORT}

-.-EÓB_CALENDAB_XEAB_19B1.

AL BUDIJERIIF DPFAATIONS DFFIT.F

UNI VFPSITY OF CALIFURNIA - LCS ALAMOS

LOS ALAMTS SCIENTITIC LARDRATCRY

FACILITY, RELEASF PDINT

NUCL InE

RC.G
CONE

$\pi$ or

NUCLIDE

CURIES

InTAL

TA-SO LIDIIID HASTE TREATMFNT PIANT

FF-1. TA-50. RUILDING 37

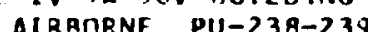

$1.210 E-07$

$10 n .000$

C. P. ANDERSON MESTN PHYSICS facility

TA-53, D HING, FE-16

AIRRTIRNF MAD

U

TA-53. MPR $-1 M, F F-3$

AIRPTPNF $A R-4$

$n r-7$

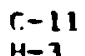

$\mathrm{H}-3$
$\mathrm{~N}-13$

$n-15$

$\begin{array}{ll}1.0606+03 & 0.303\end{array}$

$\prod_{N}^{D}$

TIITALS.... $\$ .533 E+05 \quad 100.00$

IA-53 RUILDINT MTF-3M SOUTH STACK. FF-4

AIRBTIRNF $\mathrm{H}-3$

IA-53. MPF-7. RM 200

milTCNIIM FACILITY

IA-ST NCRIII STACK, FT-15

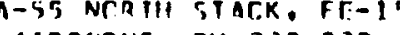

AIRPIRAF MU-?39-739

4. ADGE-C.9

ion.on

TA-SE SOUIH STACK, RE-16

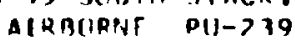

11

4. ค9RF- Oก

100.000 
11. 5. DFPARTMENT HF FNTKGYY

FIFIUINT INFDRMATION SYSTFM

FPA PILEASF PUINI ANALYSIS RFPURT

... ECL_ C SLENUAR_YEAB_1481....

AI BIICUTHOUT UPTRATIONS OFFICE

UNIVERSITY IIF CAL IFURNIA - LOS ALAMUS

lUS ALAMGS SCIENTIFIC LABURATORY

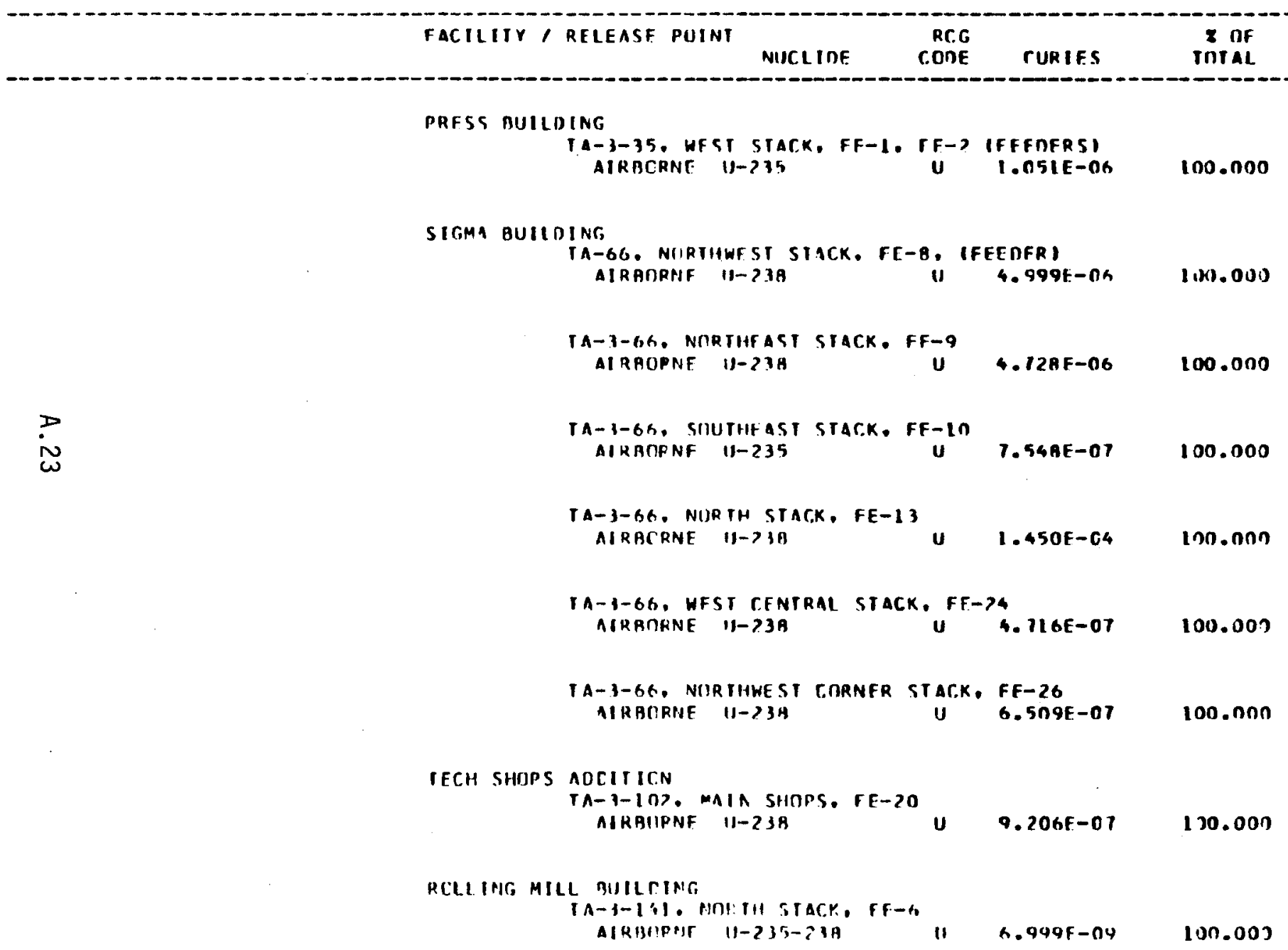




\section{U. S. DFPART OF FNFRTI \\ FFFIUENT INFORMATION SYSIFM \\ FPA RELFASF POINT ANALYSIS REPORT \\ _-_EUR_CALENDAB_YEAB_19B1_. \\ ALBUOUFROUF NPERATIONS DFF IT.F \\ UINIVFPSITY UF R.AL IFURNIA - LOS ALAMIIS \\ LDS ALAMCS SLIENTIFIC IARORATOKY}

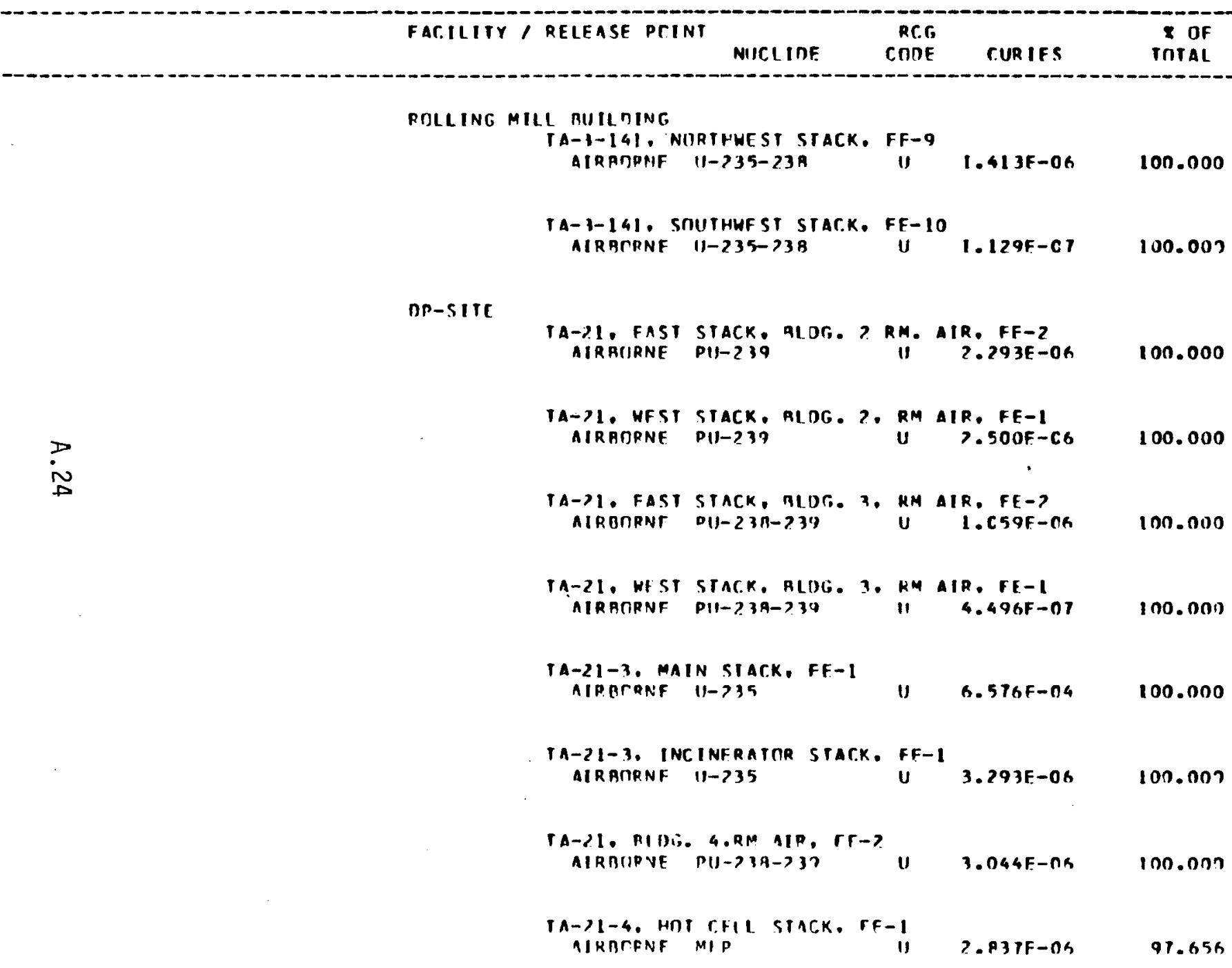


U.S. TFPADTMENT OF FNFRGYY EIFLUTNT INFORMATION SYSTFM

\section{EPA DFI FASF POINT ANALYSIS RFPORT}

_._EUR_CALENDAK_YEAB_1981_._.

AI MUCUFROUF UPERATIUNS OFFICF

WiNIVEFSIIY OF CALIFIRRIA - ICS AL AMOS

IIIS AI AMRS SC. IENTIFIC LABORATURY

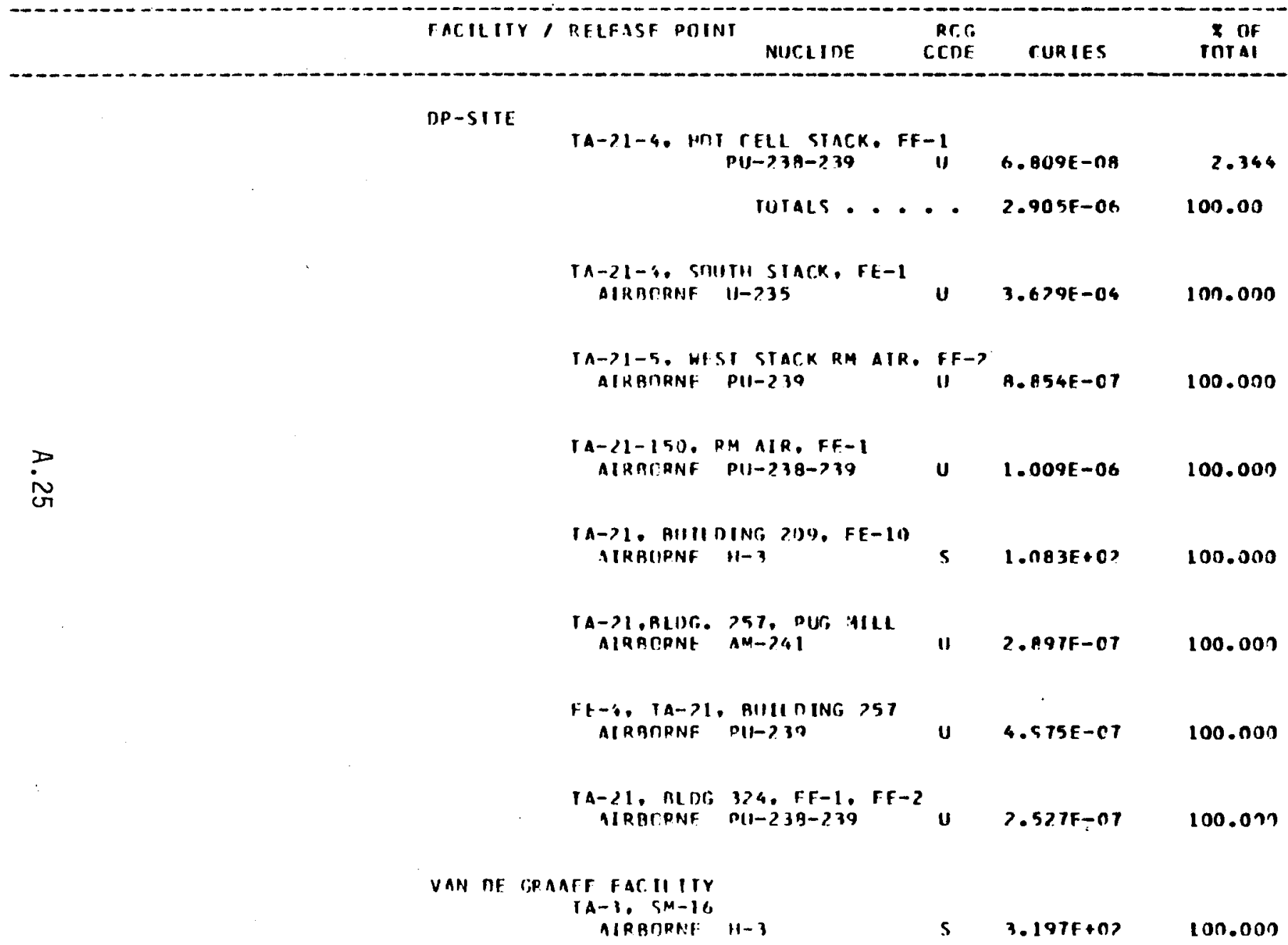


U.S. DFPART. OT ENFRGY
EFILIFNT INITRMATION SYSTFM

FPA RELFASF POINT ANALYSIS RFPRRT

___EOR_CALENDAB_YEAB_1981_._.

AL DUCUEPOIIF OPERATIONS RFF IC.F

UNIVFRSITY DF CALIFORNIA - LOS ALAMOS

L.OS ALAMCS SCIENIIFIC LAROPATORY

racility / RELEASF POINT

NIICIIDE

Rr.G

CONE

2 of

VAN DF GRAAFF FACILITY

TA-1, SM-16. TE $\mathrm{H}-1$

AIRACRNF H-3

$\mathbf{S}$

$5.755 F \cdot 0 ?$

100.000

CRYGIGFICS LAPORATUPY

IA-3. SM-74. FF-52

AIRICONF H-3

S.PG9F+on

100.000

SITF

FAIERIALS DISFOSAL SITF

TA-54 CIMPAC. TUP-DALER EXHAUST,FE-1

in

ARRIONF PII-219

(1)

TA-54 COMPAC, TMR-BALER ROTM AIR EXHAUST FF-?

AIRATPNE PUIT39 O.990F-09

100.000 
U.S. DFPART AFHT OF FNFRGY

EFFLIIFN INFIJHMATION SYSTEM

FPA RTIFASE MIIHT ANALYSIS REPURT

_._EOR_CALENDAB_XEAB_ $1281 \ldots$

LLAIJCUFRUUF RPERATIONS OFFICE

GENEPAL FI CC.TRIC COYPANY

PINFII AS PLANT

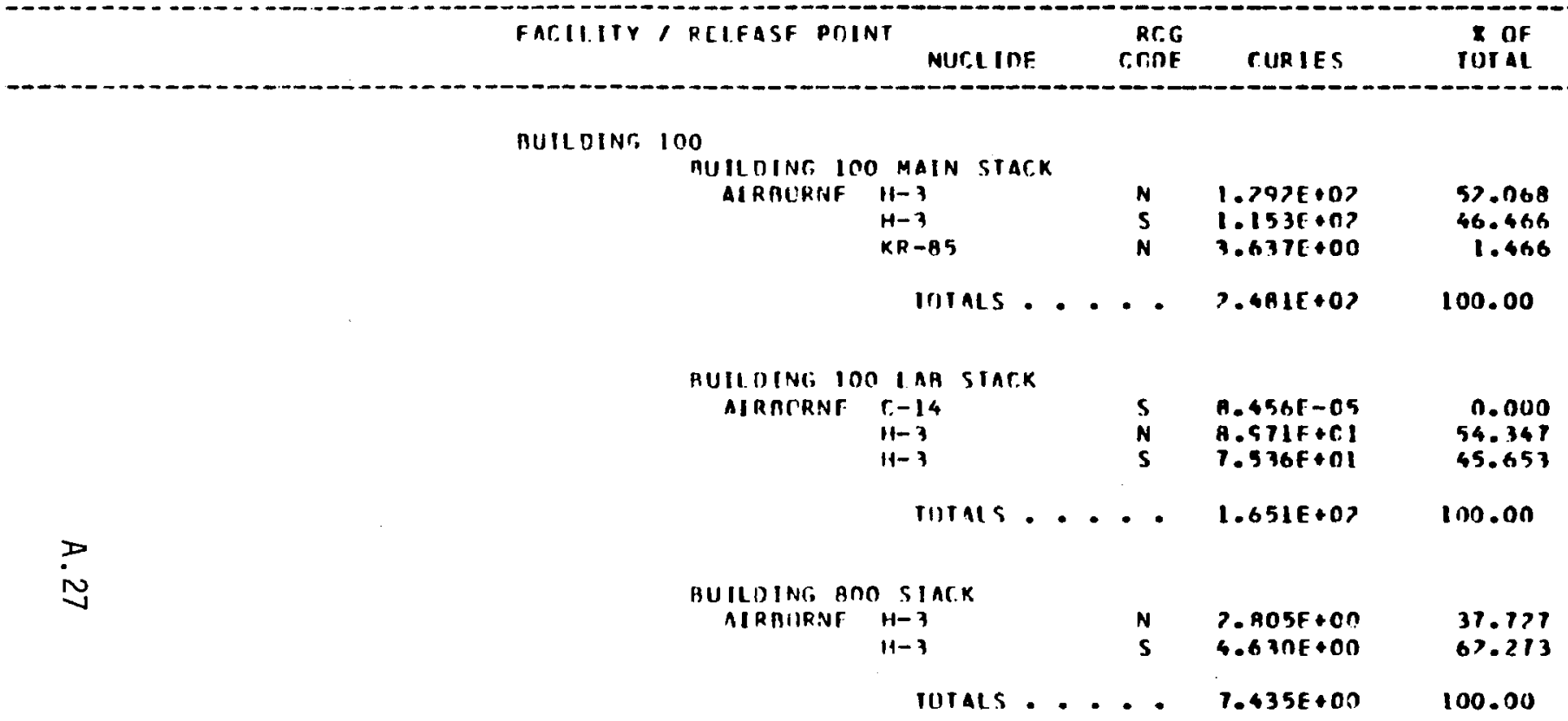



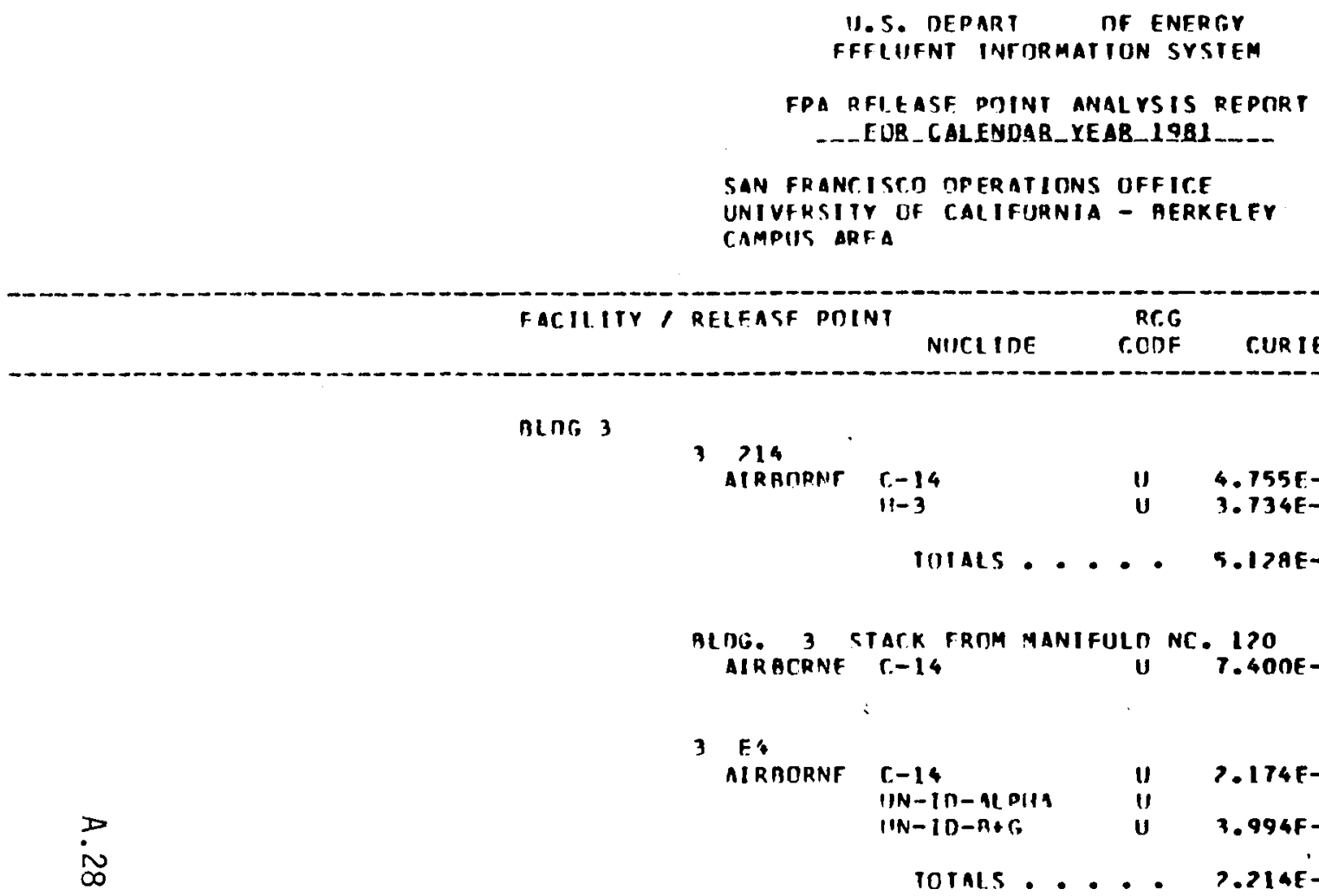

RELFASF POINT

NIICLIDE RT.G C.ODF TURES ITIAL

inc, 3

3714

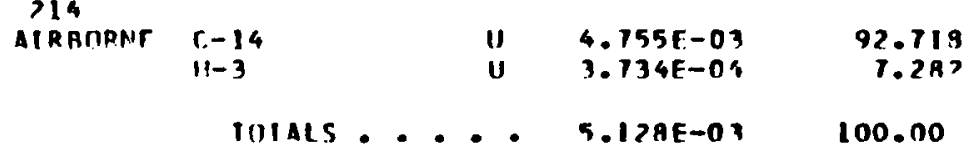

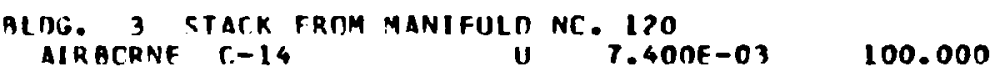

3 E'

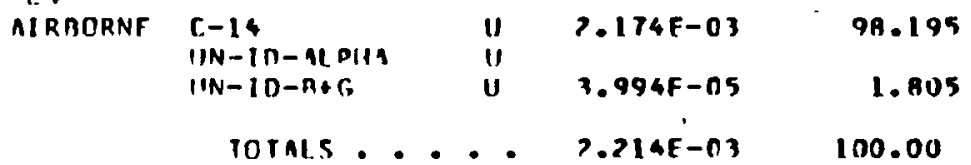

3318

AIRRTPNF r-IS

3 F5

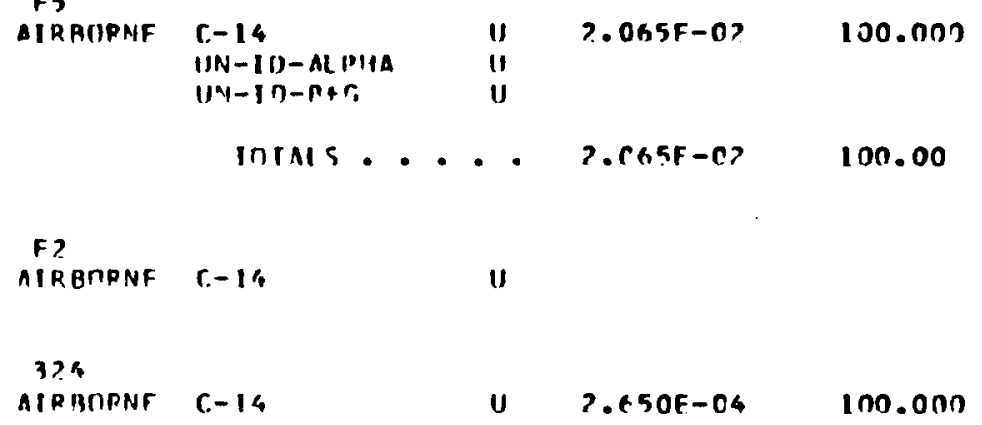


U.S. UEPARTVENT IIF ENTRGYY FRFLUENT IAF UHMATION SYSIFM

$$
\begin{aligned}
& \text { FPA RFLFASF PIINT ANAL YSIS REPIIRT }
\end{aligned}
$$

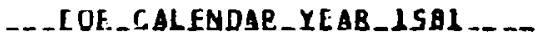

SAN TRANCISCI OPFRATIONS OFFICF

UNIVERSIIY UI T.AIIFIIRNIA - BFRKFLFY

HILL ARFA

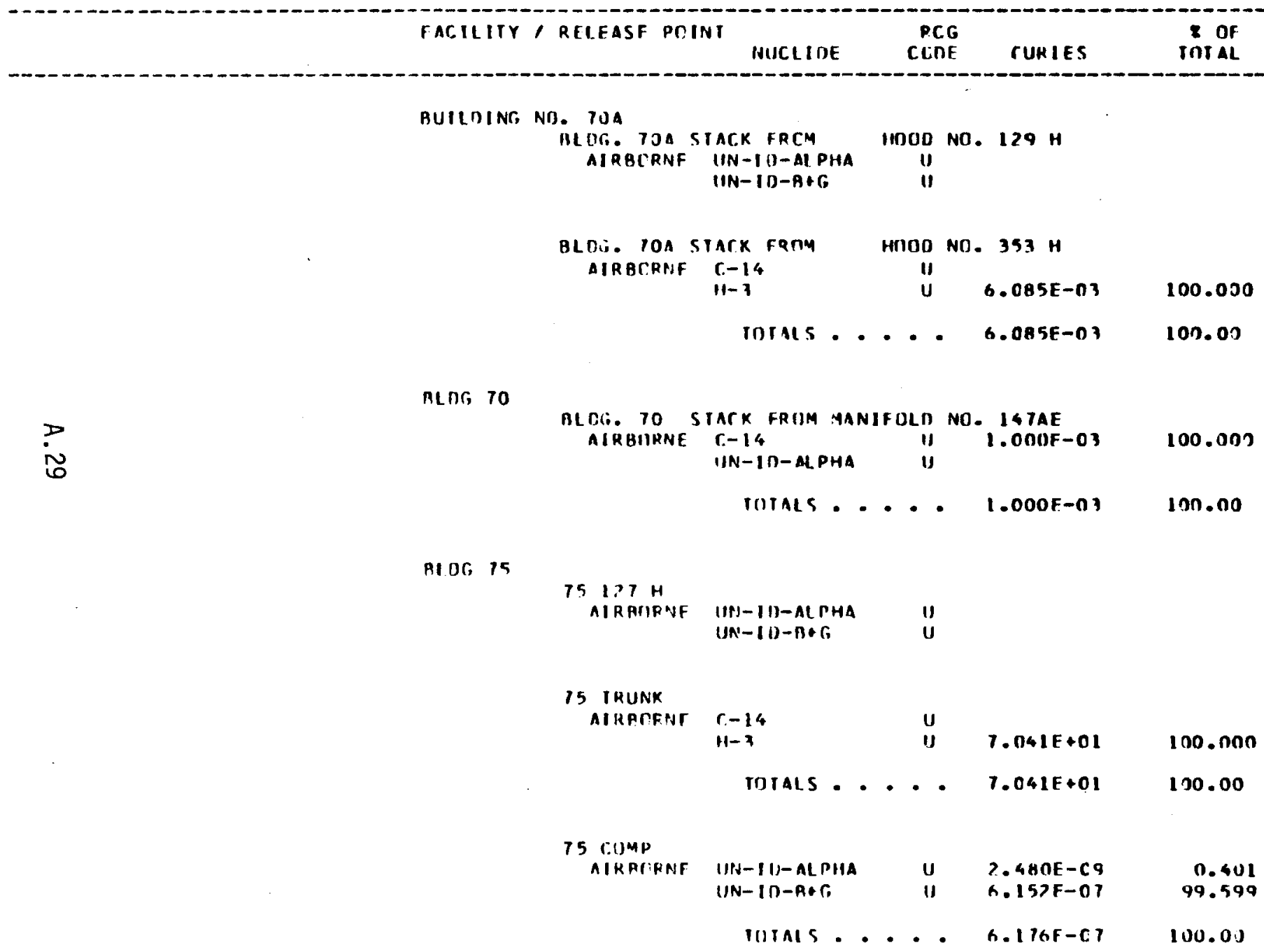


U.S. UTPART UF FNFRGY

FFE LUI:NT INFURMATION SYSTFM

FPA REITASF POINI ANAL YSIS AFPOR

_._EOR_CALENDAP_Y[AR_1981_

SAN FPANT, ISTC RPFPATIONS OFFICF

UNIVFRSIIY OF CALIFURNIA - RERKFIEY

HILL ARFA

fariliti / REIFASF mOINT

NUCLI IDE

BLDG 75

BLDI. 75 STACK FRCM MANITOLO NE. $127 \mathrm{C}$

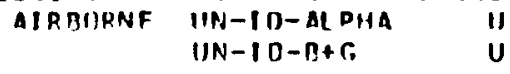

BLDG 74

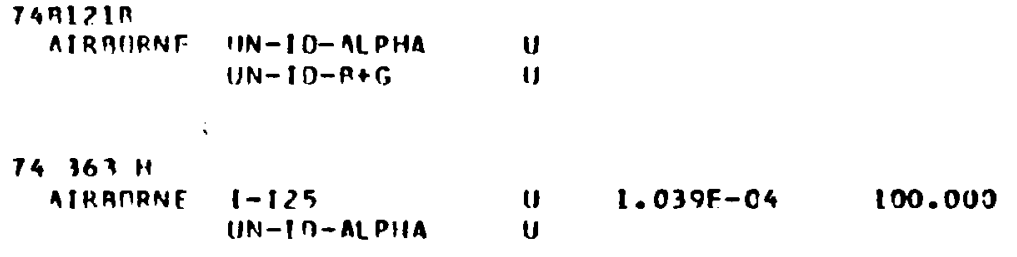

74AI?IR

AIRAIIRNF IIN-IO- MLPHA U

UN-ID-P+G

$74361 \mathrm{H}$

$\begin{array}{lllll}\text { AIRATRNE } & 1-125 & U & 1.039 F-04 & 100.000 \\ \text { UNN-IM-ALPHA } & U & & \end{array}$

$\stackrel{P}{\omega}$

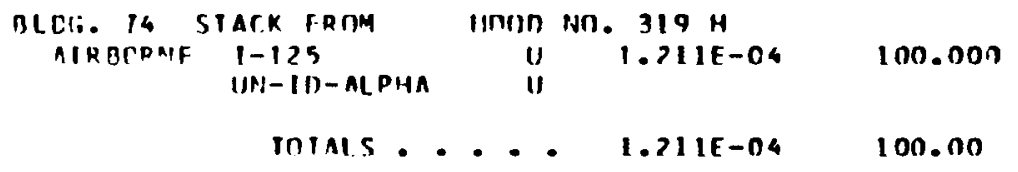

ALOG. T4 STACK FRIIM YANIFOLO NII. 363

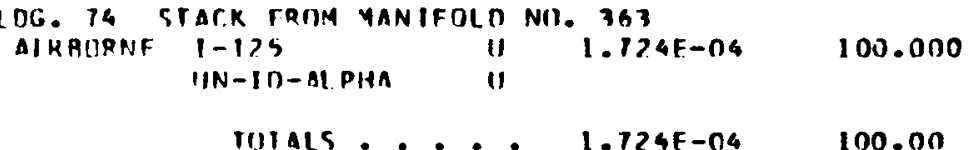


U.S. DFPARTMENT OF ENFRGY FFFLIJFNT INFIJRMAIION SYSIFM

$$
\begin{aligned}
& \text { FPA RELFASF PUINT ANALYSIS RFPOST } \\
& \text { _._EOB_CALENDAB_YEAB__ } 1981 . \ldots
\end{aligned}
$$

SAN TRAMCISCO UPFRATIONS DF TCE

IINIVERSITY DF CAIIFIJRNIA - AFRKFIFY

LAHRENC,F BTRKELFY I.ABMRATIJRY OFFSITE RIDG.

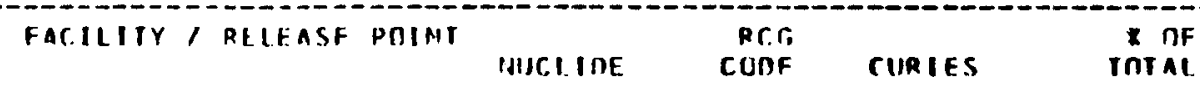

BUILIING NO. SI4

$$
\begin{aligned}
& \text { BL DǴ. } 434 \text { STACK FRIM YANIFIILD NO. AL } \\
& \text { AIRACPNF } 1-125 \text { U } 1.733 \text { E-04 } 100.000 \\
& \text { ION-IO-ALPHA } \\
& \text { rotnls.... 1.733E-04 } 100.00
\end{aligned}
$$




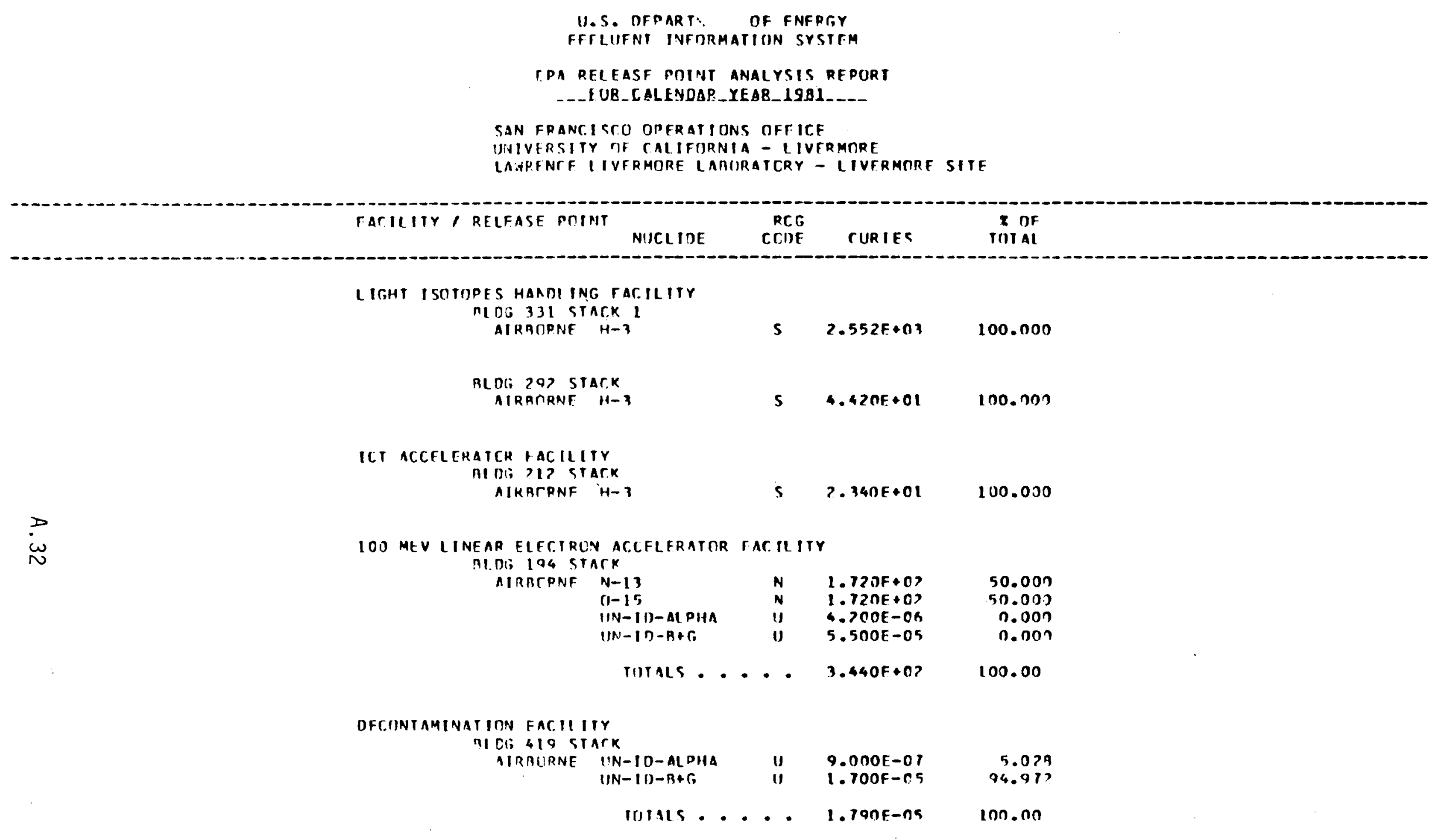


11. S. OFPARTYLNT DF ENFRG,

ERFIUINT INFORMATION SYSTEM

EPA RFITASE POINT ANAI YSIS REPQRT

_._EOB_CALENDAB_YEAB_1981____

SAN FFANTISTO UPERATIONS OFF ICE

ROCKHFLL IHTIRNATIONAL CORPOPATION

ENEPGY SYSTFMS GRUIIP, ROCKHELL INTERNATIONAL

FACILITY, RELEASE PTINI

NUC LIDE

RCG

ruRIES

$2 \mathrm{nF}$

InTAL

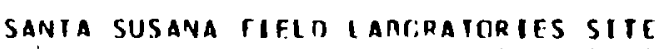

DrE FarIL IIIS AI SANIA SUSANA SITF

AIRAORNF MFP

U $\quad 4 \cdot 100 E-06$

100.000 
11. S. DEPART. OF. ENFRGY

FFFLUENT INFIPMATION SYSTEM

FPA RII.EASF RIINT ANALYSIS PEPDRT

_-_EOR_CALENDAB_YEAB_1981_..-

CHICAGT RPFPATIONS RFTIC.F

UNIVIPSITY OE CHICAGI

AKGONNT NATIUNAL LAMIIRAIITR

TACILIIY, RELEASF POINT

NIICI I DF:

PC.

COnF

CURIES

7 of

IIII AI

RUILDING 202 JANUS RFACTOR

AUILDING $20 ?$ JANUS RFAC,TOR STACK

AIRAOPNF AR-4I

n

3. ROOE-OI

$100.00 n$

BUILOING, PI) 3 LAB AIT?

BUILDING, PI2 F WING. HOT CELL FXHAUST STACK

AIRBOPNF KR-85 N h.650F+0O

100.000

SA-175 U I.69DE-05

0.000

JOTALS.... G.650E+On

100.0n

EXTIUSI SIACK FIIR J-135. ALDG. 205
AI RPARNF H-?
II h. annf-Or
$100.0 n 9$ 
U. S. OEPARTYAFT TI FNFRGY

FFFLUFNT INFIRMATIIIN SYSTFM

TPA RELFASF POINT ANAL YSIS RFPORT

_._EUR_ CALFADAB _ YEAR_ 1981_...

CHIT.AGO RPFPATICAS DFFIC.F

UNIVERSITY TF T.HICAGO

URGONNF - WFSI

acilitr, RleleAsF point

NIICLIDE RC. C.ODE

r.UR IES

2 $\mathrm{nF}$

Intal

LAACRATORY ANE OFFICF RUIUNING 1152

BUIL DIHG, 752 - 15 METER SIAC.K

\begin{tabular}{|c|c|c|c|c|}
\hline AI RAMANF & $\begin{array}{l}11-3 \\
K R-85 \\
X F-133 \\
X F-115\end{array}$ & $\begin{array}{l}u \\
u \\
u \\
u\end{array}$ & $\begin{array}{l}\text { 5. A76E-02 } \\
1.400 F+01 \\
7.376 E-01 \\
1.000 E-n 1\end{array}$ & $\begin{array}{r}0.795 \\
94.008 \\
4.026 \\
0.611\end{array}$ \\
\hline
\end{tabular}

TOIAIS.... 1.6A9F+RI 100.00

ZFRU POHER PLLICNIIIM PFACTIOR IZPPP I

DUII TING; TTT - ? I METER STACK

AIRBORNF XT-133

5.314F-01 14.454

$\begin{array}{llll}X F-135 & U & 1.145 E+00 & 95.546\end{array}$

w

ImILS... 3.676F.00 130.0n

EAR-II. HOT FUEI. FXAMINAIIUN FAC.IIITYISCUTH SUSPCET SIACK FACILITY - 61 MFIFR SIACX

AIRPORYF AR-41 U P.4DYF-

\begin{tabular}{|c|c|c|c|}
\hline $\begin{array}{l}A R-41 \\
P R-A ?\end{array}$ & $\begin{array}{l}u \\
u\end{array}$ & $\begin{array}{l}\text { A. } 404 F-01 \\
9.040 E-01\end{array}$ & $\begin{array}{l}1.015 \\
1.156\end{array}$ \\
\hline $11-3$ & ") & $3.2 \times 7 F+00$ & $4.20 ?$ \\
\hline$K R-85$ & u & $1 .+26++01$ & 20.195 \\
\hline$k P-854$ & u & $1.544 F+00$ & 1.914 \\
\hline$\times R-87$ & u & $2.367 F+00$ & 3.026 \\
\hline$x F-17 x$ & u & $3.9476+01$ & 50.463 \\
\hline$X E-135$ & u & $1.283 F+01$ & 16.403 \\
\hline$x F-1354$ & u & $2.515 E-01$ & 0.322 \\
\hline$x F-139$ & $\mathbf{u}$ & $4.567 F-01$ & $0.5 A_{4}$ \\
\hline
\end{tabular}

TOTALS.... T.A27F+01 100.00

HCT FURL FXANINATICH: FACIIITYINIRRIH

RIIIIDING TQS MAIN SIACK

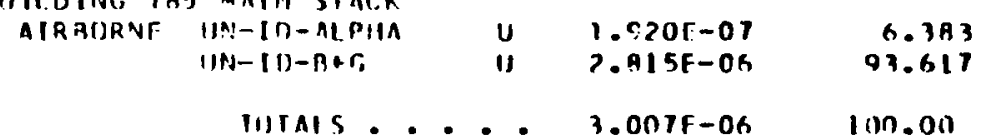

NITIE: NO FNIRY IN CODLIIMN _.. O DATA OR NOT APPI ICABLF 
1.S. DEDARTIA. TF ENFRGY

FFFLUENT INFTRMATION SYSTEM

FPA RFLFASF POINT ANALYSIS RFPURT

_._EOB_C ALENDAB_YEAB_1981_.

CHICAGO NPFRAIIONS DFFICE

UNIVFRSITY TF C.HICACO

ARGCNAE-HEST

FaCilitr, RFLEASE POINI

NUCLIIDE CCDE CURIES

z of

FUEI ASSFMBLY INT STORAGF AIITIDING IFASAI

BUILDINC 787 - 10 METER STACK

AIRRORNF IIN-ID-ALPHA U 4.38NE-0T 19.753 IIN-ID-B+C,

$\begin{array}{ll}4.380 E-07 & 19.753 \\ 1.779 F-06 & 00.247\end{array}$

IRTALS.... ?.217E-66 100.00

NCN-NESIRUIIIVF ASSAY LABCRATCRY IIN AUILOING 1521

BIII DING 75? - II MFTER SIACK

AIRACRNF IIN-III-ALPIIA II 4.P44F-OR

IIN-ID-R+r, II $\quad 7.150 F-07 \quad 93.656$

tntals.... 7.635F-07 100.00

SCOIUM COMPUNFNIS MAINTFNANCE SHUP

BUILDING; 793 - 15 MFIER SIACK

\begin{tabular}{|c|c|c|c|c|}
\hline AIRAMPNF & $\begin{array}{l}U N-I D-A \mid \text { PHA } \\
U N-I D-B+C\end{array}$ & $\begin{array}{l}u \\
u\end{array}$ & $\begin{array}{l}1.681 E-06 \\
1.627 F-05\end{array}$ & $\begin{array}{r}9.365 \\
90.635\end{array}$ \\
\hline
\end{tabular}

IIITLS.... 1.795F-05 190.00

IRINSIENT RFACTIRR IFST HACILITY ITREATI

RUII.DIAG TOR STACK

AIRACPAI AR-4I

\begin{tabular}{|c|c|c|c|}
\hline $\begin{array}{l}A R-41 \\
R A-(A-143\end{array}$ & $\begin{array}{l}\text { II } \\
\text { II }\end{array}$ & $\begin{array}{l}0.714 E+01 \\
7.444 F-05\end{array}$ & $\begin{array}{r}97.847 \\
0.003\end{array}$ \\
\hline$K R-A R$ & $\mathbf{u}$ & $9.947 \mathrm{E}-\mathrm{n} 1$ & 1.563 \\
\hline 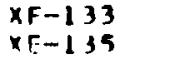 & $\begin{array}{l}u \\
u\end{array}$ & $\begin{array}{l}1.243 F-01 \\
7.486 E-01\end{array}$ & $\begin{array}{l}0.196 \\
0.391\end{array}$ \\
\hline
\end{tabular}

IOIALS.... 6.351E.01 100.00 
U.S. DEPARTATNT OF ENFRTYY

FFFI UFET INFURMATION SYSTFM

FPA RFLFASF PUINT ANALIYSIS REPORI

_._EOR_GALENUAB_YEAB_1981.

CHICAC, IIPFRATICNS DFFICF

ASSIICIAIFI UNIVFPSIIIFS. INC. - AROOKHAVEN

GRORKHAVFN MAIIIINAI LABORATREY

FACIIITY $/$ HELFASF POIN

NISC.L. IDE

RCG

r.URIES

\section{nf}

C.HEMISTPY AL DG-555

BIDG; -555 HOND FXHAUST

AIRATPNF 11-3

$4.300 E \cdot 00$

100.non

VAN DE GRAFE ACCFIERAIOP-RL DG-ONI

DI Di-901 SIACK

AI RBURNF H-

$4.100 E+02$

100.000

hIGH-CLUX atak RFACITR

IIT RR-HOT I ARORATORY STACK

AIRATUNF H-3

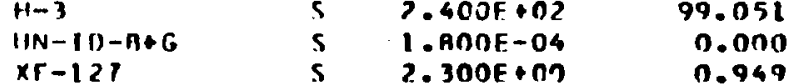

$\begin{array}{rrrr}x r-127 & S & 2.300 E+09 & 0.949 \\ \text { rUTALS..... } & 2.423 E \cdot 0 ? & 100.00\end{array}$

HAIAPDOMS WASIF MANAGFMFNT ARFA 445

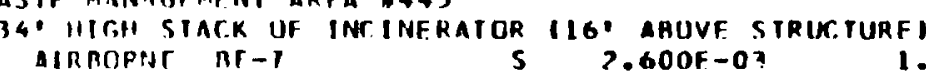

\begin{tabular}{|c|c|c|c|}
\hline $\mathrm{nr}-1$ & 5 & $2.600 F-0 ?$ & 1.363 \\
\hline$c-14$ & s & $6.100 E-04$ & $0.4>5$ \\
\hline$F F-59$ & 5 & $7.500 \mathrm{E}-04$ & 0.111 \\
\hline $11-7$ & 5 & 1. AONF-01 & 94.359 \\
\hline $1-125$ & s & $9.900 E-04$ & 0.519 \\
\hline$p-32$ & $\mathbf{S}$ & $1.500 \mathrm{~F}-\mathrm{C} 4$ & 0.019 \\
\hline $5-15$ & s & $5.700 E-03$ & 2.9A \\
\hline $5 N-113$ & $S$ & $7.600 E-04$ & 0.134 \\
\hline
\end{tabular}

IIITALS.... 1.90AF-OI 100.00

MECICAL RESFART.H CFNIFP
AL 1$) ;-490$ SIACK
$5 \quad 1.100 \mathrm{~F}+\mathrm{Cn}$
I 90.019
MECICAI PFAS UTIF SIACK
AIRAURNF AP-4I
S $\quad$ 1. 100F: 4 ?
100.000

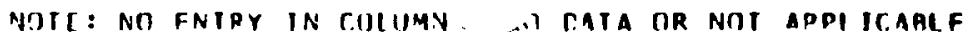


11. S. DFPART

OF ENFRGY

FFFIUENT INFORMATION SYSIEP

\section{ERA PFIFASF ONINI AMALYSIS RFPHR}

__EOB_GALENDAB_XEAB__1981

CHICAGD OIPFRATIONS OFFIC.F

ASSOCIAIFD UNIVERSITIES. INC. - PROOKHAVFN

RKIOKKHAVFN NAIIITNAL LARIIRAIIIRY

FACIIITY I RFLFASF POINT

NIISI I UE

RC.G CURIES

of

inta

LINAT. ISIITHE FACILIIY INI IF

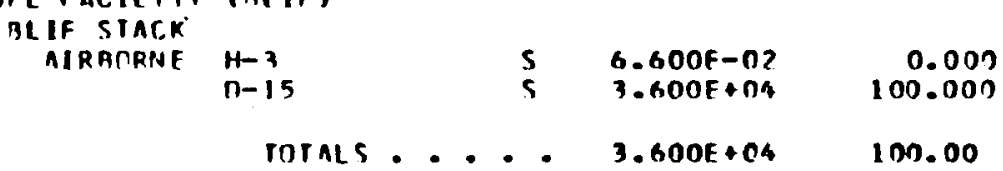

$\omega$ 
II. S. DFPARTITNI TIF ENFRTYY

FFPIIIENT INFORYATION SYSIEM

EPA RELEASE POINT ANALYSIS REPORT

_._EOB_C ALENDAB_YESB__1981_.__

CHICAGC TIPCAATICNS DFTIT.E

PATTELLF MrMIIRI AL INSTIIUTE

PATTELLF COLIMBOS

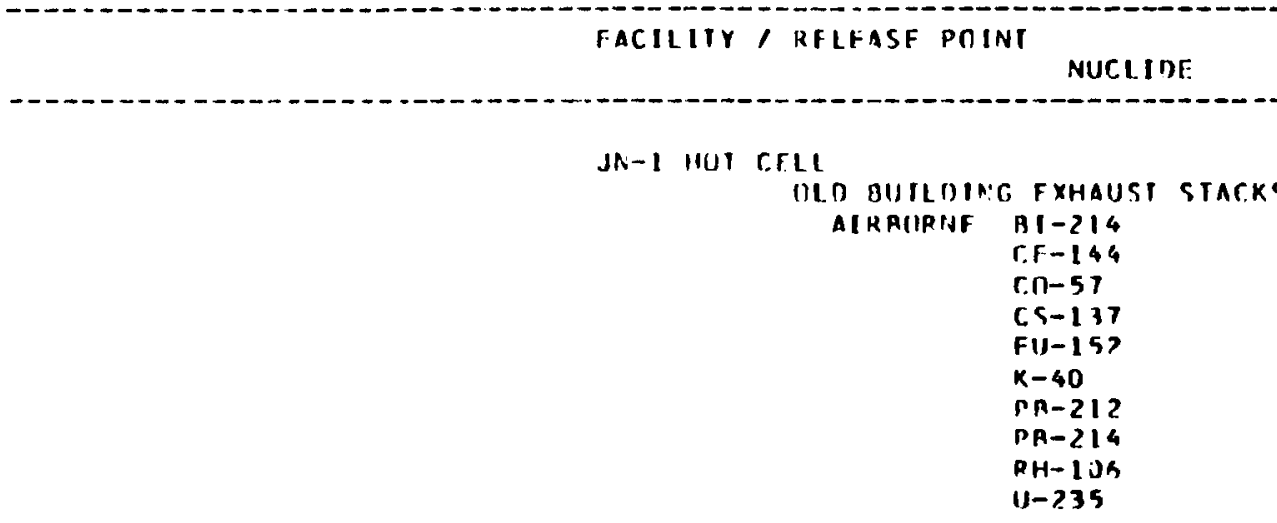

arce

RURIES RF

totial.

JA-4 PLUTONIUR LAA

RLCA 41 TE EAST EXHALST STACKS

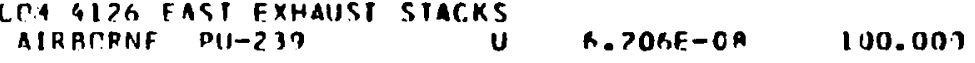

HQIN QILG HEST EXHAUST STACKS

AIRBIIRNF PU-Z39 U.G27E-OB 100.000

IA-I HIII CEIL

LIOUIN WASTI FVAPCRATUR EXHAUST STAC,

AIRAORNE

\begin{tabular}{|c|c|c|}
\hline B $1-214$ & U & $1.346 E-07$ \\
\hline$C F-144$ & $u$ & $5.371 F-09$ \\
\hline$(0)-60$ & II & $1.699 \mathrm{~F}-07$ \\
\hline C S-134 & U & $1.156 F-06$ \\
\hline $4.5-137$ & u & $125 F-06$ \\
\hline$[1]-15]$ & $u$ & $2.030 E-0 \%$ \\
\hline$x-40$ & U & $1.296 \mathrm{~F}-\mathrm{OA}$ \\
\hline$P B-212$ & u & $7.779 F-08$ \\
\hline $1011-214$ & U & $2.160 \mathrm{~F}-07$ \\
\hline $11-2 \times 5$ & ij & $3.960 \mathrm{~F}-\mathrm{C} ?$ \\
\hline
\end{tabular}

2. 179

0.866

2. 717

18.640

50.372

0.131

20.89 ?

0.449

3. 4 ? ?

0.064

IIIIALS... 6. . $203 F-n 6 \quad$ IOM.OO 
U.S. DFPARIR, IIF ENFRTY

EFTLIIFNI INFTRMATION SYSTFM

FPA RFLEASF POINT ANALYSIS REPTR

_EUB_CALENDAB_YEAB_19B1

CHICACO CPERATIONS OFFICE

AATTILIF MTMORIAL INSTITUTE

PATIFLLF COLUMaUS

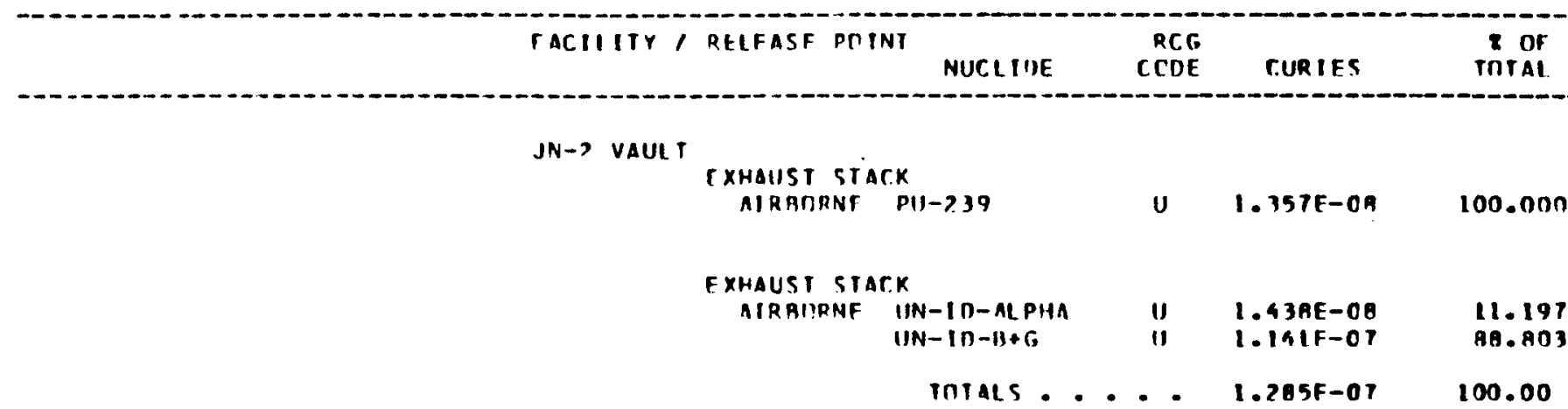

D

JA-I HOT CELL

DLI BUILOING EXHAIIST STACKS

AIRRONNE BI-?14

$n 1-214$
$r . r-144$
$r n-60$
$C S-134$
$C S-137$
$K-4 n$
$P A-212$
$1 P-214$
$5 A-125$
$U-735$

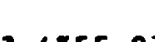

2.793

$5.199 F-O A$

$1.72 B F-07$

$1.72 B F-01$
$1.75 A F-C B$

3. T12F-Ch

?. $609 F-0$ OA

2. 6AAF-OA

$3.994 E-07$

$6.435 F-06$

0.344

0.878

A. 716

24.926

17.240

0.179

2.639

47.524

intals 0.0 .0

100.00

OLD AIJILING TXHAUST STAC.KS

AIRAOFNF HI->IS

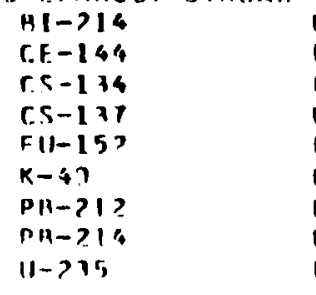

$1.513 E-05$

MUIALS.... 1.45AF-CB 130.00 
U.S. DEPARTYFNI OF FNFRGY

EFFLUENT INFTEMATION SYSTEM

FPA RELFAST DOINT ANALYSIS RFPORT

_._EUB_CALENDAB_YEAB_1SB1.

CHIT.AGO IPFRATIONS TFFITE

PATTFILF MEMORIAL INSTITUTE

AATIFLLF CULUMAUUS

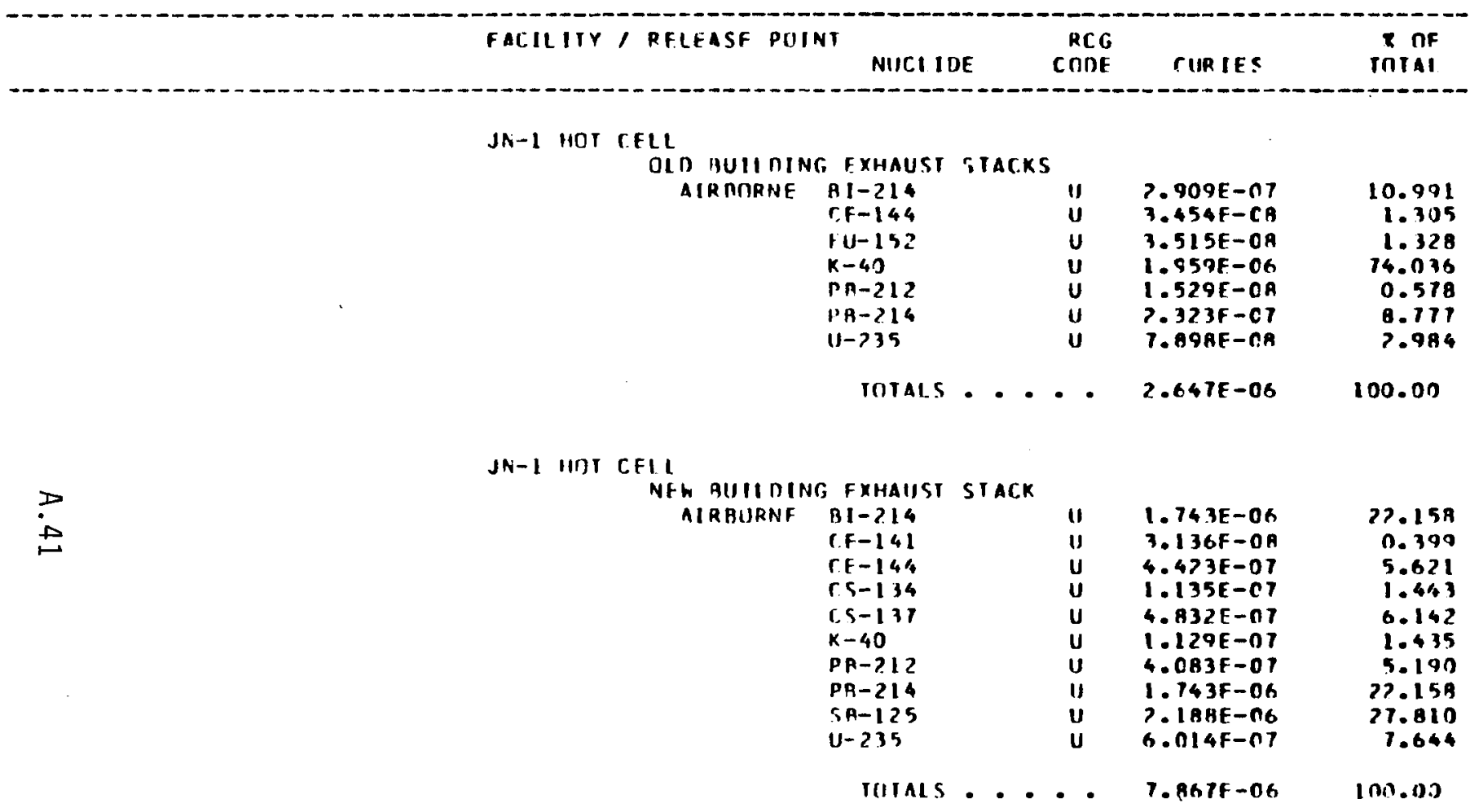


II.S. DFPART: OF FNFRGY

FFFLUENT INFIRMATION SYSTEM

FPA PELCASF PMIVT ANALYSIS REPRRT

_. LOB__CALENOAR_YEAB_1.281.

T.HICAGT IIPFRAIITNS DFFIT.F

ICHA STAIE UNIVFRSITY

AMES IARIIRAITRY

FACILITY, RELEISF PIINI

NIICL I DE

ACG

CIURIES

2 nF

TOTAI

AMES LARORATCRY RFSFARC.H RFACTMR

CCNIAINMENT STACK

AIRBARNF

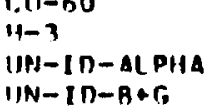

IN-65

N $\quad 2.220 E-01$

$S \quad 4.490 F+00$

$1.590 E-07$

2. $140 \mathrm{OE}-\mathrm{OH}$

0.000

0.000

0.000

0.000

intals....4 4.490F+00 100.00 
11. S. DFPARTMFNI OF ENFACY

FFFI IFNT INFITRMATION SYSTFM

\section{EPA RELFASF POINT ARALYSIS REPORT}

_._EDB_CAL EUCAR_YEAB_19B1.

IJAHC TPFRATINNS DFFICH

Fr, E, INAIII

ARA-:

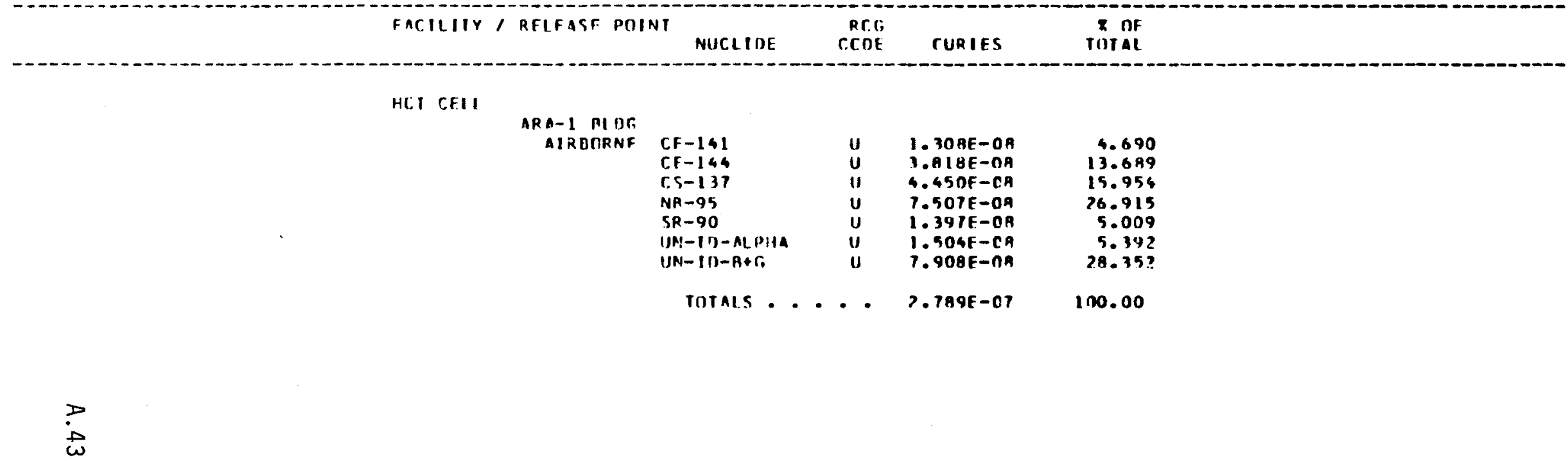


U.S. DEPART. DF FNFRTIY

EFFLUFNT INTTRMATION SYSTFM

FPA RELEASF POINT ANALYSIS REPORT

-_EDB_CALENDAB_YEAR_1981_._.

IJAHO RPFRATIONS DFFICF

FGGG II)AHT

CESS OF FLIIN TEST

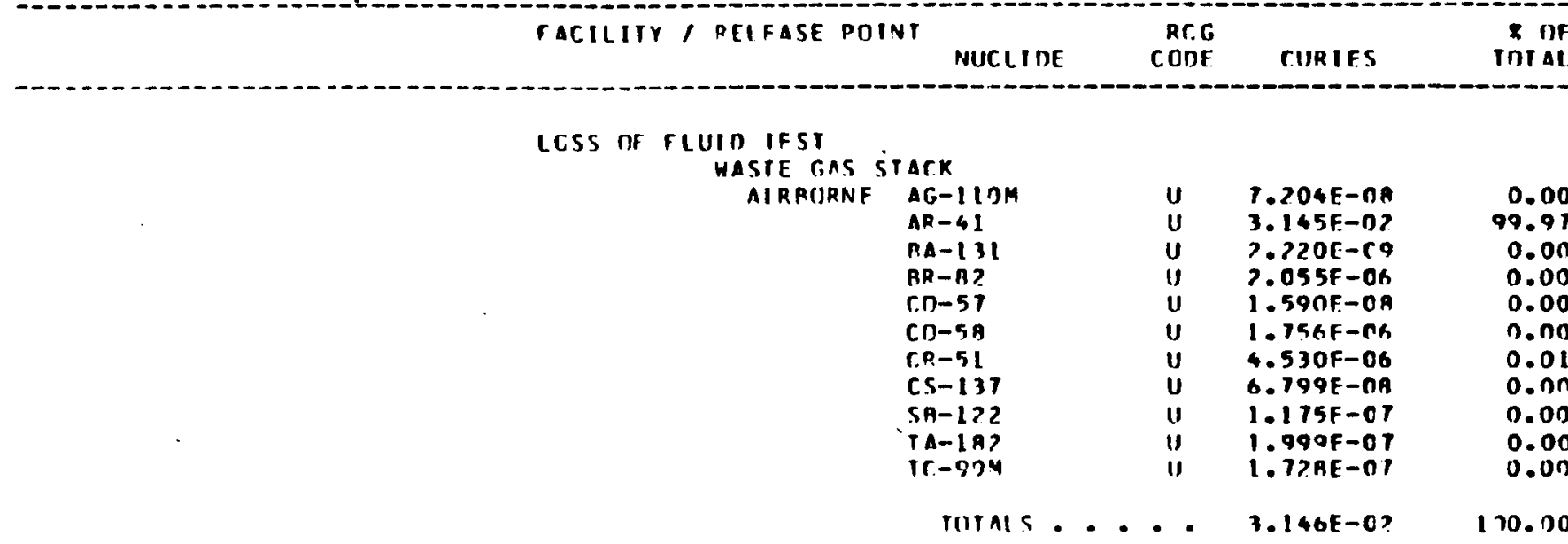

$\stackrel{D}{D}$ 
U.S. DFPAKIMENT DFF ENFRTYY FFFLITRA INFORMAIION SYSIEM

FPA RFLEASF PIJINT ARIALYIS RFPORT

_-_EOE_CALENDAB_YEAB_1281_...

I1) HHO MPFRATIONS DFFICE

FiEg IDAHA

IFST ARFA NURTH

facility, RELEASF POINT

NUCL I DE

RRG
C.ODF

C.UR I ES

n $\mathrm{nF}$

TECHNICAL SUPPCRT FACILITY

IAN STACK

AIRBORNF BF-1

AF -7
C. -141
C.F -144

C.F -144
C. $11-58$

(.)-5B

$(C,-5)$

$C . R-51$
$C S-13 T$

HF- 191

$M N-54$

$M N-54$

$N A-95$
HU- 101

RIJ-1 I)
SR -90

i

$S R-90$
UN-III-ALPHA

IIN-I $\mathrm{I}-\mathrm{B}+\mathrm{C}$,

$1.297 F-05$
$1.293 E-06$
$1.409 F-05$
$3.445 E-05$
$9.584 F-06$
$7.336 F-05$
$1.048 E-04$
$3.638 F-06$
$1.400 E-06$
$8.091 F-06$
$1.966 F-07$
$1.634 F-04$
$1.523 F-06$
$1.759 F-04$

2. 339

0.273

2. $54 ?$

6.214
1.548

4.214

18.903

0.656

0.253

1. 459

29.162

29.674

0.775
31.778

InTALS.... 5.5445-04 100.00 
II. S. DFPARTI. UF FNFRGY

FFTINFNI INTIRRAIION SYSTFM

FPA PFIFASE PMINT ANALYSTS REPORT

_._EOB_GGLEUDAB_XEAB_1981_._.

IDAHO DPFRATIUNS OFFICE

EREG IDAHE

SPERT - PBF

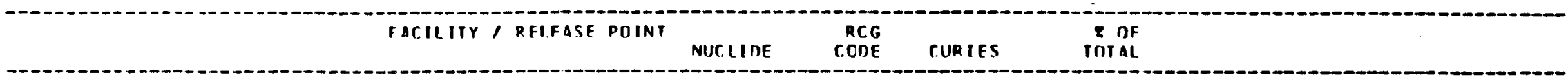

POWFR RURST FACILITY

PAF STACK

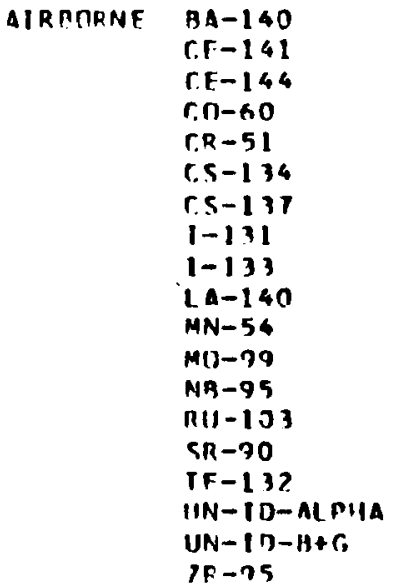

\section{a.327F-0}

$4.041 E-07$

$1.126 E-06$

1. $126 E-06$
$9.161 E-n T$

$9.167 F-07$

1. $561 \mathrm{~F}-0 \mathrm{~K}$

1. $115 \mathrm{~F}-04$

1. $053 \mathrm{E}-0 \mathrm{~S}$

$1.841 F-06$

7. $997 \mathrm{E}-0 \mathrm{CH}$

$3.650 E-07$

9. CAIE-05

B. $487 E-O$

$4.540 F-07$

के

TOIALS.... T.4P2E-n4 100.0N

$$
\begin{array}{r}
3.437 \\
0.167 \\
0.465 \\
0.378 \\
0.378 \\
0.644 \\
46.077 \\
4.747 \\
0.740 \\
3.301 \\
0.151 \\
37.486 \\
0.350 \\
0.187 \\
0.691 \\
0.046 \\
0.018 \\
1.107 \\
0.043
\end{array}
$$

1. $312 E-0$ E

$4.312 E-00$ 
U.S. DF DARTYFNT UF ENFRGY

FFFLIIFNT INTORMATION SYSTEM

\section{FPA RFIFASF POIVI ANALYSIS REPORT}

$$
\text { _._EUR_CALENDAB_YEAB_1981. }
$$

IOAHC CPFRATIIINS OFFICF

FiBSG IIAAHO

IFST RFACTIRA ARFA

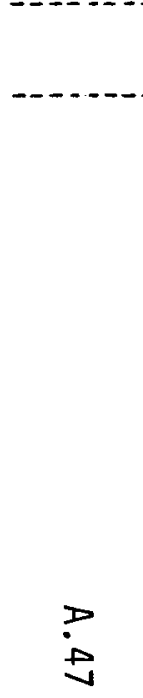

FACILIIY, hELFASE PCINT

NuCLINE

RC. G

CURIES

InTAL
Int

nOVANCED IEST REATIUP

WASIF GAS STACK

AIRBTRNF AR-4I

BA- 137

$C . S-13$ म

$K A-B 5 M$
$K R-B)$

$K R-A B$

RA-BR

$X F-133$

$X F-135$

$X F-135 M$
$X F-139$

rntals.... A.309F+n3 100.00

FAGINET:P.ING IFSI PFACTIIR

WASIE GAS SIACK

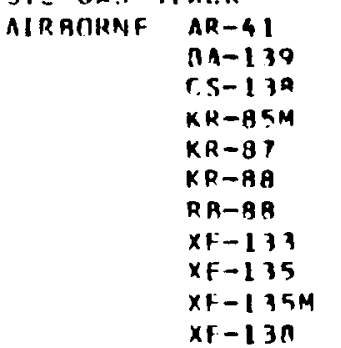

\section{B. $350 F+00$}

5. 4 OUF -01

$4.000 F-02$

ค. $500 E-n 1$

$3.210 \mathrm{E}+\mathrm{ON}$

$3.140 F+D n$

4. $100 \mathrm{OF}-02$

5. 70OF-OI

2. $750 E+00$

A. ODOE-OI

5. $900 F+0$ n

29. 795

1.690
0.207

2.602

10.375

9.673

ก. 121

1.464

9.349

5.044

10. ก2?

$X F-13 n$

TOIAIS.... 2.569E+Q 1100.00

32.503

2.107

0.156

3.309

17.495

12.273

0.15 A

2.219

ค. 759

3.114

7). 966

IRA HOT CELL

STALK

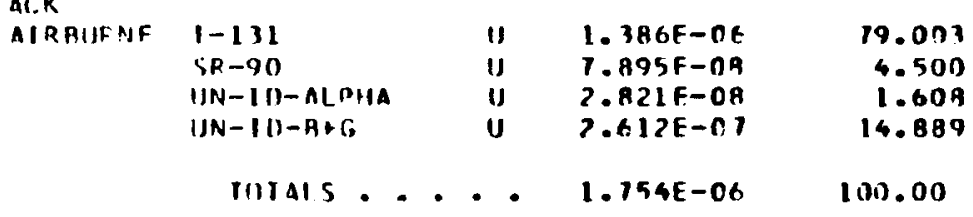

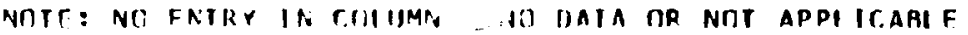


U. S. DEPART

OF FNERGY

FFFLIIFNT INFDRMATION SYSTEM

FPA RFLEASF POINT ANAL YSIS REPORT

___EUB_CALFNDAB_YEAB__19BL___

Ii)AHO UPFRAIIONS OTFICE

EIEEG InAFH

IFST PFACTOR ART:A

Facility, pFLEASF POINT

NUT.LIDE

RCr
CrOF

x of

Intal

TRA MLPHA AND C.HEM LAT

SIAC.K

AIRBDRNF CE-14I

C. $-5-60$

C.S-1 131

$\mathrm{I}-131$
$\mathrm{I}-90$

INN-ID-NLPHA U I.146E-OT

INA-ID-B+C, U $1.73 A E-O B$

$2.033 E-06$

THIAL.... 5.233E-06

100.00

$i_{\infty}^{\infty}$ 
U.S. DFPARTYENT IIF FNFRGY

FERIUFNT INT DRMATIIIN SYSIEM

FPA REIFASF POINT ANALYSIS REPORT

_...ECR_CALENOAR_YEAB_19R1_...

I. OAHO RIPFRATIONS OFFICL

ALLIF THFMICAL TORPURATION

ibaho ChFmical oruc.essing plant

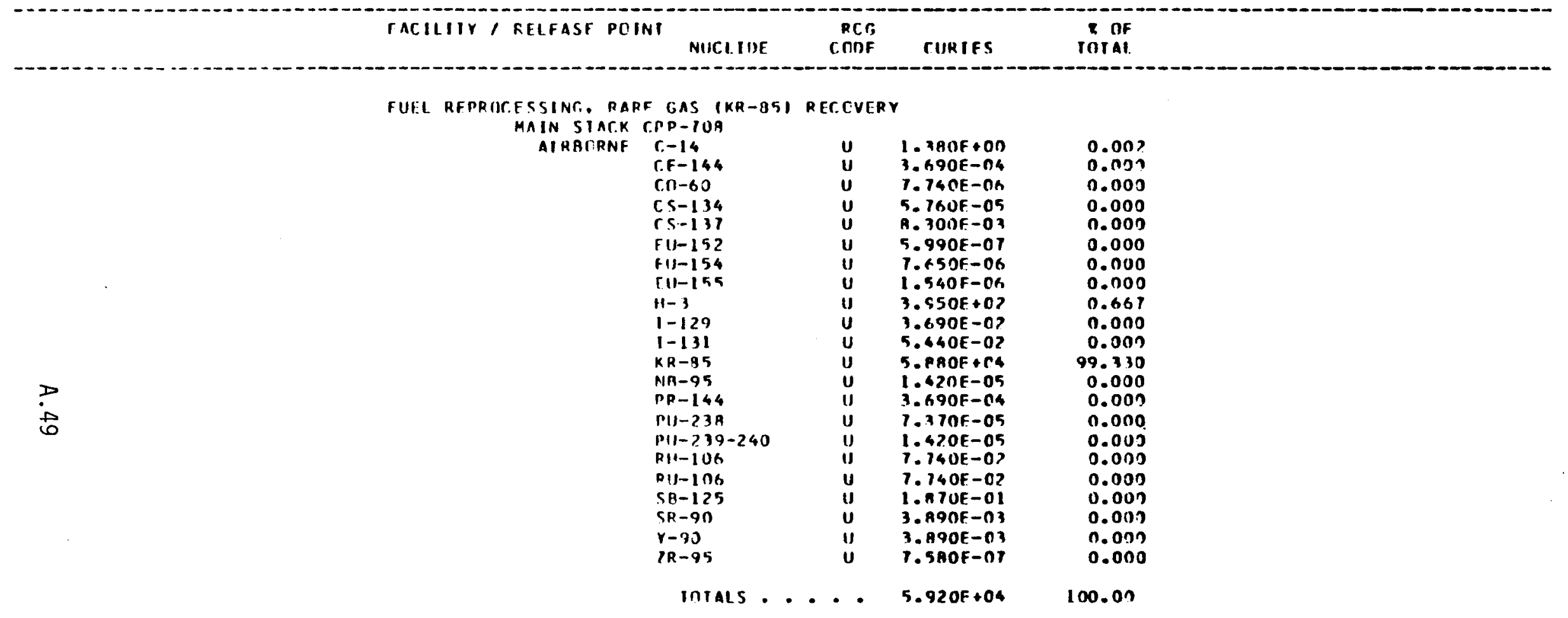


W. S. DERART. DF FNFRTIV

FTRLUFNT INTORMATION SYSTEM

TPA RELFASF POINT ANALYSIS RFPORT

-__EOR_CALENUAB_YEAB_1981_.

NEVATA RPERATIONS DFFIC.F

UNIVFPSITY IIF CAIIFORNIA - LOS ALAMOS

NEVABA TFST SITE.

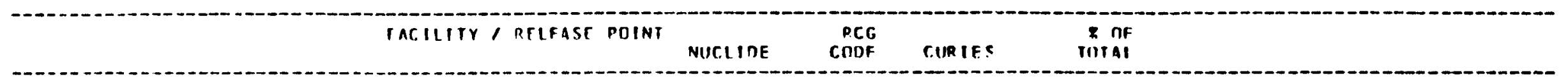

LASL TESI AREA 6

U3IJ PTST SHUT DRILLING RIG

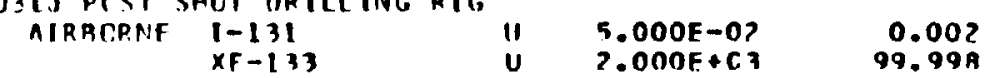

rotal.s.... $2.0 n 0 E+03 \quad 100.00$ 
11.5. DFPARTIMENT DF ENFRGY

EFPLUFNT INTURMATION SYSTEM

FPA REITASE POINT ANAL YSIS RFPURT

_. EUB_CALENDAB_YEAB_ISBL...

NFVATA DPFPAIIONS DTFICT

UNIVFPSITY UF CALIFORNIA - LIVFRHORF

LAHRFNCE LIVFRMURE NATIONAL IARORATUR

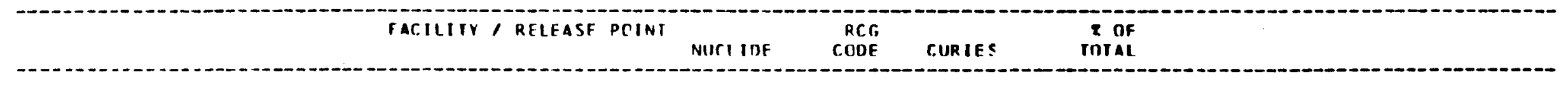

$\sum_{i}$

PCSISHTT DRILLING CPERATINNS

POSISHCT DPILI ING VENT LINE STACK

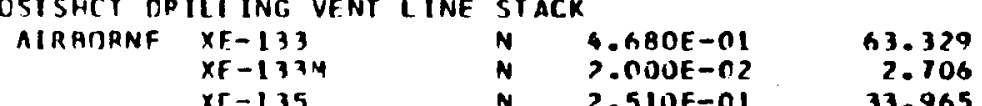

$\begin{array}{lll}x+135 & N \quad 2.510 E-01 & 33.965\end{array}$

IIITALS.... 7.390F-01 100.00

DCSISIICT DRILI ING VENT LINE STACK

\begin{tabular}{|c|c|c|c|c|}
\hline AIRPIRANF & 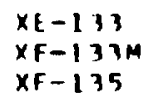 & $\begin{array}{l}\mathbf{N} \\
\mathbf{N} \\
\mathbf{N}\end{array}$ & $\begin{array}{l}7.0 O O F+0 ? \\
2.8 A O E+01 \\
1.42 O F+0 ?\end{array}$ & $\begin{array}{r}80.396 \\
3.307 \\
16.307\end{array}$ \\
\hline
\end{tabular}

PCSISIUTT DRILLING VENT LINE STACK

$\begin{array}{llllr}\text { AIRARRNF } & X F-133 & \text { N } & 7.490 E+00 & 95.402 \\ X F-133 M & N & 9.000 E-02 & 3.065\end{array}$

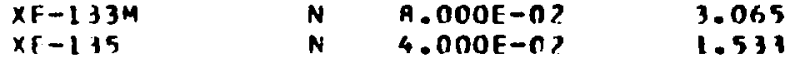

intals.... T.610F+on 100.00

PUSISHOI ORIILING RPFRATICNS

PLISISHEI URILLING VENT I INF STAC.K,
AIRAURNE H-I 
U.S. DFPART, UF ENFRGY

EFFLUIFNT INFORMATION SYSTFM

EPA REIFASF POIIUT ANALYSIS PEPORT

__EOB_CALENDAB_YEAB_1281_...

NEVADA OPERATIONS OFFICE

SANDIA CORPIJEATION

FACIIIIY, RELEASE PCINT NICLIDE

ARFA 12 SITE UI ZR

UL2G TUNNEL VENIILATION SYSTEM
AIRACPIIE H-3
$5.600 F+0 ?$
$100 . n 00$

i 
U. S. DIPARTIIENT UF FNFRTYY

FTFLIIFNT INFUPMATION SYSIEM

EPA RFLEASE PTIVT ANALYSIS RFPURT

___EB_CALENDAB_YEAB__1981_.

CAK PINGE OPFRATIONS OFFICE

OAK FIIIGF ASSOCIATEI) UNIVERSITIFS

CAK RIOCE ASSOCIATED UNIVERSITIFS

SAC ILITY 1 RELEASF POINT

NIICLIIDE

RCG
CRnF

RURIES

I IIF

•

CARL DIVISION

MULTIPIF TRCATIUNS IN VARIOUS BUILDINGS

AIRACRNF

$00.00 n$

NARHOSET RESEARCII FACILITY

MAR.ACSFT RTSLARCH FACILITY

AIRBCRNF H-

$\begin{array}{lrrr}H-3 & \text { S } & ? .000 \mathrm{~F}-04 & 57.143 \\ 1-125 & S & 1.500 \mathrm{~F}-04 & 42.857 \\ \text { TOTALS } & . . . & 3.500 \mathrm{~F}-04 & 100.00\end{array}$

is

MFOICAL DIVISION

\begin{tabular}{|c|c|c|c|c|}
\hline AIRBITRNE & $\begin{array}{l}c-14 \\
H-3 \\
1-125 \\
1-131 \\
x \in-133\end{array}$ & $\begin{array}{l}5 \\
5 \\
5 \\
5 \\
5\end{array}$ & $\begin{array}{l}1.000 E-03 \\
5.000 F-03 \\
1.000 E-04 \\
1.000 F-04 \\
7.000 E-03\end{array}$ & $\begin{array}{r}12.195 \\
60.976 \\
1.220 \\
1.270 \\
24.390\end{array}$ \\
\hline & & & A. $200 E-03$ & 100.00 \\
\hline
\end{tabular}

SPFCIAL TRAINING CIVISION

SPFCIAI IRAINING DIVISION

AIPAURNE

$5 \quad 1.000 E-04$

100.000 
11. S. DFPART. OF EMERGY

ETFLIIFNT INFORMATION SYSTFM

FPA PELEASF POINT ANALYSIS REPDRT

_._EOB_CALENDAB_YEAB_1981.

CAK RIDGE OPFRATIONS OFFICE

REACIIVE MFTALS INT

PMI T.CMPANY

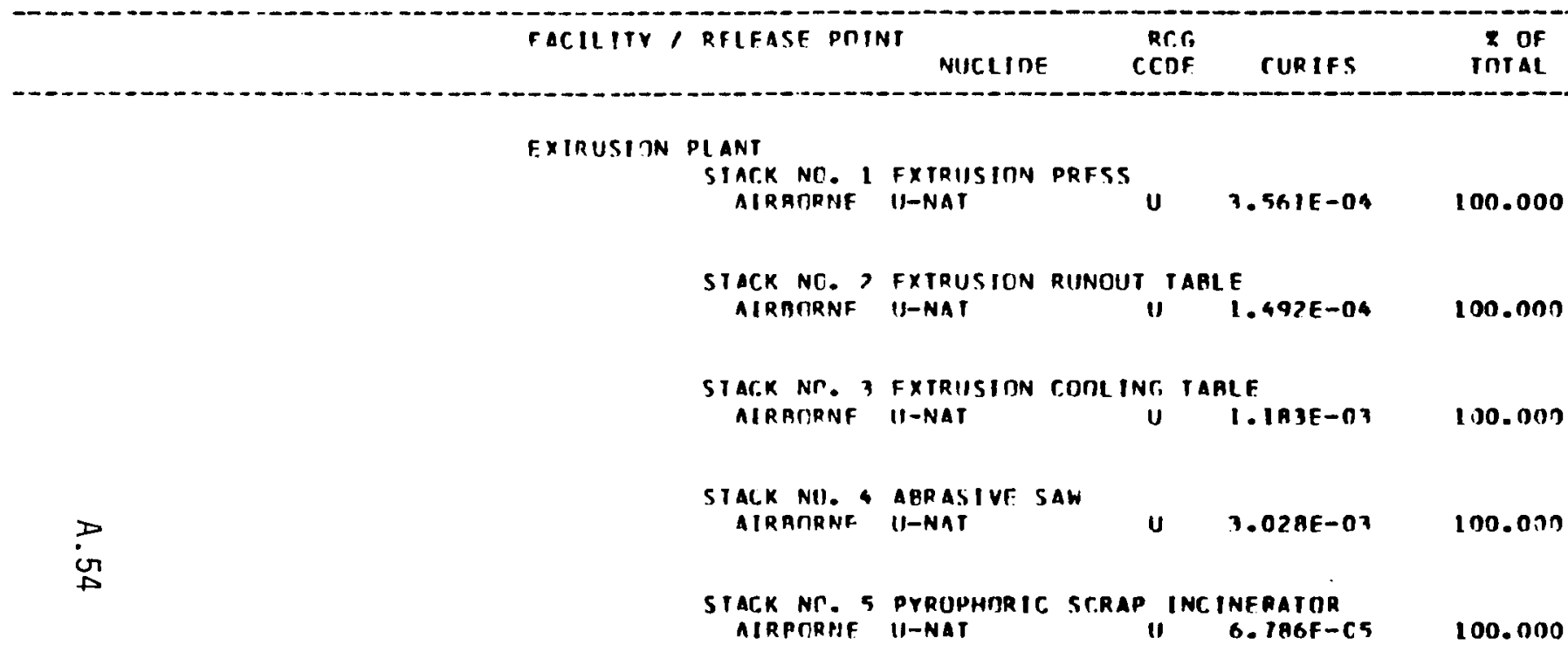


U.S. DEPART AFNT IIF FNFRTOY

FFFLIJFNT INTIHAAIION SYSTFM

FPA RELFAST POINI ANAL YSIS RFPORT

_._EUR_CALENUAR__YEAR_12B1

PAX RIDCF MPFRATIONS DFFIC.F

LVION TARAIDF CORPIIRATION-AUCLFAR DIVISICN

CAK RIUGF GASERUS MIFFUSION PLANT

FACUIITY, RELFASE POINT

MUCL InE

ACG

CURIES

$7 \mathrm{nF}$

K- 1420 DECOHATAMINATION FACILITY

$K-1420$ DRUM DP.YFRS

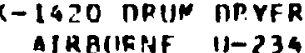

$\begin{array}{rrrr}11-234 & 5 & 5.600 E-04 & 90.970 \\ 11-235 & 5 & 2.000 F-05 & 7.174 \\ 11-736 & 5 & 1.000 E-C 5 & 1.087 \\ 11-23 A & 5 & 3.300 E-04 & 35.810\end{array}$

TOTALS.... 9.700E-O4 100.00

is

G

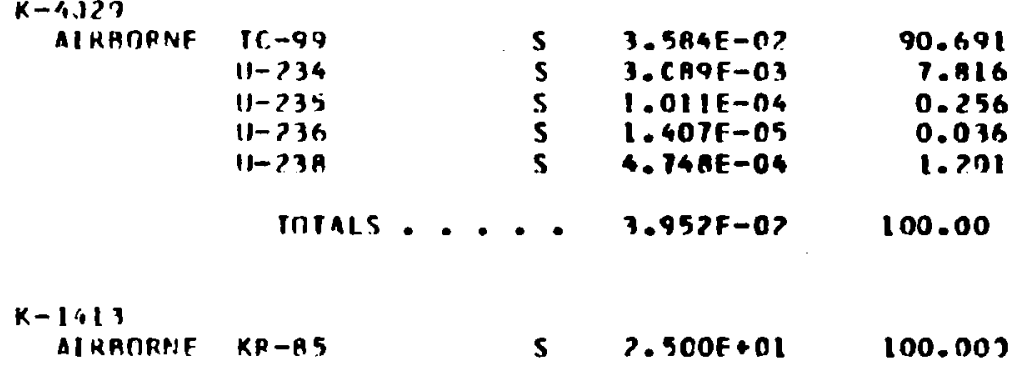




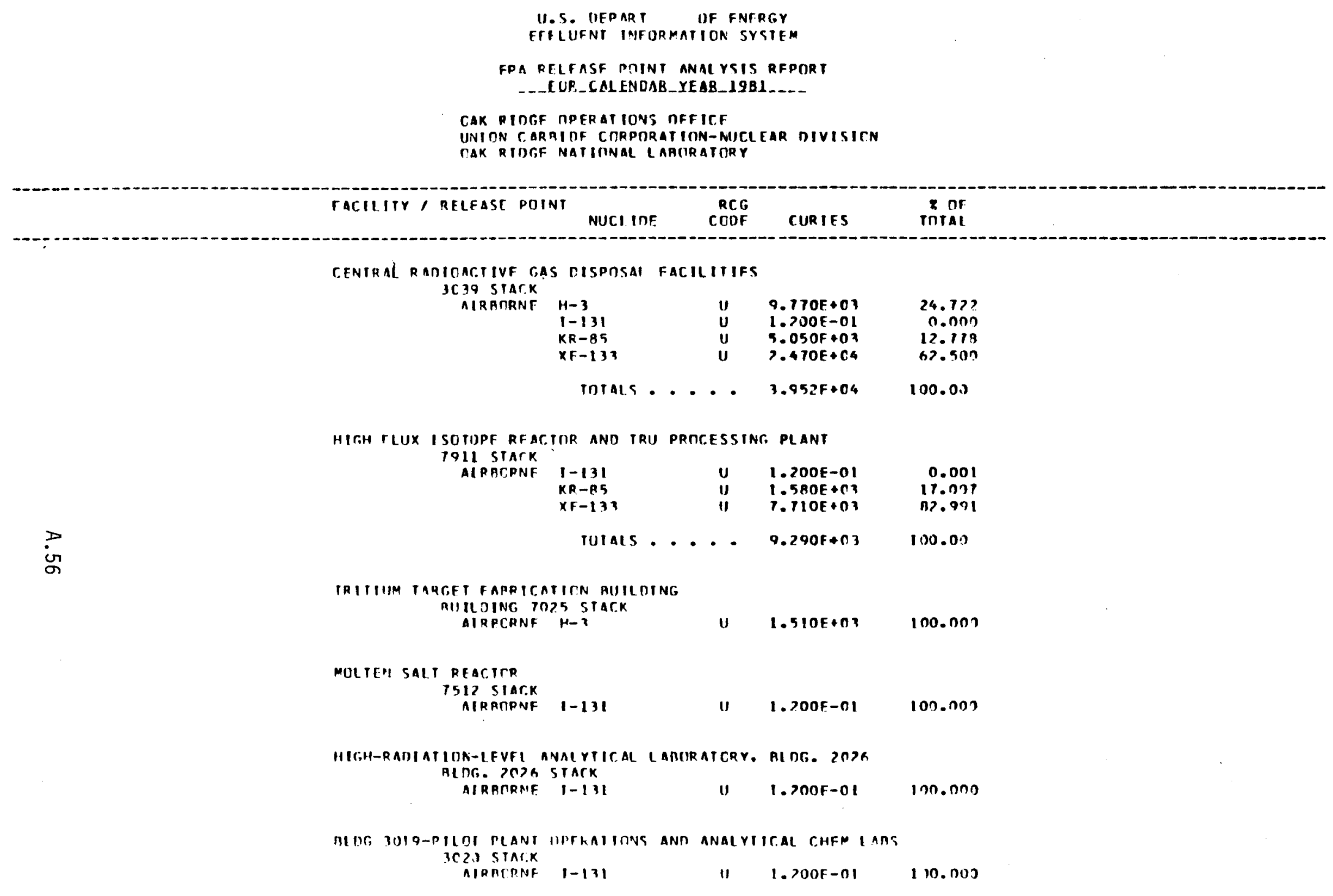


11. S. DFOARTYFNT OF ENFRGY

FFFLUENT INFIHMAIIUN SYSTEM

FPA RFLFASE PNINT ANAL YSIS RFPOR

_-_ CUR_CALENDAB_YIAR_ 19A_.

CAK PIDGF DOPRATIIINS DFTIC,

UNIOA CARPIDF C.URPORATION-AUCLEAR DIVISION

CAK RIOGF NATIONAL LAATRATORY

FATIIIIY, RELEASE POINT

RC.G

RC.G

CURIES

8 OF

NUCLIDE

TOTAL.

CAK RIUGE GRAPHIIF RFACIDR

HCCI AAD GI CVF BOX FXHAUST DUCTS

AIRAORNF IIN-IO-ALPHA

N 3.890E-OA

100.000

AIII OING 4508 STACK

IIRAOPNF UN-IO-ALPHA

N $3.900 E-08$

10n.noo

is 
11.S. DFPARTI IFF FNFRGY

FFFLUFNT INFORMATION SYSTEM

FPA RELEASF POINT ANALYSIS RFPORT

-_-FOB_CALINDAB_YEAB_19R1_.

CAK RIUGF DPFRATIONS OFFICF

UVIUN CAPHIDE CORPOIRATIOH-PUICTEAR DIVISION

CAK-RI DGF-Y-I?-PLANT

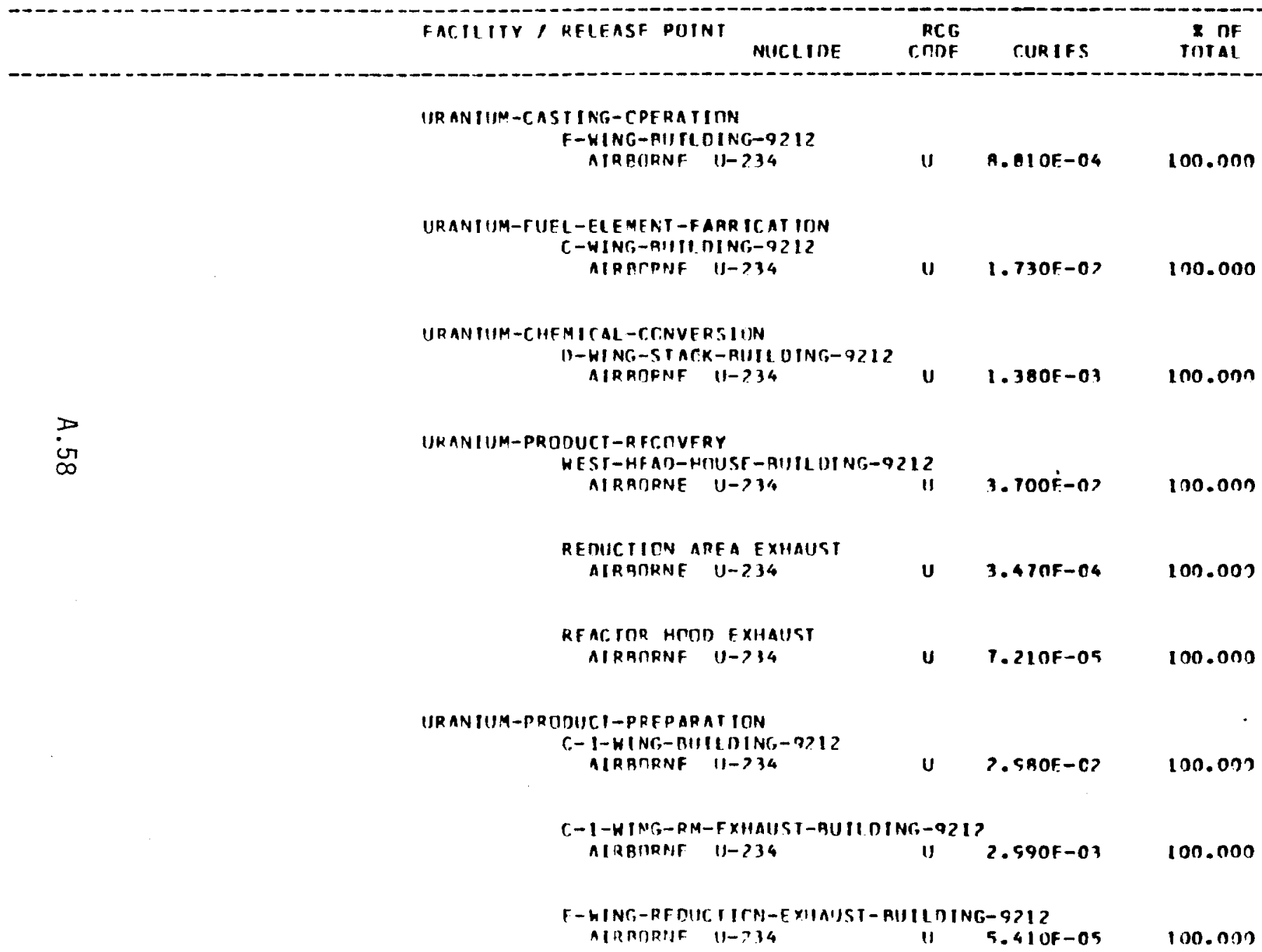


11. S. DT OARTMFNT TF ENFRGY

FFFLUFNT IPJTIRMATICN SYSTFM

TPA FFLFASE 'OMINT ANALYSIS REPORT

_._EOR_CALENDAB_YEAR_1991_...

UAK RTIISF OIIERATIIINS OFFICF

WUION CARAIDE COPPURATIDN-NUCLFAR DIVISICN

OAK-R IDTE - Y-12-PIANT

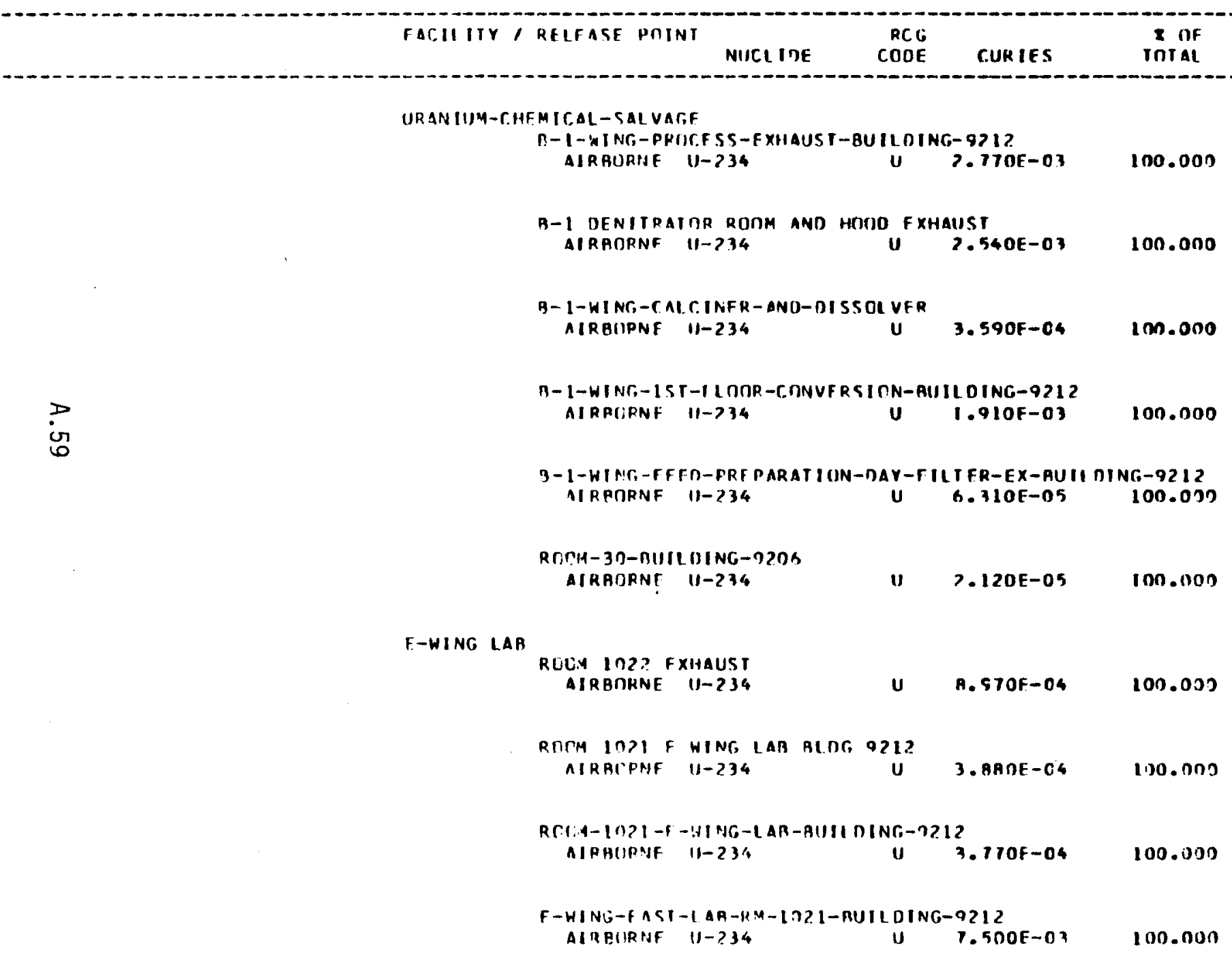


U.S. OERARTM OF ENERGY

FFFIUENT INFTRMATION SYSTFM

FPA RELEASF PEINT ANALYSIS RFPRRT

_._ECB_CALENDAR_YEAB_1281__.

OAK RIDTE OPFRATIONS DFFIC.E

UNIDN CARRIDE CORPORATIINN-NUCIFAR DIVISICN

OAK-RIIGG-Y-12-PLANT

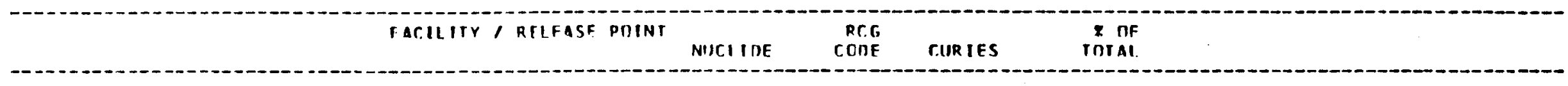

URANIUM-MACHIAING

F-HING-MACHINE-SHOP-FXHAUST-AUILDING-9212

AIRACRNF U-234

O-HING-MIIL-AND-RORM-EXHAUST

AIPBORNF $11-734$ U $9.120 E-04 \quad 100.003$

M-HING-MAC.HINF-SHUP-AUILDING,-0215

AIRATRNF $11-2344$ U

ITRANIIJM-T DUNDRY

FXHAUST DUC.TS ROOMS $\rightarrow 3$ AND $\rightarrow 7$

AIRAORNE 11-234 U $1.100 F-03$ 100.00?

UPANIUM-T, ARBCA RURNFR

CAPAOUN-AIIRNF R-RIIILDINC,-9706
AIRACKNF II- 34
(1) 3. $200 \mathrm{~F}-\mathrm{CS}$
100.010

ISRANIUM-TIFNITRATOD-AND-PROH-FXHAUST

DENI TRATRR-FXHAUST-DUI I DING-920K

AIRAMRNF II-234 U $1.290 F-03 \quad 100.00 ?$

URANIUM-INC INFRATHR-FXHAUST

INCINFRAINR-FXHAISST-AIJII DING-9.206
AIRAORNT U-PX4

E-WINC-PRTIIVERY

C-HING-AECHVFP Y-EXHAIJS T-RIIIL DING,-9212

AIRATPNF II-734 II $1.140 E-03$ 100.0N.) 
U.S. DFPAR TYFNT UF FNFRGY

FFTLUENT INFURMATICA SYSTFE

\section{FIA RFIFASF PIIIVT MIAL VSIS REPORT}

-__LB_CAL CYDAB_XEAB__19B]_-_

CAK RIDGF OPFHATIIINS DFFICE

UNION CARMIOE CODROIRATION-NIICLFAR DIVISION

CAK-RIOGF-Y-12-PLANI

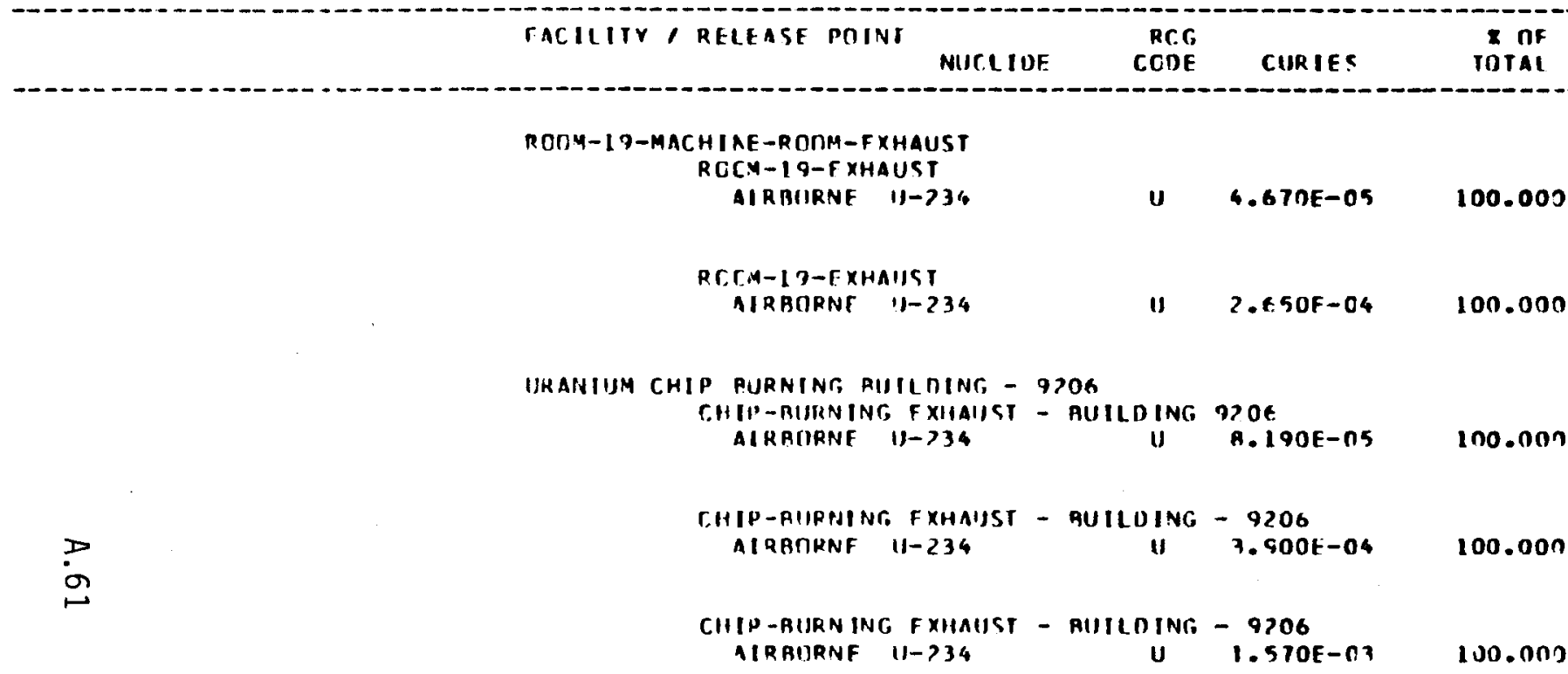




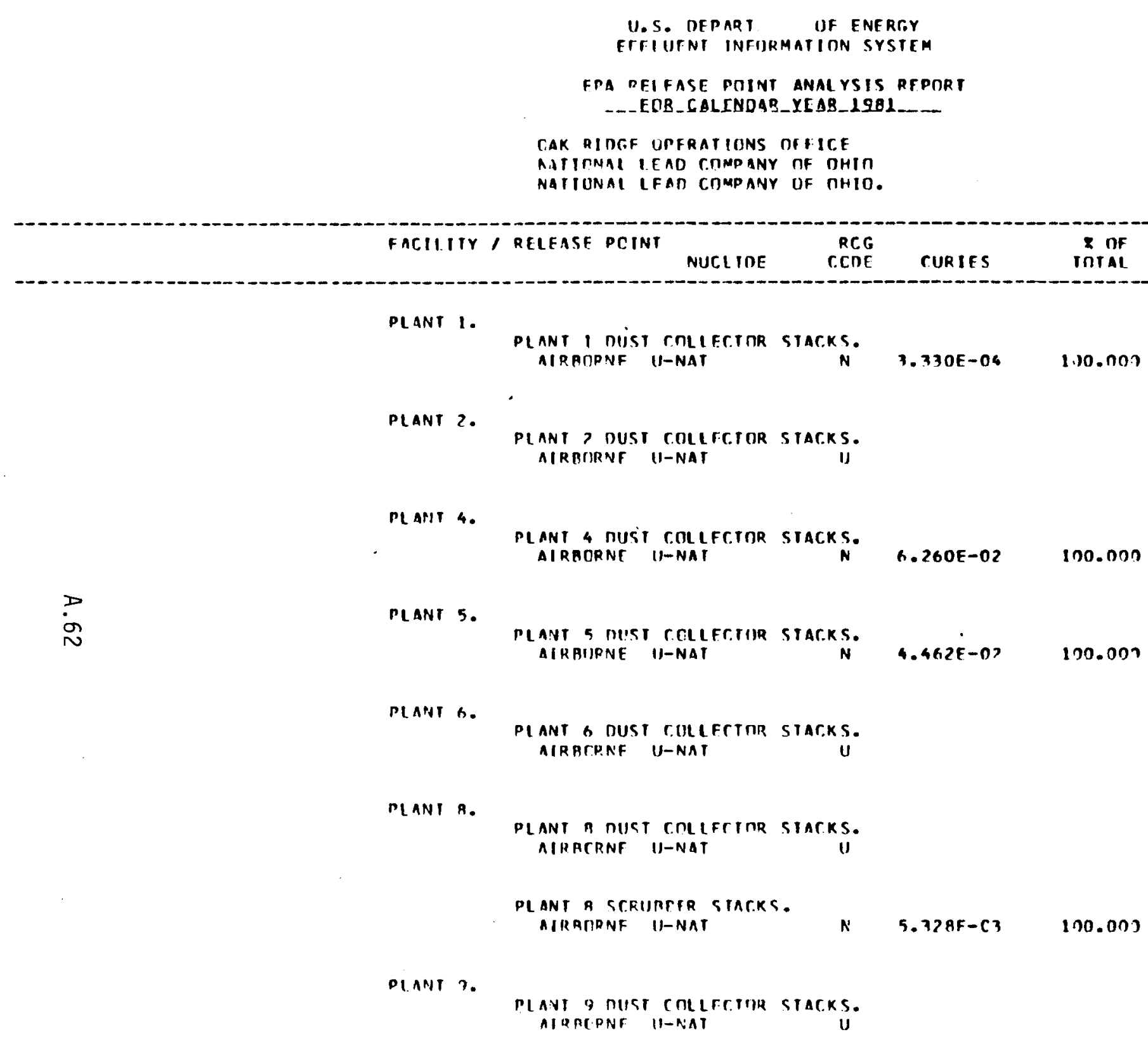


11. S. UFPARTMFNT OH FNERT.Y

FFFLUIFNI INFIOPMAIIUN SYSIEM

FPA REIEASF PIIITI ANALYSIS REPORT

_._EUB_CALINDAB_YEAB_1981___-

CAK PIDGF OPCPATISNS OFFICE

AATITNAL I TAD COMPANY OF OHID

NATICNAL LEAD COMPANY DF OHIT.

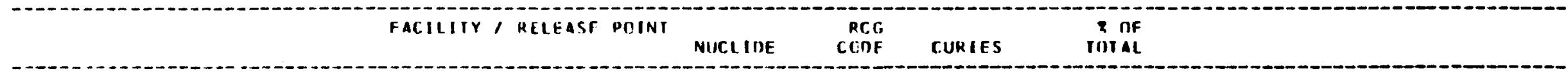

CIITI PLANT

PILBI PI ANI DUST COLLECTOR STACKS.

AIRBRRNF II-NAT II

DIL BURNFR TACILITY

GPAPIII IF RURNFR

AIRBTRNIF ULNAT

INCINERATOP. BUILUING,

INCINFRAITR SIACK

AI HOERNE U-NAT

INC.INFRAT
AI HAORNE

U-NAT

$4.146 E-04$

100.000

$D$

w 
U. S. DEPARTR.

OF FNERTiY

FFFIUENT INFORMATION SYSTEM

FPA PELEASE POINT ANALYSIS REPTRT

_._EOB_CALENDAB_YEAR_1981_...

CAK RIDGE IIPERATIONS OFFICF

GIODPFAR AIOMIC CORPIIRATION

GASFRUS NIFTUSION PLANT

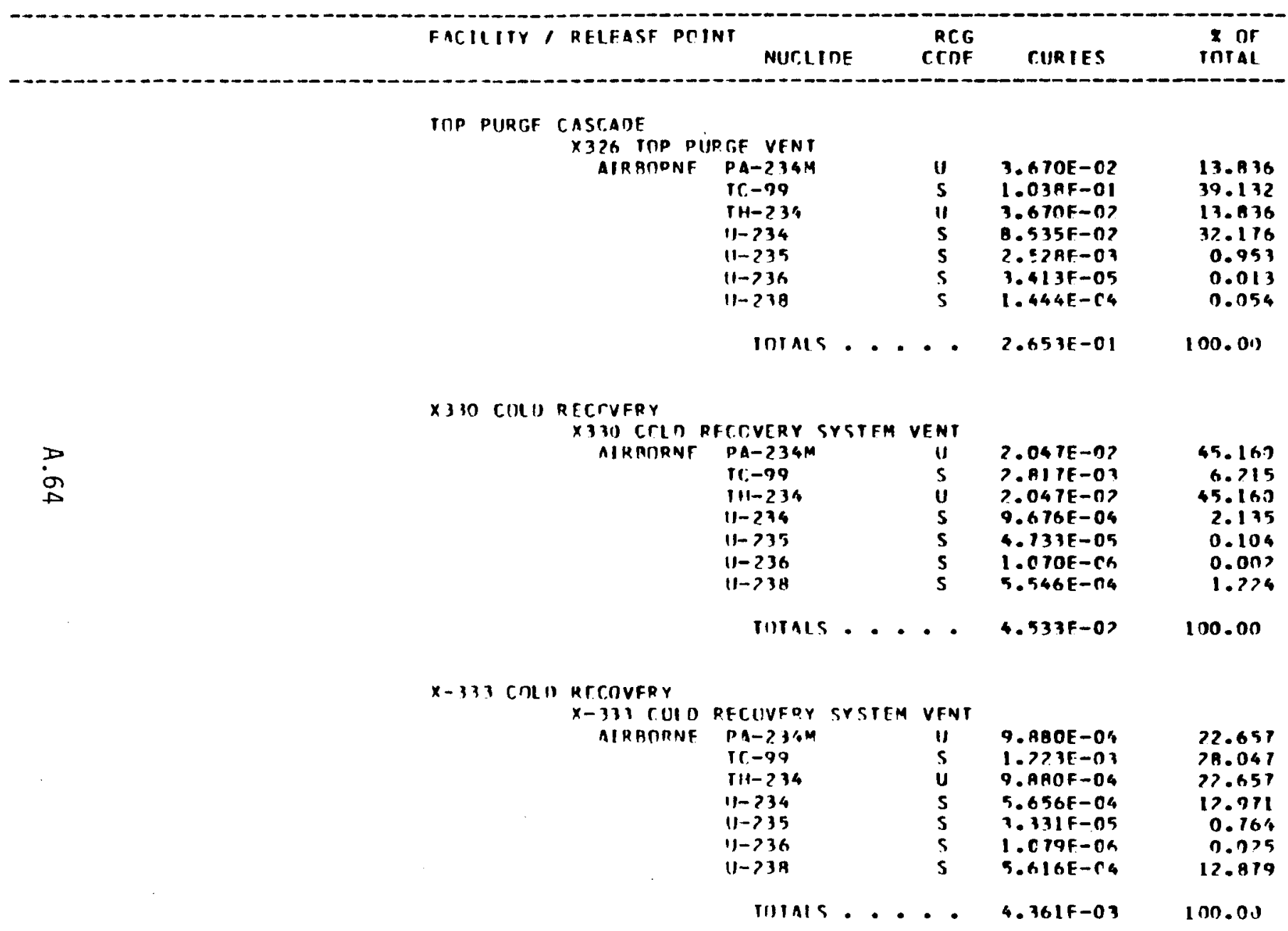


U. S. DFPARTIMENT DF FNFRGY

FFFLUTNI INFIIRMATION SYSIEM

FPA RELFASE POINT ANAL YSIS RFPORT

_._EOB_CAL ENDAB_YEAB_19.81 _...

CAK RIITGF UPERAIIONS TFFICF

GOUDYFAR ATIIMIC CORPURATIOA

GASERUS DIFFUSION PLANI

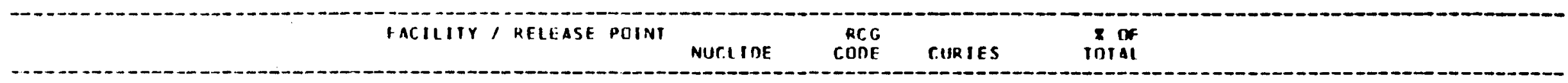

$X-144-6$, IXIOE SANPIIAC, IACIIIIY

$X-764-C$ CXIDE SAMPLING FACILIIY HOOD EXHAUST VENT

AIRRTRNF: PA-234M 11 1.010E-05 40.321

41.371

$11-234 \quad 5 \quad 4.582 \mathrm{E}-06 \quad 18.275$

$\begin{array}{llll}11-235 & 5 & 2.347 F-07 & 0.937 \\ 11-236 & 5 & 4.549 F-09 & 0.018\end{array}$

$\begin{array}{llll}11-236 & 5 & 4.549 F-109 & 0.018\end{array}$

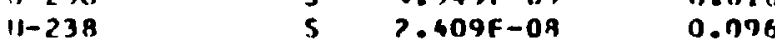

TIIALS... 2.5O5E-05 100.00

or 
U. S. DFPAR T: OF FNERGYY

PFFLUENT INFIORMATION SYSTFM

FPA RELFASF POINT ANAL YSIS REPORT

_EDR_GALINDIR_YEAB_1281...

CIK RIDGF TPFRATIIINS OFFICE

UIJION C.ARBIIDE T.MRPORAT ION-NIICLEAR DIVISINN

Pacucah risfous diffusion pLant

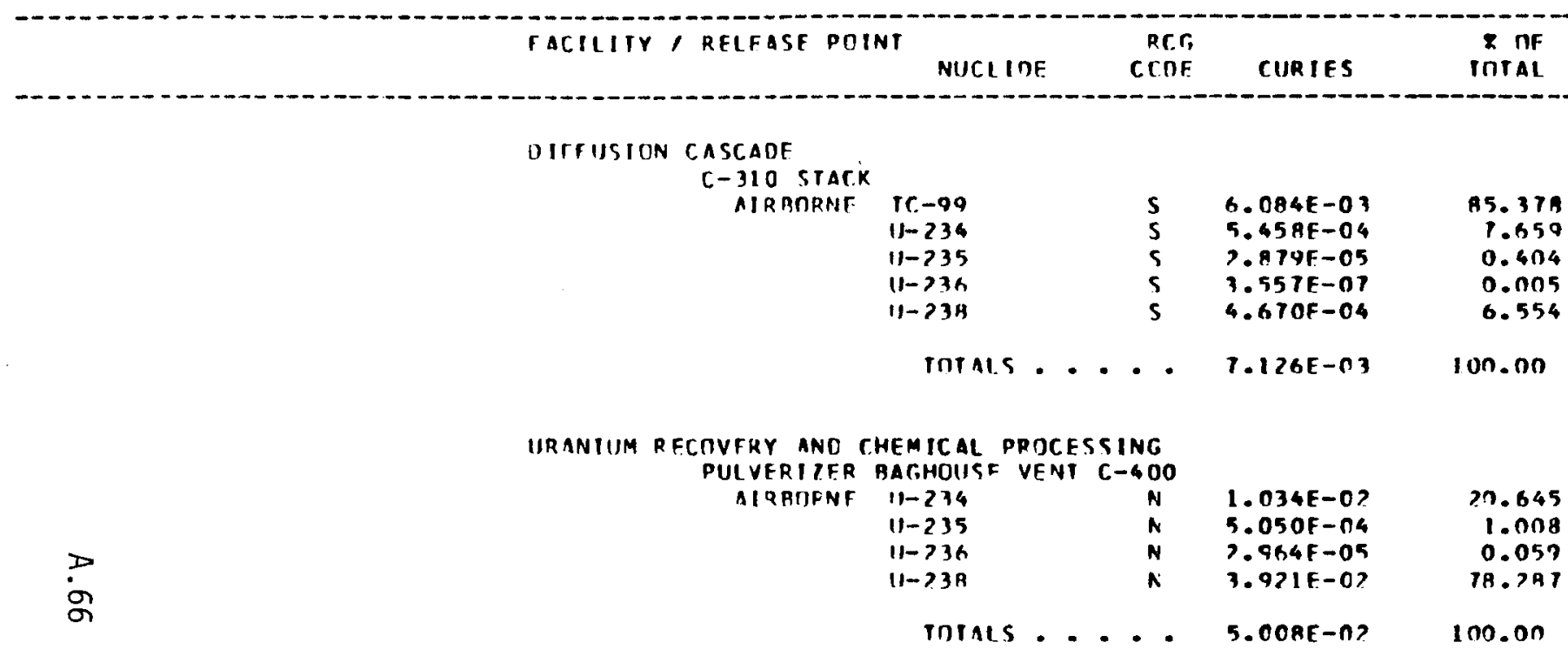


11. S. DEPAP.THFNT UF FAFRGY

FFFLUENT INFTRMAIION SYSIEM

FPA RFLFASE POINI ANAI YSIS RFPMRT

. - ECB_CAL ENDAB Y YEAB_19B1.

PITTSMUPGH NAVAL RFACTORS OPFRATION DFFICF

WESTINCHHUSE ELERTRIC COBRPGRATION

NAVAL PEACTORS FACIL ITYINATIONAL RFACITR TFSTING STATION

FACILITY, RELEASF POINT

NUCLIINE CODE

CURIES

$8 \mathrm{nF}$

InIAL

NAVAL. REACTORS FACILIIY NRF-601 TC ATMCSPHERE

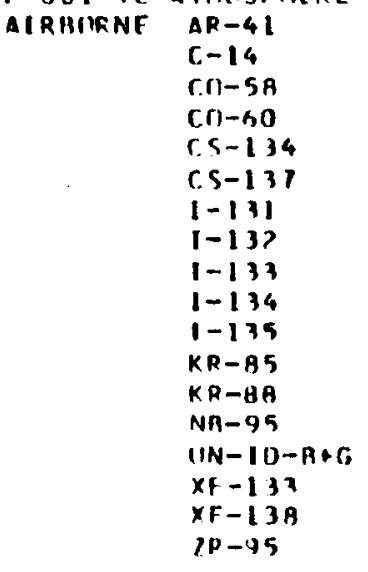

InIALs....

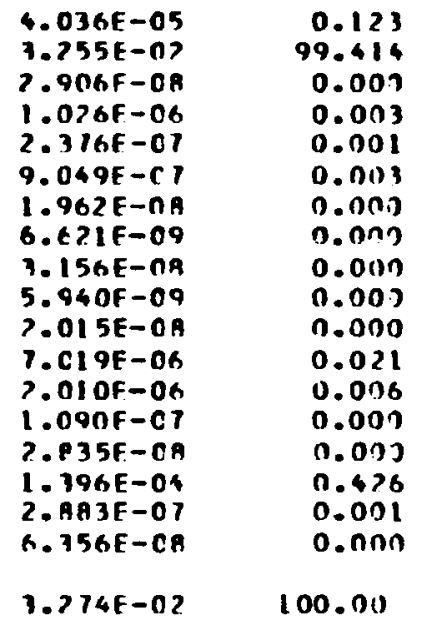

AIW REACTIOR PLANT - NPF-GIT

NFT-617 IT ATMTSPHFQF

AlRBORMF AC-1109

\begin{tabular}{|c|c|c|c|}
\hline $\begin{array}{l}A G-110 M \\
A A-140\end{array}$ & u & $\begin{array}{l}7.830 F-07 \\
1.079 F-O R\end{array}$ & $\begin{array}{l}2.526 \\
1.481\end{array}$ \\
\hline$c, 1-b u$ & u & i. $184 t-05$ & 34.144 \\
\hline$(5-137$ & u & $1.908 F-07$ & 0.615 \\
\hline$r F-59$ & u & $1.005 E-07$ & 0.374 \\
\hline $1 A-140$ & $\mathbf{u}$ & $1.745 \mathrm{~F}-06$ & 4.016 \\
\hline$M N-54$ & $\mathbf{u}$ & $5.522 \mathrm{~F}-06$ & 17.813 \\
\hline$M(:-79$ & u & $9.963 E-06$ & 32.139 \\
\hline$S N-117$ & II & $1.814 E-07$ & 0.585 \\
\hline$(1)+1()-A+C$ & U & $9.50 A E-0 B$ & 0.301 \\
\hline
\end{tabular}

$(1)-1(1)-h+C$

$9.5 O A E-0 B$

0.301

IUINL.... 3.100F-05 100.00 


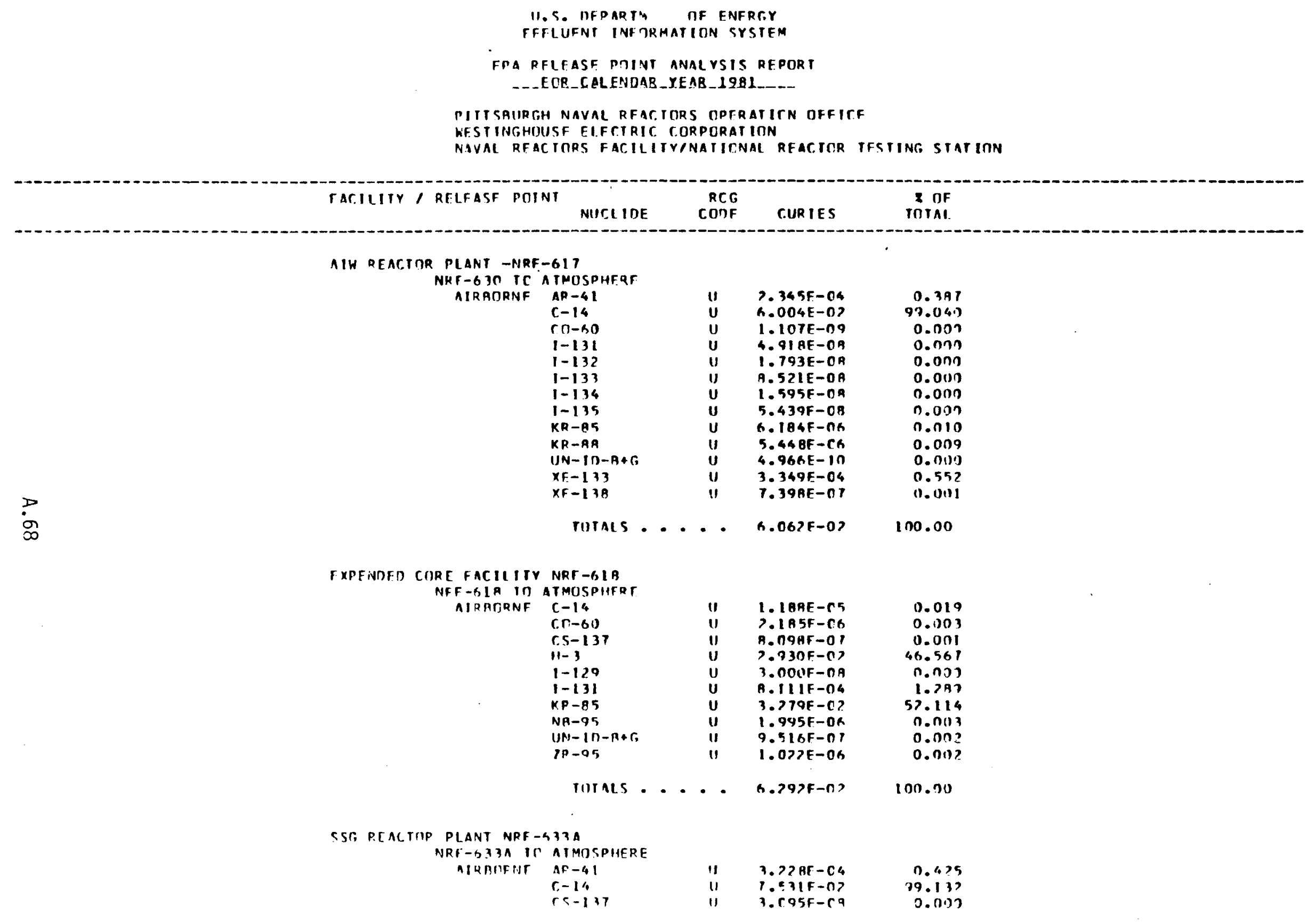


U.S. DEPARTMENT TF ENFRTYY

EFFLUENT INFORMATION SYSTFM

FPA RELFASE PUINT ANALYSIS RFPORT

_._EDB_CALENDAB_YEAB_1981...

PIIISHURGH NAVAL RFACTORS CPERATICN OFFICE

WESTINGHOUSE FLFC.TPIC CORRPIRATION

AAVAL REACICKS FACILIIYINATICNAL REACICR IFSIING, SIATIOM

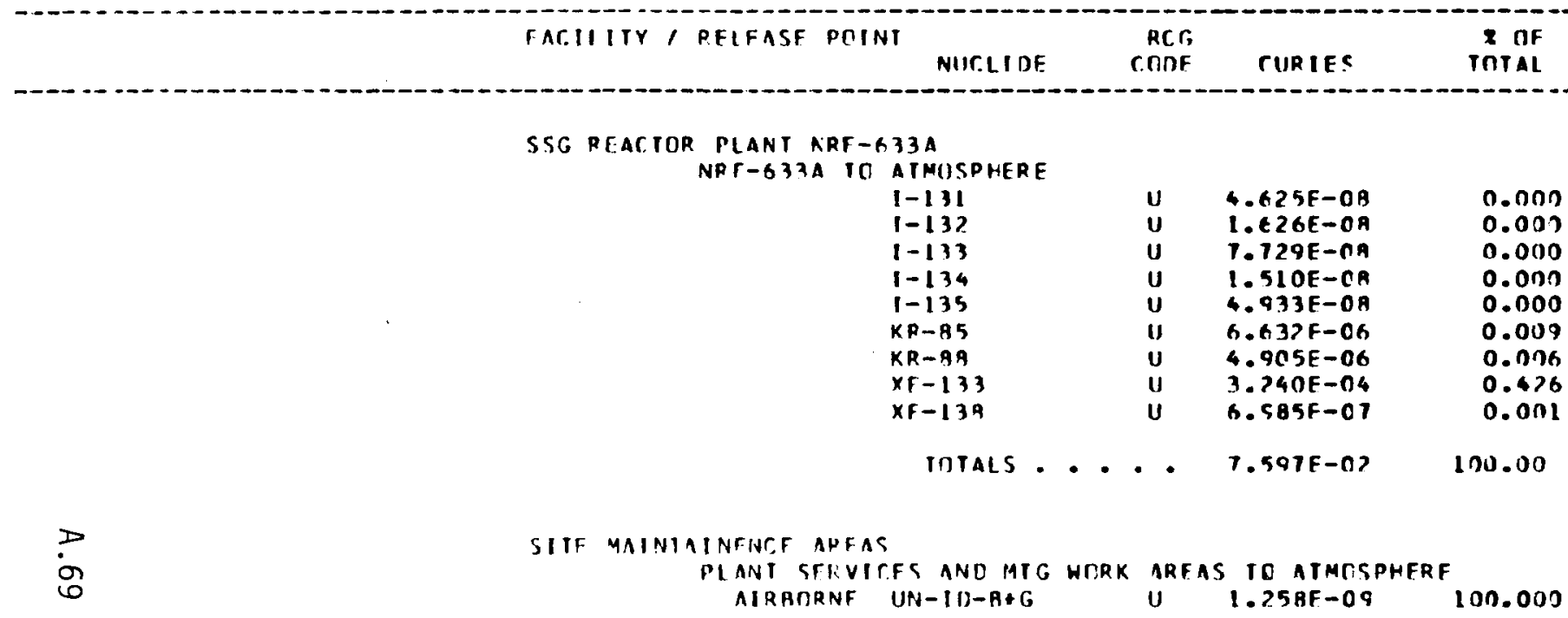


11.S. DEPAPIYENT OF ENFRCY

FFIIIFHT IHFUHAMTION SYSTFM

FPA PELFAST POINT ANAL YSIS PFPORT

_._EDB_CALENDAB_YEAB_1981_...

PIITSAIIRTIH NAVAL RFACTURS DPFRATITN GFFITF

HESTINGHIUSE ELFCIRIC CORPCRATION

HFTIIS AIOMIS. PINER LABORATIRY

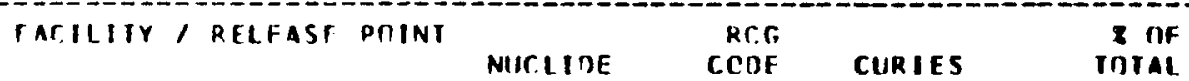

YAIN IABONAICRY AAD NORIHFAST AREA DF SIIE

ATMIDSPHTRF

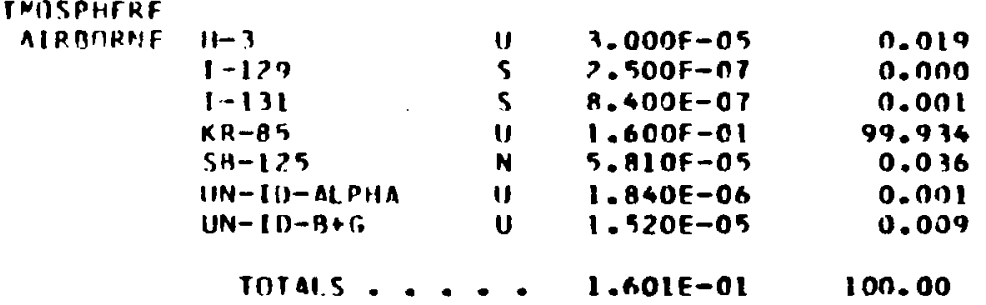

I 
U.5. DEPARTA, TF FNFRTYY

FFFIUFNT IYFRRMATION SYSTEM

FPA RFLFASF POINT ANAL YSIS REPORT

_._.EUB_CALENDAB_YEAB__1981___

RICHIAND OPERAIIONS UFFICE

ROCKHFIL HANFORD COMPANY

PUD EAST ARFA

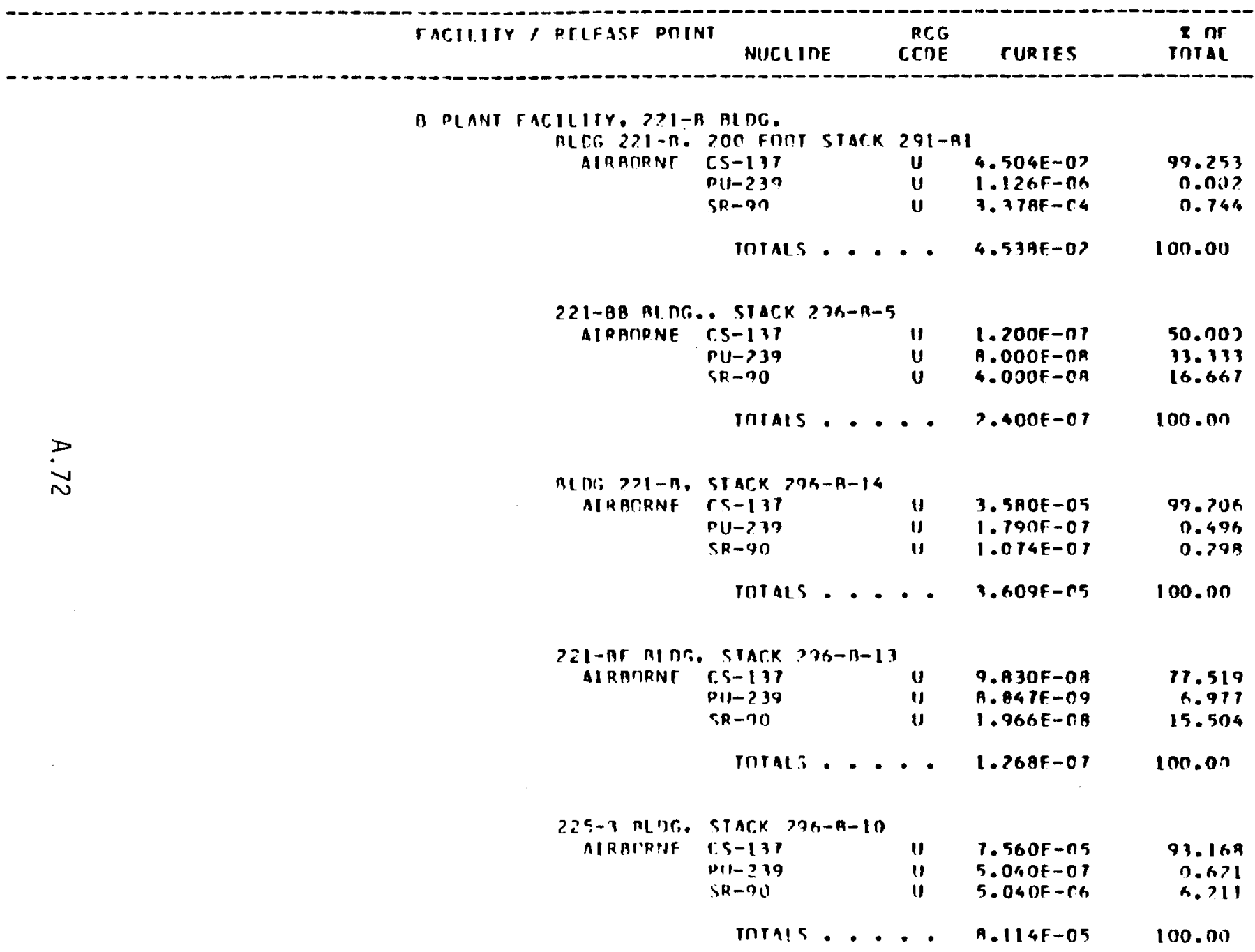


U. S. DEPARIMENT OF ENERGY

EFFLUFNT INFERMATIIN SYSTFM

\section{FPA RELEASF PIINT ANAI.YSIS REPTRT}

_._EDR_CALENUAR_YEAB__ $281 \ldots \ldots$

RICHLAND UPFRATIIUNS OFFICE

RICKHFLI HANFORD C.OMPANY

2.10 EAST ARFA

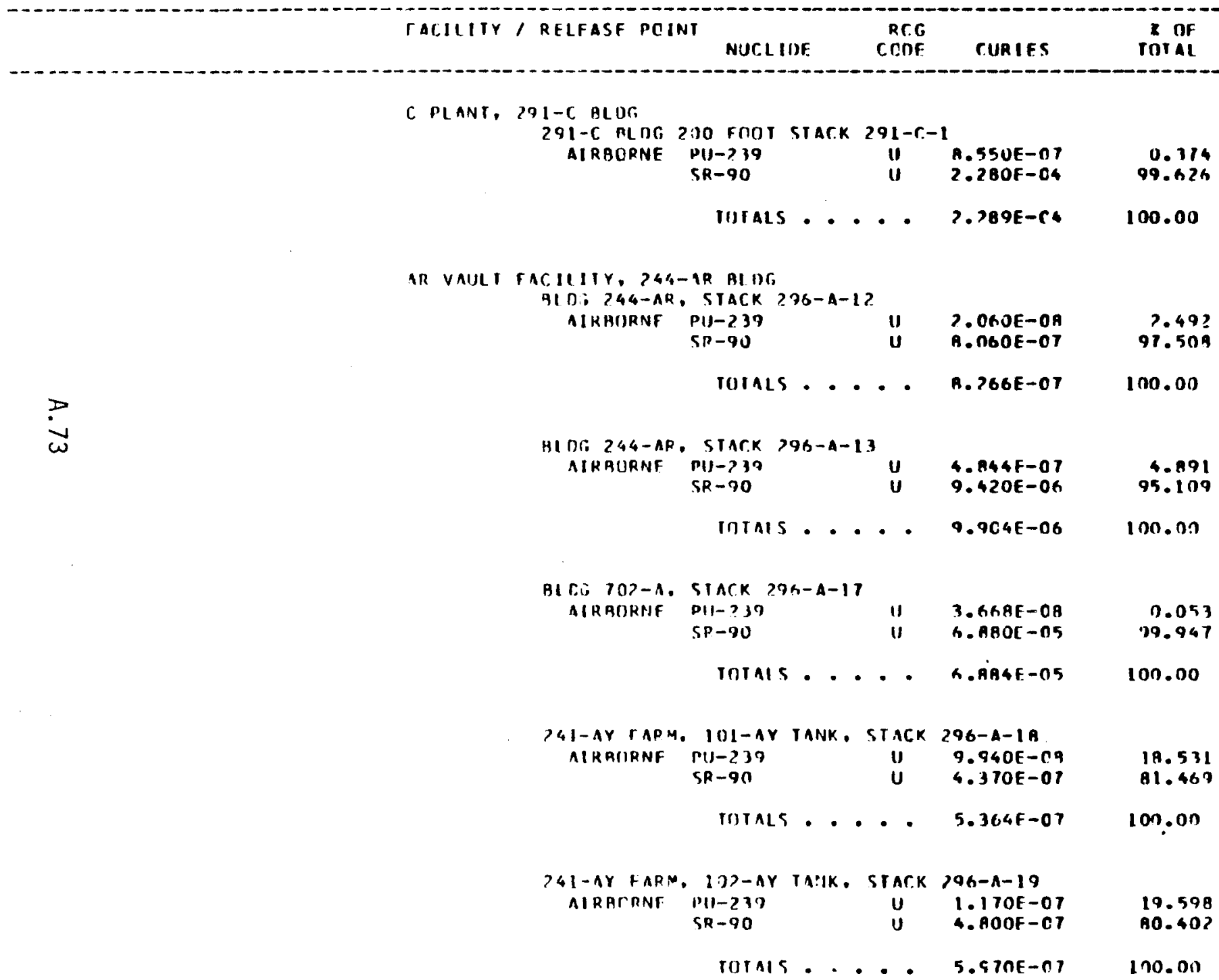

NIIT: AC, FNIRY IN COJIUMY ... II DATA TR HOT APPLICABLF 


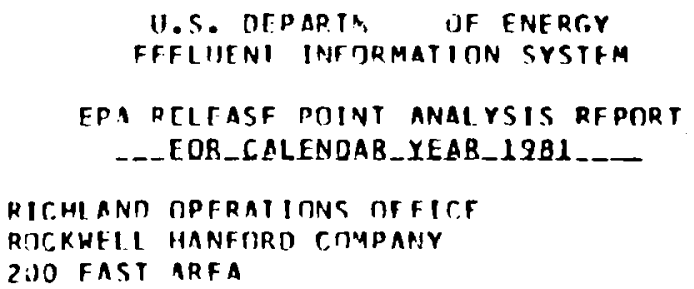

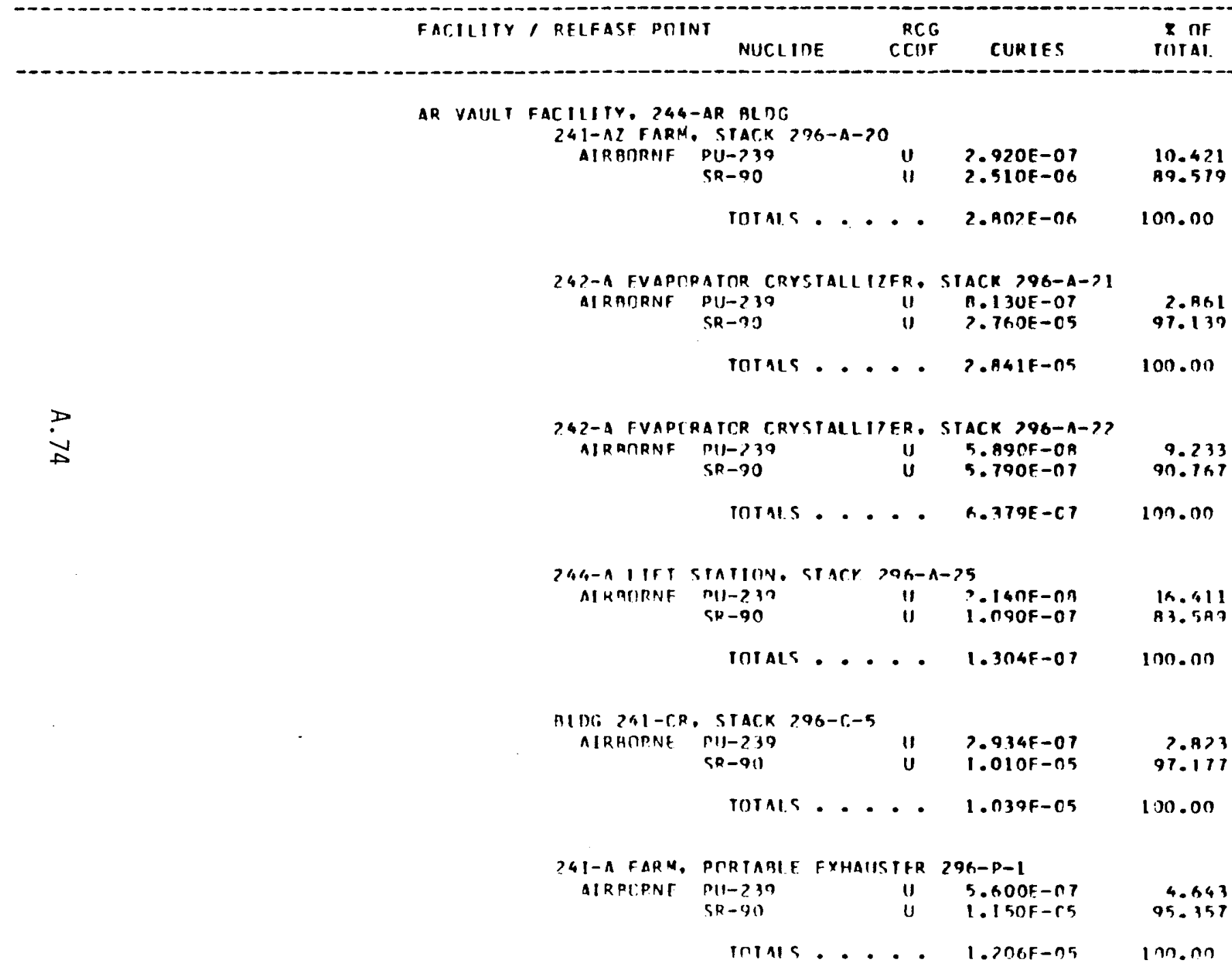


U. S. DEPAR TMFNT IIF FNFRGY

ETFLUFNT INFURMATION SYSTEM

FPA RFITASE PDIVT ANALYSIS RFPORT

-_EOR_CALENDAR_YEAB_1981.

RICHIAND DPFRATIIINS RFFICE

RUCKWFIL HANFORD CNIPANY

2.)O FASI AFFA

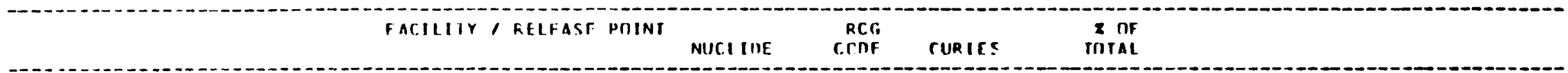

AR VAIII T FACILITY, >44-AR BLOF.

241-C TARK FARM. PORTABLF FXHAUSTFR 296-P-16

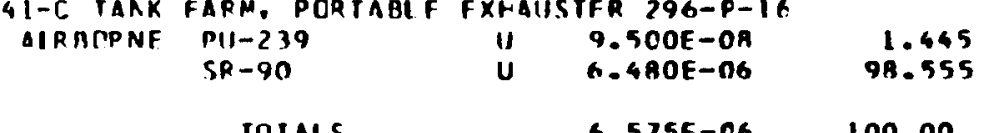

TOIALS.... h.575F-06 100.00

241-AW TANK FARM, SIACK 296-A-?T

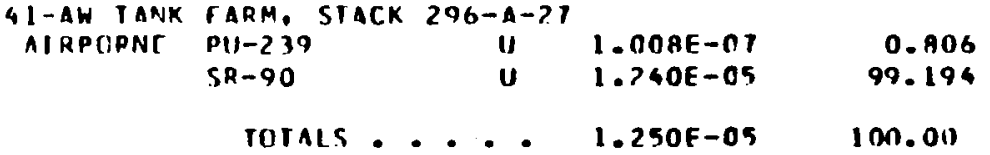

जे

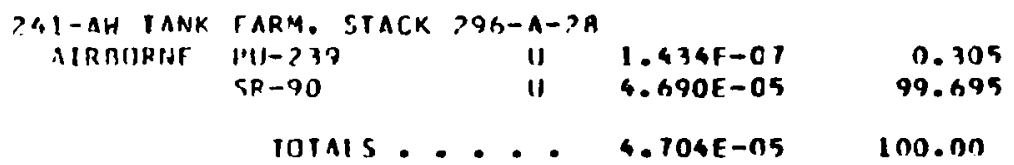

PUREX FACILITY, ,OD-A BUILOING

\begin{tabular}{|c|c|c|c|c|c|}
\hline $\begin{array}{l}\text { PLUI; } 202-A \text {. } \\
\text { AIRRORNFF }\end{array}$ & $\begin{array}{l}200 F O C I \\
1.5-131 \\
P U-239 \\
T R-93\end{array}$ & SIACK. & $\begin{array}{l}29 \\
u \\
u \\
u\end{array}$ & $\begin{array}{l}1-1 \\
7.980 F-05 \\
5.320 F-05 \\
3.990 F-05\end{array}$ & $\begin{array}{l}46.154 \\
30.169 \\
23.017\end{array}$ \\
\hline & II) rAIS & & & $1.729 E-04$ & 100.00 \\
\hline
\end{tabular}
QLDI ?OP-A, STACK 296-4-1
AIRAMRNF CII-239

$\begin{array}{llll}5 R-41 & 0 & 1.146 F-06 & 38.012 \\ & U & 2.940 E-06 & 61.979\end{array}$

InIALS.... 4.5AGF-OS 130.00

ALDG, ?27-1. SIACK ?')6-A-?

AIRIIPNT [S-1BT II I.IOBF-OT 24.138 
11.5. OFDARTM. JF ENFRGY

FTFLUFAT INFUKMAIICN SYSTFM

TPA RELEASF POINI ANAL YSIS REPTRT

_-_FOB_CALFNDAB_YEAR_1981___

RICHLAND IIPFRAIIINAS NFFICE

ROCKWEIL HAMIORD COMPANY

ZOD EAST APFA

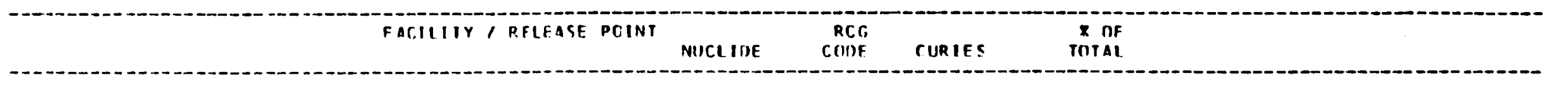

PURFX FAr.ILITY, 202-A PUILOING

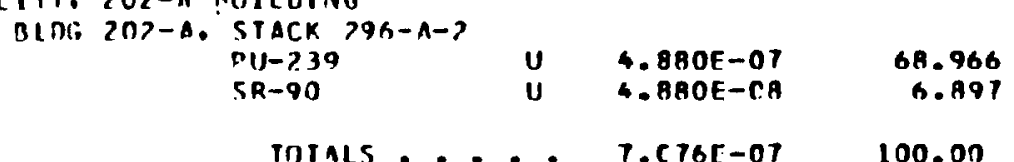

TIITLS... T.C76r-07 100.0

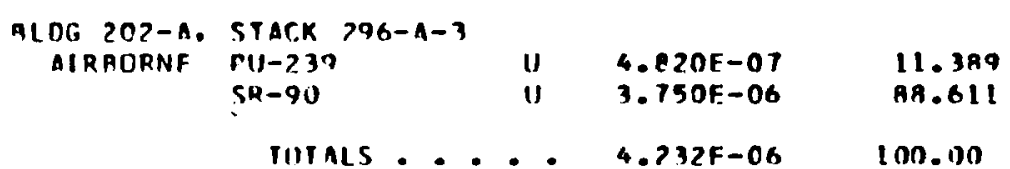

के
BLDG 2OP-A. STACK PQR-A-5A. HEST DUC.T

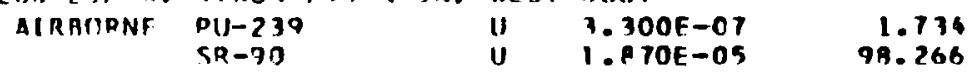
rotals.... 1.903F-05 100.00

ALDI, POZ-A, 296-A-5A, FAST RUC, T.

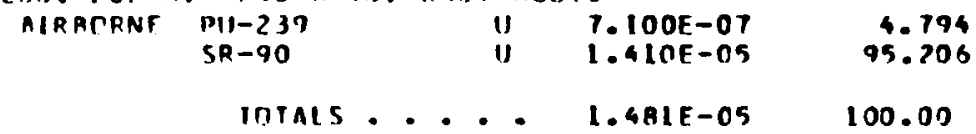

\begin{tabular}{|c|c|c|c|c|}
\hline AIRROPNF & $\begin{array}{l}P U-213 \\
S R-O 0\end{array}$ & $\begin{array}{l}11 \\
11\end{array}$ & $\begin{array}{l}7.140 E-08 \\
9.710 E-06\end{array}$ & $\begin{array}{r}0.791 \\
39.207\end{array}$ \\
\hline & TOIALS & • & $9.787 \mathrm{E}-06$ & ח. \\
\hline
\end{tabular}

BLDI, 2OZ-A. STAC,K POR-A-G

BLD: POZ-A, STACK POG-A-T

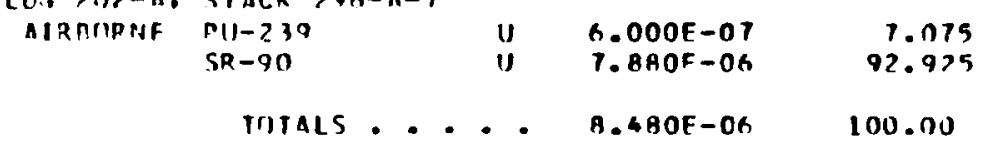


FPA RFIFASE PUINT ANALYSIS RFPORI

... EUB_CALENUAB_YEAB_19B1 ...

RICHI AND MPFRAIIINNS DFFIT.E

RIICKHELI HANFURD C,OMPANY

ZUO FASI AREA

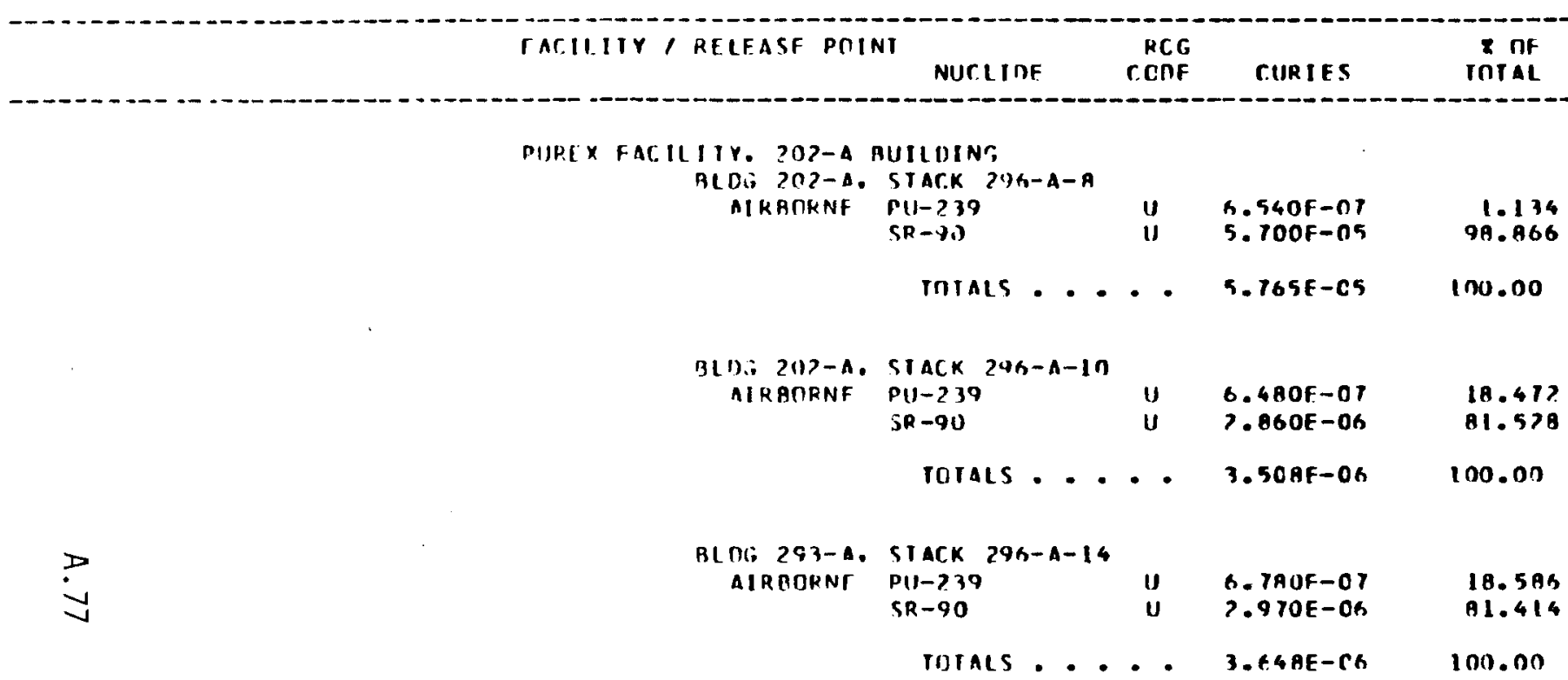




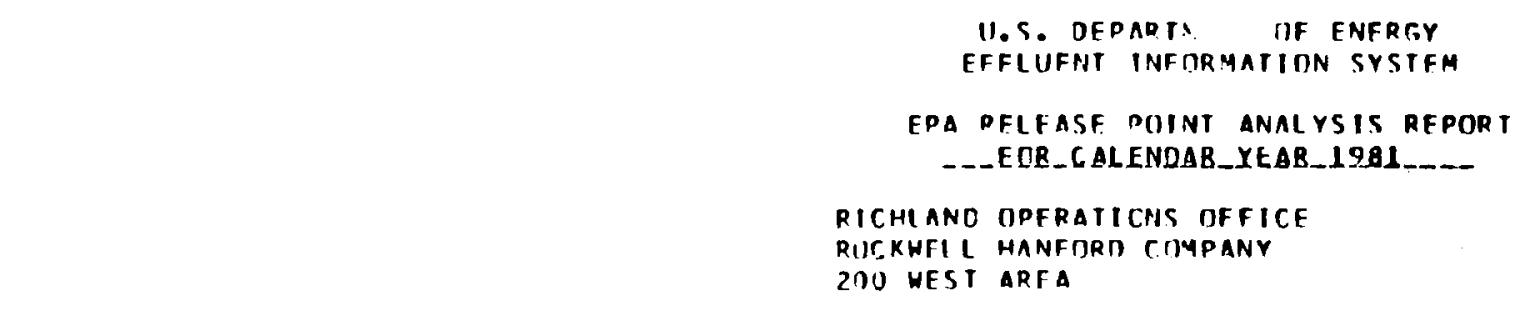

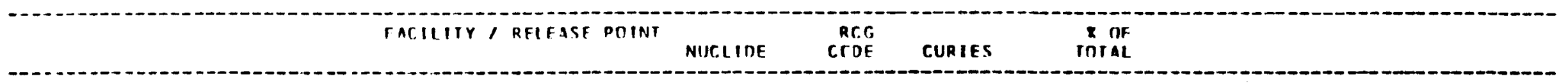

TANK FAPM FACILITY, 241-TX

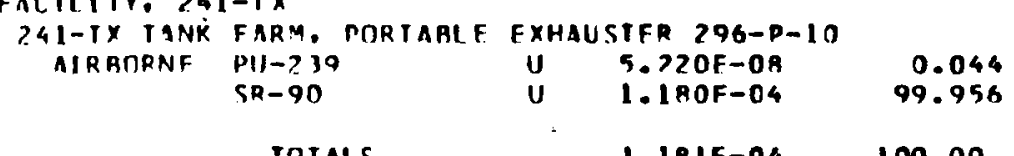

rotals.... 1.181E-04 100.00
241-S TANK FARM, PTRIABLE EXHAUSTFR 296-P-14
AIRRORNF PII-23?

$\begin{array}{llll}S n-90 & U & 1.110 F-0 T & 29.249 \\ & & \end{array}$
rotAls.... 1.547E-07 $100.0 n$

$\stackrel{D}{\infty}$

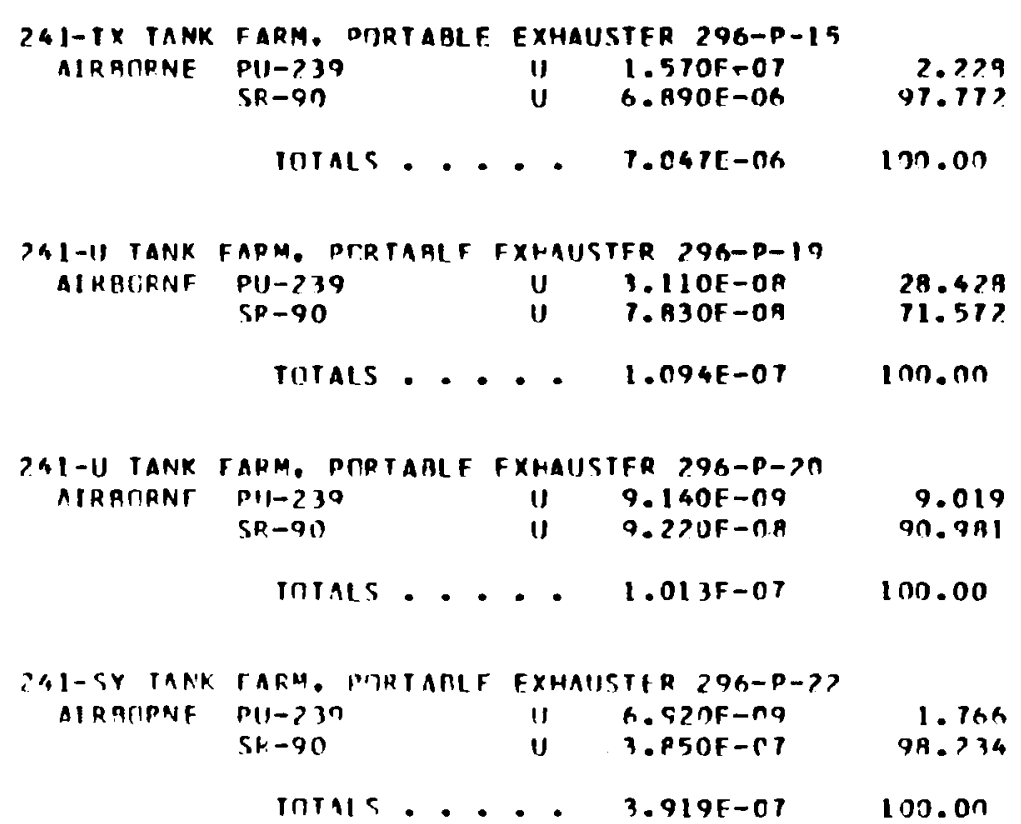


I. S. DEPARTIAENT DF FNFRTYY

FFFLUENT INFIFMATION SYSTFM

FPA RTLFASF PIINI ANALYSIS REPURT

-._EUB_CALENUAB_YEAR_1981_.

RICHI AND OPERATIONS NFFICE

RLCKWFUL HAAFDRD COAPANY

QU J HEST ARTA

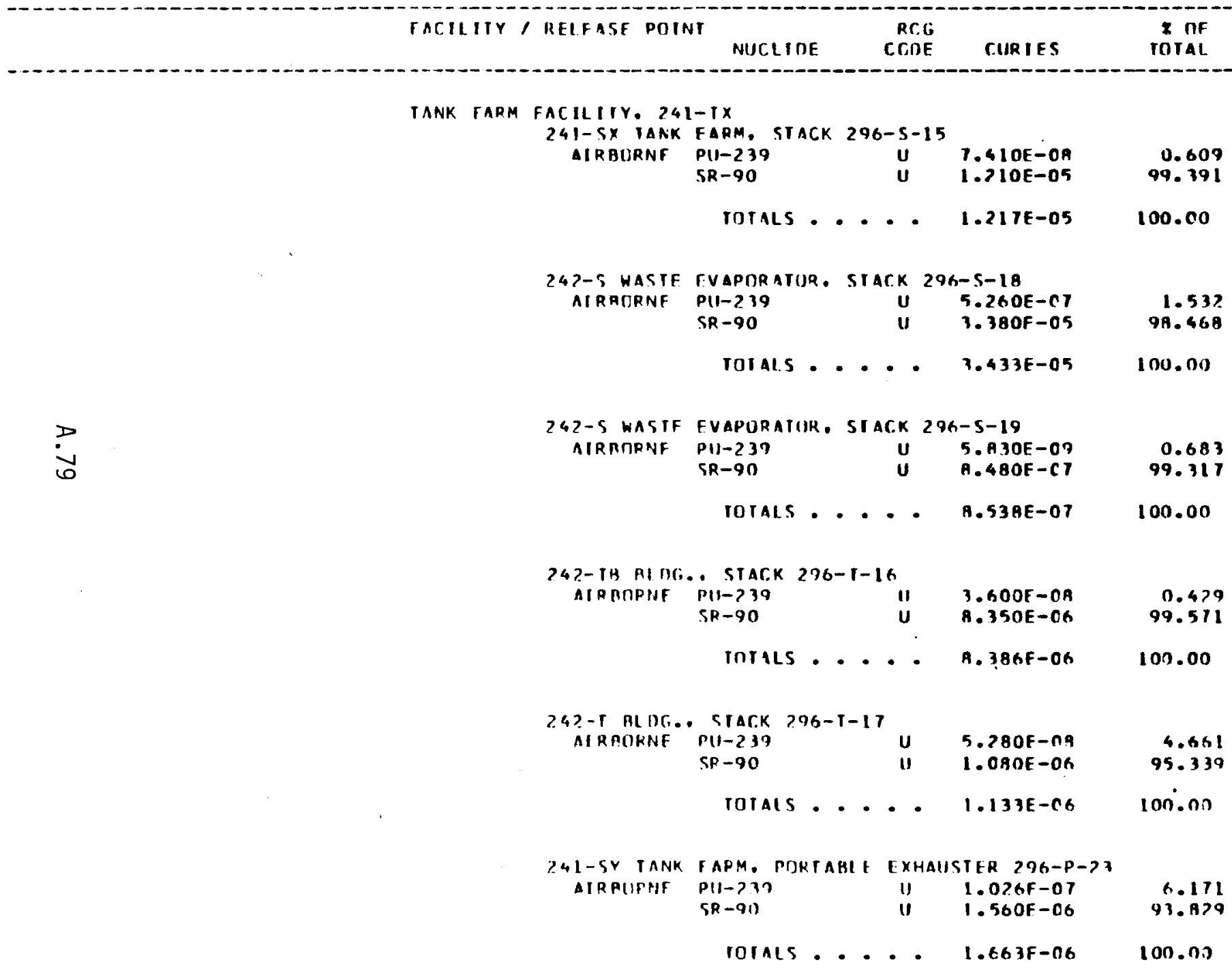


U.S. REPARTY TF ENFRC.Y

FFFLUFNT INFIRMATION SYSTEM

FPA RTIEASF PIIVT ANALYSIS REPORT

___ED__CALENDAB_YEAB_1981_.

RICHIAND TPERATITNS RFFICE

RUIKHFLL HANFORD COMPANY

?OO KFST AREA

FACILIIY, RELEASE POINT

NUCLIDE PC.

CODE

CUR IES

กF

TANK FARM FACILITY, 241-TX

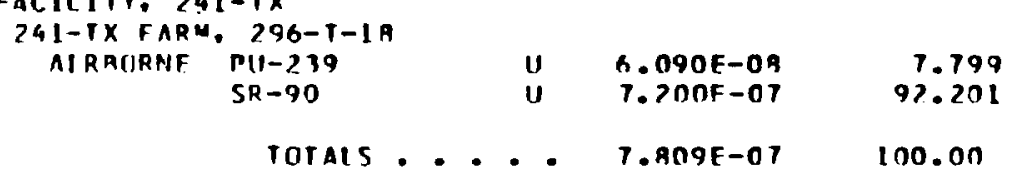

torats... T.8ngF-07 100.00

LARLRATURY FACILITY. TZ2-S AL DG.

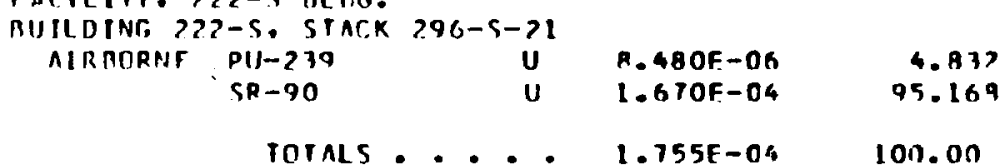

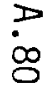

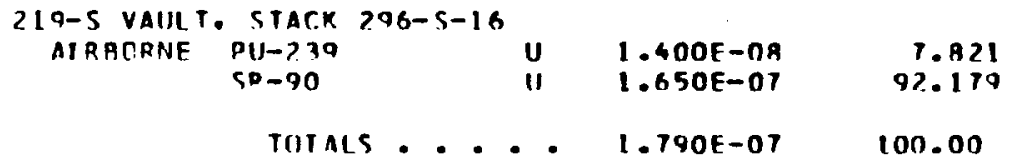

RFDOX FACILIIY. 207-S ALDG.

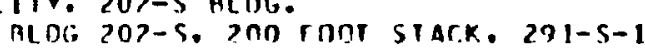

$\begin{array}{llll}\text { AIRAIRNE. } & \text { PUI-237 } \\ S P-90 & 11 & 1.249 F-06 & 4.791 \\ & 11 & 3.480 F-05 & 35.702\end{array}$

IIIIALS.... 2.605F-05 IOn.01)

BLOC: 202-S. STAC.K POG-S-2

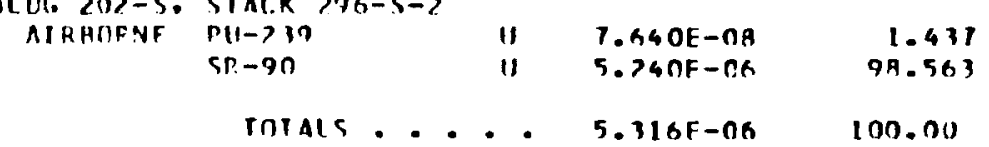

ALCL 207-5. STACK 736-5-4

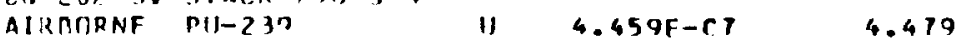


U.S. OTPARTMENT OF ENFRGY

FFFLUENT INFORMATION SYSTEM

EPA RFLFASE OOINT AHAL YSTS RFPORT

___EUB_CALENDAB_YEAB_1981_.

RICHLAND DPFPATIIINS OFFICE

ROCKHELL HANFORO CCMPANY

2,US HEST APFA

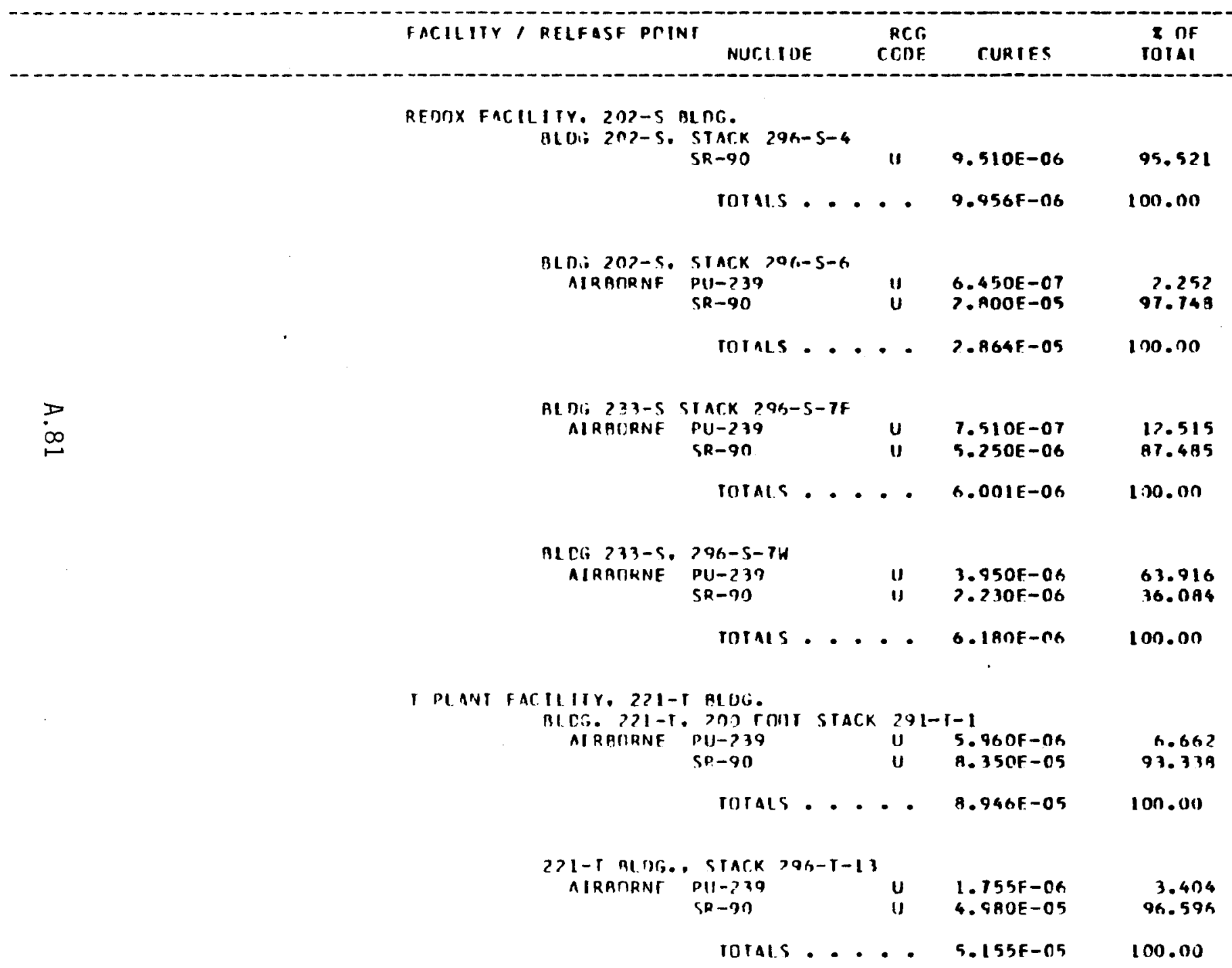


11. S. DEPARTM, JF FNFPGY

FFFLUFNT INFIRMAIION SYSTEM

FPA PFLFASE PIINT ANALYSIS RFPORT

_._EOE_CALENDAB_YEAB_1981...

RICHLAND TPFRATIONS RFFICF

RICKHFLL HANFIJR C CMUPANY

?UO WFST ARFA

FACILIIY, RELFASE PCINT

NUCIIDE RC.G

CCNE

TURIES

IIITAL

4 PLANT FAC,ILITY, ??I-U BLDG.

521-U RUDG. STACK $391-11-1$

AIRANRNF CS-137

$C . S-137$
$P(1-239$
$S R-90$

$\mathbf{u}$
$\mathbf{u}$

$4.640 E-04$

$4.040 E-07$

B3.264

9. AOE-OS

0.083

rotals....

$5.573 E-04$

$100 \cdot 0 n$

a auHnRr fac ILITr. 2.724-W RL DG.

2724-W AIILDING. SIACK $296-W-1$

24-

$\prod_{\infty}^{\infty}$

$\begin{array}{lllr}P U-239 & U & 4.680 F-0 K & 4.762 \\ S R-90 & U & 9.360 F-05 & 95.238 \\ \text { TOTALS. . . . } & 9.92 A E-05 & 100.00\end{array}$

2 PLANT FACILIIY, 7-12 CRIB

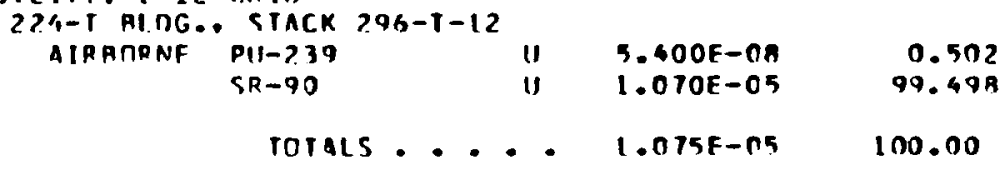

234-5-7 RLNT,.. POA FONT STACK 291-7-1

AIP.BTPMF C.S-13T U T.C4OE-ก3 A0.97?

$\begin{array}{llll}P U-239 & U & 7.464 F-O 4 & 7.974 \\ \text { PR-OO } & 11 & 1.40 \mathrm{PE}-03 & 16.194\end{array}$

TOTALS.... R.R94F-n3 100.00

$341-2$ MI Mr... STACK $796-1-3$

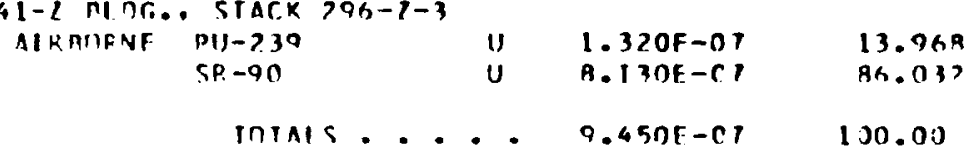


11. S. OEPAR TMENT OF FNFRTYY

EFFIUENI INFURMAIIUN SYSTFM

\section{FPA RTLTASE POINI ANAL YSIS REPOR}

_. EUE_CALEYOAE_YEAB_I2BI.

RICHIAND TPFRAIITNS OFTICE

PC., KHFIL HAP.F DED COMPANY

2.): WRST APFA

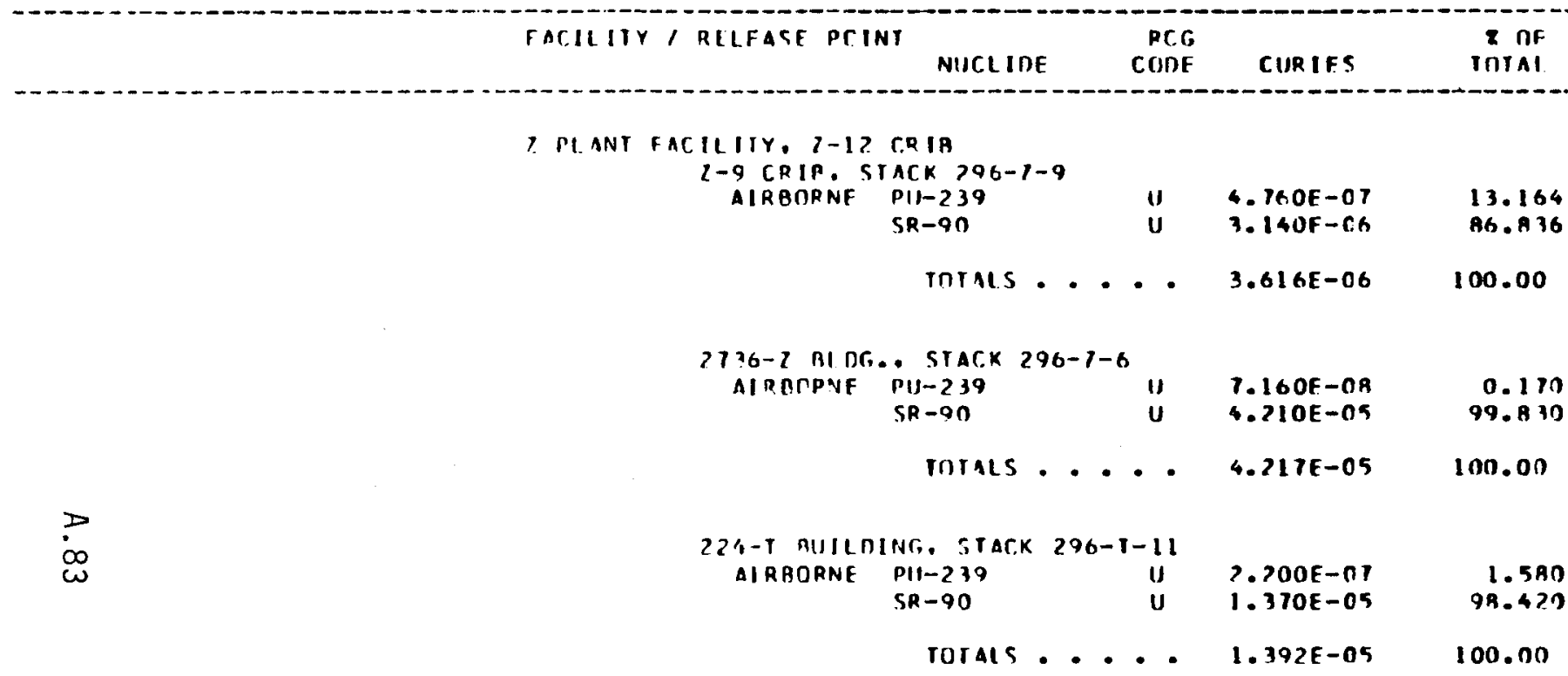


U. 5. DEPARTI. NF FNTRGY

EFFLUFNT INTURMATION SYSIEM

HPA RELEASE POINT ANALYSIS REPURT

___EOB_CALENDAB_YEAB_1981_.

RICIILANO UPERATIONS UFFICE

BATIFLLF MEMURI AL INSTITUTE

CHEMICAL PROCESSING PIANT, 200 EAST AREA

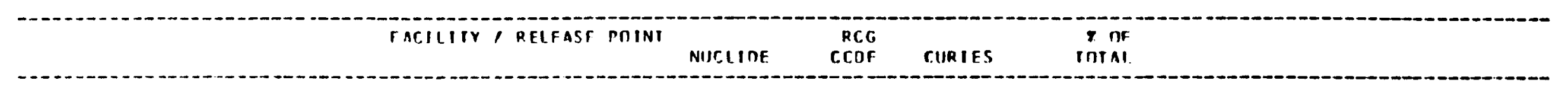

CRITICAL MASS LARORATORY, ZN9-F AIIILOING

MLOG. 209-F STAC.K EXHAUST

MIRDTRNF PII-?3?

$\underset{\infty}{\infty}$ 
U.S. DFPART'AFNT UF ENFRTYY

FFFIUFAI INFIIRMATILN SYSTFM

FPA PFLFASF MOINT ANALYSIS RFPCRT

_._EOR_C CLENDAB_YEAB_1981_.

RICHLAND OPIRATICNS OFFICE

RATIFILE MEMORIAL INSTIIUTE

100-K ARFA

FACILITY I RELEASF PCINT RC.G

NUT.LI IDE

COOE

CURIES

a 111

IIITAL

LABURATORY FACILITY 1706 KFL

ITSG KFI STACK

AIRBNRNF $\begin{array}{r}\text { PII-? } \\ S P-90\end{array}$

U) $5.400 F-n$ t

5.000F-ne

9.147

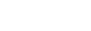

IOIALS... 5.54OF-OB

.253

100.00

市 


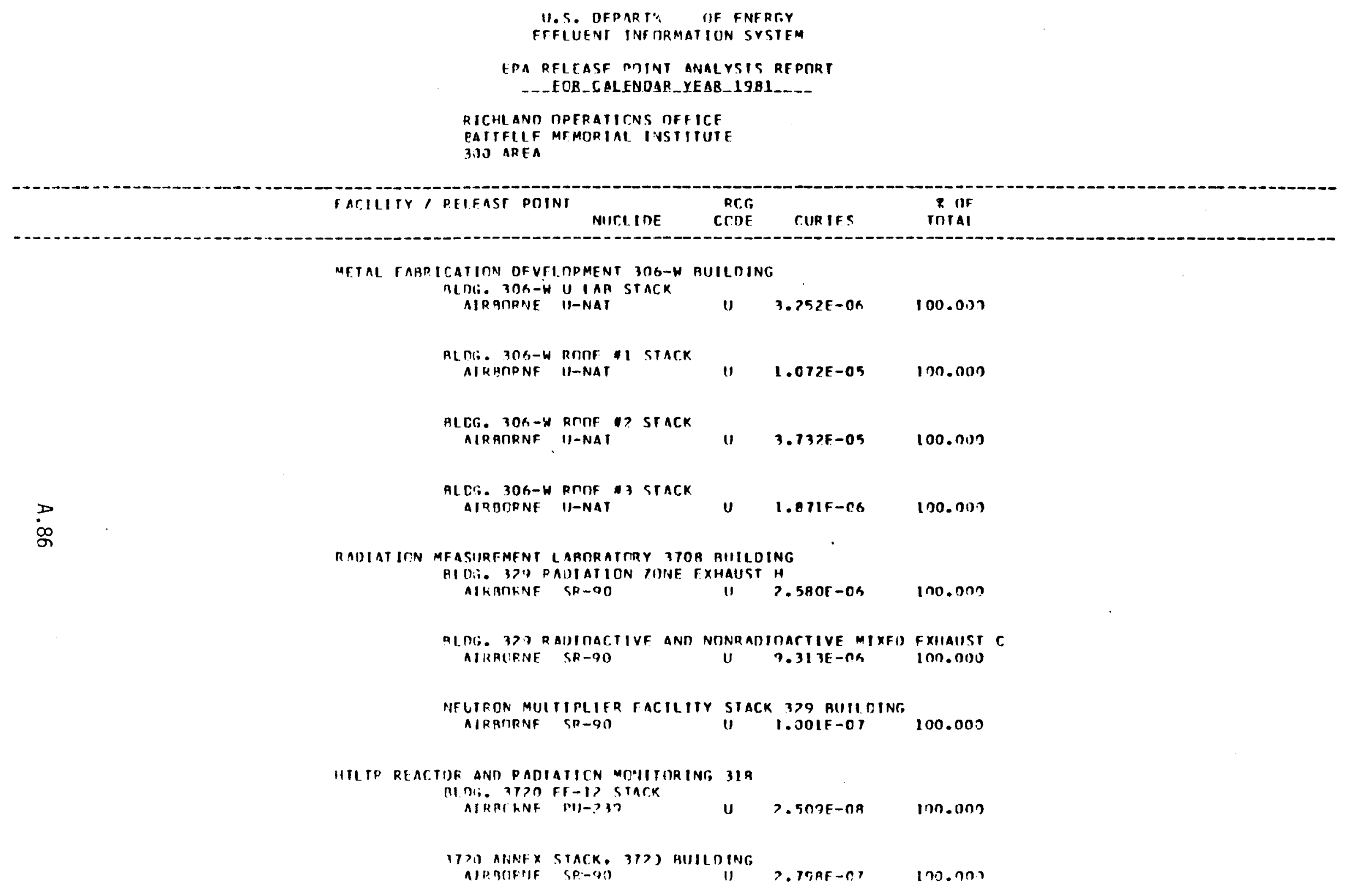


11. S. DFPARTMFNT UF ENFRGY

FFFI UFNT IINFIDRATION SYSTEM

FPA RELIASF DOINT ANALYSIS REPTRT

_._EUR_CALENUAL_YEAB_1281...

PICHLAND DPERATIONS OFFITE

PAIIFILF MFMORIAL INSIITIIIE

310 ARFA

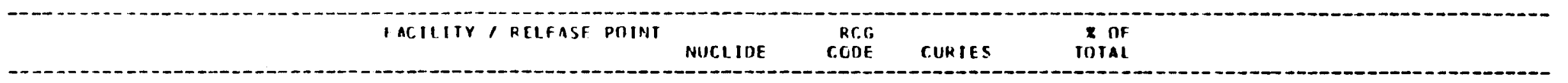

HILIR RTACIITR AND RACIATILIN MONITOR ING 318

MAIN SIAC.K 3770 RUIIIIIING

AIRATRNE SR-90

u $\quad 1.865 \mathrm{E}-06$

100.000

LITE SCIENCFS HIJILOING 331

BLCG. 331 S SIACK EXHAUST

AIRAORNF SH-Q0

I) $2.55 .3 E-06 \quad 100.000$

BI OF. 3XI SIACK D FXHAIIST

AIKAORNE PU-239

11 1.485F-0n ino.010)

BLDG. 331 A STACK

AIRBORHE C-14

$114.474 F-07 \quad 100.000$

LIOUIN HASTE TRANSTER STACK

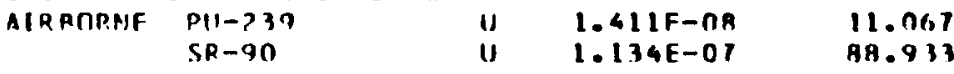

rUIALS.... $1.275 E-07 \quad 100.00$

INHALATION ARNTX STICK

AIRPGRNF PU-?39 U 3.191F-OB ION.UDO

FISSILE MATLRIAL SICRAIF BIIILING 303-C

BIDG. 103-C STACK

AIKIIIENF PU-Z30

1. 996F-09

$100.00 n$

ANALYSIS AMID NIBCLFAR RFSFARTH 3OT BUILOIHS

BLOG:. TOO MAIN SIACK

AIITRIRRF SR-GO

$u$

$6.903 E-06$

100.000 
U.S. DEPARTA DF ENERTYY

FFFLIIFNT INFORMATIUN SYSTFM

FPA RELFASF POIVT ANALYSIS REPORT

_._FDB_CAL CNDIB_YEAB_1981_...

PICHLAND cIPFRATITNS DFFIC.F.

PATTFLLE MFMUP.IAL INSTITUTF

3.JO AREA

FACILITY, RELFASF POINI

NUCLIDE

RCC

$\operatorname{cont}$

C.URIES

x nf

TnIAl

RAMIATION MFASUREMENT I ARURATIRY 3708 BIILDING

BLDG. 3TOA FXHAUST

AIRPIJRN PU-239

4. $467 E-O A$

100.000 
1).S. DEPARTMFNT UIF ENFRGYY

EFFUIIFT IHFORMATION SYSTEM

FPA RFIFASF MIINT ANALYSIS REPIORT

_._EUR_CALENDJB_YEAB_12R1_.

RICHLAND DPFRATIONS DFFIC.F

DITTEIIF MTMORIAL INSTITUIE

CHEMICAL PROCESSING plani. pOn hest area

FACILITY, RELEASE PDINT

NIJC, IIIE

RC.G

rURIES

2 DF

IOIAL

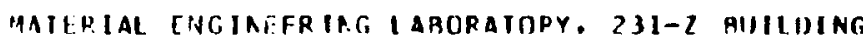

BI UG. TZI-I F-4 FXHAIIST SYSIFM

AIRAURNF DII-239

$\operatorname{lnn.00n}$ 
11.S. OFPARTY. III FNFR.GY

FFFIUENT INFORMATIUN SYSTEM

FPA RFLFASF ROINT ANALYSIS RFPORT

_._EUB_CALENDAB_YEAB_1981_.._

PICHI AND TPFRATICNS TFFICF

UNITFD NUCLEAR INDUSTRIFS

100-K ARFA

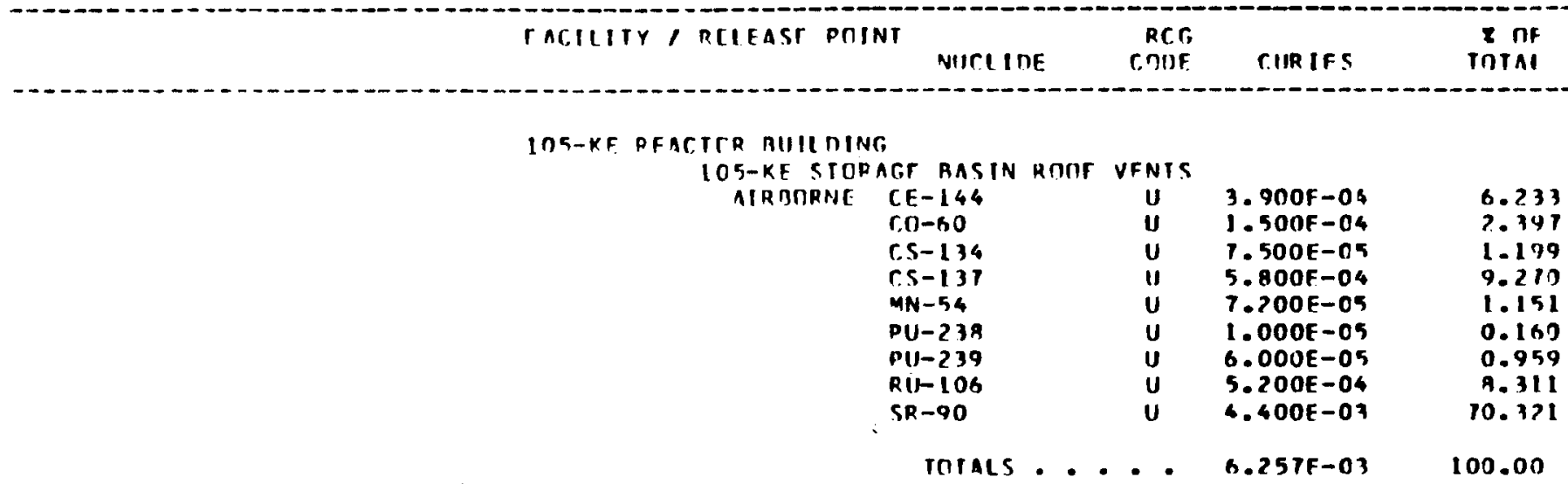

io 
11.S. DEPART'AFNI IIF FNFRTY

FFFLUFNT INFIJRMATION SYSIEM

EPA PELFAST PIINI ANALYSIS RFPI?RT

_._EOE_CAL_EDAE_YEAB_1981_._-

RICHLANT RPFAATIONS OFFICE

UNIITD NUCLEAR INOUSTRIES

A REACTOR PLANI

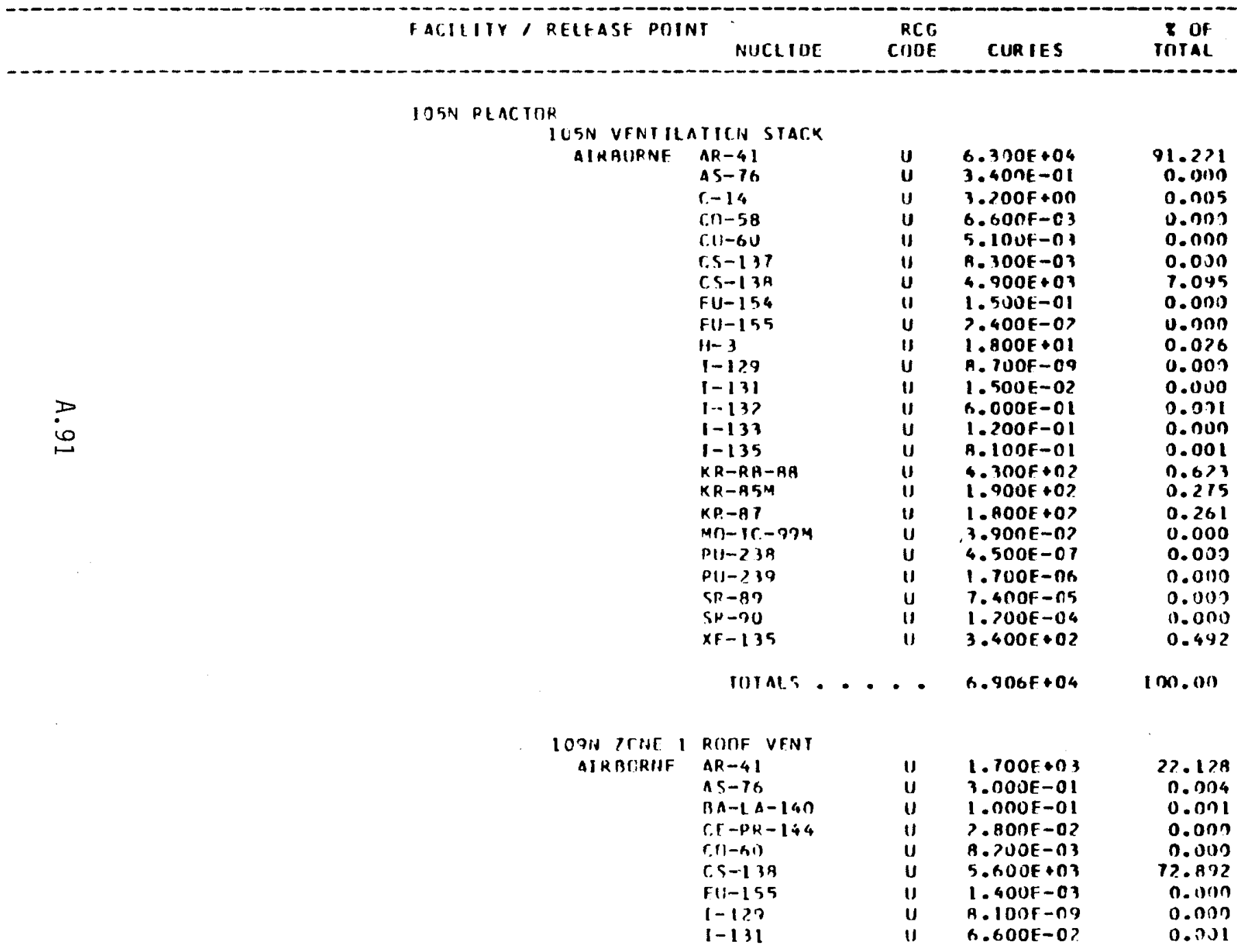


U.S. DEPARIT DF ENERTYY

FFFLUENT INFURMATION SYSTEM

FPA PELEASF PUINT ANAIYSIS REPORT

_._EOR_CALENDAB_YEAB_1981_.

RICHLAND DPERATICNS OFFICE

UNITED NUSLEAP INDUSTRIFS

UNITEOTOR PI ANT

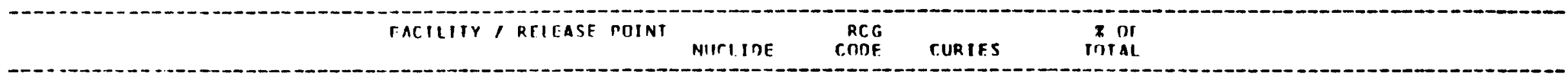

$105 N$ REACINR

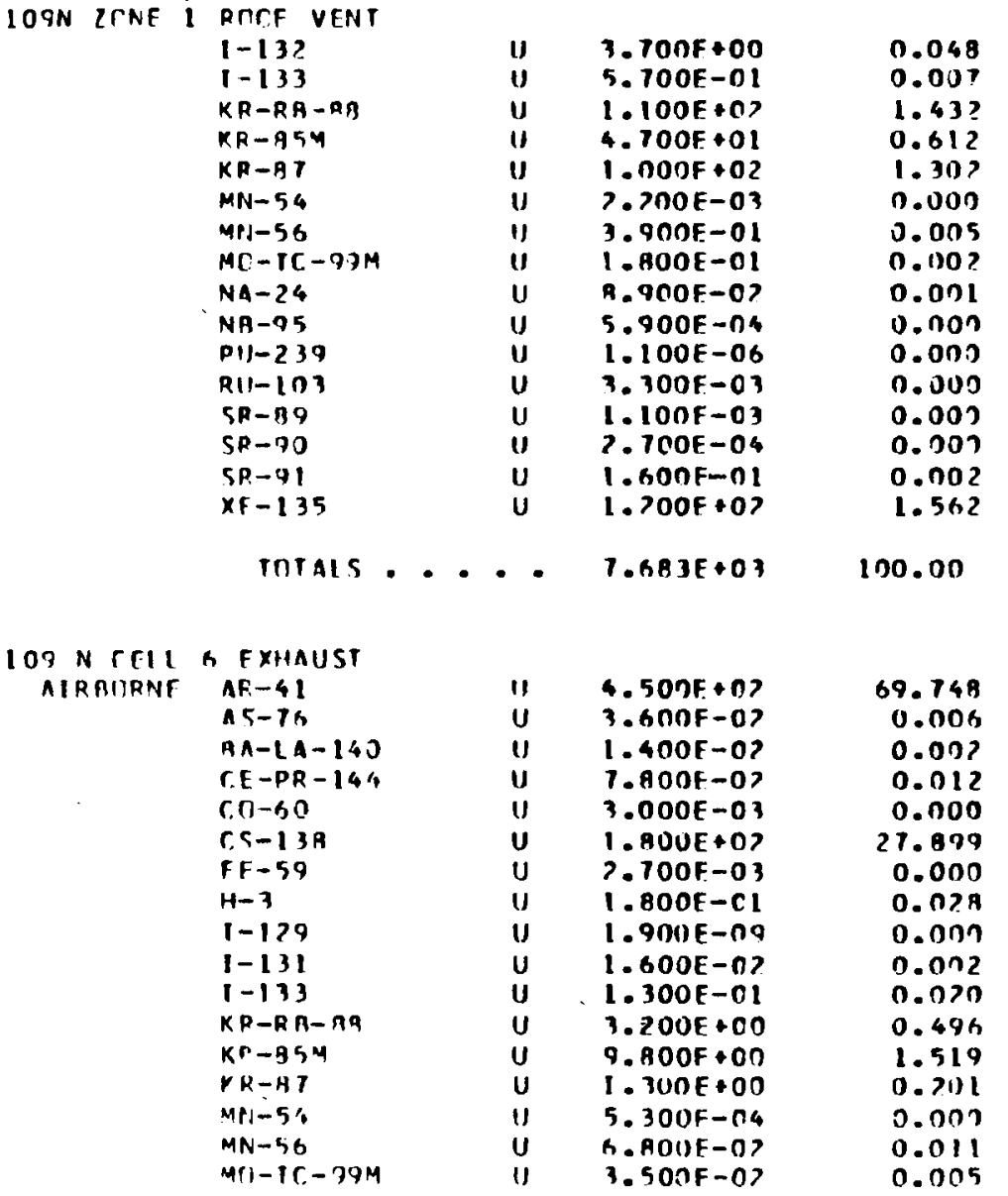


11. 5. DFPARTYENT UF ENFPTYY

FFFIUFNT INRTIRMAIION SYSIFM

EPA REI TASF POIVI ANAI YSIS REPTRT

_-_EUB_CALEUOAB_YCAB_1GRL_...

RICIII AND IIPERATIIINS OFFIC.F

UINITID NUCLEAR INIUUSIRIES

UIJTFO NICLFAR

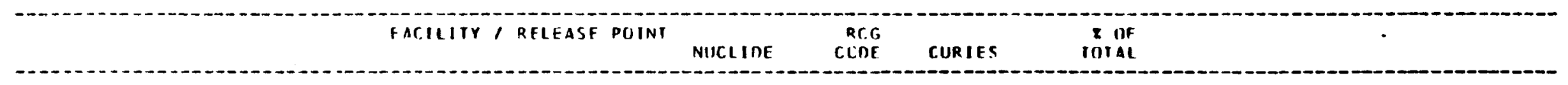

IOFN REACIOR

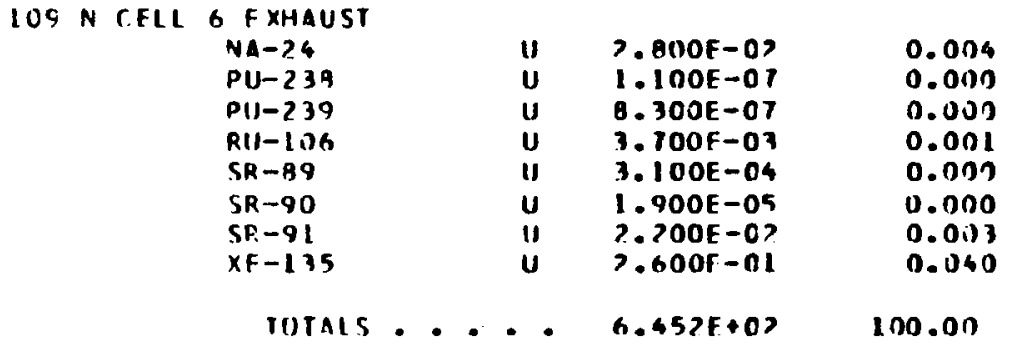


U.S. DEDARTM TF FNERTYY

EFFLUFAT INFURMATION SYSTFM

FPA PFLFASE POINT ANAL YSIS RFPORT

_._EOR_CALENDAB_YEAB_1981.

RICHI.AND TPERATIINNS DFFICE

UNITED NIICLFAR INDUSTRIFS

L. 330 AREA

FAT,IUITY, RELFASF POINT

NUCLIDE

RCG

CIUR IES

I OF

IOIA

33 RIIILDING

URANIUM CUTOFF SAH FXHAUST STACK

AIRBTRNF II-NAT

U

2. 200F-05

100.000

is 
FPA REIFASF DTINT MHAL YSIS HEPORT

_-_EOR_CALENUAB_YEAB_1981_...

RICHIANO RPFRAIICNS IIFFICF

WESTINCINIUISL HAMTIIRD COMPANY

HANFOPD INGINEERING DEVFLOPAFNT LABURAITRY

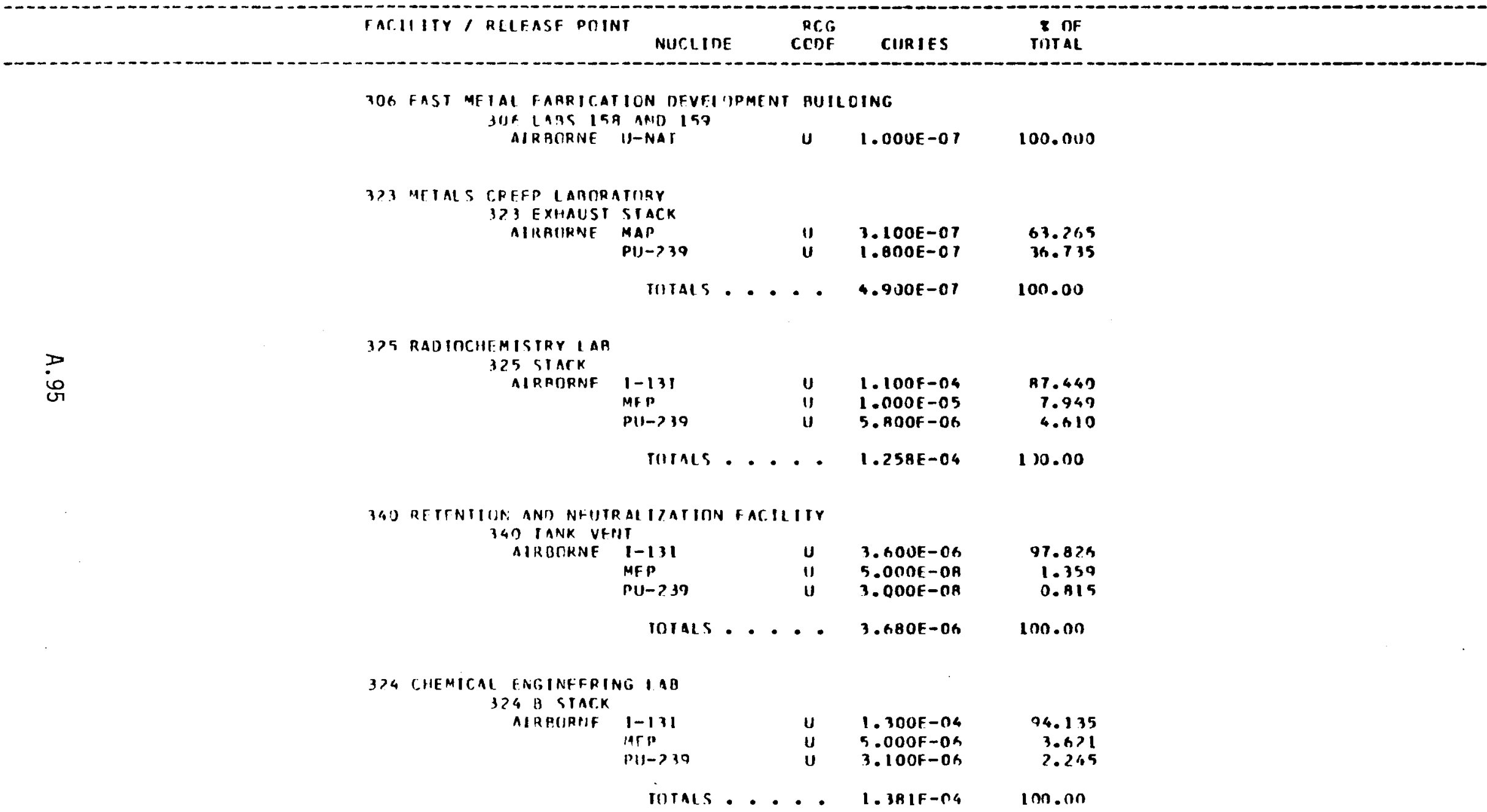


U. S. DFPARIM. DIF ENERGYY

FFFLUFNT INFORMATION SYSTEM

FPA REIFASF DIINT ANALYSIS RFPORT

__EOP_CALENDAB_YLAB_1981 _ _

PICHLAND OPERATIONS OFFICE

WFSTINGHOIISF HANTCIRD C.DMPANY

HANFERD FNGINEER ING DEVFL RPMFNT LABURATORY

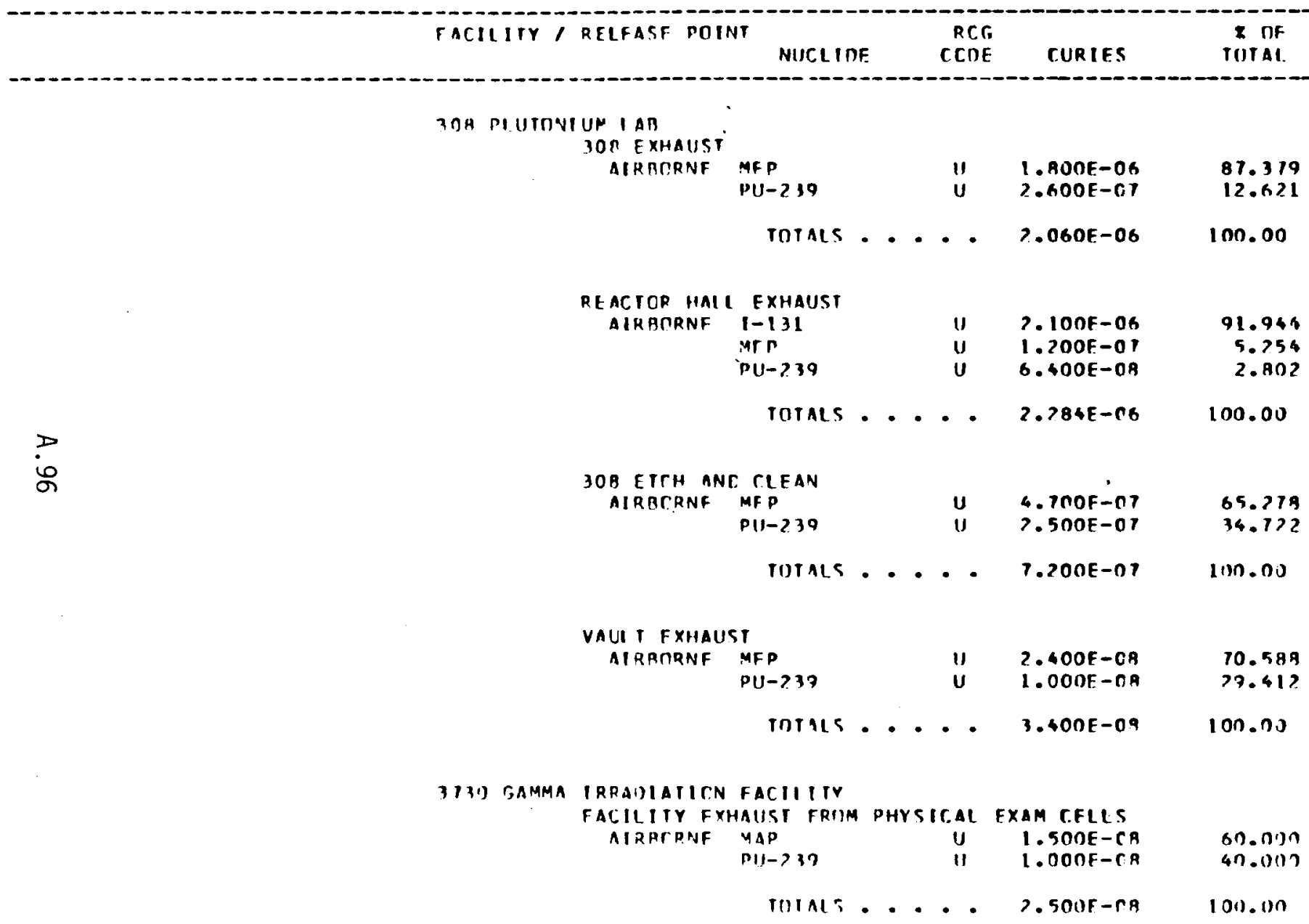


11.S. UFP TRTMFNT OF ENFRGY

FFHLUFNI INF TRMATION SYSIEM

LPA RELFASE POINT ANALYSIS REPTRT

_._EOB_CALENDAB_YEAB_19B1...-

RICHLAND MPFRATIIINS TFEITE

WFSIINGHTIUSE HANFIIR) CLMPANY

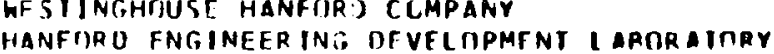

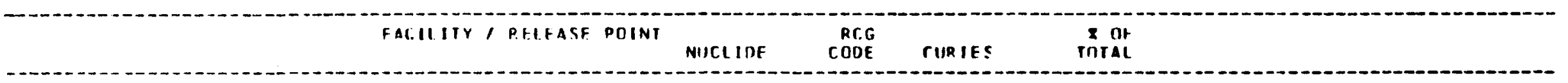

327 RAUIOME I ALLURGY LARORAIORY

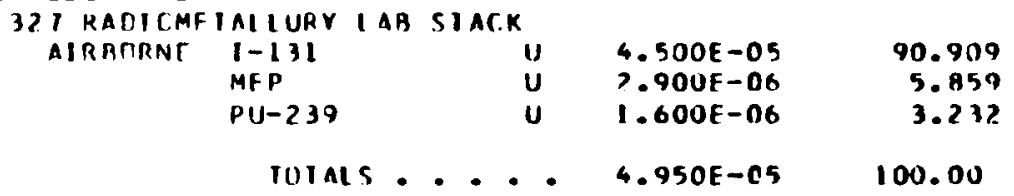

327 DECONIAMINATIUN C.ELL EXIHAIIST

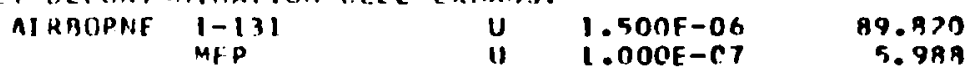

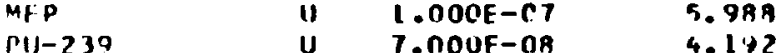

D

IIITAL..... 1.670E-06 100.00

376 PHYSICS ANII MFIALLURGY

326 STAC.K

AIRBCENF PIJ-T39 U $4.500 E-06$ 10M.0ON

Bng PHTR

\begin{tabular}{|c|c|c|c|c|}
\hline $\begin{array}{l}\text { 309 SIARK } \\
\text { AIRRORNF }\end{array}$ & $\begin{array}{l}\text { MrP } \\
\text { PU-2 } 39\end{array}$ & u & $\begin{array}{l}3.200 F-06 \\
1.900 F-07\end{array}$ & $\begin{array}{r}94.395 \\
5.605\end{array}$ \\
\hline & IOIAIs & & $3.390 E-06$ & 100.00 \\
\hline
\end{tabular}


U.S. DEPARTIM UF FNFRGY

EFFIUFNT INFORMATION SYSTFM

FPA RELEASF PIINT ANALYSIS REPORT

_._EUB_CALENDIB_YEAB_1981_...

DICHLAND OPERAIIONS OTTICE

WFSTINT,HOUSE: HANFOR? CCMPANY

WF. $\mathrm{DL}$

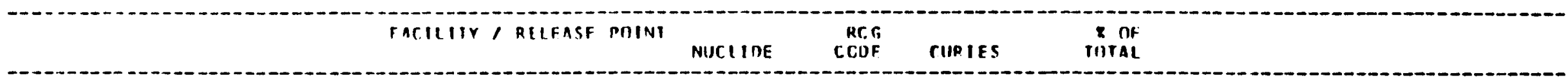

TAST FLUX TEST FAC.LITY

CCMAINED FXHAUST (BIIILOINGS 405, 4621, 4717)

AIPBOPNF I-131 U $1.000 E-05 \quad 0.000$

$\begin{array}{llll}\text { KR-9B } & U & \text { T.POOE+0? } & 100.000\end{array}$

PU-239 $U$ G.300E-C6 0.007

SR-90 U $\quad 3.700 E-05 \quad 0.000$

THIAls.... T.700E+02 100.00

PUILDINC; 491-S H ANT V OISCHAPGF (HIS-SNUTH)

ATRBCPNE KP-BA $\quad I J 5$ 5.000F+0I 100.000

$\begin{array}{llll}S R-90 & U & 1.300 \mathrm{~F}-06 & 0.003\end{array}$

$i_{\infty}^{\infty}$

TuTALS.... 5.000E+01 100.0n

\begin{tabular}{|c|c|c|c|c|c|c|c|}
\hline $\begin{array}{l}\text { RUII. DING } 411 \\
\text { AIRRTRNF }\end{array}$ & $\begin{array}{l}\text { LTHER } \\
1-131 \\
K P-A R \\
S P-90\end{array}$ & MREA & & $\begin{array}{r}\text { ANC } \\
U \\
U \\
U\end{array}$ & & $\begin{array}{l}\text { FXHAUST } \\
3.1000 E-06 \\
1.300 F+07 \\
7.300 E-O B\end{array}$ & $\begin{array}{r}0.000 \\
100 . \text { n? } \\
0.00 \text { ? }\end{array}$ \\
\hline
\end{tabular}


11. S. TLPARTITNT OF ENFRTYY

FFHIUFNT INFORMATION SYSTEM

FPA RFIFASF PMINT ANALYSIS REPTRT

_._EUB_CALEUUAB_YEAB_1981_...

PICIII AND RFEPATITNS DFFIT.F

hESIINGHOUSF HANTURI) COMPANY

2OO-W ARFA

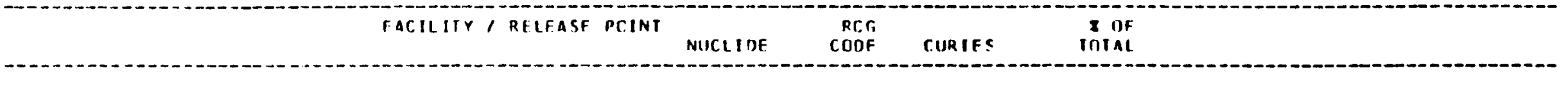

Z PLANT FACIIIITY, RAOIII

RACIU FXHAUST

ALRPIRNF PU-239 U $1.000-07$ 100.000

Do 
11. S. DFPARTY OT FNERGY

EFFLUFNT IIFGRMATION SYSTEM

EPA RELEASF PIINT ANALYSIS REPORT

_._EOR_CALINDAB_YEAB_1981 _.

SAVAANAH RIVER DPERATIONS DFFICF

DU PCNI DE NFMUURS IF.I.I E C.O

SAVANNAH RIVER DIANT

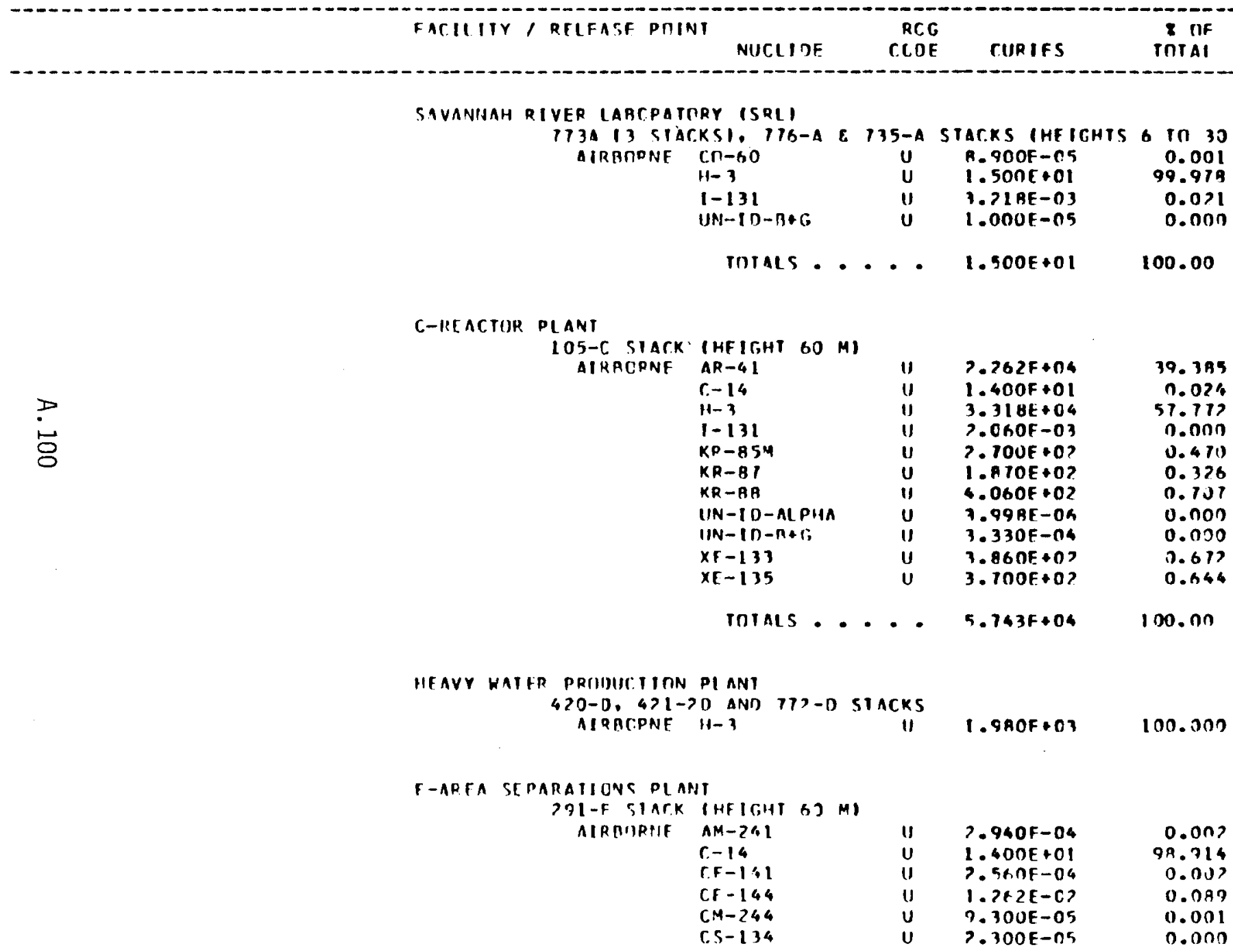


U.S. DFPALTAFNT OF ENFRGY

FFFLUENI INFIJHMATION SYSTFM

FOA RFLFASF POINT ANALYSIS PEPITI

_._EUB_CALENDAR_YEAB_19B1_.

SAUANNAH PIVER BPERATIONS TFFICF

DU PCNT OE NHMOURS IF.1.1 C CC.

SAYANNAH RIVER PLANT

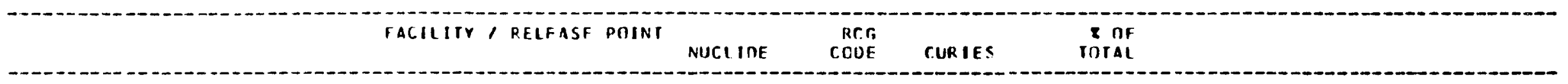

F-IP [A SEPARAIITNS PI.ANT

ZYIT SIACK IHFIGHT hO MI

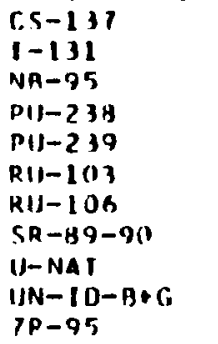

$1.292 F-n 3$
$1.264 E-0 ?$
$6.083 E-07$
$4.490 E-04$
$7.710 F-04$
$7.795 F-03$
$2.252 E-07$
$1.573 E-C 3$
$4.303 F-03$
$4.700 E-05$
$1.317 E-02$

0.009

0.211

0.430

0.0113

0.0 .15

0.025

0.159

0.011

$0.03 n$

0.003

0.073

TUIALS.... 1.415E+0L 100.03

r- AND H-AREAS SEPARATIITNS plants

SOO-F F. - H STAKKS

AIRACIRNF H-3

$H-1$
$1-129$
$K R-8 ;$

$X F-131 M$

$.3106+05$
$1.000 F-01$

$1.600 F-01$

B. 41 IEtON

21.593

9.003

$x+131 m$

$1.070 E+06$

0.021

TUIALS ...

291-11 SIACK IHFIGHT GO MI

AIRBIIPNE

AM-24l

$r .-14$

C.E-141

C.E-14A

C.M-2:4

i. $5-134$

r. $5-131$
$1.5-134$

$\mid-131$

nR-T2

nt)-2 $3 n$

PII-239

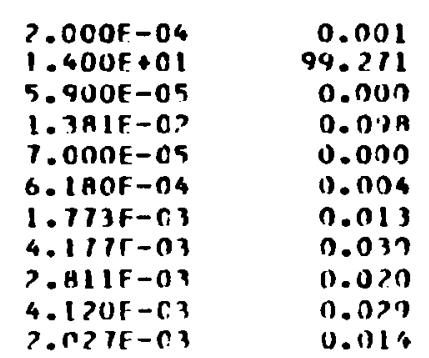


11. 5. UFPARTA TF FNFRGY

FFFLUENT INFIRMATION SYSIEM

FPA RELEAST PUINT ANALYSIS RFPORT

_._EUB_CALENDAB_YEAB_1981

SAVANNAH RIVER OPERATIONS CTFICF

DU PCAT CF NFMIJURS IE. I.I E CO

SAVANAAHE RIVER PIANI

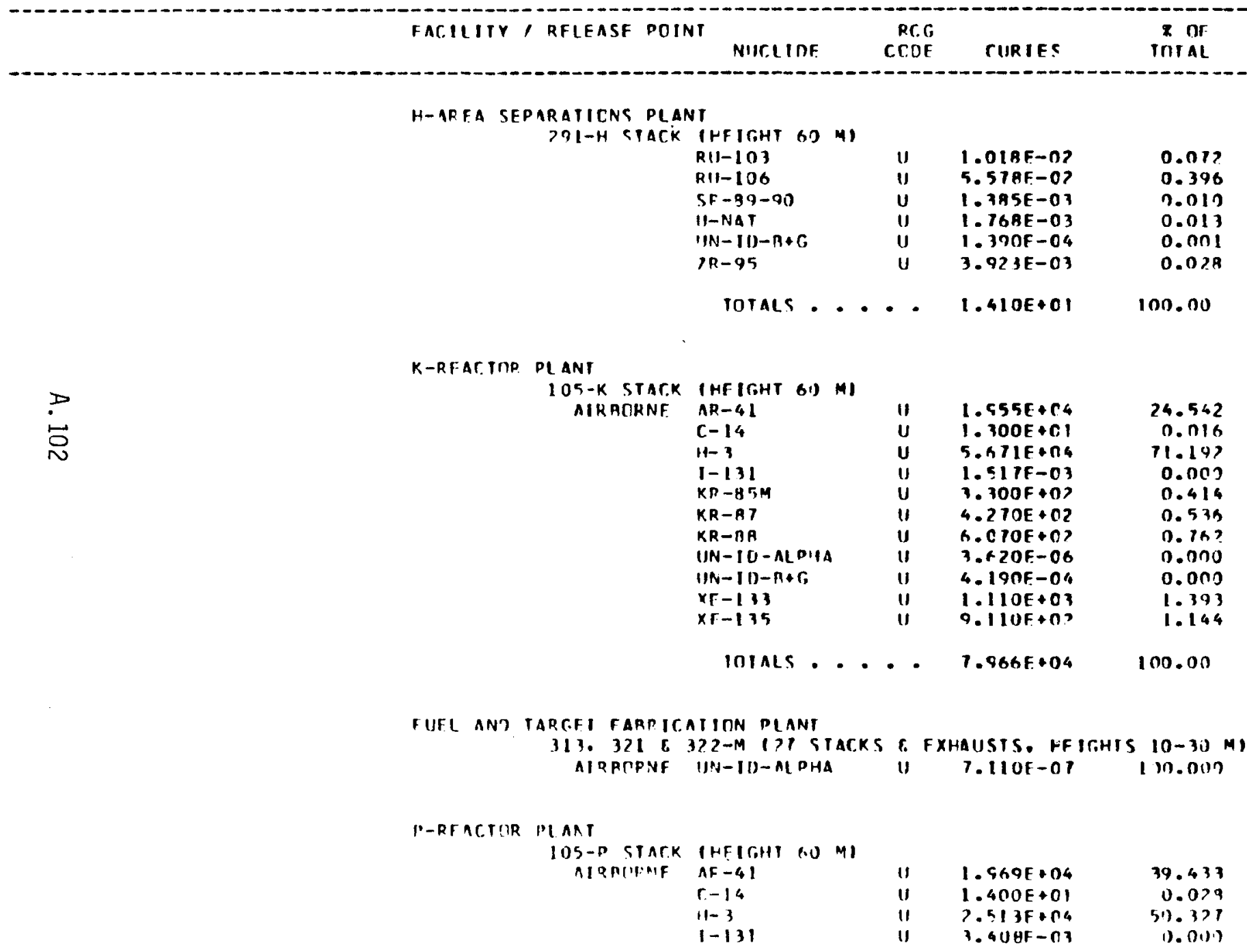


11. S. DERARTMENT OF FNFRGY

FFFLUENT [AIFITRMATIUN SYSTEM

FPA RFLEASF PIINT ANALYSIS REPORT

_._EUG_CAL_ENDAB_YEAB_19B1_._.

SAVANNAH RIVFR DPFRAIICNS GFFICF

CU PINI DE NEMUURS IE.I.I 6 CO

SAVANNAH RIVER PLANT

FACIITY, PELFASF POINT

NIICLINE

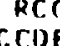

TURIES

iniat

P-RFACIOTR PLANI

105-P STACK (HEIGHT 6) MI

KP-85M
$K R-87$
$K R-8 B$
$U N-1 D-A L P I I A$
$U N-1 D-B+G$
$X F-133$
$X F-135$

U $6.990 F \cdot n ?$

$7.550 F+02$

$4.630 \mathrm{E}+\mathrm{C}$ ?

1.CTOE-CB

$1.530 F-04$

$2.431 F+03$

0.511

0.977

0.0010

$x F-135$

$1.251 F+03 \quad 4.869$

TUIALS ... 4.993E+04 100.00 
11.S. DEPARTM. OF ENFRTYY

FFFIIIENT INFOHMATION SYSTEM

FPA RELFASF PIINT ANMLYSIS REPORT

__EUB_CALEYLAB_YEAR_1981 _...

SCHEAFC,IADY NAVAL RFACIORS OPFRATIONS TFF.

T.FNFRAI FIFTTRIC COMYPANY

KITLLS ATOAIC POHTR LABORATURY

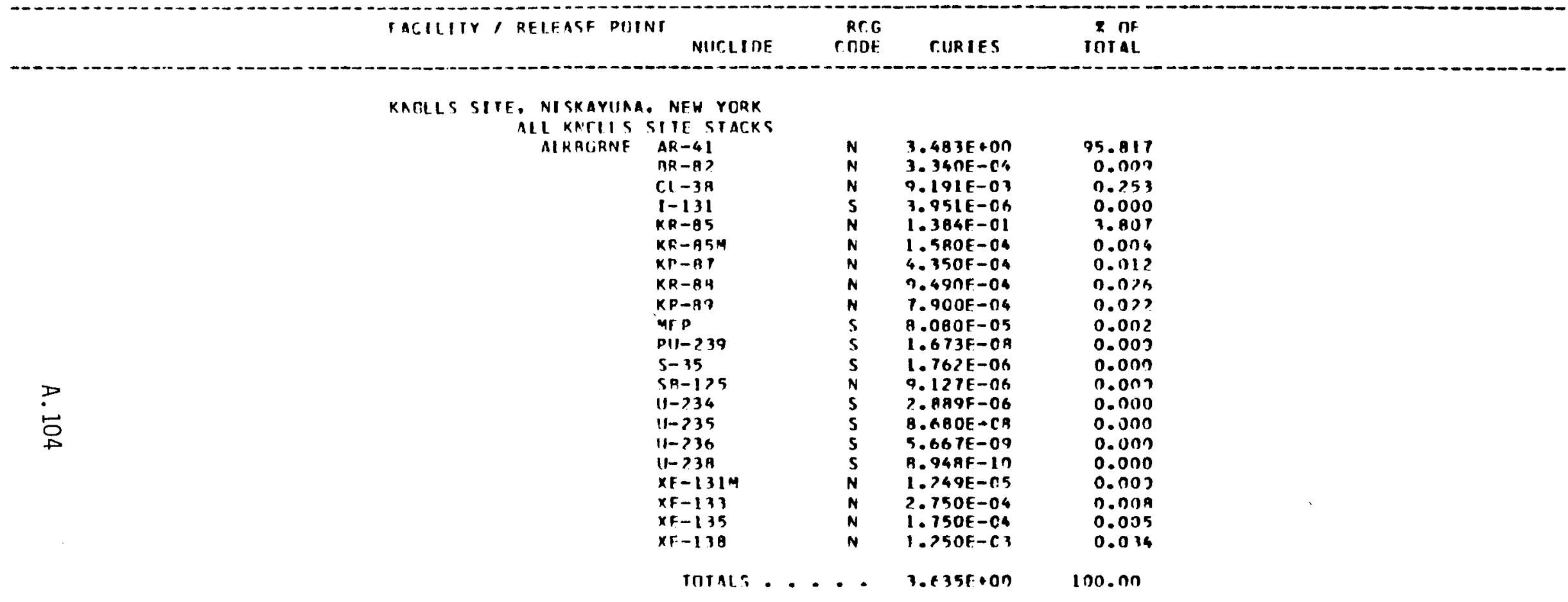


11.S. DFPARTMFNI OF TNFRGY

FTFLUENT IIAFJRMATION SYSTEM

FPA PFLFAST PIIII ANALYSIS PFPUP.I

_.. EUR_ C AL ENDAB_XEAB_1481_._.

SCHENFC.TADY NAVAL REACTIIRS OPERATIONS CFF.

GH NFPAI CLECTRIC COMPANY

KNCLLS ATOMIC. POHER LABORATORY

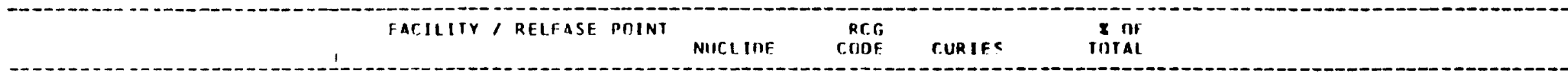

KESSERKESSFIRIVG SITF. WFSI MILTON. NEW YIJRK

ALI KFSSFI WIAT, SITE STACKS

IIKBIIRNF TIS, SI

$A R-4$
$C-14$

KR -814

$K R-85$

$K K-B 2 M$
$K R=-82$

$K R-B 2$

$K R-87$

$K H-B$

MAP
$X F-111$

$X F-131 M$
$X F-13]$

$X E-133 M$

$X F-135$

$3.132 \mathrm{E}-\mathrm{nI}$

1. 786F-CI

1. $109 E-03$

4. 460F-OB

1. $550 E-03$

2.961E-03

$6.010 E-0 ?$

4. 605 E-06

$2.317 E-C 4$

$4.132 E-02$

$1.427 E-03$

号

IOIALS... 5.8ATE-OI 100.00

53.199

30.311

0.1ค9

0.0 .11

0.603

0.503

1.157

0.001

0.039

7.017

0.242

6.111 
U.S. DFPARTM JF ENFRT,Y

FIFIUFN INFURMATION SYSTFM

FPA PFLEASF BIINT ANALYSIS REPTRT

_._EDP_CALENDAB_YEAB_19B1___-

SC.HFNECIAOY NAVAL REACIORS DPERATIONS RFF.

S.FNFRAL FLFCIKIC COUPANY

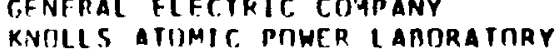

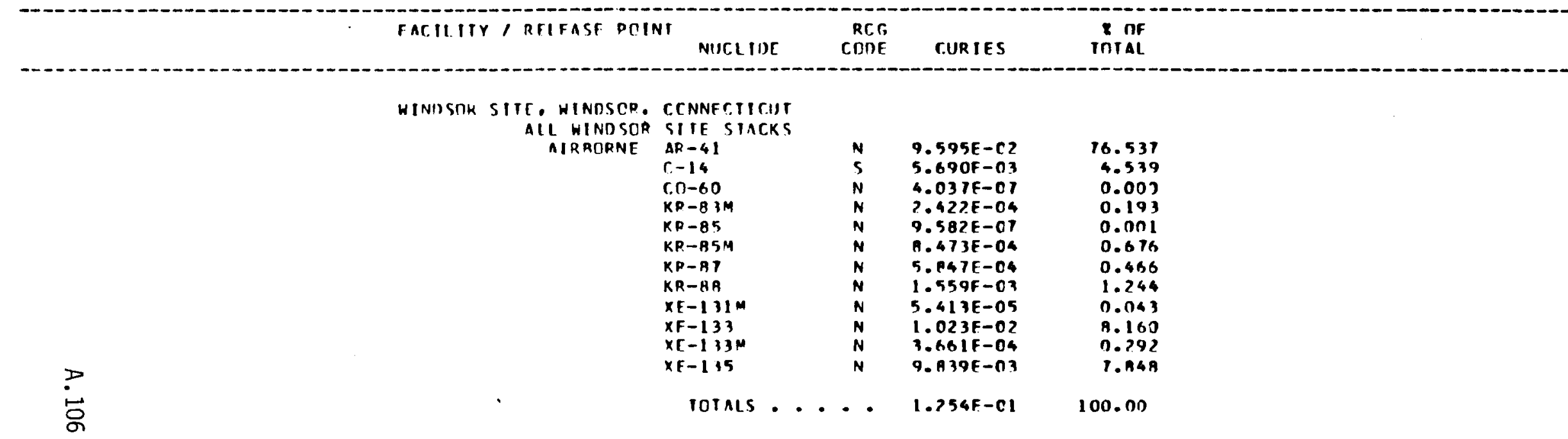


APPENDIX B

STUDY PARTICIPANTS 
Listed in this appendix are the PNL authors of each section of the document, the DOE operations offices from which information was secured, and the DOE field office representatives.

\begin{tabular}{|c|c|c|}
\hline Section & $\begin{array}{l}\text { DOE Operations } \\
\text { Office }\end{array}$ & $\begin{array}{l}\text { PNL } \\
\text { Author }\end{array}$ \\
\hline Introduction & & E.B. Moore, project manager \\
\hline History & & D. A. Dingee \\
\hline Particulates & & J. Mishima \\
\hline Iodine & & L.L. Burger \\
\hline Rare Gases & & E.D. MCClanahan \\
\hline Tritium & & L.L. Burger \\
\hline ANL & Chicago & J.D. Ludwick \\
\hline BNL & Chicago & C.A. Counts \\
\hline FMPC & Oak Ridge & L.G. Morgan \\
\hline FNAL & Chicago & H.T. Fullam \\
\hline Hanford & Richland & A.M. Schreiber \\
\hline INEL & Idaho/Chicago & G.H. Bryan \\
\hline LLNL/SNL-L & San Francisco/Nevada & C.A. Counts \\
\hline LANL & Albuquerque & H.T. Fullam \\
\hline ORNL & Oak Ridge & J.D. Ludwick \\
\hline Paducah & Oak Ridge & C.M. Heeb \\
\hline Portsmouth & Oak Ridge & C.M. Heeb \\
\hline Rocky Flats & Albuquerque & G.H. Bryan \\
\hline SRP & Savannah River & R.I. Smith \\
\hline SLAC & San Francisco & H.T. Fullam \\
\hline Other DOE Sites & & R.L. Aaberg \\
\hline
\end{tabular}




\begin{tabular}{|c|c|}
\hline DOE Operations Office & DOE Representatives \\
\hline Albuquerque & $\begin{array}{l}\text { Daryl Mercer } \\
\text { George Werkema }\end{array}$ \\
\hline Chicago & Jerry Nelson \\
\hline Idaho & Peter Dirkmaat \\
\hline Naval Reactors & James Mangeno \\
\hline Nevada & Frank Markwell \\
\hline Oak Ridge & $\begin{array}{l}\text { Bobby Joe Davis } \\
\text { Gabriel Marciante } \\
\text { Jerry Wing }\end{array}$ \\
\hline Richland & Donald Elle \\
\hline San Francisco & $\begin{array}{l}\text { George Luense } \\
\text { W.E. Kehely }\end{array}$ \\
\hline Savannah River & $\begin{array}{l}\text { Mel Sires } \\
\text { Grover Smithwick }\end{array}$ \\
\hline
\end{tabular}

Carl Welty of DOE headquarters supplied the names of DOE operations office representatives. Dexter Lien and Luther Smith of Kaiser Engineers Hanford (KEH) provided structural consulting and conceptual designs for emission control systems, respectively. Mitch Howard of KEH reviewed or prepared cost estimates, and Dave Payson of PNL was the report editor. 